Metals and Ceramics Division

\title{
INTERIM REPORT ON THE POST IRRADIATION EXAMINATION OF CAPSULES 2 AND 3 OF THE HFR-B1 EXPERIMENT
}

\author{
B. F. Myers, editor \\ Oak Ridge National Laboratory \\ Oak Ridge, Tennessee \\ and \\ G. Pott, W. Schenk, R. Schroder, W. Kuhlein, H. J. Bucker, H. Dahmen, K. Landsgesell \\ and F. Nieveler \\ Forschungszentrum Jalich GmbH, Julich \\ Julich, Germany
}

Date Published: September 1994

\author{
Prepared for the \\ U.S. Department of Energy \\ Office of Advanced Reactor Programs \\ AF 2050101 \\ Prepared by \\ OAK RIDGE NATIONAL LABORATORY \\ Oak Ridge, Tennessee 37831-6285 \\ managed by \\ MARTIN MARIETTA ENERGY SYSTEMS, INC. \\ and the \\ FORSCHUNGSZENTRUM JULICH GmbH \\ Jalich, Germany \\ for the \\ U.S. Department of Energy \\ under Contract DE-AC05-84OR21400
}




\section{DISCLAIMER}

This report was prepared as an account of work sponsored by an agency of the United States Government. Neither the United States Government nor any agency thereof, nor any of their employees, make any warranty, express or implied, or assumes any legal liability or responsibility for the accuracy, completeness, or usefulness of any information, apparatus, product, or process disclosed, or represents that its use would not infringe privately owned rights. Reference herein to any specific commercial product, process, or service by trade name, trademark, manufacturer, or otherwise does not necessarily constitute or imply its endorsement, recommendation, or favoring by the United States Government or any agency thereof. The views and opinions of authors expressed herein do not necessarily state or reflect those of the United States Government or any agency thereof. 


\section{DISCLAIMER}

Portions of this document may be illegible in electronic image products. Images are produced from the best available original document. 
CONTENTS

Page

LIST OF FIGURES $\ldots \ldots \ldots \ldots \ldots \ldots \ldots \ldots \ldots \ldots \ldots \ldots \ldots \ldots \ldots \ldots \ldots \ldots$

LIST OF TABLES $\ldots \ldots \ldots \ldots \ldots \ldots \ldots \ldots \ldots \ldots \ldots \ldots \ldots \ldots \ldots \ldots \ldots \ldots \ldots \ldots \ldots$

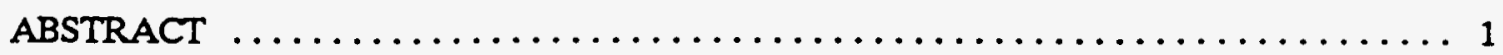

1. INTRODUCTION $\ldots \ldots \ldots \ldots \ldots \ldots \ldots \ldots \ldots \ldots \ldots \ldots \ldots \ldots \ldots \ldots \ldots \ldots \ldots$

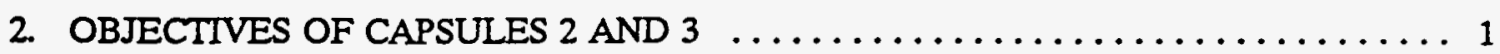

3. CONFIGURATION OF CAPSULES 2 AND $3 \ldots \ldots \ldots \ldots \ldots \ldots \ldots \ldots \ldots$

4. PIE OF CAPSULES 2 AND $3 \ldots \ldots \ldots \ldots \ldots \ldots \ldots \ldots \ldots \ldots \ldots \ldots \ldots \ldots \ldots \ldots \ldots \ldots \ldots \ldots$

4.1 PIE TEST PLAN FOR CAPSULES 2 AND $3 \ldots \ldots \ldots \ldots \ldots \ldots \ldots \ldots \ldots \ldots \ldots$

4.2 DISASSEMBLY OF CAPSULES 2 AND $3 \ldots \ldots \ldots \ldots \ldots \ldots \ldots \ldots$

4.2.1 Visual Inspection and Photography $\ldots \ldots \ldots \ldots \ldots \ldots \ldots \ldots$

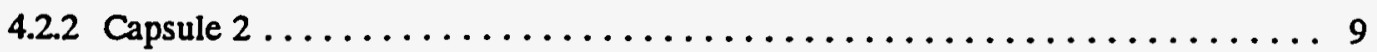

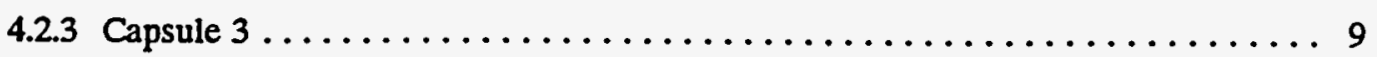

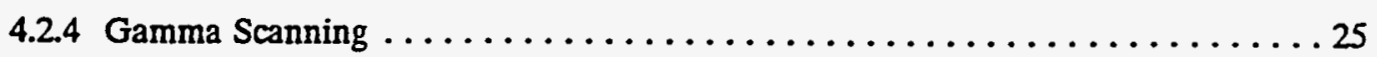

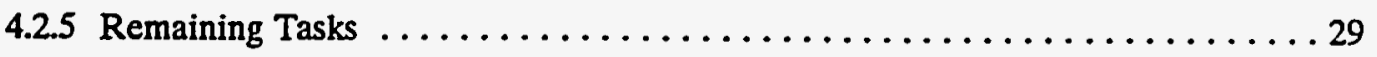

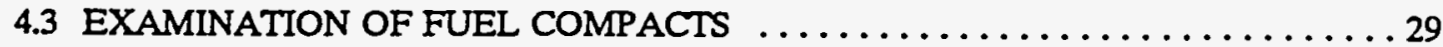

4.3.1 Visual Inspection and Photography $\ldots \ldots \ldots \ldots \ldots \ldots \ldots \ldots \ldots \ldots$

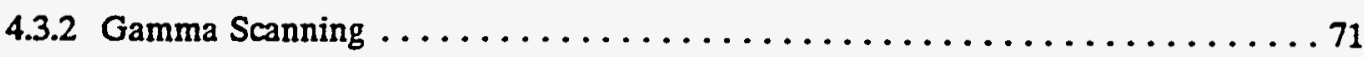

4.3.3 Gamma Counting $\ldots \ldots \ldots \ldots \ldots \ldots \ldots \ldots \ldots \ldots \ldots \ldots \ldots \ldots$

4.3.4 Dimensional and Weight Measurements $\ldots \ldots \ldots \ldots \ldots \ldots \ldots \ldots \ldots$

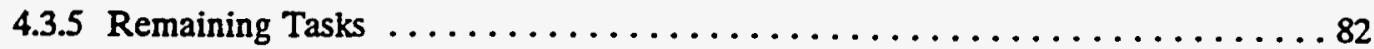

4.4 EXAMINATION OF UNFUELED GRAPHITE BODIES $\ldots \ldots \ldots \ldots \ldots \ldots$.

4.4.1 Visual Inspection and Photography $\quad \ldots \ldots \ldots \ldots \ldots \ldots \ldots \ldots$

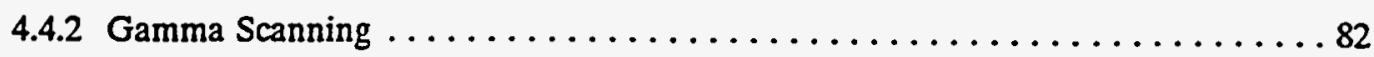


CONTENTS (Continued)

4.4 .3 Gamma Counting of Graphite Sectors $\ldots \ldots \ldots \ldots \ldots \ldots \ldots \ldots$

4.4.4 Gamma Counting of Small Graphite Components ............. 102

4.4.5 Cesium Distribution Between Fuel Compacts and The Graphite . . . . . . 102

4.4.6 Summary of Inventory Measurements $\ldots \ldots \ldots \ldots \ldots \ldots \ldots \ldots \ldots$

4.4.7 Dimensional Measurements $\ldots \ldots \ldots \ldots \ldots \ldots \ldots \ldots \ldots \ldots \ldots \ldots \ldots$

4.5 EXAMINATION OF INERT COMPACTS AND GRAPHITE CYLINDERS $\ldots 111$

4.5.1 Visual Inspection and Photography $\ldots \ldots \ldots \ldots \ldots \ldots \ldots \ldots \ldots \ldots$

4.5.2 Dimensional and Weight Measurements $\ldots \ldots \ldots \ldots \ldots \ldots \ldots \ldots$

4.6 UNBONDED COATED FUEL PARTICLES $\ldots \ldots \ldots \ldots \ldots \ldots \ldots \ldots \ldots$

4.6.1 Visual Inspection and Photography $\ldots \ldots \ldots \ldots \ldots \ldots \ldots \ldots \ldots \ldots \ldots$

4.6.2 Gamma Counting of Kernels, Coatings and Particles .......... . . 137

4.6.3 Kernel Retention of Fission Products $\ldots \ldots \ldots \ldots \ldots \ldots \ldots \ldots \ldots \ldots$

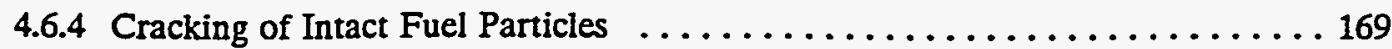

4.7 HEATING WITH INTERMITTENT WATER-VAPOR INJECTIONS $\ldots . \ldots . . .69$

4.7.1 Water-Vapor Injection Tests with Fuel Compacts 2.2 .1 and $2.2 .2 \ldots \ldots 177$

4.7.2 Water-Vapor Injection Tests with Fuel Compacts 3.2 .1 and $3.2 .2 \ldots \ldots \ldots 177$

4.7.3 Water-Vapor Injection Tests with UCO Kernels $\ldots \ldots \ldots \ldots \ldots \ldots \ldots$

4.8 STATUS OF THE PIE OF CAPSULES 2 AND $3 \ldots \ldots \ldots \ldots \ldots \ldots \ldots$

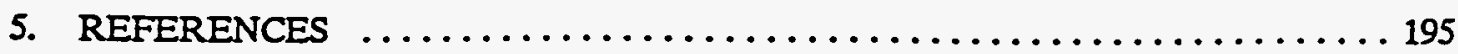




\section{LIST OF FIGURES}

Figure

3.1 Cross-sectional view representative of capsules 2 and $3 \ldots \ldots \ldots \ldots \ldots \ldots$

3.2 Perspective view of the contents of capsule $2 \ldots \ldots \ldots \ldots \ldots \ldots \ldots \ldots \ldots \ldots$

3.3 Perspective view of the contents of capsule $3 \ldots \ldots \ldots \ldots \ldots \ldots \ldots \ldots \ldots$

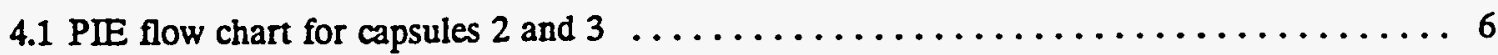

4.2 Definition of icons in the PIE flow chart $\ldots \ldots \ldots \ldots \ldots \ldots \ldots \ldots \ldots \ldots \ldots$

4.3 Modified PIE flow chart with major tasks outlined for capsules 2 and $3 \ldots \ldots \ldots 11$

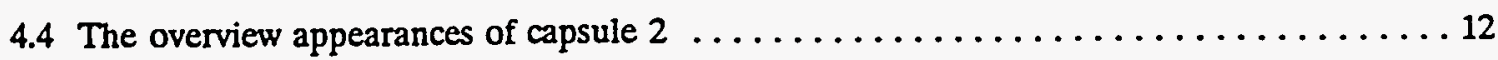

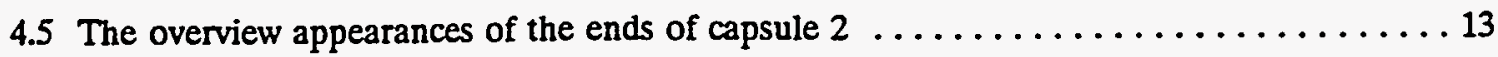

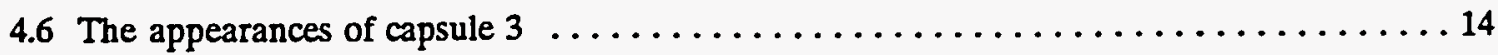

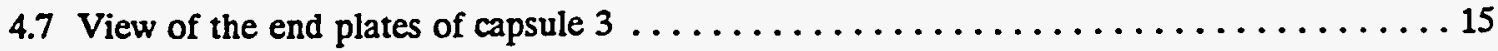

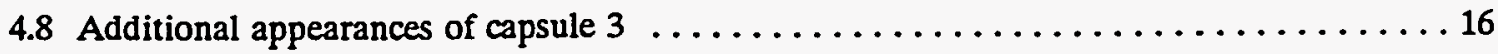

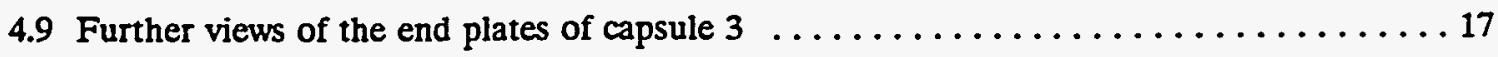

4.10 Detailed views of the end plates of capsule 3 and a heat shield $\ldots \ldots \ldots \ldots \ldots \ldots$

4.11 Selected views of components after opening capsule $2 \ldots \ldots \ldots \ldots \ldots \ldots \ldots \ldots$

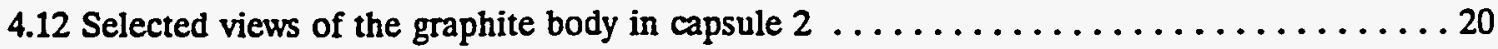

4.13 Removal of the end plate, thermocouple protection tubes and adjacent heat shield $\ldots \ldots 21$

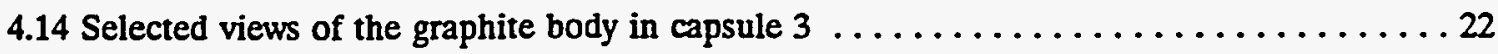

4.15 Selected views of the ends of the graphite body in capsule $3 \ldots \ldots \ldots \ldots \ldots \ldots$

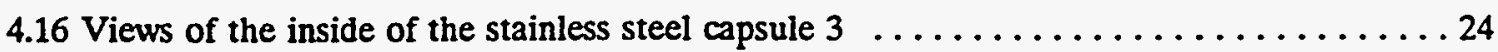

4.17 Gamma scam of the steel capsule for ${ }^{60} \mathrm{Co}$ focused on fuel hole $1 \ldots \ldots \ldots \ldots \ldots$

$4.18 \mathrm{Gamma}$ scam of the steel capsule for ${ }^{60} \mathrm{Co}$ focused on fuel hole 1 (enlarged) ....... 30

4.19 Gamma scam of the steel capsule for ${ }^{134} \mathrm{Cs}$ focused on fuel hole $1 \ldots \ldots \ldots \ldots \ldots$

4.20 Gamma scam of the steel capsule for ${ }^{277} \mathrm{Cs}$ focused on fuel hole $1 \ldots \ldots \ldots \ldots$ 


\section{LIST OF FIGURES (continued)}

4.21 Gamma scam of the steel capsule for ${ }^{54} \mathrm{Mn}$ focused on fuel hole $1 \ldots \ldots \ldots \ldots \ldots$

4.22 Gamma scam of the steel capsule for ${ }^{60} \mathrm{Co}$ focused on fuel hole $2 \ldots \ldots \ldots \ldots \ldots$

4.23 Gamma scam of the steel capsule for ${ }^{60} \mathrm{Co}$ focused on fuel hole 2 (enlarged) ....... 33

4.24 Gamma scam of the steel capsule for ${ }^{134} \mathrm{Cs}$ focused on fuel hole $2 \ldots \ldots \ldots \ldots \ldots$

4.25 Gamma scam of the steel capsule for ${ }^{137} \mathrm{Cs}$ focused on fuel hole $2 \ldots \ldots \ldots \ldots$

4.26 Gamma scam of the steel capsule for ${ }^{54} \mathrm{Mn}$ focused on fuel hole $2 \ldots \ldots \ldots \ldots \ldots$

4.27 Gamma scam of the steel capsule for ${ }^{60} \mathrm{Co}$ focused on fuel hole $3 \ldots \ldots \ldots \ldots \ldots$

$4.28 \mathrm{Gamma}$ scam of the steel capsule for ${ }^{60} \mathrm{Co}$ focused on fuel hole 3 (enlarged) ....... 36

4.29 Gamma scam of the steel capsule for ${ }^{134} \mathrm{Cs}$ focused on fuel hole $3 \ldots \ldots \ldots \ldots . \ldots 37$

4.30 Gamma scam of the steel capsule for ${ }^{137} \mathrm{Cs}$ focused on fuel hole $3 \ldots \ldots \ldots \ldots$

4.31 Gamma scam of the steel capsule for ${ }^{54} \mathrm{Mn}$ focused on fuel hole $3 \ldots \ldots \ldots \ldots \ldots$

4.32 Gamma scam of graphite bodies 2 and 3 focused on fuel holes 1,2 , and 3 for ${ }^{14} \mathrm{Ce} \ldots 39$

4.33 Gamma scam of graphite bodies 2 and 3 focused on fuel holes 1,2 , and 3 for ${ }^{134} \mathrm{Cs} \ldots 40$

4.34 Gamma scam of graphite bodies 2 and 3 focused on fuel holes 1,2 , and 3 for ${ }^{137} \mathrm{Cs} \ldots 41$

4.35 Gamma scam of graphite bodies 2 and 3 focused on fuel holes 1,2 , and 3 for ${ }^{106}$ Ru $\ldots 42$

4.36 Gamma scam of graphite bodies 2 and 3 focused on fuel holes 1,2 , and 3 for ${ }^{\text {sr }} \mathrm{Zr} \ldots 43$

4.37 Gamma scam of graphite bodies 2 and 3 focused on fuel holes 1,2 , and 3 for ${ }^{60} \mathrm{Co} \ldots \ldots 44$

4.38 The gamma spectrum of the graphite body from capsule $2 \ldots \ldots \ldots \ldots \ldots \ldots$

4.39 Gamma scan of the gamma scan wires 3.1 and 21 for ${ }^{60} \mathrm{Co}$ in capsules 2 and $3 \ldots \ldots 46$

4.40 Gamma scan of the gamma scan wires 3.1 and 2.1 for ${ }^{54} \mathrm{Mn}$ in capsules 2 and $3 \ldots \ldots 46$

4.41 Gamma scan of the gamma scan wires 3.2 and 2.2 for ${ }^{60} \mathrm{Co}$ in capsules 2 and $3 \ldots \ldots 4$

4.42 Gamma scan of the gamma scan wires 3.2 and 2.2 for ${ }^{54} \mathrm{Mn}$ in capsules 2 and $3 \ldots \ldots 47$

4.43 Gamma scan of the gamma scan wires 3.3 and 2.3 for ${ }^{60} \mathrm{Co}$ in capsules 2 and $3 \ldots \ldots 48$

4.44 Gamma scan of the gamma scan wires 3.3 and 2.3 for ${ }^{54} \mathrm{Mn}$ in capsules 2 and $3 \ldots \ldots 48$

4.45 Four views of the fuel compact from position 1 in hole 1 of capsule $2 \ldots \ldots \ldots \ldots$ 


\section{LIST OF FIGURES (continued)}

4.46 Four views of the fuel compact from position 2 in hole 1 of capsule $2 \ldots \ldots \ldots \ldots 68$

4.47 Four views of the fuel compact from position 3 in hole 1 of capsule $2 \ldots \ldots \ldots \ldots 6$

4.48 Four views of the fuel compact from position 4 in hole 1 of capsule $2 \ldots \ldots \ldots \ldots 70$

4.49 Four views of the fuel compact from position 1 in hole 1 of capsule $3 \ldots \ldots \ldots 72$

4.50 Four views of the fuel compact from position 2 in hole 1 of capsule $3 \ldots \ldots \ldots 73$

4.51 Four views of the fuel compact from position 3 in hole 1 of capsule $3 \ldots \ldots \ldots \ldots 74$

4.52 Four views of the fuel compact from position 4 in hole 1 of capsule $3 \ldots \ldots \ldots \ldots 75$

4.53 View of the loose particles upon opening fuel hole 1 of capsule $3 \ldots \ldots \ldots \ldots 76$

4.54 Gamma scan of the fuel compacts from hole 1 of capsules 2 and 3

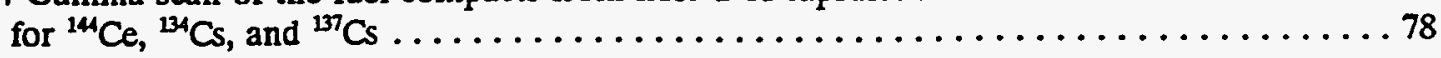

4.55 Gamma scan of the fuel compacts from hole 1 of capsules 2 and 3

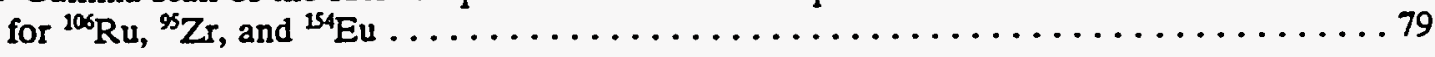

4.56 The gamma spectrum of the fuel compact 2.1 .1 hole 1 , capsule $2 \ldots \ldots \ldots \ldots \ldots$

4.57 The cesium inventory of the fuel compacts from fuel holes 1,2 , and $3 \ldots \ldots \ldots \ldots$

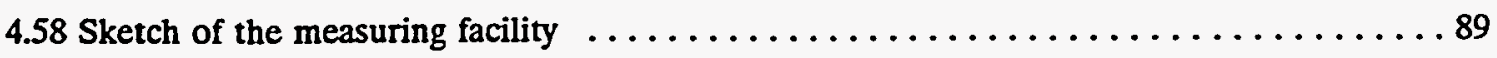

4.59 The gamma spectrum of graphite sector $2.3 \ldots \ldots \ldots \ldots \ldots \ldots \ldots \ldots \ldots \ldots \ldots \ldots \ldots \ldots$

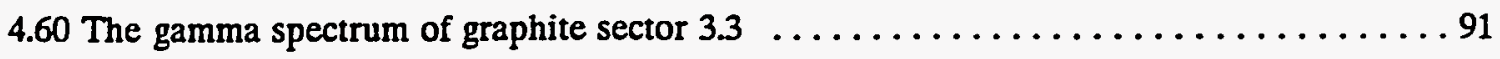

4.61 Gamma scan of graphite sectors from hole 1 of capsules 2 and 3

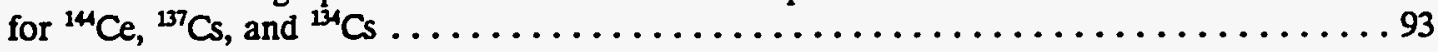

4.62 Gamma scan of graphite sectors from hole 1 of capsules 2 and 3

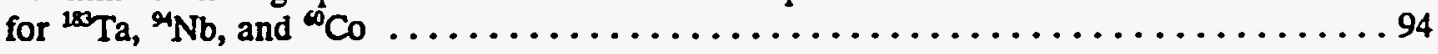

4.63 Gamma scan of graphite sectors from hole 2 of capsules 2 and 3

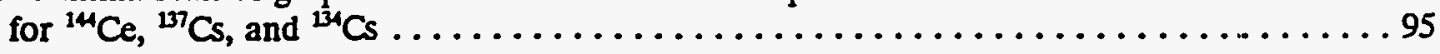

4.64 Gamma scan of graphite sectors from hole 2 of capsules 2 and 3

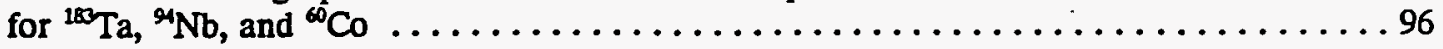

4.65 Gamma scan of graphite sectors from hole 3 of capsules 2 and 3

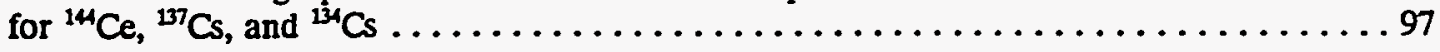




\section{LIST OF FIGURES (continued)}

4.66 Gamma scan of graphite sectors from hole 3 of capsules 2 and 3

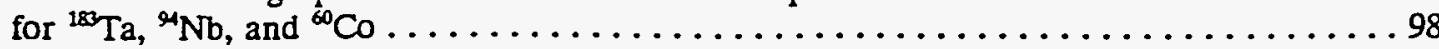

4.67 The activities of ${ }^{137} \mathrm{Cs}$ and ${ }^{134} \mathrm{Cs}$ in the graphite sectors 2.1 and $3.1 \ldots \ldots \ldots \ldots \ldots 10 \ldots \ldots$

4.68 The activities of ${ }^{137} \mathrm{Cs}$ and ${ }^{134} \mathrm{Cs}$ in the graphite sectors 2.2 and $3.2 \ldots \ldots \ldots \ldots \ldots 1$

4.69 The activities of ${ }^{137} \mathrm{Cs}$ and ${ }^{134} \mathrm{Cs}$ in the graphite sectors 2.3 and $3.3 \ldots \ldots \ldots \ldots 1$

4.70 The inventories $(\mathrm{Bq})$ of the plugs and screws from capsule 2

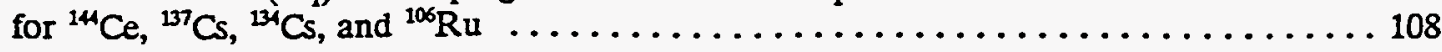

4.71 The inventories $(\mathrm{Bq})$ of the plugs and screws from capsule 3

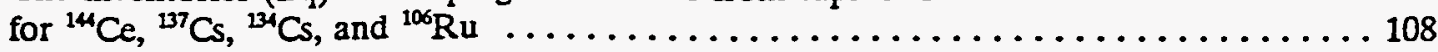

4.72 The inventories $(\mathrm{Bq})$ of the graphite cylinders and sleeves from capsule 2

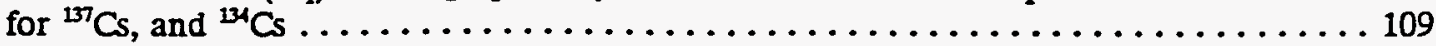

4.73 The inventories $(\mathrm{Bq})$ of the graphite cylinders and sleeves from capsule 3

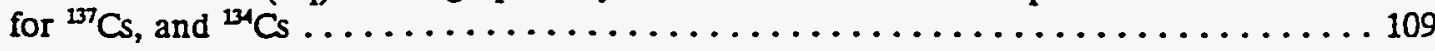

4.74 The inventories $(\mathrm{Bq})$ of the particle trays from capsule 2

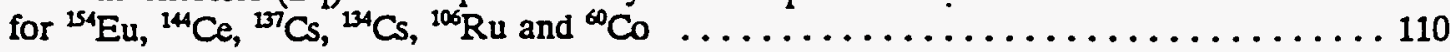

4.75 The inventories $(\mathrm{Bq})$ of the particle trays from capsule 2

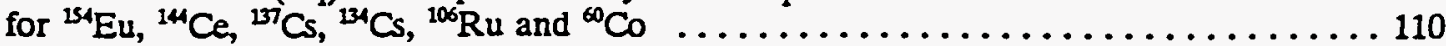

4.76 The inventories of ${ }^{137} \mathrm{Cs}$ and ${ }^{134} \mathrm{Cs}$ in the fuel compacts and graphite

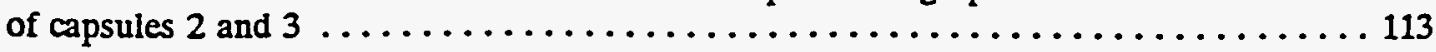

4.77 The distribution of ${ }^{177} \mathrm{Cs}$ and ${ }^{134} \mathrm{Cs}$ between fuel compacts and graphite

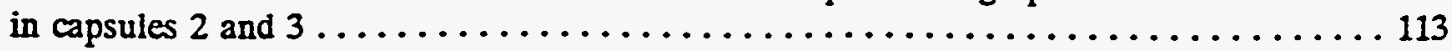

4.78 Diameter and length measurements on graphite bodies from

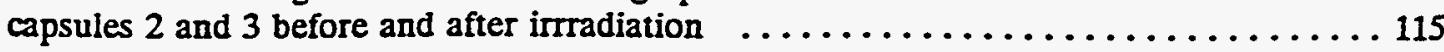

4.79 Three views of the inert compact and associated graphite sleeve from position 2.4 .1

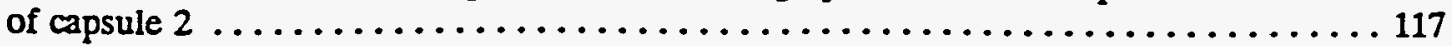

4.80 Three views of the inert compact and associated graphite sleeve from position 2.5 .1

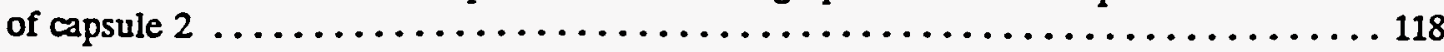

4.81 Three views of the inert compact and associated graphite sleeve from positions 26.1

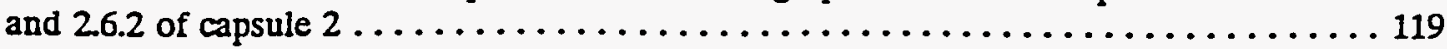

4.82 Three views of the inert compact and associated graphite sleeve from positions 2.6 .3

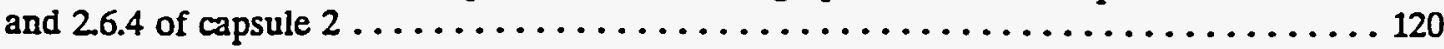

4.83 Three views of the graphite cylinders from positions 2.4 .2 and 2.4 .3 of capsule $2 \ldots \ldots 121$ 


\section{LIST OF FIGURES (continued)}

4.84 Three views of the graphite cylinders from positions 2.4 .4 and 2.4 .5 of capsule $2 \ldots \ldots 122$ 4.85 Three views of the graphite cylinders from positions 2.5 .2 and 2.5 .3 of capsule $2 \ldots \ldots 123$

4.86 Three views of the graphite cylinders from positions 2.5 .4 and 2.5 .5 of capsule $2 \ldots \ldots 124$

4.87 Four views of the inert compact and associated graphite sleeve from position 3.4.1

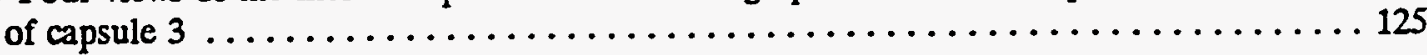

4.88 Three views of the inert compact and associated graphite sleeve from position 3.5.1

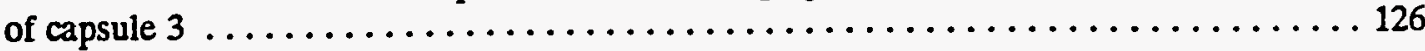

4.89 Three views of the inert compact and associated graphite sleeve from position 3.6 .1

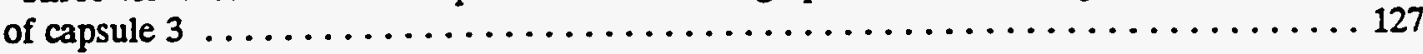

4.90 Three views of the inert compact and associated graphite sleeve from position 3.6.2

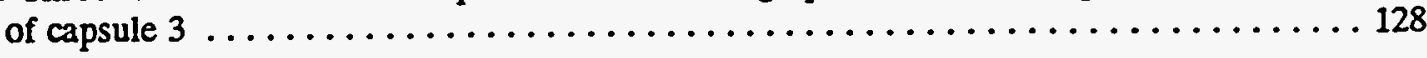

4.91 Three views of the inert compact and associated graphite sleeve from position 3.6.3

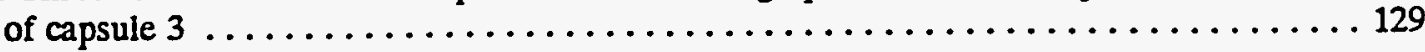

4.92 Three views of the inert compact and associated graphite sleeve from position 3.6.4

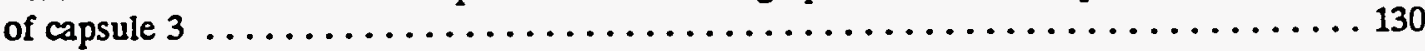

4.93 Three views of the graphite cylinders from positions $3.4 .2,3.4 .3,3.4 .4$, and 3.4 .5

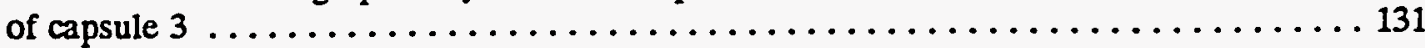

4.94 Three views of the graphite cylinders from positions 3.5.2, 3.5.3, 3.5.4, and 3.5.5

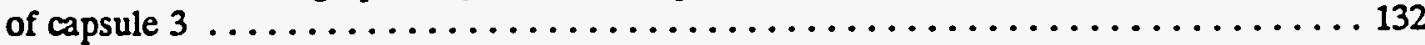

4.95 Components of the particle trays before irradiation $\ldots \ldots \ldots \ldots \ldots \ldots \ldots \ldots$

4.96 The assembled trays after irradiation $\ldots \ldots \ldots \ldots \ldots \ldots \ldots \ldots \ldots \ldots \ldots \ldots \ldots \ldots \ldots \ldots$

4.97 The graphite crucible and niobium encapsulated fuel particles before irradiation . . . . 139

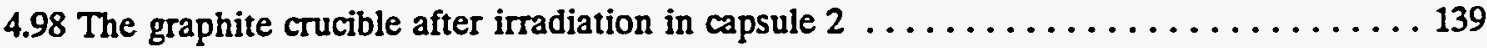

4.99 Views of the opened unbonded particle trays $2-3,2-4,2-7$, and $2-8$ from capsule $2 \ldots \ldots 140$

4.100 Views of the opened unbonded particle trays $3-3,3-4,3-7$, and 3-8 from capsule $3 \ldots 141$

4.101 Inventory $(\mathrm{Bq})$ of individual fissile particies for selected nuclides from particle

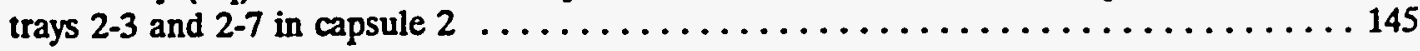

4.102 Inventory $(\mathrm{Bq})$ of individual fertile particles for selected nuclides from particle

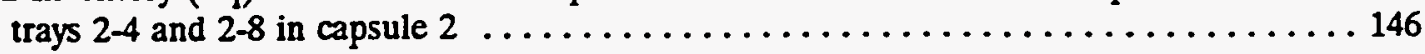

4.103 Inventory $(\mathrm{Bq})$ of individual fissile particles for selected nuclides from particle

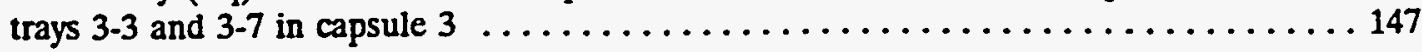




\section{LIST OF FIGURES (continued)}

4.104 Inventory $(\mathrm{Bq})$ of individual fertile particles for selected nuclides from particle

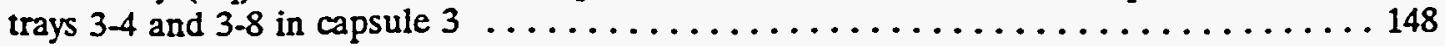

4.105 Inventory $(\mathrm{Bq})$ of individual kernels from fissile particles for selected nuclides from

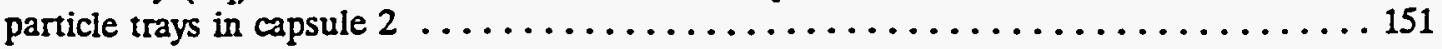

4.106 Inventory $(\mathrm{Bq})$ of individual kemels from fertile particles for selected nuclides from

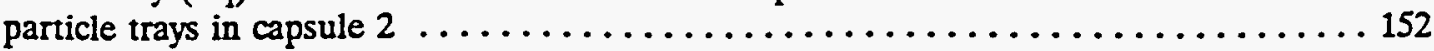

4.107 Inventory $(\mathrm{Bq})$ of individual kernels from fissile particles for selected nuclides from

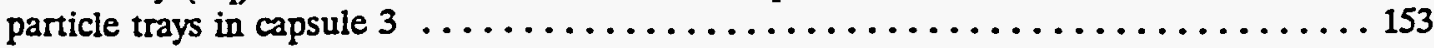

4.108 Inventory $(\mathrm{Bq})$ of individual kernels from fertile particles for selected nuclides from

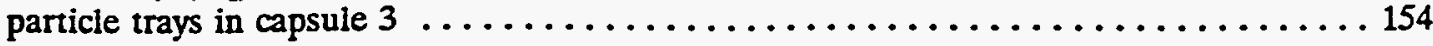

4.109 Inventory $(\mathrm{Bq})$ of the coatings from fissile particles for selected nuclides from

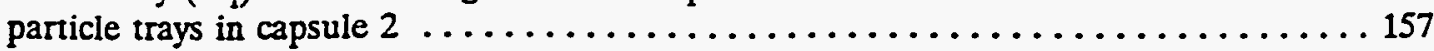

4.110 Inventory $(\mathrm{Bq})$ of the coatings from fertile particles for selected nuclides from

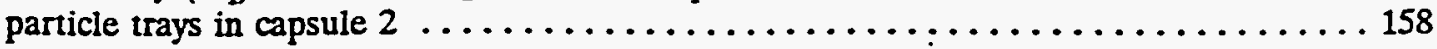

4.111 Inventory $(\mathrm{Bq})$ of the coatings from fissile particles for selected nuclides from

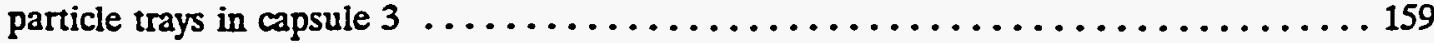

4.112 Inventory $(\mathrm{Bq})$ of the coatings from fertile particles for selected nuclides from

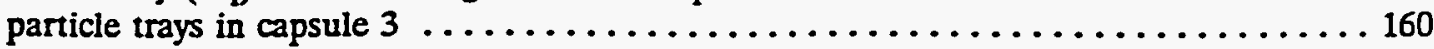

4.113 The percent retention of fission products in the kernels of intact fissile particles for

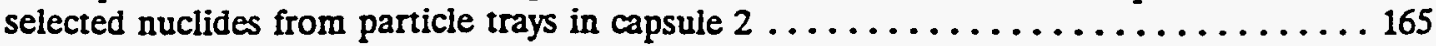

4.114 The percent retention of fission products in the kernels of intact fertile particles for

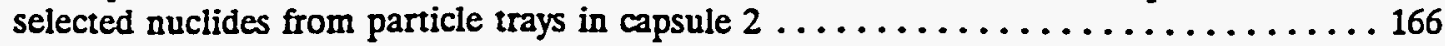

4.115 The percent retention of fission products in the kernels of intact fissile particles for selected nuclides from particle trays in capsule $3 \ldots \ldots \ldots \ldots \ldots \ldots \ldots \ldots \ldots$

4.116 The percent retention of fission products in the kernels of intact fertile particles for selected nuclides from particle trays in capsule $3 \ldots \ldots \ldots \ldots \ldots \ldots \ldots \ldots \ldots$

4.117 Force and movement conditions under which fissile particles from capsule 2 crack $\ldots 172$

4.118 Force and movement conditions under which fertile particles from capsule 2 crack $\ldots 173$

4.119 Force and movement conditions under which fissile particles from capsule 3 crack $\ldots 174$

4.120 Force and movement conditions under which fertile particles from capsule 3 crack $\ldots 175$ 


\section{LIST OF FIGURES (continued)}

4.121 The fractional release and release rate of ${ }^{85} \mathrm{Kr}$ at $800^{\circ} \mathrm{C}$ from compacts 2.2 .1 and 2.2 .2 as a function of time and the partial pressure of water vapor $\ldots \ldots \ldots \ldots 180$

4.122 The fractional release and release rate of ${ }^{85} \mathrm{Kr}$ at $800^{\circ} \mathrm{C}$ from compacts 3.2.1 and 3.2 .2 as a function of time and the partial pressure of water vapor $\ldots \ldots \ldots \ldots 183$

4.123 The fractional release and release rate of ${ }^{85} \mathrm{Kr}$ at $800^{\circ} \mathrm{C}$ from compacts 3.2 .1 and 3.2 .2 during the second $1 \mathrm{kPa}$ water vapor injection $\ldots \ldots \ldots \ldots \ldots \ldots \ldots$

4.124 The fractional release and release rate of ${ }^{85} \mathrm{Kr}$ at $800^{\circ} \mathrm{C}$ from $5 \mathrm{UCO}$ kernels taken from particles in tray 3-7 as a function of time and the partial pressure of water vapor . 189

4.125 The fractional release and release rate of ${ }^{85} \mathrm{Kr}$ at $800^{\circ} \mathrm{C}$ from $5 \mathrm{UCO}$ kernels taken from particles in tray 3-7 as a function of time and the partial pressure of water vapor . 189

4.126 Modified flow chart for capsules 2 and 3 with remaining tasks to be completed or

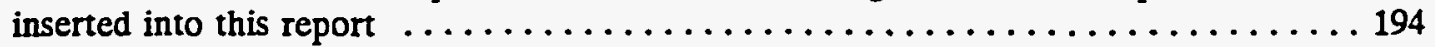




\section{LIST OF TABLES}

Table

4.1 Definition of the symbols used on the PIE flow chart $\ldots \ldots \ldots \ldots \ldots \ldots \ldots \ldots$

4.2 Packing the fluence monitors from capsules 2 and $3 \ldots \ldots \ldots \ldots \ldots \ldots \ldots \ldots \ldots \ldots \ldots \ldots \ldots \ldots$

4.3 Measurement conditions for the stainless steel capsules 2 and $3 . \ldots \ldots \ldots \ldots \ldots \ldots$

4.4 Measurement conditions for the graphite bodies of capsules 2 and $3 \ldots \ldots \ldots \ldots 27$

4.5 Measurement conditions for the gamma scan wires from capsules 2 and $3 \ldots \ldots \ldots 28$

4.6 Impuises during gamma scan of gamma scan wire 21 from capsule $2 \ldots \ldots \ldots \ldots .49$

4.7 Impulses during gamma scan of gamma scan wire 2.2 from capsule $2 \ldots \ldots \ldots \ldots . \ldots 52$

4.8 Impulses during gamma scan of gamma scan wire 2.3 from capsule $2 \ldots \ldots \ldots \ldots 5$

4.9 Impulses during gamma scan of gamma scan wire 3.1 from capsule $3 \ldots \ldots \ldots \ldots$

4.10 Impulses during gamma scan of gamma scan wire 3.2 from capsule $3 \ldots \ldots \ldots \ldots 61$

4.11 Impulses during gamma scan of gamma scan wire 3.3 from capsule $3 \ldots \ldots \ldots \ldots 64$

4.12 Measurement conditions for the graphite bodies of capsules 2 and $3 \ldots \ldots \ldots \ldots 77$

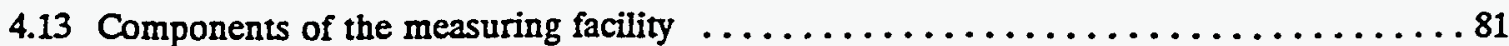

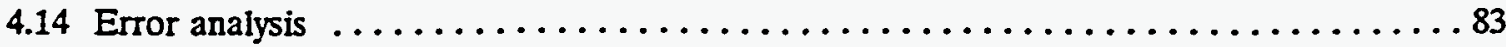

4.15 The measured activities (Bq) of selective isotopes of the fuel compacts from capsule $2 \ldots 84$

4.16 The measured activities $(\mathrm{Bq})$ of selective isotopes of the fuel compacts from capsule $3 \ldots 85$

4.17 Dimensional measurements on eight compacts from hole 1 of capusles 2 and $3 \ldots \ldots 87$

4.18 Weight measurements of eight compacts from hole 1 of capsules 2 and $3 \ldots \ldots \ldots 7$

4.19 Measurements conditions for the graphite bodies of capsules 2 and $3 \ldots \ldots \ldots 92$

4.20 The inventory in the graphite cylindrical sector from capsule $2 \ldots \ldots \ldots \ldots \ldots \ldots$

4.21 The inventory in the graphite cylindrical sector from capsule $3 \ldots \ldots \ldots \ldots \ldots$

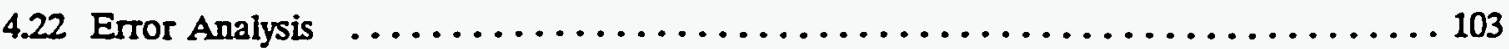

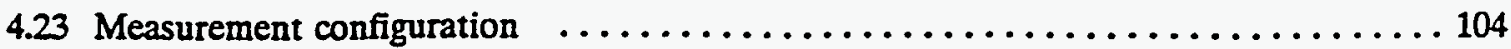




\section{LIST OF TABLES (continued)}

4.24 The inventories $(\mathrm{Bq})$ of the plugs and screws from capsule 2

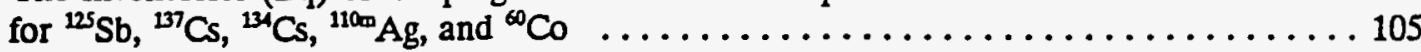

4.25 The inventories $(\mathrm{Bq})$ of the plugs and screws from capsule 3

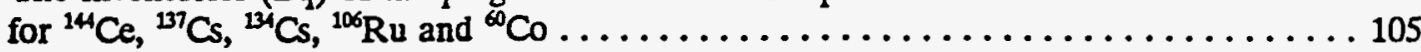

4.26 The inventories $(\mathrm{Bq})$ of the graphite cylinders and sleeves from capsule 2

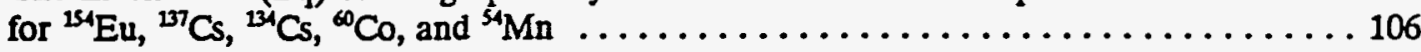

4.27 The inventories $(\mathrm{Bq})$ of the graphite cylinders and sleeves from capsule 3

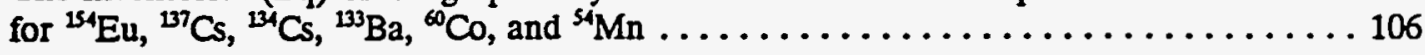

4.28 The inventories $(\mathrm{Bq})$ of the particle trays from capsule 2 and 3

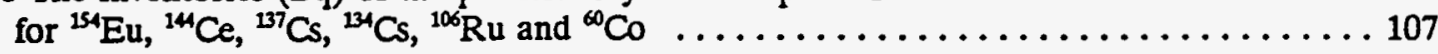

4.29 Distribution of cesium between the fuel compacts and the graphite in the fuel element 112

4.30 Summary of inventory measurements on the graphite components of the fuel element $\ldots 114$

4.31 Dimensional measurements on cylinders of grade $\mathrm{H}-451$ and $\mathrm{H}-451 \mathrm{I}$ graphite from

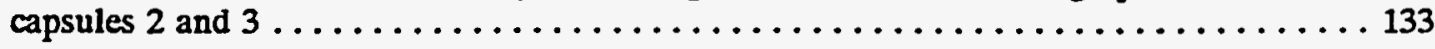

4.32 Weight measurements on cylinders of grade $\mathrm{H}-451$ and $\mathrm{H}-451 \mathrm{I}$ graphite from

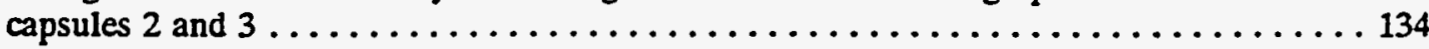

4.33 Dimensional measurements on inert compacts and selected graphite annuli from

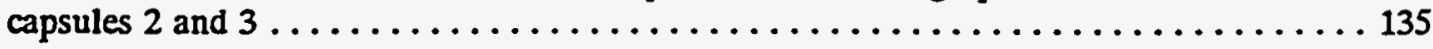

4.34 Weight measurements on inert compacts and selected graphite annuli from

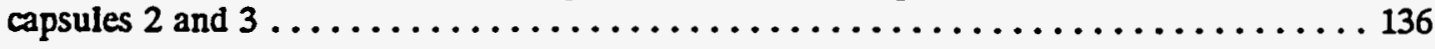

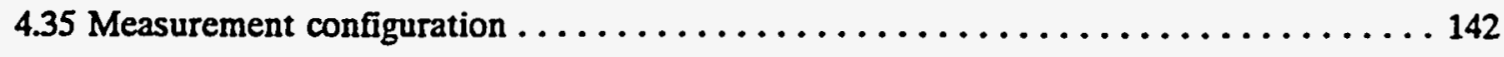

4.36 Inventory $(\mathrm{Bq})$ of individual fissile particles for selected nuclides from

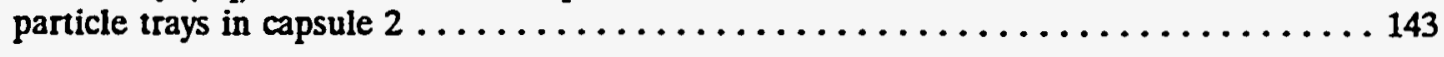

4.37 Inventory $(\mathrm{Bq})$ of individual fertile particles for selected nuclides from

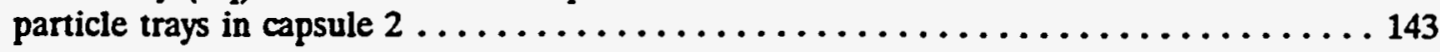

4.38 Inventory $(\mathrm{Bq})$ of individual fissile particles for selected nuclides from

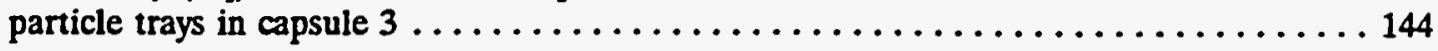

4.39 Inventory $(\mathrm{Bq})$ of individual fertile particles for selected nuclides from

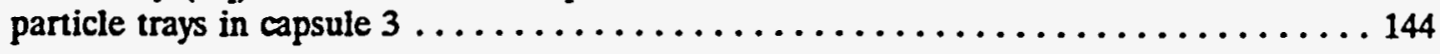

4.40 Inventory $(\mathrm{Bq})$ of individual kernels from fissile particles for selected nuclides from

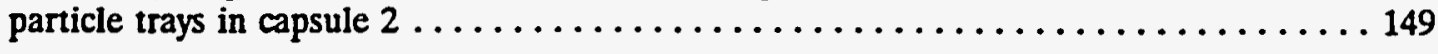




\section{LIST OF TABLES (continued)}

4.41 Inventory $(\mathrm{Bq})$ of individual kernels from fertile particles for selected nuclides from

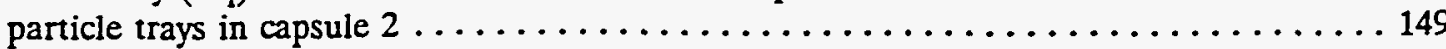

4.42 Inventory $(\mathrm{Bq})$ of individual kernels from fissile particles for selected nuclides from

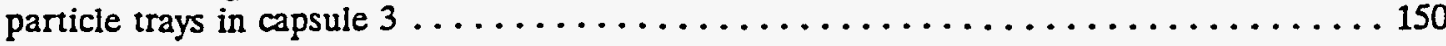

4.43 Inventory $(\mathrm{Bq})$ of individual kernels from fertile particles for selected nuclides from

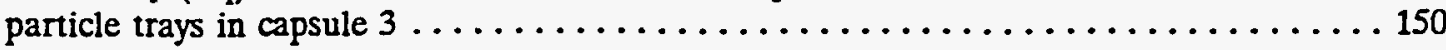

4.44 Inventory $(\mathrm{Bq})$ of the coatings from fissile particles for selected nuclides from

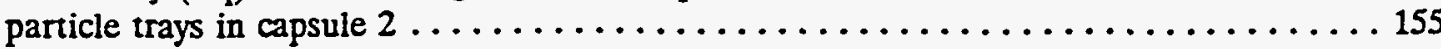

4.45 Inventory $(\mathrm{Bq})$ of the coatings kernels from fertile particles for selected nuclides from

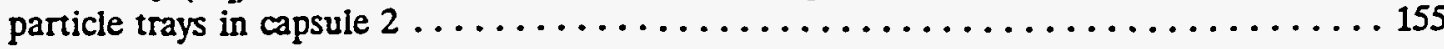

4.46 Inventory $(\mathrm{Bq})$ of the coatings from fissile particles for selected nuclides from

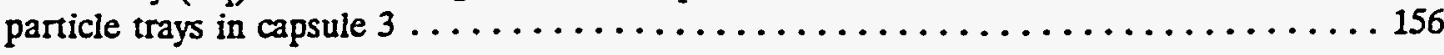

4.47 Inventory $(\mathrm{Bq})$ of the coatings from fertile particles for selected nuclides from

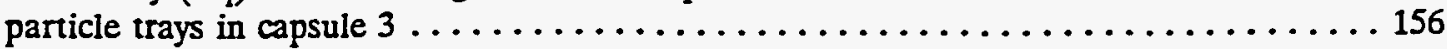

4.48 Inventory (Bq) of bare kernels plus the associated coatings from fissile particles for selected nuclides from particle trays in capsule $2 \ldots \ldots \ldots \ldots \ldots 16 \ldots$

4.49 Inventory (Bq) of bare kernels plus the associated coatings from fertile particles for selected nuclides from particle trays in capsule $2 \ldots \ldots \ldots \ldots \ldots 1$

4.50 Inventory $(\mathrm{Bq})$ of bare kernels plus the associated coatings from fissile particles for selected nuclides from particle trays in capsule $3 \ldots \ldots \ldots \ldots \ldots 2$

4.51 Inventory $(\mathrm{Bq})$ of bare kernels plus the associated coatings from fertile particles for selected nuclides from particle trays in capsule 3

4.52 The percent retention of fission products in the kernels of intact

fissile particles for selected nuclides from particle trays in capsule $2 \ldots \ldots \ldots \ldots \ldots$

4.53 The percent retention of fission products in the kernels of intact fertile particles for selected nuclides from particle trays in capsule $2 \ldots \ldots \ldots \ldots \ldots 163$

4.54 The percent retention of fission products in the kernels of intact fissile particles for selected nuclides from particle trays in capsule 3

4.55 The percent retention of fission products in the kernels of intact fertile particles for selected nuclides from particle trays in capsule $3 \ldots \ldots \ldots \ldots \ldots$

4.56 Force and movement conditions under which fissile particles from capsule 2 crack $\ldots 170$ 4.57 Force and movement conditions under which fertile particles from capsule 2 crack $\ldots 170$ 


\section{LIST OF TABLES (continued)}

4.58 Force and movement conditions under which fissile particles from capsule 3 crack $\ldots 171$

4.59 Force and movement conditions under which fertile particles from capsule 3 crack $\ldots 171$

4.60 Technical data for the KORA facility $\ldots \ldots \ldots \ldots \ldots \ldots \ldots \ldots \ldots \ldots \ldots \ldots \ldots \ldots \ldots \ldots$

4.61 Property data on the fuel compacts and fuel kernels used in the heating tests with intermitent injections of water vapor $\ldots \ldots \ldots \ldots \ldots \ldots \ldots \ldots \ldots \ldots \ldots$

4.62 Irradiation conditions, ${ }^{85} \mathrm{Kr}$ inventory at the beginning of test and test conditions for the fuel compacts and fuel kernels used in the heating tests with intermittent injections of water vapor

4.63 The fractional release and release rate of ${ }^{85} \mathrm{Kr}$ at $800^{\circ} \mathrm{C}$ from compacts 2.2 .1 and 2.2.2 as a function of time and the partial pressure of water vapor

4.64 The fractional release and release rate of ${ }^{85} \mathrm{Kr}$ at $800^{\circ} \mathrm{C}$ from compacts 3.2 .1 and 3.2.2 as a function of time and the partial pressure of water vapor

4.65 The fractional release and release rate of ${ }^{85} \mathrm{Kr}$ at $800^{\circ} \mathrm{C}$ from $5 \mathrm{UCO}$ kernels taken from particles in tray 3-7 as a function of time and the partial pressure of water vapor

4.66 The fractional release and release rate of ${ }^{85} \mathrm{Kr}$ at $800^{\circ} \mathrm{C}$ from $5 \mathrm{UCO}$ kernels taken from particles in tray 3-7 as a function of time and the partial pressure of water vapor 193 


\title{
INTERIM REPORT ON THE POST IRRADIATION EXAMINATION OF CAPSULES 2 AND 3 OF THE HFR-B1 EXPERIMENT
}

\author{
B. F. Myers
}

\begin{abstract}
This is an interim report on the post irradiation examination (PIE) of capsules 2 and 3 of the HFR-B1 experiment. The PIE has been conducted by the Forschungszentrum Jalich and is nearing completion. After disassembly of the capsules, the examination focused on capsule components including fuel compacts, inert compacts fired in different media, graphite cylinders of different grades, unbonded coated fuel particles and unfueled graphite; in addition, heating experiments with intermittent injections of water vapor were conducted using fuel compacts and the kernels of uranium oxycarbide. Measurement involved gamma scanning and counting, photography, metallography, dimensional and weight changes, burnup determination and fission product release.
\end{abstract}

\section{INTRODUCTION}

Capsules 2 and 3 were part of the HFR-B1 experiment. Experiment HFR-B1 was a cooperative experiment conducted under the US/FRG Umbrella Agreement for.Cooperation in Gas Cooled Reactor Development at the Joint Research Centre, Petten, The Netherlands. The experiments were designed to provide for measurement of fission gas and metallic fission product release in simulated, prismatic core, fuel elements over the range of MHTGR normal operating conditions and in the presence of significant quantities of water vapor. The irradiation was begun in April 1987 and ended in July 1989, during which 445 effective full power days were accumulated.

Following the irradiation phase of experiment HFR-B1, the fuel elements were sent to the Forschungszentrum, Julich GmbH (KFA) for postirradiation examination (PIE). The fuel elements were contained in three capsules designated 1,2, and 3. The PIE of capsules 2 and 3 began in 1991 under the US/FRG Umbrella Agreement for Cooperation in Gas Cooled Reactor Development. This agreement was in force in 1991. By 1993, the support for work in gas-cooled reactor research had largely been terminated at the KFA and the Umbrella Agreement was no longer regarded as an appropriate basis by the KFA for cooperative work. As a consequence, the PIE of capsule 1 is being conducted under subcontract with the KFA.

\section{OBJECTIVES OF CAPSULES 2 AND 3}

The main objectives of capsules 2 and 3 were as follows:

1. measurement of the release of fission gas at temperatures near and above the upper limit of HTGR normal operating temperatures (capsule 2),

'Research sponsored by the Forschungszentrum Jalich GmbH, Jalich, Germany and by the Office of Advanced Reactor Programs, Division of HTGRs, U.S. Department of Energy under contract DE-AC05-84OR21400 with Martin Marietta Energy Systems, Inc. 
2. measurement of the effect of hydrolysis on coated fuel particles with exposed uranium oxycarbide (UCO) kernels and on the surrounding fuel compact matrix and graphite (capsule 3),

3. measurement of the irradiation response of grades $H-451$ and $H-451 I$ graphite and of inert compacts fired in alumina and silicon carbide molds and,

4. provision of unbonded, coated fuel particles and of fuel compacts for use in postirradiation tests including the determination of the release of fission products from the kernels.

The most important measurements for capsules 2 and 3 were, however, the on-line fission gas release measurements during the irradiation. The resulting data satisfy objectives 1 and 2 above and provided the basis for the analysis of the effect of high temperatures and water vapor on fission gas release. The other objectives were, to a large degree, independent and supplemental.

\section{CONFIGURATION OF CAPSULES 2 AND 3}

A capsule consists of a stainless steel container which houses a cylindrical graphite body, heat shields, and fluence detectors, and has sweep gas inlet and outlet lines. The graphite body itself contains seven, full length holes in which are placed fuel compacts, inert compacts, graphite specimens, trays of unbonded particles and three, niobium-encapsulations. ${ }^{1}$ A cross sectional view representative of capsules 2 and 3 is shown in Fig. 3.1. Perspective views of capsules 2 and 3 are shown in Figs. 3.2 and 3.3; in these figures, the numbers xy.z indicate the capsule number $(x)$, the hole number $(y)$ and the axial stacking position (z). The stacking position numbers are ordered with number 1 in the top position. The fuel compacts are in holes.1,2, and 3; the inert compacts and the graphite specimens are in holes 4,5 , and 6 and trays of unbonded particles are in the unnumbered central hole. Where the letters $a$ and $b$ are appended to the three number identification, there are, in those positions, a fuel compact and graphite sleeve, respectively.

\section{PIE OF CAPSULES 2 AND 3}

The PIE of capsules 2 and 3 consists esentially of five major tasks: (1) the disassembly of the capsules, and the examination of (2) the fuel compacts, (3) the unfueled graphite bodies, (4) the unbonded coated fuel particles and (5) the inert compacts and graphite specimens.

\subsection{PIE TEST PLAN FOR CAPSULES 2 AND 3}

The PIE test plan for capsules 2 and $3^{1}$ is represented by the flow chart of Fig. 4.1. The definitions of the symbols used in the flow chart are presented in Table 4.1 and the icons are identified in Fig. 4.2 There are six tasks on the flow chart that were not done. These tasks involved measurements of the coefficient of thermal expansion (CTE) and Young's modulus (YM); the shipping of capsule 1 and encapsulated samples to ORNL; measurements of the gamma scan wires at the Joint Research Centre, Petten, The Netherlands (JRC); and heating of graphite sectors. Furthermore, the heating tests were altered by using only 2 fuel compacts per capsule and 10 unbonded fuel particles from capsule 3. The KFA hot cells did not have the equipment to measure the CTE and YM; the expense of shipping capsule 1 to to ORNL and performing the PIE was too great and a subcontract was made with the KFA to conduct the PIE for the available funds. The gamma scan wires were measured at the KFA. The samples on which the KFA was requested to measure the CTE and YM can be readily shipped to the U.S. for measurements if requested. The same applies to the encapsulated samples as the necessary equipment to analyze them is at General Atomics (GA). 
ORNL-DWG 90-2299R

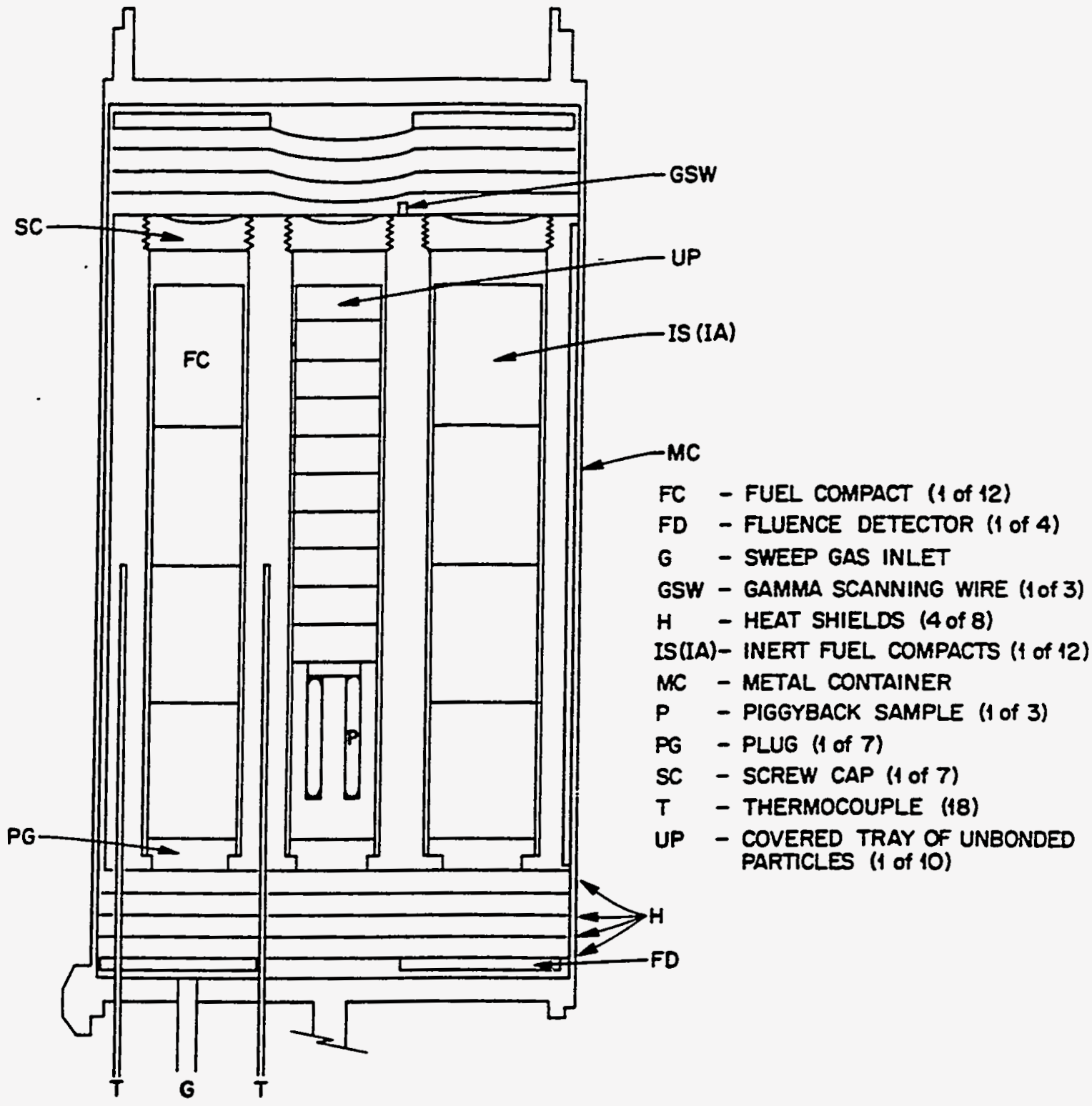

Fig. 3.1 Cross-sectional representative of capsules 2 and 3 


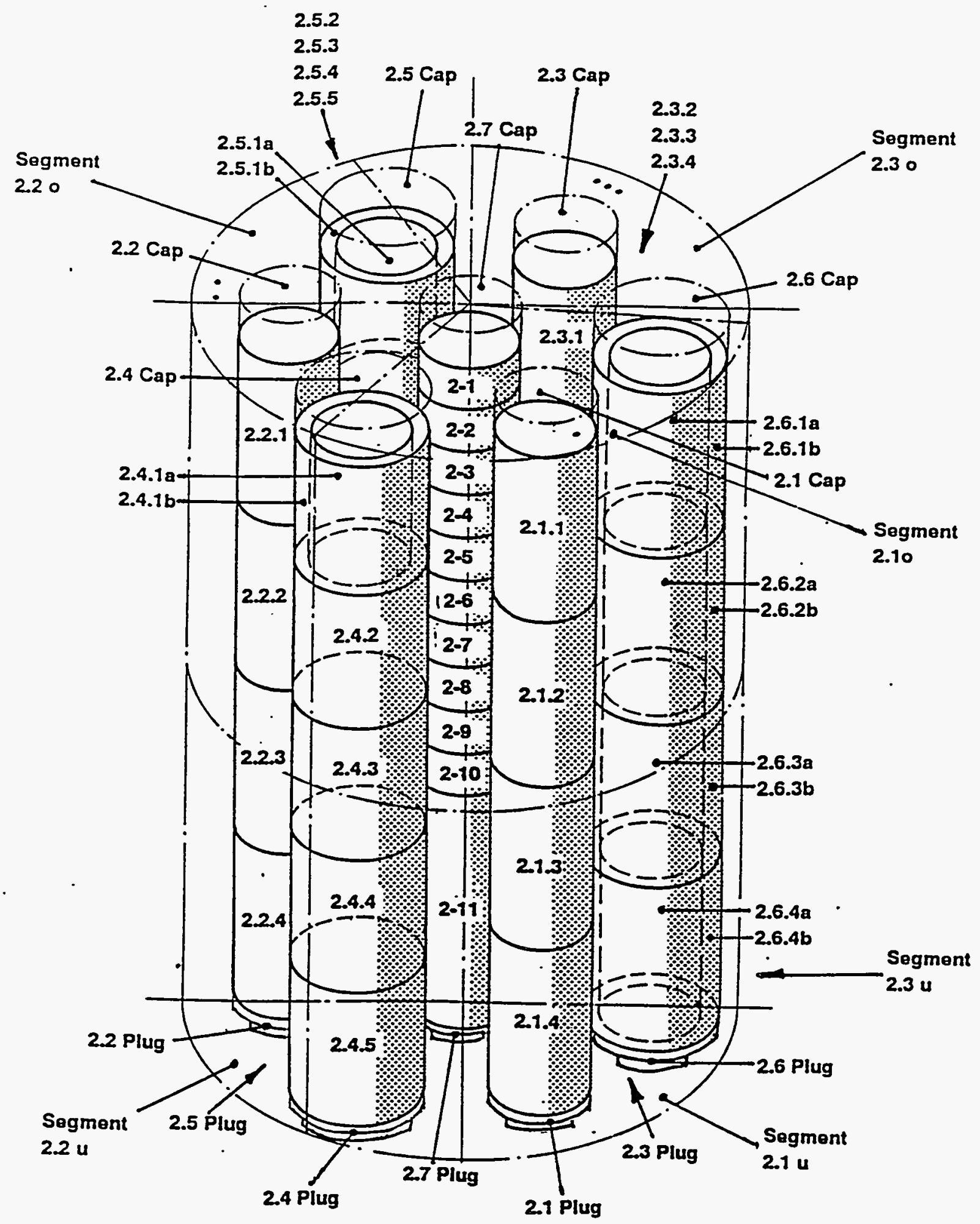

Fig. 3.2 Perspective view of the contents of capsule 2

Source: Forschungszentrum Jalich GmbH, Jalich, Germany 


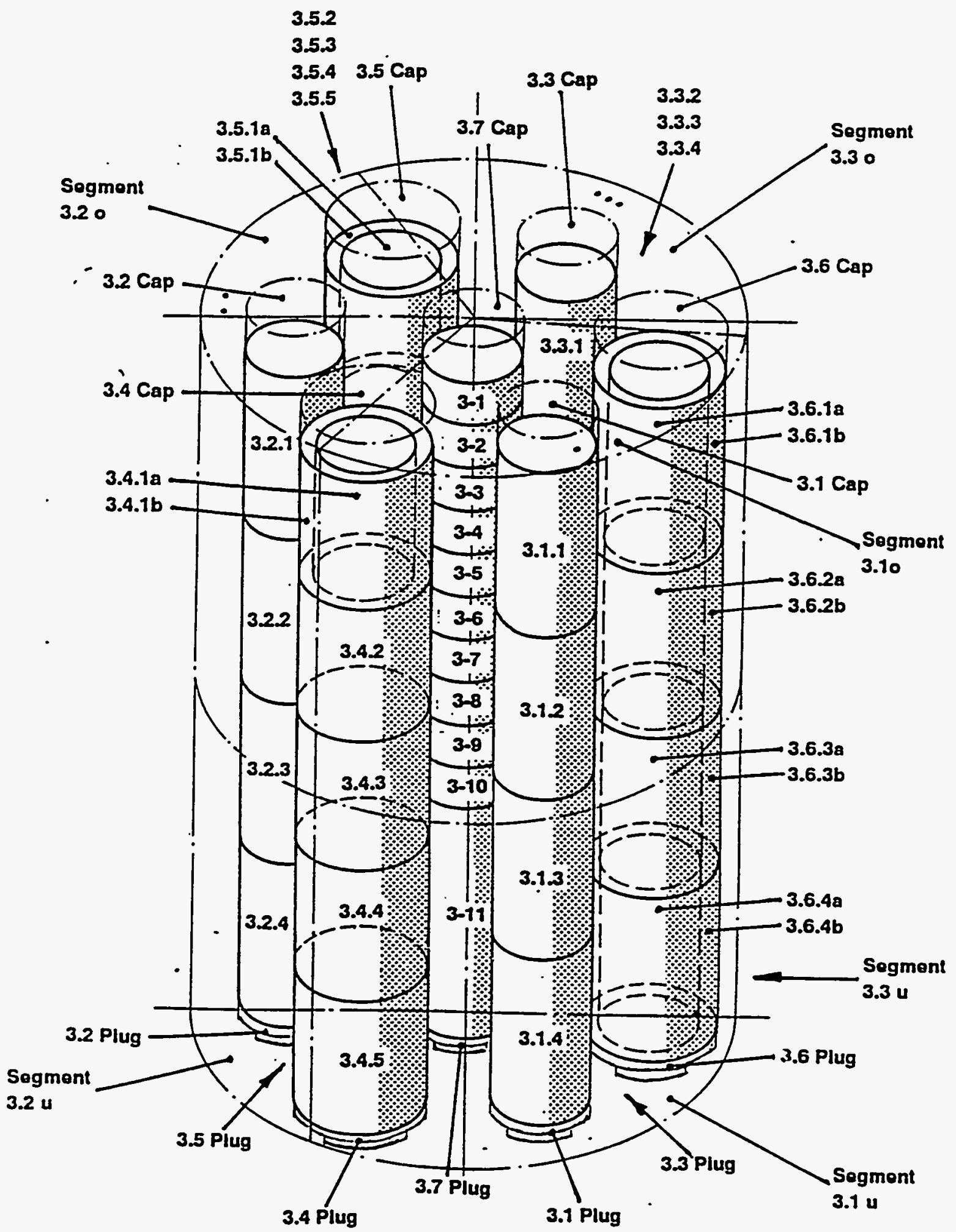

Fig. 3.3 Perspective view of the contents of capsule 3

Source: Forschungszentrum Jalich GmbH, Jalich, Germany 


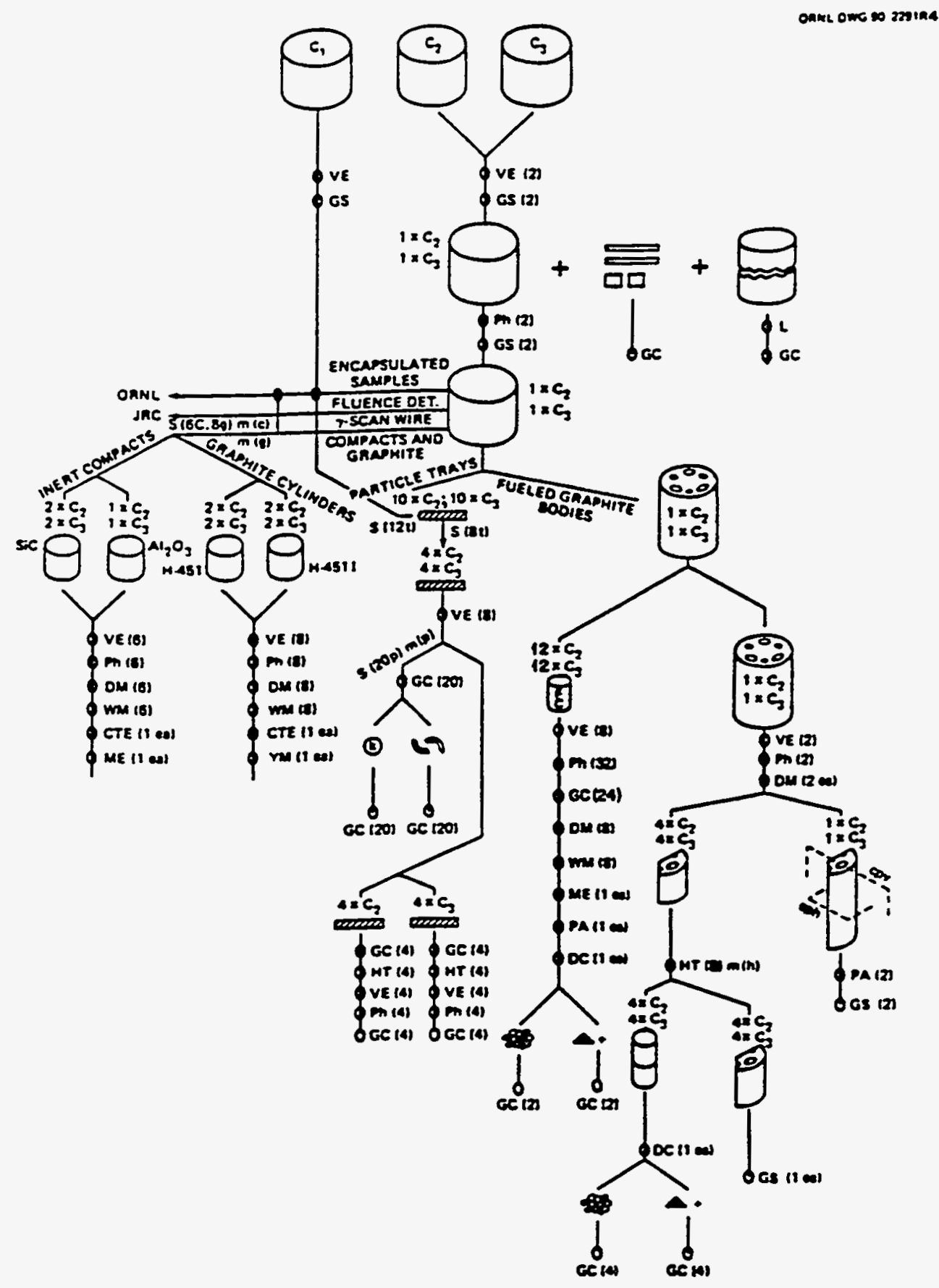

Fig. 4.1 PIE flow chart for capsules 2 and 3 
Table 4.1 Definitions of symbols used on the PIE flow chart

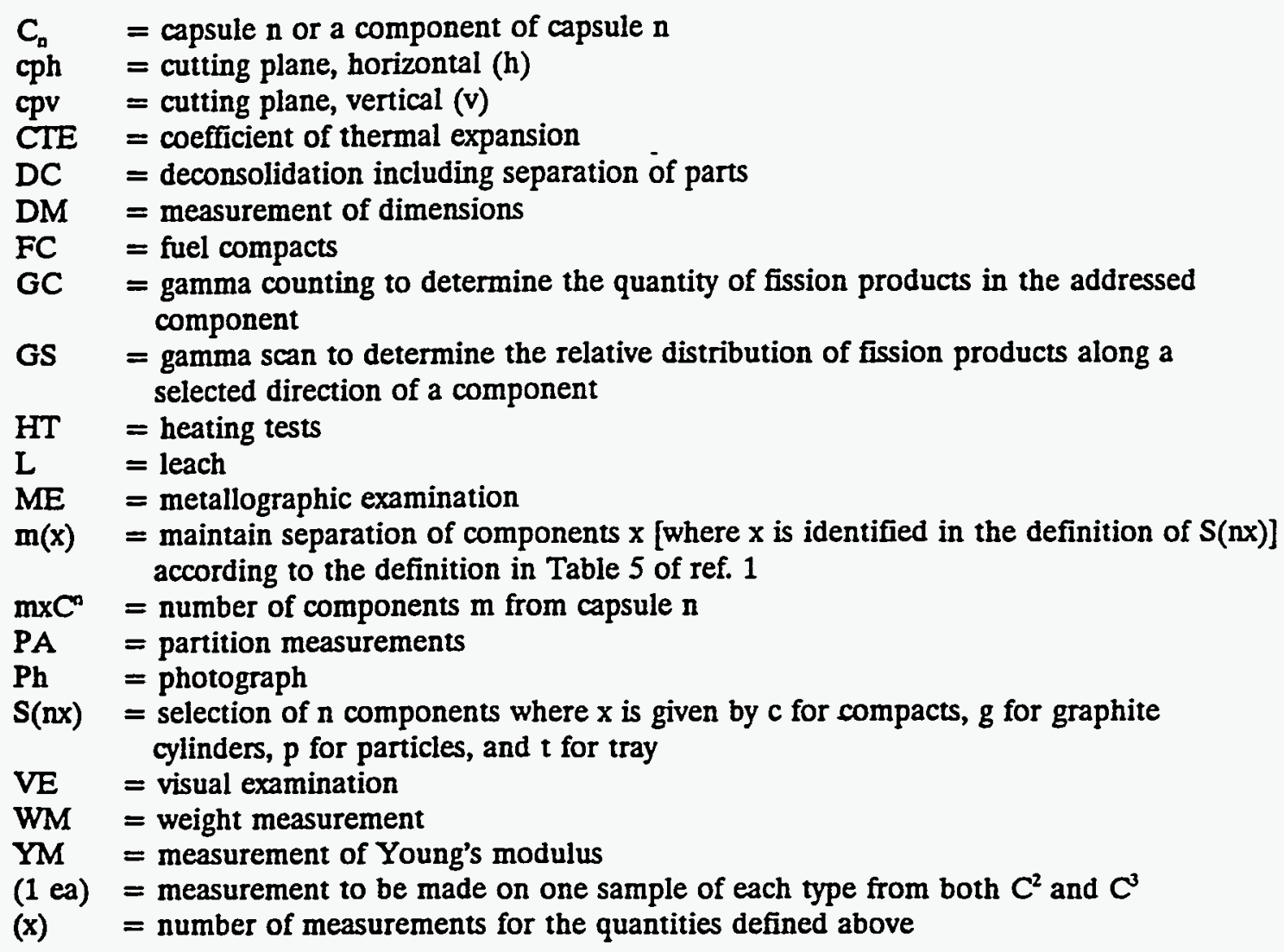


ORNL-DWG 90-2282B

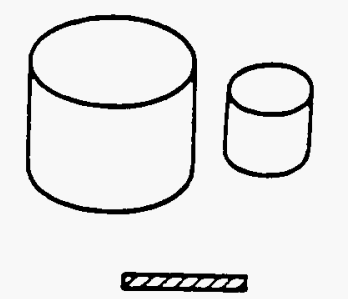

CAPSULE, INERT COMPACT, GRAPHITE CYLINDER

(k)

TRAY OF UNBONDED PARTICLES

6

BARE KERNEL

E

REMOVED PARTICLE COATINGS

-FUEL COMPACT

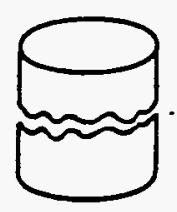

STAINLESS STEEL CAPSULE CONTAINER AFTER DISASSEMBLY

FUELED FUEL HOLES

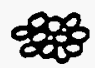

COATED PARTICLES

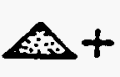

MATRIX AFTER DECONSOLIDATION PLUS LIQUID

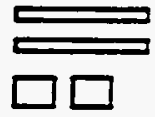

GRAPHITE CAPS AND PLUGS FROM DISASSEMBLY

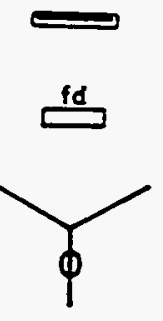

GAMMA SCANNING WIRE

FLUENCE DETECTORS

DO THE SAME EXPERIMENT ON THE DIFFERENT SAMPLES INDICATED ABOVE THE BRANCH POINT

Fig. 4.2 Definition of icons used on the PIE flow chart 
The flow chart, modified by deleting the tasks that could not be done at the KFA and by outlining the major tasks, is shown as Fig. 4.3.

\subsection{DISASSEMBLY OF CAPSULES 2 AND 3}

The three capsules of HFR-B1 were received by the KFA. Capsules 1 and 2 were joined by a cross bar; the cross bar was severed and capusle 1 was placed in storage in anticipation of shipping it the ORNL. The process and operations of disassembly are identified in Figs. 4.3, 4.2 and Table 4.1.

\subsubsection{Visual Inspection and Photography ${ }^{2}$}

The stainless steel capsules showed light, spotted red-brown doscoloration on the outer surfaces. The overview appearances of capsule 2 are shown in Figs. 4.4 and 4.5 by photographs 468/26; 28 ; $B 1 ; B 2$; and 135 . On capsule 2 , the welding joint of the gas tube on the upper end plate is strongly corroded as shown in Fig. 4.5, photograph 468/36. The overview appearances of capsule 3 are shown in Figs.4.6, 4.7, 4.8, 4.9, and 4.10. Capsule 3 exhibits corrosion on the lower welding joint, the joint for the thermocouple protection tube and on the exit gas tube on the end plate which showns light corrosion developing (see photographs 468/18; $119 ; 122 ; 123 ; 124$; and 469/17-25; 31 ).

\subsubsection{Capsule $2^{2}$}

By circumferential grinding of the capsule at the level of the welding joints, the end plates were removed. The graphite appeared, aftr removing the heat shields, as shown in Fig. 4.11, photograph 468/40. The heat shields were warped but shiny and appeared as shown by the examples in Fig. 4.11, photographs $468 / 1$ and 468/2. The gamma scan wires were removed and placed in aluminum cans. The theroelements, shown in Fig. 4.11, photograph 468/4, exhibited no visible damage. Thereafter, the graphite body was removed from the remaining capsule. The visible inspection of the graphite body, as shown in Fig. 4.12, photgraphs $468 / 41-43$, brought no special feature to light, all markings were well recognized.

To loosen the upper and lower flux monitors on the underside of the end plates (Fig. 4.11, photograph $468 / 2$ ), the retaining bands were cut by means of a grinding disk. The flux monitors were removed from the encapsulations by grinding on a lathe with a special holding configuration. Thereafter, the capsule content was placed in an aluminum can.

\subsubsection{Capsule $3^{2}$}

The opening of capsule 3 was analogous to the procedure used for capsule 2. The thermoelements were easily pulled and there were no noteworthy features. The end plate, thermocouple protection tubes and adjacent heat shield are shown in Fig. 4.13, photographs 469/33-35. All protection tubes remained intact in the bore holes on the graphite body. The heat shields showed a light discoloration but were otherwise in order. The withdrawal of the gamma scan wires was arranged with more difficulty than in capsule 2. This difficulty may be the result of the oxidation of the niobium protection tubes by the water vapor added in the experiments in capsule 3 . By pushing, the graphite bodies slid out to an extent that permitted their removal from the bore holes with forceps. Visual inspection of the graphite bodies found no special features. The bodies are shown in Fig. 4.14, photographs 469/30;37;/41 and in Fig. 4.15,photographs 469/26-29. The inside of the stainless steel capsule is shown oin Fig. 4.16, photographs 469/38-40.

The fluence detectors from capsules 2 and 3 were sent to Petten for evaluation on 12.02.91. The packing and identification of the fluence monitors is shown in Table 4.2. The steel capsules with end plates and heat shields were sent to the KFA hot cell 1 on 11.03.91. 
Table 4.2 Packing the fluence monitors from capsules 2 and 3

\begin{tabular}{|c|c|c|c|c|}
\hline \multirow[b]{2}{*}{ Can No. } & \multicolumn{2}{|c|}{ Identification } & \multirow{2}{*}{$\begin{array}{l}\text { Capsule No. \& } \\
\text { Detector Pos. }\end{array}$} & \multirow{2}{*}{$\begin{array}{l}\text { Remark } \\
\text { Content } \\
\end{array}$} \\
\hline & upper & lower & & \\
\hline 5 & $x x x x x$ & o & 2, north upper & in order \\
\hline 6 & $x$ & $x$ & 2 , south upper & in order \\
\hline 7 & $x x$ & $x$ & 2, north lower & broken \\
\hline 8 & $x x$ & $x x$ & 2 , south lower & broken \\
\hline 9 & $x \mathbf{x x}$ & $x$ & 3 , north upper & broken \\
\hline 10 & $x \alpha x$ & $x x$ & 3 , south upper & broken \\
\hline 11 & $\operatorname{sox} x$ & $x$ & 3, north lower & in orde \\
\hline 12 & $x 00 x$ & $x x$ & 3 , south lower & in orde \\
\hline
\end{tabular}




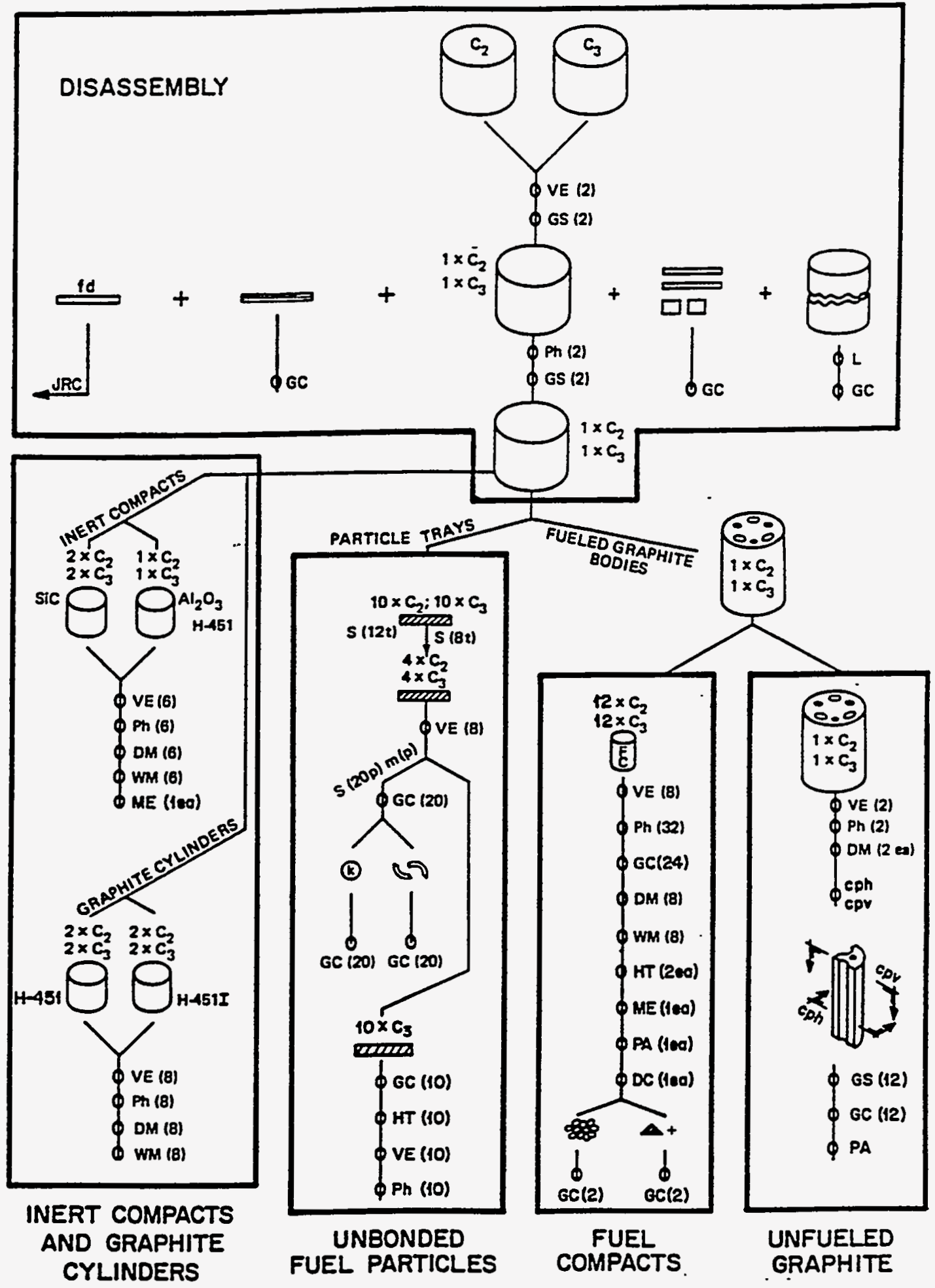

Fig. 4.3 Modified PIE flow chart with major tasks outlined for capsules 2 and 3 


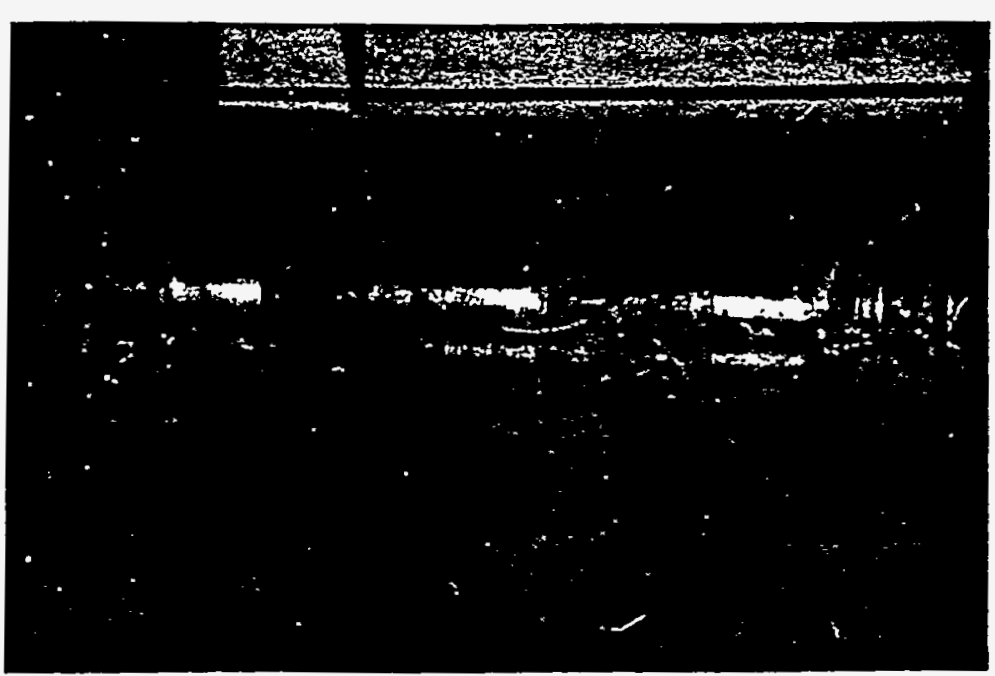

$\frac{\text { HFR-B1 }}{\text { Kapsel } 2}$

$468 / 26$

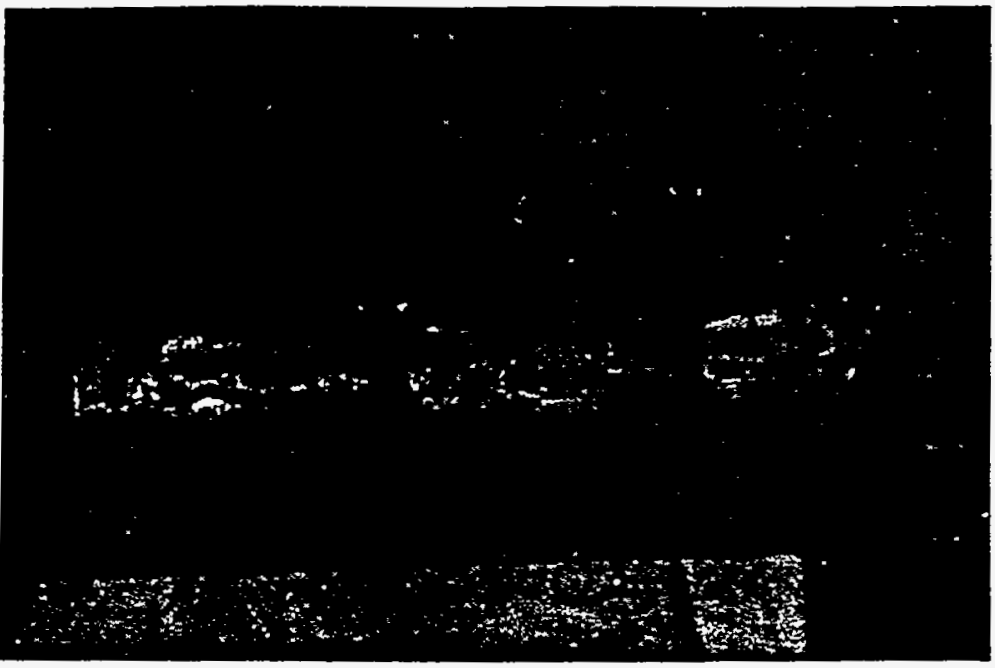

$468 / 28$

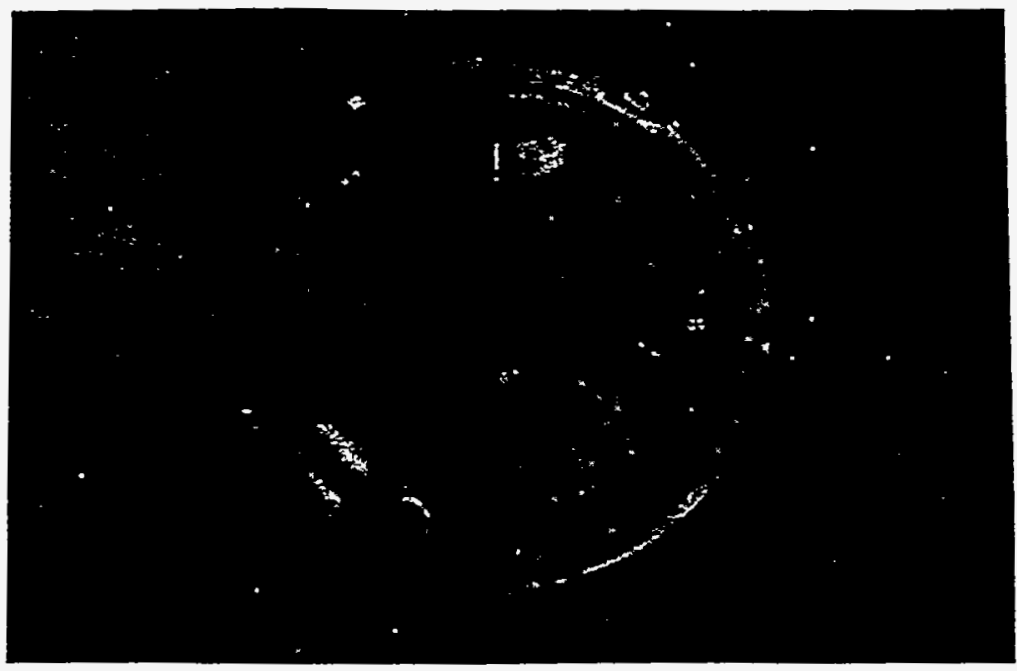

$468 / 31$

Fig. 4.4 The overview appearances of capsule 2 Source: Forschungszentrum Jalich GmbH, Julich, Germany 


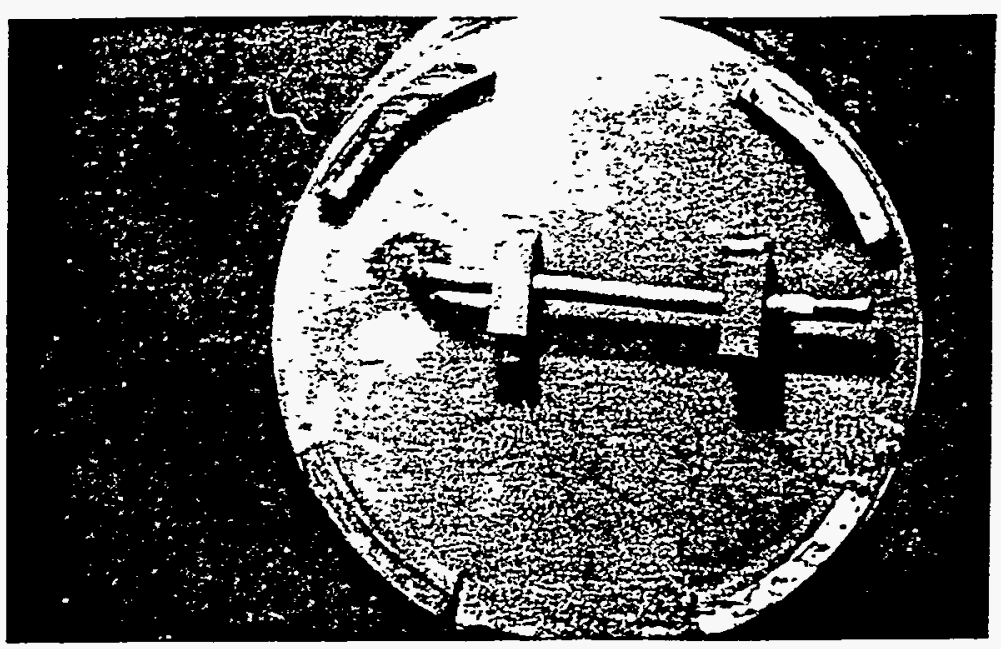

$\frac{\text { HFR B1 }}{\text { Kapsel } 2}$

$468 / 35$

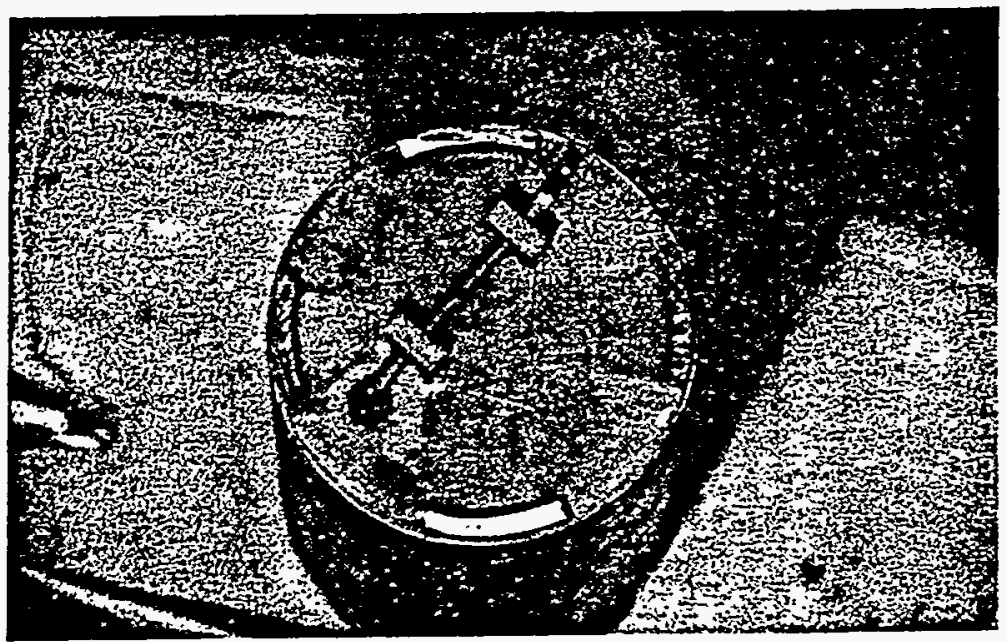

\section{$468 / 32$}

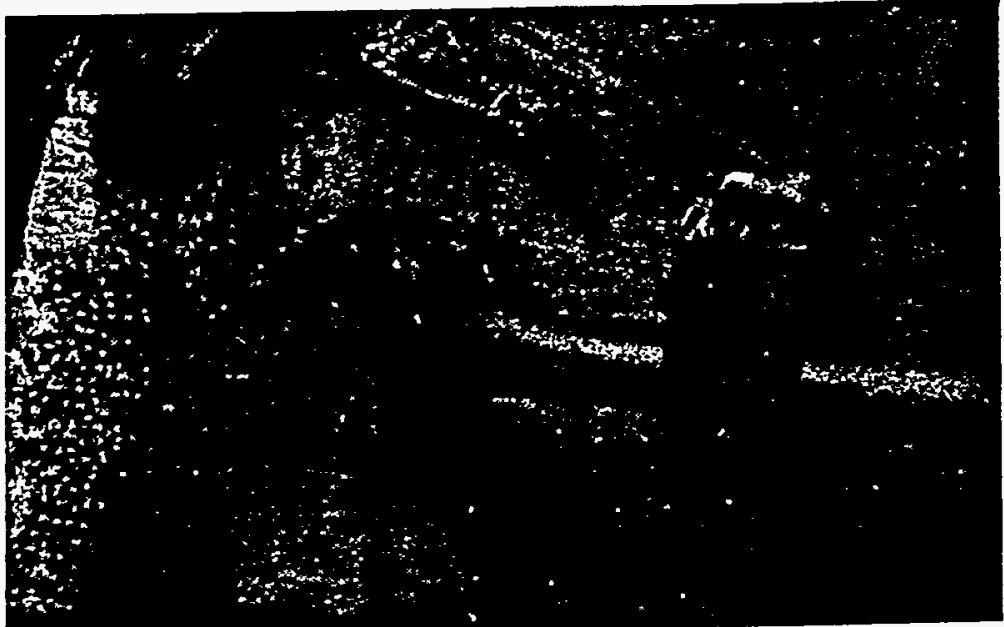

Fig. 4.5 The overview appearances of the ends of capsule 2 Source: Forschungszentrum Jalich GmbH, Jalich, Germany 


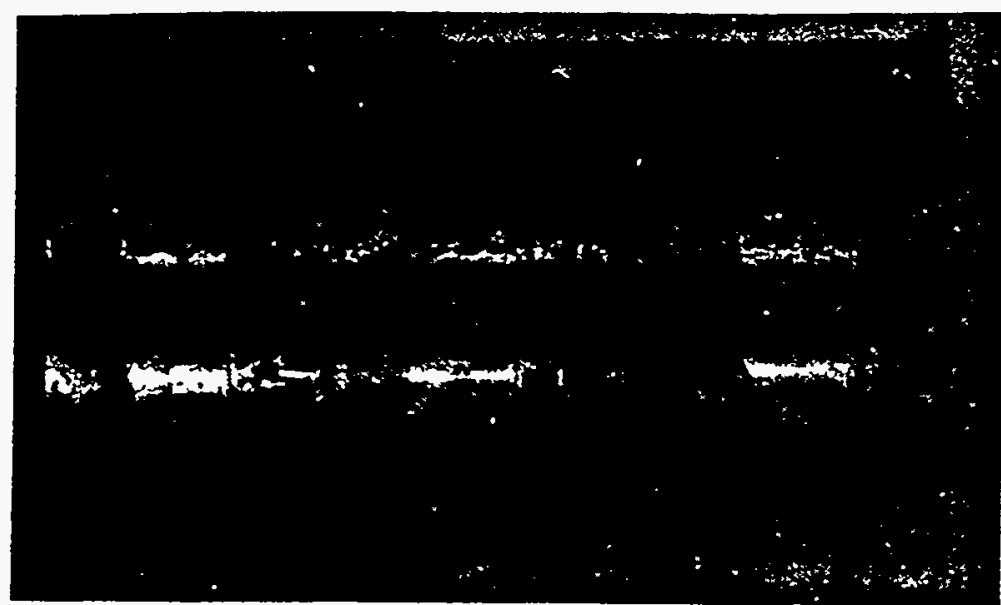

\section{HFR-B1 Kapsel 3}

$468 / 18$

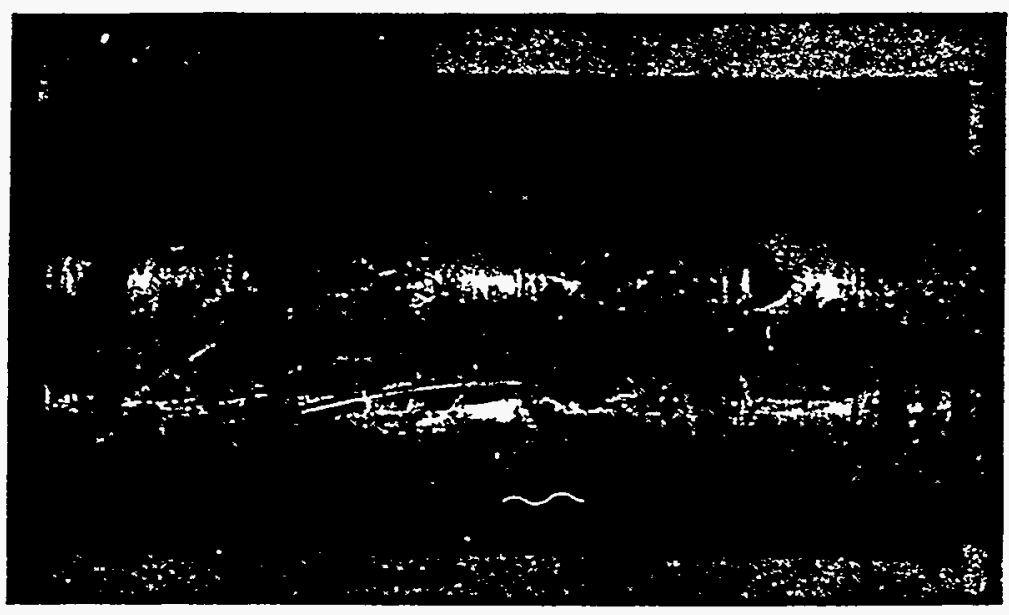

$468 / 19$

Fig. 4.6 The appearances of capsule 3

Source: Forschungszentrum Julich GmbH, Julich, Germany 


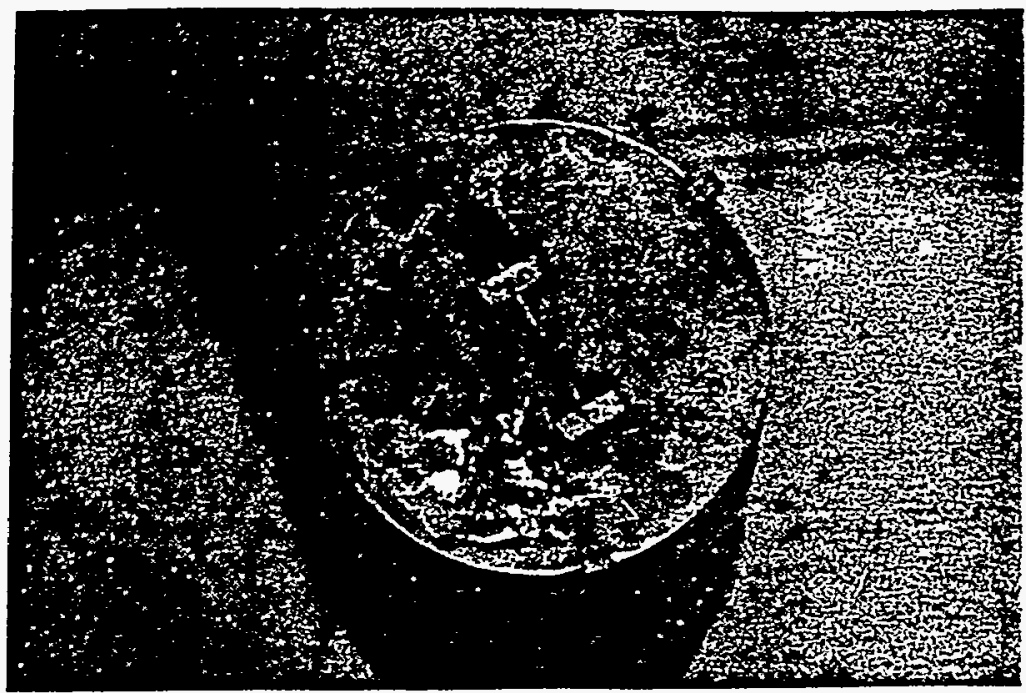

\section{HFR-B1 Kapsel 3}

468123

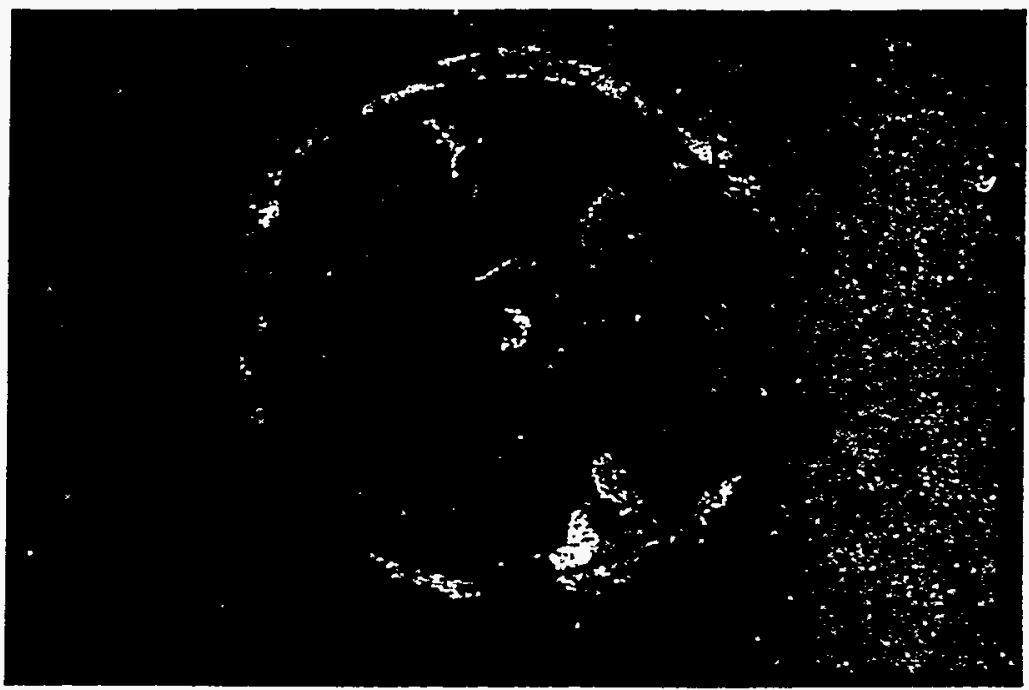

$468 / 24$

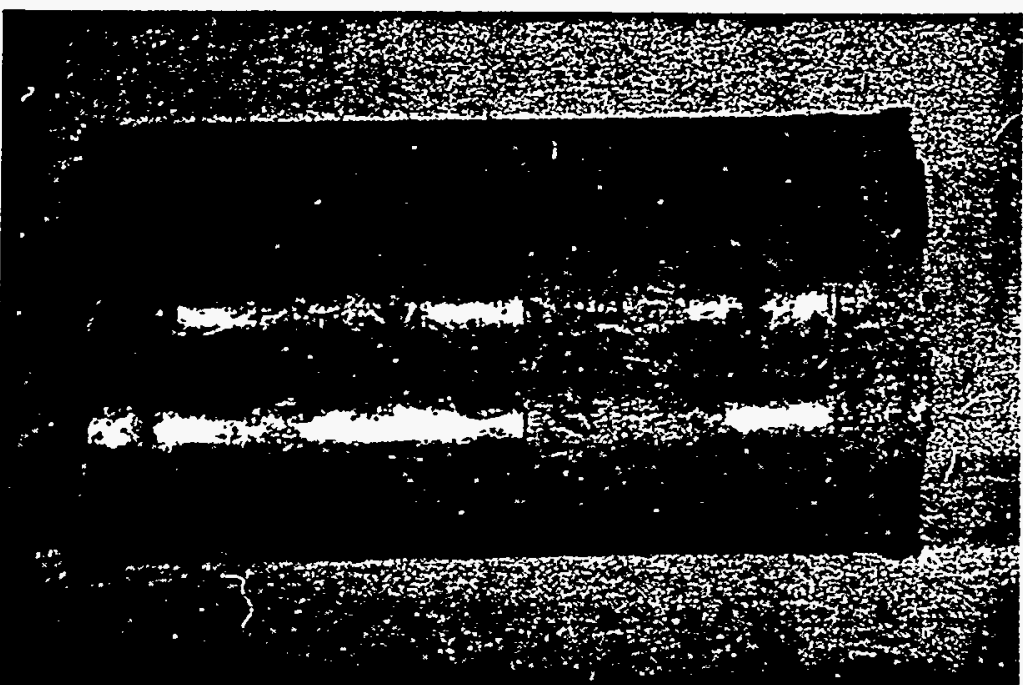

$468 / 22$

Fig. 4.7 View of the end plates of capsule 3

Source: Forschungszentrum Jalich GmbH, Jalich, Germany 


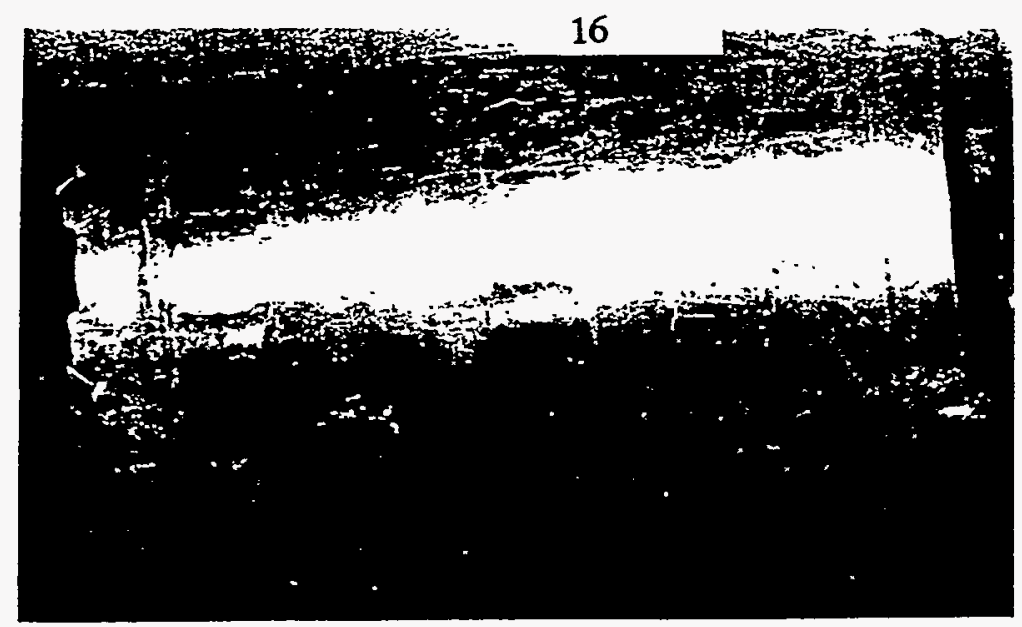

$\frac{H F R-B 1}{\text { Kapsel } 3}$
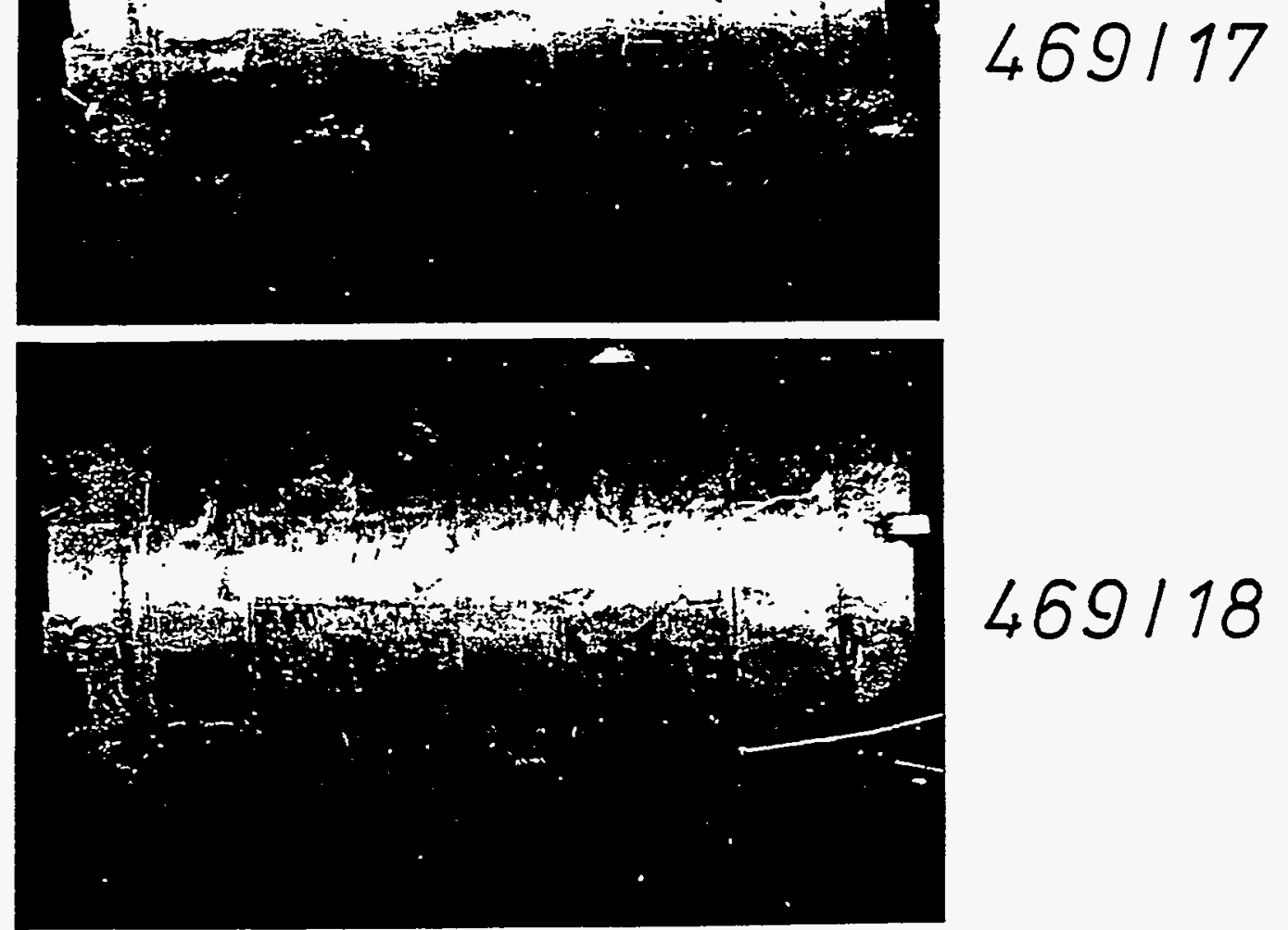

\section{$469 / 18$}

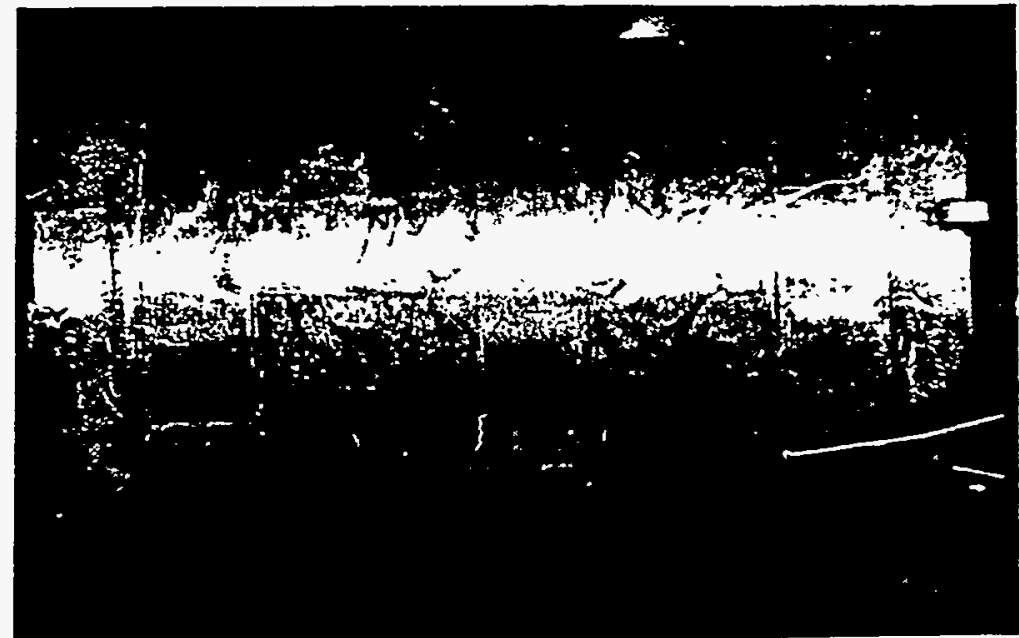

$469 / 19$

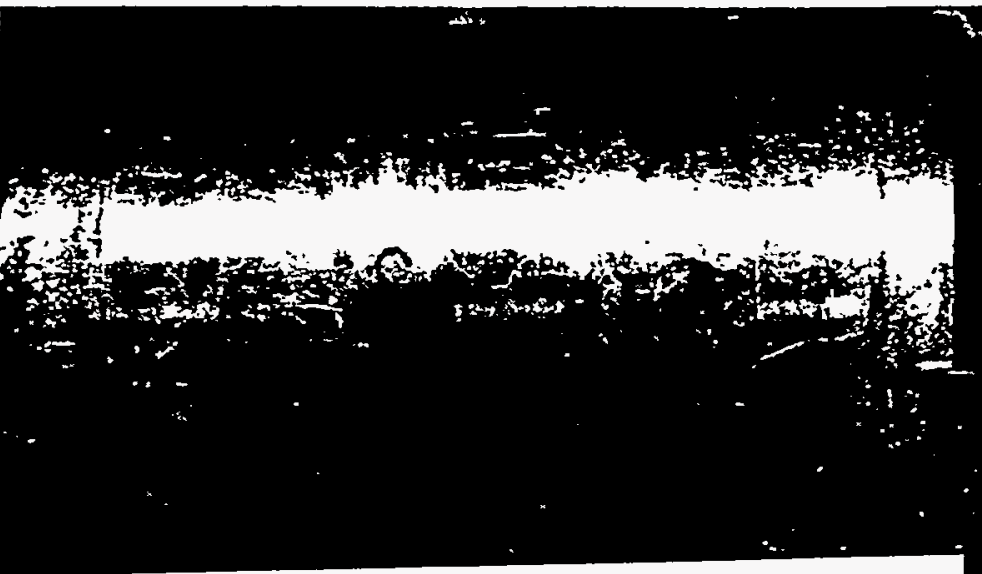

Fig. 4.8 Additional appearances of capsule 3 Source: Forschungszentrum Julich GmbH, Julich, Germany 

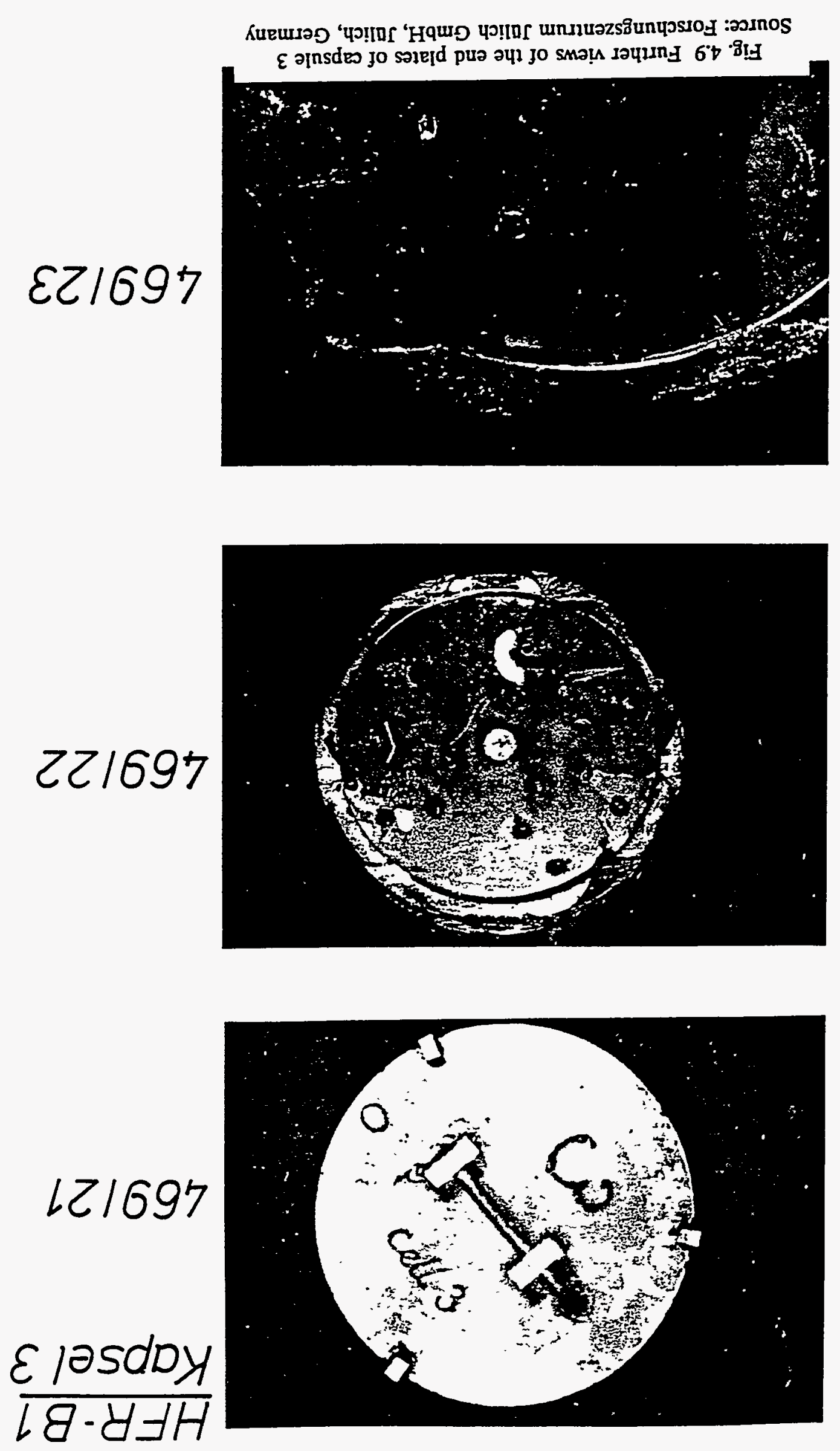


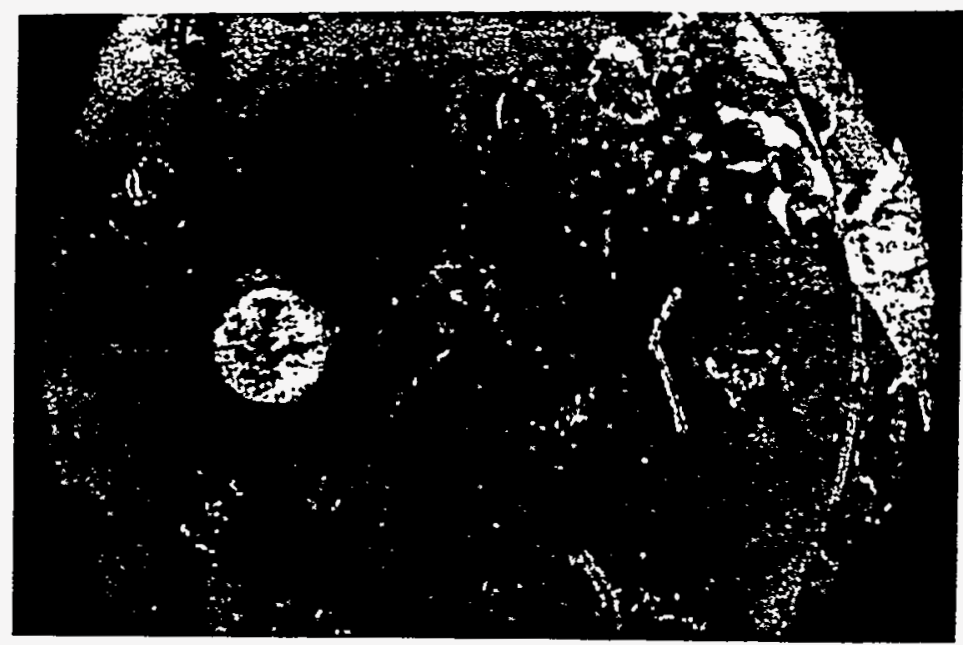

$\frac{H F R-B 1}{\text { Kapsel } 3}$

$469 / 24$

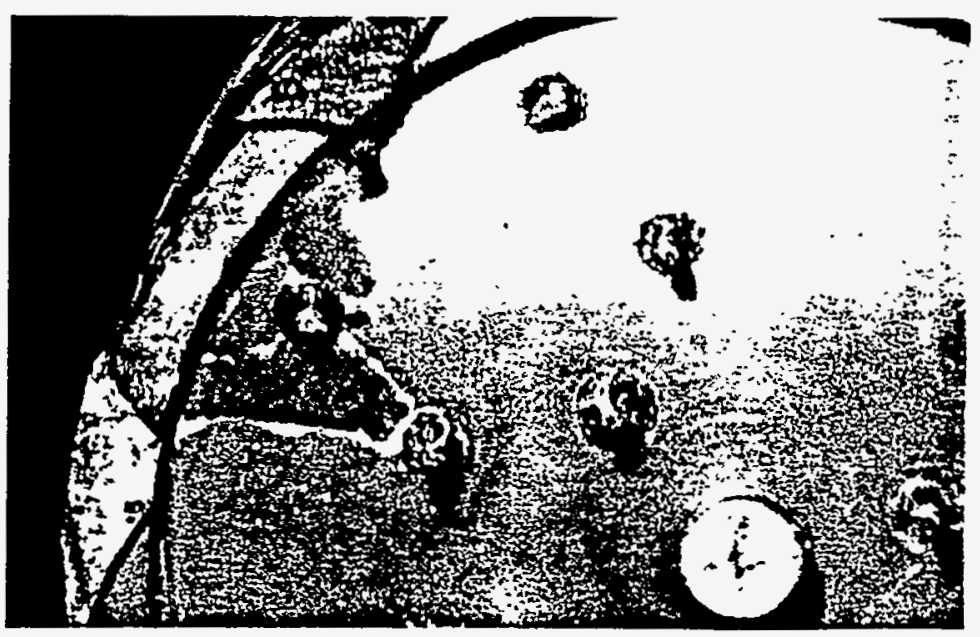

$469 / 25$

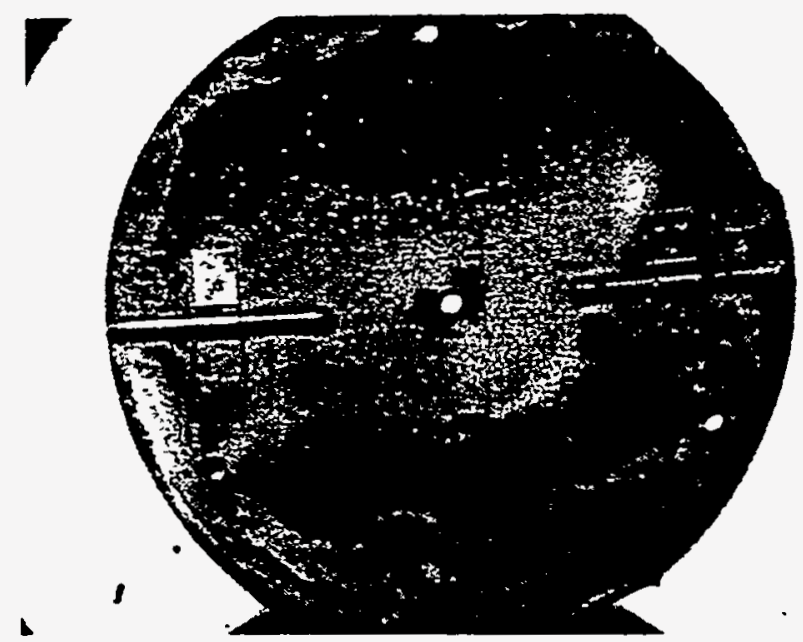

\section{$469 / 31$}

Fig. 4.10 Detailed views of the end plates of capsule 3 and a heat shield Source: Forschungszentrum Julich GmbH, Jalich, Germany 


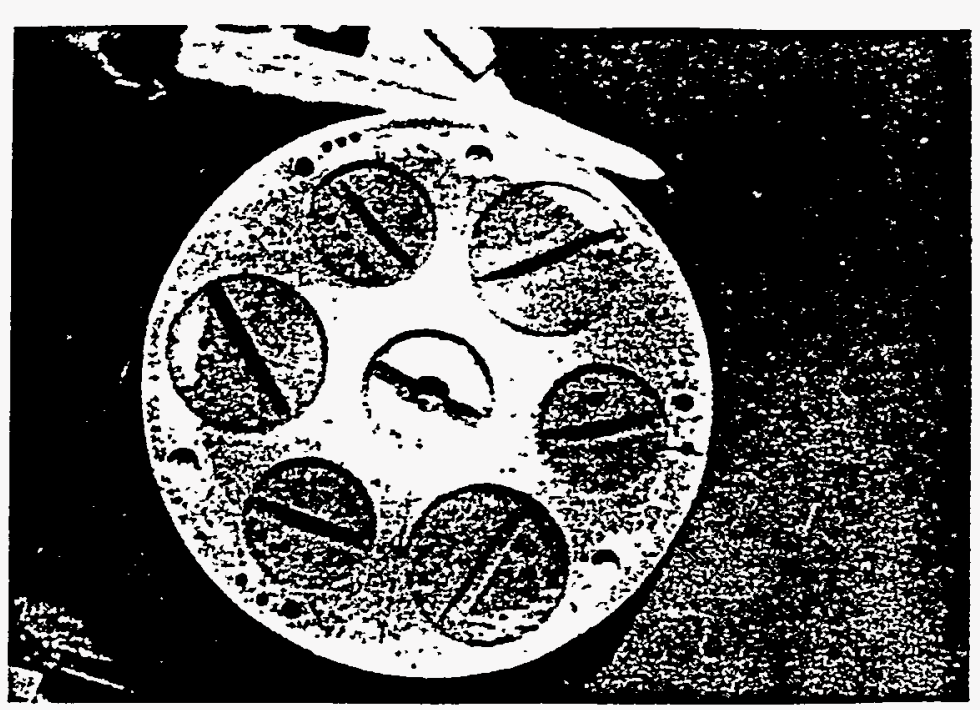

$\frac{\text { HFR-B1 }}{\text { Kapsel } 2}$

468142

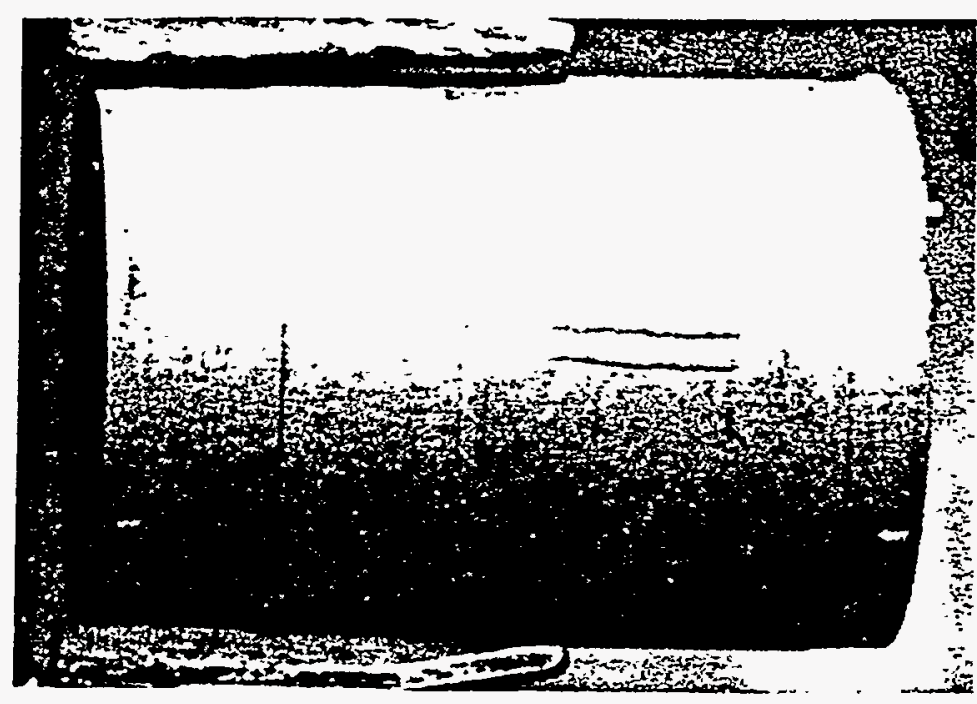

$468 / 43$

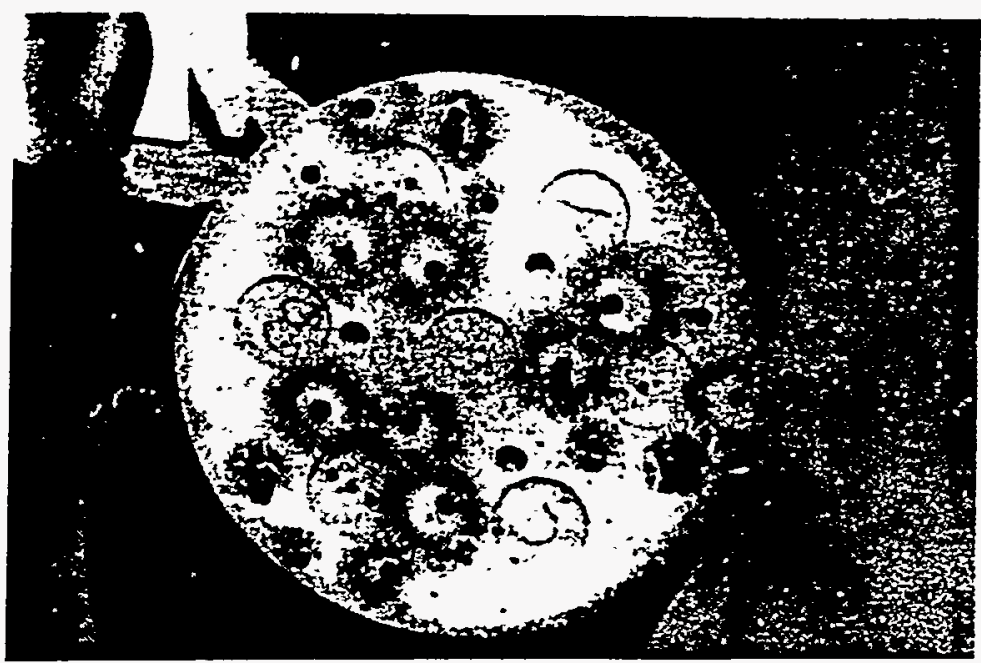

$468 / 41$

Fig. 4.11 Selected views of components after opening capsule 2 Source: Forschungszentrum Jülich GmbH, Julich, Germany 


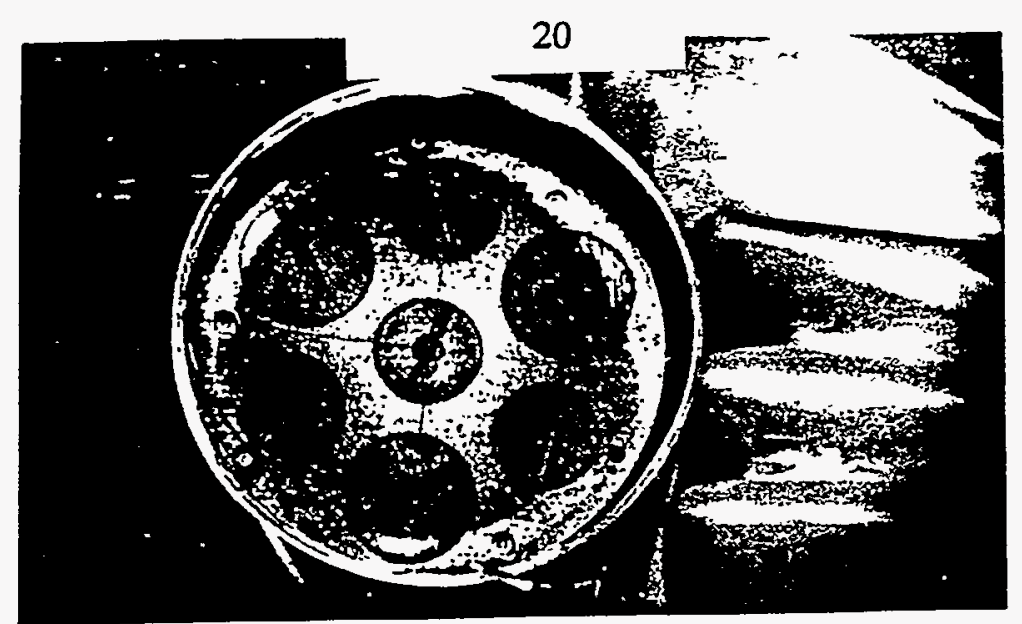

$\frac{\text { HFR B1 }}{\text { Kapsel } 2}$

468140

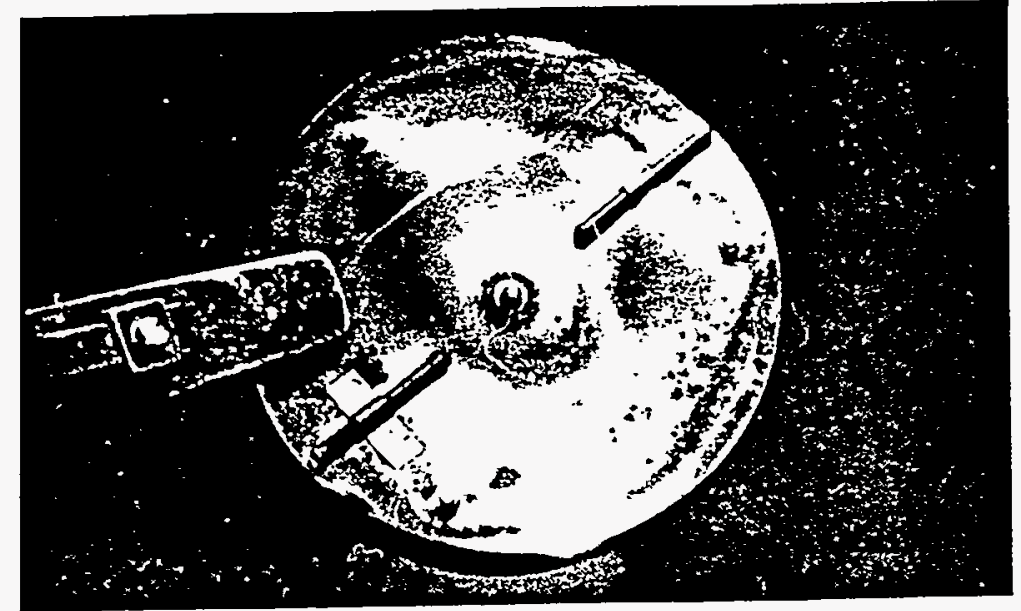

Oberer Wärmeschild - oben

$468 / 2$

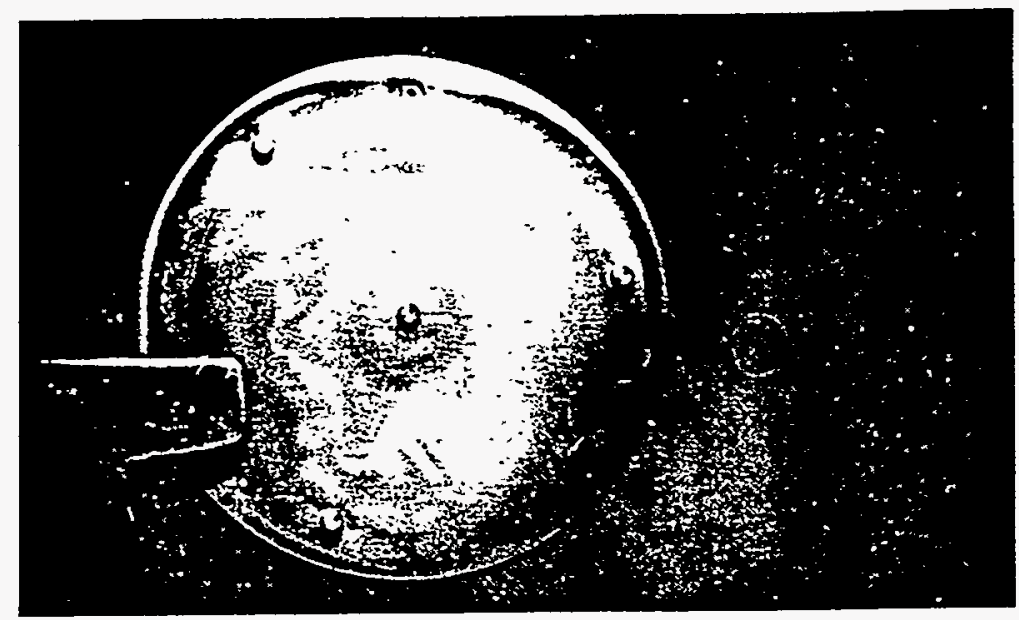

Oberer Wärmeschild-unten

468/1

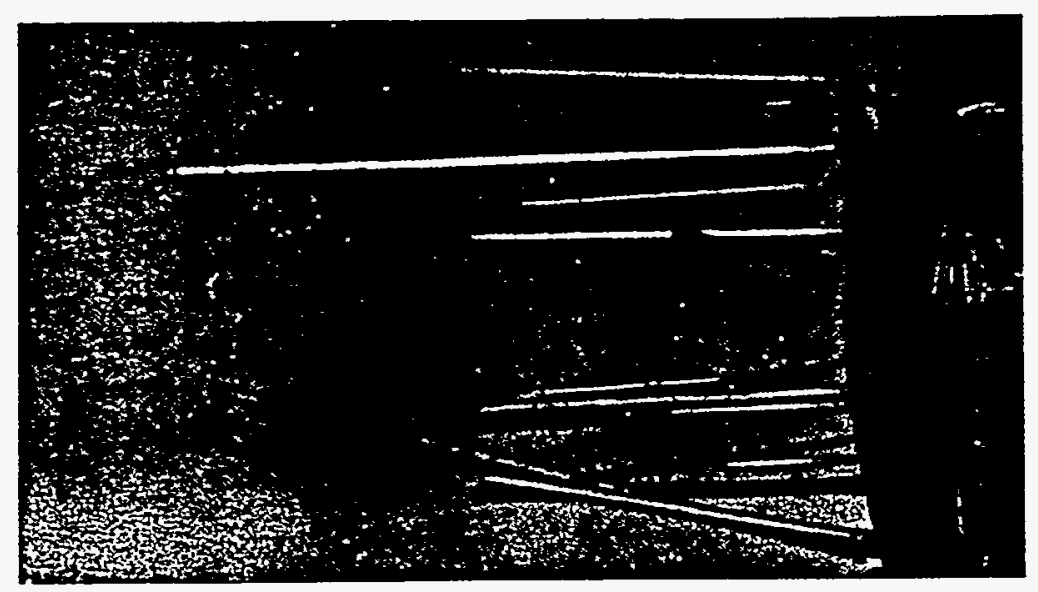

$468 / 4$

Fig. 4.12 Selected views of the graphite body in capsule 2 Source: Forschungszentrum Julich GmbH, Julich, Germany 


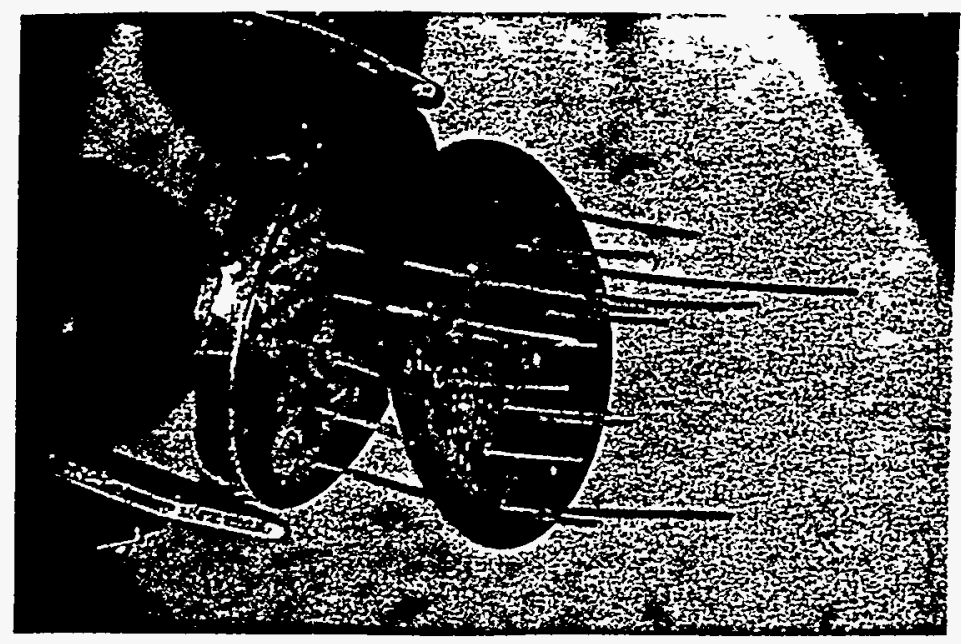

$\frac{H F R-B 1}{\text { Kapsel } 3}$

$469 / 34$

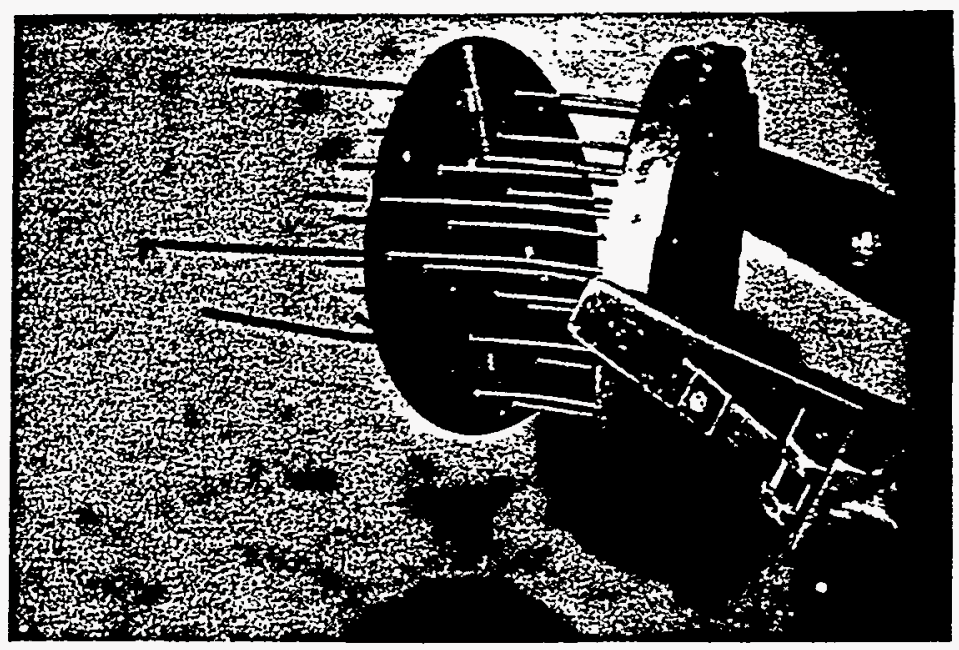

\section{$469 / 35$}

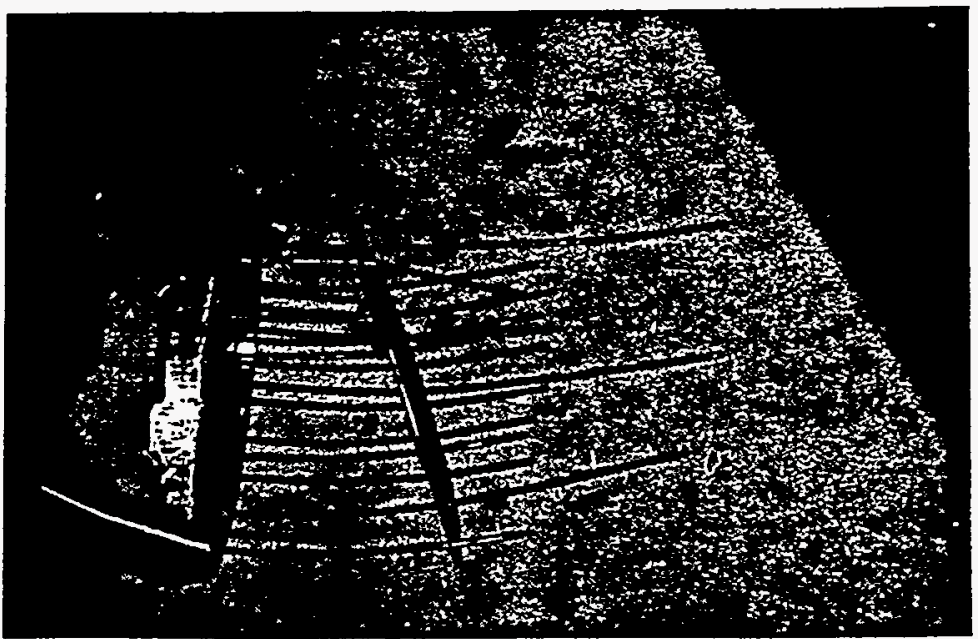

$469 / 33$

Fig. 4.13 Removal of the end plate, thermocouple protection tubes and adjacent heat shield Source: Forschungszentrum Julich GmbH, Jalich, Germany 

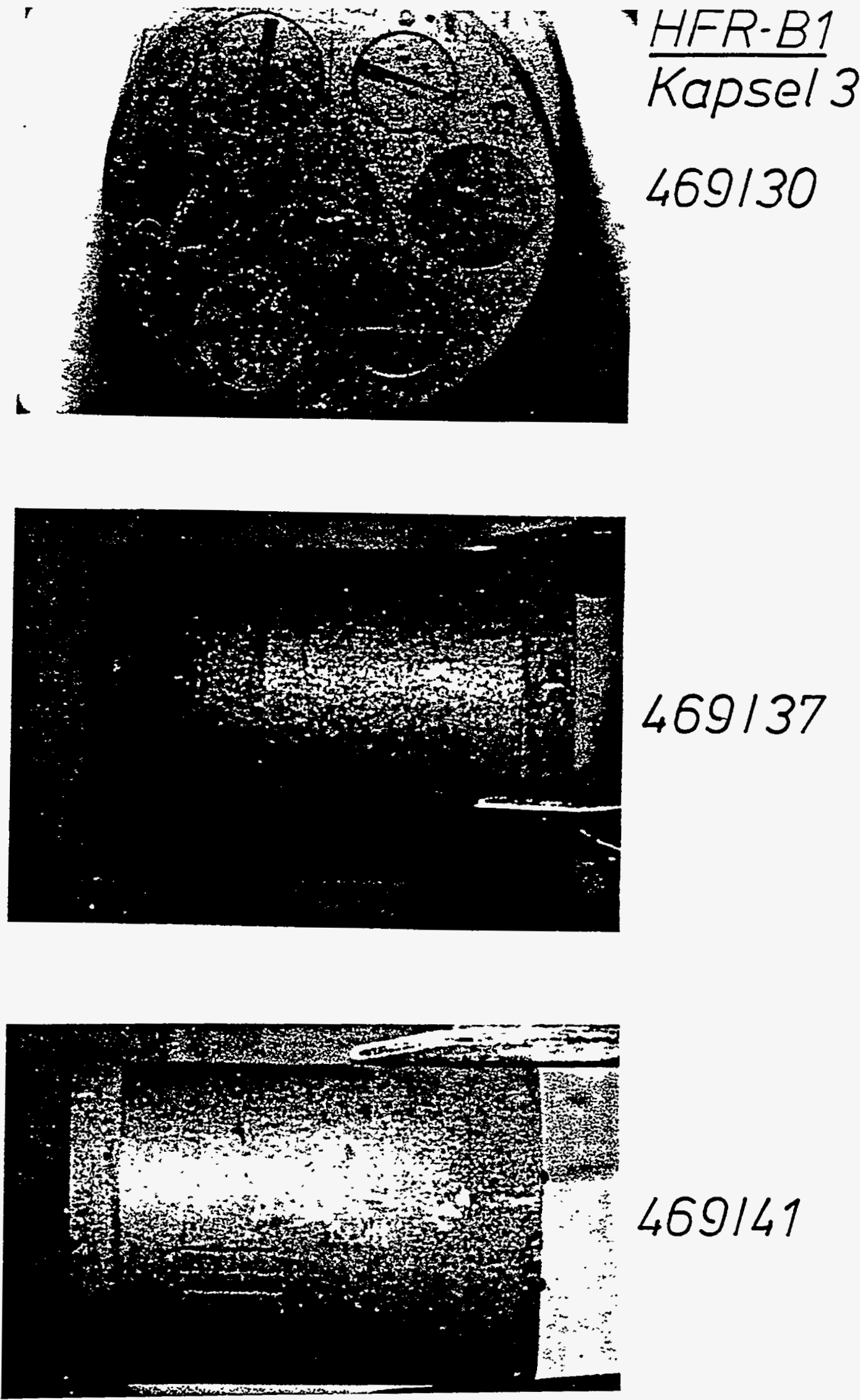

Fig. 4.14 Selected views of the graphite body in capsule 3 Source: Forschungszentrum Jalich GmbH, Julich, Germany 

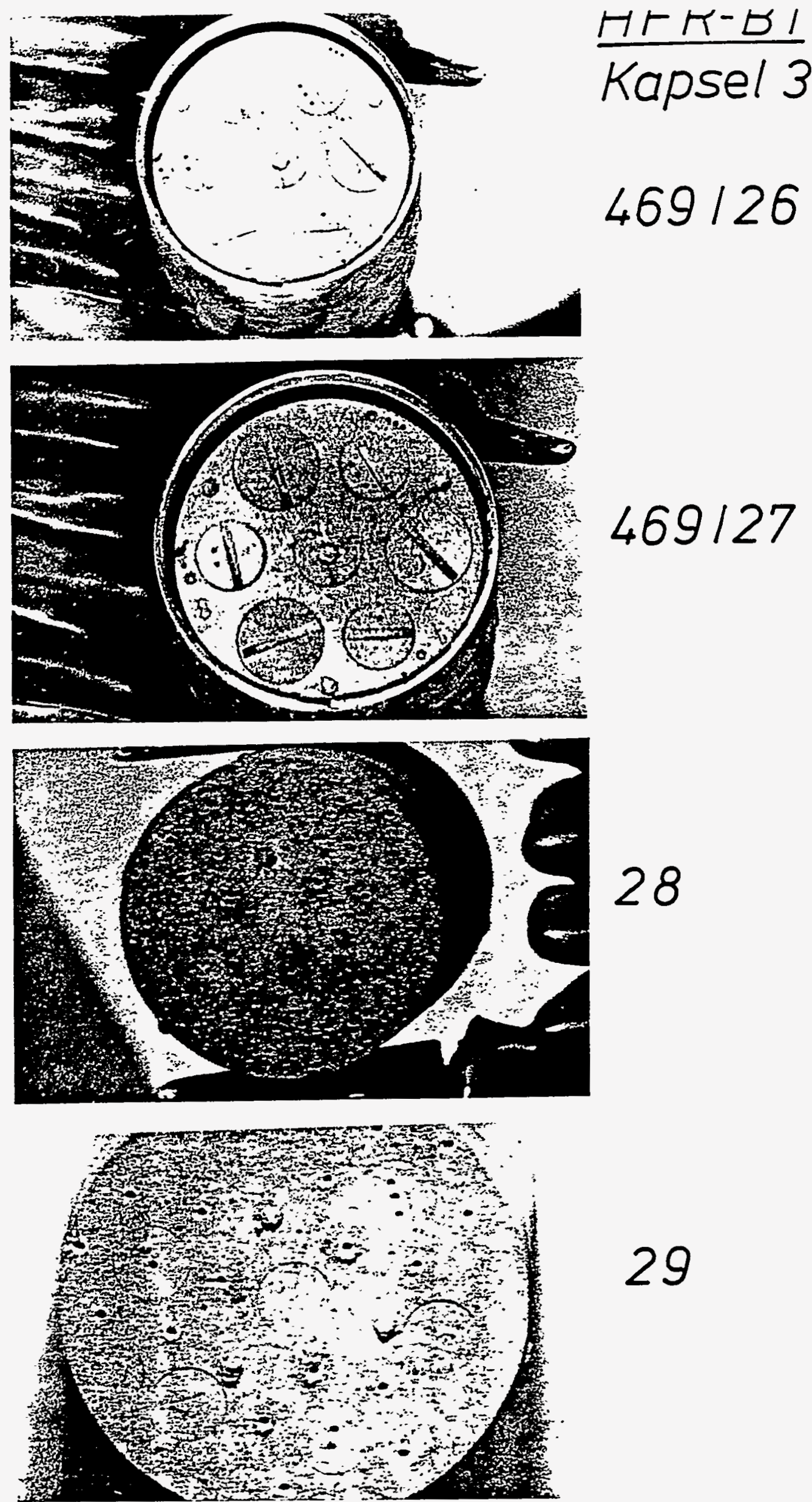

29

Fig. 4.15 Selected views of the ends of the graphite body in capsule 3 Source: Forschungszentrum Julich GmbH, Jalich, Germany 


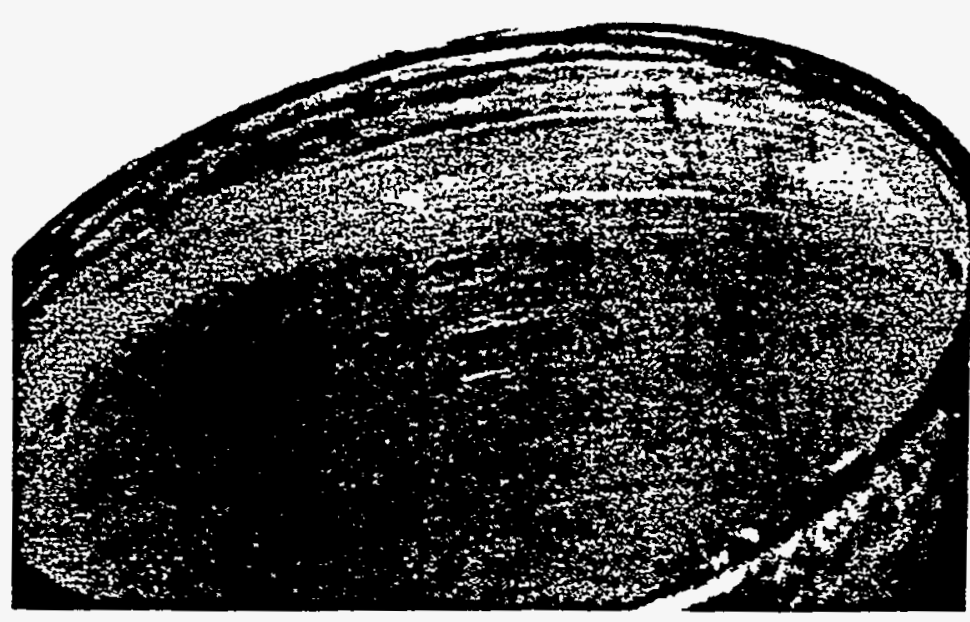

$\frac{H F R-B 1}{\text { Kapsel } 3}$

Stahl Kapsel

innen

$469 / 38$

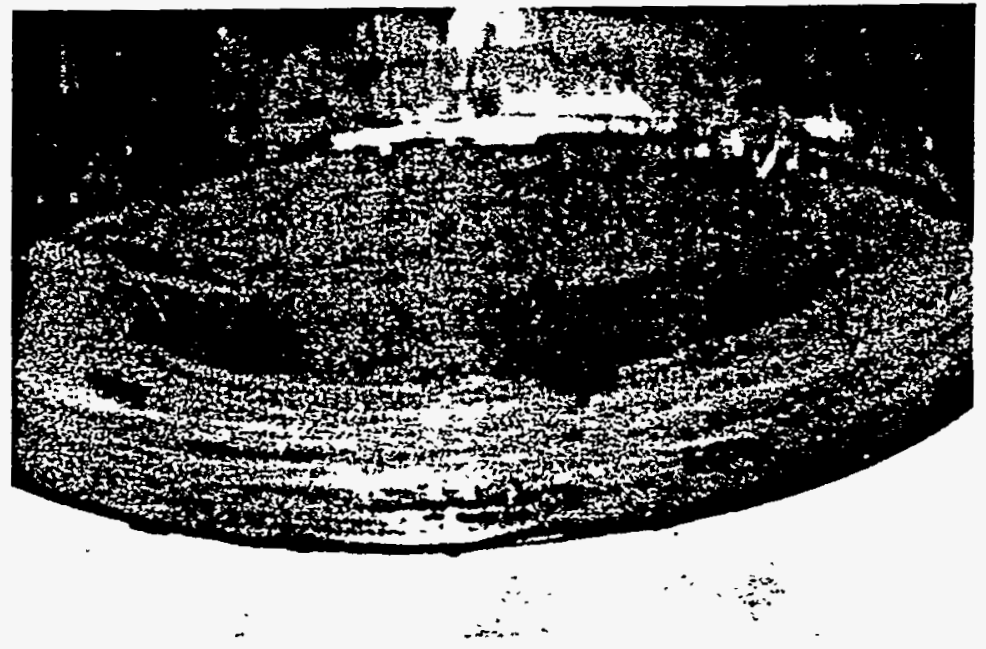

39

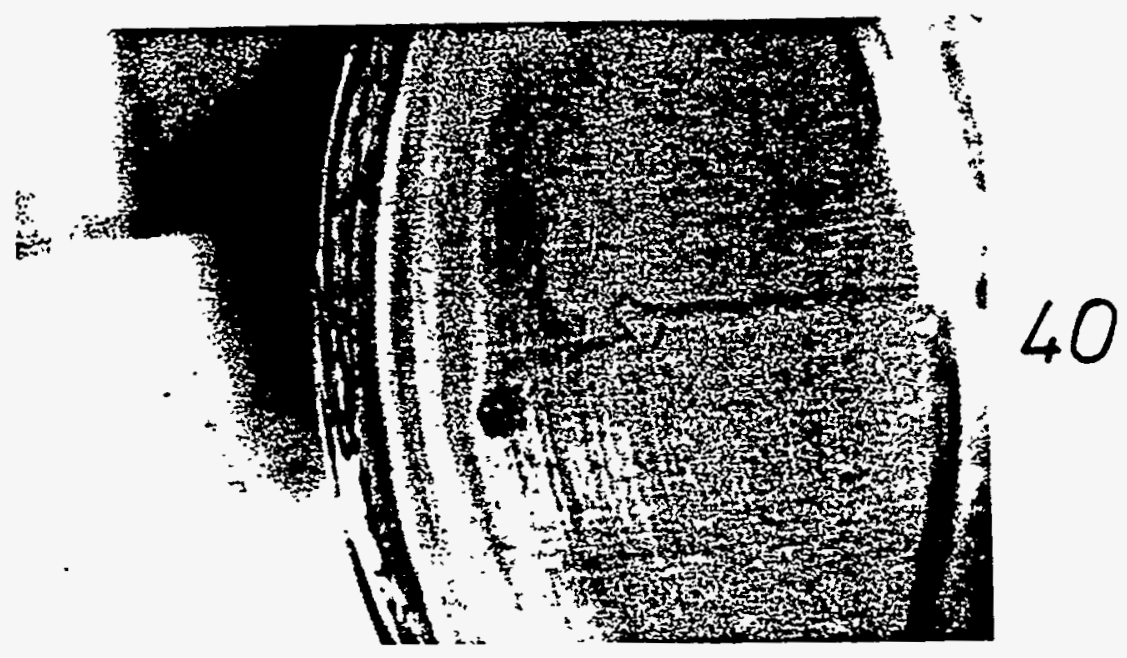

Fig. 4.16 Views of the inside of the stainless steel capsule 3 Soui ت: Forschungszentrum Julich GmbH, Jalich, Germany 


\subsubsection{Gamma Scanning}

As a part of the disassembly of the capsules, gamma scans have been made of the steel-encased graphite bodies ${ }^{3}$, of the graphite bodies after removal from the steel containers ${ }^{4}$ and of the three gamma scan wires ${ }^{s}$ in each capsule.

\subsubsection{Apparatus}

The measuring apparatus is in the Brennstoffzellenlabor (BZL) of the hot cells (HZ). It consists of a measurement bench which is installed horizontally parallel to the cell wall in cell 3 . A step motor drives a carriage along the bench. A mechanical counter on the spindle controls the set distance.

A passage in the cell wall between the measuring bench and the outside of the cell serves for the insertion of the collimator with different narrow, high slits, which are aligned at right angles to movement path of the carriage. Gamma rays travel through the collimator to a crystal of pure germanium. The impulses produced in the detector by the gamma quanta are amplified and lead to a gamma scan system which is installed in a personal computer.

\subsubsection{Measurements}

Measurements were made with the three types of sample: the stainless steel capsule and contents, the graphite body and the gamma scan wires. The latter were removed from the niobium tubes in which they were irradiated and placed, for the scans, in steel tubes with a $6 \mathrm{~mm}$ outer diameter and a wall thickness of $1 \mathrm{~mm}$.

The samples were laid in the receiving cradle of the carriage and so aligned, in the cases of the stainless steel capsules and the graphite bodies, that a fuel hole was in line with the detector. Then a sample was moved before the collimator slit. In this position, a suitable collimator was chosen and then a gamma spectrum taken. With this spectrum, the energy window, in which the peak of the interesting nuclide occurred, was determined; likewise the measurement time at the measurement point. The stainless steel capsules, the graphite bodies, and the gamma scan wires were measured at each meassurement point for $500 \mathrm{~s}$ except for gamma scan wire number 1 in capsule 3 . In the latter case the measurement time was $300 \mathrm{~s}$; the results were corrected to a measurement time of $500 \mathrm{~s}$.

Thereafter, the beginning of the sample was placed before the collimator opening and the step motor with the chosen step width started. For each step a gamma spectrum was taken. With this, in the energy region of the individual peaks, the net peak areas were determined. To that end, the impulse numbers were summed and the spectrum background, an average value of the impulse number calculated from the three channels, left and right of the photopeak, substracted. Per sample, three scans were made, in the cases of the stainless steel capsules and the graphite bodies, whereby each of the three fuel holes in turn was aligned to the detector. The peak net areas were stored in the PC and after the end of the scans were transferred to a spreadsheet. Here, the results were back calculated to a common date, 22.1.91. the date of the first measurement in the cases of the stainless steel capsules and the graphite bodies and to 1.3 .91 in the case of the gamma scan wires.

The instruments and conditions of the measurements for the stainless steel capsules, for the graphite bodies they contained and the gamma scan wires are given in Tables $4.3,4.4$ and 4.5 , respectively. 
Table 4.3 Measurement conditions for the stainless steel capsules 2 and 3

Collimator: Length

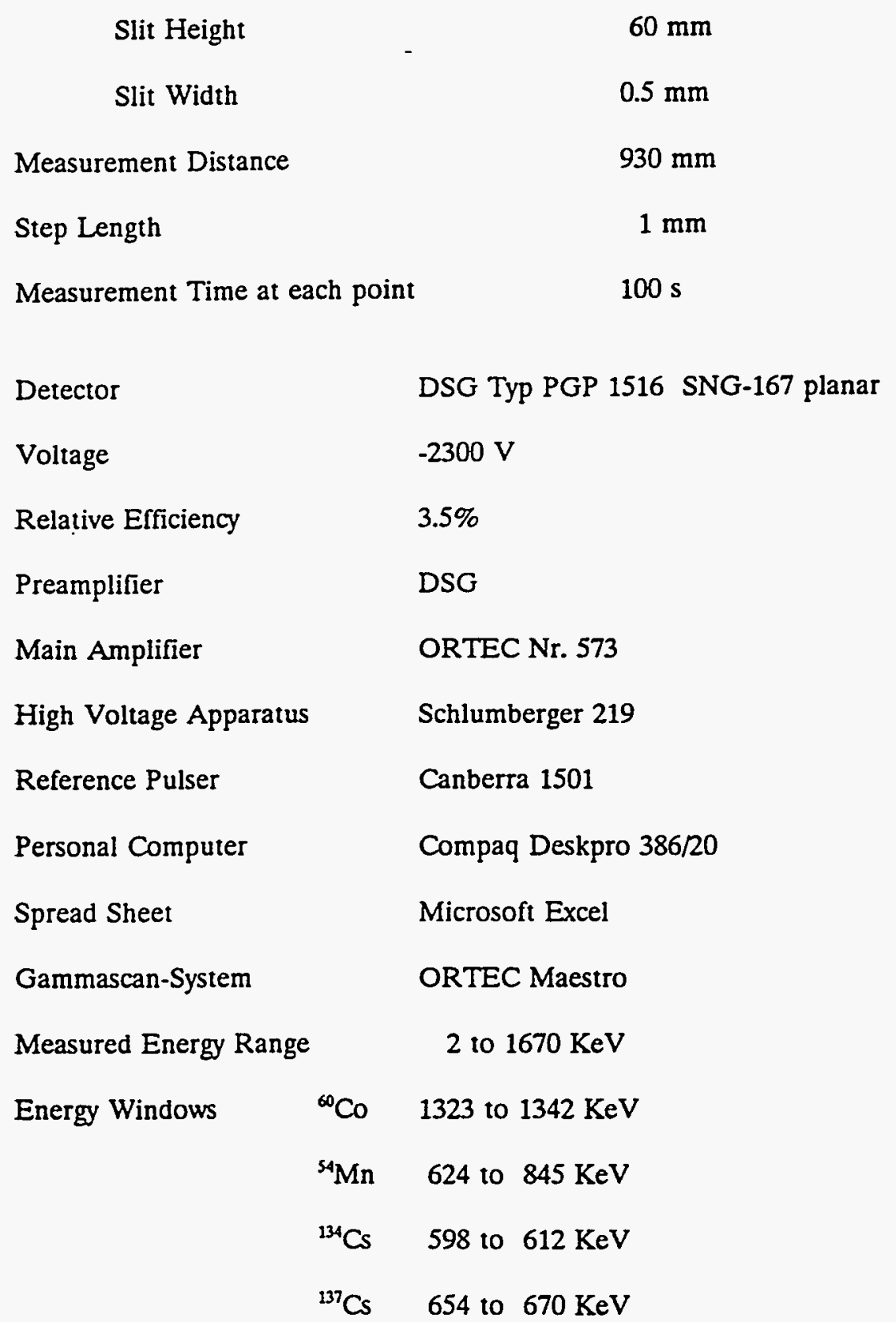


Table 4.4 Measurement conditions for the graphite bodies of capsules 2 and 3

$\begin{array}{cc}\text { Collimator: } & \text { Length } \\ \text { Slit Height } & 545 \mathrm{~mm} \\ \text { Slit Width } & 10 \mathrm{~mm} \\ \text { Measurement Distance } & 1 \mathrm{~mm} \\ \text { Step Length } & 930 \mathrm{~mm} \\ \text { Measurement Time at each point } & 1 \mathrm{~mm}\end{array}$

Detector

Voltage

Relative Efficiency

Preamplifier

Main Amplifier

High Voltage Apparatus

Reference Pulser

Personal Computer

Spread Sheet

Gammascan-System

Measured Energy Range

Energy Windows; ${ }^{144} \mathrm{Ce}$

${ }^{134} \mathrm{Cs}$

${ }^{106} \mathrm{Ru}$

${ }^{137} \mathrm{Cs}$

${ }^{95} \mathrm{Zr}$

${ }^{25} \mathrm{Eu}$

${ }^{60} \mathrm{Co}$
DSG Typ PGP 1516 SNG-167 planar

$-2300 \mathrm{~V}$

$3.5 \%$

DSG

ORTEC Nr. 573

Schlumberger 219

Canberra 1501

Compaq Deskpro 386/20

Microsoft Excel

ORTEC Maestro

20 to $1670 \mathrm{KeV}$

129 to $140 \mathrm{KeV}$

598 to $612 \mathrm{KeV}$

616 to $629 \mathrm{KeV}$

654 to $670 \mathrm{KeV}$

715 to $732 \mathrm{KeV}$

1267 to $1283 \mathrm{KeV}$

1323 to $1342 \mathrm{KeV}$ 
Table 4.5 Measurement conditions for the gamma scan wires from capsules 2 and 3

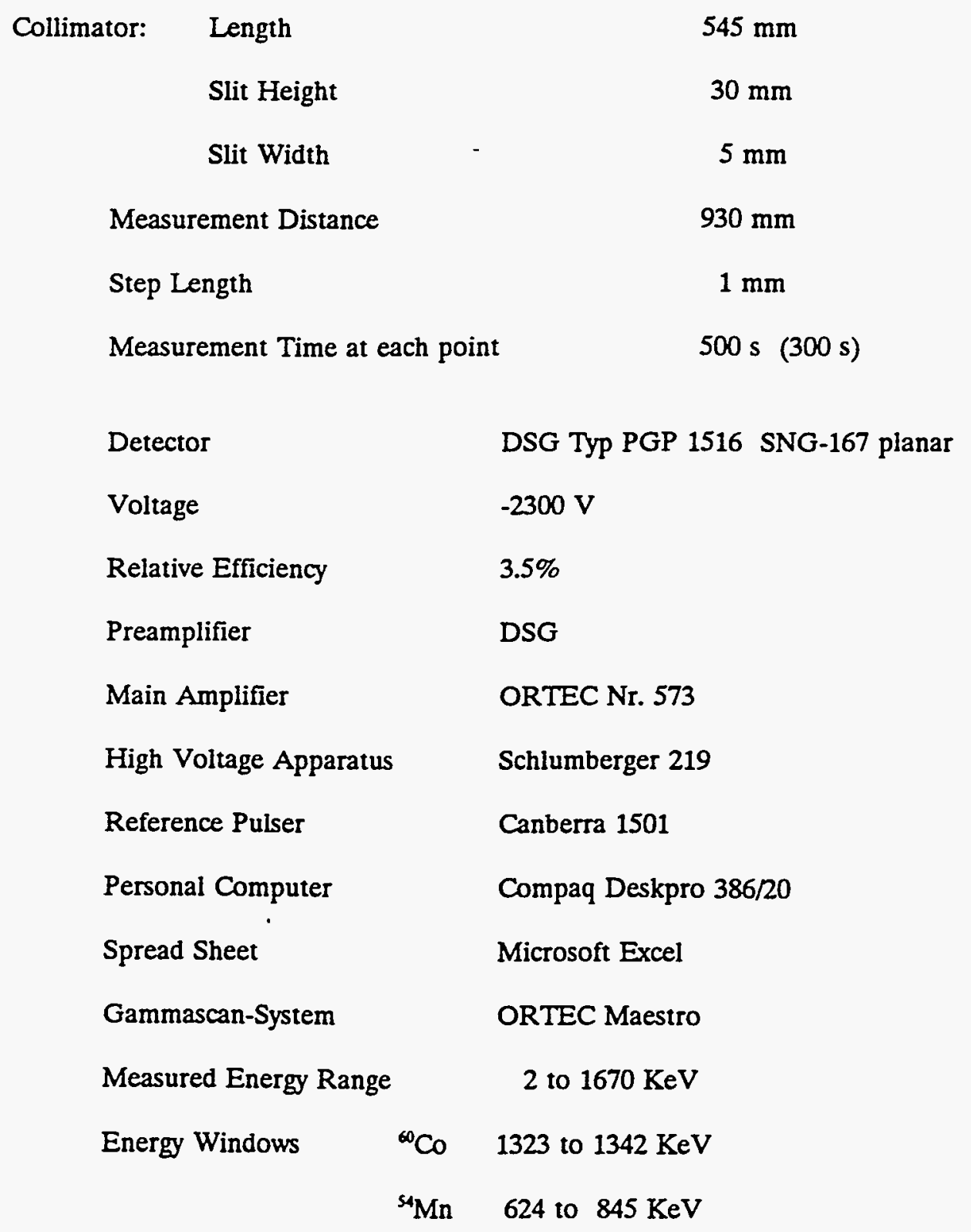




\subsubsection{Results}

The gamma scans of the stainless steel capsule, having the graphite bodies within, for the nuclides ${ }^{137} \mathrm{Cs},{ }^{134} \mathrm{Cs},{ }^{60} \mathrm{Co}$, and ${ }^{54} \mathrm{Mn}$ are presented in Figs. 4.17 through 4.31 . The figures show the relative activity distributions of the three aligned capsules oriented by rotation so that each of the fuel holes with their compliment of fuel compacts was, in turn, scanned in the axial direction. The activities (impulses) are referenced to the common date 22.1.91. The capsules are ordered as they were positioned during the irradiation. The activity profiles for ${ }^{60} \mathrm{Co}$, which have the least scatter, qualitatively match the axial profile of burnup ${ }^{6}$ for the three capsules.

The gamma scans of the fueled graphite bodies for the nuclides ${ }^{14} \mathrm{Ce},{ }^{137} \mathrm{Cs},{ }^{134} \mathrm{Cs},{ }^{106} \mathrm{Ru},{ }^{95} \mathrm{Zr}$, and ${ }^{60} \mathrm{Co}$ are presented in Figs. 4.32 through 4.37. In Fig. 4.37, the relatively large activity in capsule 3 for ${ }^{60} \mathrm{Co}$ results from the gamma scan wire assembly stuck in graphite body 3 . The spectrum of the graphite body from capsule 2 is shown in Fig. 4.38.

The gamma scans of the three gamma scan wires, 1,2 , and 3, for the nuclides ${ }^{54} \mathrm{Mn}$ and ${ }^{60} \mathrm{Co}$ are presented in Figs. 4.39 through 4.44. The capsules are ordered in the figures as they were positioned during the irradiation. Measaurements for the nuclides ${ }^{51} \mathrm{Cr}$ amd ${ }^{58} \mathrm{Co}$ were not successful as the dead time was too long. In tables 4.6 through 4.11 , the gamma scan measurements are presented; all measurements have been corrected to the common time of 1.3.91.

\subsubsection{Remaining Tasks}

Two tasks in the disassembly remain to be done or reported. The leaching of the inside surfaces of the stainless steel capsules remains to be done. The results of gamma counting the graphite caps and plugs from the disassembly are report below in Sect. 6 on the examination of the unfueled graphite bodies.

\subsection{EXAMINATION OF FUEL COMPACTS}

In each of capsules 2 and 3 there were three fuel holes and in each fuel hole there were four compacts. The examination of these fuel compacts involved visual inspection and photography, gamma counting, dimensional and weight measurements, metallography, fission product distribution between the fuel compacts and the contiguous graphite and deconsolidation. The process and operations of examining the fuel compacts are identified in Figs. 4.3, 4.2 and Table 4.1.

\subsubsection{Visual Inspection and Photography ${ }^{2}$}

In each capsule, fuel hole number 1 was opened for inspection and photography of the contents.

\subsubsection{Capsule $2^{2}$}

By means of a specially made screw apparatus equipped with a small borehole, the end plate of the fuel hole was opened. A glance into the channel showed that several small broken pieces of the compact lay loosely. By means of a dust filter nozzle, the four fuel compacts which stood loose in the fuel hole were now removed and a white mark made on the upper end. Because the compacts stood loose in the fuel hole, marking the orientation of the upper compact in the channel was waived. Photographs of four views of each fuel compact from fuel hole 1 of the graphite body are shown in Fig. 4.45, photographs 472/24-27, Fig. 4.46, photographs 472/28-31, Fig. 4.47, photographs 472/32-35 and Fig. 4.48, photographs 473/1-4. 


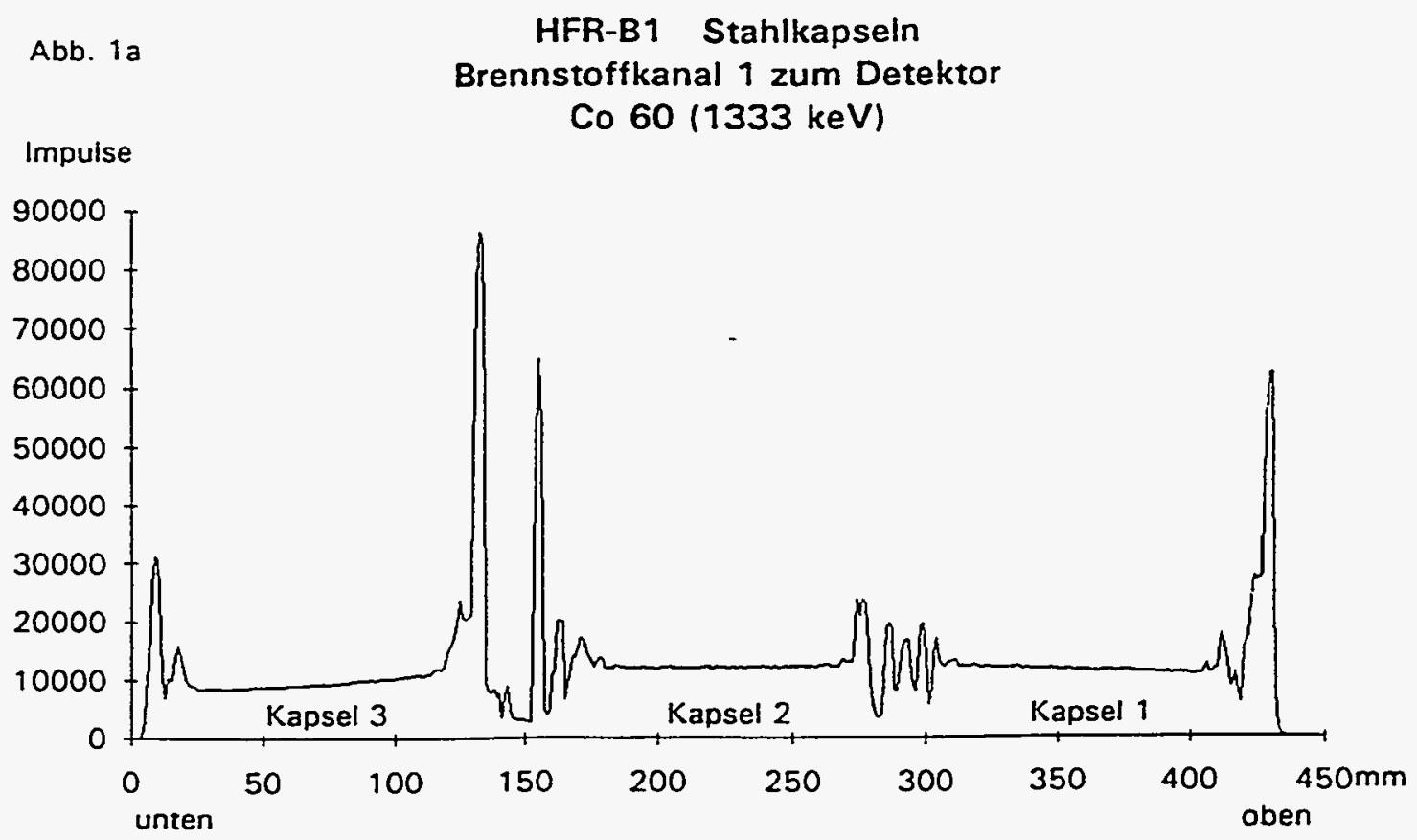

Fig. 4.17 Gamma scam of the steel capsule for ${ }^{60} \mathrm{Co}$ focused on fuel hole 1 Source: Forschungszentrum Julich GmbH, Julich, Germany

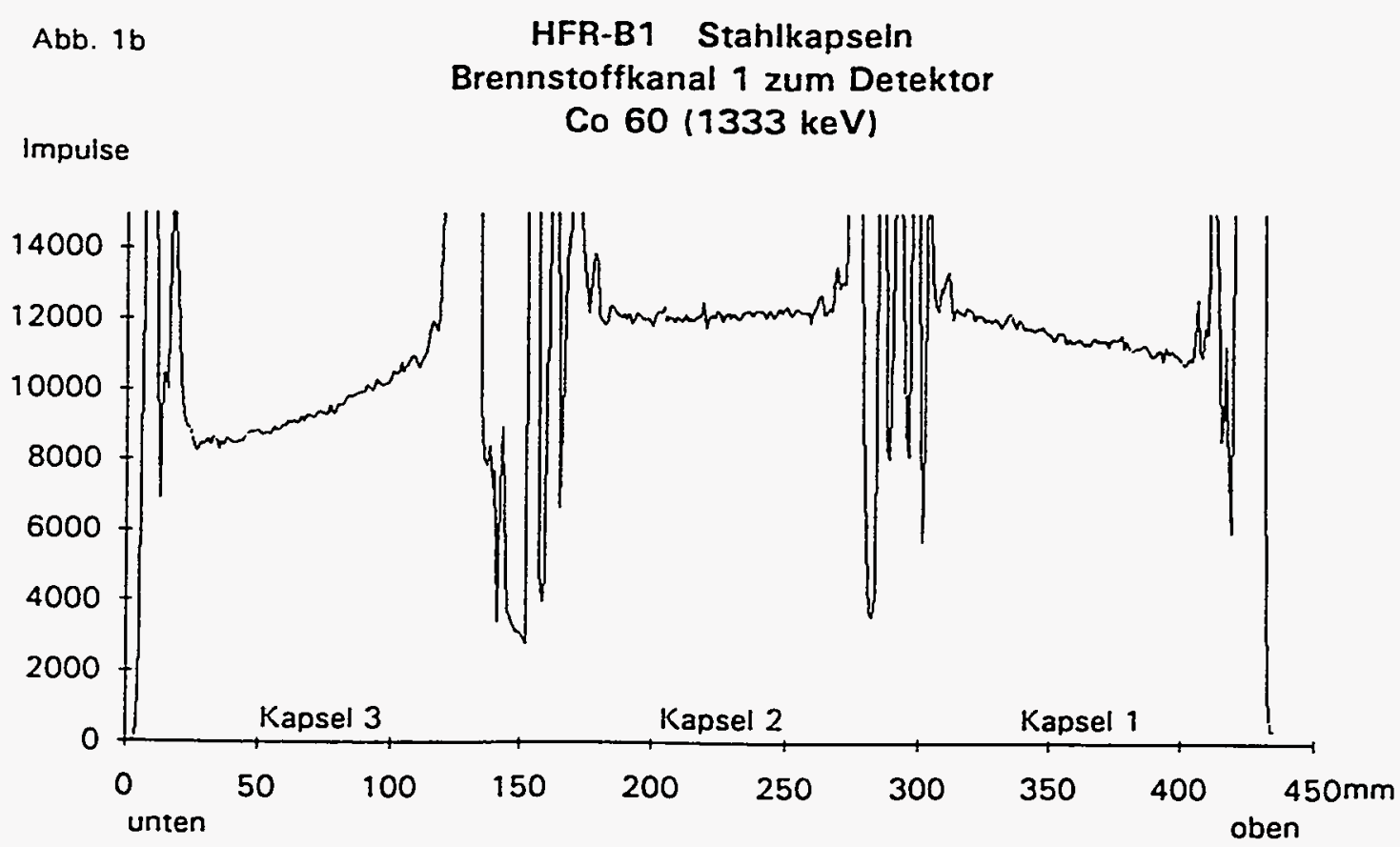

Fig. 4.18 Gamma scam of the steel capsule for ${ }^{60} \mathrm{Co}$ focused on fuel hole 1 (enlarged) Source: Forschungszentrum Jalich $\mathrm{GmbH}$, Jalich, Germany 
Abb. 1c

HFR-B1 Stahlkapsein

Brennstoffkanal 1 zum Detektor

Cs134 (605 keV)

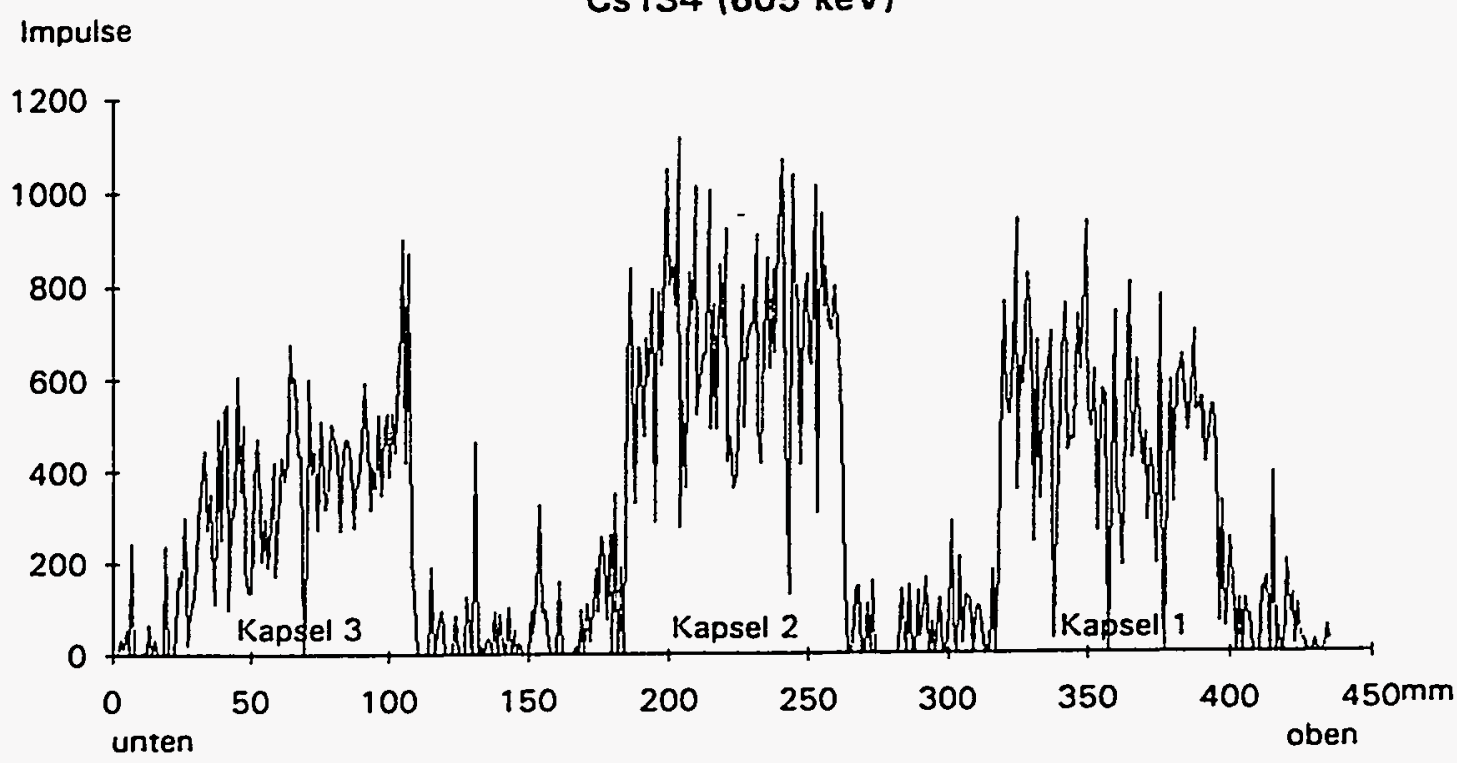

Fig. 4.19 Gamma scam of the steel capsule for ${ }^{124} \mathrm{Cs}$ focused on fuel hole 1 Source: Forschungszentrum Julich GmbH, Julich, Germany

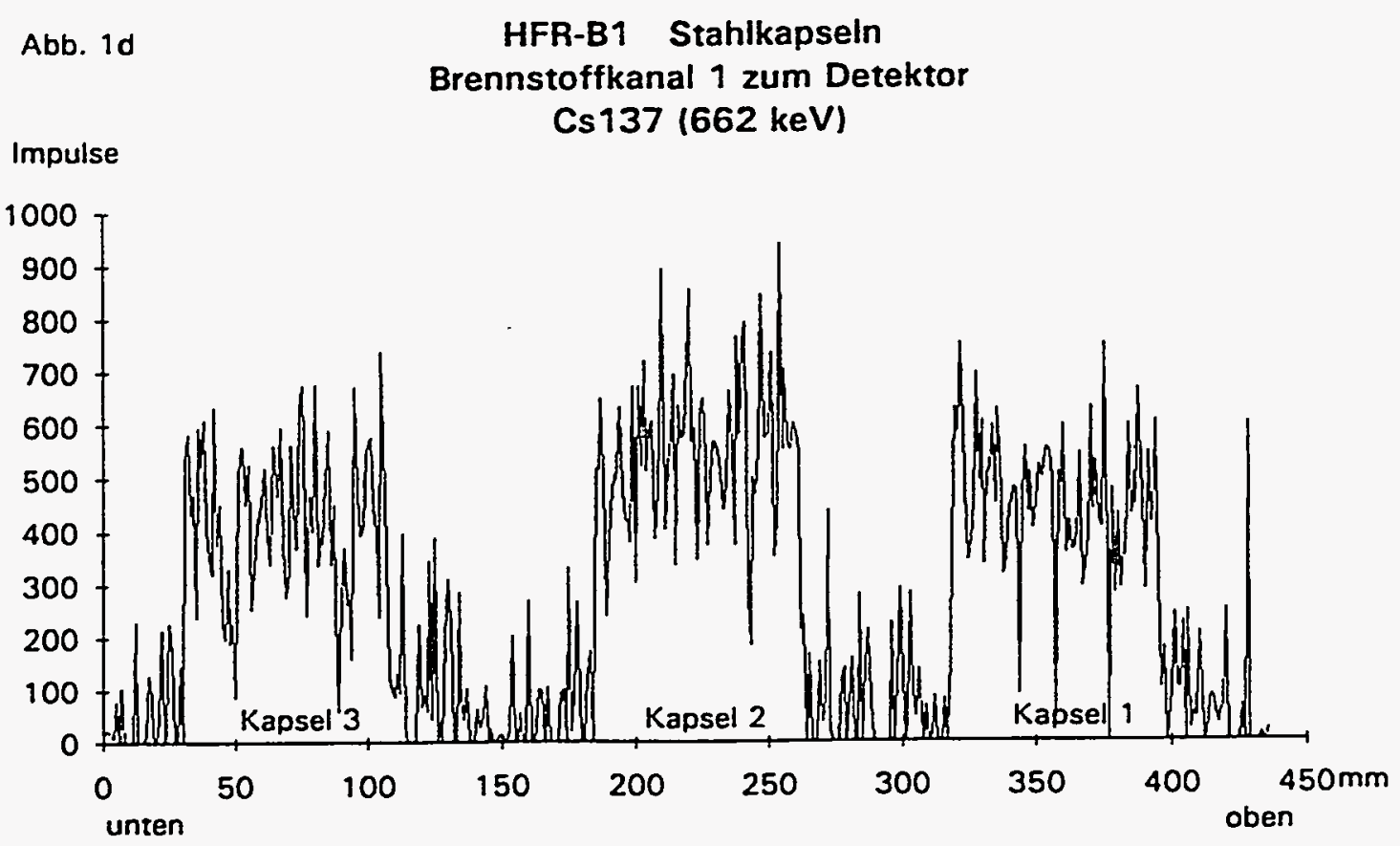

Fig. 4.20 Gamma scam of the steel capsule for ${ }^{137} \mathrm{Cs}$ focused on fuel hole 1 Source: Forschungszentrum Julich $\mathrm{GmbH}$, Julich, Germany 


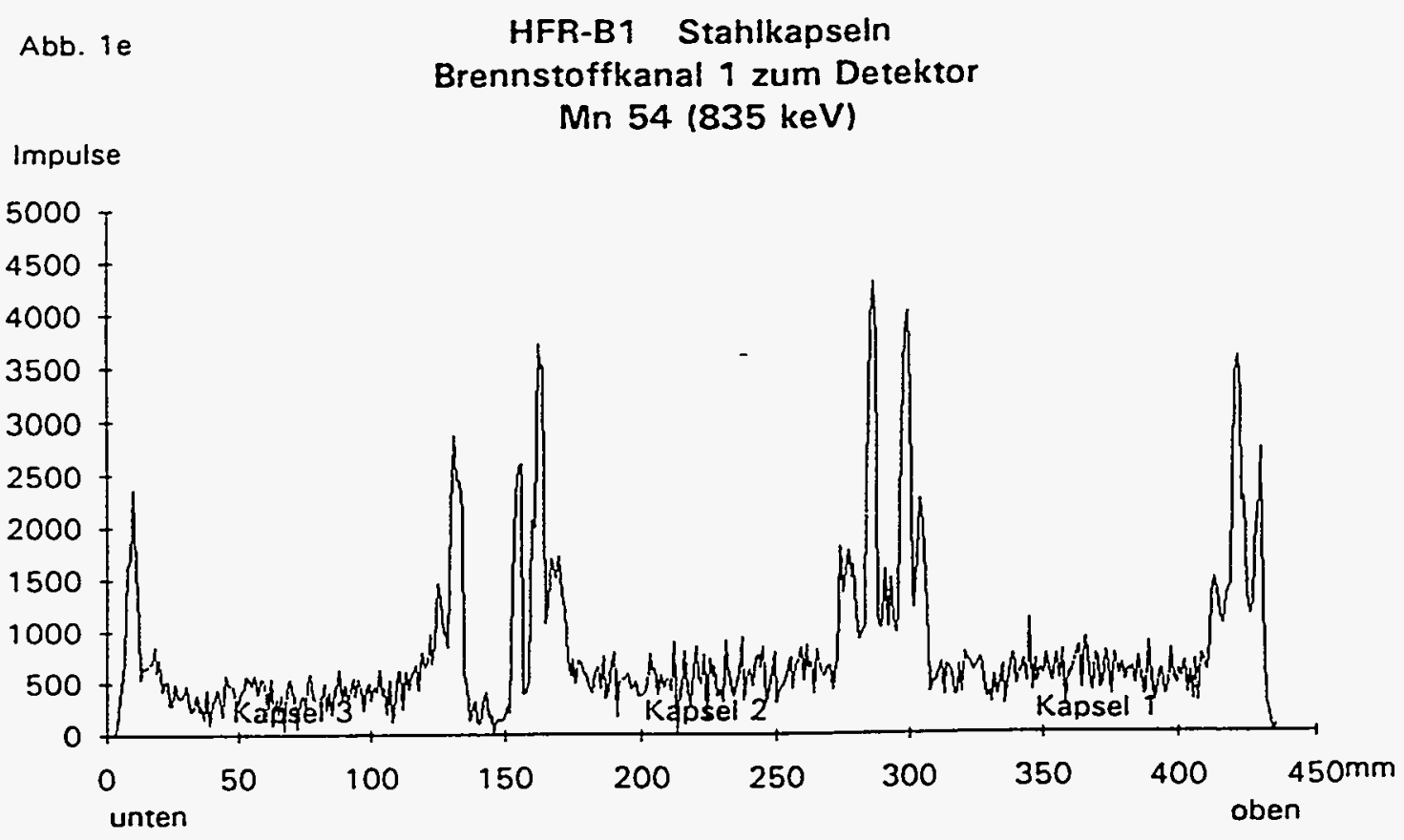

Fig. 4.21 Gamma scam of the steel capsule for ${ }^{54} \mathrm{Mn}$ focused on fuel hole 1 Source: Forschungszentrum Julich GmbH, Julich, Germany 


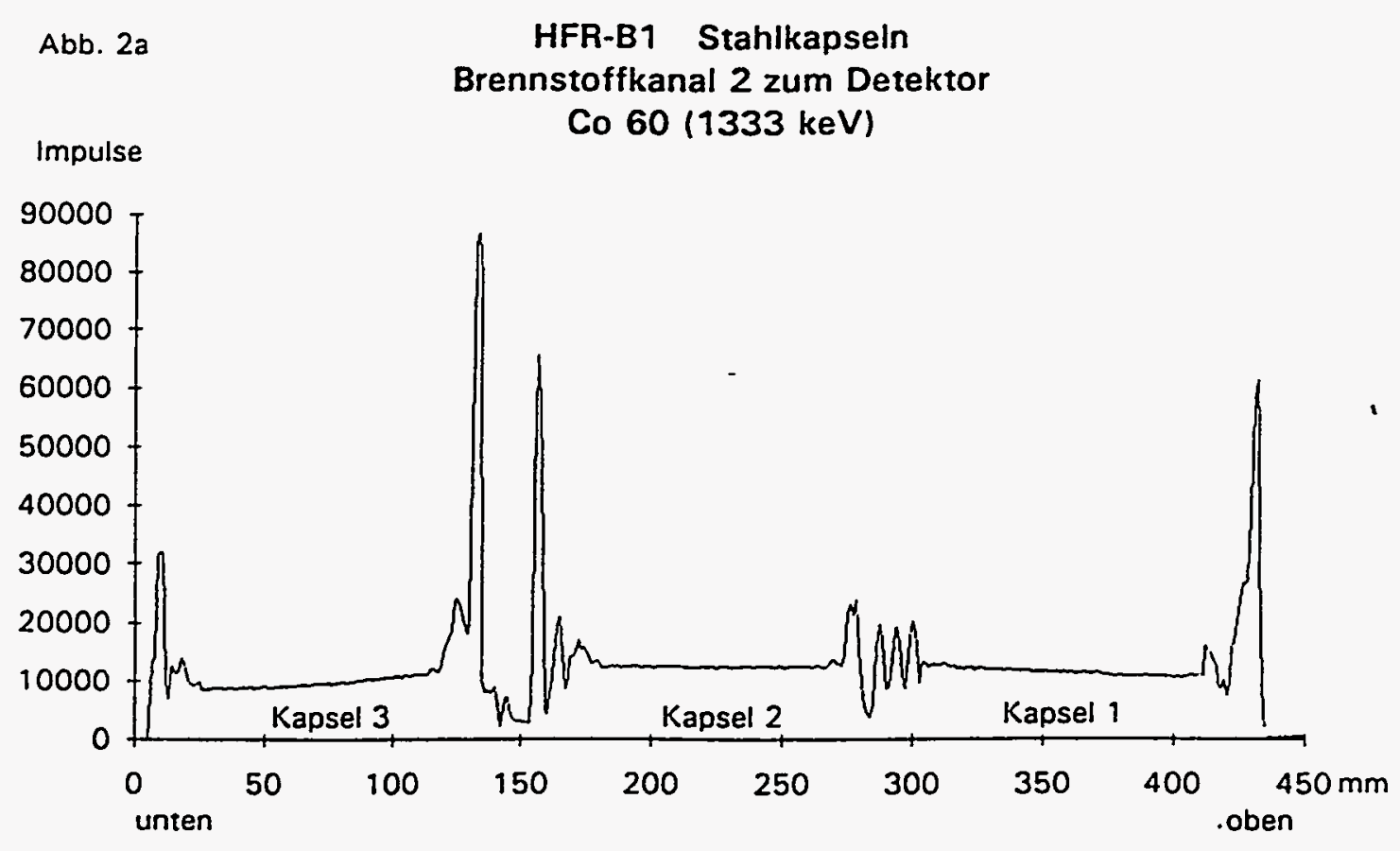

Fig. 4.22 Gamma scam of the steel capsule for ${ }^{60} \mathrm{Co}$ focused on fuel hole 2 Source: Forschungszentrum Julich $\mathrm{GmbH}$, Julich, Germany

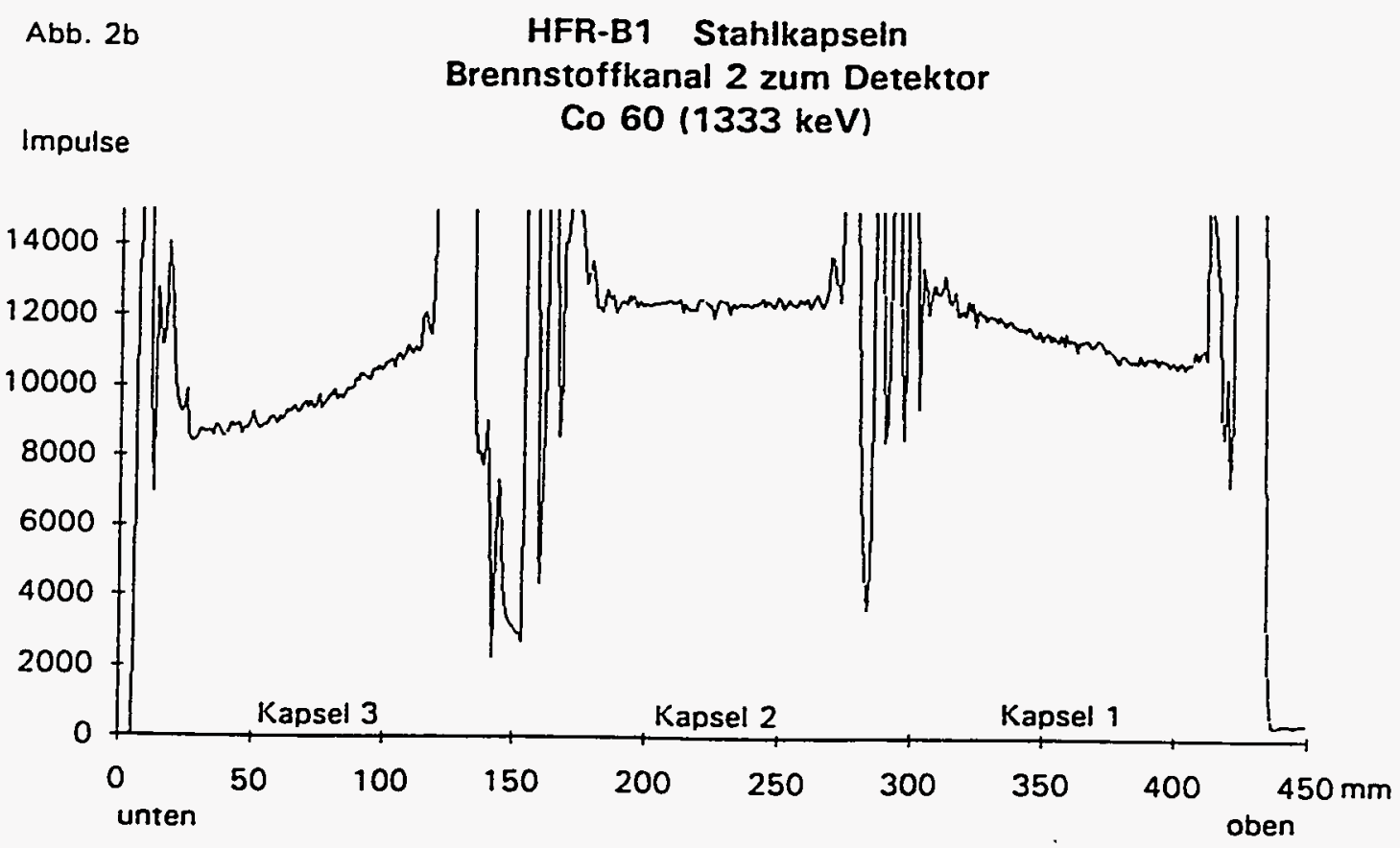

Fig. 4.23 Gamma scam of the steel capsule for ${ }^{60} \mathrm{Co}$ focused on fuel hole 2 (enlarged) Source: Forschungszentrum Julich GmbH, Jalich, Germany 


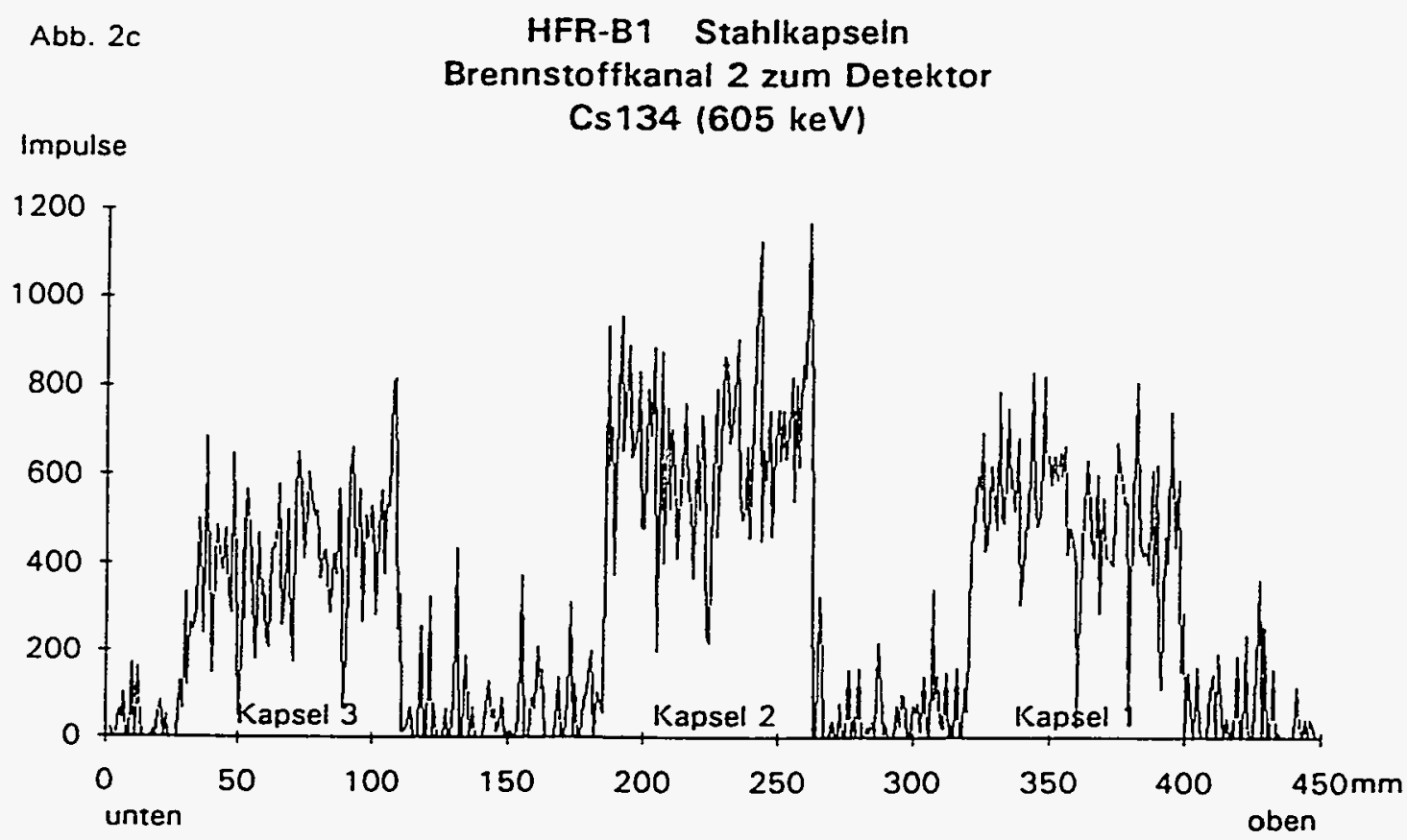

Fig. 4.24 Gamma scam of the steel capsule for ${ }^{134} \mathrm{Cs}$ focused on fuel hole 2 Source: Forschungszentrum Julich GmbH, Julich, Germany

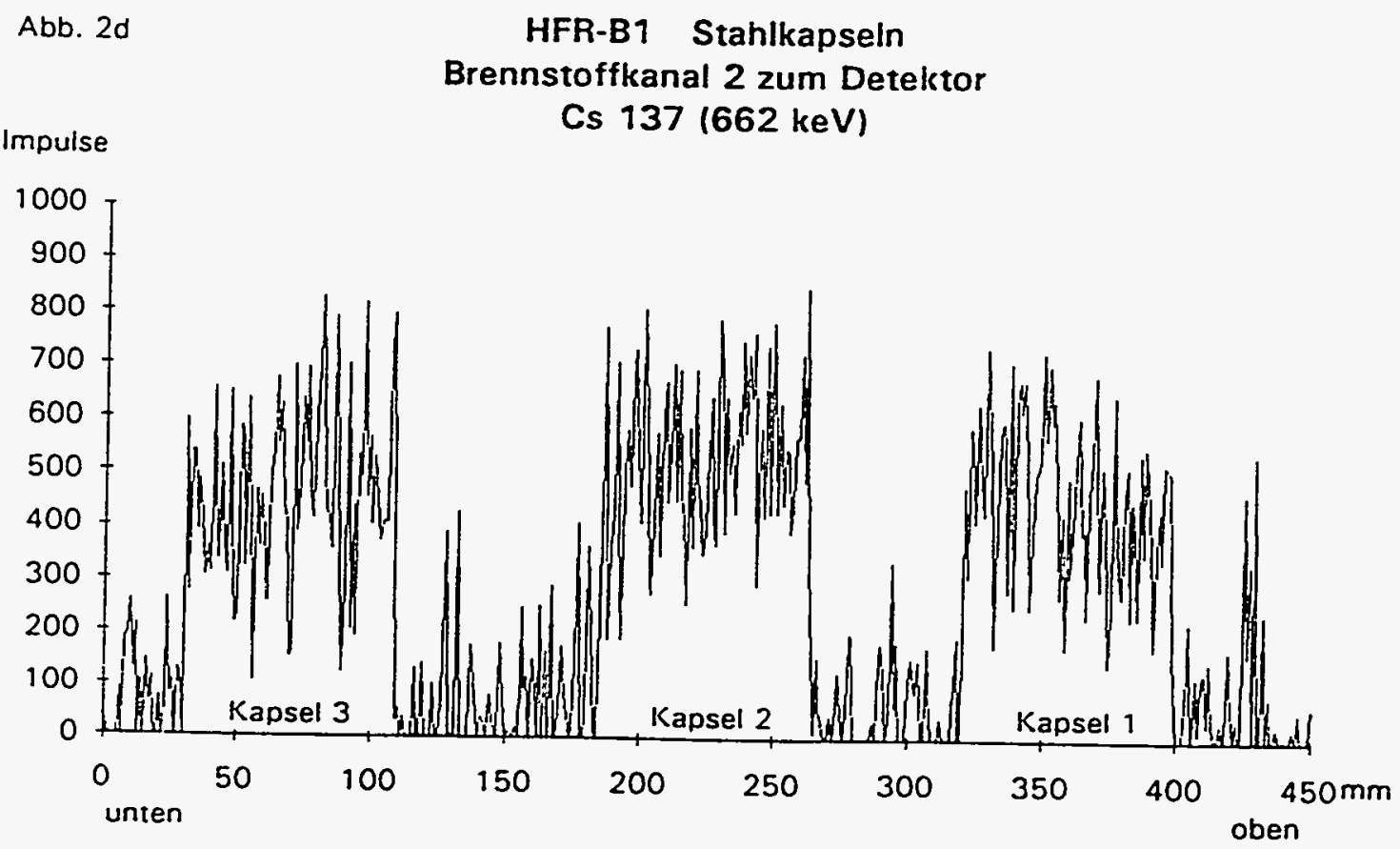

Fig. 4.25 Gamma scam of the steel capsule for ${ }^{137} \mathrm{Cs}$ focused on fuel hole 2 Source: Forschungszentrum Jalich $\mathrm{GmbH}$, Julich, Germany 


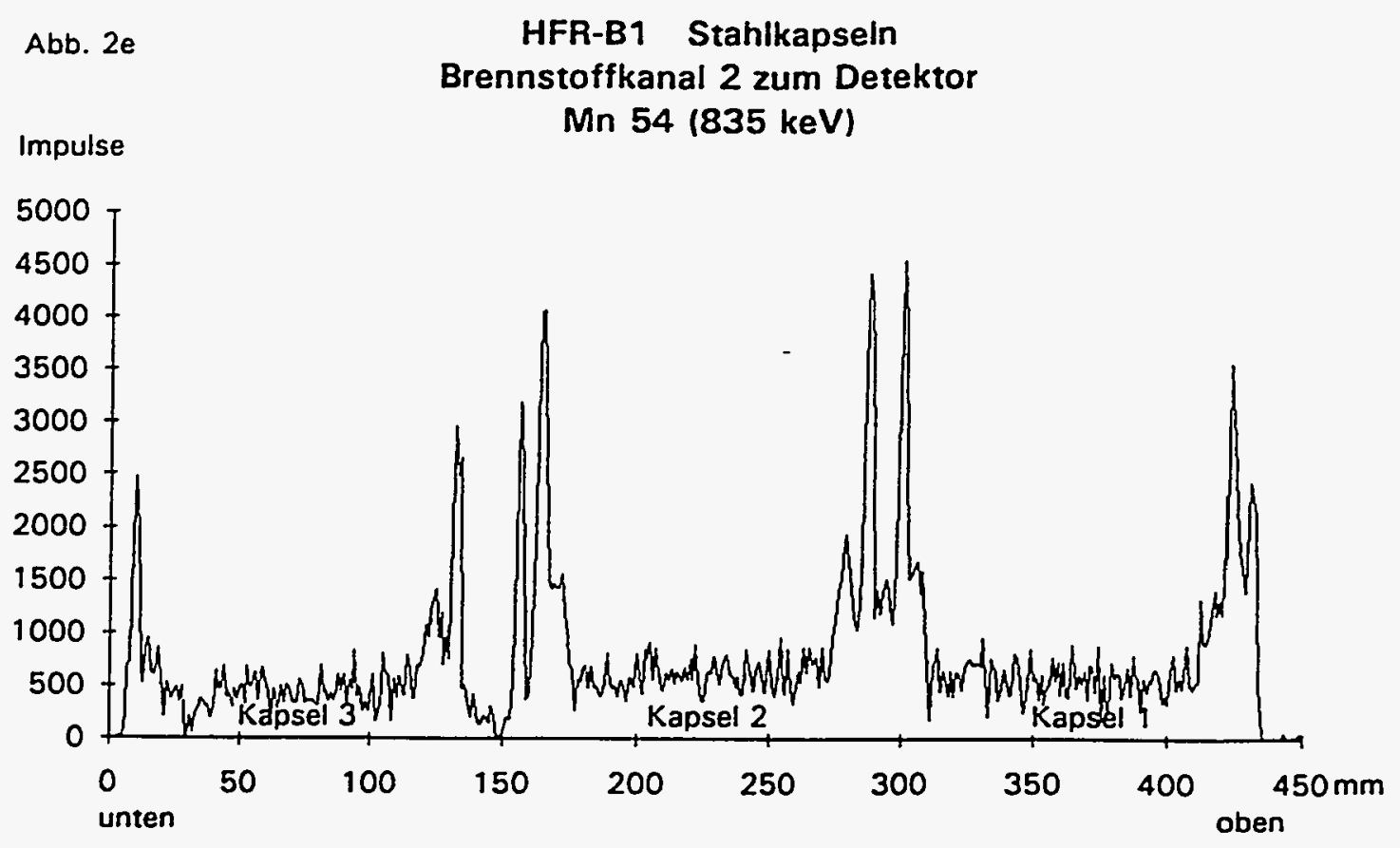

Fig. 4.26 Gamma scam of the steel capsule for ${ }^{54} \mathrm{Mn}$ focused on fuel hole 2 Source: Forschungszentrum Julich GmbH, Jalich, Germany 


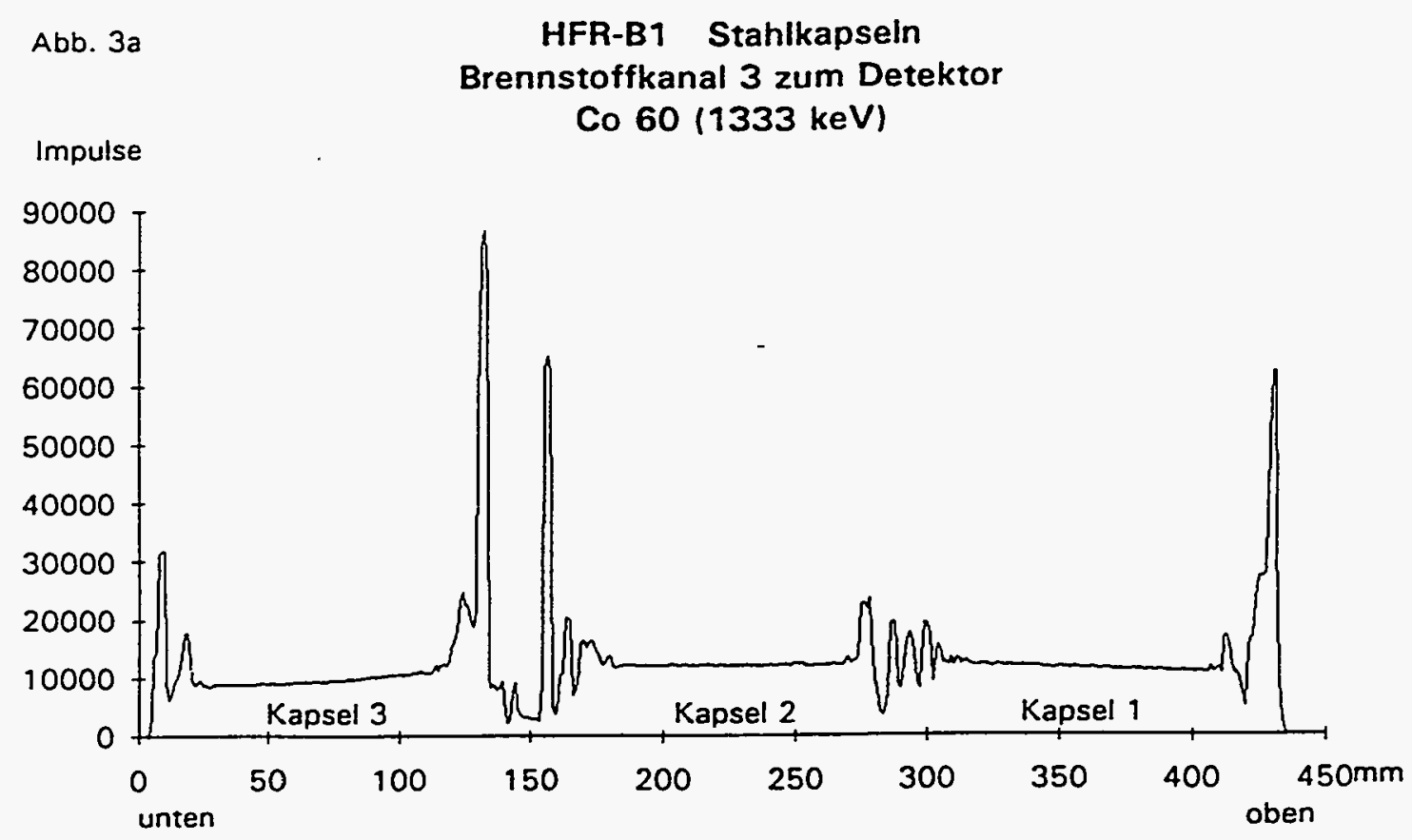

Fig. 4.27 Gamma scam of the steel capsule for ${ }^{60} \mathrm{Co}$ focused on fuel hole 3 Source: Forschungszentrum Jalich GmbH, Julich, Germany

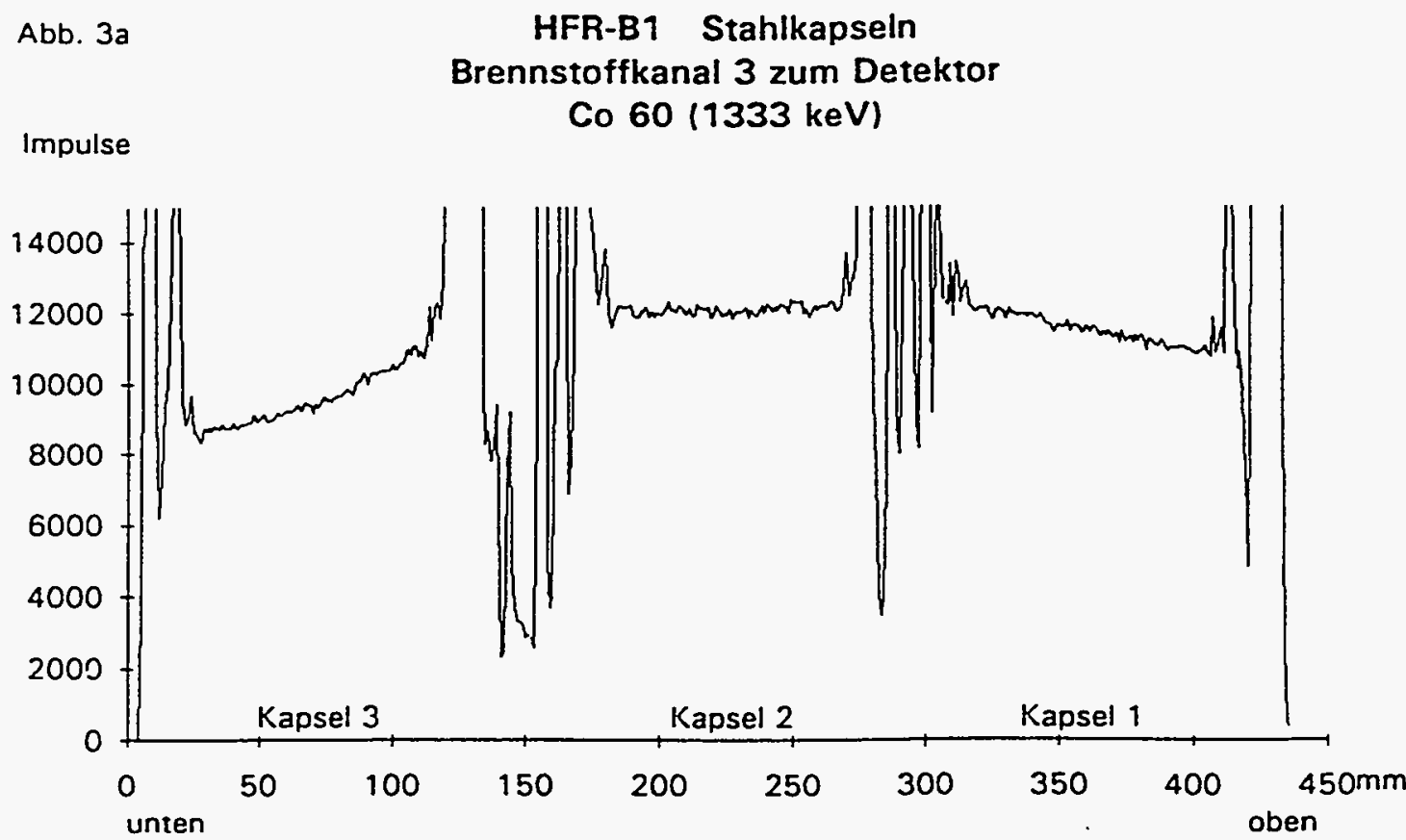

Fig. 4.28 Gamma scam of the steel capsule for ${ }^{60} \mathrm{Co}$ focused on fuel hole 3 (enlarged) Source: Forschungszentrum Julich $\mathrm{GmbH}$, Julich, Germany 


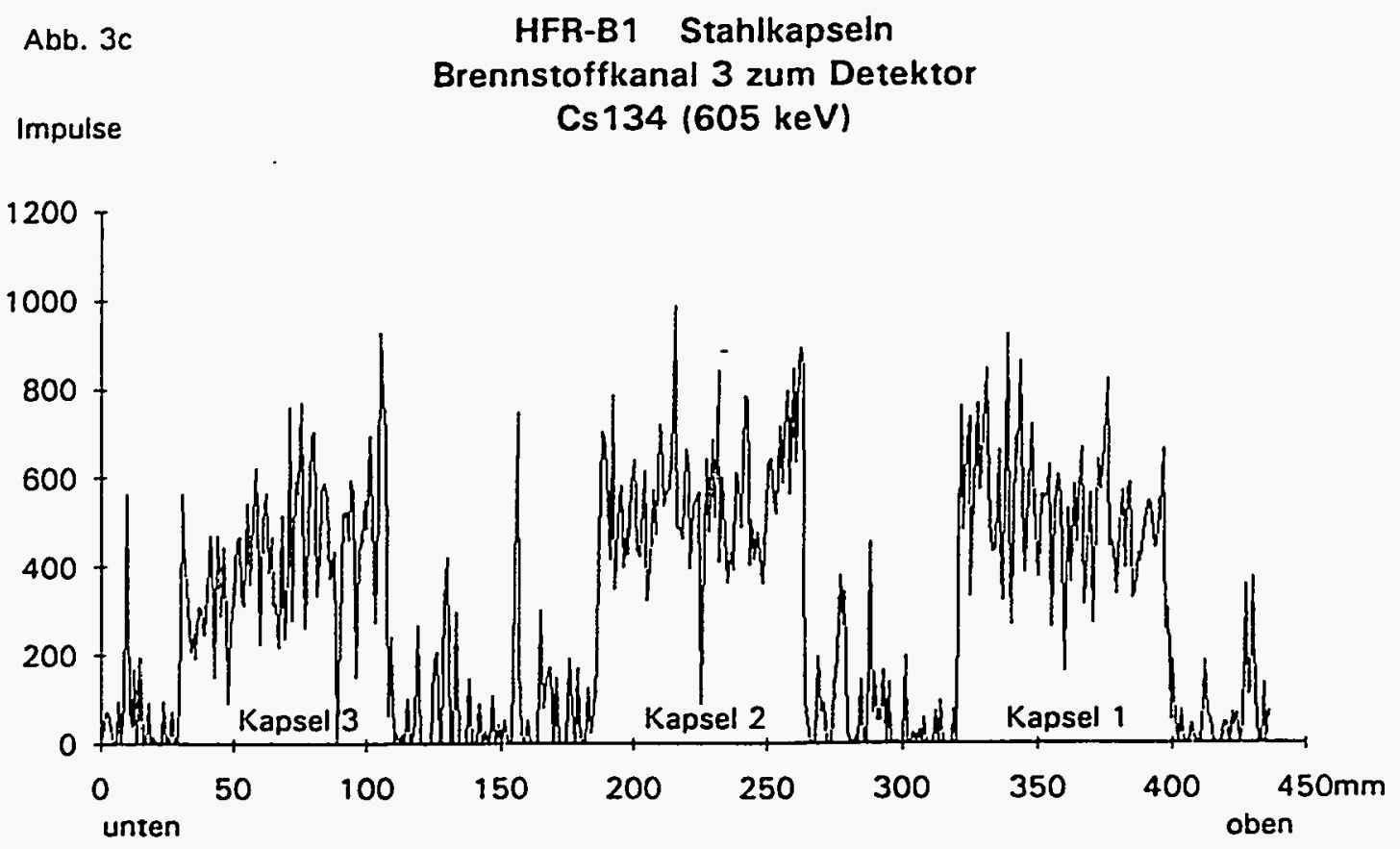

Fig. 4.29 Gamma scam of the steel capsule for ${ }^{134} \mathrm{Cs}$ focused on fuel hole 3 Source: Forschungszentrum Julich GmbH, Julich, Germany

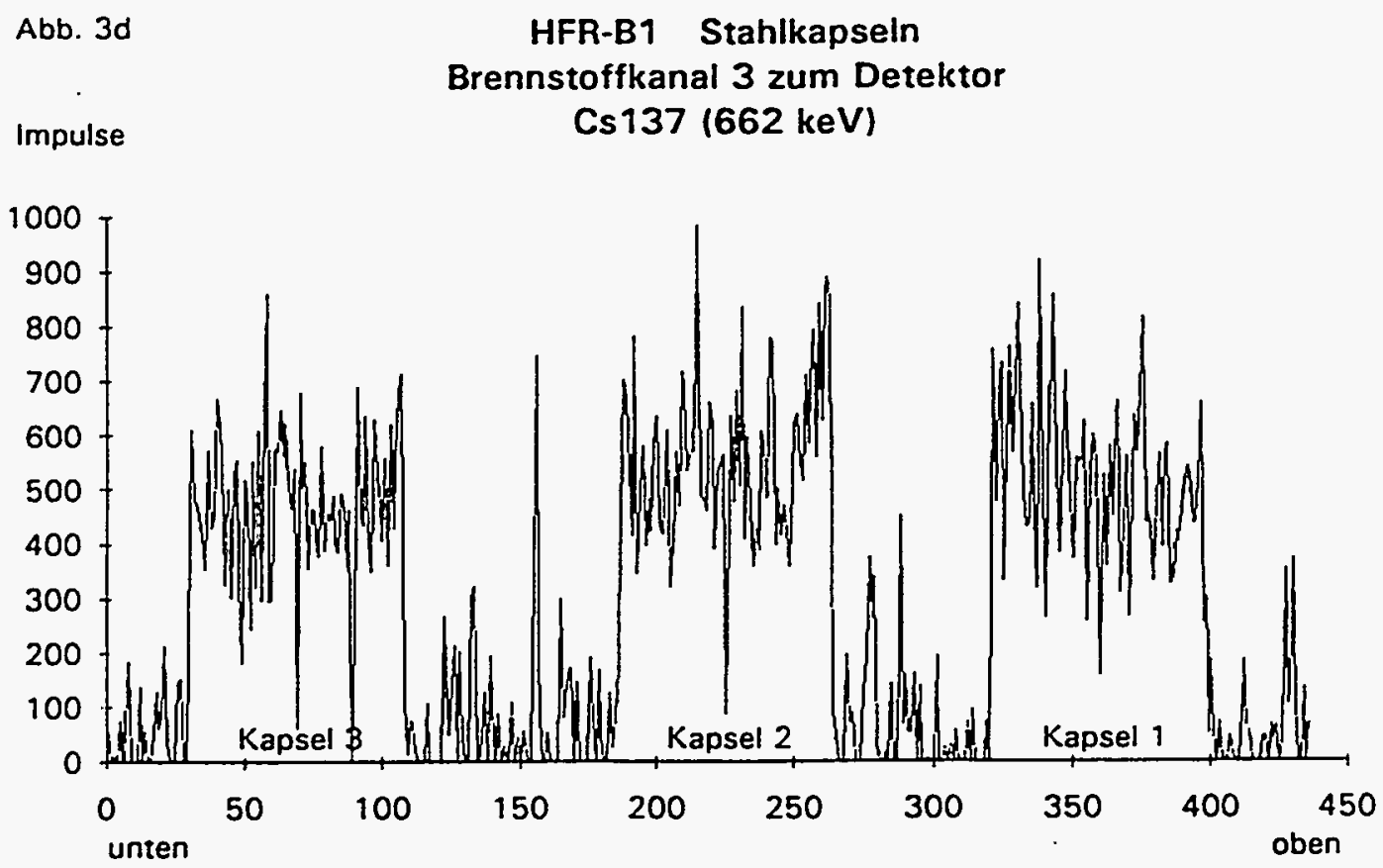

Fig. 4.30 Gamma scam of the steel capsule for ${ }^{137} \mathrm{Cs}$ focused on fuel hole 3 Source: Forschungszentrum Julich GmbH, Julich, Germany 


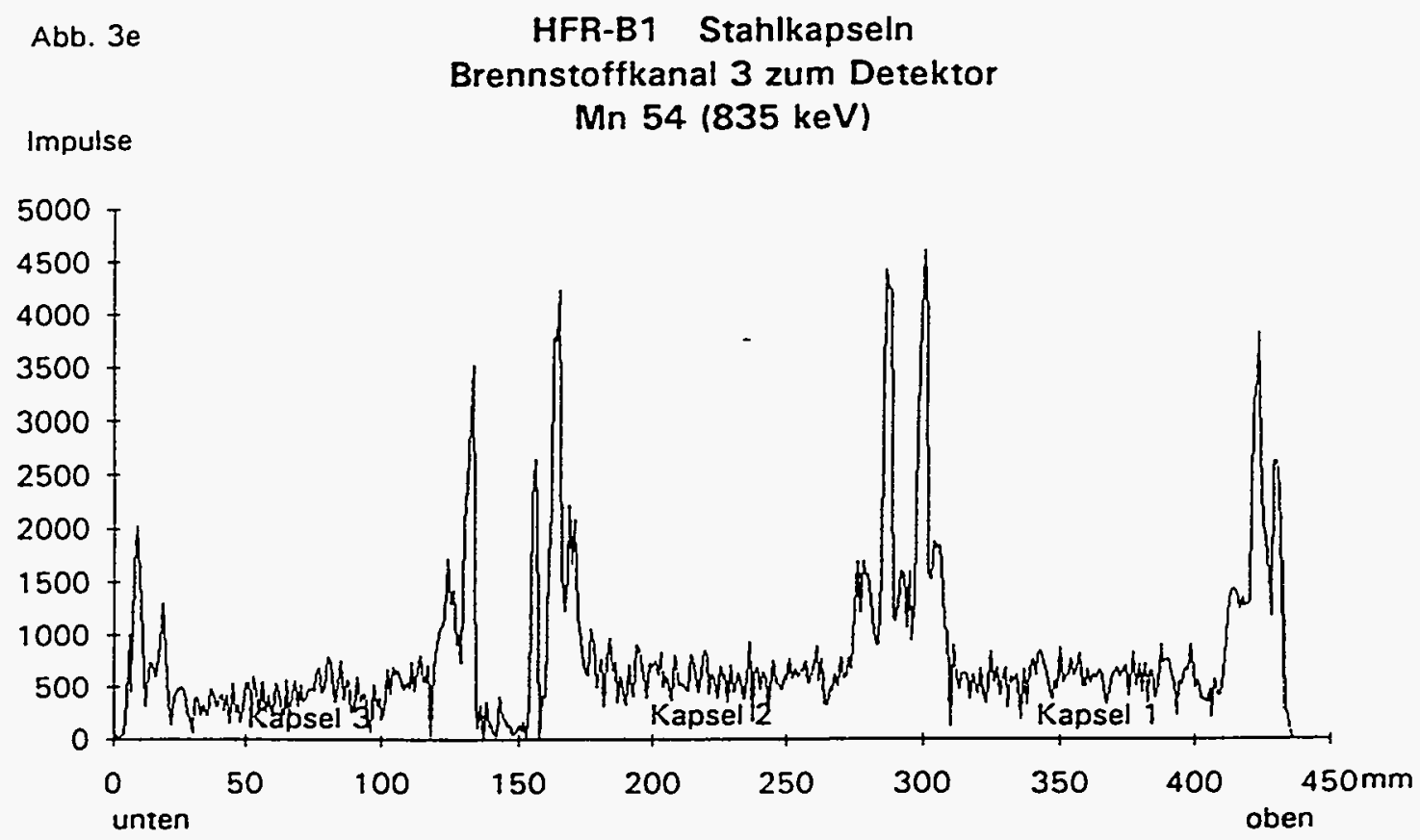

Fig. 4.31 Gamma scam of the steel capsule for ${ }^{54} \mathrm{Mn}$ focused on fuel hole 3 Source: Forschungszentrum Julich GmbH, Julich, Germany 


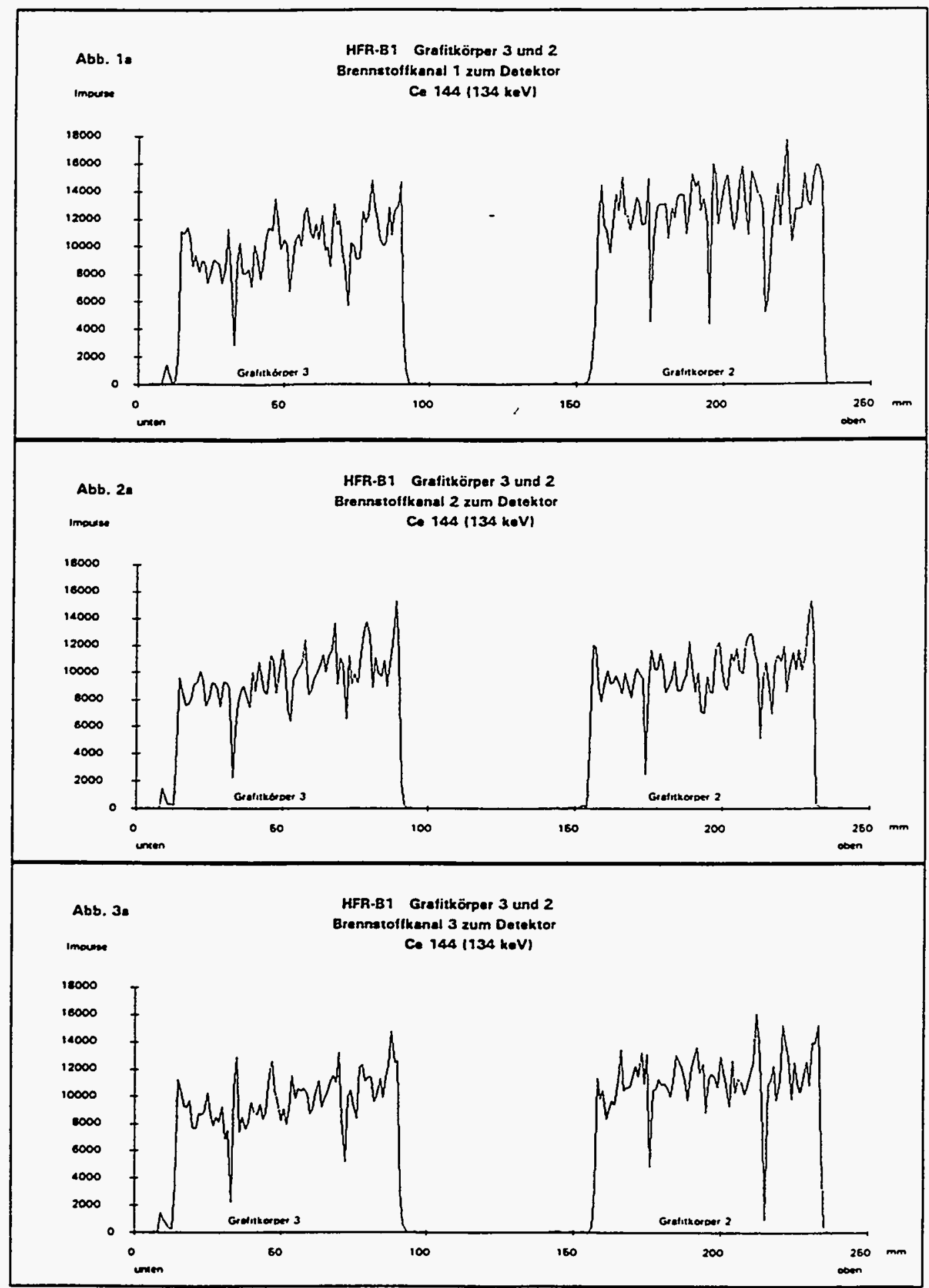

Fig. 4.32 Gamma scam of graphite bodies 2 and 3 focused on fuel holes 1,2 , and 3 for ${ }^{144} \mathrm{Ce}$ Source: Forschungszentrum Jalich GmbH, Julich, Germany 


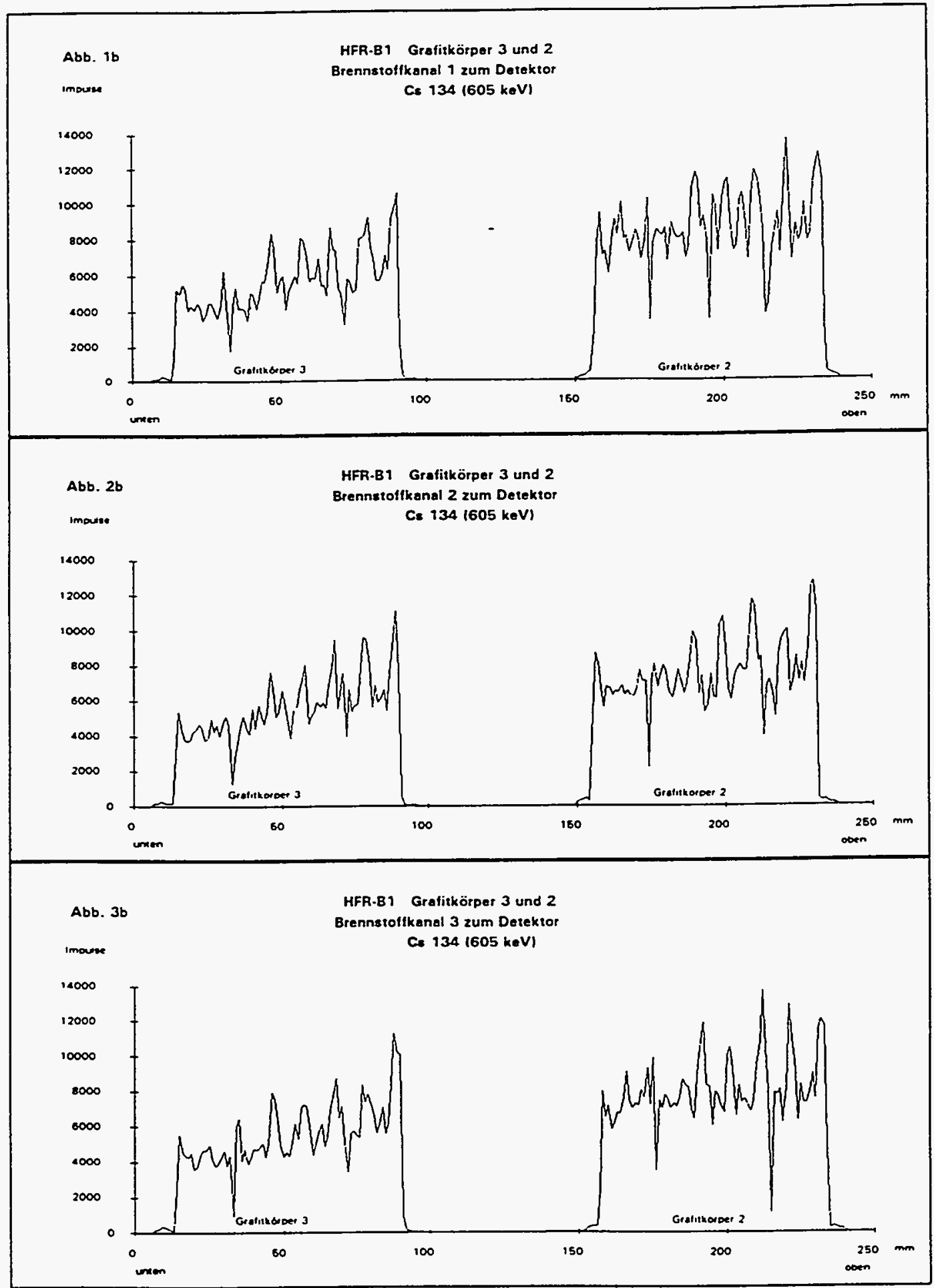

Fig. 4.33 Gamma scam of graphite bodies 2 and 3 focused on fuel holes 1,2 , and 3 for ${ }^{134} \mathrm{Cs}$ Source: Forschungszentrum Julich GmbH, Julich, Germany 


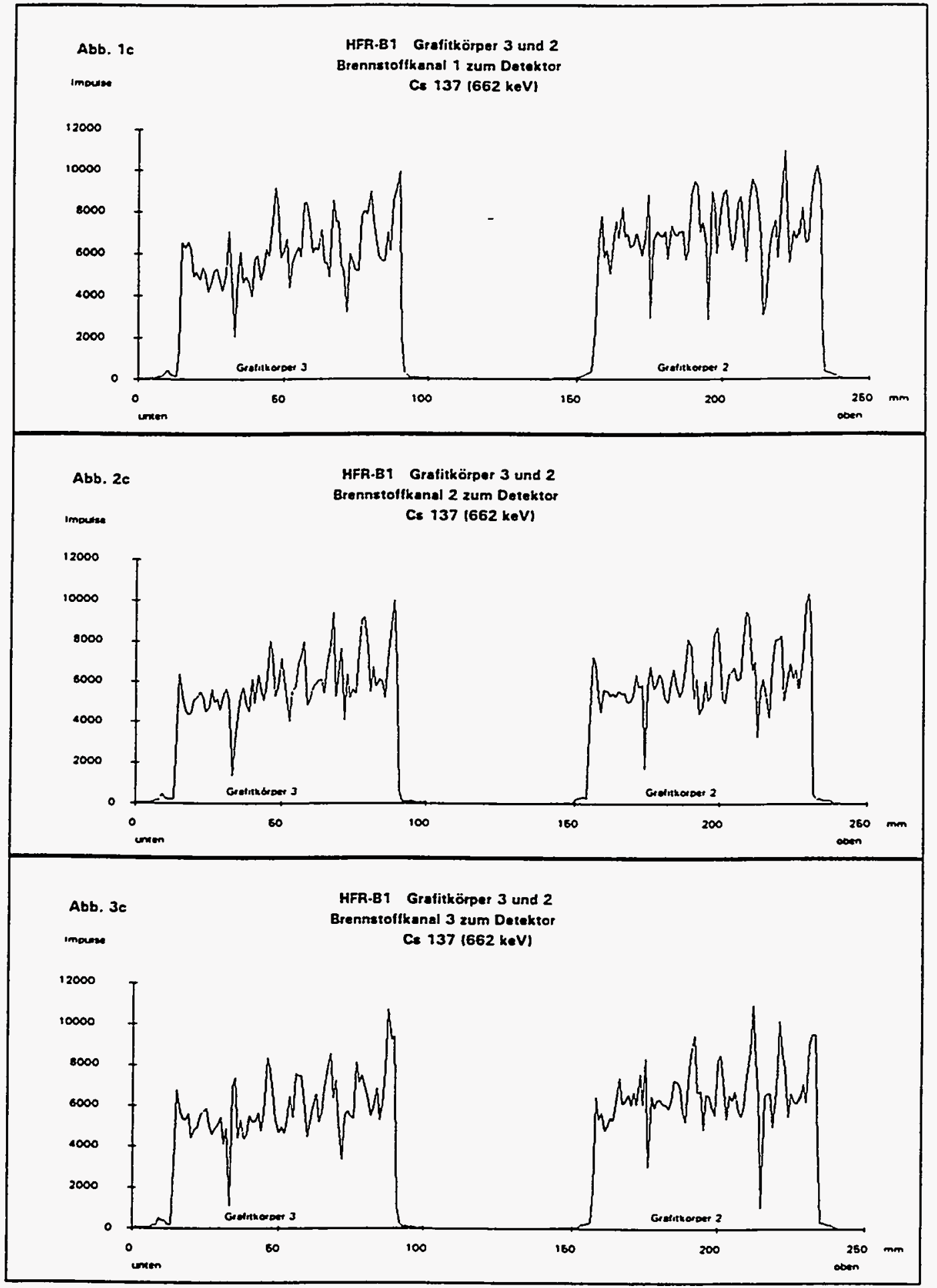

Fig. 4.34 Gamma scam of graphite bodies 2 and 3 focused on fuel holes 1, 2, and 3 for ${ }^{137} \mathrm{Cs}$ Source: Forschungszentrum Jalich GmbH, Jalich, Germany 


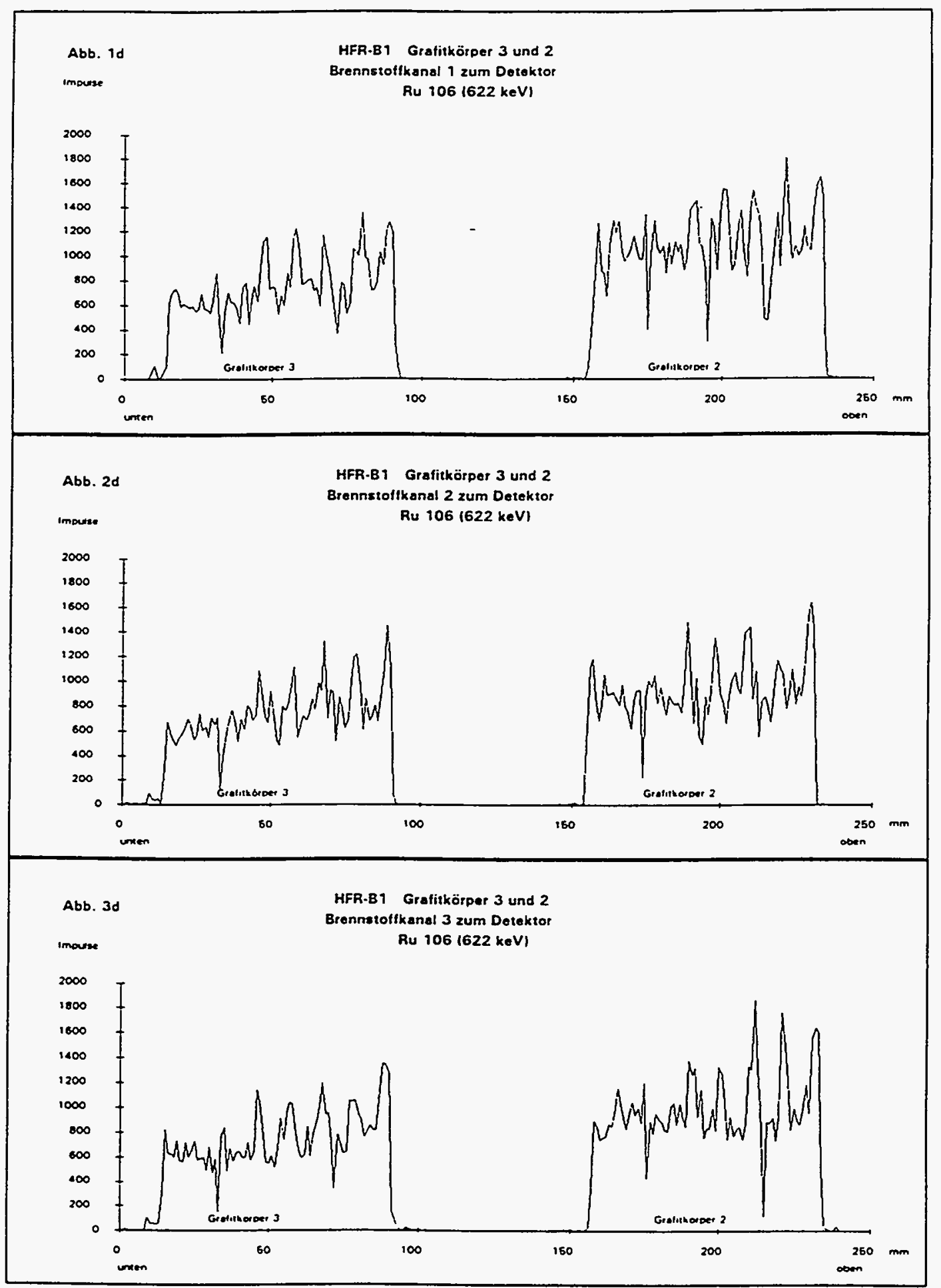

Fig. 4.35 Gamma scam of graphite bodies 2 and 3 focused on fuel holes 1, 2, and 3 for ${ }^{106} \mathrm{Ru}$ Source: Forschungszentrum Julich GmbH, Julich, Germany 


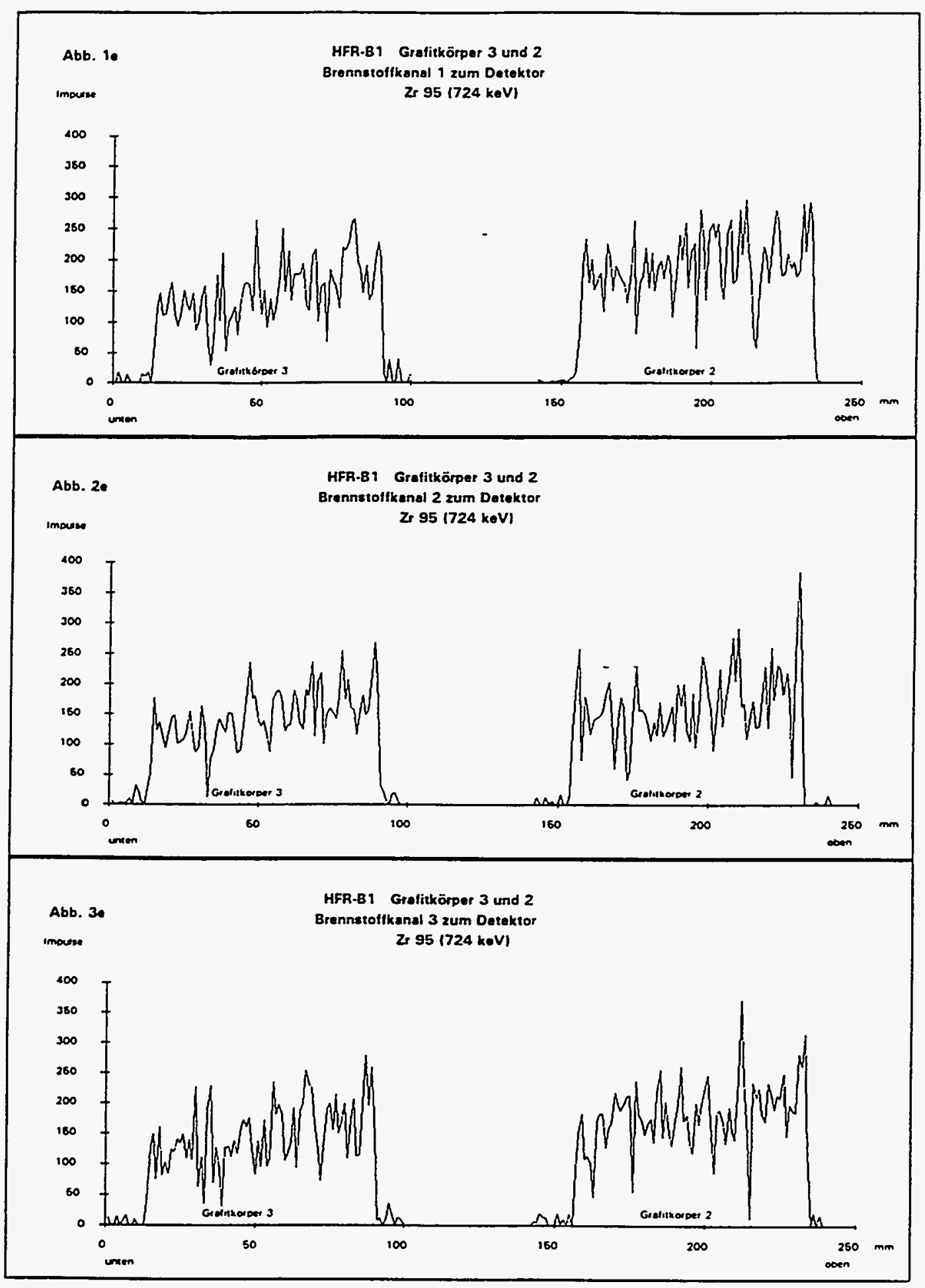

Fig. 4.36 Gamma scam of graphite bodies 2 and 3 focused on fuel holes 1, 2, and 3 for ${ }^{95} \mathrm{Zr}$ Source: Forschungszentrum Julich GmbH, Julich, Germany 


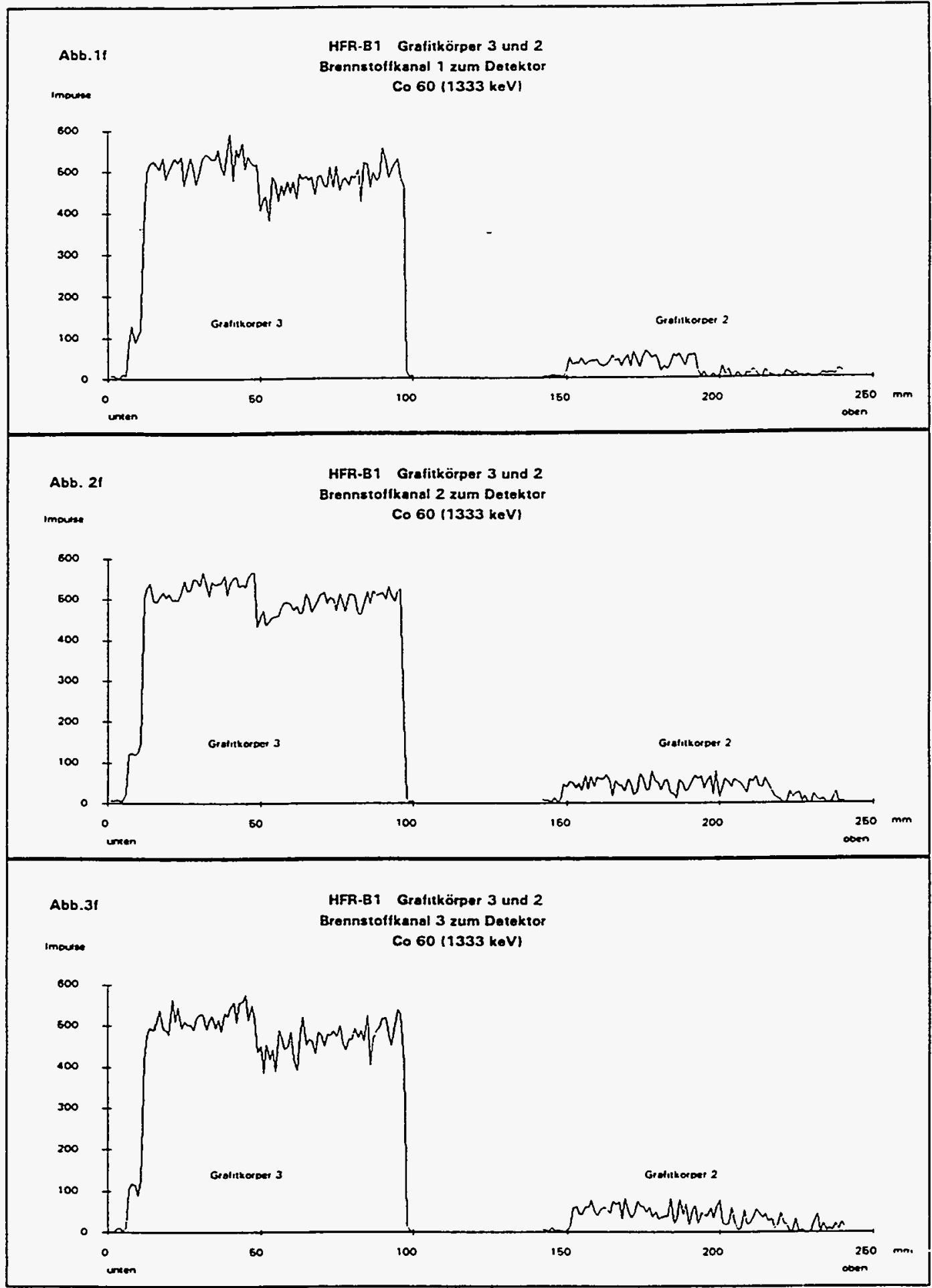

Fig. 4.37 Gamma scam of graphite bodies 2 and 3 focused on fuel holes 1,2 , and 3 for ${ }^{60} \mathrm{Co}$ Source: Forschungszentrum Julich GmbH, Julich, Germany 


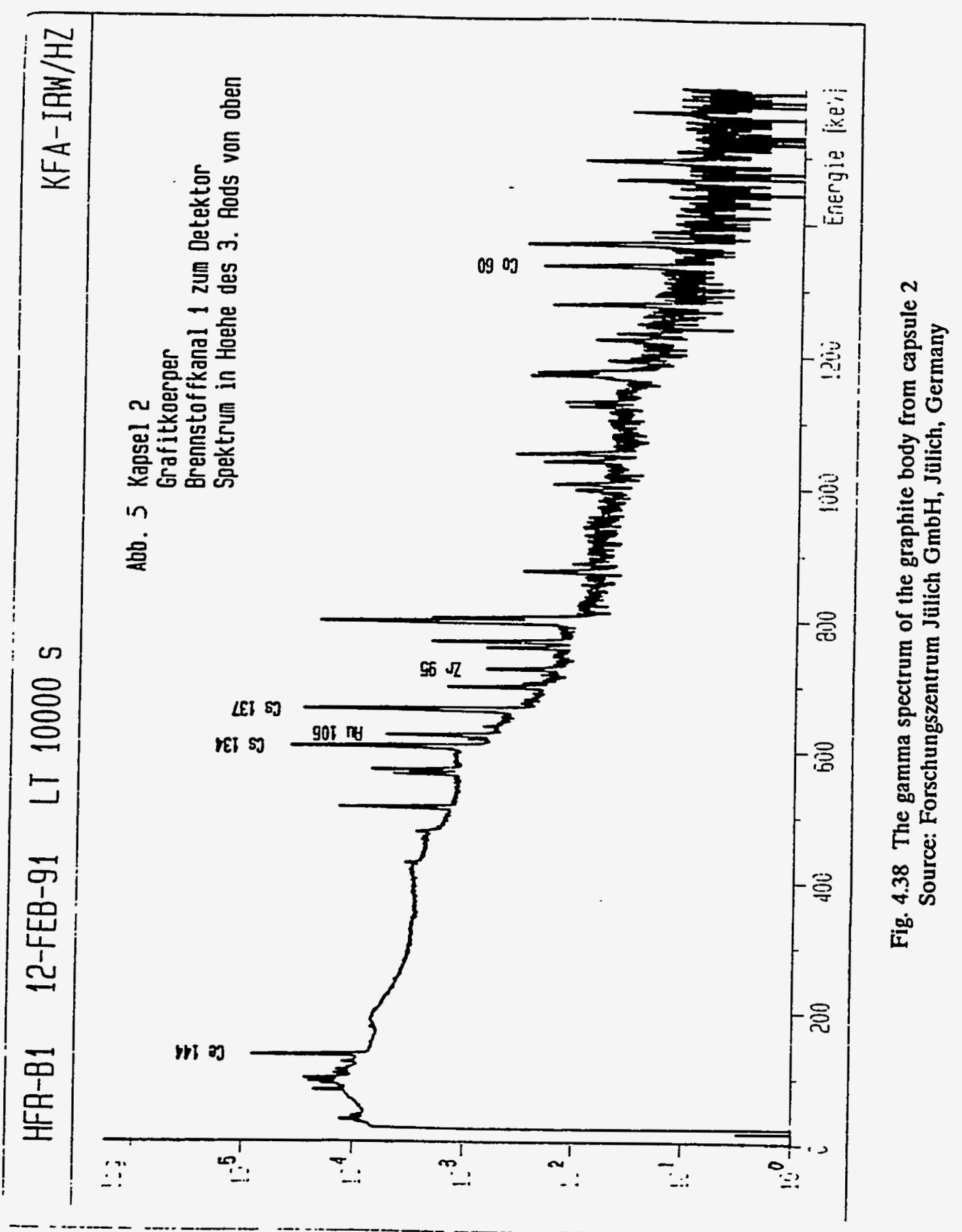




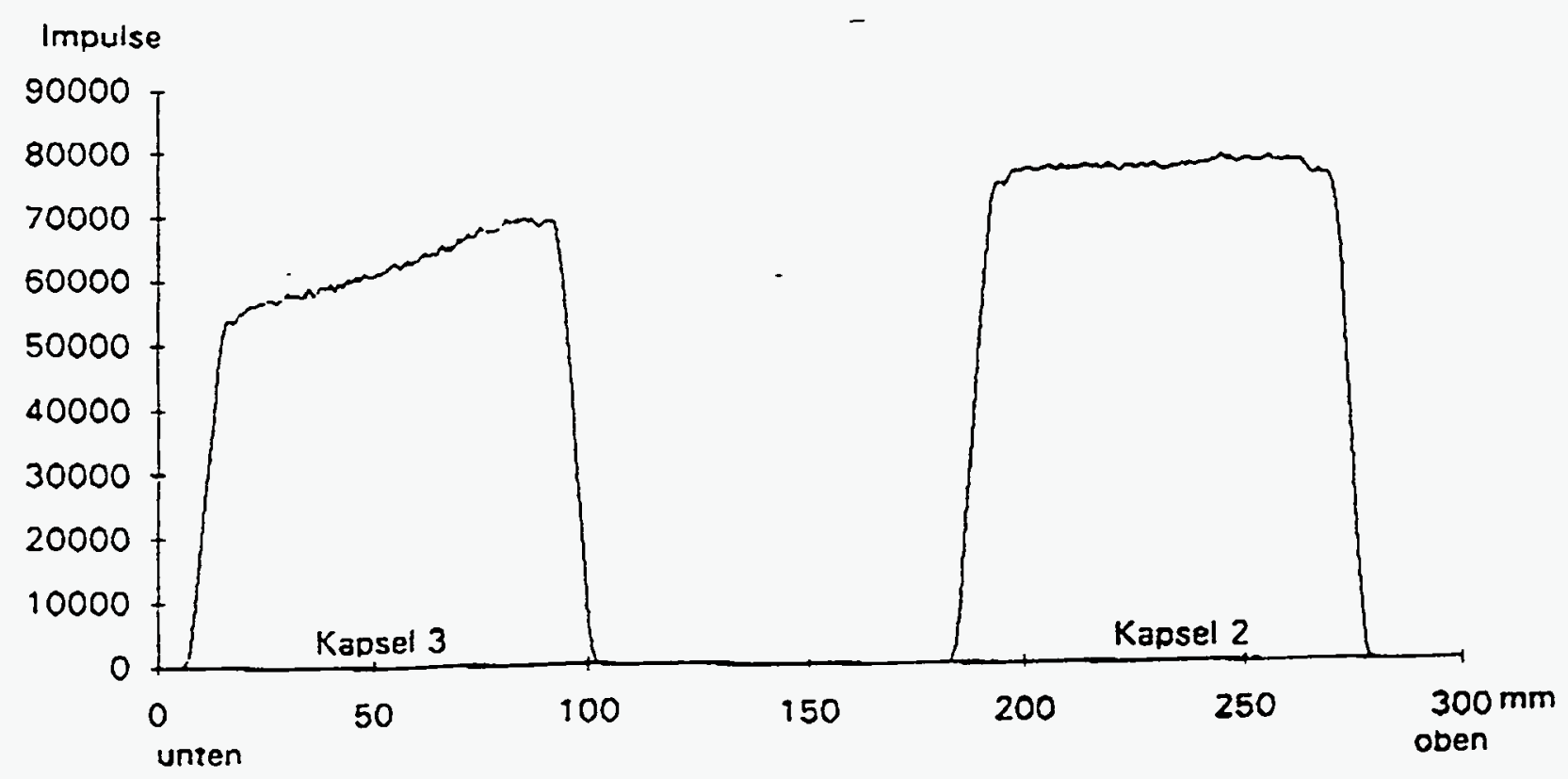

Fig. 4.39 Gamma scan of the gamma scan wires 3.1 and 2.1 for ${ }^{60} \mathrm{Co}$ in capsules 2 and 3 Source: Forschungszentrum Julich GmbH, Julich, Germany

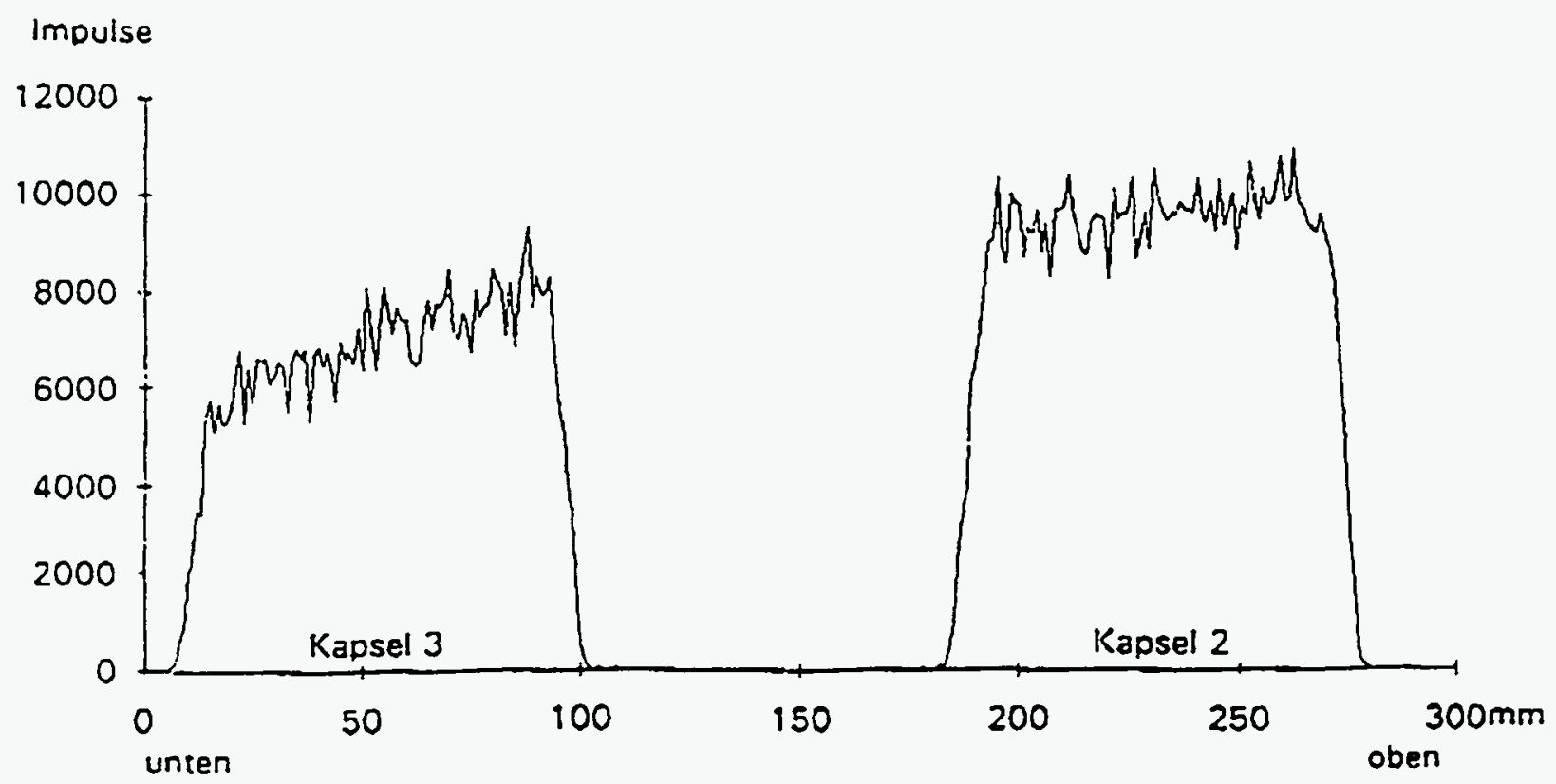

Fig. 4.40 Gamma scan of the gamma scan wires 3.1 and 2.1 for ${ }^{54} \mathrm{Mn}$ in capsules 2 and 3 Source: Forschungszentrum Jalich GmbH, Julich, Germany 


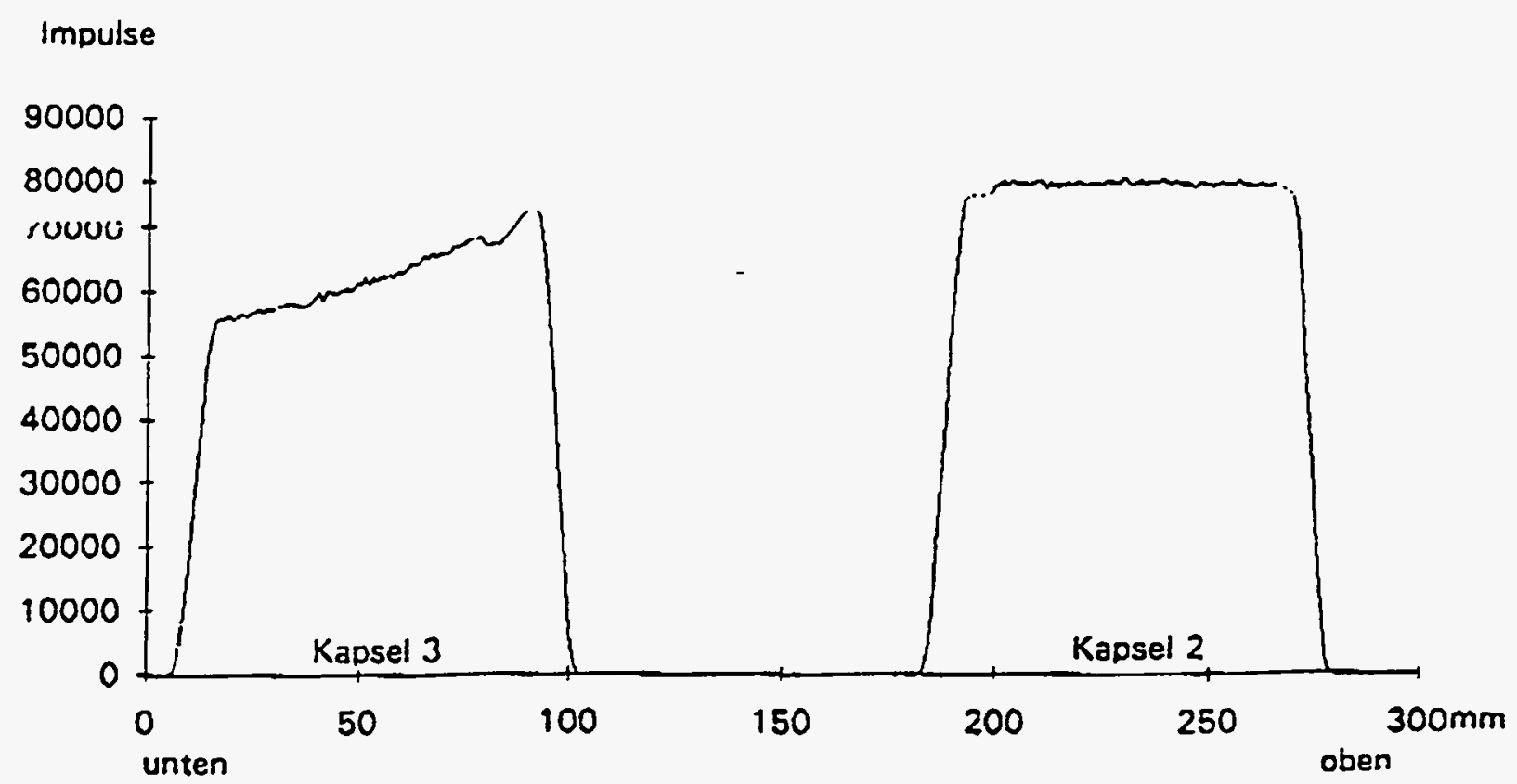

Fig. 4.41 Gamma scan of the gamma scan wires 3.2 and 2.2 for ${ }^{60} \mathrm{Co}$ in capsules 2 and 3 Source: Forschungszentrum Julich $\mathrm{GmbH}$, Julich, Germany

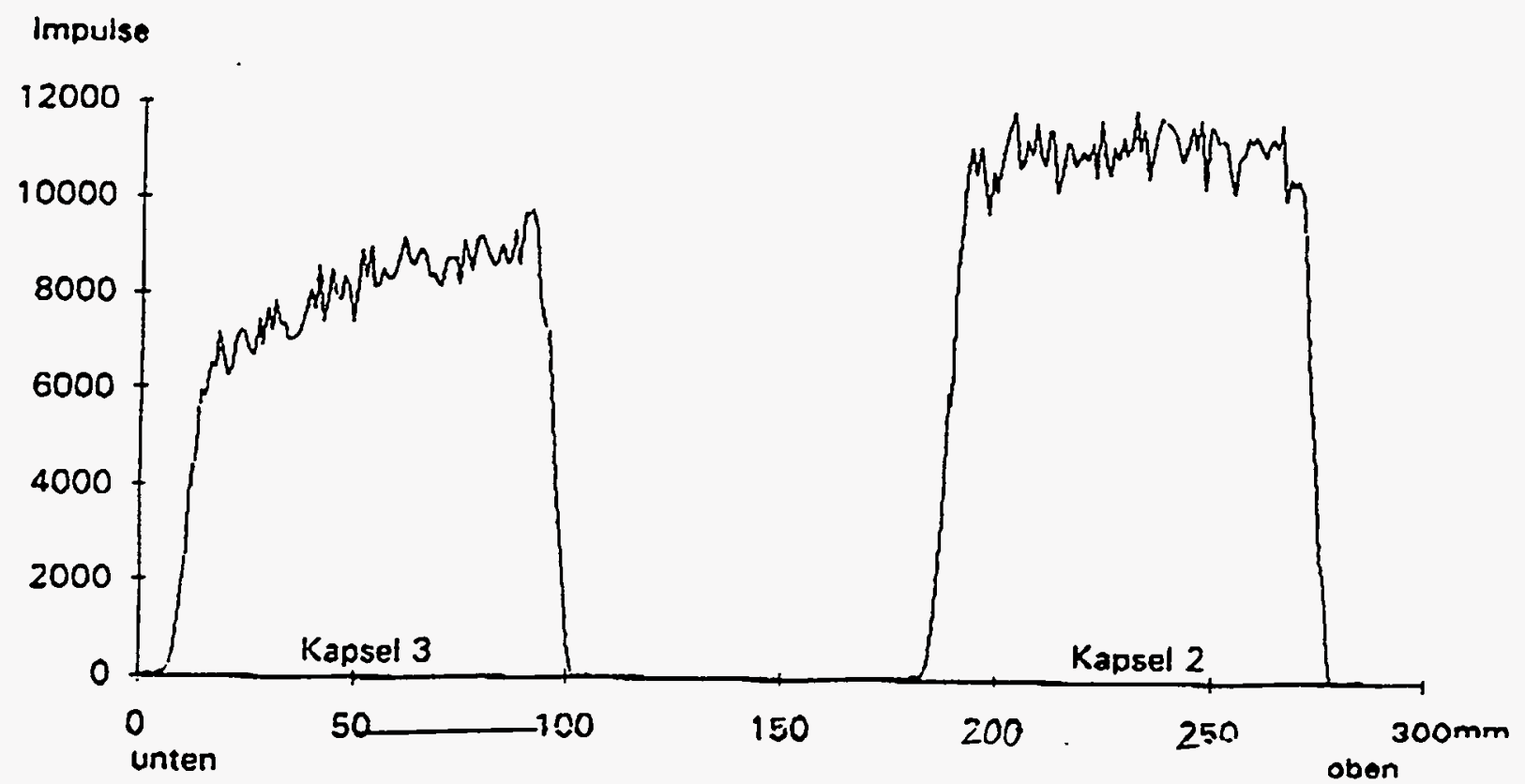

Fig. 4.42 Gamma scan of the gamma scan wires 3.2 and 2.2 for ${ }^{54} \mathrm{Mn}$ in capsules 2 and 3 Source: Forschungszentrum Julich GmbH, Julich, Germany 


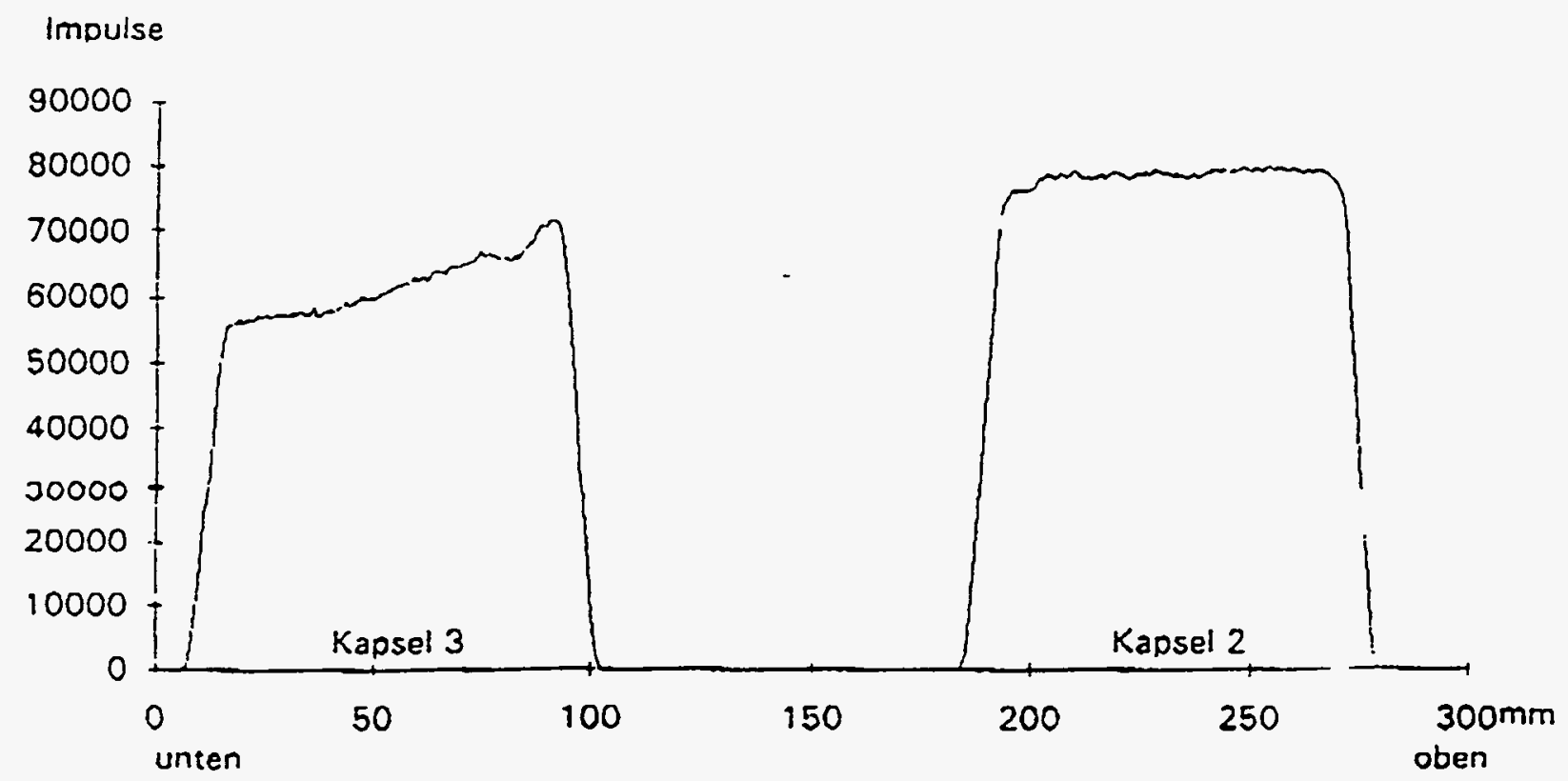

Fig. 4.43 Gamma scan of the gamma scan wires 3.3 and 2.3 for ${ }^{60} \mathrm{Co}$ in capsules 2 and 3 Source: Forschungszentrum Julich $\mathrm{GmbH}$, Julich, Germany

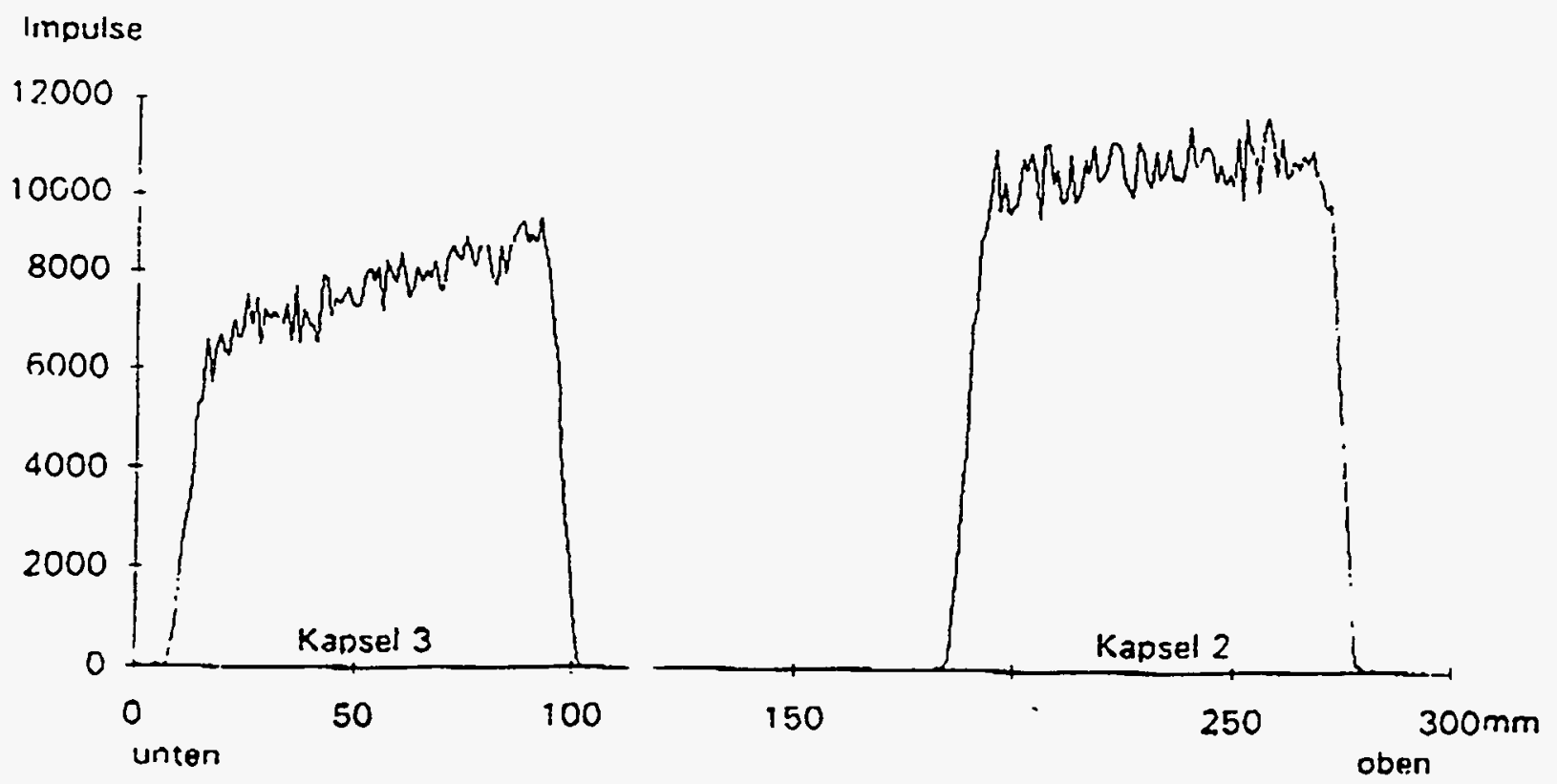

Fig. 4.44 Gamma scan of the gamma scan wires 3.3 and 2.3 for ${ }^{54} \mathrm{Mn}$ in capsules 2 and 3 Source: Forschungszentrum Jalich GmbH, Julich, Germany 
Table 4.6 Impulses during gamma scan of gamma scan wire 2.1 from capsule 2 Source: Forschungszentrum Julich GmbH, Jalich, Germany

Measurement date: 18.3 .91

Measurement time: $500 \mathrm{~s} /$ point

Data corrected to: 1.3 .91
Step size: $1 \mathrm{~mm}$

Collimator: $5 \times 30 \mathrm{~mm}$

\begin{tabular}{|c|c|c|c|c|c|}
\hline $\begin{array}{c}\text { Distance } \\
(\mathrm{mm})\end{array}$ & ${ }^{54} \mathrm{Mn}: \mathrm{I}(\mathrm{t})^{(2)}$ & ${ }^{60} \mathrm{Co:I}(\mathrm{t})^{(\mathbf{t})}$ & $\begin{array}{c}\text { Distance } \\
(\mathrm{mm})\end{array}$ & ${ }^{54} \mathrm{Mn}: \mathrm{I}(\mathrm{t})^{(2)}$ & ${ }^{60} \mathrm{Co}: \mathrm{I}(\mathrm{l})^{(2)}$ \\
\hline 0 & 45 & 57 & 23 & 8663 & 76799 \\
\hline 1 & 6 & 2 & 24 & 9256 & 76744 \\
\hline 2 & 0 & 47 & 25 & 9123 & 76506 \\
\hline 3 & 0 & 33 & 26 & 9618 & 76908 \\
\hline 4 & 64 & 142 & 27 & 0009 & 77330 \\
\hline 5 & 40 & 539 & 28 & 9353 & 77137 \\
\hline 6 & 371 & 3100 & 29 & 8222 & 76348 \\
\hline 7 & 991 & 9589 & 30 & 9655 & 77474 \\
\hline 8 & 2180 & 18728 & 31 & 9625 & 76948 \\
\hline 9 & 3131 & 28757 & 32 & 9654 & 76841 \\
\hline 10 & 4009 & 38172 & 33 & 10346 & 77207 \\
\hline 11 & 6094 & 47143 & 34 & 9663 & 76787 \\
\hline 12 & 6402 & 56228 & 35 & 9248 & 77249 \\
\hline 13 & 7220 & 65017 & 36 & 8779 & 77288 \\
\hline 14 & 7896 & 71231 & 37 & 8710 & 76814 \\
\hline 15 & 8966 & 74328 & 38 & 9305 & 77467 \\
\hline 16 & 9037 & 74773 & 39 & 9507 & 76640 \\
\hline 17 & 10316 & 74252 & 40 & 9469 & 77291 \\
\hline 18 & 8968 & 76461 & 41 & 9447 & 77246 \\
\hline 19 & 8516 & 76696 & 42 & 8210 & 76782 \\
\hline 20 & 9959 & 76357 & 43 & 10061 & 76149 \\
\hline 21 & 9768 & 76696 & 44 & 9400 & 76981 \\
\hline 22 & 9740 & 76866 & 45 & 9532 & 77286 \\
\hline
\end{tabular}

(a) $\mathrm{I}(\mathrm{t})=$ impulses $/ 500 \mathrm{~s}$ at $835 \mathrm{KeV}$ for ${ }^{54} \mathrm{Mn}$ and $1333 \mathrm{KeV}$ for ${ }^{60} \mathrm{Co}$ 
Table 4.6 (Continued)

Measurement date: 18.3 .91

Measurement time: 500 s/point

Data corrected to: 1.3 .91
Step size: $1 \mathrm{~mm}$

Collimator: $5 \times 30 \mathrm{~mm}$

\begin{tabular}{|c|c|c|c|c|c|}
\hline $\begin{array}{c}\text { Distance } \\
\text { (mm) }\end{array}$ & ${ }^{s 4} \mathrm{Mn}: \mathrm{I}(\mathrm{t}){ }^{(\mathfrak{s})}$ & ${ }^{60} \mathrm{Co:I}(\mathrm{t})^{(\mathfrak{t})}$ & Distance & ${ }^{54} \mathrm{Mn}: \mathrm{I}(\mathrm{t})^{(2)}$ & ${ }^{80} \mathrm{Co}: \mathrm{I}(\mathrm{t})^{(2)}$ \\
\hline 46 & 9527 & 77051 & 69 & 9288 & 78199 \\
\hline 47 & 10285 & 76685 & 78 & 9626 & 77234 \\
\hline 48 & 8611 & 77288 & 71 & 9958 & 77377 \\
\hline 49 & 9086 & 76898 & 72 & 8786 & 77796 \\
\hline 50 & 9575 & 77094 & 73 & 9693 & 77912 \\
\hline 51 & 8817 & 77551 & 74 & 9471 & 77677 \\
\hline 52 & 8817 & 77551 & 75 & 10602 & 77666 \\
\hline 53 & 10431 & 76741 & 76 & 9816 & 77603 \\
\hline 54 & 9752 & 76383 & 77 & 9380 & 77811 \\
\hline 55 & 9635 & 76705 & 78 & 10071 & 78360 \\
\hline 56 & 9355 & 76850 & 79 & 9701 & 77391 \\
\hline 57 & 9538 & 76981 & 80 & 9722 & 77633 \\
\hline 58 & 9507 & 77384 & 81 & 10066 & 77461 \\
\hline 59 & 9763 & 77172 & 82 & 10691 & 77902 \\
\hline 60 & 9611 & 77381 & 83 & 9779 & 77630 \\
\hline 61 & 9608 & 76936 & 84 & 9872 & 77534 \\
\hline 62 & 9559 & 77315 & 85 & 10874 & 77541 \\
\hline 63 & 10294 & 77666 & 86 & 9733 & 76670 \\
\hline 64 & 9410 & 77590 & 87 & 9628 & 75772 \\
\hline 65 & 9367 & 77955 & 88 & 9391 & 75175 \\
\hline 66 & 9769 & 77961 & 89 & 9169 & 76144 \\
\hline 67 & 9168 & 78652 & 90 & 9135 & 75082 \\
\hline 68 & 10242 & 77909 & 91 & 9529 & 75633 \\
\hline
\end{tabular}


Table 4.6 (Continued)

Measurement date: 18.3 .91

Measurement time: 500 s/point

Data corrected to: 1.3 .91
Step size: $1 \mathrm{~mm}$

Collimator: $5 \times 30 \mathrm{~mm}$

\begin{tabular}{|c|c|c|c|c|c|}
\hline $\begin{array}{c}\text { Distance } \\
\text { (mm) }\end{array}$ & ${ }^{54} \mathrm{Mn}: \mathrm{I}(\mathrm{t})^{(2)}$ & ${ }^{60} \mathrm{Co}: \mathrm{I}(\mathrm{t})^{(x)}$ & $\begin{array}{c}\text { Distance } \\
(\mathrm{mm})\end{array}$ & ${ }^{54} \mathrm{Mn}: \mathrm{I}(\mathrm{t})^{(\mathfrak{a})}$ & ${ }^{60} \mathrm{Co}: \mathrm{I}(\mathrm{t})^{(2)}$ \\
\hline 92 & 9091 & 74794 & 101 & 132 & 985 \\
\hline 93 & 8813 & 70645 & 102 & 114 & 77 \\
\hline 94 & 8062 & 63568 & 103 & 0 & 39 \\
\hline 95 & 7074 & 54006 & 104 & 51 & 61 \\
\hline 96 & 5814 & 44284 & 105 & 22 & 37 \\
\hline 97 & 4155 & 34099 & 106 & 57 & 50 \\
\hline 98 & 2775 & 23733 & 107 & 0 & 36 \\
\hline 99 & 1726 & 13844 & 108 & 0 & 49 \\
\hline 100 & 482 & 5680 & 109 & 0 & 31 \\
\hline
\end{tabular}


Table 4.7 Impulses during gamma scan of gamma scan wire 2.2 from capsule 2 Source: Forschungszentrum Jalich $\mathrm{GmbH}$, Jalich, Germany

Measurement date: 19.3.91 Step size: $1 \mathrm{~mm}$

Measurement time: $500 \mathrm{~s} /$ point Collimator: $5 \times 30 \mathrm{~mm}$

Data corrected to: 1.3 .91

\begin{tabular}{|c|c|c|c|c|c|}
\hline $\begin{array}{c}\text { Distance } \\
(\mathrm{mm})\end{array}$ & ${ }^{54} \mathrm{Mn}: \mathrm{I}(\mathrm{t})^{(2)}$ & ${ }^{60} \mathrm{Co:} \mathrm{I}(\mathrm{t}){ }^{(a)}$ & $\begin{array}{c}\text { Distance } \\
(\mathrm{mm})\end{array}$ & ${ }^{54} \mathrm{Mn}: \mathrm{I}(\mathrm{t})^{(2)}$ & ${ }^{60} \mathrm{Co}: \mathrm{I}(t)^{(2)}$ \\
\hline 0 & 16 & 44 & 23 & 11298 & 79718 \\
\hline 1 & 0 & 49 & 24 & 11522 & 79047 \\
\hline 2 & 0 & 46 & 25 & 11850 & 79675 \\
\hline 3 & 106 & 70 & 26 & 10684 & 79501 \\
\hline 4 & 51 & 134 & 27 & 10817 & 79409 \\
\hline 5 & 68 & 565 & 28 & 11244 & 79576 \\
\hline 6 & 326 & 3250 & 29 & 10967 & 79208 \\
\hline 7 & 1080 & 9664 & 30 & 11634 & 79625 \\
\hline 8 & 2021 & 19878 & 31 & 11033 & 79700 \\
\hline 9 & 3382 & 29854 & 32 & 10723 & 79866 \\
\hline 10 & 5999 & 40115 & 33 & 11436 & 78581 \\
\hline 11 & 5774 & 50933 & 34 & 11457 & 79467 \\
\hline 12 & 8540 & 61480 & 35 & 10197 & 78985 \\
\hline 13 & 9441 & 69756 & 36 & 10598 & 79001 \\
\hline 14 & 10470 & 75033 & 37 & 11229 & 79321 \\
\hline 15 & 11101 & 76967 & 38 & 11235 & 79620 \\
\hline 16 & 10552 & 77100 & 39 & 10742 & 78992 \\
\hline 17 & 11136 & 76695 & 40 & 10907 & 79557 \\
\hline 18 & 10503 & 77198 & 41 & 11030 & 79602 \\
\hline 19 & 9731 & 76915 & 42 & 10859 & 79059 \\
\hline 20 & 10602 & 78196 & 43 & 11226 & 79233 \\
\hline 21 & 10157 & 78785 & 44 & 10516 & 79301 \\
\hline 22 & 10801 & 79308 & 45 & 11678 & 79322 \\
\hline
\end{tabular}

(a) $\mathrm{I}(\mathrm{t})=$ impulses $/ 500 \mathrm{~s}$ at $835 \mathrm{KeV}$ for ${ }^{54} \mathrm{Mn}$ and $1333 \mathrm{KeV}$ for ${ }^{60} \mathrm{Co}$ 
Table 4.7 (Continued)

Measurement date: 19.3 .91

Measurement time: 500 s/point

Data corrected to: 1.3 .91
Step size: $1 \mathrm{~mm}$

Collimator: $5 \times 30 \mathrm{~mm}$

\begin{tabular}{|c|c|c|c|c|c|}
\hline $\begin{array}{c}\text { Distance } \\
\text { (mm) }\end{array}$ & ${ }^{s 4} \mathrm{Mn}: \mathrm{I}(\mathrm{t})^{(\mathfrak{l})}$ & ${ }^{80} \mathrm{Co:I}(\mathrm{t})^{(\mathrm{z})}$ & $\begin{array}{c}\text { Distance } \\
(\mathrm{mm})\end{array}$ & ${ }^{54} \mathrm{Mn}: \mathrm{I}(\mathrm{t})^{(\mathbf{2})}$ & ${ }^{60} \mathrm{Co}: \mathrm{I}(\mathrm{t})^{(2)}$ \\
\hline 46 & 10844 & 79024 & 69 & 10201 & 79191 \\
\hline 47 & 10542 & 79861 & 70 & 11540 & 78784 \\
\hline 48 & 11122 & 79532 & 71 & 11521 & 78795 \\
\hline 49 & 10874 & 79173 & 72 & 11223 & 78540 \\
\hline 50 & 11311 & 79369 & 73 & 11264 & 78998 \\
\hline 51 & 10972 & 80321 & 74 & 11210 & 79198 \\
\hline 52 & 11147 & 79485 & 75 & 10522 & 78842 \\
\hline 53 & 11894 & 78803 & 76 & 10122 & 79122 \\
\hline 54 & 11044 & 79354 & 77 & 10833 & 78719 \\
\hline 55 & 11523 & 79714 & 78 & 10977 & 79476 \\
\hline 56 & 10487 & 79155 & 79 & 11325 & 78916 \\
\hline 57 & 11061 & 79496 & 80 & 11171 & 78904 \\
\hline 58 & 11403 & 79550 & 81 & 11350 & 78754 \\
\hline 59 & 11723 & 79490 & 82 & 11135 & 78431 \\
\hline 60 & 11650 & 79738 & 83 & 10910 & 79113 \\
\hline 61 & 11620 & 79382 & 84 & 11156 & 78466 \\
\hline 62 & 11444 & 79129 & 85 & 11298 & 78640 \\
\hline 63 & 11060 & 79449 & 86 & 11053 & 78987 \\
\hline 64 & 10829 & 79060 & 87 & 11621 & 78414 \\
\hline 65 & 11189 & 78933 & 88 & 9975 & 78451 \\
\hline 66 & 11584 & 78927 & 89 & 10450 & 76830 \\
\hline 67 & 11083 & 78623 & 90 & 10311 & 76581 \\
\hline 68 & 11694 & 78683 & 91 & 10413 & 74664 \\
\hline
\end{tabular}


Table 4.7 (Continued)

Measurement date: 19.3 .91

Step size: $1 \mathrm{~mm}$

Measurement time: $500 \mathrm{~s} /$ point

Collimator: $5 \times 30 \mathrm{~mm}$

Data corrected to: 1.3 .91

\begin{tabular}{|c|c|c|c|c|c|}
\hline $\begin{array}{c}\text { Distance } \\
(\mathrm{mm})\end{array}$ & ${ }^{54} \mathrm{Mn}: \mathrm{I}(\mathrm{t})^{(\mathbf{a})}$ & ${ }^{60} \mathrm{Co}: \mathrm{I}(\mathrm{t})_{-}^{(2)}$ & $\begin{array}{c}\text { Distance } \\
(\mathrm{mm})\end{array}$ & ${ }^{54} \mathrm{Mn}: \mathrm{I}(\mathrm{t})^{(\mathbf{(})}$ & ${ }^{60} \mathrm{Co}: \mathrm{I}(\mathrm{t})^{(\mathbf{2})}$ \\
\hline 92 & 10170 & 70262 & 101 & 0 & 72 \\
\hline 93 & 8505 & 61930 & 102 & 21 & 50 \\
\hline 94 & 6744 & 51323 & 103 & 12 & 70 \\
\hline 95 & 5371 & 43097 & 104 & 2 & 38 \\
\hline 96 & 3933 & 32297 & 105 & 40 & 34 \\
\hline 97 & 2595 & 22727 & 106 & 52 & 18 \\
\hline 98 & 1983 & 13142 & 107 & 91 & 21 \\
\hline 99 & 599 & 5325 & 108 & 0 & 53 \\
\hline 100 & 20 & 915 & 109 & 0 & 40 \\
\hline
\end{tabular}


Table 4.8 Impulses during gamma scan of gamma scan wire 2.3 from capsule 2 Source: Forschungszentrum Julich GmbH, Julich, Germany Measurement date: 20.3 .91 Measurement time: 500 s/point Step size: $1 \mathrm{~mm}$ Data corrected to: 1.3 .91

\begin{tabular}{|c|c|c|c|c|c|}
\hline $\begin{array}{c}\text { Distance } \\
(\mathrm{mm})\end{array}$ & ${ }^{s /} \mathrm{Mn}: \mathrm{I}(\mathrm{t})^{(\mathrm{s})}$ & ${ }^{60} \mathrm{Co:I}(\mathrm{t})^{(1)}$ & $\begin{array}{c}\text { Distance } \\
(\mathrm{mm})\end{array}$ & ${ }^{s 4} \mathrm{Mn}: \mathrm{I}(\mathrm{t})^{(2)}$ & ${ }^{60} \mathrm{Co:I}(\mathrm{t}){ }^{(2)}$ \\
\hline 0 & 0 & 68 & 23 & 10816 & 77856 \\
\hline 1 & 5 & 60 & 24 & 10564 & 77880 \\
\hline 2 & 5 & 85 & 25 & 10937 & 78548 \\
\hline 3 & 0 & 71 & 26 & 10546 & 78158 \\
\hline 4 & 0 & 74 & 27 & 9456 & 77944 \\
\hline 5 & 27 & 176 & 28 & 11050 & 78822 \\
\hline 6 & 32 & 513 & 29 & 11138 & 78159 \\
\hline 7 & 256 & 2631 & 30 & 10290 & 78254 \\
\hline 8 & 1131 & 8554 & $31 \quad-$ & 10597 & 79298 \\
\hline 9 & 2105 & 18305 & 32 & 9861 & 78327 \\
\hline 10 & 3873 & 28498 & 33 & 9978 & 77968 \\
\hline 11 & 4451 & 38722 & 34 & 10902 & 78013 \\
\hline 12 & 6907 & 48898 & 35 & 9899 & 77717 \\
\hline 13 & 7300 & 58945 & 36 & 10092 & 78318 \\
\hline 14 & 8778 & 67894 & 37 & 10811 & 78488 \\
\hline 15 & 9253 & 738377 & 38 & 10518 & 77838 \\
\hline 16 & 10276 & 74987 & 39 & 11098 & 78541 \\
\hline 17 & 11024 & 70209 & 40 & 10353 & 79006 \\
\hline 18 & 9710 & 75856 & 41 & 10427 & 78807 \\
\hline 19 & 10328 & 76049 & 42 & 10617 & 78220 \\
\hline 20 & 9588 & 76233 & 43 & 11169 & 77859 \\
\hline 21 & 9805 & 76267 & 44 & 11143 & 78204 \\
\hline 22 & 9871 & 76446 & 45 & 11101 & 78473 \\
\hline
\end{tabular}

(s) $\mathrm{I}(\mathrm{t})=$ impulses/500s at $835 \mathrm{KeV}$ for ${ }^{54} \mathrm{Mn}$ and $1333 \mathrm{KeV}$ for ${ }^{60} \mathrm{Co}$

Collimator: $5 \times 30 \mathrm{~mm}$ 
Table 4.8 (Continued)

Measurement date: 20.3 .91

Measurement time: 500 s/point

Step size: $1 \mathrm{~mm}$

Data corrected to: 1.3 .91

Collimator: $5 \times 30 \mathrm{~mm}$

\begin{tabular}{|c|c|c|c|c|c|}
\hline $\begin{array}{c}\text { Distance } \\
(\mathrm{mm})\end{array}$ & ${ }^{s 4} \mathrm{Mn}: \mathrm{I}(\mathrm{t})^{(\boldsymbol{\omega})}$ & ${ }^{\infty} \mathrm{Co:I}(\mathrm{t})^{(\boldsymbol{t})}$ & $\begin{array}{c}\text { Distance } \\
(\mathrm{mm})\end{array}$ & ${ }^{s 4} \mathrm{Mn}: \mathrm{I}(\mathrm{t})^{(2)}$ & ${ }^{\infty} \mathrm{Co}: \mathrm{I}(\mathrm{t})^{(\boldsymbol{(})}$ \\
\hline 46 & 10315 & 78600 & 69 & 10278 & 79564 \\
\hline 47 & 10184 & 78732 & 70 & 10516 & 79373 \\
\hline 48 & 10007 & 78218 & 71 & 10252 & 78809 \\
\hline 49 & 11158 & 79322 & 72 & 11268 & 79295 \\
\hline 50 & 10945 & 78985 & 73 & 9953 & 79161 \\
\hline 51 & 10444 & 78527 & 74 & 11649 & 78876 \\
\hline 52 & 10212 & 78718 & 75 & 10980 & 79720 \\
\hline 53 & 10997 & 78051 & 76 & 10851 & 78952 \\
\hline 54 & 10371 & 78566 & 77 & 10114 & 79363 \\
\hline 55 & 10544 & 78438 & 78 & 11353 & 79219 \\
\hline 56 & 11024 & 78150 & 79 & 11660 & 78969 \\
\hline 57 & 10384 & 78081 & 80 & 11339 & 79144 \\
\hline 58 & 10463 & 78618 & 81 & 10403 & 79378 \\
\hline 59 & 10344 & 77854 & 82 & 11260 & 78861 \\
\hline 60 & 10877 & 78513 & 83 & 10409 & 78841 \\
\hline 61 & 11502 & 78768 & 84 & 10484 & 79083 \\
\hline 62 & 10661 & 79091 & 85 & 10799 & 78703 \\
\hline 63 & 10750 & 79247 & 86 & 10583 & 79134 \\
\hline 64 & 11013 & 78750 & 87 & 10902 & 79054 \\
\hline 65 & 11059 & 79414 & 88 & 10695 & 78807 \\
\hline 66 & 10903 & 78552 & 89 & 10981 & 77724 \\
\hline 67 & 10349 & 79141 & 90 & .10477 & 77489 \\
\hline 68 & 10744 & 78936 & 91 & 10283 & 76605 \\
\hline
\end{tabular}


Table 4.8 (Continued)

Measurement date: 20.3 .91

Measurement time: $500 \mathrm{~s} /$ point

Data corrected to: 1.3 .91
Step size: $1 \mathrm{~mm}$

Collimator: $5 \times 30 \mathrm{~mm}$

\begin{tabular}{|c|c|c|c|c|c|}
\hline $\begin{array}{c}\text { Distance } \\
(\mathrm{mm})\end{array}$ & ${ }^{{ }^{54} \mathrm{Mn}: \mathrm{I}(\mathrm{t})^{(\mathrm{s})}}$ & ${ }^{60} \mathrm{Co}: \mathrm{I}(\mathrm{t})^{(\mathrm{s})}$ & $\begin{array}{c}\text { Distance } \\
(\mathrm{mm})\end{array}$ & ${ }^{{ }^{s 4} \mathrm{Mn}: \mathrm{I}(\mathrm{t})^{(\mathrm{s})}}$ & ${ }^{{ }^{60} \mathrm{Co}: \mathrm{I}(\mathrm{t})^{(\mathbf{s})}}$ \\
\hline 92 & 9742 & 74699 & 101 & 140 & 380 \\
\hline 93 & 9868 & 69201 & 102 & 50 & 112 \\
\hline 94 & 8552 & 59204 & 103 & 35 & 24 \\
\hline 95 & 6535 & 49214 & 104 & 85 & 50 \\
\hline 96 & 4887 & 39469 & 105 & 0 & 45 \\
\hline 97 & 4140 & 29737 & 106 & 41 & 40 \\
\hline 98 & 2671 & 19907 & 107 & 30 & 60 \\
\hline 99 & 1235 & 10600 & 108 & 54 & 76 \\
\hline 100 & 132 & 3545 & 109 & 0 & 39 \\
\hline
\end{tabular}


Table 4.9 Impulses during gamma scan of gamma scan wire 3.1 from capsule 3 Source: Forschungszentrum Julich $\mathrm{GmbH}$, Jalich, Germany

Measurement date: 6.3 .91

Step size: $1 \mathrm{~mm}$

Measurement time: $500 \mathrm{~s} /$ point

Collimator: $5 \times 30 \mathrm{~mm}$

Data corrected to: 1.3 .91

\begin{tabular}{|c|c|c|c|c|c|}
\hline $\begin{array}{c}\text { Distance } \\
\text { (mm) }\end{array}$ & ${ }^{54} \mathrm{Mn}: \mathrm{I}(\mathrm{t})^{(2)}$ & ${ }^{60} \mathrm{Co:I}(\mathrm{t})^{(2)}$ & $\begin{array}{c}\text { Distance } \\
(\mathrm{mm})\end{array}$ & ${ }^{s 4} \mathrm{Mn}: \mathrm{I}(\mathrm{t})^{(2)}$ & ${ }^{60} \mathrm{Co}: \mathrm{I}(\mathrm{t})^{(2)}$ \\
\hline 0 & 27 & 65 & 23 & 6406 & 56564 \\
\hline 1 & 32 & 45 & 24 & 5715 & 56528 \\
\hline 2 & 45 & 28 & 25 & 6622 & 57031 \\
\hline 3 & 35 & 67 & 26 & 6603 & 56556 \\
\hline 4 & 54 & 72 & 27 & 6622 & 56482 \\
\hline 5 & 66 & 267 & 28 & 6087 & 57005 \\
\hline 6 & 170 & 1461 & 29 & 6268 & 57922 \\
\hline 7 & 604 & 5279 & 30 & 6552 & 57750 \\
\hline 8 & 888 & 12020 & 31 & 6457 & 57745 \\
\hline 9 & 2011 & 19629 & 32 & 5507 & 57431 \\
\hline 10 & 2192 & 25987 & 33 & 6530 & 57354 \\
\hline 11 & 3432 & 32982 & 34 & 6815 & 58711 \\
\hline 12 & 3331 & 39113 & 35 & 6628 & 57519 \\
\hline 13 & 5267 & 45960 & 36 & 6809 & 57891 \\
\hline 14 & 5776 & 50937 & 37 & 5316 & 58875 \\
\hline 15 & 5042 & 53806 & 38 & 6734 & 58814 \\
\hline 16 & 5665 & 53487 & 39 & 6860 & 59162 \\
\hline 17 & 5239 & 53261 & 40 & 6434 & 58287 \\
\hline 18 & 5302 & 54975 & 41 & 6746 & 59315 \\
\hline 19 & 5639 & 55093 & 42 & 6305 & 59044 \\
\hline 20 & 6205 & 55771 & 43 & 5739 & 59873 \\
\hline 21 & 6839 & 56044 & 44 & 6976 & 59636 \\
\hline 22 & 5212 & 56031 & 45 & 6587 & 60388 \\
\hline
\end{tabular}

(s) $\mathrm{I}(\mathrm{t})=$ impulses $/ 500 \mathrm{~s}$ at $835 \mathrm{KeV}$ for ${ }^{54} \mathrm{Mn}$ and $1333 \mathrm{KeV}$ for ${ }^{60} \mathrm{Co}$ 
Table 4.9 (Continued)

Measurement date: 6.3 .91

Measurement time: $500 \mathrm{~s} /$ point

Data corrected to: 1.3 .91
Step size: $1 \mathrm{~mm}$

Collimator: $5 \times 30 \mathrm{~mm}$

\begin{tabular}{|c|c|c|c|c|c|}
\hline $\begin{array}{c}\text { Distance } \\
\text { (mm) }\end{array}$ & ${ }^{54} \mathrm{Mn}: \mathrm{I}(\mathrm{t})^{(\mathfrak{)})}$ & ${ }^{60} \mathrm{Co}: \mathrm{I}(\mathrm{t})^{(\imath)}$ & $\begin{array}{c}\text { Distance } \\
\text { (mm) }\end{array}$ & ${ }^{s 4} \operatorname{Mn}: I(t)^{(\mathbf{a})}$ & ${ }^{60} \mathrm{Co}: \mathrm{I}(\mathrm{t})^{(2)}$ \\
\hline 46 & 6772 & 59847 & 69 & 8459 & 65941 \\
\hline 47 & 6503 & 60974 & 70 & 7147 & 65740 \\
\hline 48 & 7230 & 60400 & 71 & 7035 & 66659 \\
\hline 49 & 6367 & 60698 & 72 & 7549 & 66330 \\
\hline 50 & 8085 & 60800 & 73 & 7385 & 66616 \\
\hline 51 & 7200 & 60773 & 74 & 6730 & 67923 \\
\hline 52 & 6364 & 61644 & 75 & 8027 & 67311 \\
\hline 53 & 7246 & 61869 & 76 & 7446 & 67080 \\
\hline 54 & 8126 & 62663 & 77 & 7686 & 67104 \\
\hline 55 & 7500 & 61780 & 78 & 7731 & 67663 \\
\hline 56 & 7108 & 62195 & 79 & 8465 & 68000 \\
\hline 57 & 7655 & 62823 & 80 & 8194 & 69205 \\
\hline 58 & 7414 & 62474 & 81 & 8008 & 68611 \\
\hline 59 & 7435 & 63003 & 82 & 7074 & 68874 \\
\hline 60 & 6642 & 63189 & 83 & 8178 & 69038 \\
\hline 61 & 6458 & 63975 & 84 & 6852 & 69291 \\
\hline 62 & 6549 & 63565 & 85 & 8165 & 69110 \\
\hline 63 & 7285 & 64112 & 86 & 8650 & 69331 \\
\hline 64 & 7840 & 63839 & 87 & 9303 & 68095 \\
\hline 65 & 7185 & 65232 & 88 & 7616 & 68440 \\
\hline 66 & 7716 & 64395 & 89 & 8321 & 69085 \\
\hline 67 & 7703 & 64774 & 90 & 7901 & 69040 \\
\hline 68 & 7909 & 64714 & 91 & 7957 & 68669 \\
\hline
\end{tabular}


Table 4.9 (Continued)

Measurement date: 6.3 .91

Measurement time: $500 \mathrm{~s} /$ point

Data corrected to: 1.3 .91
Step size: $1 \mathrm{~mm}$

Collimator: $5 \times 30 \mathrm{~mm}$

\begin{tabular}{|c|c|c|c|c|c|}
\hline $\begin{array}{c}\text { Distance } \\
(\mathrm{mm})\end{array}$ & ${ }^{54} \mathrm{Mn}: \mathrm{I}(\mathrm{t})^{(\mathbf{a})}$ & ${ }^{60} \mathrm{Co}: \mathrm{I}(\mathrm{t})^{(\mathbf{(})}$ & $\begin{array}{c}\text { Distance } \\
(\mathrm{mm})\end{array}$ & ${ }^{54} \mathrm{Mn}: \mathrm{I}(\mathrm{t})^{(\mathbf{(})}$ & ${ }^{{ }^{6} \mathrm{Co}: \mathrm{I}(\mathrm{t})^{(\mathbf{2})}}$ \\
\hline 92 & 8275 & 65327 & 101 & 42 & 132 \\
\hline 93 & 6654 & 59441 & 102 & 5 & 57 \\
\hline 94 & 5526 & 50653 & 103 & 54 & 28 \\
\hline 95 & 5028 & 41882 & 104 & 0 & 33 \\
\hline 96 & 4000 & 32506 & 105 & 0 & 22 \\
\hline 97 & 3339 & 23777 & 106 & 0 & 50 \\
\hline 98 & 1343 & 14362 & 107 & 56 & 17 \\
\hline 99 & 553 & 6405 & 108 & 3 & 45 \\
\hline 100 & 145 & 1479 & 109 & 0 & 42 \\
\hline
\end{tabular}


Table 4.10 Impulses during gamma scan of gamma scan wire 3.2 from capsule 3 Source: Forschungszentrum Jalich $\mathrm{GmbH}$, Jalich, Germany

Measurement date: $7.3 .91 \quad$ Step size: $1 \mathrm{~mm}$

Measurement time: 500 s/point Collimator: $5 \times 30 \mathrm{~mm}$

Data corrected to: 1.3 .91

\begin{tabular}{|c|c|c|c|c|c|}
\hline $\begin{array}{c}\text { Distance } \\
(\mathrm{mm})\end{array}$ & ${ }^{54} \mathrm{Mn}: \mathrm{I}(\mathrm{t})^{(2)}$ & ${ }^{60} \mathrm{Co:} I(t)^{(2)}$ & $\begin{array}{c}\text { Distance } \\
(\mathrm{mm})\end{array}$ & ${ }^{54} \mathrm{Mn}: \mathrm{I}(\mathrm{t})^{(2)}$ & ${ }^{60} \mathrm{Co}: \mathrm{I}(\mathrm{t})^{(2)}$ \\
\hline 0 & 9 & 9 & 23 & 7166 & 56489 \\
\hline 1 & 25 & 15 & 24 & 6774 & 56998 \\
\hline 2 & 39 & 38 & 25 & 6720 & 57206 \\
\hline 3 & 19 & 72 & 26 & 7439 & 56706 \\
\hline 4 & 59 & 68 & 27 & 6876 & 57419 \\
\hline 5 & 66 & 263 & 28 & 7671 & 57266 \\
\hline 6 & 229 & 1458 & 29 & 7212 & 57696 \\
\hline 7 & 452 & 5315 & 30 & 7829 & 57806 \\
\hline 8 & 1193 & 11997 & 31 & 7346 & 57897 \\
\hline 9 & 2170 & 19193 & 32 & 7389 & 58208 \\
\hline 10 & 2609 & 26244 & 33 & 7033 & 58149 \\
\hline 11 & 4175 & 33739 & 34 & 7100 & 58050 \\
\hline 12 & 4724 & 40702 & 35 & 7127 & 58072 \\
\hline 13 & 5957 & 47753 & 36 & 7256 & 57969 \\
\hline 14 & 5847 & 52070 & 37 & 7625 & 58293 \\
\hline 15 & 6545 & 55516 & 38 & 8078 & 59052 \\
\hline 16 & 6446 & 55839 & 39 & 7636 & 59820 \\
\hline 17 & 7184 & 55778 & 40 & 8599 & 58503 \\
\hline 18 & 6660 & 56325 & 41 & 7395 & 60225 \\
\hline 19 & 6283 & 55507 & 42 & 7894 & 59915 \\
\hline 20 & 6402 & 56075 & 43 & 8491 & 60039 \\
\hline 21 & 7094 & 56489 & 44 & 7941 & 59967 \\
\hline 22 & 7246 & 56312 & 45 & 7872 & 60450 \\
\hline
\end{tabular}

(a) $\mathrm{I}(\mathrm{t})=$ impulses/500s at $835 \mathrm{KeV}$ for ${ }^{54} \mathrm{Mn}$ and $1333 \mathrm{KeV}$ for ${ }^{60} \mathrm{Co}$ 
Table 4.10 (Continued)

Measurement date: 7.3.91

Step size: $1 \mathrm{~mm}$

Measurement time: $500 \mathrm{~s} /$ point Collimator: $5 \times 30 \mathrm{~mm}$

Data corrected to: 1.3 .91

\begin{tabular}{|c|c|c|c|c|c|}
\hline $\begin{array}{c}\text { Distance } \\
\text { (mm) }\end{array}$ & ${ }^{s+M n: I(t)^{(2)}}$ & ${ }^{60} \mathrm{Co:I}(\mathrm{t})^{(\mathrm{z})}$ & $\begin{array}{c}\text { Distance } \\
(\mathrm{mm})\end{array}$ & ${ }^{54} \mathrm{Mn}: \mathrm{I}(\mathrm{t})^{(2)}$ & ${ }^{60} \mathrm{Co:I}(\mathrm{t})^{(2)}$ \\
\hline 46 & 8351 & 60300 & 69 & 8137 & 65805 \\
\hline 47 & 8134 & 60156 & 70 & 8743 & 65679 \\
\hline 48 & 7405 & 61284 & 71 & 8749 & 66810 \\
\hline 49 & 8184 & 61180 & 72 & 8769 & 67006 \\
\hline 50 & 8939 & 61984 & 73 & 8160 & 67150 \\
\hline 51 & 8324 & 61137 & 74 & 9074 & 67345 \\
\hline 52 & 8994 & 62141 & 75 & 8717 & 68090 \\
\hline 53 & 8124 & 61574 & 76 & 8463 & 67634 \\
\hline 54 & 8174 & 62335 & 77 & 9114 & 68290 \\
\hline 55 & 8494 & 62378 & 78 & 9225 & 67375 \\
\hline 56 & 8329 & 62578 & 79 & 9055 & 66941 \\
\hline 57 & 8262 & 62111 & 80 & 8750 & 67109 \\
\hline 58 & 8468 & 63097 & 81 & 8557 & 67528 \\
\hline 59 & 8853 & 62856 & 82 & 8654 & 67298 \\
\hline 60 & 9171 & 63331 & 83 & 9002 & 68082 \\
\hline 61 & 8768 & 64131 & 84 & 8608 & 68828 \\
\hline 62 & 8578 & 64148 & 85 & 8751 & 69871 \\
\hline 63 & 8745 & 64187 & 86 & 9324 & 70645 \\
\hline 64 & 8915 & 65274 & 87 & 8582 & 71772 \\
\hline 65 & 8785 & 64917 & 88 & 9630 & 72742 \\
\hline 66 & 8331 & 65642 & 89 & 9634 & 73141 \\
\hline 67 & 8412 & 65130 & 90 & - 9730 & 73014 \\
\hline 68 & 8185 & 65798 & 91 & 9315 & 72123 \\
\hline
\end{tabular}


Table 4.10 (Continued)

Measurement date: 7.3 .91

Measurement time: 500 s/point

Data corrected to: 1.3 .91
Step size: $1 \mathrm{~mm}$

Collimator: $5 \times 30 \mathrm{~mm}$

\begin{tabular}{|c|c|c|c|c|c|}
\hline $\begin{array}{c}\text { Distance } \\
\text { (mm) }\end{array}$ & ${ }^{s} \mathrm{Mn}: \mathrm{I}(\mathrm{t})^{(2)}$ & ${ }^{60} \mathrm{Co:I}(t)^{(t)}$ & $\begin{array}{c}\text { Distance } \\
(\mathrm{mm})\end{array}$ & ${ }^{s 4} \mathrm{Mn}: \mathrm{I}(\mathrm{t})^{(\boldsymbol{a})}$ & ${ }^{60} \mathrm{Co:I}(\mathrm{t})^{(0)}$ \\
\hline 92 & 7939 & 68669 & 101 & 20 & 106 \\
\hline 93 & 7414 & 62353 & 102 & 39 & 50 \\
\hline 94 & 7167 & 52631 & 103 & 23 & 12 \\
\hline 95 & 5428 & 42968 & 104 & 89 & 12 \\
\hline 96 & 4125 & 33269 & 105 & 0 & 6 \\
\hline 97 & 2906 & 23556 & 106 & 10 & 6 \\
\hline 98 & 1720 & 14193 & 107 & 0 & 27 \\
\hline 99 & 726 & 6202 & 108 & 0 & 17 \\
\hline 100 & 93 & 1394 & 109 & 80 & 40 \\
\hline
\end{tabular}


Table 4.11 Impulses during gamma scan of gamma scan wire 3.3 from capsule 3 Source: Forschungszentrum Julich $\mathrm{GmbH}$, Jalich, Germany Measurement date: 8.3.91 Step size: $1 \mathrm{~mm}$ Measurement time: $500 \mathrm{~s} /$ point Collimator: $5 \times 30 \mathrm{~mm}$ Data corrected to: 1.3 .91

\begin{tabular}{|c|c|c|c|c|c|}
\hline $\begin{array}{c}\text { Distance } \\
(\mathrm{mm})\end{array}$ & ${ }^{54} \mathrm{Mn}: \mathrm{I}(\mathrm{t})^{(2)}$ & ${ }^{60} \mathrm{Co:I}(\mathrm{t})^{(2)}$ & $\begin{array}{c}\text { Distance } \\
(\mathrm{mm})\end{array}$ & ${ }^{s 4} \mathrm{Mn}: \mathrm{I}(\mathrm{t})^{(\mathbf{l})}$ & ${ }^{60} \mathrm{Co}: \mathrm{I}(\mathrm{t})^{(\bullet)}$ \\
\hline 0 & 43 & 51 & 23 & 6676 & 56751 \\
\hline 1 & 0 & 13 & 24 & 7543 & 57360 \\
\hline 2 & 0 & 40 & 25 & 6902 & 56850 \\
\hline 3 & 0 & 01 & 26 & 7445 & 57151 \\
\hline 4 & 75 & 40 & 27 & 6423 & 57285 \\
\hline 5 & 0 & 196 & 28 & 7215 & 57236 \\
\hline 6 & 0 & 802 & 29 & 6994 & 57015 \\
\hline 7 & 281 & 3497 & 30 & 7176 & 57414 \\
\hline 8 & 868 & 9124 & 31 & 7029 & 57439 \\
\hline 9 & 2030 & 16496 & 32 & 6915 & 57623 \\
\hline 10 & 2715 & 23903 & 33 & 7358 & 57468 \\
\hline 11 & 3219 & 30865 & 34 & 6552 & 57270 \\
\hline 12 & 4005 & 38290 & 35 & 7691 & 58345 \\
\hline 13 & 5303 & 45498 & 36 & 6495 & 56769 \\
\hline 14 & 5364 & 51281 & 37 & 7203 & 57534 \\
\hline 15 & 6645 & 55363 & 38 & 6890 & 57862 \\
\hline 16 & 5733 & 55888 & 39 & 6867 & 58029 \\
\hline 17 & 6390 & 55955 & 40 & 6505 & 57994 \\
\hline 18 & 6681 & 56291 & 41 & 7896 & 58465 \\
\hline 19 & 6330 & 56025 & 42 & 7873 & 59101 \\
\hline 20 & 6251 & 56436 & 43 & 7062 & 58696 \\
\hline 21 & 7001 & 56343 & 44 & .7447 & 59013 \\
\hline 22 & 6616 & 57017 & 45 & 7300 & 59451 \\
\hline
\end{tabular}

(a) $\mathrm{I}(\mathrm{t})=$ impulses $/ 500 \mathrm{~s}$ at $835 \mathrm{KeV}$ for ${ }^{54} \mathrm{Mn}$ and $1333 \mathrm{KeV}$ for ${ }^{60} \mathrm{Co}$ 
Table 4.11 (Continued)

Measurement date: 8.3.91

Step size: $1 \mathrm{~mm}$

Measurement time: $500 \mathrm{~s} /$ point

Collimator: $5 \times 30 \mathrm{~mm}$

Data corrected to: 1.3 .91

\begin{tabular}{|c|c|c|c|c|c|}
\hline $\begin{array}{c}\text { Distance } \\
\text { (mm) }\end{array}$ & ${ }^{s+} \mathrm{Mn}: I(t)^{(\mathbf{l})}$ & ${ }^{60} \mathrm{Co:I}(\mathrm{t})^{(2)}$ & $\begin{array}{c}\text { Distance } \\
(\mathrm{mm})\end{array}$ & ${ }^{54} \mathrm{Mn}: I(t)^{(2)}$ & ${ }^{60} \mathrm{Co}: \mathrm{I}(\mathrm{t})^{(2)}$ \\
\hline 46 & 7519 & 59902 & 69 & 7641 & 64704 \\
\hline 47 & 7672 & 59660 & 70 & 8389 & 65098 \\
\hline 48 & 7319 & 59698 & 71 & 8498 & 65271 \\
\hline 49 & 7282 & 59667 & 72 & 8273 & 65391 \\
\hline 50 & 7388 & 60257 & 73 & 8217 & 66611 \\
\hline 51 & 7944 & 60610 & 74 & 8877 & 65988 \\
\hline 52 & & & 75 & 8350 & 66519 \\
\hline 53 & 7788 & 61022 & 76 & 8067 & 65911 \\
\hline 54 & 8071 & 61539 & 77 & 8447 & 65816 \\
\hline 55 & 7165 & 61481 & 78 & 8660 & 65567 \\
\hline 56 & 8204 & 62154 & 79 & 8486 & 65712 \\
\hline 57 & 7969 & 61777 & 80 & 7817 & 65307 \\
\hline 58 & 7762 & 62755 & 81 & 7710 & 66069 \\
\hline 59 & 8365 & 62440 & 82 & 8506 & 65828 \\
\hline 60 & 8029 & 63079 & 83 & 7912 & 66869 \\
\hline 61 & 7435 & 62414 & 84 & 8480 & 67783 \\
\hline 62 & 7705 & 63593 & 85 & 9035 & 68240 \\
\hline 63 & 8074 & 63743 & 86 & 9226 & 69530 \\
\hline 64 & 7786 & 63802 & 87 & 9318 & 70638 \\
\hline 65 & 7996 & 63309 & 88 & 8724 & 70394 \\
\hline 66 & 7870 & 64364 & 89 & 8968 & 71209 \\
\hline 67 & 8220 & 64623 & 90 & 8712 & 71406 \\
\hline 68 & 7605 & 64266 & 91 & 9509 & 70694 \\
\hline
\end{tabular}


Table 4.11 (Continued)

Measurement date: 8.3 .91

Step size: $1 \mathrm{~mm}$

Measurement time: 500 s/point

Data corrected to: 1.3 .91

Collimator: $5 \times 30 \mathrm{~mm}$

\begin{tabular}{|c|c|c|c|c|c|}
\hline $\begin{array}{c}\text { Distance } \\
(\mathrm{mm})\end{array}$ & ${ }^{54} \mathrm{Mn}: \mathrm{I}(\mathrm{t})^{(\mathrm{s})}$ & ${ }^{60} \mathrm{Co}: \mathrm{I}^{(\mathrm{t})^{(\mathrm{s})}}$ & $\begin{array}{c}\text { Distance } \\
(\mathrm{mm})\end{array}$ & ${ }^{54} \mathrm{Mn}: \mathrm{I}(\mathrm{t})^{(\mathrm{s})}$ & ${ }^{{ }^{6} \mathrm{Co}: \mathrm{I}(\mathrm{t})^{(\mathrm{s})}}$ \\
\hline 92 & 8609 & 68999 & 101 & 37 & 160 \\
\hline 93 & 7990 & 62553 & 102 & 0 & 52 \\
\hline 94 & 6839 & 53586 & 103 & 0 & 18 \\
\hline 95 & 6100 & 44072 & 104 & 30 & 36 \\
\hline 96 & 4458 & 34563 & 105 & 0 & 66 \\
\hline 97 & 3060 & 25319 & 106 & 21 & 21 \\
\hline 98 & 2185 & 16083 & 107 & 0 & 6 \\
\hline 99 & 1167 & 7706 & 108 & 0 & 19 \\
\hline 100 & 177 & 2128 & 109 & 13 & 13 \\
\hline
\end{tabular}



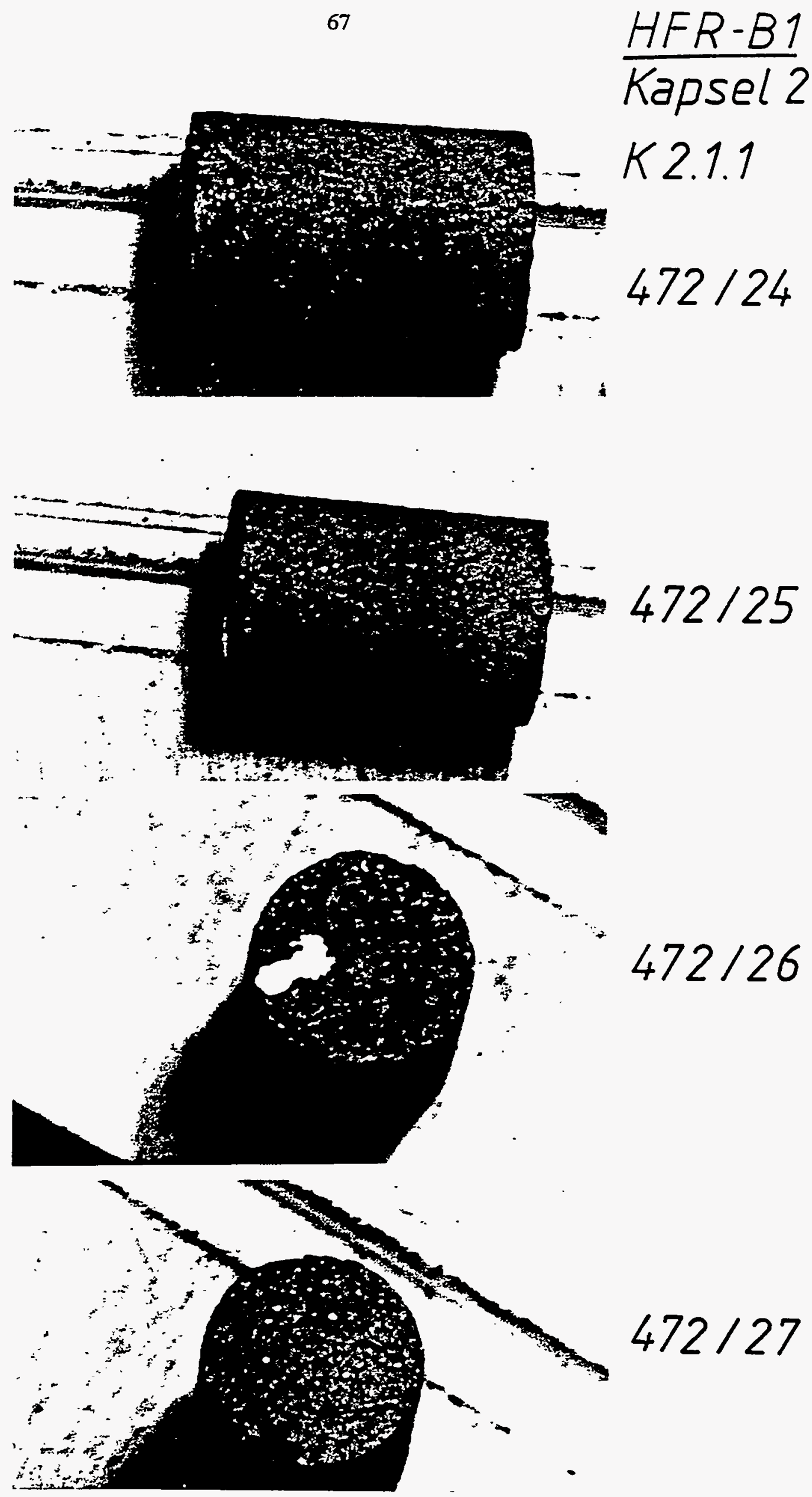

Fig. 4.45 Four views of the fuel compact from position 1 in hole 1 of capsule 2 Source: Forschungszentrum Jalich GmbH, Julich, Germany 

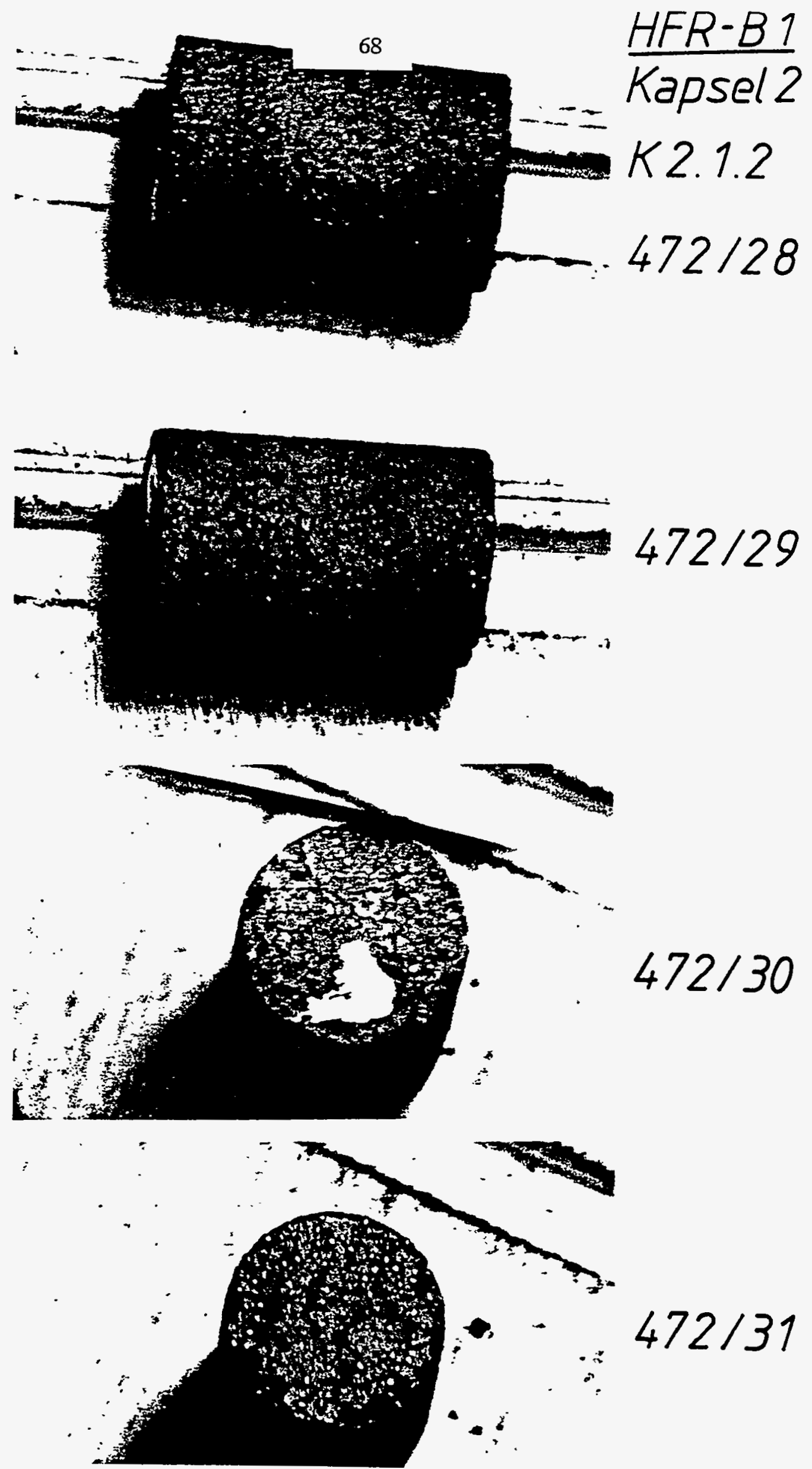

Fig. 4.46 Four views of the fuel compact from position 2 in hole 1 of capsule 2 Source: Forschungszentrum Julich GmbH, Jalich, Germany 

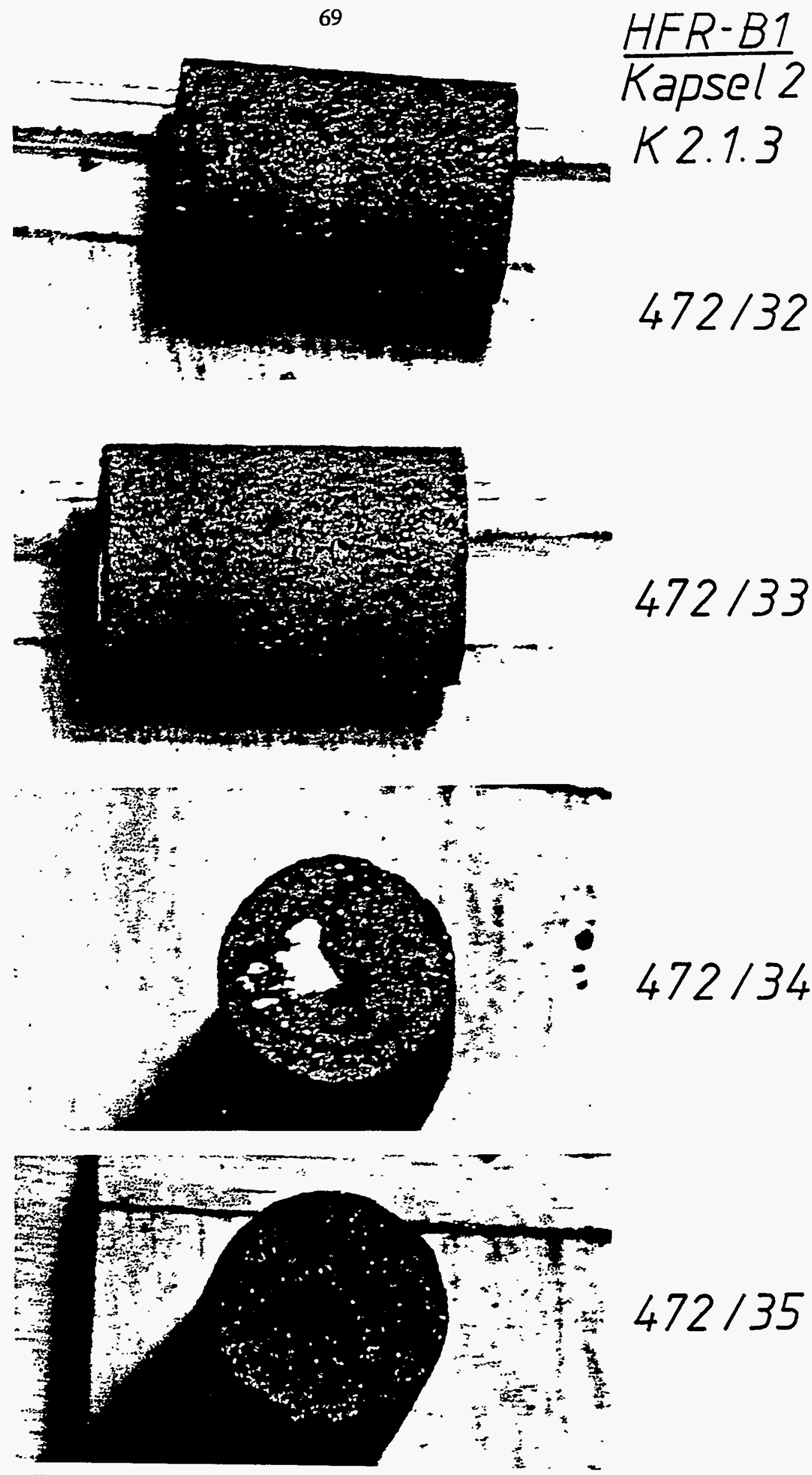

Fig. 4.47 Four views of the fuel compact from position 3 in hole 1 of capsule 2 Source: Forschungszentrum Julich $\mathrm{GmbH}$, Julich, Germany 

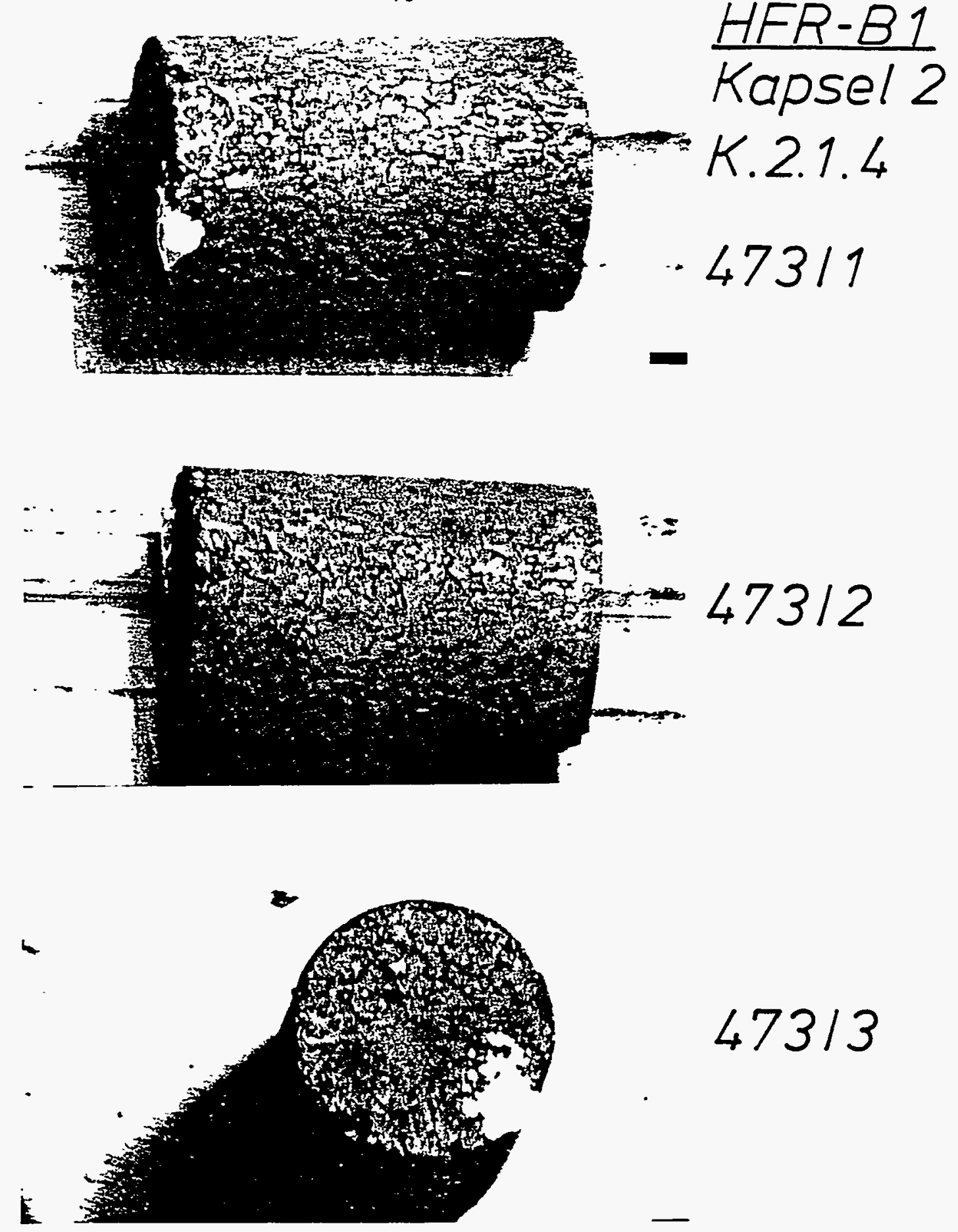

\section{$473 / 3$}
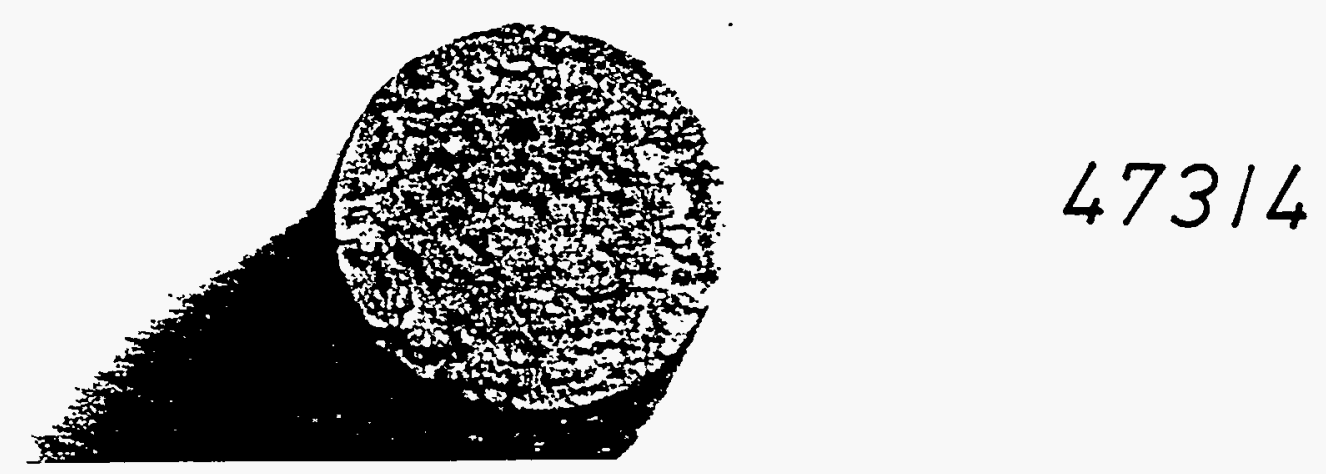

Fig. 4.48 Four views of the fuel compact from position 4 in hole 1 of capsule 2 Source: Forschungszentrum Julich GmbH, Julich, Germany 


\subsubsection{Capsule $3^{2}$}

Here, the screw cap could be easily twisted off. On the top of the uppermost compact, there lay about ten individual particles which, to be sure, were broken from the compact surface. Removing the loose coated particles to a filter by suction allowed one to see that the compacts lay loose in the borehole and could rotate. On this basis, also here a marking of the north side was waived. However, a white mark was put on top of all four compacts. The three other compacts were lightly held in the borehole and could be pressed out however from the underside of the fuel hole. Photographs of four views of each fuel compact from fuel hole 1 of the graphite body are shown in Fig. 4.49, photographs 470/29-32, Fig. 4.50, photographs 471/38-41, Fig. 4.51, photographs 471/0-2, and $471 / 42$ and Fig. 4.52, photographs 471/3-6. The loose particles observed upon opening capsule 3 are shown in Fig. 4.53, photograph 480/18.

\subsubsection{Gamma Scanning}

The fuel compacts were gamma scanned ${ }^{4}$ after removal of them from the graphite bodies. The apparatus and the measurements are essentially described in paragraphs 4.2.4.1 and 4.2.4.2. The instruments and conditions of the measurements for the fuel compacts are presented in Table 4.12

The gamma scans of the fuel compacts from hole 1 of capsules 2 and 3 are shown in Figs. 4.54 and 4.55 for the nuclides ${ }^{14} \mathrm{Ce},{ }^{134} \mathrm{Cs},{ }^{137} \mathrm{Cs},{ }^{106} \mathrm{Ru},{ }^{95} \mathrm{Zr}$ and ${ }^{154} \mathrm{Eu}$. The spectrum for fuel compact 2.1 .1 of hole 1 in capsule 2 ia shown in Fig. 4.56.

\subsubsection{Gamma Counting}

The inventory of selected fission products was determined ${ }^{7}$ from measurement of the gamma radiation on all 24 fuel compacts from graphite bodies 2 and 3 . The fuel,compacts were designated according to their position during the irradiation. The first number designates the capsule, the second, the fuel hole, and the third the position of the compact in the fuel hole numbered from top to bottom.

\subsubsection{Apparatus}

The measuring apparatus is located in the Brennstoffzellenlabor of the hot cells. It consists of a rotatable specimen table in the cell, a double collimator [doppelkonuskollimator] in the cell wall and a planar germanium detector in the service area. The nuclear electronics, a multichannel analyzer, a PC with gamma analysis and evaluation software are located in the service area. The components of the apparatus are identified in Table 4.13.

\subsubsection{Measurements}

The fuel compacts were packed in aluminum cans of $20 \mathrm{~mm}$ diameter and $0.3 \mathrm{~mm}$ wall thickness, and stood on a slowing rotating turntable during the measurements. ${ }^{7}$ The gamma radiation encountered the germanium detector in passing through the shuttered double collimator (doppelkonuskollimator). The impulse produced in the detector was amplified and collected as a spectrum in the multichannel analyzer. The spectrum was transferred to a PC and evaluated therewith. 

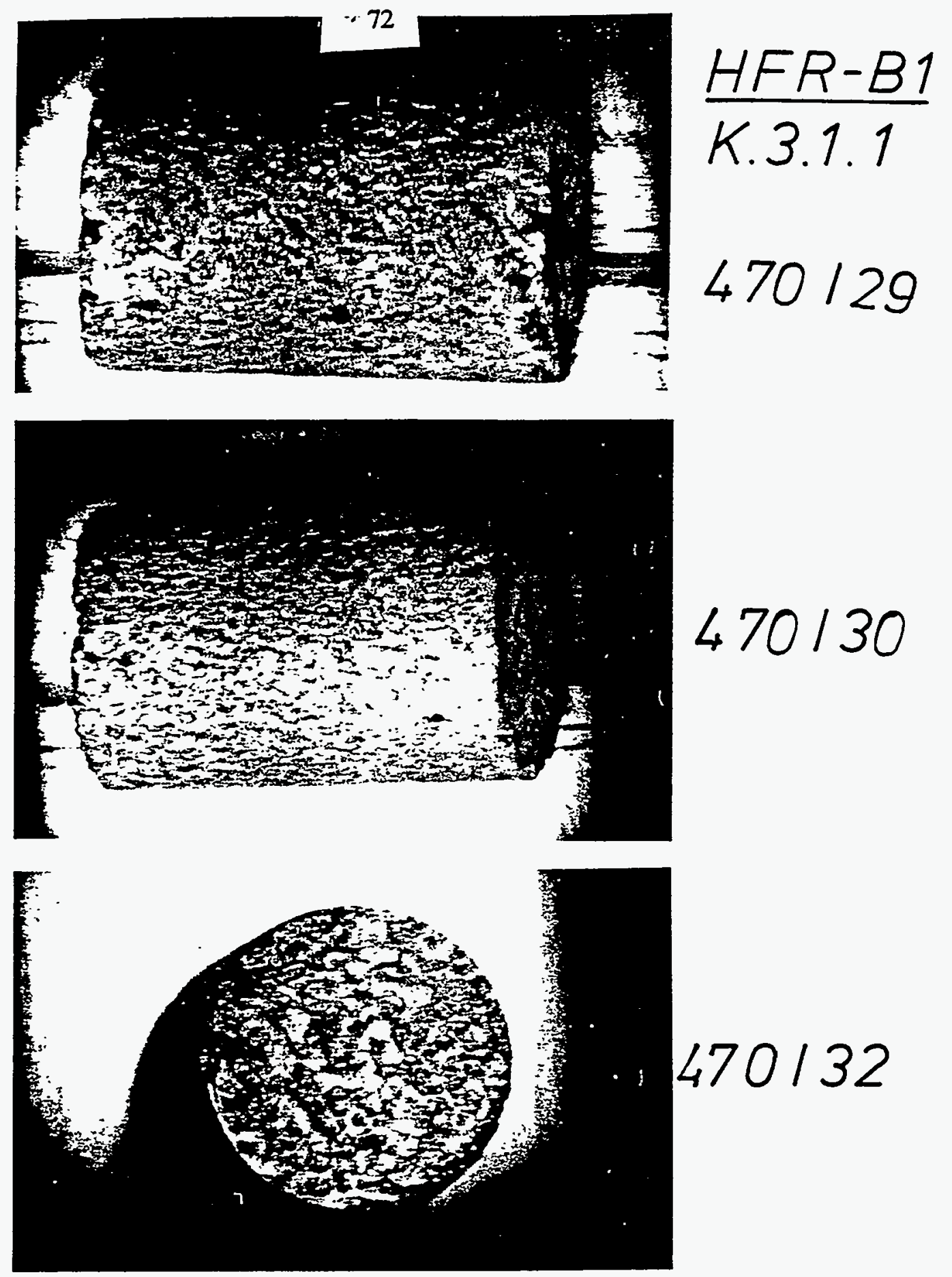

$470 / 32$

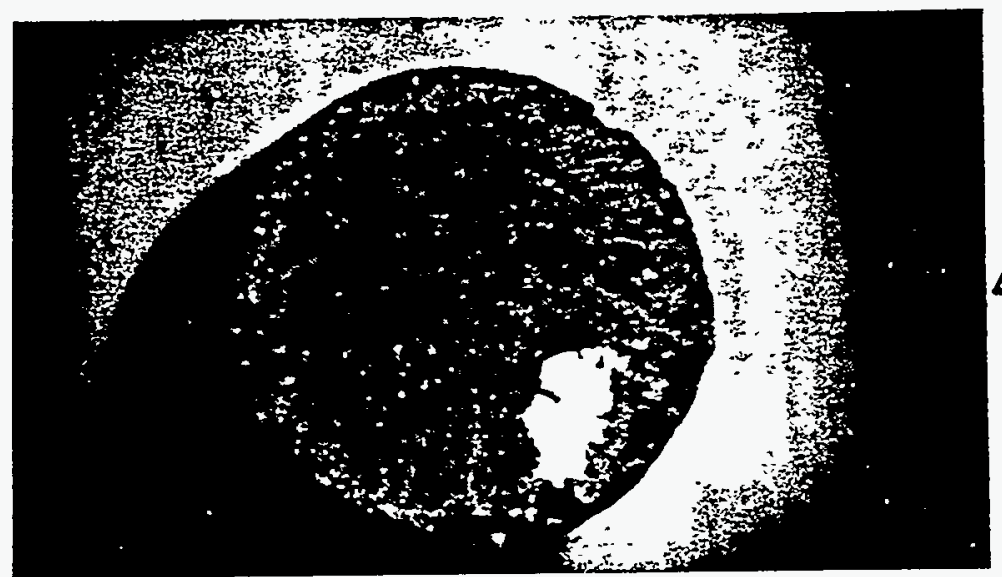

$470 / 31$

Fig. 4.49 Four views of the fuel compact from position 1 in hole 1 of capsule 3 Source: Forschungszentrum Julich $\mathrm{GmbH}$, Julich, Germany 

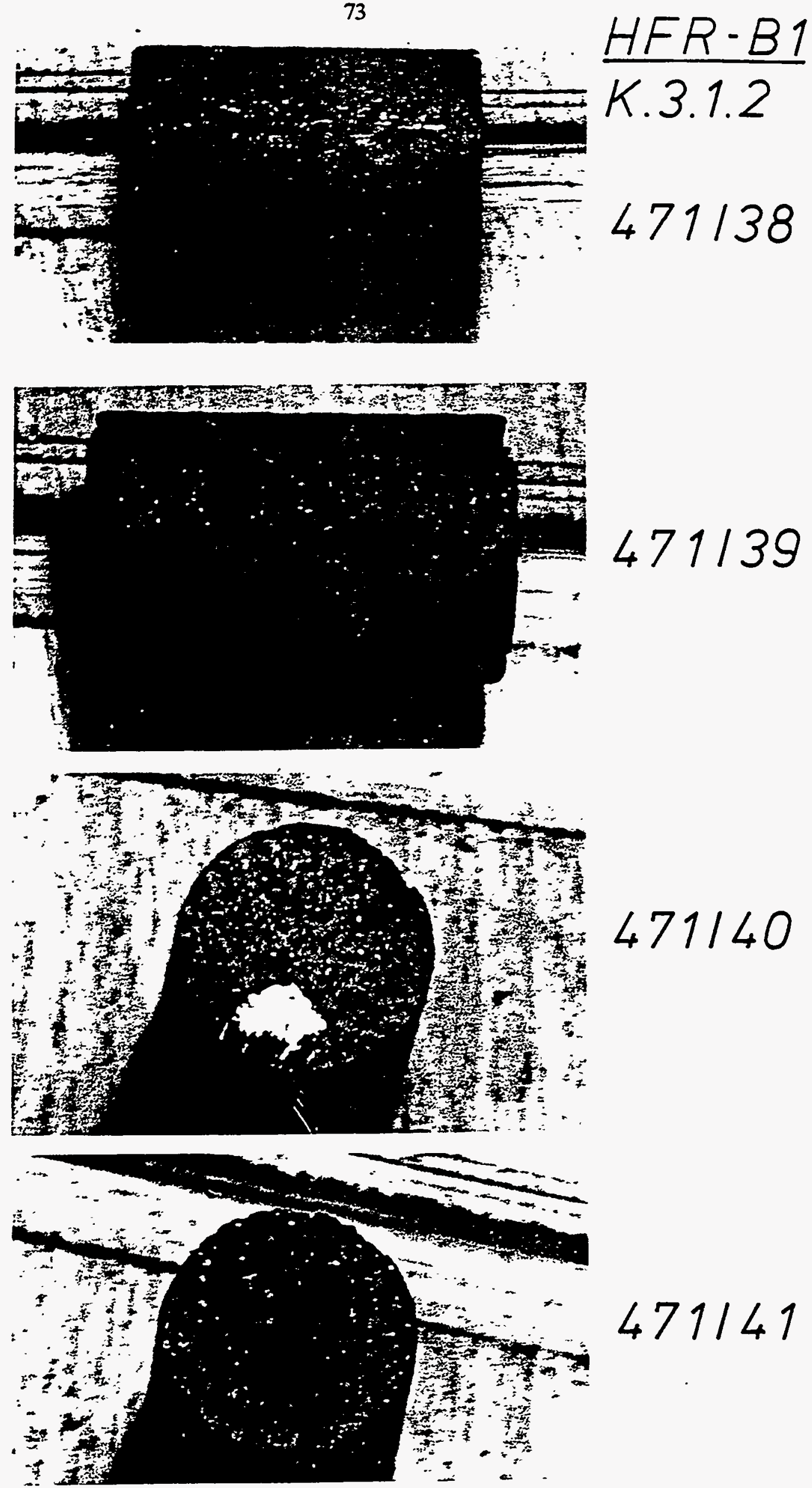

\section{$471 / 41$}

Fig. 4.50 Four views of the fuel compact from position 2 in hole 1 of capsule 3 Source: Forschungszentrum Julich GmbH, Julich, Germany 

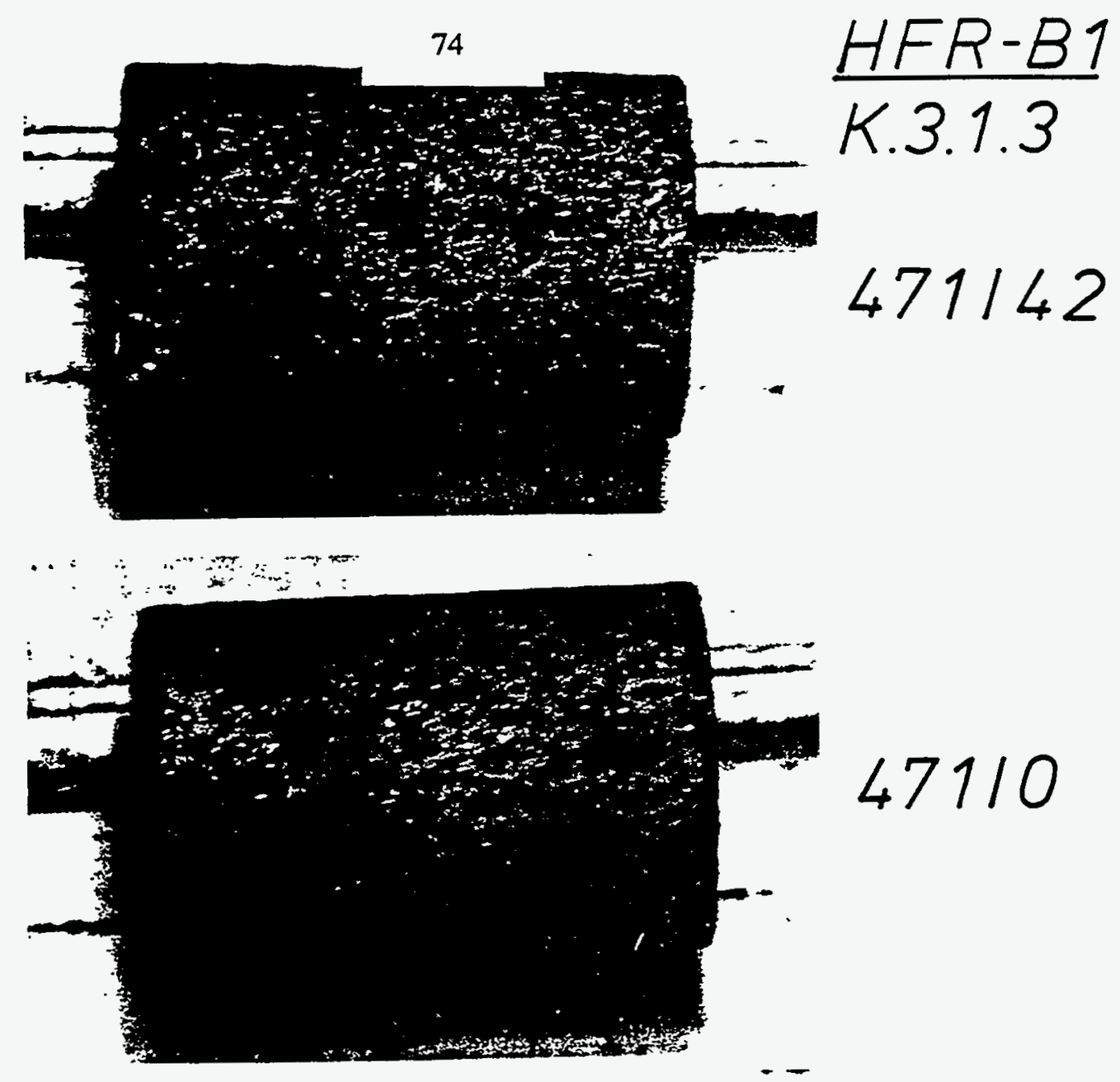

$471 / 42$

47110

$471 / 1$

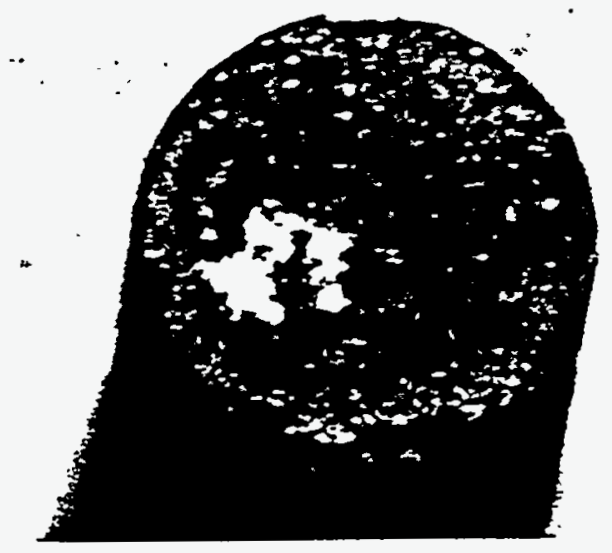

$471 / 2$

rig. 4.51 rous visws of the fuel compact from position 3 in hole 1 of capsule 3

Source: Forschungszentrum Jalich GmbH, Jalich, Germany 


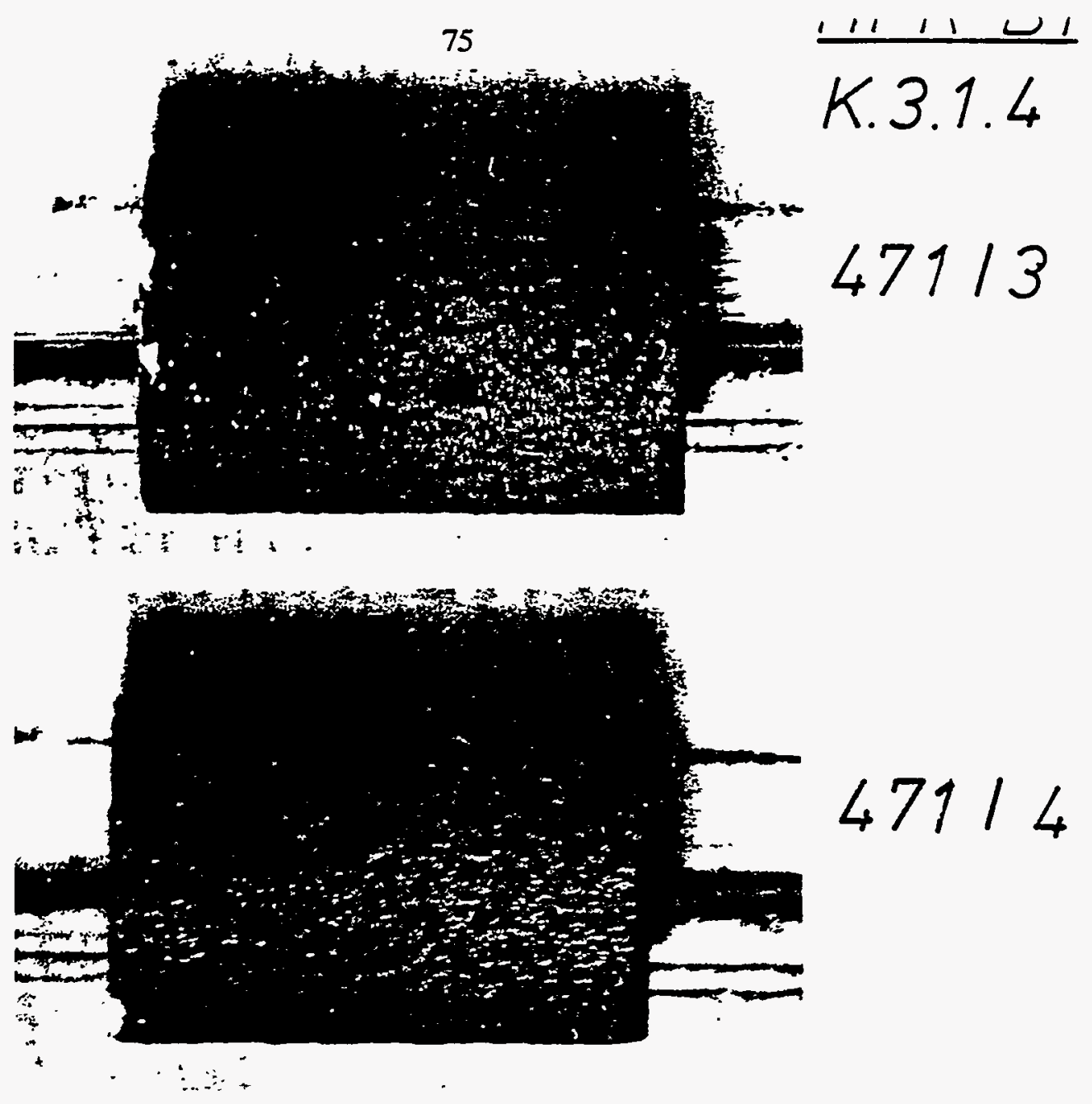




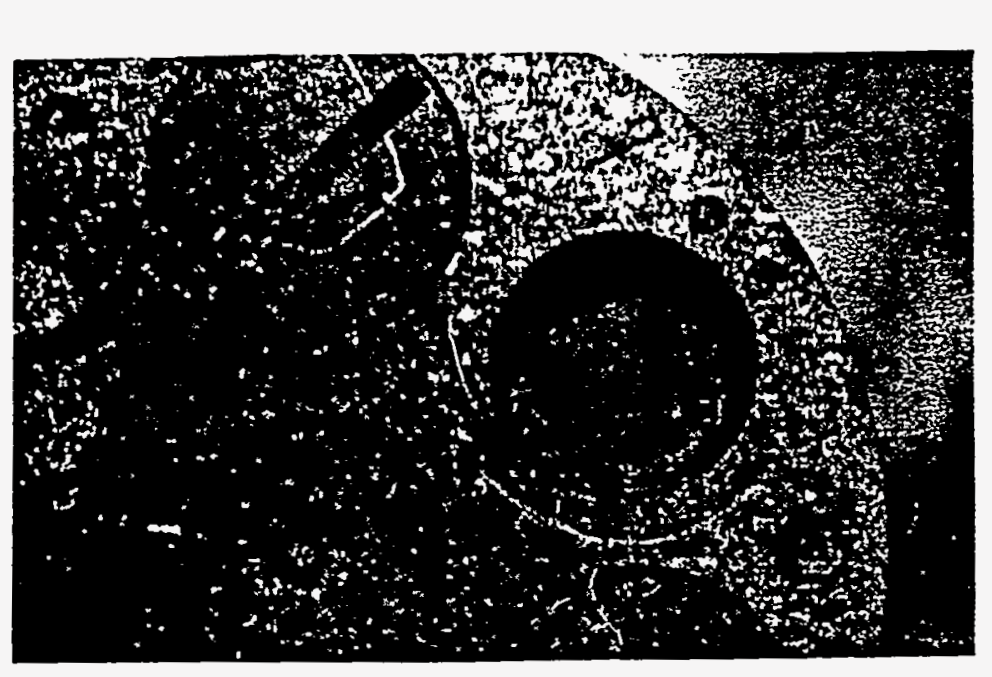

\section{$\frac{\text { HFR B 1 }}{\text { Kapsel } 3}$}

Brennstoff

Kanal 1

$470 / 18$

Fig. 4.53 View of the loose particles upon opening fuel hole 1 of capsule 3 Source: Forschungszentrum Julich $\mathrm{GmbH}$, Julich, Germany 
Table 4.12 Measurement conditions for the graphite bodies of capsules 2 and 3

Collimator: Length

Slit Height

Slit Width

Measurement Distance

Step Length

Measurement Time at each point

Detector

Voltage

Relative Efficiency

Preamplifier

Main Amplifier

High Voltage Apparatus

Reference Pulser

Personal Computer

Spread Sheet

Gammascan-System

Measured Energy Range

Energy Windows:
$545 \mathrm{~mm}$

$30 \mathrm{~mm}$

$0.5 \mathrm{~mm}$

$930 \mathrm{~mm}$

$1 \mathrm{~mm}$

$1000 \mathrm{~s}$

DSG Typ PGP 1516 SNG-167 planar

$-2300 \mathrm{~V}$

$3.5 \%$

DSG

ORTEC Nr. 573

Schlumberger 219

Canberra 1501

Compaq Deskpro 386/20

Microsoft Excel

ORTEC Maestro

20 to $1670 \mathrm{KeV}$

129 to $140 \mathrm{KeV}$ 598 to $612 \mathrm{KeV}$ 616 to $629 \mathrm{KeV}$ 654 to $670 \mathrm{KeV}$ 715 to $732 \mathrm{KeV}$ 1267 to $1283 \mathrm{KeV}$ 1323 to $1342 \mathrm{KeV}$ 


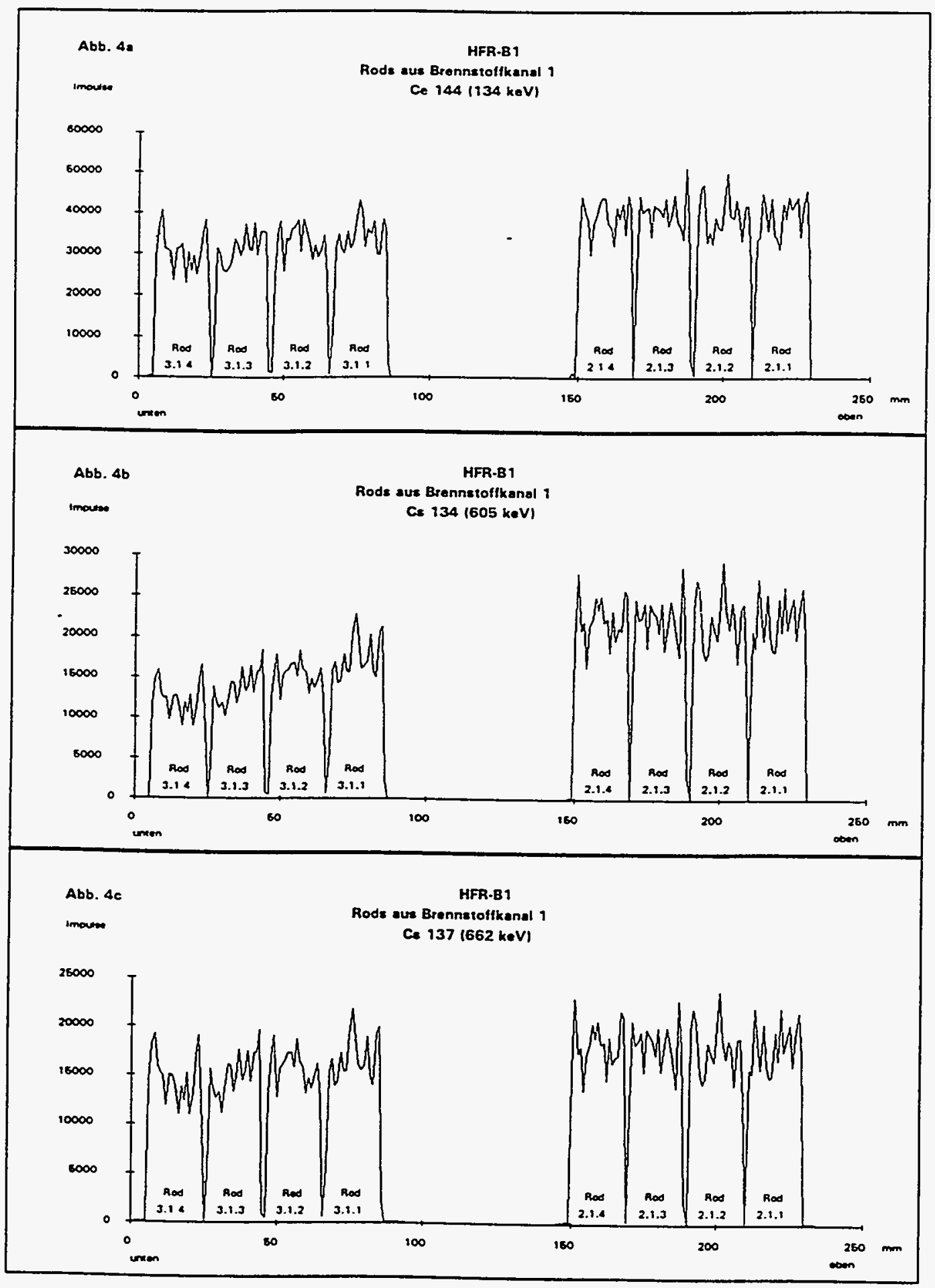

Fig. 4.54 Gamma scan of the fuel compacts from hole 1 of capsules 2 and 3 for ${ }^{14} \mathrm{Ce},{ }^{134} \mathrm{Cs}$, and ${ }^{137} \mathrm{Cs}$ Source: Forschungszentrum Julich $\mathrm{GmbH}$, Julich, Germany 


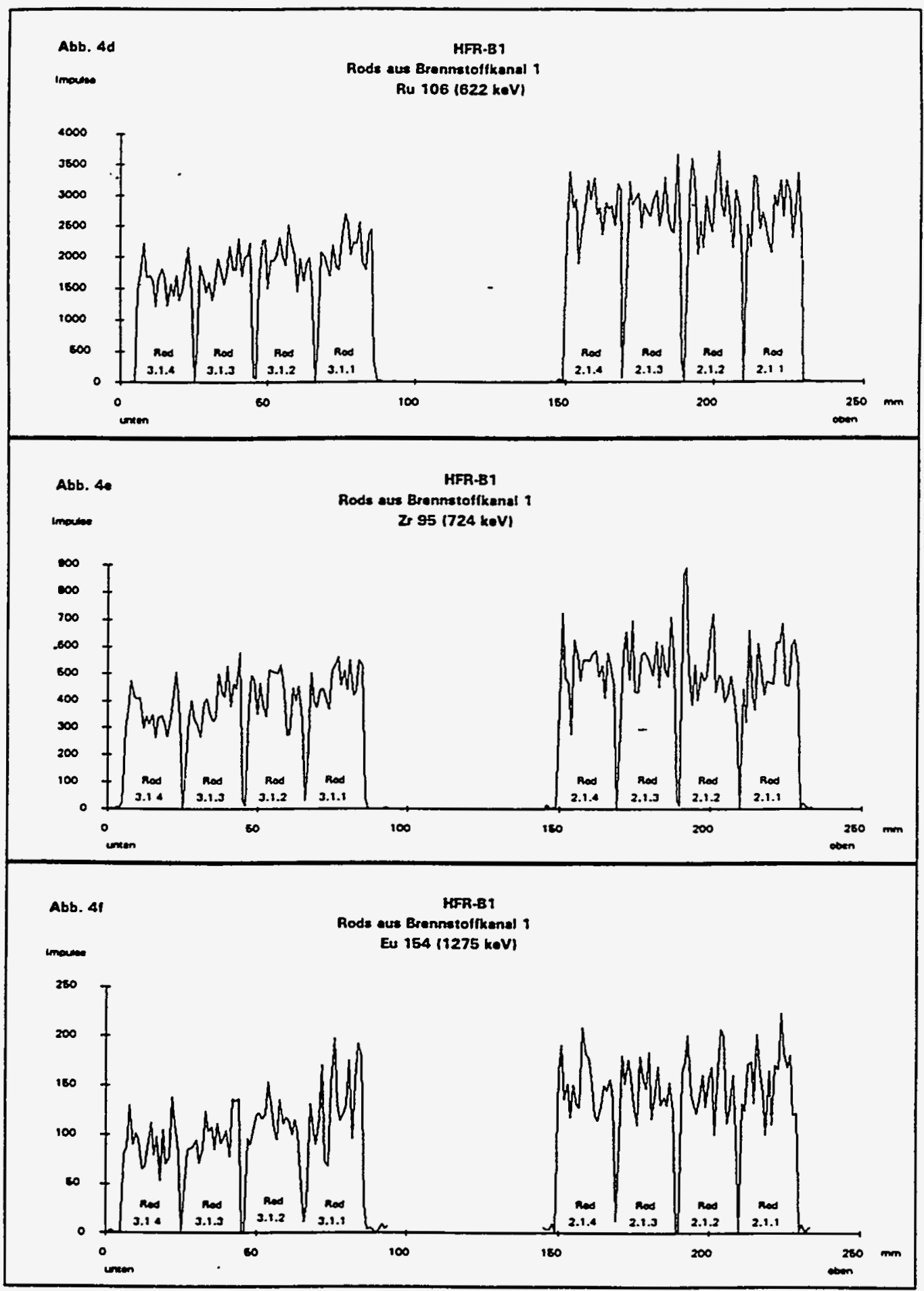

Fig. 4.55 Gamma scan of the fuel compacts from hole 1 of capsules 2 and 3 for ${ }^{106} \mathrm{Ru}$, ${ }^{9} \mathrm{Zr}$, and ${ }^{154} \mathrm{Eu}$ Source: Forschungszentrum Julich GmbH, Julich, Germany 


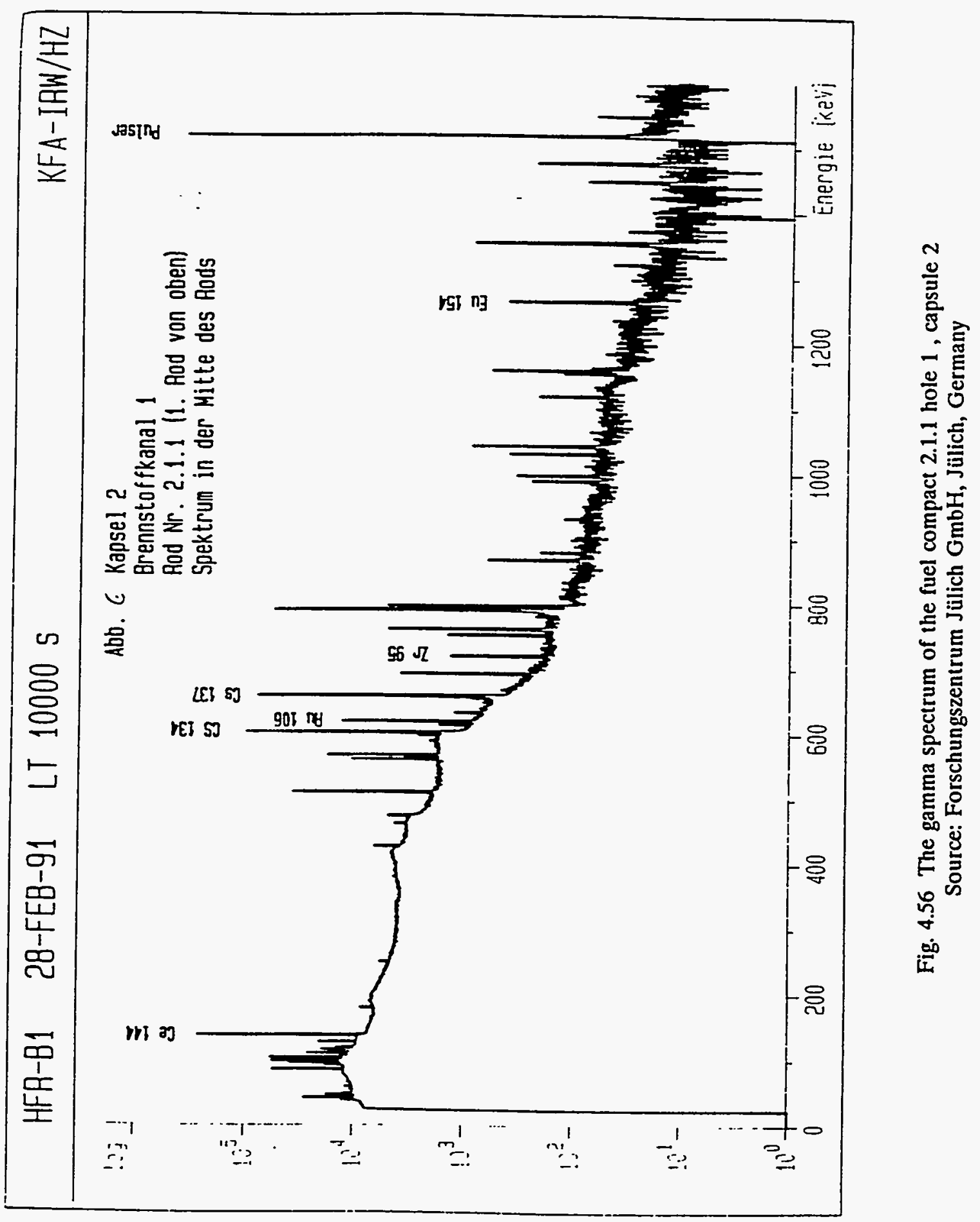


Table 4.13 Components of the measuring facility

Turning apparatus:

5 rotations $/ \mathrm{min}$

Double collimator:

$\begin{array}{lc}\text { smallest slit } & 0.8 \mathrm{~mm} \\ \begin{array}{l}\text { opening angle } \\ \text { measurement distance }\end{array} & 209 \mathrm{~mm} \\ \begin{array}{l}\text { (narrow collimator - } \\ \text { turn table center) }\end{array} & \end{array}$

Detector

DSG Typ PGP 1516 SNG-167 planar

Voltage

$-2300 \mathrm{~V}$

Relative Efficiency

$3.5 \%$

Preamplifier

DSG $51 \mathrm{P}$

Main Amplifier

ORTEC Nr. 573

High Voltage Apparatus

Schlumberger 219

Reference Pulser

Canberra 1501

Multichannel analyzer

Canberra 35 plus

Personal Computer

Compaq Deskpro 386/20

Gamma analysis and evaluation system Canberra Spectran F 
The measurement configuration was calibrated with an AVR fuel element whose ${ }^{137} \mathrm{Cs}$ inventory had been determined by comparison with a standard from the firm Buchler. This fuel element likewise was measured in an aluminum can with $0.3 \mathrm{~mm}$ wall thickness. The different self absorption of the calibrated fuel element and of the fuel compacts was taken into account in the calibration function of the evaluation software.

The results of an error analysis for the inventory is presented in Table 4.14.

\subsubsection{Results}

The fission product inventory was determine for all fuel compacts from graphite bodies 2 and 3 . The results were back corrected to the common time 10.07 .89 , the reactor shutdown time. The results are presented in Tables 4.15 and 4.16. The ${ }^{137} \mathrm{Cs}$ and ${ }^{134} \mathrm{Cs}$ values are graphically given in Fig. 4.57.

\subsubsection{Dimensional and Weight Measurements ${ }^{2}$}

Since the compacts all had a very rough surface and the edges of the cylinders were very easily broken, the dimensional measurements were taken with a measuring microscope having a micrometer stage. This meant that the measurement could not be made to the desired accuracy of $0.1 \mathrm{~mm}$. The results are presented in Table 4.17

The compacts were weighed with a Mettler balance. The specified accuracy ${ }^{2}$ of $0.1 \mathrm{mg}$ was not attainable under the hot cell conditions. The results are presented in Table 4.18.

\subsubsection{Remaining Tasks}

The remaining tasks are the determination of the partition coefficient (i.e., the distribution of fission products between the fuel compact matrix material and the contiguous graphite), metallography and deconsolidation of two fuel compacts.

\subsection{EXAMINATION OF UNFUELED GRAPHITE BODIES}

The unfueled graphite bodies were prepared by removing, from the fueled graphite bodies ${ }^{1}$ of capsules 2 and 3 (see Fig. 3.2 and in reference 9 Figs. 1 and 2), per capsule, 12 fuel compacts (see Sects. 4.3.1.1 and 4.3.1.2) from the fuel holes, 10 trays of unbonded particles, and 3 graphite crucibles of niobiumencapsulated particles from the central hole ${ }^{1}$ of each capsule, 6 graphite cylinders and the 6 surrounding graphite sleeves, and 8 fuel-free compacts. The 7 holes from which these specimens were removed each had a graphite screw at the top and a graphite plug at the bottom as shown, for example, in Fig. 3.2.

\subsubsection{Visual Inspection and Photography ${ }^{2}$}

The unfueled graphite bodies were inspected but not photographed. The external appearance of the graphite bodies are, however, shown in Fig. 4.11, photographs 468/41-43 for capsule 2 and in Fig. 4.14, photographs 469/30; 37; 41 for capsule 3.

\subsubsection{Gamma Scanning}

To prepare the unfueled graphite bodies for gamma scanning as well as gamma counting (see Sect. 4.4.3), the two graphite bodies were each cut into $120^{\circ}$ cylindrical sectors in the process of which the cut was vertically through the centers of the simulated coolant holes (see Fig. 3.2). Thereafter, these cylindrical sectors were cut in half to provide 6 cylindrical sector halves per capsule. 
Table 4.14 Error analysis

The determination of the activity at the end of the irradiation is calculated with the equation:

$$
\begin{aligned}
& A=F^{*}\left(\exp \left\{\lambda^{*} t_{2}\right\} /\left(\gamma^{*} t_{m}^{*} e^{*} x\right)\right. \\
& \text { where } F=\text { net peak area } \\
& \text { where } \lambda=\text { decay constant } \\
& \mathrm{t}_{\mathbf{2}}=\text { decay time } \\
& \gamma=\text { gamma yield } \\
& \mathrm{t}_{\mathrm{w}}=\text { counting time } \\
& e=\text { detector efficiency } \\
& x=\text { self absorption correction factor }
\end{aligned}
$$

As the essential sources of error were taken:

$\Delta \mathrm{F}-0.4 \%$ the error in the peak area determination for the Spectran $\mathrm{F}$

$\Delta \mathrm{t}_{\mathrm{m}}-1 \%$ error in the total time correction

$\Delta e-5 \%$ error of the calibration including the calibration standard

$\Delta x-3 \%$ error in the determination of the self absorption of the calibration standard and of the fuel compacts

the total error is $\leq 10 \%$ 
Table 4.15 The measured activities $(\mathrm{Bq})$ of selective isotopes of the fuel compacts from capsule 2 Source: Forschungszentrum Jülich $\mathrm{GmbH}$, Jülich, Germany

Compact x.y.z represents capsule $x$, fuel hole $y$ and compact $z(z=1$ at top of stack)

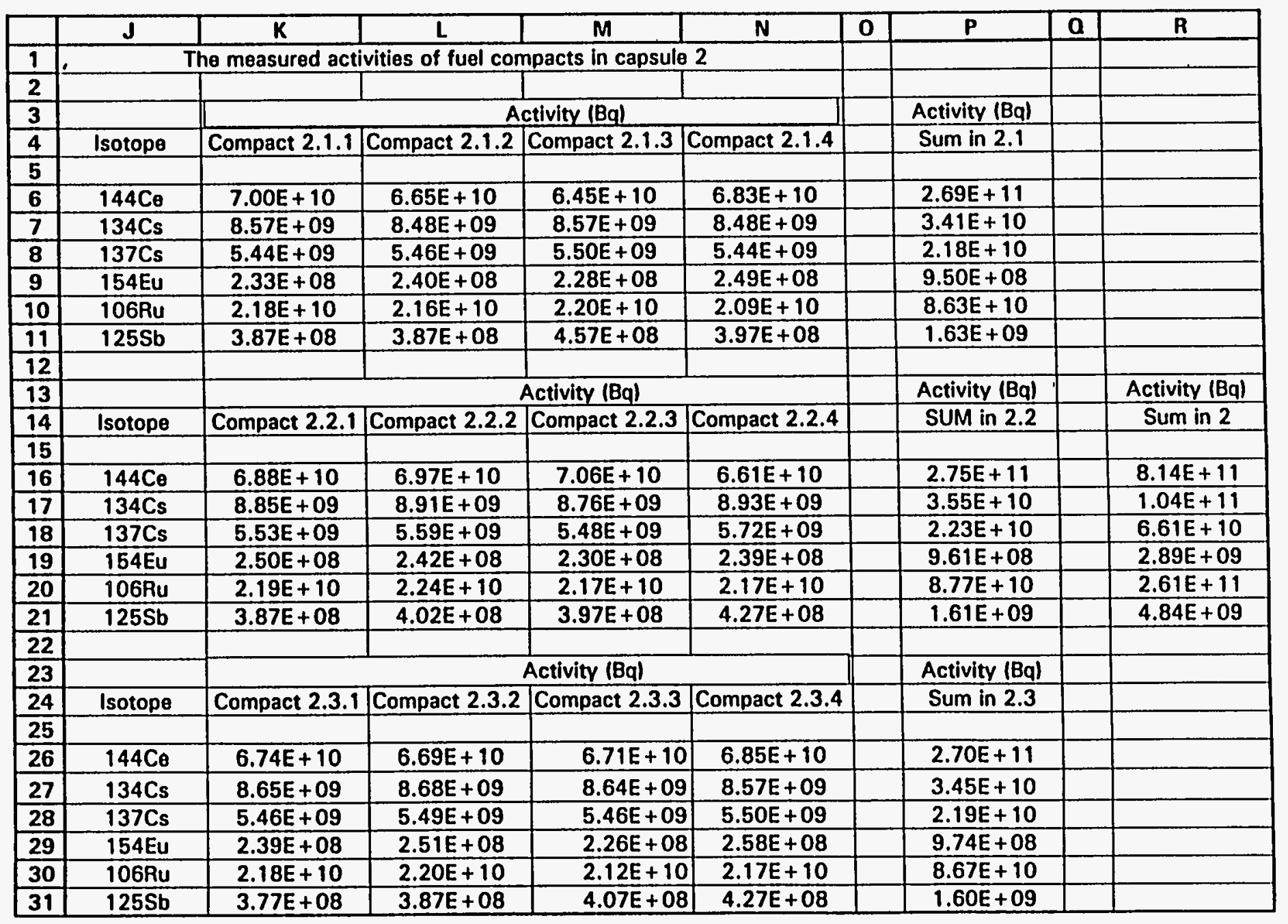


Table 4.16 The measured activities $(\mathrm{Bq})$ of selective isotopes of the fuel compacts from capsule 3 Source: Forschungszentrum Jülich $\mathrm{GmbH}$, Jülich, Germany

Compact x.y.z represents capsule $x$, fuel hole $y$ and compact $z(z=1$ at top of stack)

\begin{tabular}{|c|c|c|c|c|c|c|c|c|c|}
\hline & $\mathbf{J}$ & $\mathbf{K}$ & $L$ & $M$ & $\mathbf{N}$ & $\mathbf{0}$ & $\mathbf{P}$ & $\mathbf{a}$ & $\mathbf{R}$ \\
\hline 32 & \multicolumn{5}{|c|}{ The measured activities of fuel compacts in capsule 3} & & & & \\
\hline \multicolumn{10}{|c|}{ 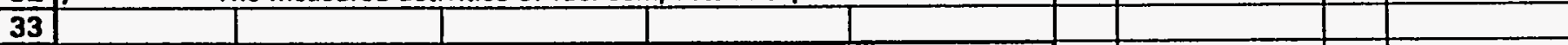 } \\
\hline 34 & & \multicolumn{4}{|c|}{ Activity $(\mathrm{Ba})$} & & Activity (Bq) & & \\
\hline 35 & Isotope & Compact 3.1.1 & Compact3.1.2 & Compact3.1.3 & Compact3.1.4 & & Sum in 3.1 & & \\
\hline \multicolumn{10}{|c|}{ - } \\
\hline 37 & $144 \mathrm{Ce}_{0}$ & $5.95 E+10$ & $5.76 E+10$ & $5.83 E+10$ & $5.22 E+10$ & & $2.28 \mathrm{E}+11$ & & \\
\hline 38 & $134 \mathrm{Cs}$ & $6.61 E+09$ & $5.87 E+09$ & $5.20 \mathrm{E}+09$ & $4.78 E+09$ & & $2.25 E+10$ & & \\
\hline 39 & $137 \mathrm{Cs}_{\mathrm{s}}$ & $4.96 E+09$ & $4.71 E+09$ & $4.52 E+09$ & $4.37 E+09$ & & $1.86 E+10$ & & \\
\hline 40 & 154EU & $2.00 E+08$ & $1.73 E+08$ & $1.54 E+08$ & $1.29 E+08$ & & $6.56 \mathrm{E}+08$ & & \\
\hline 41 & 106Ru & $1.60 E+10$ & $1.46 E+10$ & $1.35 \mathrm{E}+10$ & $1.28 E+10$ & & $5.69 E+10$ & & \\
\hline 42 & $125 \mathrm{Sb}$ & $3.67 E+08$ & $3.57 E+08$ & $2.88 E+08$ & $3.28 \mathrm{E}+08$ & & $1.34 \mathrm{E}+09$ & & \\
\hline \multicolumn{10}{|l|}{43} \\
\hline 44 & & \multicolumn{4}{|c|}{ Activity (Bq) } & & Activity (Bq) & & Activity (Ba) \\
\hline 45 & Isotope & Compact 3.2.1 & Compact 3.2.2 & Compact 3.2.3 & Compact 3.2.4 & & Sum in 3.2 & & Sum in 3 \\
\hline \multicolumn{10}{|c|}{ 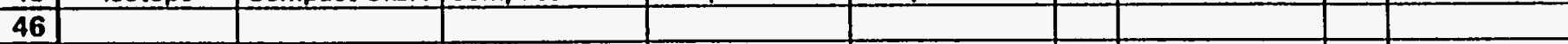 } \\
\hline 47 & $144 \mathrm{C}_{\theta}$ & $5.91 E+10$ & $5.73 E+10$ & $5.23 E+10$ & $5.48 E+10$ & & $2.24 E+11$ & & $6.63 E+11$ \\
\hline 48 & $134 \mathrm{Cs}$ & $6.89 E+09$ & $6.10 E+09$ & $5.46 \mathrm{E}+09$ & $4.93 E+09$ & & $2.34 E+10$ & & $6.80 E+10$ \\
\hline 49 & $137 \mathrm{Cs}$ & $5.04 \mathrm{E}+09$ & $4.86 E+09$ & $4.57 E+09$ & $4.43 \mathrm{E}+09$ & & $1.89 E+10$ & & $5.57 E+10$ \\
\hline 50 & 154Eu & $2.10 E+08$ & $1.89 E+08$ & $1.82 E+08$ & $1.39 E+08$ & & $7.20 E+08$ & & $2.04 E+09$ \\
\hline 51 & 106Ru & $1.69 \mathrm{E}+10$ & $1.60 E+10$ & $1.47 E+10$ & $1.25 E+10$ & & $6.01 E+10$ & & $1.73 E+11$ \\
\hline 52 & $125 S b$ & $4.27 E+08$ & $3.08 E+08$ & $2.48 \mathrm{E}+08$ & $2.68 E+08$ & & $1.25 E+09$ & & $3.89 E+09$ \\
\hline \multicolumn{10}{|l|}{53} \\
\hline 54 & & \multicolumn{4}{|c|}{ Activity (Ba) } & & Activity (Bq) & & \\
\hline 55 & Isotope & Compact 3.3.1 & Compact3.3.2 & Compact 3.3.3 & Compact3.3.4 & & Sum in $\mathbf{3 . 3}$ & & \\
\hline \multicolumn{10}{|l|}{56} \\
\hline 57 & $144 \mathrm{Ce}$ & $5.72 E+10$ & $5.21 \mathrm{E}+10$ & $5.36 \mathrm{E}+10$ & $4.88 \mathrm{E}+10$ & & $2.12 \mathrm{E}+11$ & & \\
\hline 58 & $134 \mathrm{Cs}$ & $6.50 E+09$ & $5.78 E+09$ & $5.09 E+09$ & $4.76 E+09$ & & $2.21 E+10$ & & \\
\hline 59 & $137 \mathrm{Cs}$ & $4.86 \mathrm{E}+09$ & $4.63 \mathrm{E}+09$ & $4.41 \mathrm{E}+09$ & $4.36 \mathrm{E}+09$ & & $1.83 E+10$ & & \\
\hline 60 & 154Eu & $1.92 E+08$ & $1.63 E+08$ & $1.69 E+08$ & $1.38 \mathrm{E}+08$ & & $6.62 E+08$ & & \\
\hline 61 & 106Ru & $1.60 \mathrm{E}+10$ & $1.45 E+10$ & $1.33 E+10$ & $1.23 E+10$ & & $5.61 E+10$ & & \\
\hline 62 & $125 \mathrm{Sb}$ & $3.40 E+08$ & $3.87 E+08$ & $2.78 E+08$ & $2.98 E+08$ & & $1.30 E+09$ & & \\
\hline
\end{tabular}




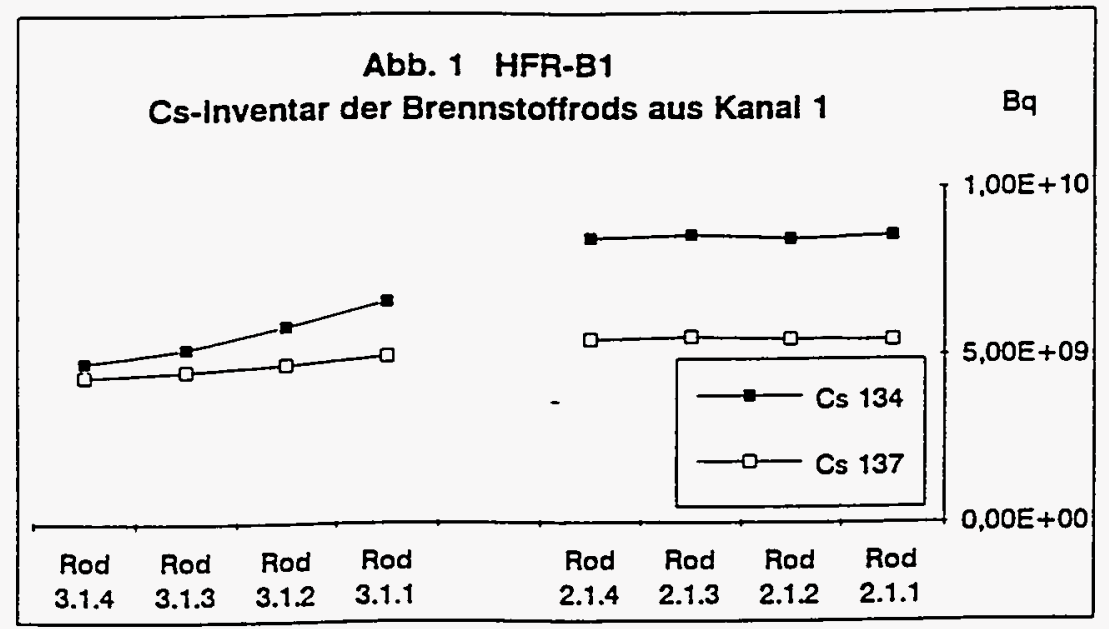

Abb. 2 HFR-B1

Cs- Inventar der Brennstoffrods aus Kanal 2
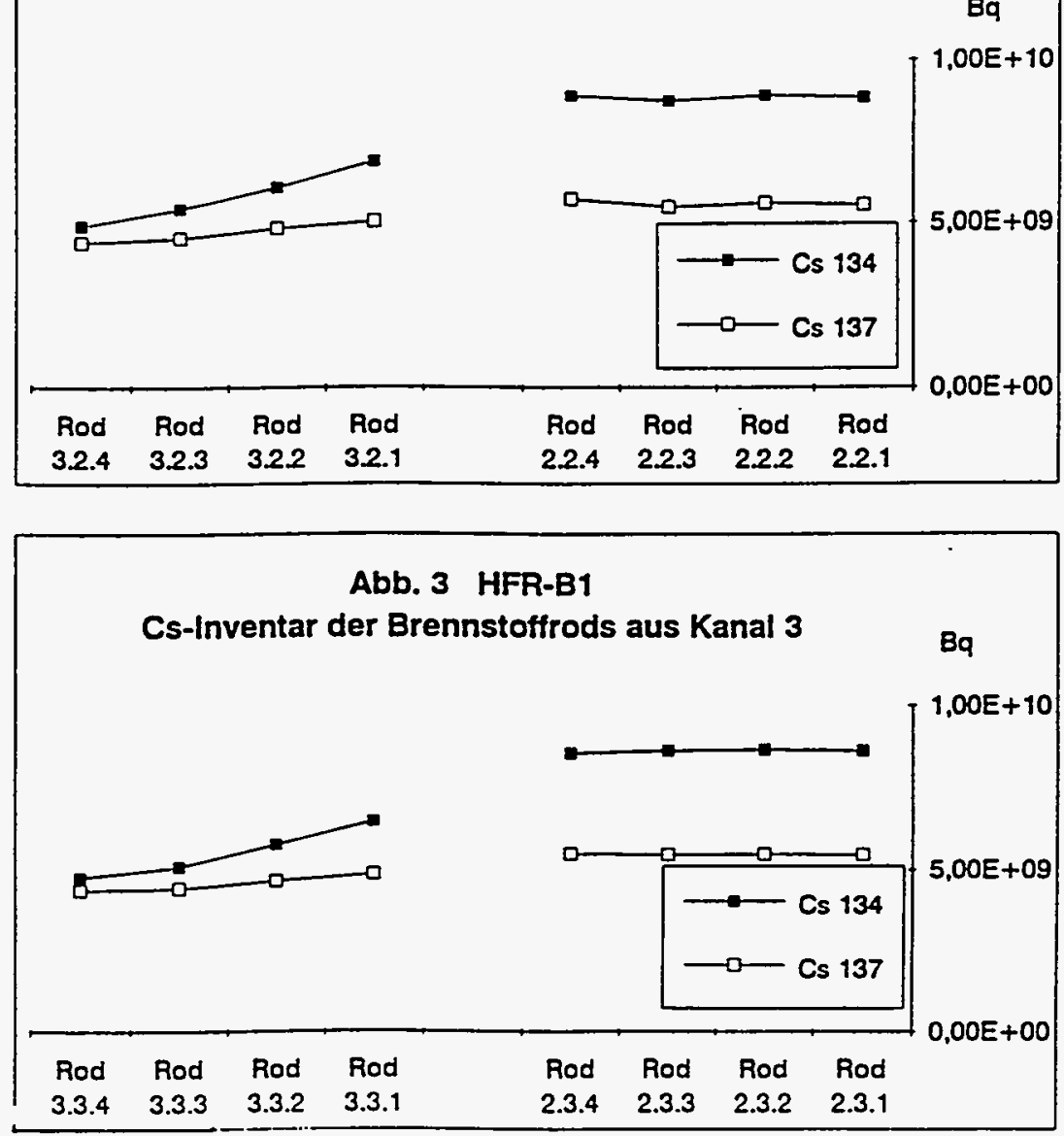

Fig. 4.57 The cesium inventory of the fuel compacts from fuel holes 1,2 , and 3 Source: Forschungszentrum Julich GmbH, Julich, Germany

Compact x.y.z represents capsule $x$, fuel hole $y$ and compact $z$ ( $z=1$ at top of stack) 
Table 4.17 Dimensional measurements on eight compacts from hole 1 of capusles 2 and 3 Source: Forschungszentrum Julich GmbH, Julich, Germany

$$
\begin{array}{ll}
\text { Measurement apparatus: } & \text { Micrometer stage } \\
\text { Measurement accuracy: } & \pm 0.05 \mathrm{~mm}
\end{array}
$$

\begin{tabular}{|c|c|c|c|c|c|c|c|c|c|}
\hline \multirow{2}{*}{$\begin{array}{l}\text { Capsule } \\
\text { Position }\end{array}$} & \multirow{2}{*}{$\begin{array}{l}\text { Compact } \\
\text { No. }\end{array}$} & \multicolumn{2}{|c|}{ Length (mm) } & \multicolumn{2}{|c|}{$\Delta$ Length } & \multicolumn{2}{|c|}{ Diameter (mm) } & \multicolumn{2}{|c|}{$\Delta$ Diameter } \\
\hline & & before & after & (mm) & $\%$ & before & after & $(\mathrm{mm})$ & $\%$ \\
\hline 2.1 .1 & $7161-019-01-48$ & 19.12 & 19.00 & 0.12 & 0.6 & 12.46 & 12.40 & 0.06 & 0.5 \\
\hline 2.1 .2 & 149 & 19.05 & 19.00 & 0.05 & 0.3 & 12.45 & 12.35 & 0.10 & 0.8 \\
\hline 2.1 .3 & 164 & 19.06 & 18.90 & 0.16 & 0.8 & 12.45 & 12.30 & 0.15 & 1.2 \\
\hline 2.1.4 & 14 & 18.99 & 18.85 & 0.14 & 0.7 & 12.47 & 12.35 & 0.12 & 1.0 \\
\hline 3.1.1 & 138 & 19.06 & 18.85 & 0.21 & 1.1 & 12.44 & 12.35 & 0.09 & 0.7 \\
\hline 3.1.2 & 35 & 19.05 & 18.90 & 0.15 & 0.8 & 12.46 & 12.35 & 0.11 & 0.9 \\
\hline 3.1.3 & 145 & 19.02 & 18.90 & 0.12 & 0.6 & 12.45 & 12.35 & 0.10 & 0.8 \\
\hline 3.1 .4 & 97 & 19.02 & 18.90 & 0.12 & 0.6 & 12.46 & 12.40 & 0.06 & 0.5 \\
\hline
\end{tabular}

Table 4.18 Weight measurements of eight compacts from hole 1 of capsules 2 and 3 Source: Forschungszentrum Julich GmbH, Jalich, Germany

Weighing apparatus: Mettler PT 320 SE

\begin{tabular}{|c|c|c|c|c|c|}
\hline \multirow{2}{*}{$\begin{array}{l}\text { Capsule } \\
\text { Position }\end{array}$} & \multirow{2}{*}{$\begin{array}{c}\text { Compact } \\
\text { No. }\end{array}$} & \multicolumn{2}{|c|}{ Weight (g) } & \multicolumn{2}{|c|}{$\Delta$ Weight } \\
\hline & & before & after & (g) & $\%$ \\
\hline 2.1.1 & 7161-019-01-48 & 3.5772 & 3.535 & 0.0422 & 1.18 \\
\hline 2.1 .2 & 149 & 3.5704 & 3.532 & 0.0384 & 1.07 \\
\hline 2.1 .3 & 164 & 3.5630 & 3.537 & 0.0260 & 0.73 \\
\hline 2.1 .4 & 14 & 3.5604 & 3.555 & 0.0050 & 0.15 \\
\hline 3.1 .1 & 138 & 3.5695 & 3.519 & 0.0505 & 1.41 \\
\hline 3.1 .2 & 35 & 3.5731 & 3.529 & 0.0441 & 1.23 \\
\hline 3.1 .3 & 145 & 3.5701 & 3.532 & 0.0381 & 1.07 \\
\hline 3.1.4 & 97 & 3.5687 & 3.546 & 0.0227 & 0.64 \\
\hline
\end{tabular}

Weighing accuracy: $\quad \pm 0.05 \mathrm{~mm}$ 


\subsubsection{Apparatus}

The description of the apparatus has already been given in Sect. 4.2.4.1.

\subsubsection{Measurement}

Two cylindrical sector halves were laid in the receiving cradle of the carriage with a cut surface of the sectors against the cradle; see Fig. 4.58. Then the sectors were moved before the collimator slit. In this position, a suitable collimator was chosen and then a gamma spectrum taken. With this spectrum, the energy window, in which the peak of the interesting nuclide occurred, was determined; likewise the measurement time at the measurement point.

Thereafter, the beginning of the first sector was placed before the collimator opening and the step motor with the chosen step width started. For each step a gamma spectrum was taken. Illustrative gamma spectra for graphite sectors 2.3 and 3.3 are shown in Figs. 4.59 and 4.60, respectively. With these, in the energy region of the individual peaks, the net peak areas were determined. To that end, the impulse numbers were summed and the spectrum background, an average value of the impulse number calculated from the three channels, left and right of the photopeak, substracted. The peak net areas were stored in the PC and after the end of the scans were transferred to a spreadsheet.

The scans were performed between 2.9.92 and 11.9.91. Because of the short measuement time, the results were not back calculated to a common time.

The instruments and conditions of the measurements for the cylindrical sectors are given in Table 4.19.

\subsubsection{Results}

The results are presented in Figs. 4.61 through 4.66. They show the relative distribution of the fission products ${ }^{144} \mathrm{Ce},{ }^{137} \mathrm{Cs}$, and ${ }^{134} \mathrm{Cs}$ as well as the activities of ${ }^{183} \mathrm{Ta},{ }^{94} \mathrm{Nb}$, and ${ }^{60} \mathrm{Co}$ at the measurement time. The results from capsule 2 and 3 are shown in a comparative mode; the upper graph in each figure represents capsule 2 for halves from the same sector, sectors being designated as 1,2 , or 3 and the lower graph in each figure represents capsule 3 for halves from the same sector. The indentation in the middle of the scan profile marks the contiguous boundaries of the sector halves. Note that on the figures, the German designation for the cylindrical sector halves is "Graphitsegments"; also, note that the screws and plugs are in the fuel holes except for sector 2.1.

Gamma scans of the graphite bodies with the fuel compacts removed were obtained for the nuclides ${ }^{144} \mathrm{Ce},{ }^{134} \mathrm{Cs},{ }^{137} \mathrm{Cs},{ }^{60} \mathrm{Co},{ }^{94} \mathrm{Nb}$, and ${ }^{182} \mathrm{Ta}$. These scans illustrate that the cesium activity in the graphite body of capsule 2 is about 3 times larger than that in the graphite body of capsule 3. By contrast, the inverse occurs with the concentrations of ${ }^{60} \mathrm{Co},{ }^{94} \mathrm{Nb}$, and ${ }^{182} \mathrm{Ta}$; their activities in the graphite body of capsule 3 are about 3 times larger than those in the graphite body of capsule 2. These relations are likely to be the result of the frequent injections of water vapor into capsule 3 ; capsule 2 experienced no water vapor injection. The factorial differences in burnup and temperature in capsules 2 and 3 are small compared to the factorial differences in activities cited.

A general postulate accounting for the activity differences is the following. Water vapor oxidizes the binder of the graphite body thus reducing the retentivity of the graphite for fission products. For example, the diffusion coefficient of cesium increases with increasing graphite oxidation. ${ }^{10}$ Thus ${ }^{233} \mathrm{Cs}$ and ${ }^{137} \mathrm{Cs}$ spend less time moving through the oxidized graphite and have lower activities in the graphite. In transit, less time is available for activation of ${ }^{133} \mathrm{Cs}$ to ${ }^{134} \mathrm{Cs}$. Consequently, the ratio of 


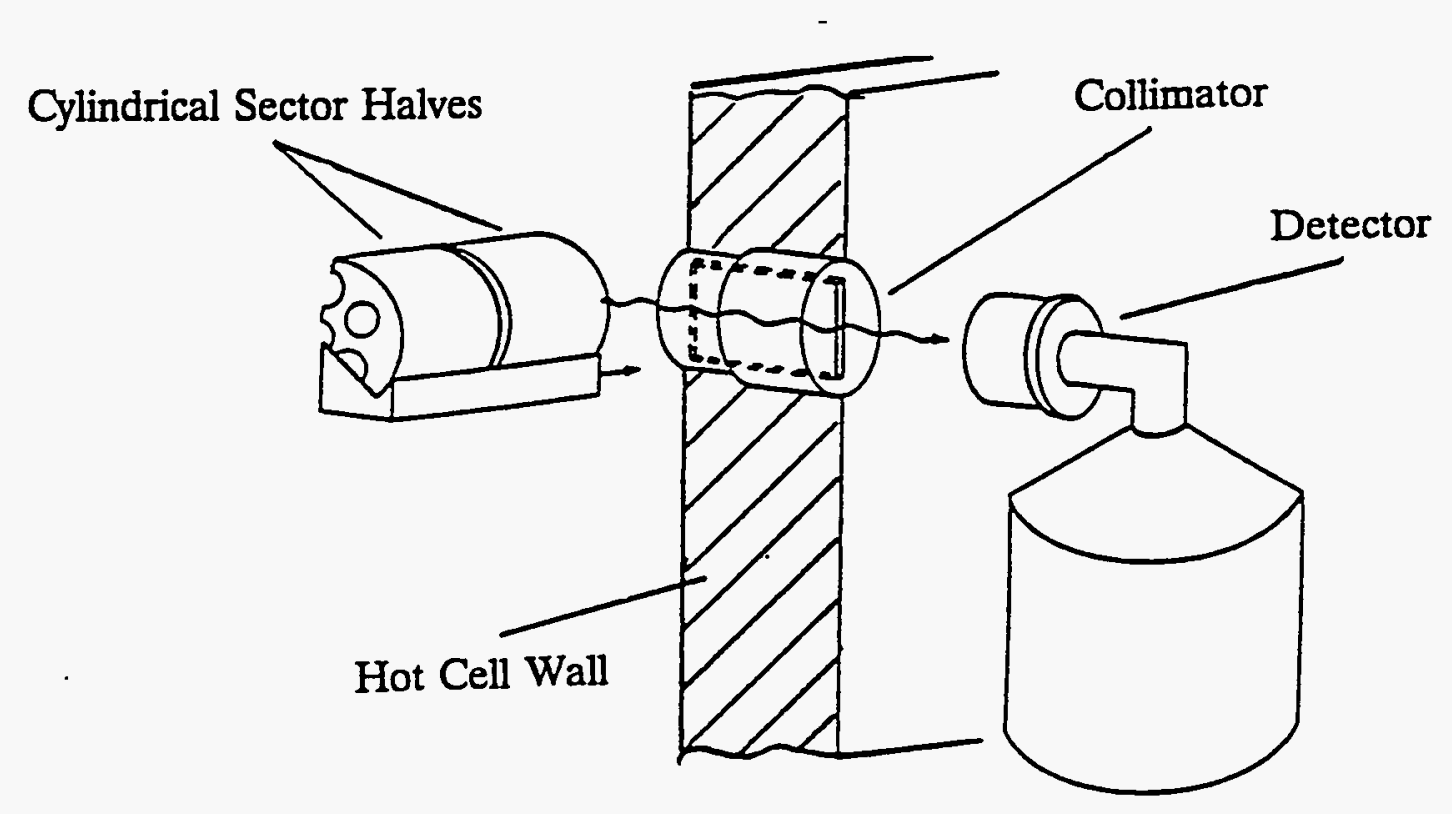

Fig. 4.58 Sketch of the measuring facility

Source: Forschungszentrum Julich GmbH, Julich, Germany 


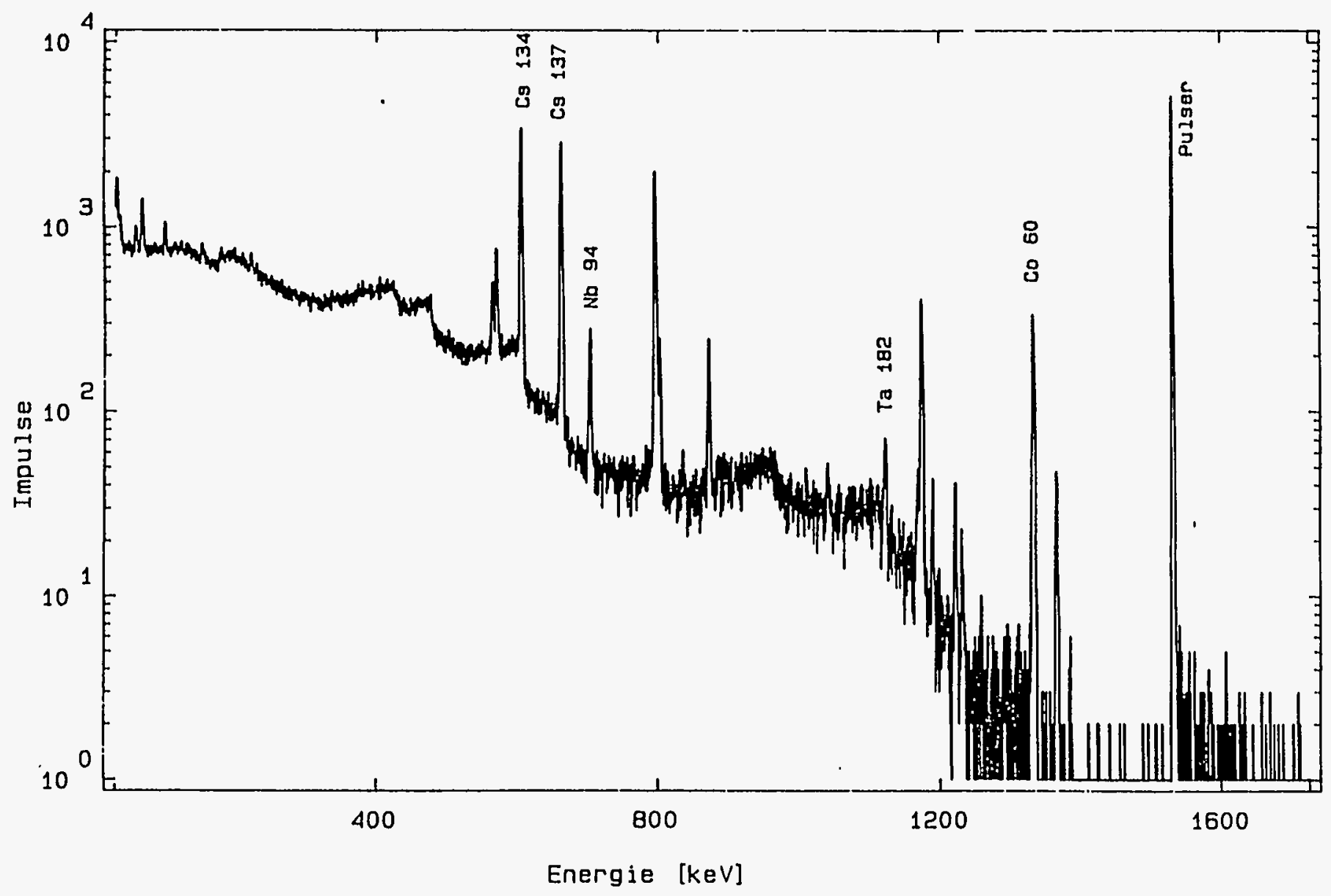

Fig. 4.59 The gamma spectrum of graphite sector 2.3 at the axial location $15 \mathrm{~mm}$ above the bottom of the graphite sector on 12.9 .91 Source: Forschungszentrum Jülich $\mathrm{GmbH}$, Jülich, German 


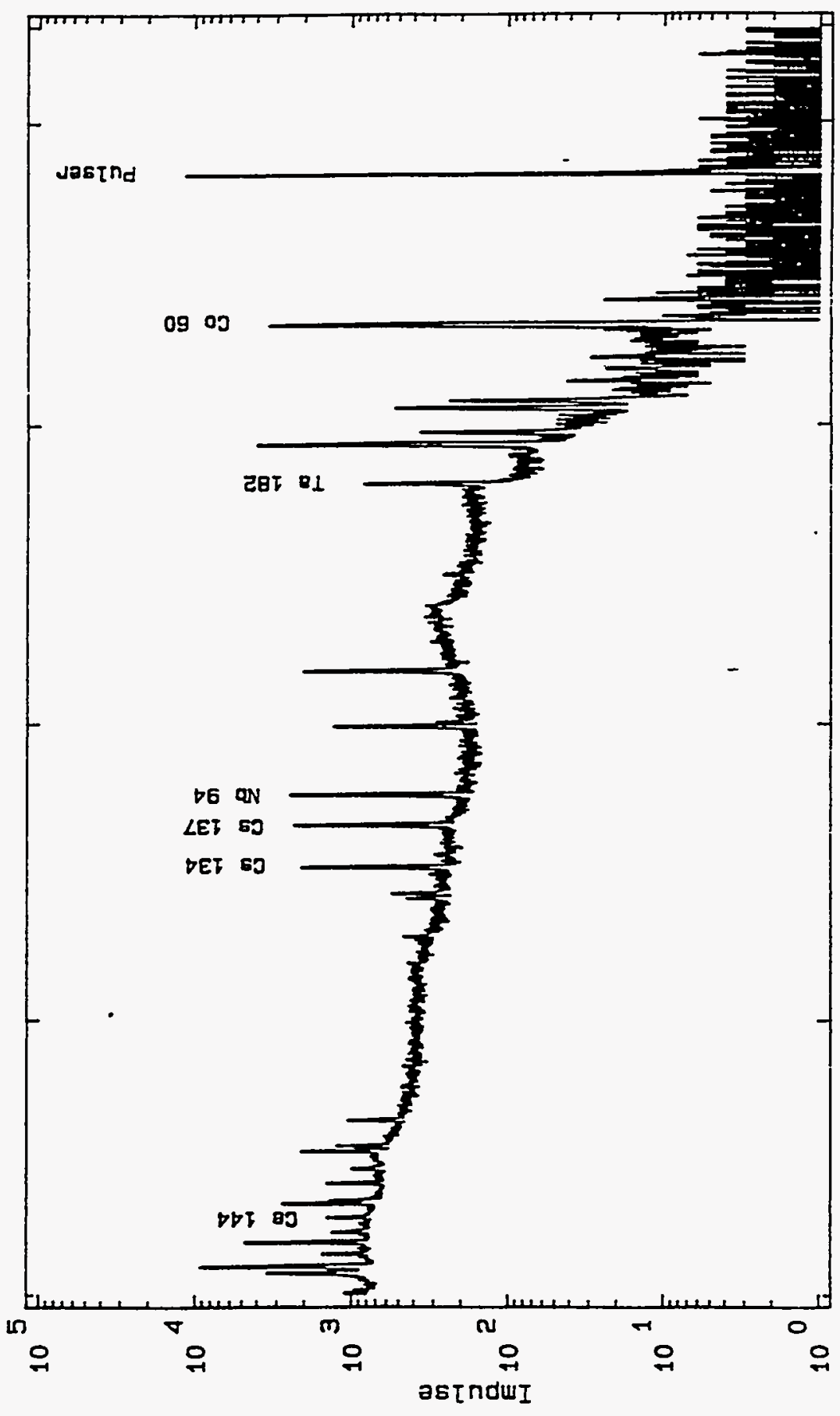

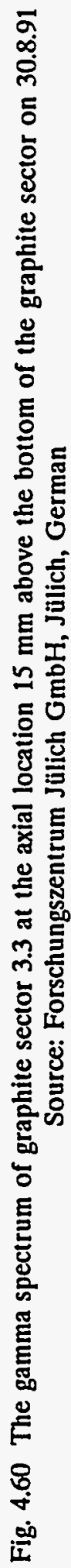


Table 4.19 Measurement conditions for the graphite bodies of capsules 2 and 3

\section{Collimator: Length}

Slit Height

Slit Width

Measurement Distance

Step Length

Measurement Time at each point

Detector

Voltage

Relative Efficiency

Preamplifier

Main Amplifier

High Voltage Apparatus

Reference Pulser

Personal Computer

Spread Sheet

Gammascan-System

Measured Energy Range

Energy Windows:

${ }^{144} \mathrm{Ce}$

${ }^{134} \mathrm{Cs}$

${ }^{106} \mathrm{Ru}$

${ }^{137} \mathrm{Cs}$

${ }^{95} \mathrm{Nb}$

${ }^{181} \mathrm{Ta}$

${ }^{60} \mathrm{Co}$
$545 \mathrm{~mm}$

$30 \mathrm{~mm}$

$5 \mathrm{~mm}$

$930 \mathrm{~mm}$

$1 \mathrm{~mm}$

$500 \mathrm{~s}$

DSG Typ PGP 1516 SNG-167 planar

$-2300 \mathrm{~V}$

$3.5 \%$

DSG 51 P

ORTEC Nr. 573

Schlumberger 219

Canberra 1501

Compaq Deskpro 386/20

Microsoft Excel

ORTEC Maestro

20 to $1670 \mathrm{KeV}$

127 to $139 \mathrm{KeV}$

598 to $612 \mathrm{KeV}$

616 to $622 \mathrm{KeV}$

654 to $670 \mathrm{KeV}$

696 to $711 \mathrm{KeV}$

1116 to $1128 \mathrm{KeV}$

1324 to $1339 \mathrm{KeV}$ 
HFR-B1

Abb: $3 a$

Impuise $\quad \begin{gathered}\text { Scan des Grafitsegments } 2.1 \\ \text { (Schraubkappe auf dem Brennstoffkanal) }\end{gathered}$

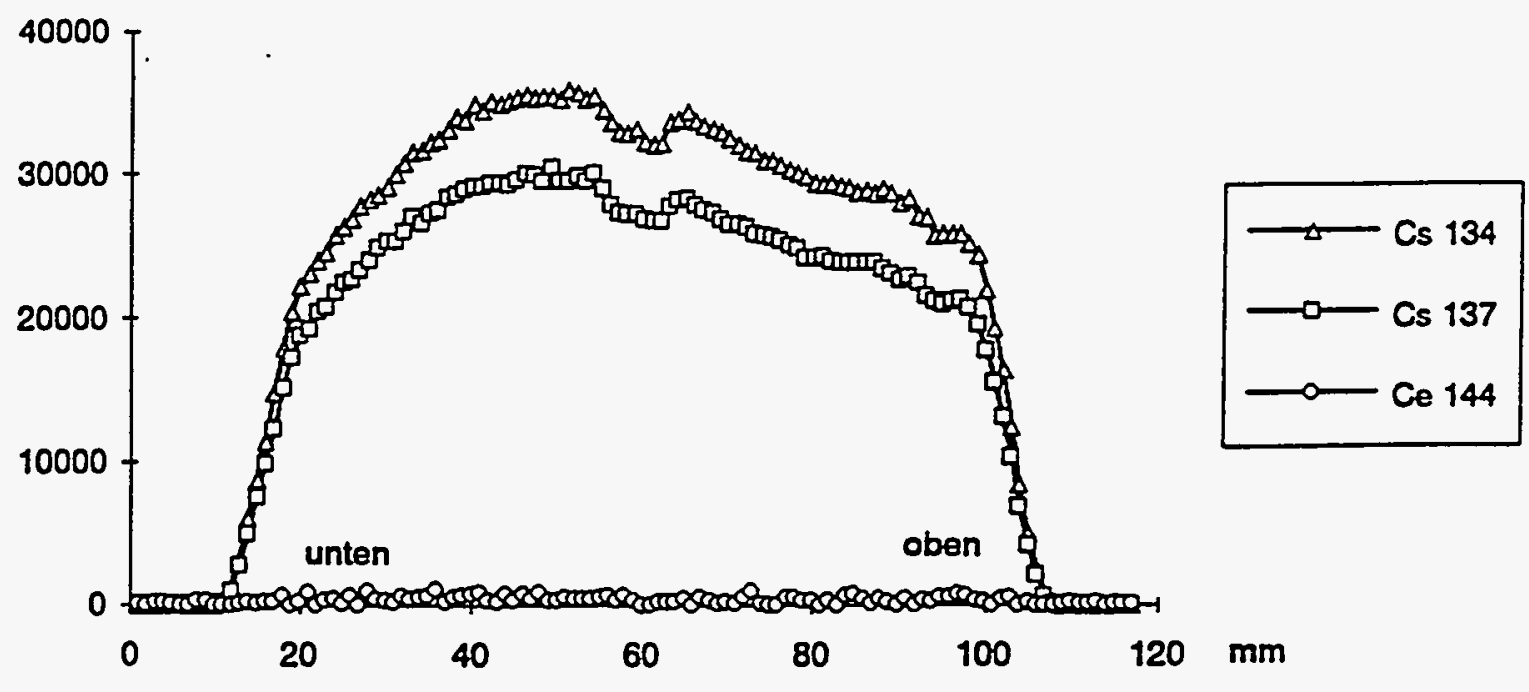

HFR-B1

Abb. $6 a$

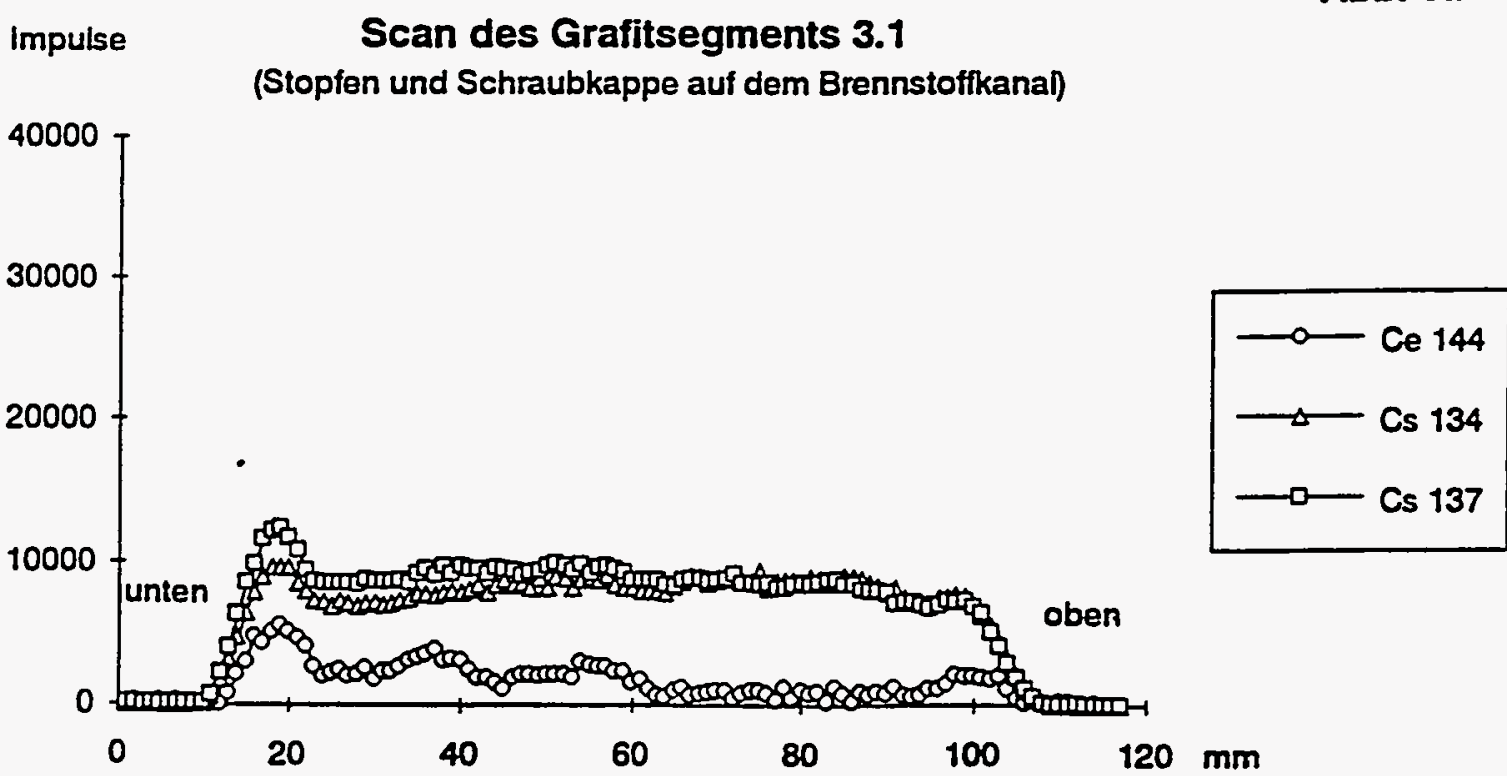

Fig. 4.61 Gamma scan of graphite sectors from hole 1 of capsules 2 and 3 for ${ }^{14} \mathrm{Ce},{ }^{137} \mathrm{Cs}$, and ${ }^{134} \mathrm{Cs}$ Source: Forschungszentrum Julich $\mathrm{GmbH}$, Julich, Germany 
HFR-B1

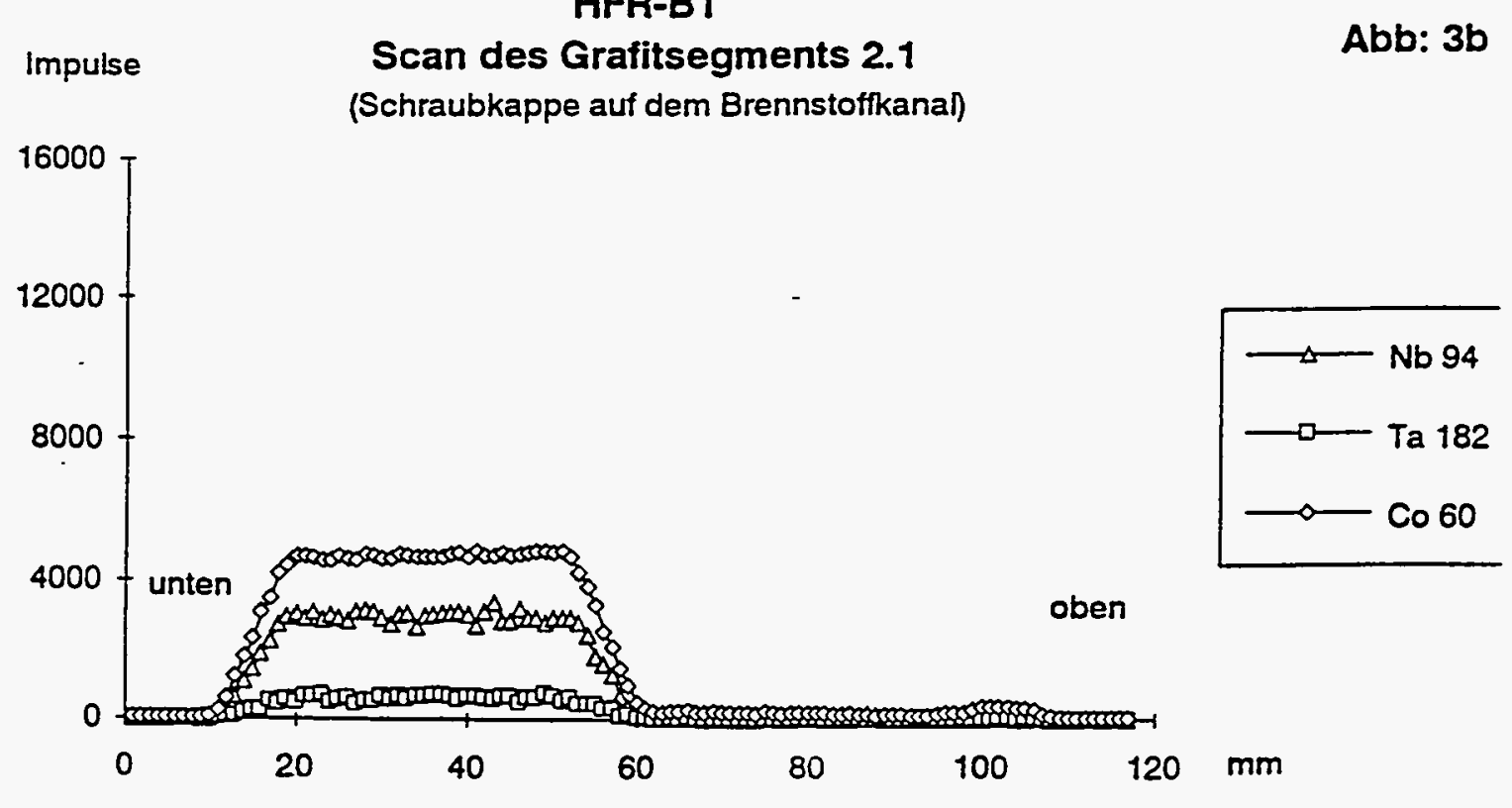

HFR-B1

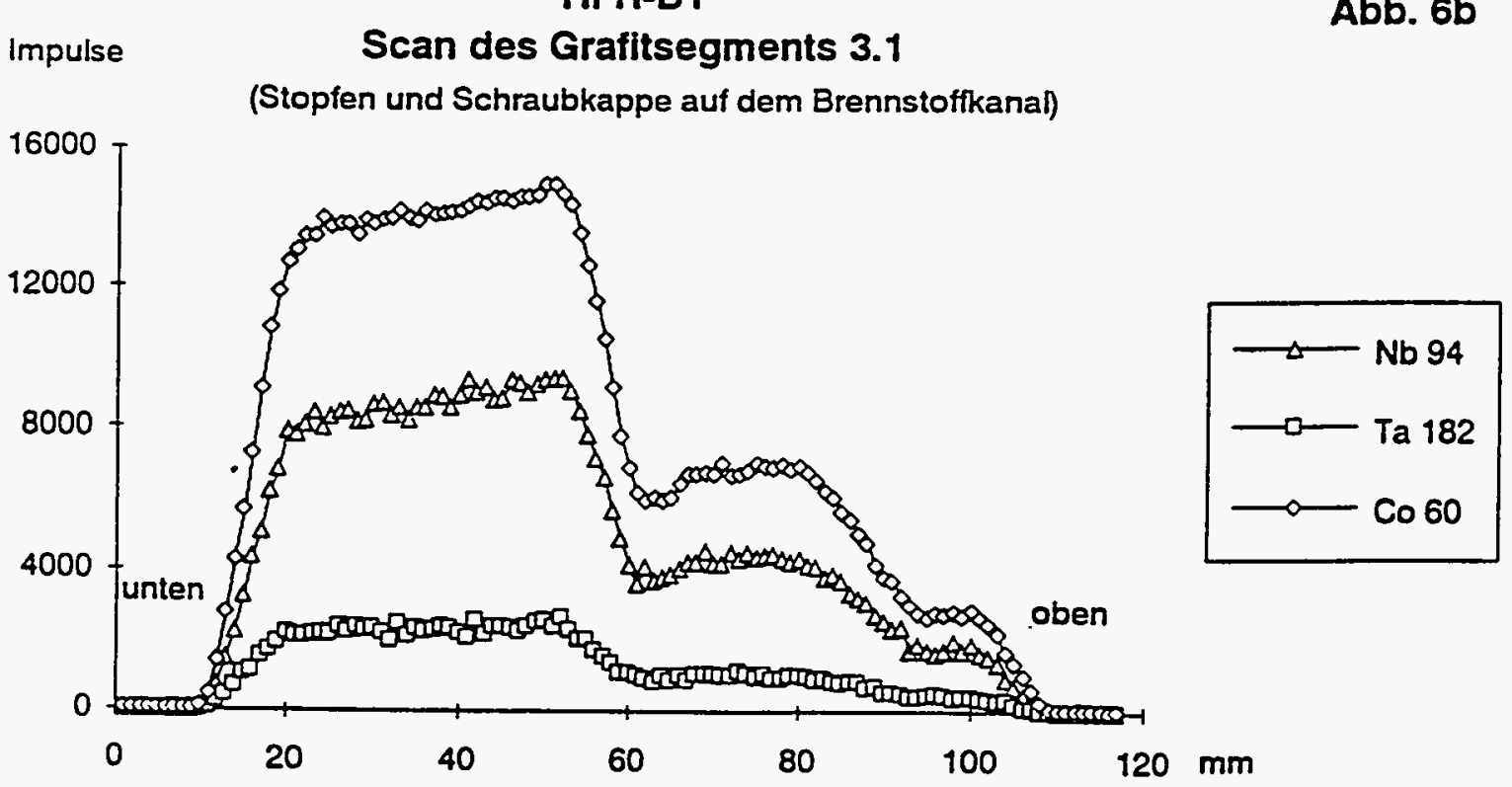

Fig. 4.62 Gamma scan of graphite sectors from hole 1 of capsules 2 and 3 for ${ }^{182} \mathrm{Ta},{ }^{94} \mathrm{Nb}$, and ${ }^{60} \mathrm{Co}$ Source: Forschungszentrum Jalich GmbH, Jalich, Germany 
HFR-B1

Abb.4a

Scan des Grafitsegments 2.2

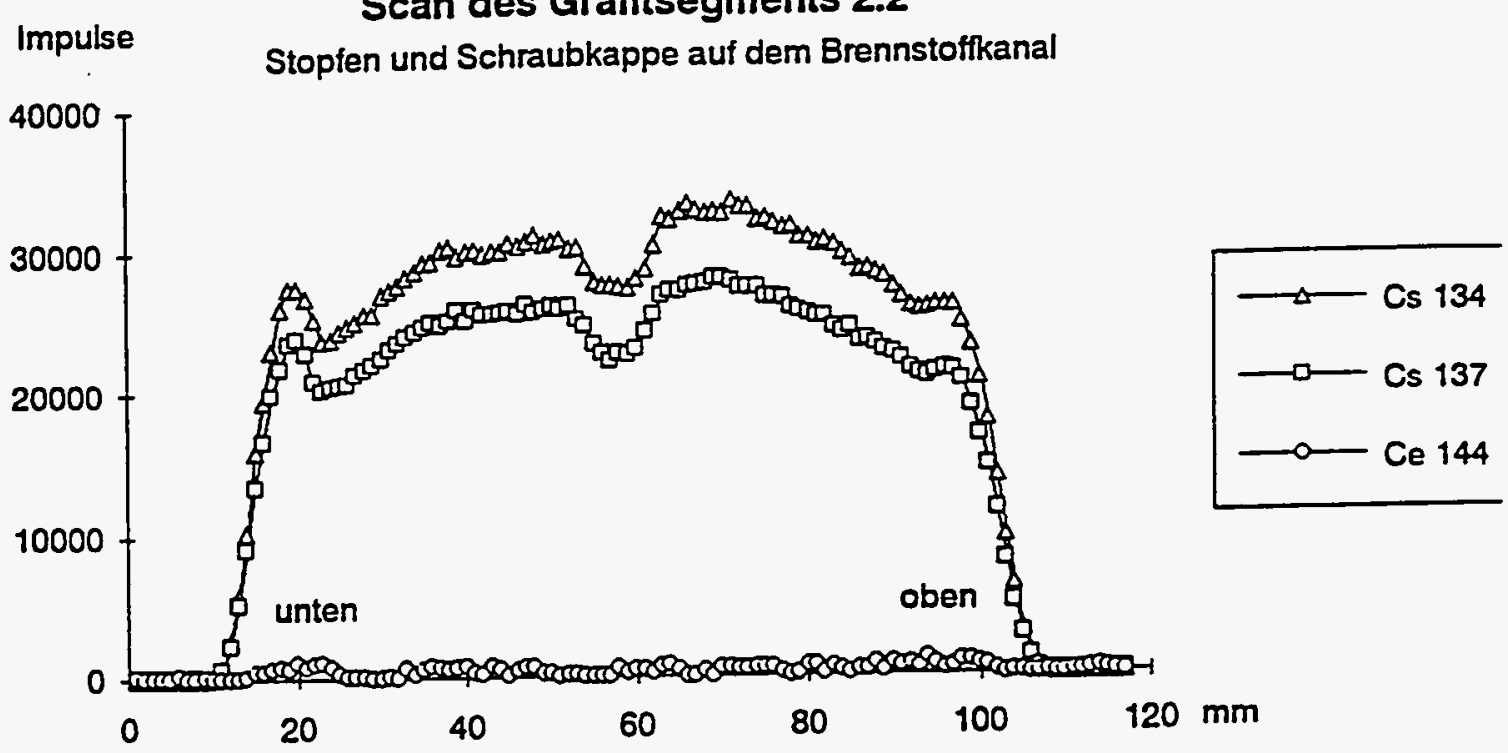

HFR-B1

Abb. 7a

Impulse

Scan des Grafitsegments 3.2

(Stopfen und Schraubkappe auf dem Brennstofikanai)

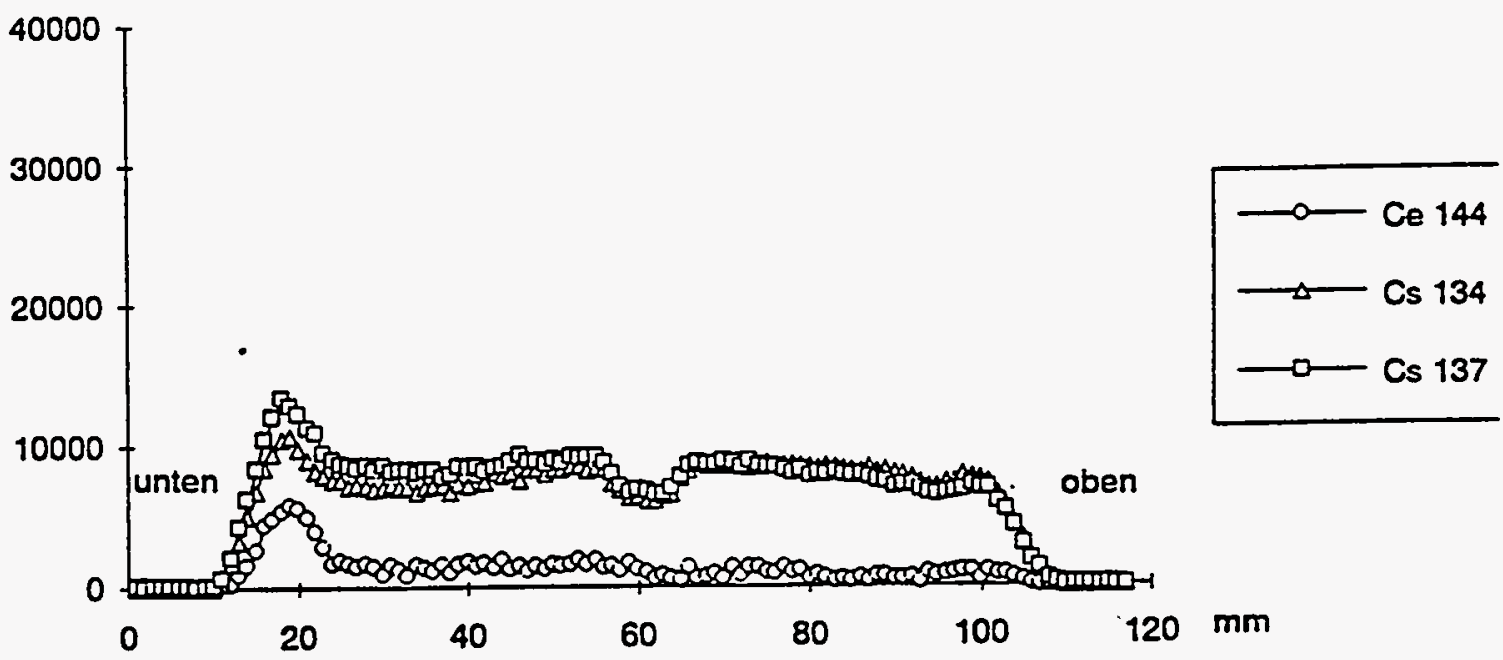

Fig. 4.63 Gamma scan of graphite sectors from hole 2 of capsules 2 and 3 for ${ }^{144} \mathrm{Ce},{ }^{137} \mathrm{Cs}$, and ${ }^{134} \mathrm{Cs}$ Source: Forschungszentrum Julich GmbH, Julich, Germany 
HFR-B1

Abb. $4 b$

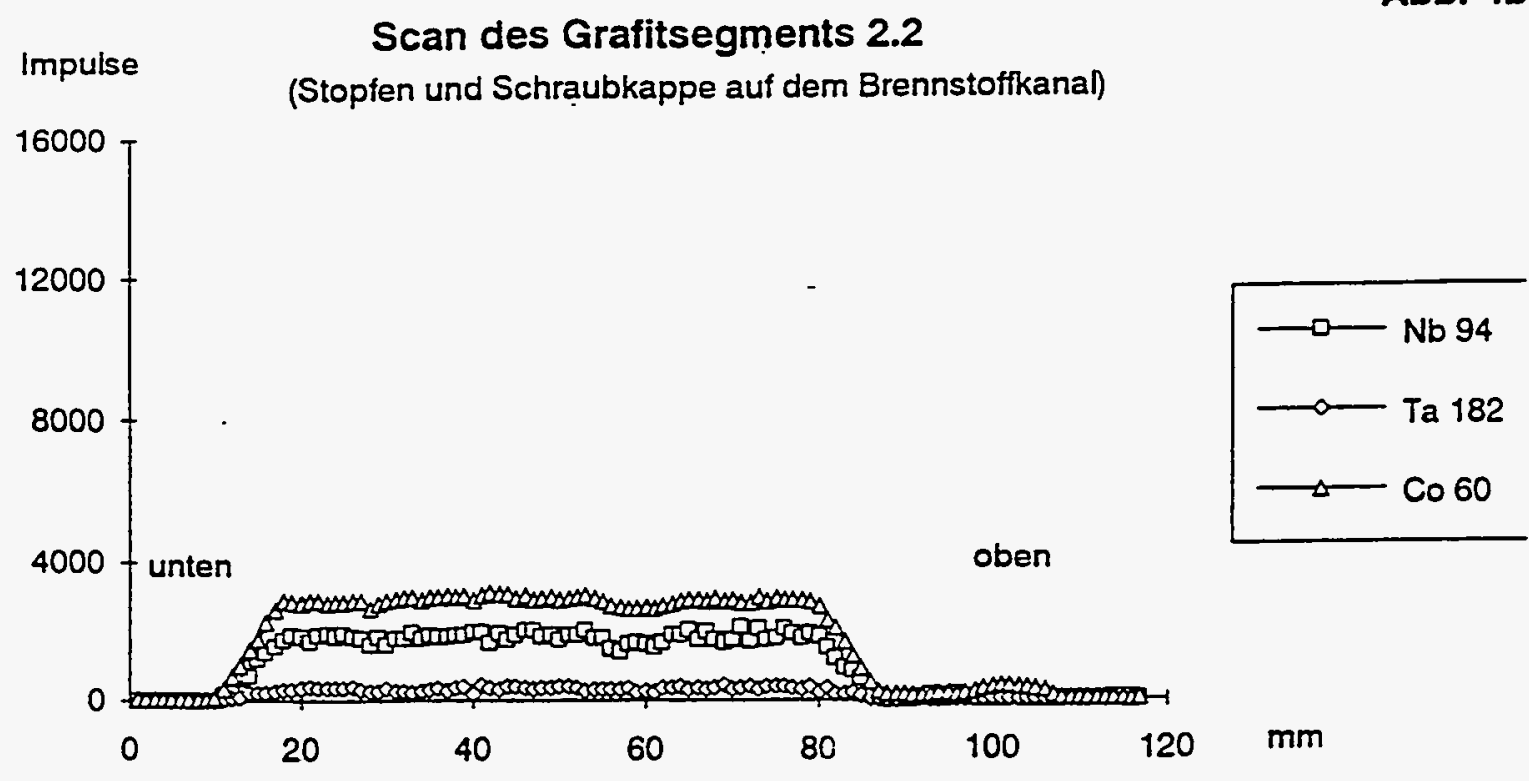

HFR-B1

Abb. $7 b$

Impuise $\quad$ Scan des Grafitsegments 3.2

(Stopfen und Schraubkappe auf dem Brennstoffkanal)

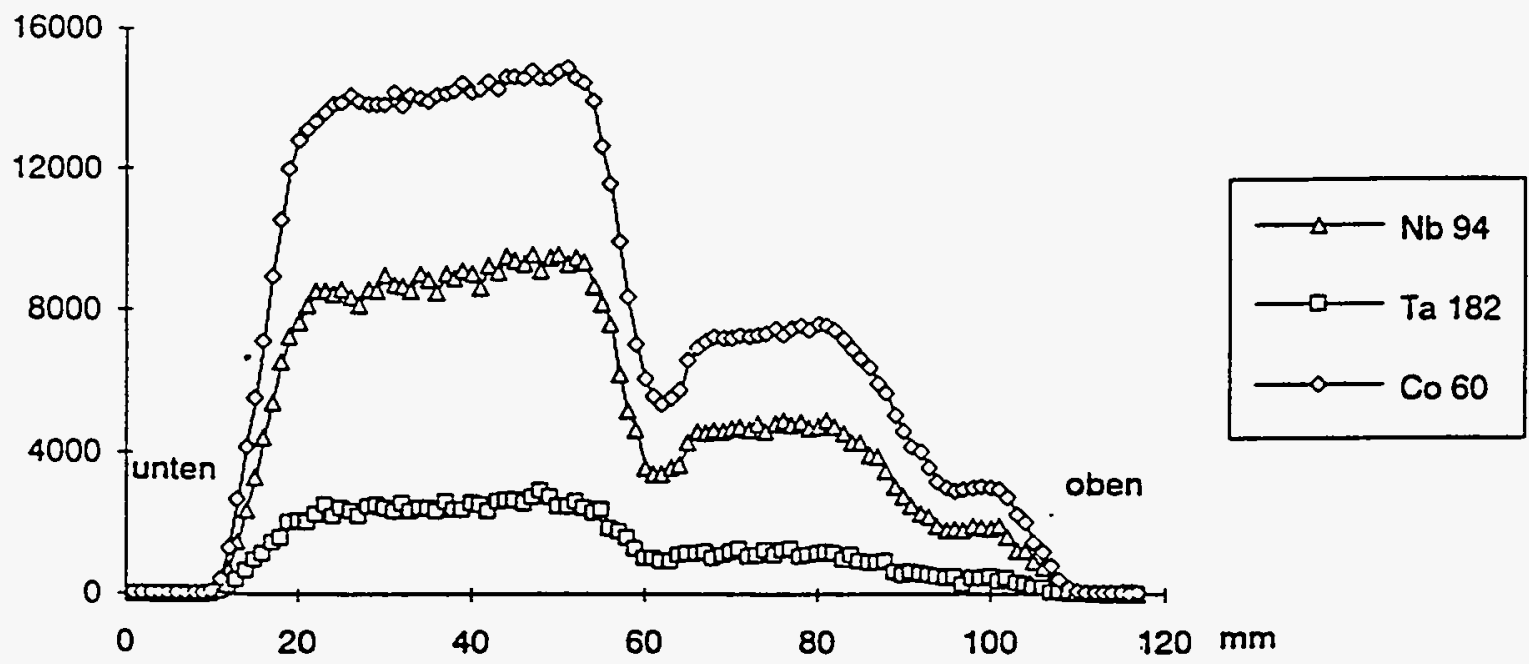

Fig. 4.64 Gamma scan of graphite sectors from hole 2 of capsules 2 and 3 for ${ }^{182} \mathrm{Ta},{ }^{94} \mathrm{Nb}$, and ${ }^{60} \mathrm{Co}$ Source: Forschungszentrum Julich GmbH, Jalich, Germany 
HFR-B1

Abb. 5a

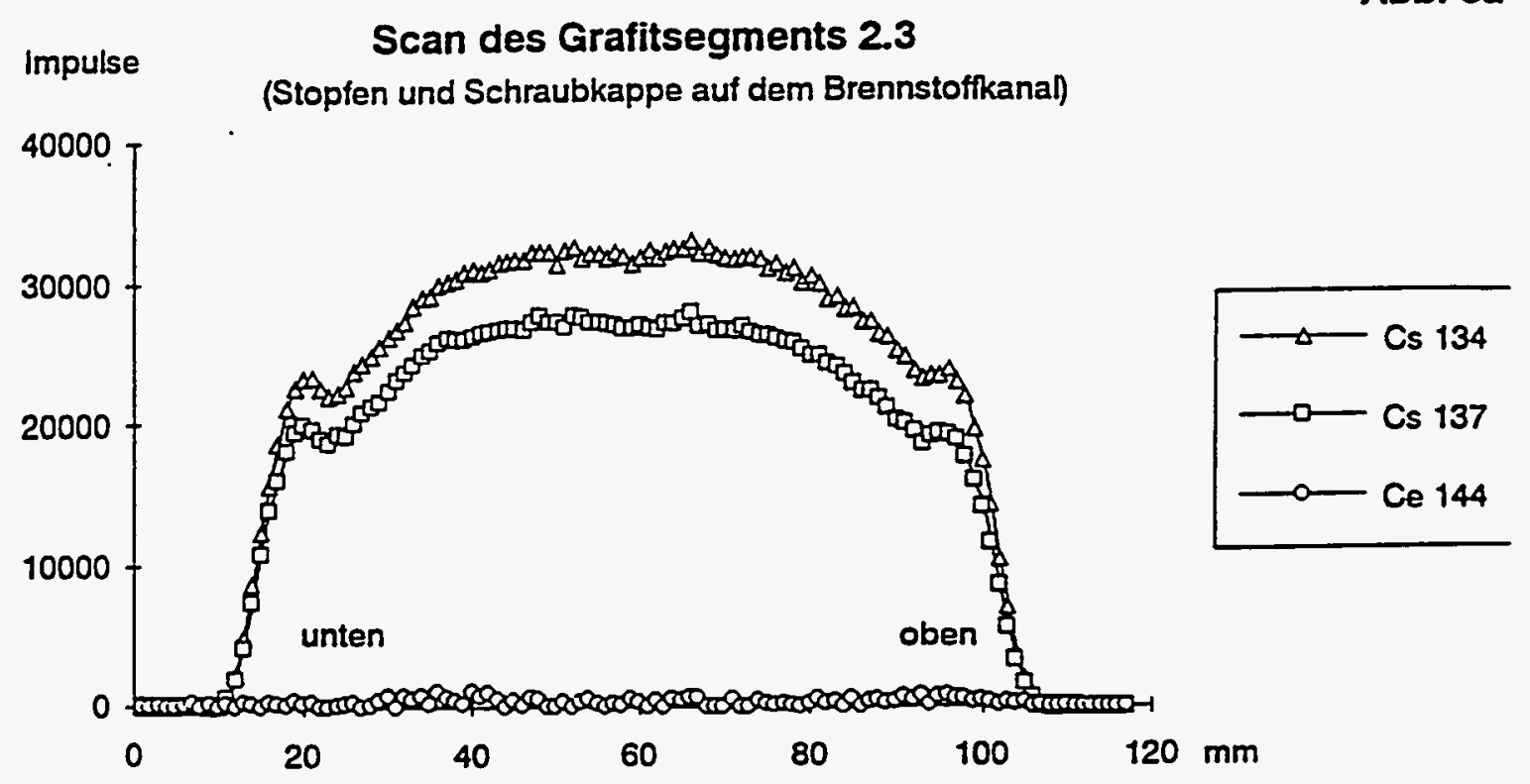

HFR-B1

Impulse Scan des Grafitsegments 3.3

Abb 8a

(Stopfen und Schraubkappe auf dem Brennstofikanal)

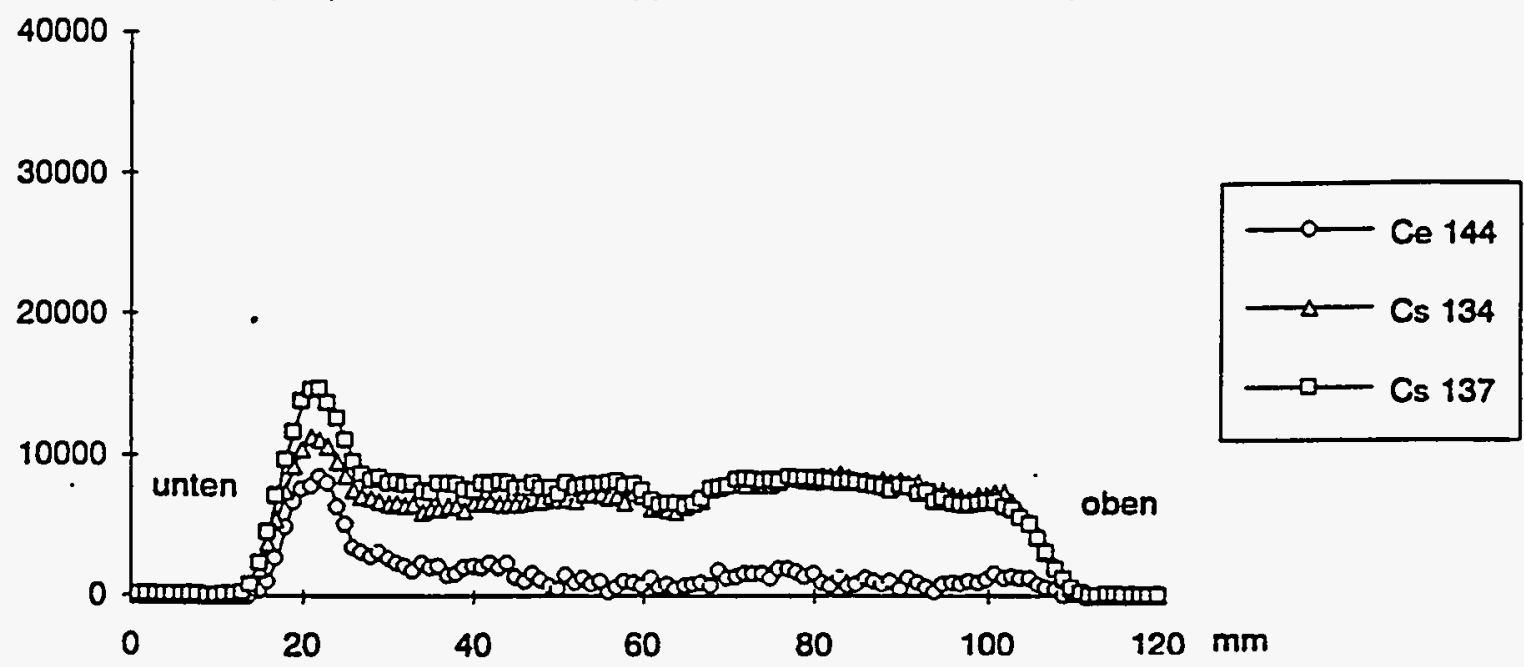

Fig. 4.65 Gamma scan of graphite sectors from hole 3 of capsules 2 and 3 for ${ }^{144} \mathrm{Ce},{ }^{137} \mathrm{Cs}$, and ${ }^{134} \mathrm{Cs}$ Source: Forschungszentrum Julich GmbH, Julich, Germany 
HFR-B1

Abb. 5b

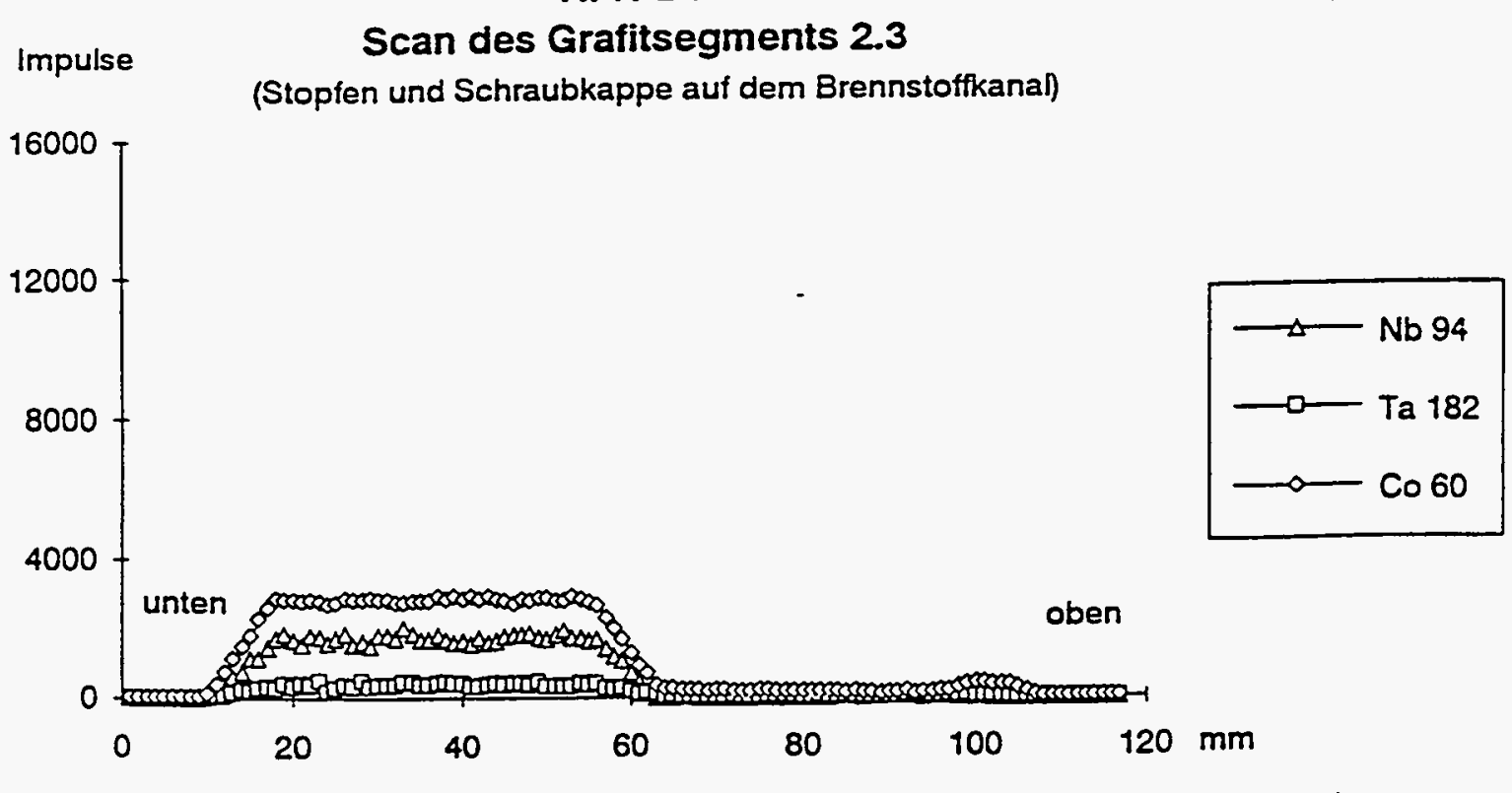

HFR-B1

Impulse

Scan des Grafitsegments $\mathbf{3 . 3}$

Abb. 8b

(Stopfen und Schraubkappe auf dem Brennstoffkanal)

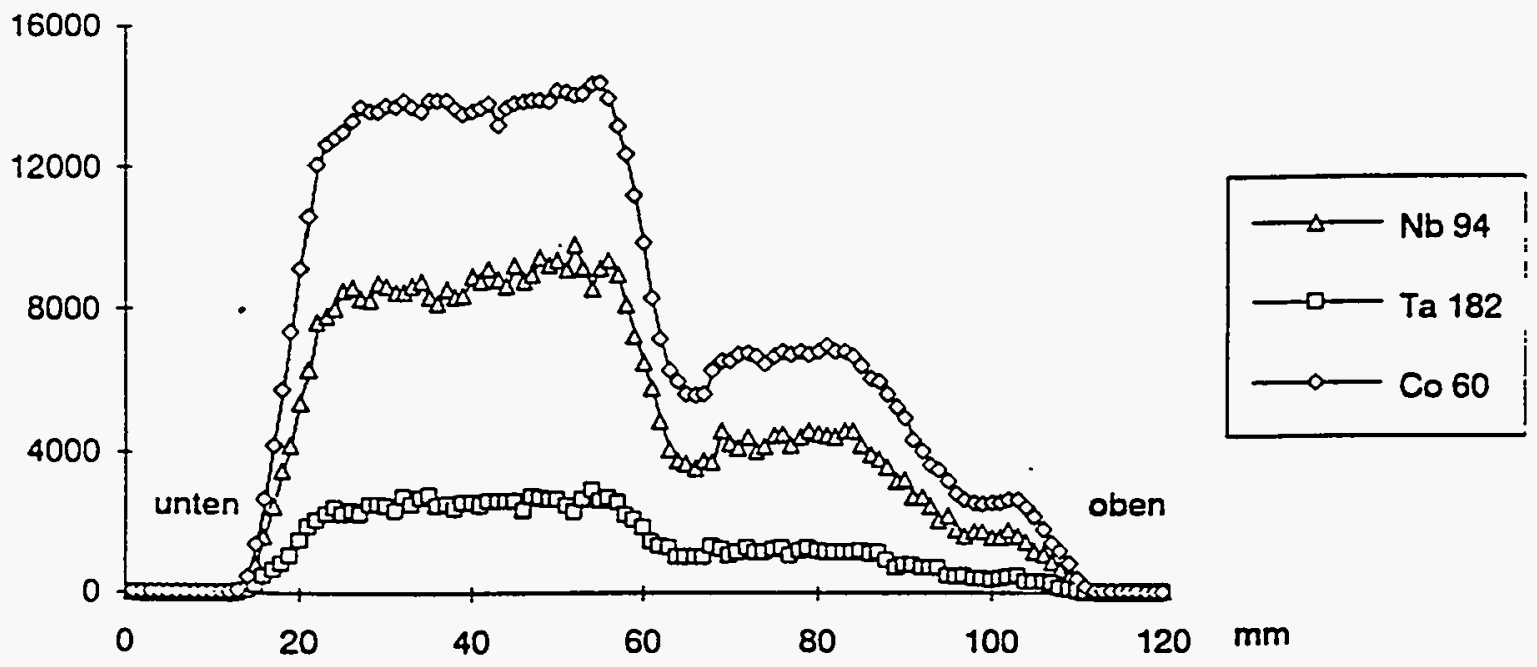

Fig. 4.66 Gamma scan of graphite sectors from hole 3 of capsules 2 and 3 for ${ }^{180} \mathrm{Ta}$, ${ }^{94} \mathrm{Nb}$, and ${ }^{60} \mathrm{Co}$ Source: Forschungszentrum Julich GmbH, Julich, Germany 
${ }^{234} \mathrm{Cs} /{ }^{137} \mathrm{Cs}$ is expected to be less in the oxidized graphite of capsule 3 than in the unoxidized graphite of capsule 2. These deductions are consistent with the gamma scan results. The water vapor can also attack the metal components in such a way that the reaction products become mobile and then move into the graphite; this would happen to a greater extent in capsule 3 than in capsule 2; this is observed for reaction products involving ${ }^{60} \mathrm{Co},{ }^{91} \mathrm{Nb}$, and ${ }^{182} \mathrm{Ta}$.

The gamma scans also illlustrate that the cesium activity in the graphite from capsule 2 is far greater than the cerium activity. This reflecte the known, greater retentivity of cerium than of cesium, in this instance, by the fuel (UCO) in particles with exposed kernels. The reduced cesium to cerium activity ratio in the graphite from capsule 3 as compared to capsule 2 is thought to result from a combination of factors involving the relative effects of water vapor in inducing the release of cerium and cesium from the fuel and the reduced retentivity or increased diffusivity of cerium and cesium on the graphite surfaces. Note that the release of cerium fom UCO fuel is much smaller than that of cesium in the absence of water vapor but comparable to that of cesium in the presence of water vapor. The diffusivity in graphite of cerium is smaller than that of cesium in the absence of water vapor; comparative data are not available under conditions involving water vapor.

\subsubsection{Gamma Counting of Graphite Sectors}

\subsubsection{Apparatus}

The apparatus is the same as described in Sect. 4.3.3.1. The components of the apparatus are identified in Table 4.13.

\subsubsection{Measurements}

The cylindrical sector halves with plugs in the bottom and screws in the top of the fuel holes stood during the measurements on a slowly rotating table. The gamma radiation passed through a double collimator and encountered the germanium planar detector. The impulses produced in the detector were processed as before (see Sect. 4.3.3.2).

The calibration of the measurement facility was made with an AVR fuel element whose ${ }^{137} \mathrm{Cs}$ inventory had been determined with a standard from the Buchler firm. For the determination of the self absorption in the sectors, a graphic cylinder with the same cross sectional surface was taken as the basis.

\subsubsection{Results}

The results are presented in Tables 4.20 and 4.21. In addition, the inventories of ${ }^{137} \mathrm{Cs}$ and ${ }^{134} \mathrm{Cs}$ are graphically displayed in Figs. 4.67, 4.68, and 4.69. In Tables 4.20 and 4.21, the identification of the sector halves are indicated by the sequence $x . y . p$ where $x$ is the capsule number, $y$, is the fuel hole number and $\mathrm{p}$, when included in the sequence, is the original position of the sector half being $o$ for the upper half and $u$ for the lower half. As in Tables 4.20 and 4.21, there are identified six sectors halves and three sectors per capsule. Figs. 4.67, 4.68, and 4.69 reflect these identifications as the inventories (Bq) are given for the six sector halves for both capsules.

As the gamma scans indicated (see Sect. 4.4.2.3), the cesium activities in capsule 2 are significantly larger than those in capsule 3. As determined from Figs. 4.67, 4.68, and 4.69, the mean ratio of ${ }^{137} \mathrm{Cs}$ in capsule 2 to that in capsule 3 is 3.0 and that of ${ }^{134} \mathrm{Cs}$ is 3.8. Furthermore, the mean ratio of ${ }^{137} \mathrm{Cs}$ for the upper sector halves in capsule 2 to that in capsule 3 is 3.3 whereas the mean ratio of ${ }^{137} \mathrm{Cs}$ for the lower sector haives in capsule 2 to that in capsule 3 is 2.6. The ratios of the ${ }^{137} \mathrm{Cs}$ inventories in the upper as opposed to the lower halves of the sectors are significantly different as the standard 
Tabie 4.20 The inventory in the graphite cylindrical sector from capsule 2.

The activity (Bq) has been corrected to reactor shutdown.

Source: Forschungszentrum Jalich GmbH, Jalich, Germany

\begin{tabular}{|c|c|c|c|c|c|}
\hline Segment Nr. & Co 60 & Cs 134 & Cs 137 & Nb 94 & Ta 182 \\
\hline $\begin{array}{l}2.10 \\
2.10\end{array}$ & $\begin{array}{l}4,18 E+06 \\
1,92 E+08\end{array}$ & $\begin{array}{l}7,98 E+08 \\
8,65 E+08\end{array}$ & $\begin{array}{l}4,34 E+08 \\
4,64 E+08\end{array}$ & $4,27 E+05$ & $5,71 E+09$ \\
\hline 2.1 & $1,96 E+08$ & $1,66 E+09$ & $8,98 E+08$ & $4,27 E+05$ & $5,71 E+09$ \\
\hline $\begin{array}{l}2.20 \\
2.2 u\end{array}$ & $\begin{array}{l}7,03 E+07 \\
1,22 E+08\end{array}$ & $\begin{array}{l}8,05 E+08 \\
7,68 E+08\end{array}$ & $\begin{array}{l}4,31 E+08 \\
4,26 E+08\end{array}$ & $\begin{array}{l}1,58 E+05 \\
2,66 E+05\end{array}$ & $\begin{array}{l}2,48 E+09 \\
3,77 E+09\end{array}$ \\
\hline 2.2 & $1,92 E+08$ & $1,57 E+09$ & $8,57 E+08$ & $4,24 E+05$ & $6,25 E+09$ \\
\hline $\begin{array}{l}2.30 \\
2.3 u\end{array}$ & $\begin{array}{l}4,07 E+06 \\
1,15 E+08\end{array}$ & $\begin{array}{l}7,35 E+08 \\
8,00 E+08\end{array}$ & $\begin{array}{l}4,09 E+08 \\
4,37 E+08\end{array}$ & $2,66 E+05$ & $2,69 E+09$ \\
\hline 2.3 & $1,19 E+08$ & $1,54 E+09$ & $8,46 E+08$ & $2,66 E+05$ & $2,69 E+09$ \\
\hline Graf.-Kōrper 2 & $5,08 E+08$ & $4,77 E+09$ & $2,60 E+09$ & $1,12 E+06$ & $1,47 E+10$ \\
\hline
\end{tabular}

Table 4.21 The inventory in the graphite cylindrical sector from capsule 3. The activity $(\mathrm{Bq})$ has been corrected to reactor shutdown.

Source: Forschungszentrum Julich GmbH, Julich, Germany

\begin{tabular}{|c|c|c|c|c|c|}
\hline Sogment Nr. & Co 60 & Cs 134 & Cs 137 & Nb 94 & Ta 182 \\
\hline $\begin{array}{l}3.10 \\
3.14\end{array}$ & $\begin{array}{l}1,95 E+08 \\
5,58 E+0 B\end{array}$ & $\begin{array}{l}2,10 E+08 \\
2,41 E+08\end{array}$ & $\begin{array}{l}1,34 E+08 \\
1,77 E+08\end{array}$ & $\begin{array}{l}4,58 E+05 \\
1,26 E+06\end{array}$ & $\begin{array}{l}6,47 E+09 \\
2,12 E+10\end{array}$ \\
\hline 3.1 & $7,53 E+08$ & $4,51 E+08$ & $3,11 E+08$ & $1,71 E+06$ & $2,77 E+10$ \\
\hline $\begin{array}{l}3.20 \\
3.2 u\end{array}$ & $\begin{array}{l}2,18 E+08 \\
5,54 E+08\end{array}$ & $\begin{array}{l}2,19 E+08 \\
2,28 E+08\end{array}$ & $\begin{array}{l}1,37 E+08 \\
1,70 E+08\end{array}$ & $\begin{array}{l}5,07 E+05 \\
1,33 E+06\end{array}$ & $\begin{array}{l}9,27 E+09 \\
2.06 E+10\end{array}$ \\
\hline 3.2 & $7,72 E+08$ & $4,47 E+08$ & $3,07 E+08$ & $1,84 E+06$ & $2,99 E+10$ \\
\hline 3.30 & $1,84 E+08$ & $1,93 E+0 B$ & $1,26 E+08$ & $4,50 E+05$ & $7,54 E+09$ \\
\hline $3.3 \mathrm{u}$ & $5,44 E+08$ & $2,06 E+0 B$ & $1,61 E+08$ & $1,24 E+06$ & $2,07 E+10$ \\
\hline 3.3 & & & $2,87 E+08$ & $1,69 \mathrm{E}+06$ & $2,82 E+10$ \\
\hline Graf.-Körpor 3 & $2,25 E+09$ & $1,30 E+09$ & $9,05 E+08$ & $5,24 E+06$ & $8,58 E+10$ \\
\hline
\end{tabular}


Fig. 4.67 The Activities of ${ }^{137} \mathrm{Cs}$ and ${ }^{134} \mathrm{Cs}$ in the graphite sectors 2.1 and 3.1 Source: Forschungszentrum Jalich GmbH, Jalich, Germany

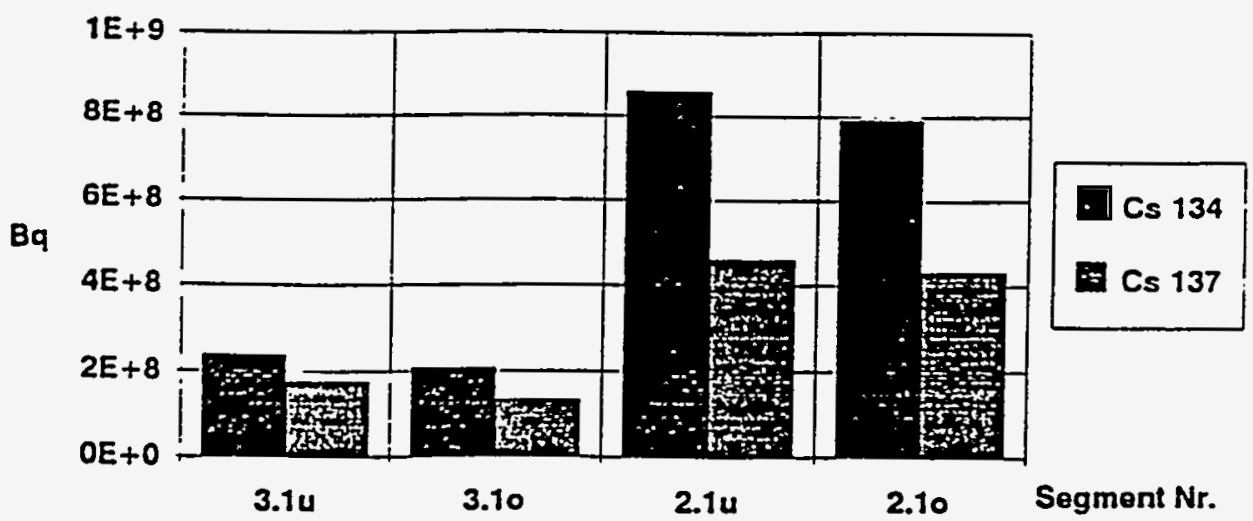

Fig. 4.68 The Activities of ${ }^{137} \mathrm{Cs}$ and ${ }^{134} \mathrm{Cs}$ in the graphite sectors 2.2 and 3.2 Source: Forschungszentrum Julich GmbH, Julich, Germany

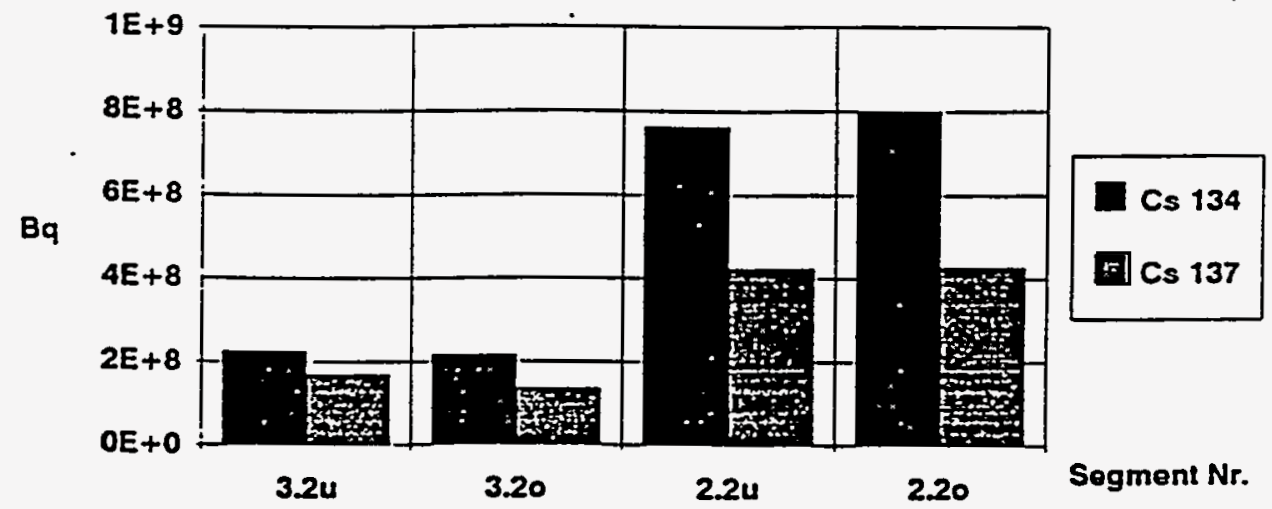

Fig. 4.69 The Activities of ${ }^{137} \mathrm{Cs}$ and ${ }^{234} \mathrm{Cs}$ in the graphite sectors 2.3 and 3.3 Source: Forschungszentrum Julich $\mathrm{GmbH}$, Julich, Germany

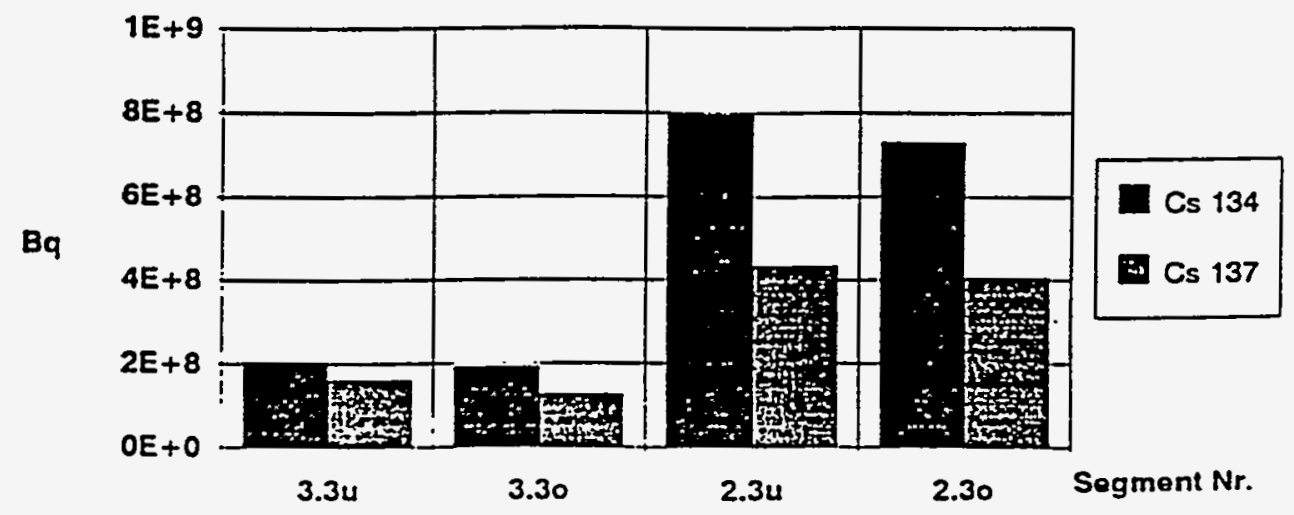


deviation in both cases is only $2 \%$. Such a difference is not found for ${ }^{134} \mathrm{Cs}$ where the corresponding ratios are 3.8 are 3.7 , respectively. In the latter cases, the standard deviations are as large as $7 \%$.

The results of an error analysis for the inventory is given in Table 4.22

\subsubsection{Gamma Counting of Smaller Graphite Components}

The plugs and screws, individual graphite cylinders and sleeves and individual particle trays were gamma counted.

\subsubsection{Measurement}

The smaller graphite components were measured for average activity levels outside the hot cells on a measurement plate. The plugs, screws, the graphite cylinders and sleeves as well as the particle trays were measured in aluminum cans with a $0.3 \mathrm{~mm}$ wall thickness. The detector was house in a lead device in order to shield against background radiation. The measurement distance was 30,50 , or 80 $\mathrm{cm}$ and the measurement time was between 5000 and $20000 \mathrm{~s}$ depending on the activity of the sample. See Table 4.23 for the other conditions of the measurements.

The calibration measurement was done with an ${ }^{154} \mathrm{Eu}$ standard, preparation number BV938, from the firm Amersham Buchler. Its activity on 1.12 .89 amounted to $407.1 \mathrm{kBq} \pm 3 \%$.

For every measured object, a gamma spectrum was taken with the Canberra 35 plus multichannel analyzer and the results evaluated in a PDP micro 11 computer with the analysis software Spectran F. These results were transferred to a PC and with the help of the spreadsheet program Excel, the self absorption was taken into account.

\subsubsection{Resuits}

In terms of the activity $(\mathrm{Bq})$ of selected isotopes, the inventories for the graphite plugs and screws are given in Tables 4.24 and 4.25 for capsules 2 and 3, respectively, for the graphite cylinders and sleeves are given in Tables 4.26 and 4.27 for capsules 2 and 3 , respectively, and for the particles trays are given in Table 4.28 for capsules 2 and 3. The graphical presentations of these data are given in Fig. 4.70 and 4.71 for the plugs and screws for capsules 2 and 3 respectively, in Figs. 4.72 and 4.73 for the graphite cylinders and sleeves from capsules 2 and 3, respectively and in Figs. 4.74 and 4.75 for the particle trays from capsules 2 and 3 , respectively. The isotopes measured vary for different graphite components and capsules; see Tables 4.24 through 4.28

\subsubsection{Cesium Distribution Between Fuel Compacts and the Graphite}

An overview of the distribution of ${ }^{137} \mathrm{Cs}$ and ${ }^{134} \mathrm{Cs}$ between the fuel compacts and the graphite in the fuel element was prepared. In this determination, the contents of the central hole were not considered, i.e., the particle trays with contained fuel particles and the graphite crucible containing the niobium-encapsulated fuel particles. The activities of the graphite cylinders and sleeves from the coolant holes which were not gamma counted were calculated using the average values for those that were. As was evident from the totality of measured activities, as shown below, the graphite sectors contained between 97 and $98 \%$ of the cesium isotopes found among graphite components; therefore, the omissions and approximations just stated did not introduce a significant error into the determination of cesium distribution. 
Table 4.22 Error Analysis

Source: Forschungszentrum Julich GmbH, Julich, Germany

As the essential sources of error were taken:

$\Delta \mathrm{F}-2.0 \%$ the error in the peak area determination for the Spectran $\mathrm{F}$

$\Delta t_{m}=1 \%$ error in the total time correction

$\Delta e-5 \%$ error of the calibration including the calibration standard

$\Delta x \sim 8 \%$ error in the determination of the self absorption of the calibration standard and of the graphite sectors

The maximum error is $\leq 16 \%$ This analysis is valid for ${ }^{137} \mathrm{Cs}$; the results for the other nuclides can involve greater errors. 
Table 4.23 Measurement configuration Source: Forschungszentrum Julich $\mathrm{GmbH}$, Julich, Germany

Measurement distance: $80,50,30 \mathrm{~cm}$

Measurement time: $\quad 5000 \mathrm{~s}$ to $20000 \mathrm{~s}$

Detector

DSG Typ PGP 1516 SNG-167 planar

Voltage $-3000 \mathrm{~V}$

Relative Efficiency

$3.5 \%$

Preamplifier

DSG $51 \mathrm{P}$

Main Amplifier

Canberra Model 2011

High Voltage Apparatus

Ortec Model 459

Multichannel analyzer

Canberra 35 plus

Computer

PDP-Micro 11

Gamma analysis and evaluation system Canberra Spectran F 
Table 4.24 The inventories $(\mathrm{Bq})$ of the plugs and screw caps from capsule 2 for ${ }^{125} \mathrm{Sb},{ }^{237} \mathrm{Cs},{ }^{134} \mathrm{Cs}$, ${ }^{1100} \mathrm{Ag}$, and ${ }^{60} \mathrm{Co}$. Source: Forschungszentrum Jalich $\mathrm{GmbH}$, Jalich, Germany

\begin{tabular}{|c|c|c|c|c|c|c|c|}
\hline & Co 60 & Cs 134 & Cs 137 & Ag $110 m$ & Sb 125 & Co 144 & Ru 106 \\
\hline 2.1 Cap & $2,52 E+05$ & $3,20 E+07$ & $1,67 E+07$ & $-1,10 E+06$ & $4,86 E+05$ & & \\
\hline $2.2 \mathrm{Cap}$ & $2,43 E+05$ & $3,17 E+07$ & $1,66 E+07$ & $1,17 E+06$ & $3,94 E+05$ & & \\
\hline 2.3 Cap & $-2,31 E+05$ & $2,90 E+07$ & $1,51 E+07$ & $1,16 E+06$ & $3,24 E+05$ & & \\
\hline 2.4 Cap & $5,96 E+05$ & $4,06 E+06$ & $2,06 E+06$ & & & & \\
\hline 2.5 Cap & $2,84 E+05$ & $4,37 E+06$ & $2,20 E+06$ & & & & \\
\hline 2.6 Cap & $1,97 E+05$ & $4,29 E+06$ & $2,16 E+06$ & & & & \\
\hline 2.7 Cap & $3,39 E+05$ & $3,81 E+06$ & $1,93 E+06$ & & & & \\
\hline 2.1 Plug & $3,00 E+05$ & $2,94 E+07$ & $1,60 E+07$ & $1,20 E+06$ & $8,21 E+05$ & & \\
\hline 2.2 Plug & $2,74 E+05$ & $3,38 E+07$ & $1,86 E+07$ & $1,63 E+06$ & $5,57 E+05$ & & \\
\hline 2.3 Plug & $2 ; 28 E+05$ & $2,41 E+07$ & $1,33 E+07$ & $9,47 E+05$ & $5,33 E+05$ & & \\
\hline 2.4 Plug & $3,33 E+05$ & $9,28 E+05$ & $4,76 E+05$ & & & & \\
\hline 2.5 Plug & $9,16 E+05$ & $9,88 E+05$ & $5,05 E+05$ & & & & \\
\hline 2.6 Plug & $3,88 E+05$ & $1,19 E+06$ & $6,18 E+05$ & & & & \\
\hline 2.7 Plug & $2,62 E+05$ & $5,84 E+05$ & $3,04 E+05$ & & & & \\
\hline
\end{tabular}

Table 4.25 The inventories (Bq) of the plugs and screw caps from capsule 3 for ${ }^{144} \mathrm{Ce},{ }^{137} \mathrm{Cs},{ }^{134} \mathrm{Cs}$, ${ }^{106} \mathrm{Ru}$, and ${ }^{60} \mathrm{Co}$. Source: Forschungszentrum Jalich $\mathrm{GmbH}$, Julich, Germany

\begin{tabular}{|c|c|c|c|c|c|c|c|}
\hline & Co 60 & Cs 134 & Cs 137 & Ag $110 \mathrm{~m}$ & Sb 125 & Co 144 & Ru 106 \\
\hline 3.1 Cap & $3,61 E+05$ & $9,99 E+06$ & $6,19 E+06$ & & & $1,08 E+07$ & $2,17 E+06$ \\
\hline 3.2 Cap & $3,20 E+05$ & $9,57 E+06$ & $5,66 \mathrm{E}+06$ & & & $2,72 E+06$ & \\
\hline 3.3 Cap & $3,09 E+05$ & $8,87 E+06$ & $5,36 E+06$ & & & $4,58 E+06$ & \\
\hline 3.4 Cap & $2,43 E+05$ & $9,41 E+04$ & $6,23 E+04$ & & & $1,32 E+04$ & \\
\hline 3.5 Cap & $3,03 E+05$ & $9,25 E+05$ & $5,19 E+05$ & & & $6,59 E+04$ & \\
\hline 3.6 Cap & $4,51 E+05$ & $7,19 E+05$ & $4,08 E+05$ & & & & \\
\hline 3.7 Cap & $2,38 E+05$ & $4,14 E+05$ & $2,32 E+05$ & & & & \\
\hline 3.1 Plug & $1,45 E+05$ & $8,84 E+06$ & $7,67 E+06$ & & & $2,77 E+07$ & $9,81 E+06$ \\
\hline 3.2 Plug & $1,69 E+05$ & $1,08 E+07$ & $9,25 E+06$ & & & $3,98 E+07$ & $1,30 E+07$ \\
\hline 3.3 Plug & $2,43 E+05$ & $1,22 E+07$ & $1,07 E+07$ & & & $4,27 E+07$ & $1,41 E+07$ \\
\hline 3.4 Plug & $1,70 E+05$ & $8,29 E+05$ & $4,65 E+05$ & & & & \\
\hline 3.5 Plug & $2,66 E+05$ & $8,47 E+04$ & $5,26 E+04$ & & & & \\
\hline 3.6 Plug & $2,84 E+05$ & $8,55 E+04$ & $5,24 E+04$ & & & & \\
\hline 3.7 Plug & $4,56 E+05$ & $8,06 E+04$ & $5,34 E+04$ & & & & \\
\hline
\end{tabular}


Table 4.26 The inventories $(\mathrm{Bq})$ of selected graphite cylinders, inert compacts and sleeves from capsule 2 for ${ }^{154} \mathrm{Eu},{ }^{137} \mathrm{Cs},{ }^{134} \mathrm{Cs},{ }^{60} \mathrm{CO}$ and ${ }^{54} \mathrm{Mn}$. Source: Forschungszentrum Jalich GmbH, Julich, Germany

\begin{tabular}{|c|c|c|c|c|c|c|}
\hline & Co 60 & Cs 134 & Cs 137 & Eu 154 & Mn 54 & Ba 133 \\
\hline 2.4.1 a & $3,56 \mathrm{E}+06$ & $6,12 E+06$ & $3,21 \bar{E}+06$ & & $2,34 E+05$ & \\
\hline $2.4 .1 \mathrm{~b}$ & $6,98 E+05$ & $3,42 E+06$ & $1,76 E+06$ & & $4,58 E+04$ & \\
\hline 2.4.2 & $3,03 E+05$ & $7,30 E+06$ & $3,79 E+06$ & & & \\
\hline 2.4 .5 & $4,79 E+06$ & $7,18 \mathrm{E}+06$ & $3,67 E+06$ & & & \\
\hline $2.5 .1 \mathrm{a}$ & $5,11 E+06$ & $6,43 E+06$ & $3,34 E+06$ & & $4,36 E+05$ & \\
\hline $2.5 .1 \mathrm{~b}$ & $8,75 E+05$ & $3,64 E+06$ & $1,86 E+06$ & & $8,67 E+04$ & \\
\hline 2.5 .2 & $2,35 E+05$ & $5,55 E+06$ & $2,79 E+06$ & & & \\
\hline 2.5.5 & $5,40 E+06$ & $1,19 E+07$ & $6,10 E+06$ & & & \\
\hline $2.6 .1 \mathrm{~b}$ & $3,65 E+05$ & $3,81 E+06$ & $1,94 E+06$ & & & \\
\hline $2.6 .2 \mathrm{a}$ & $2,51 E+06$ & $1,03 E+07$ & $5,37 E+06$ & $1,51 E+05$ & $1,59 E+05$ & \\
\hline $2.6 .2 \mathrm{~b}$ & $1,03 E+06$ & $6,13 E+06$ & $3,20 E+06$ & & & \\
\hline $2.6 .3 \mathrm{~b}$ & $6,08 E+05$ & $5,66 E+06$ & $2,93 E-06$ & & & \\
\hline $2.6 .4 \mathrm{a}$ & $2,84 E+06$ & $7,64 E+06$ & $3,93 E \div 06$ & $1,74 E+05$ & $1,13 E+05$ & \\
\hline $2.6 .4 \mathrm{~b}$ & $4,78 E+05$ & $4,04 E+06$ & $2,11 E-J 6$ & & & \\
\hline
\end{tabular}

Table 4.27 The inventories $(\mathrm{Bg})$ of selected graphite cylinders, inert compacts and sleeves from capsule 3 for ${ }^{254} \mathrm{Eu},{ }^{137} \mathrm{Cs},{ }^{134} \mathrm{Cs},{ }^{133} \mathrm{Ba},{ }^{60} \mathrm{Co}$ and ${ }^{54} \mathrm{Mn}$. Source: Forschungszentrum Julich $\mathrm{GmbH}$, Jalich, Germany

\begin{tabular}{|c|c|c|c|c|c|c|}
\hline & Co 60 & Cs 134 & Cs 137 & Eu 154 & Mn 54 & Ba 133 \\
\hline $3.4 .1 \mathrm{a}$ & $1,73 E+06$ & $9,35 E+05$ & $6,66 E+05$ & $2,34 E+04$ & $1,17 E+05$ & \\
\hline $3.4 .1 \mathrm{~b}$ & $4,88 E+05$ & $5,69 E+05$ & $3,88 E+05$ & & & \\
\hline 3.4 .2 & $2,66 E+05$ & $7,44 E+05$ & $4,98 E+05$ & & & \\
\hline 3.4 .4 & $4,21 E+06$ & $1,83 E+06$ & $1,14 E+06$ & $2,72 E+04$ & & \\
\hline $3.5 .1 \mathrm{a}$ & $1,68 E+06$ & $8,24 E+05$ & $5,77 E+05$ & $2,17 E+04$ & $1,12 E+05$ & \\
\hline 3.5.1 b & $4,81 E+05$ & $4,81 E+05$ & $3,20 E+05$ & & & \\
\hline 3.5 .2 & $3,49 E+05$ & $1,32 E+06$ & $8,00 E+05$ & & & \\
\hline 3.5 .4 & $3,94 E+06$ & $7,98 E+05$ & $5,36 E+05$ & $2,10 E+04$ & & \\
\hline $3.6 .1 \mathrm{~b}$ & $6,50 E+05$ & $1,01 E+06$ & $5,95 E+05$ & & & \\
\hline $3.6 .2 \mathrm{a}$ & $1,26 E+06$ & $2,33 E+06$ & $1,45 E+06$ & $1,68 E+05$ & $1,18 E+05$ & $8,38 E+03$ \\
\hline $3.6 .2 \mathrm{~b}$ & $4,53 E+05$ & $9,71 E+05$ & $6,01 E+05$ & & & \\
\hline $3.6 .3 \mathrm{~b}$ & $6,78 E+05$ & $7,44 E+05$ & $4,83 E+05$ & & & \\
\hline $3.6 .4 \mathrm{a}$ & $1,59 E+06$ & $1,07 E+06$ & $7,33 E+05$ & $1,72 E+05$ & $7,67 E \div 04$ & $7,55 E+03$ \\
\hline $3.6 .4 \mathrm{~b}$ & $4,88 E+05$ & $4,04 E+05$ & $2,69 E+05$ & & & \\
\hline
\end{tabular}


Table 4.28 The inventories (Bq) of the particle trays from capsules 2 and 3 for ${ }^{254} \mathrm{Eu},{ }^{144} \mathrm{Ce},{ }^{137} \mathrm{Cs},{ }^{134} \mathrm{Cs}$, ${ }^{106} \mathrm{Ru}$, and ${ }^{60} \mathrm{Co}$. Coated particles not included. Source: Forschungszentrum Julich $\mathrm{GmbH}$, Jalich, Germany

\begin{tabular}{|c|c|c|c|c|c|c|}
\hline Tray Nr. & Co 144 & Co 60 & Cs 134 & Cs 137 & Eu 154 & Ru 106 \\
\hline $\begin{array}{l}2-3 \\
2-4 \\
2-7 \\
2-8 \\
\\
3-3 \\
3-4 \\
3-7 \\
3-8\end{array}$ & $\begin{array}{c}6,53 E+06 \\
: \\
2,75 E+04 \\
2,63 E+04\end{array}$ & $\begin{array}{l}1,78 E+05 \\
1,21 E+05 \\
1,31 E+05 \\
1,18 E+05 \\
9,89 E+04 \\
1,73 E+05 \\
9,45 E+04 \\
7,33 E+04\end{array}$ & $\begin{array}{c}7,05 E+06 \\
5,10 E+06 \\
5,18 E+06 \\
5,59 E+06 \\
4,92 E+05 \\
4,72 E+05 \\
4,27 E+05 \\
3,59 E+05\end{array}$ & $\begin{array}{l}3,84 E+06 \\
2,66 E+06 \\
2,70 E+06 \\
2,87 E+06 \\
2,96 E+05 \\
2,87 E+05 \\
2,72 E+05 \\
2,31 E+05\end{array}$ & $7,40 E+04$ & $1,66 E+06$ \\
\hline
\end{tabular}




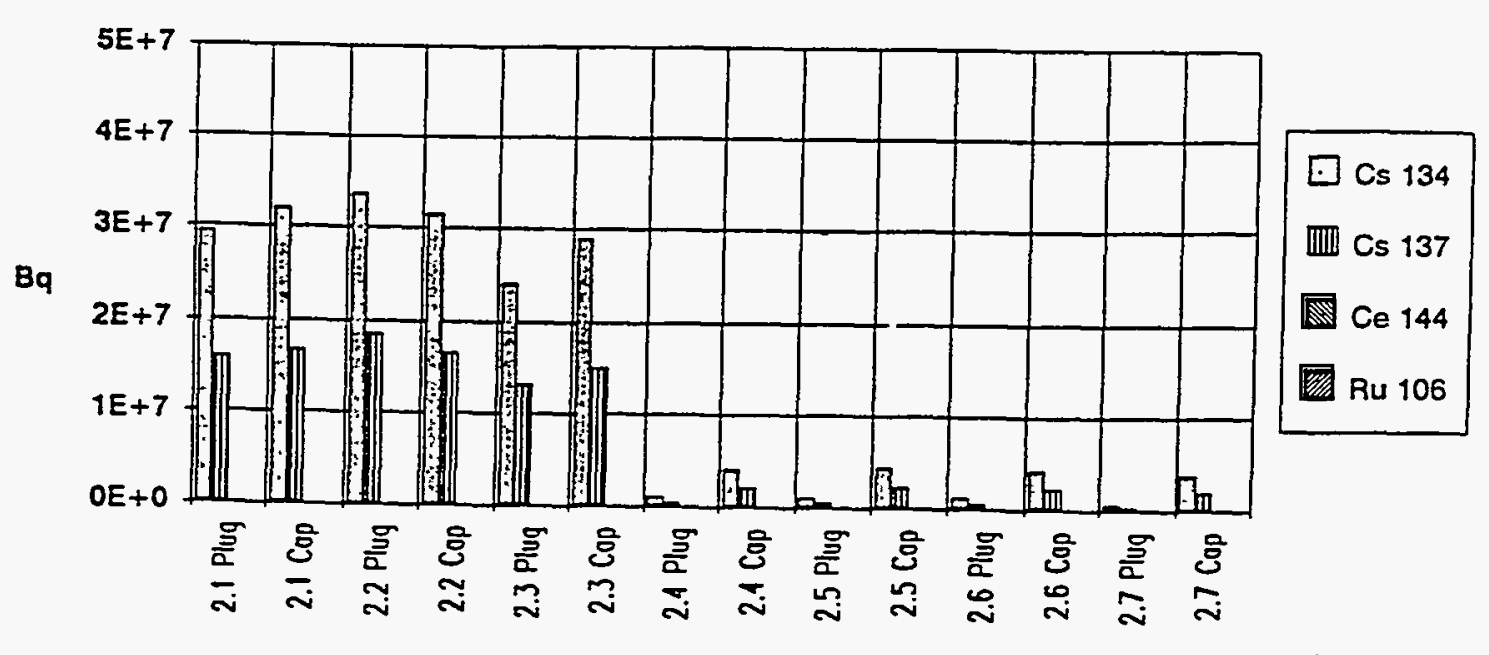

Fig. 4.70 The inventories $(\mathrm{Bq})$ of the plugs and screw caps from capsule 2 for ${ }^{144} \mathrm{Ce},{ }^{137} \mathrm{Cs},{ }^{134} \mathrm{Cs}$, and ${ }^{106} \mathrm{Ru}$. Source: Forschungszentrum Jülich $\mathrm{GmbH}$, Julich, Germany

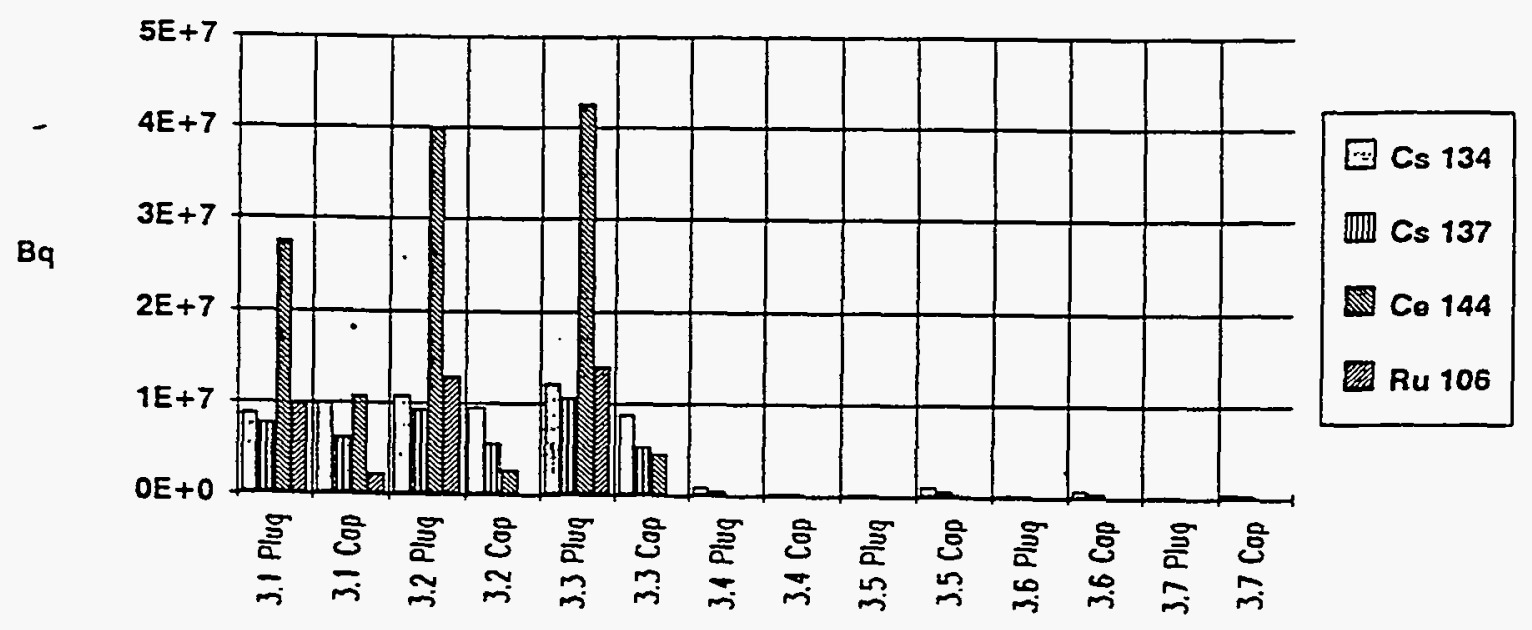

Fig. 4.71 The inventories $(\mathrm{Bq})$ of the plugs and screw caps from capsule 3 for ${ }^{144} \mathrm{Ce},{ }^{137} \mathrm{Cs},{ }^{234} \mathrm{Cs}$, and ${ }^{106} \mathrm{Ru}$ Source: Forschungszentrum Jülich GmbH, Julich, Germany 


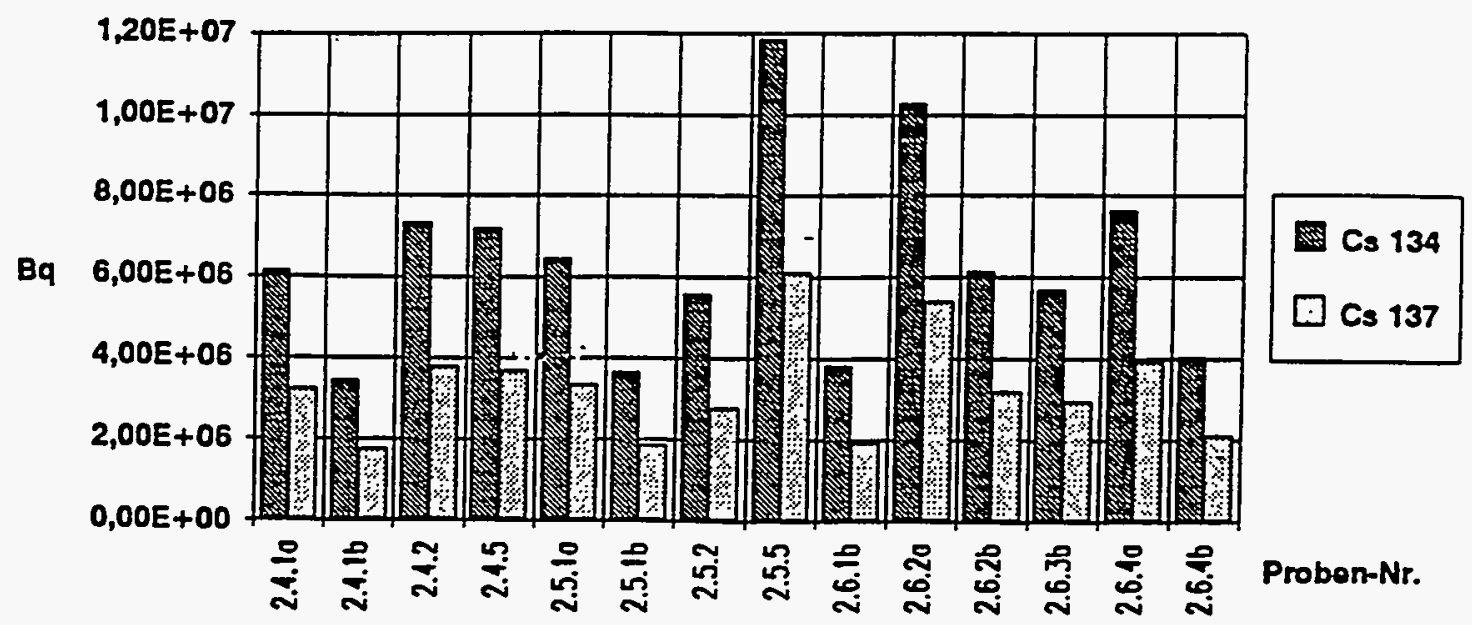

Fig. 4.72 The inventories $(\mathrm{Bq})$ of the graphite cylinders and sleeves from capsule 2 for ${ }^{137} \mathrm{Cs}$, and ${ }^{134} \mathrm{Cs}$ Source: Forschungszentrum Jalich GmbH, Jalich, Germany

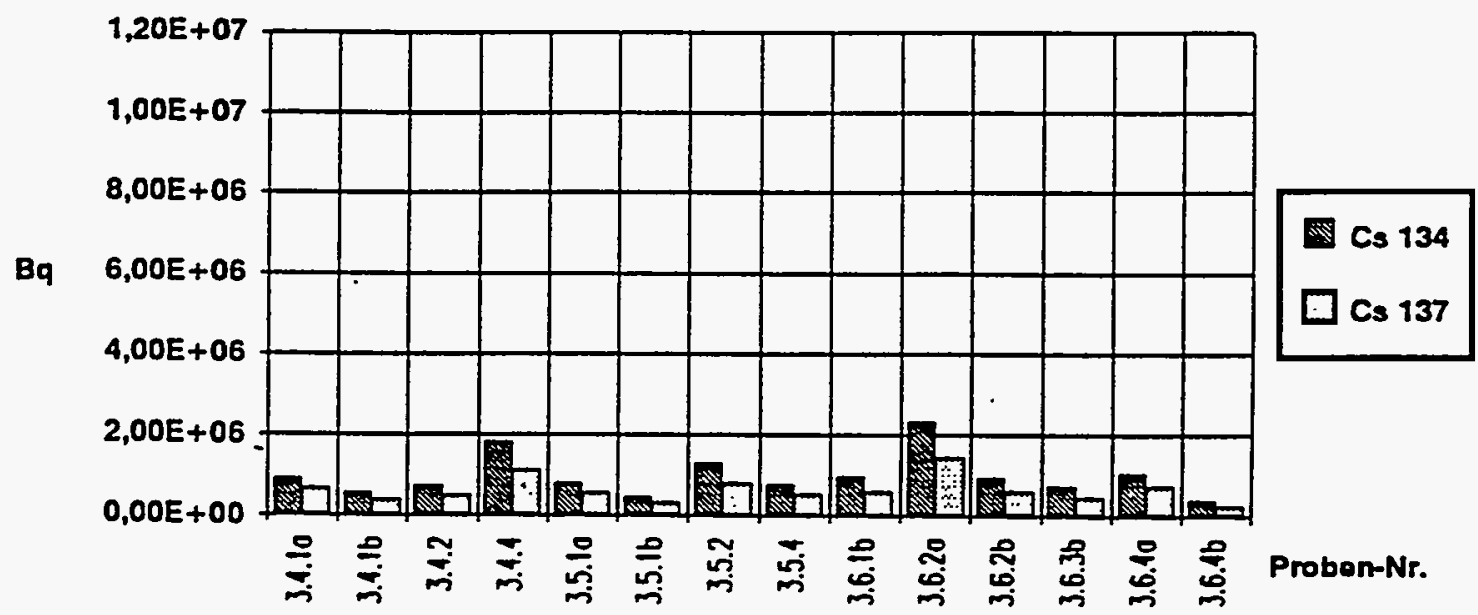

Fig. 4.73 The inventories (Bq) of the graphite cylinders and sleeves from capsule 3 for ${ }^{137} \mathrm{Cs}$, and ${ }^{134} \mathrm{Cs}$, Source: Forschungszentrum Julich $\mathrm{GmbH}$, Julich, Germany 


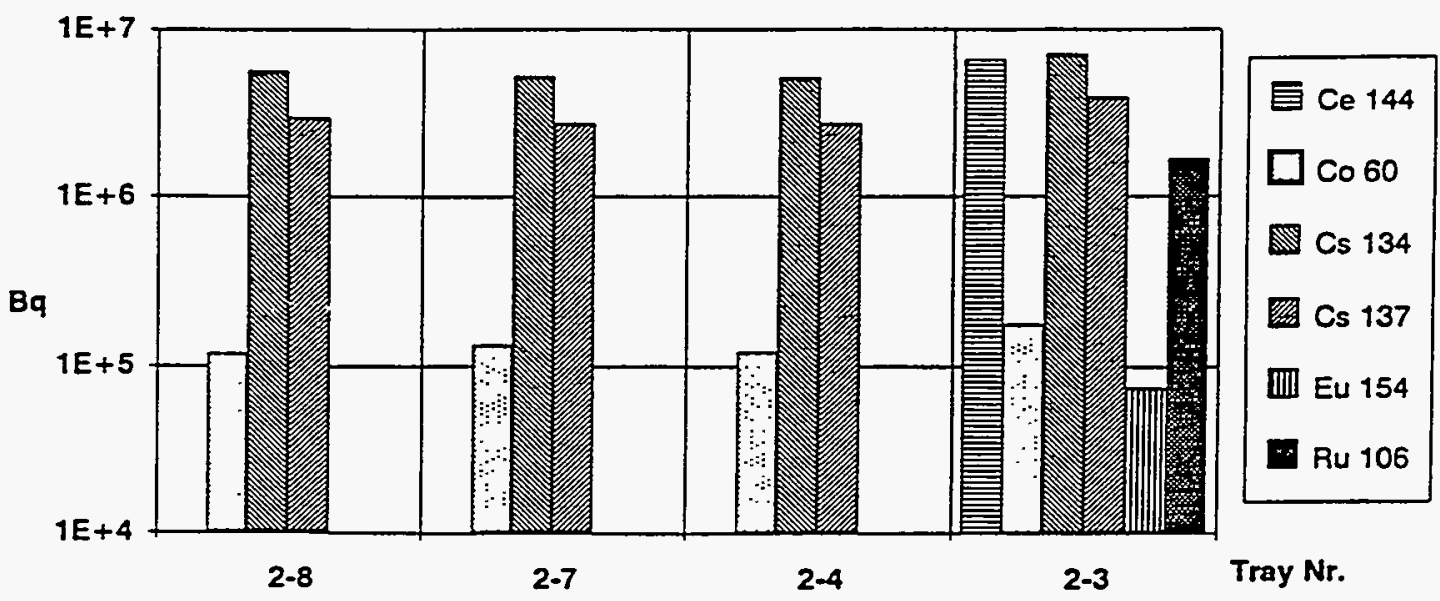

Fig. 4.74 The inventories (Bq) of the particle trays from capsule 2 for ${ }^{154} \mathrm{Eu},{ }^{144} \mathrm{Ce},{ }^{137} \mathrm{Cs},{ }^{134} \mathrm{Cs}$, ${ }^{106} \mathrm{Ru}$, and ${ }^{60} \mathrm{Co}$. Source: Forschungszentrum Julich $\mathrm{GmbH}$, Julich, Germany

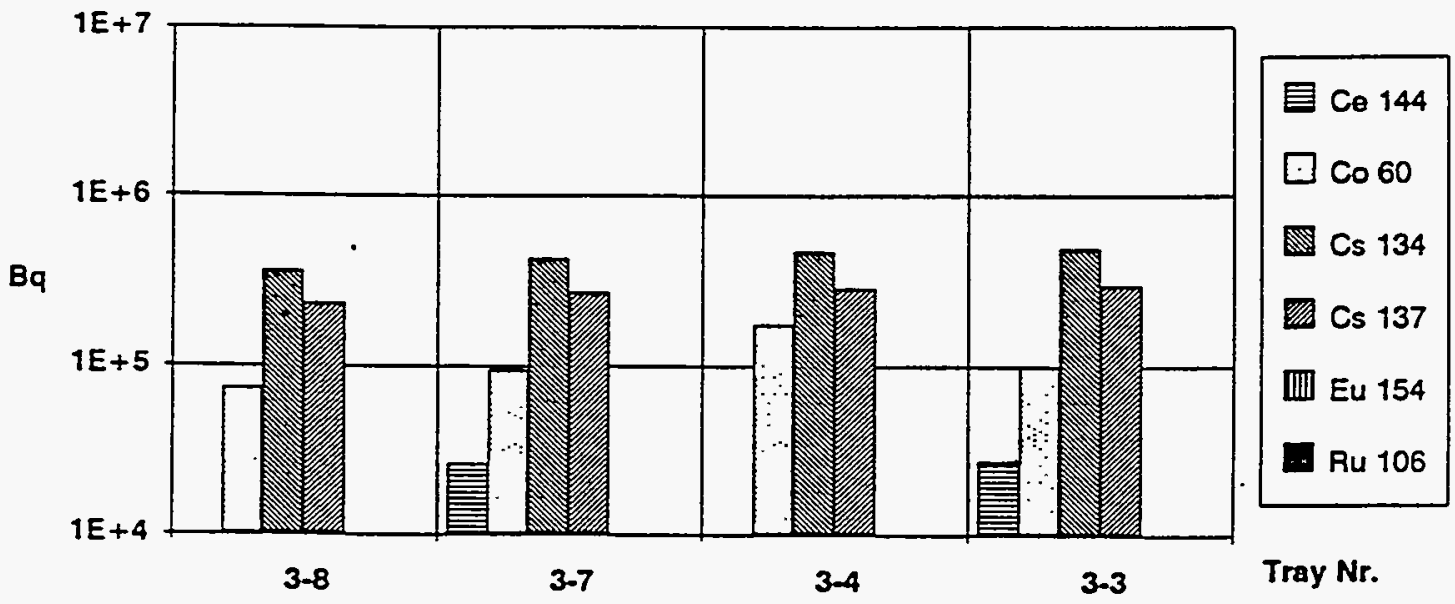

Fig. 4.75 The inventories $(\mathrm{Bq})$ of the particle trays from capsule 3 for ${ }^{154} \mathrm{Eu},{ }^{144} \mathrm{Ce},{ }^{137} \mathrm{Cs},{ }^{134} \mathrm{Cs}$, ${ }^{106} \mathrm{Ru}$, and ${ }^{60} \mathrm{Co}$. Source: Forschungszentrum Julich $\mathrm{GmbH}$, Julich, Germany 
The results of the overview calculations are shown in Table 4.29 and Figs. 4.76 and 4.77. The fraction of cesium in the graphite is small. For ${ }^{134} \mathrm{Cs}$, the fractions for capsules 2 and 3 are 0.045 and 0.019 , respectively; for ${ }^{137} \mathrm{Cs}$, the fractions for capsules 2 and 3 are 0.039 and 0.016 , respectively. The ratios of the fractional cesium content in the graphite to that in the graphite plus fuel compacts is about 2.4 for both capsules 2 and 3. This ratio is comparable to the ratio of the impluses measured for capsules 2 and 3, respectively during the gamma scan of the graphite sectors as evident from Figs. 4.61, 4.63 and 4.65. These observations are in accord with the postulate presented in Sect. 4.4.2.3.

Capsule 3 but not capsule 2 was subjected to intermittent injections of water vapor. The lower cesium content in capsule 3 is attributable to the effects of graphite hydrolysis. The diffusivity of cesium is greater in hydrolyzed than unhydrolyzed graphite ${ }^{10}$. Therefore, the transport of cesium through the graphite in capsule 3 is faster than in capsule 2 and less cesium is expected to be found in capsule 3 . To maintain a mass balance, more cesuim in capsule 3 than in capsule 2 would be expected to be adsorbed on the respective stainless steel capsule containers.

Note that in Table 4.29, activity $(\mathrm{Bq})$ data in the first data row have been taken from Tables 4.20 and 4.21 for capsules 2 and 3 , respectively. Activity $(\mathrm{Bq})$ data in the fifth data row have been taken from Tables 4.15 and 4.16 for capsules 2 and 3, respectively

\subsubsection{Summary of Inventory Measurements}

A summary is provided in Table 4.30 of the inventory measurements of the graphite parts of the fuel element as depicted in Figs. 3.2 and 3.3. The fuel element can be thought of as a graphite cylinder with 7 vertical holes containing a variety of components. The inventories were measured on the graphite body, the screw caps at the top and the plugs at the bottom of each hole, and the contents of each hole selectively.

\subsubsection{Dimensional Measurements ${ }^{7}$}

Dimensional measurements on graphite bodies from capsules 2 and 3 , both before and after irradiation, are presented in Fig. 4.78. The preirradiation measurements were taken from the Design and Safety Report (Figs. 16 and 17 of this report). The axial orientation of the fuel bodies in the capsule during irradiation are indicated by the words "oben" (top) and "unter" (bottom) and not by the pictorial orientation.

The measurements were made with a vernier micrometer. The reading accuracy amounted to \pm 0.005 $\mathrm{mm}$. The diameter was determined at two locations $90^{\circ}$ apart for each axial portion of constant diameter of which there are four (see Fig. 4.78). The length for graphite body 2 was determined at two locations $180^{\circ}$ apart and for graphite body 3, at four locations $90^{\circ}$ apart for each axial portion of constant diameter of which there are four (see Fig. 4.78).

\subsection{EXAMINATION OF INERT COMPACTS AND GRAPHITE CYLINDERS}

The three, normally, coolant holes in the graphite body of each capsule contained a complement of 6 inert compacts each within a graphite sleeve and 8 graphite cylinders. The inert compacts were fired in either $\mathrm{SiC}$ or $\mathrm{Al}$ powder; the $\mathrm{SiC}$ powder was expected to lead to increased compact strength. The sleeves surrounding the compacts were intended to bridge the diameter of the hole. The graphite cylinders were either of grade $\mathrm{H}-451$ or H-451I; the differences in dimensional change, coefficient of thermal expansion and Young's modulus were to be assessed. Unfortunately, the KFA was unable to measure the coefficient of thermal expansion or Young's modulus in their hot cells. The graphite samples are, however, available for testing elsewhere. 
Table 4.29 Distribution of cesium activity $(\mathrm{Bq})$ between the fuel compacts and the graphite in the fuel element Source: Forschungszentrum Jalich GmbH, Jalich, Germany

\begin{tabular}{|c|c|c|c|c|}
\hline & \multicolumn{2}{|c|}{ Capsule 2} & \multicolumn{2}{|c|}{ Capsule 3} \\
\hline & Cs 134 & Cs 137 & Cs 134 & Cs 137 \\
\hline $\begin{array}{l}\text { Graphite sectors with plugs } \\
\text { and screws in fuel holes }\end{array}$ & 4.77E+09 & $2.60 E+09$ & $1.30 \mathrm{E}+09$ & $9.05 E+08$ \\
\hline $\begin{array}{l}\text { Plugs and screw for holes } \\
4 \text { to } 7\end{array}$ & $2.02 E+07$ & $1.03 E+07$ & $3.23 E+06$ & $1.85 \mathrm{E}+06$ \\
\hline Graphite cylinders and sleeves & $1.39 E+08$ & $7.17 \mathrm{E}+07$ & $2.21 E+07$ & $1.42 \mathrm{E}+07$ \\
\hline Total for graphite & $4.93 E+09$ & $2.68 \mathrm{E}+09$ & $1.33 E+09$ & $9.21 E+08$ \\
\hline Fuel compacts & $1.04 \mathrm{E}+11$ & $6.61 \mathrm{E}+10$ & $6.80 \mathrm{E}+10$ & $5.57 \mathrm{E}+10$ \\
\hline Graphite/(graphite + compact) & $4.53 \%$ & $3.90 \%$ & $1.91 \%$ & $1.63 \%$ \\
\hline
\end{tabular}




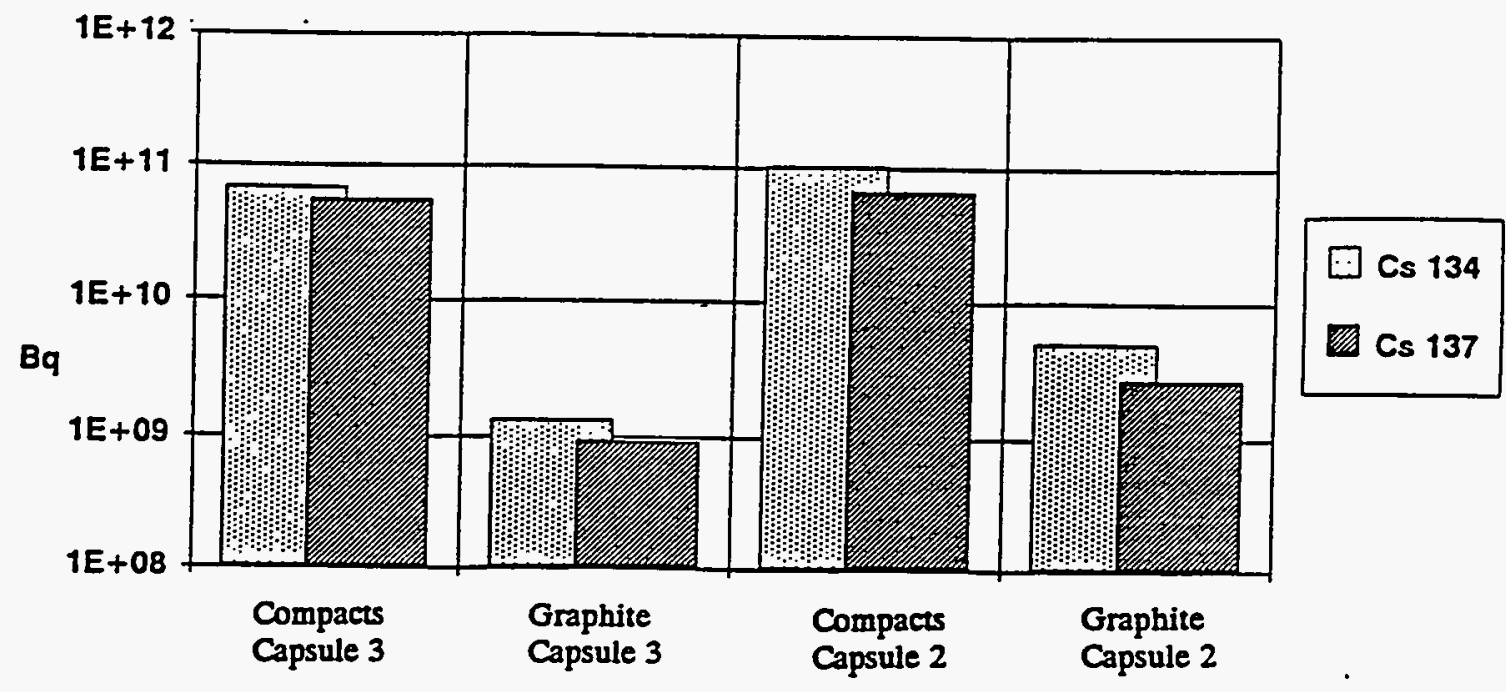

Fig. 4.76 The inventories of ${ }^{137} \mathrm{Cs}$ and ${ }^{134} \mathrm{Cs}$ in the fuel compacts and graphite of capsules 2 and 3 Source: Forschungszentrum Jalich GmbH, Julich, Germany

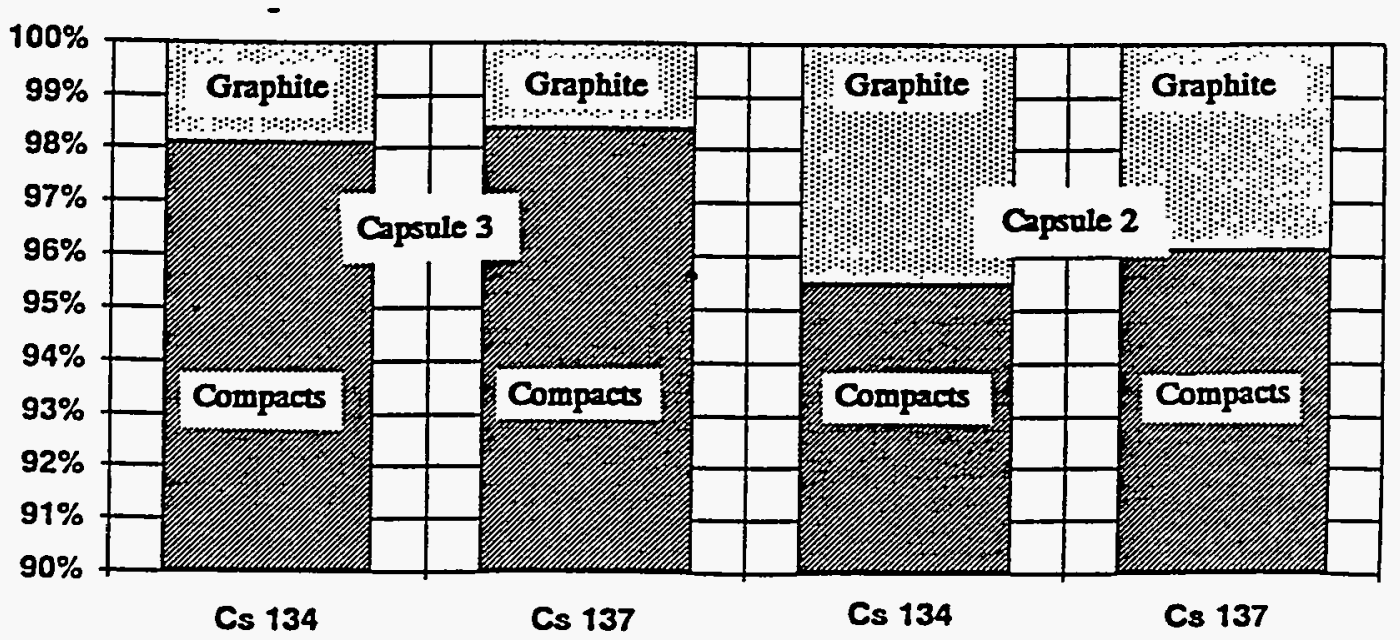

Fig. 4.77 The distribution of ${ }^{137} \mathrm{Cs}$ and ${ }^{134} \mathrm{Cs}$ between fuel compacts and graphite in capsules 2 and 3 Source: Forschungszentrum Julich GmbH, Julich, Germany 
Table 4.30 Summary of inventory measurements on the graphite components of the fuel element

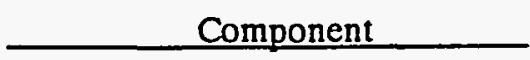

Graphite cylindrical sectors

Fuel compacts in holes $1,2,3$

Screw caps and plugs in holes $1,2,3,4,5,6$, and 7

Selected graphite cylinders, inert compoacts and graphite sleeves in holes 4,5 , and 6

particle trays in hole 7; particles not included
Tables

$4.20,4.21$

$4.15,4.16$

$4.24,4.25$

$4.26,4.27$

4.28
$4.72,4.73$

$4.74,4.75$

Figures

$4.67,4.68,4.69$

4.57

$4.70,4.71$ 


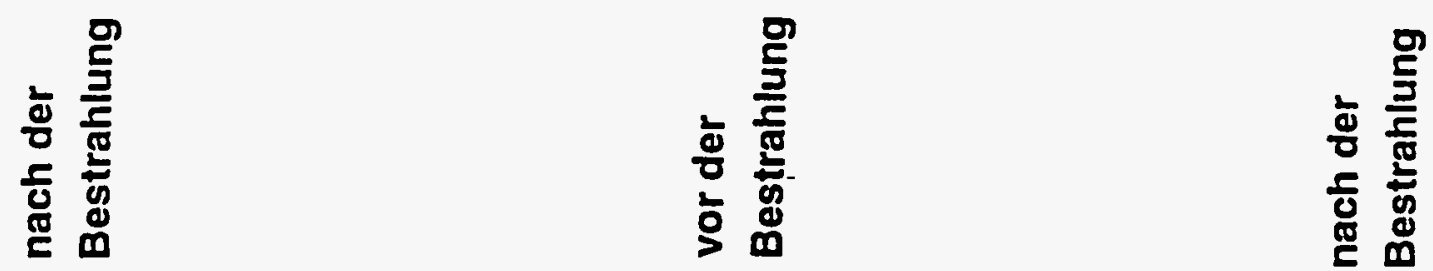<smiles>CCCC</smiles>
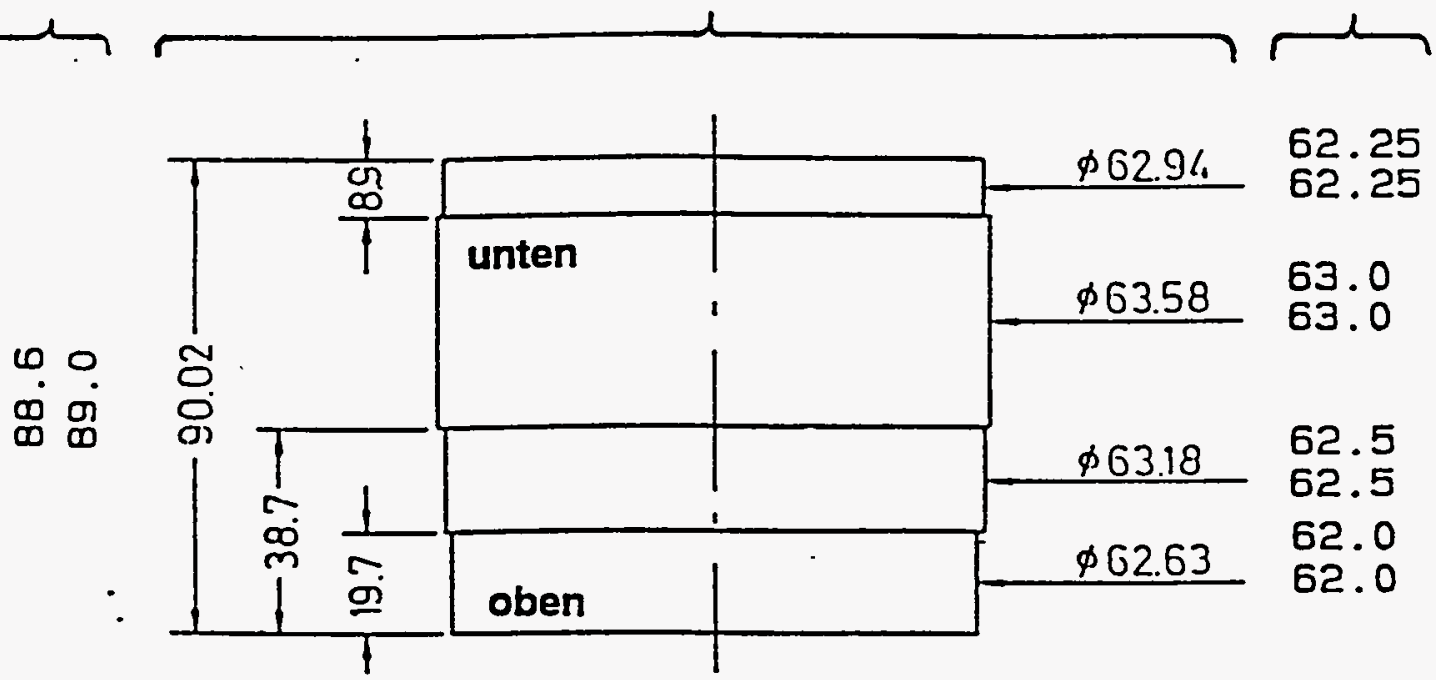

Fig.16 Outer dimensions of graphite body. cell 2

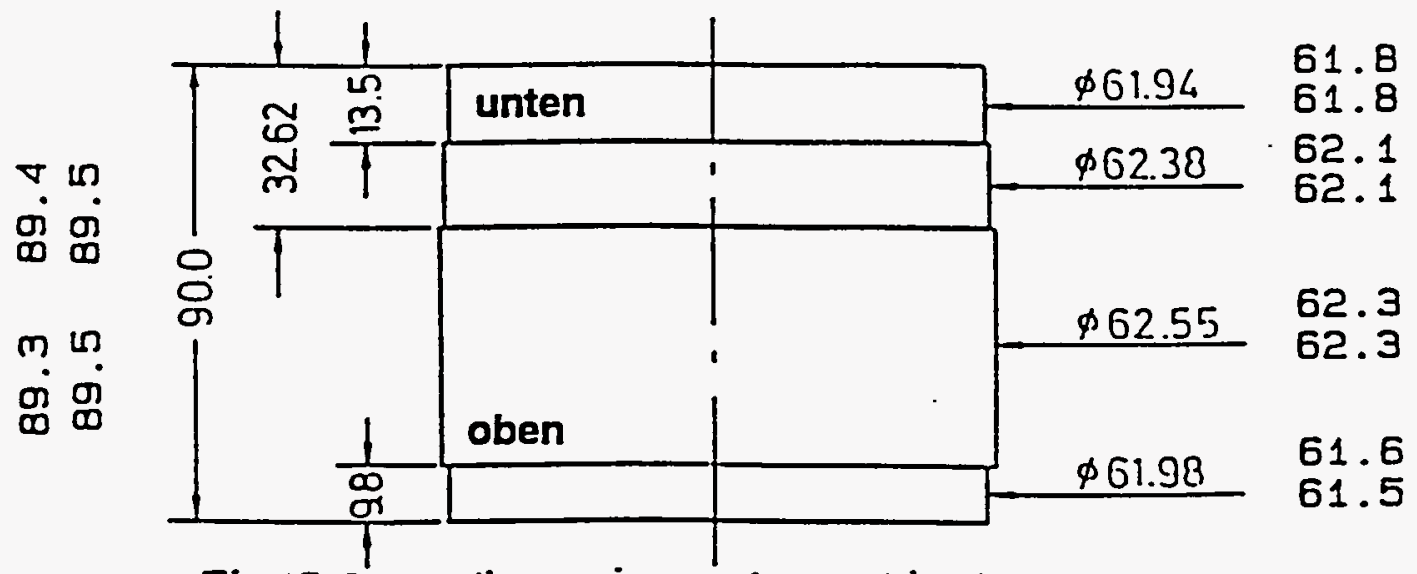

Fig.17 Outer dimensions of graphite body. cell 3

Fig. 4.78 Diameter and length measurements on graphite bodies from capsules 2 and 3 before and after irrradiation Source: Forschungszentrum Jalich $\mathrm{GmbH}$, Jalich, Germany 


\subsubsection{Visual Inspection and Photography²}

The opening of the coolant holes was not difficult. All contents could easily be removed. No remarkable features were observed. Photographs were taken; the position of the inert compact or graphite cylinder is identified on each photograph and the physical location is given in Fig. 3.2 for capsule 2 and on Fig. 3.3 for capsule 3.

The photographs of the inert compacts with the associated graphite sleeves from capsule 2 are presented in Fig. 4.79, photographs 473/5-7, Fig. 4.80, photographs 273/20-22, Fig.4.81, photographs 473/23,28,29, and Fig. 4.82, photographs 473/24-26. The photographs of the graphite cylinders are presented in Fig. 4.83, photographs 473/8-10, Fig. 4.84, photographs 473/11-13, Fig. 4.85, photographs 273/14-16, and Fig. 4.86, photographs 273/17-19.

The photographs of the inert compacts with the associated graphite sleeves (only for the sleeves from positions 3.4.1 and 3.5.1) from capsule 3 are presented in Fig. 4.87, photographs 471/7-10, Fig. 4.88, photographs 471/24,26,27, Fig.4.89, photographs 472/6,8,11, and Fig. 4.90, photographs 472/7,9,10, Fig. 491, photographs $472 / 12,15,18$, and Fig. 4.92, photographs $472 / 13,16,17$. The photographs of the graphite cylinders are presented in Fig. 4.93, photographs 472/1-4, Fig. 4.94, photographs $471 / 22,23,25,28$.

\subsubsection{Dimensional and Weight Measurements ${ }^{211}$}

The dimensions and weights of the graphite cylinders are presented in Tables 4.31 and 4.32 . Measurements were made on all eight graphite cylinders per compact. These cylinders, four per stack, were placed in holes 4 and 5 in capsules 2 and 3; see Figs. 3.2 and 3.3.

The dimensions and weights of the inert compacts and selected sleeves are presented in Tables 4.33 and 4.34. For a given capusle position, say x.y.z, for which both the inert compact and the associated sleeve were measured, the capusle position was futher distinguished by using x.y.z.a for the inert compact and x.y.z.b for the sleeve.

Measurements were made on 5 of the 6 inert compacts per capsule. In only one of the 5 were measurements made on both the inert compact and the associated graphite sleeve; in all other cases, measurements were made only on the inert compacts. The inert compacts and associated graphite sleeves for hole 5 in both capsule 2 and capsule 3 were not measured.

\subsection{UNBONDED COATED FUEL PARTICLES}

Unbonded coated fuel particles, in two configurations, ${ }^{1}$ were placed in the central hole, hole 7 , in both capsules 2 and 3 . One configuration involved 10 covered graphite trays per capsule, half of which each contained 110 fissile and the other half, 50 fertile coated fuel particles. The other configuration involved niobium encapsulated particles contained in a graphite crucible. The latter particles were one of three types: designed-to-fail fissile particles, intact fissile particles and particles with exposed kernels generated by laser drilling. The analysis of the particles from trays was conducted; for lack of equipment, analysis of the niobium encapsulated particles was not conducted. 

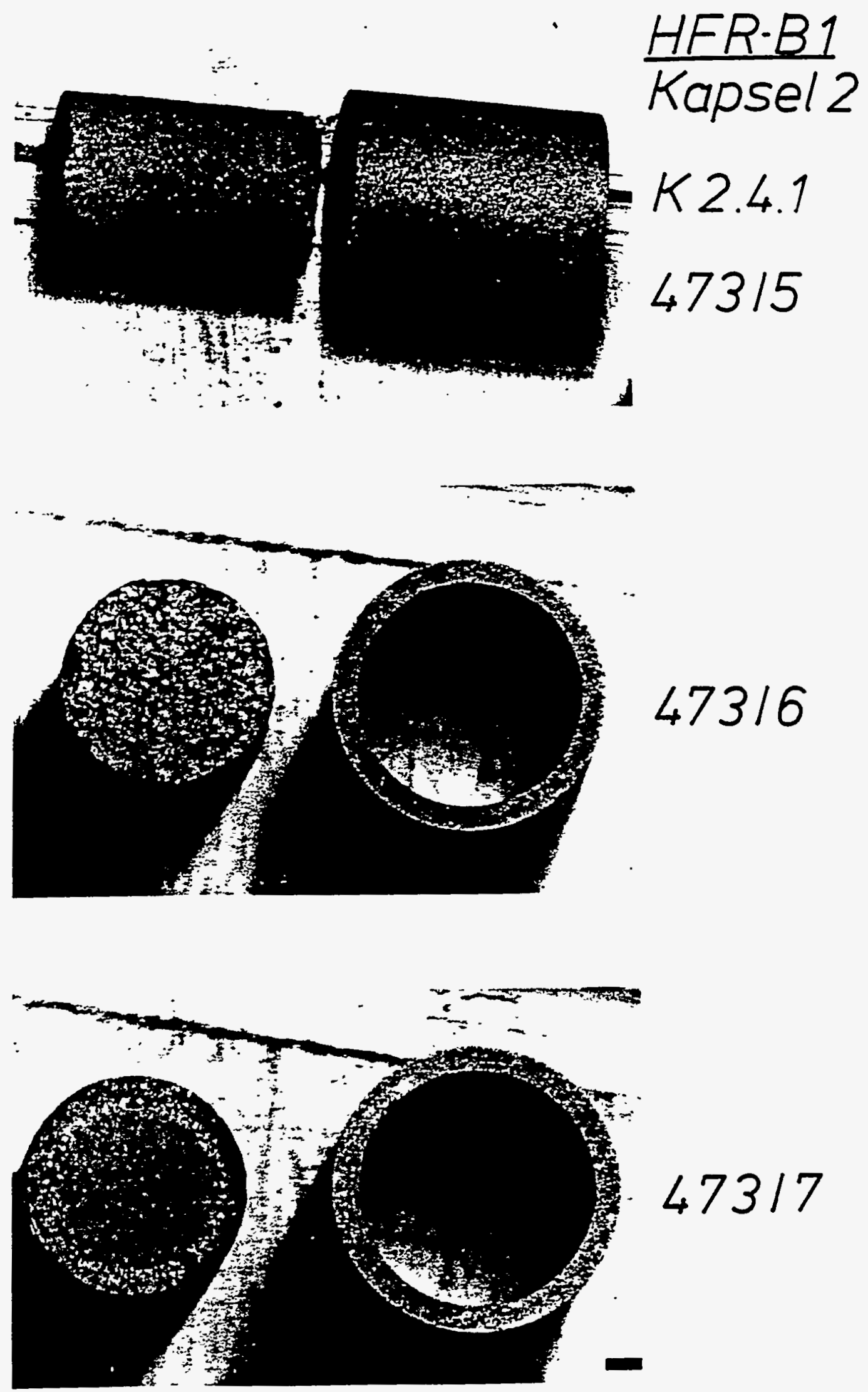

Fig. 4.79 Three views of the inert compact and associated graphite sleeve from position 2.4.1 of capsule 2 Source: Forschungszentrum Jalich GmbH, Julich, Germany 

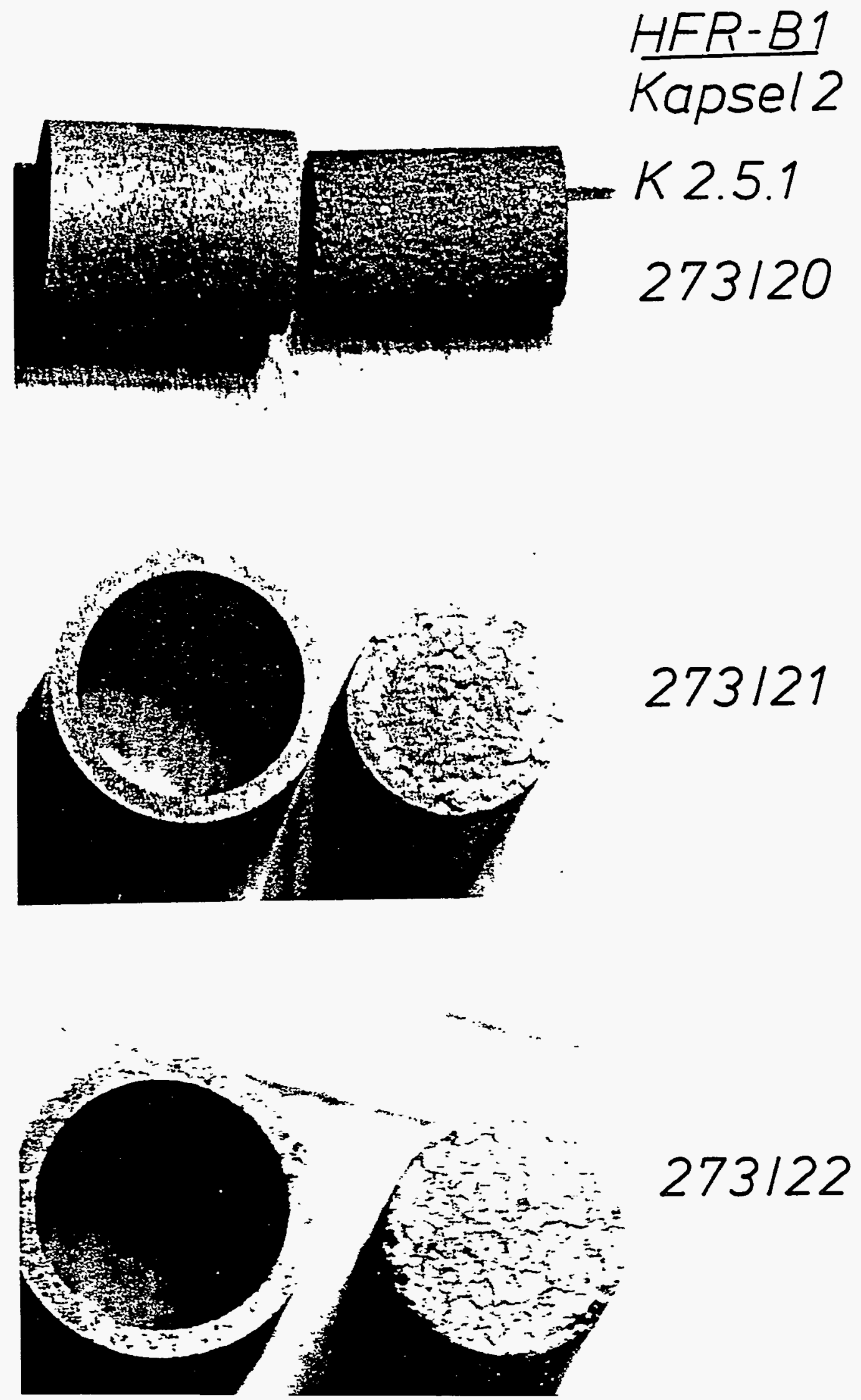

Fig. 4.80 Three views of the inert compact and associated graphite sleeve from position 2.5 .1 of capsule 2 Source: Forschungszentrum Julich GmbH, Julich, Germany 

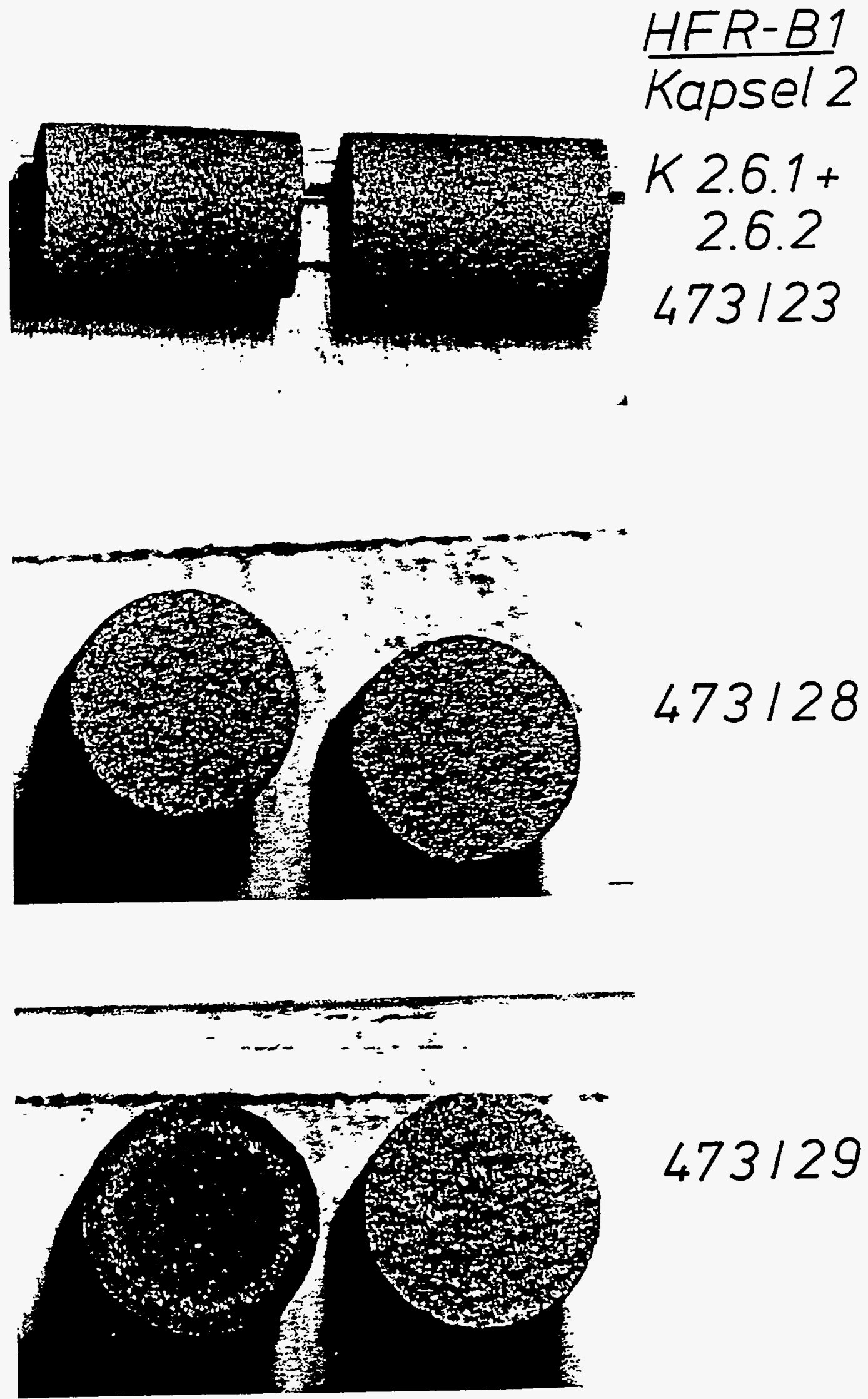

Fig. 4.81 Three views of the inert compact and associated graphite sleeve from positions 2.6.1 and 2.6.2 of capsule 2 Source: Forschungszentrum Julich GmbH, Jalich, Germany 


\section{HFR-B1 Kapsel 2}
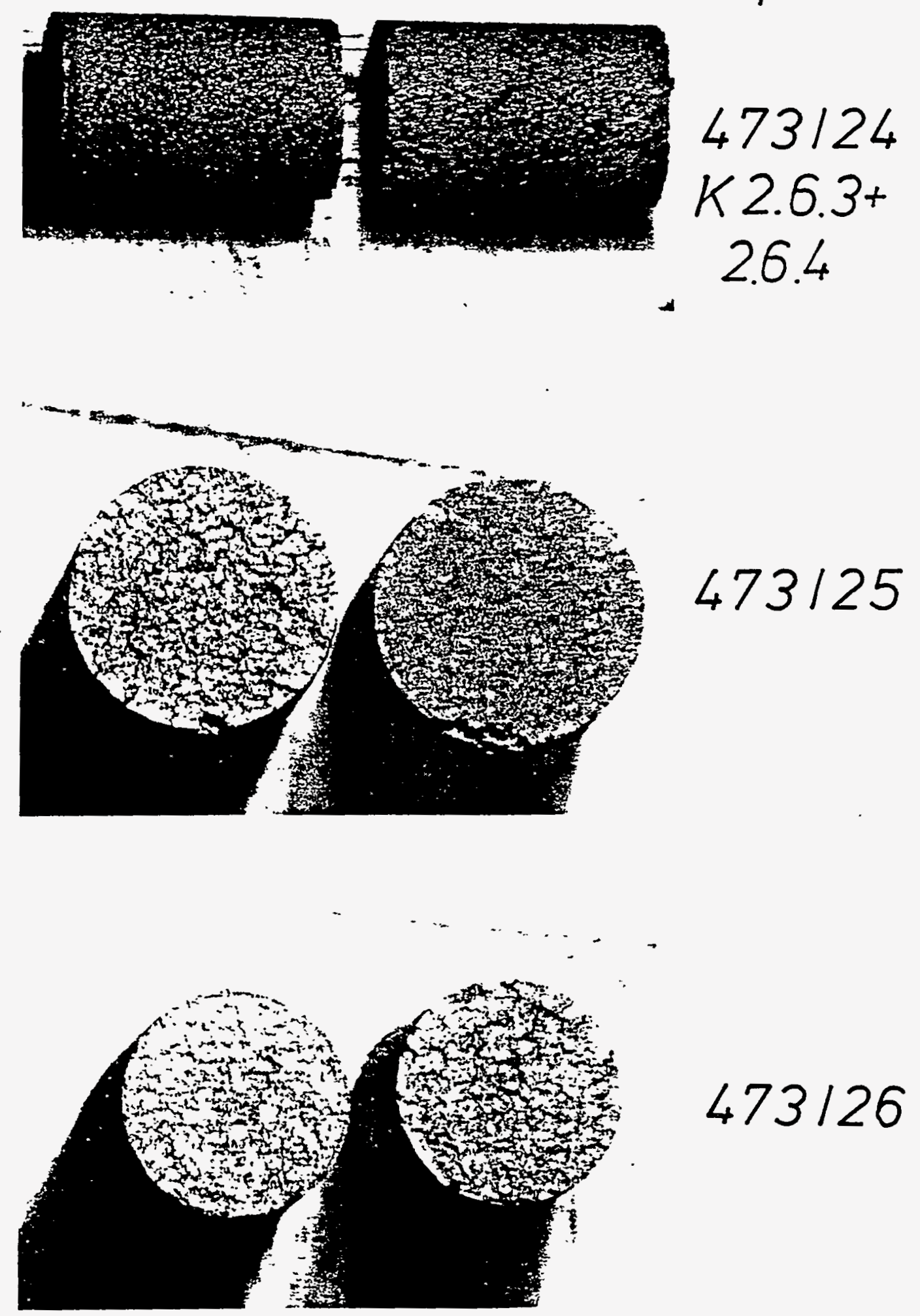

Fig. 4.82 Three views of the inert compact and associated graphite sleeve from positions 2.6.3 and 2.6.4 of capsule 2 Source: Forschungszentrum Jalich GmbH, Julich, Germany 

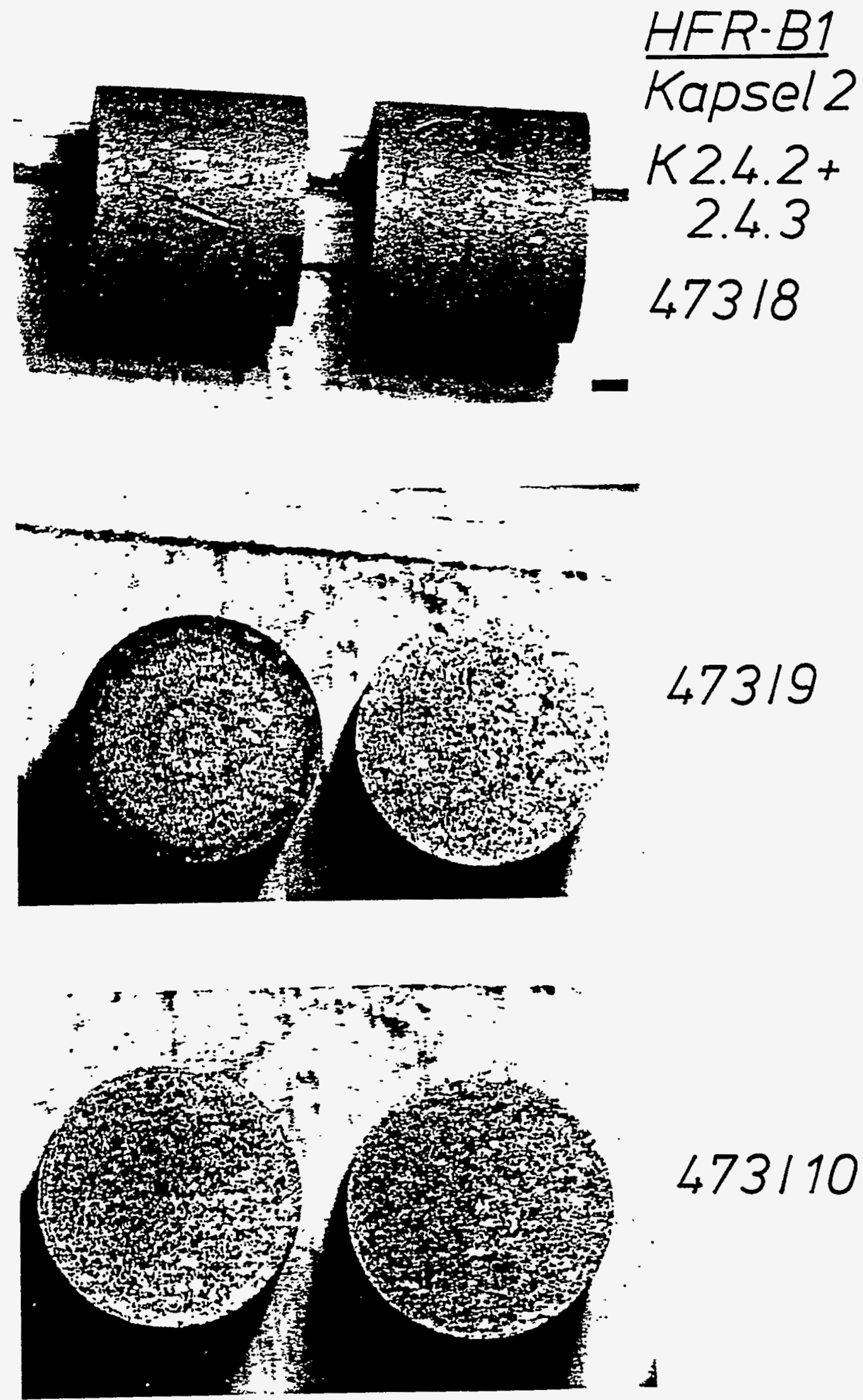

Fig. 4.83 Three views of the graphite cylinders from positions 2.4 .2 and 2.4 .3 of capsule 2 Source: Forschungszentrum Jalich GmbH, Jalich, Germany 

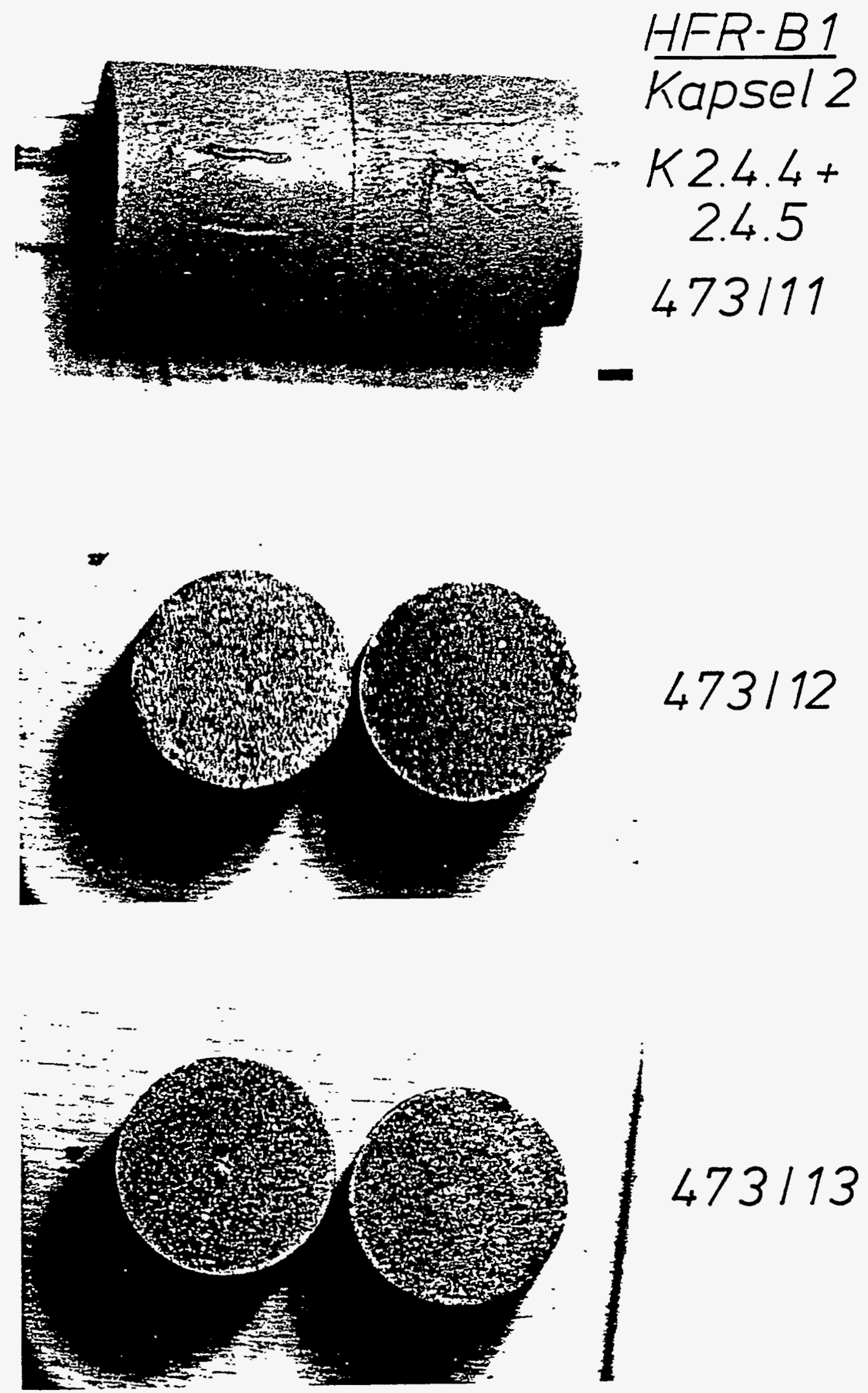

Fig. 4.84 Three views of the graphite cylinders from positions 2.4 .4 and 2.4 .5 of capsule 2 Source: Forschungszentrum Julich $\mathrm{GmbH}$, Julich, Germany 


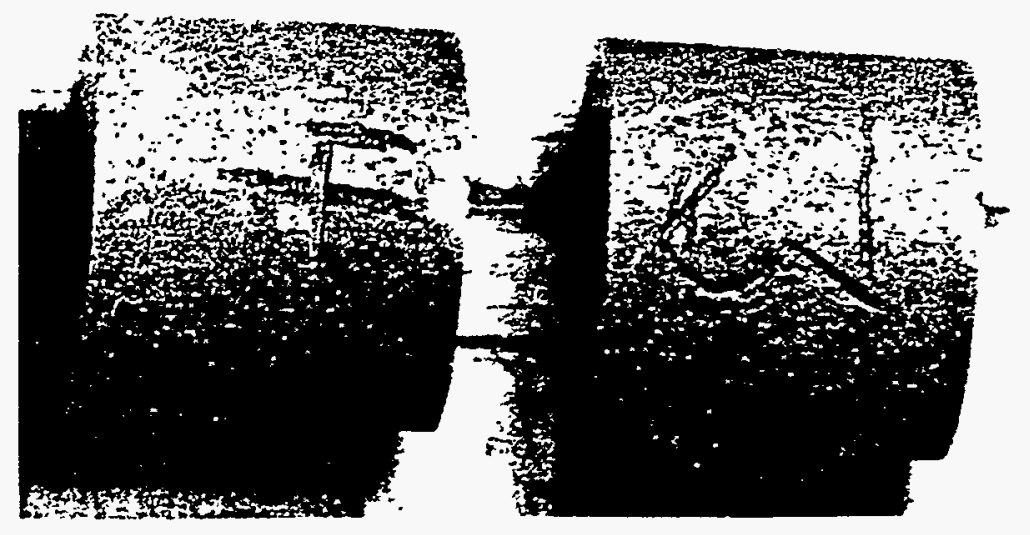

$$
\frac{\text { HFR-B1 }}{\text { Kapsel } 2}
$$

K2.5.2+

2.5 .3

$273 / 14$
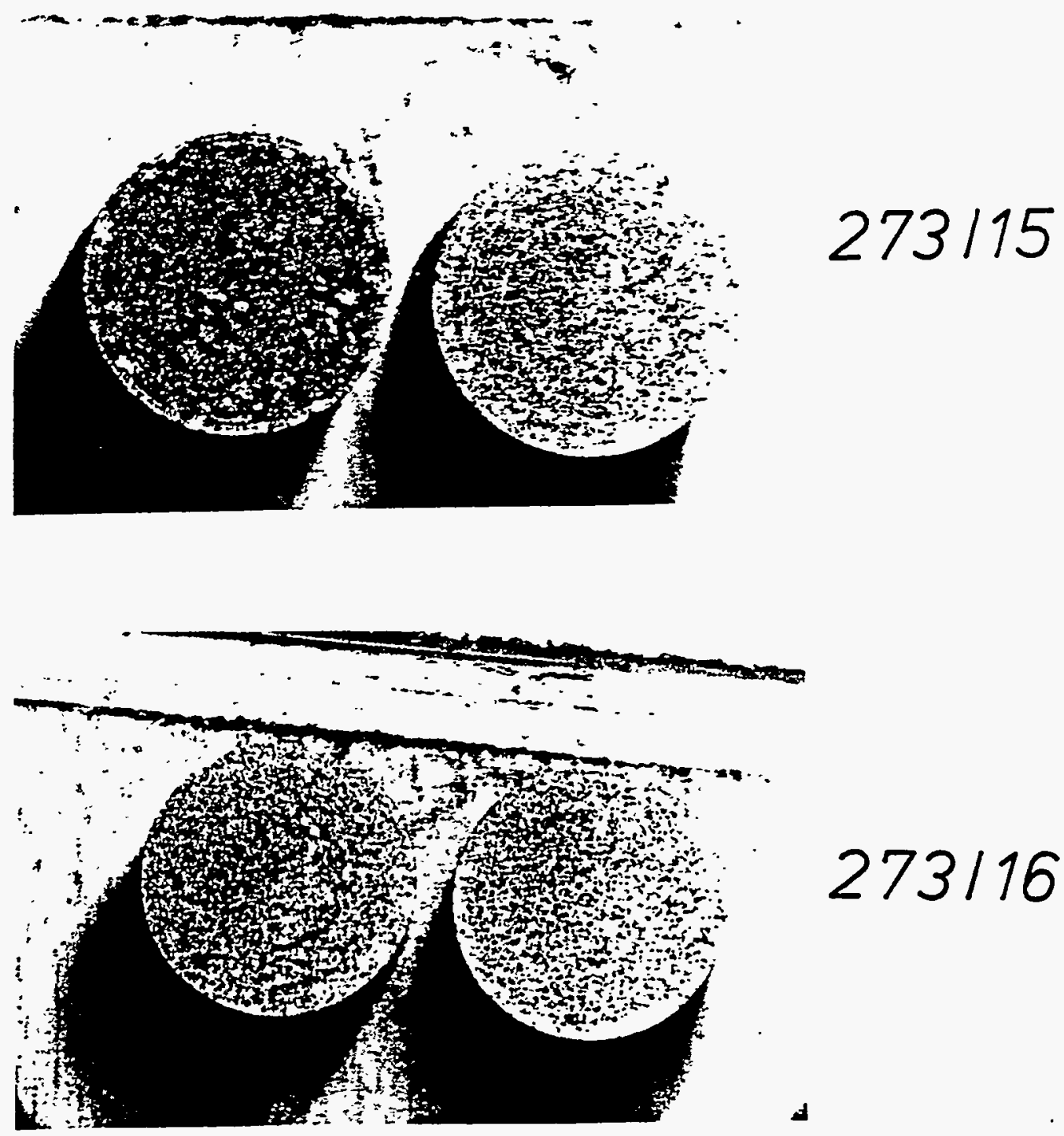

Fig. 4.85 Three views of the graphite cylinders from positions 2.5 .2 and 2.5.3 of capsule 2 Source: Forschungszentrum Julich GmbH, Julich, Germany 

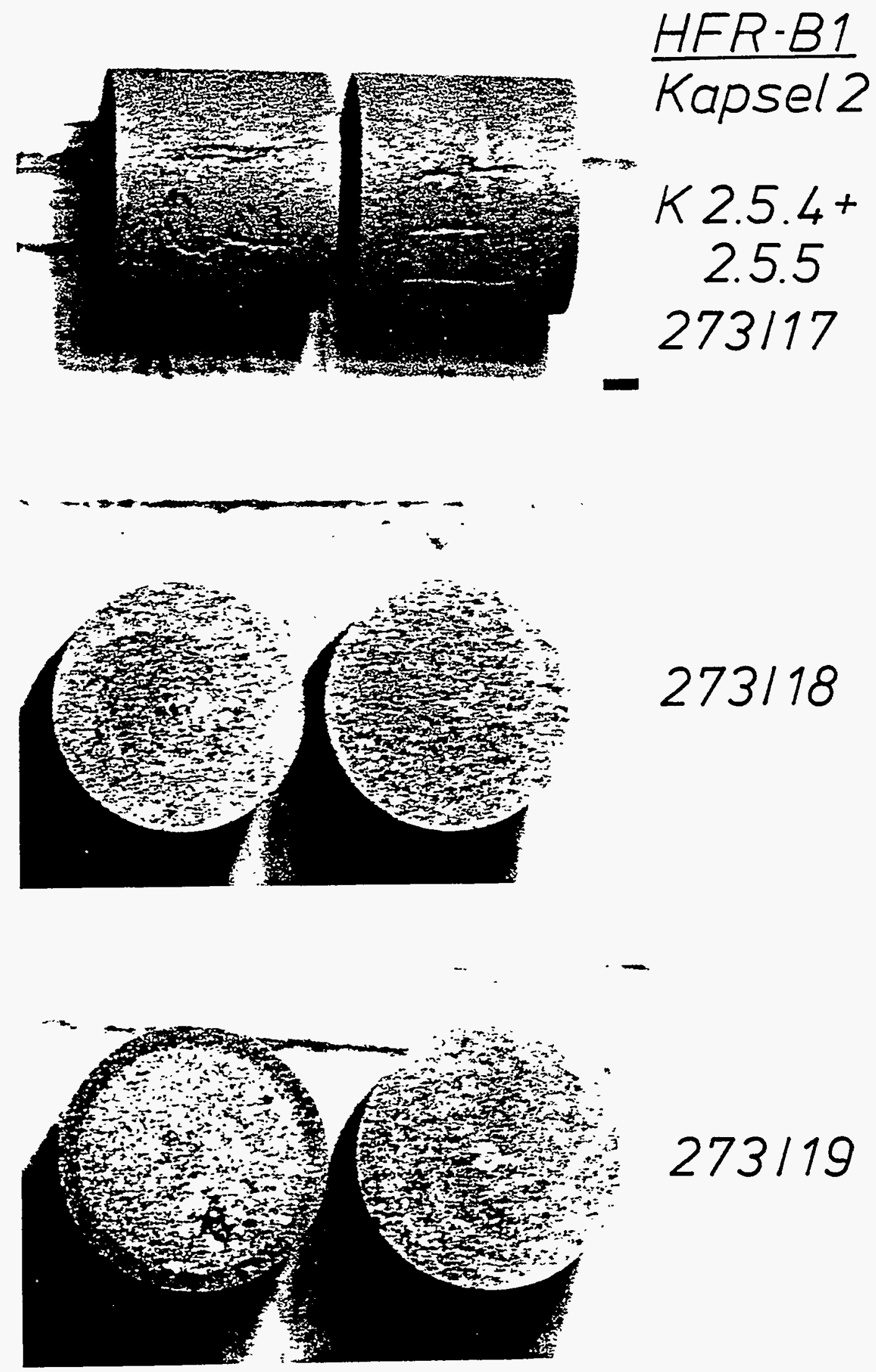

Fig. 4.86 Three views of the graphite cylinders from positions 2.5.4 and 2.5.5 of capsule 2 Source: Forschungszentrum Julich GmbH, Julich, Germany 

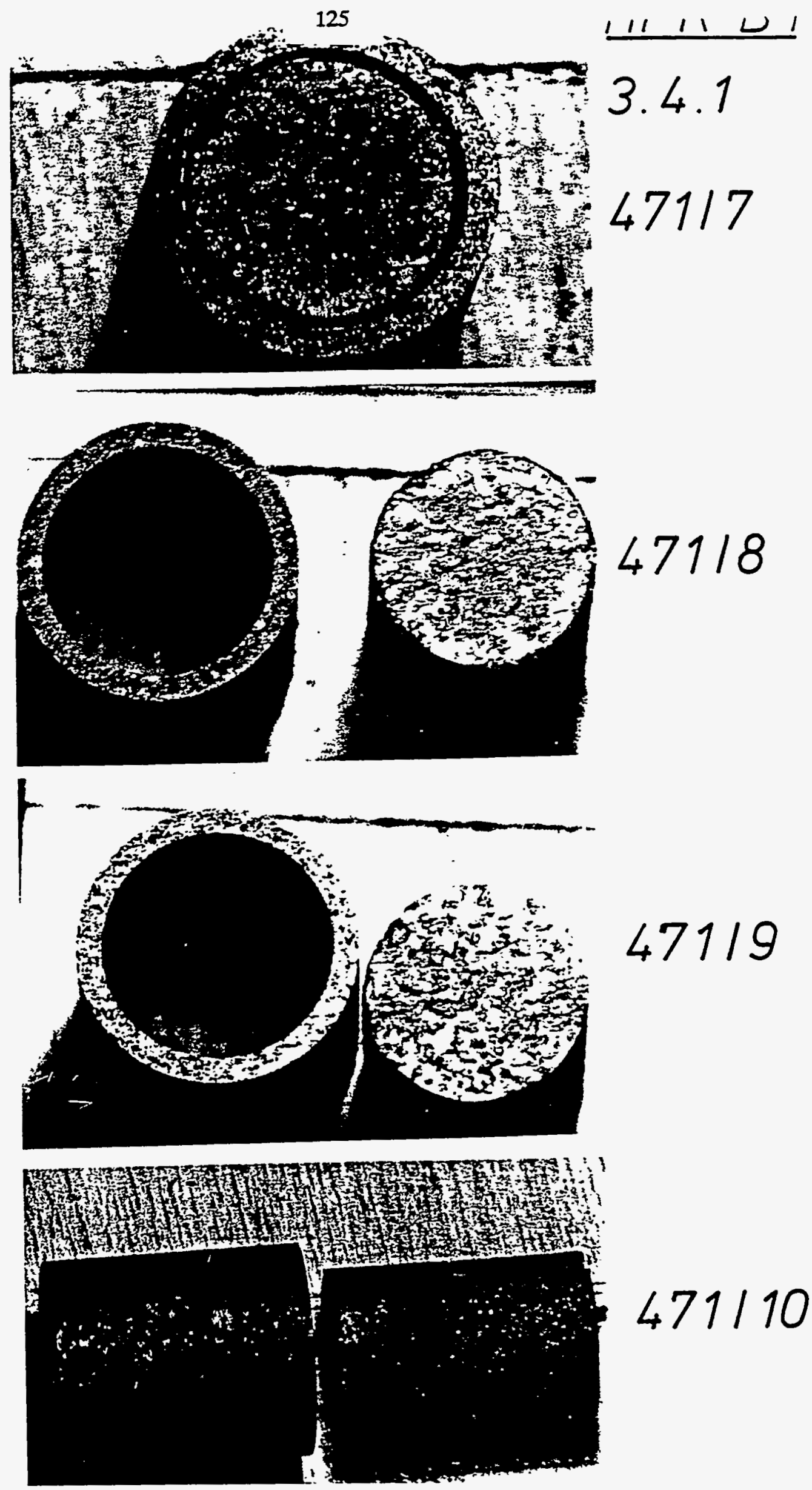

Fig. 4.87 Four views of the inert compact and associated graphite sleeve from position 3.4.1 of capsule 3 Source: Forschungszentrum Julich GmbH, Julich, Germany 

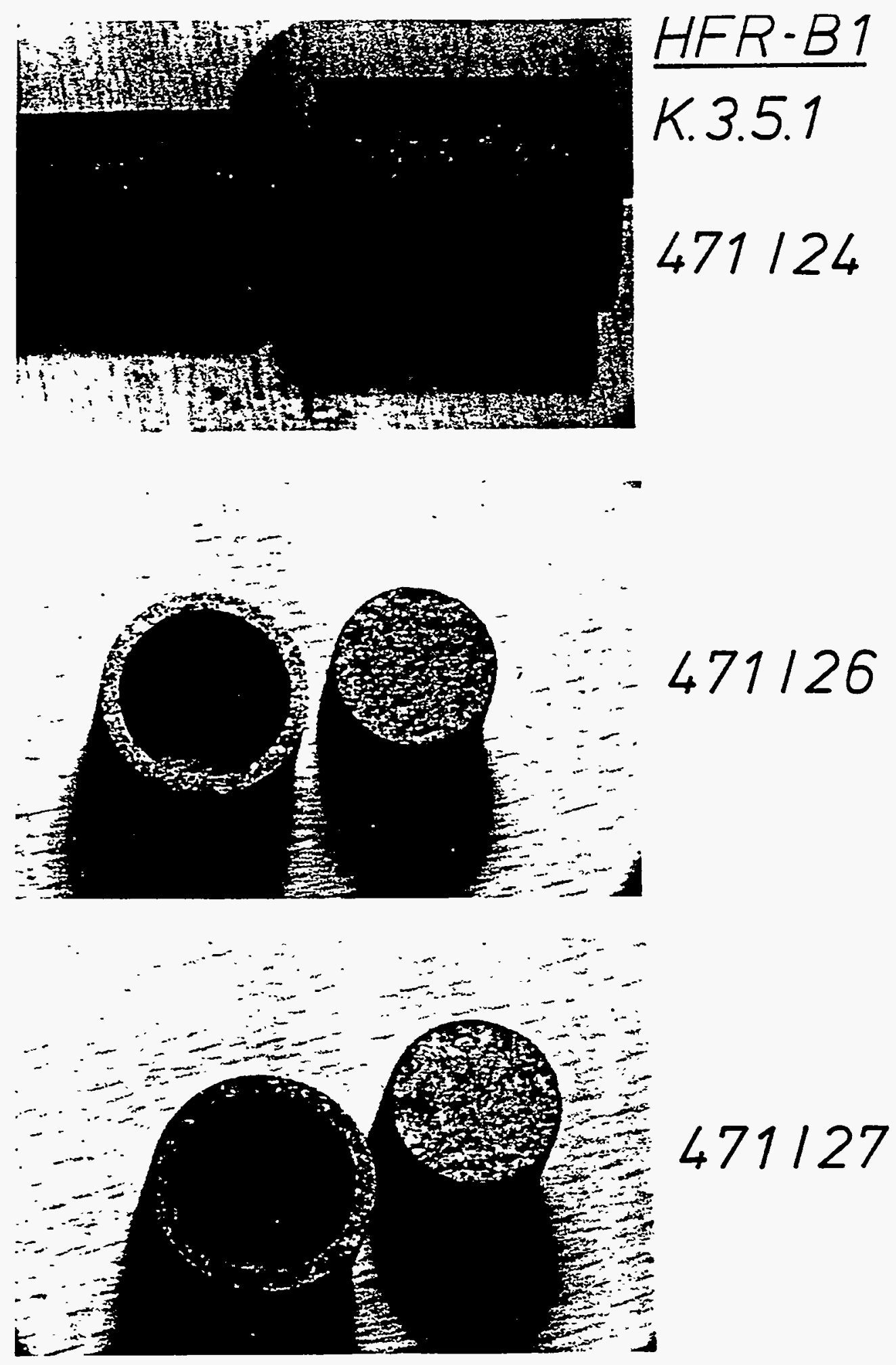

Fig. 4.88 Three views of the inert compact and associated graphite sleeve from position 3.5.1 of capsule 3 Source: Forschungszentrum Julich GmbH, Julich, Germany 


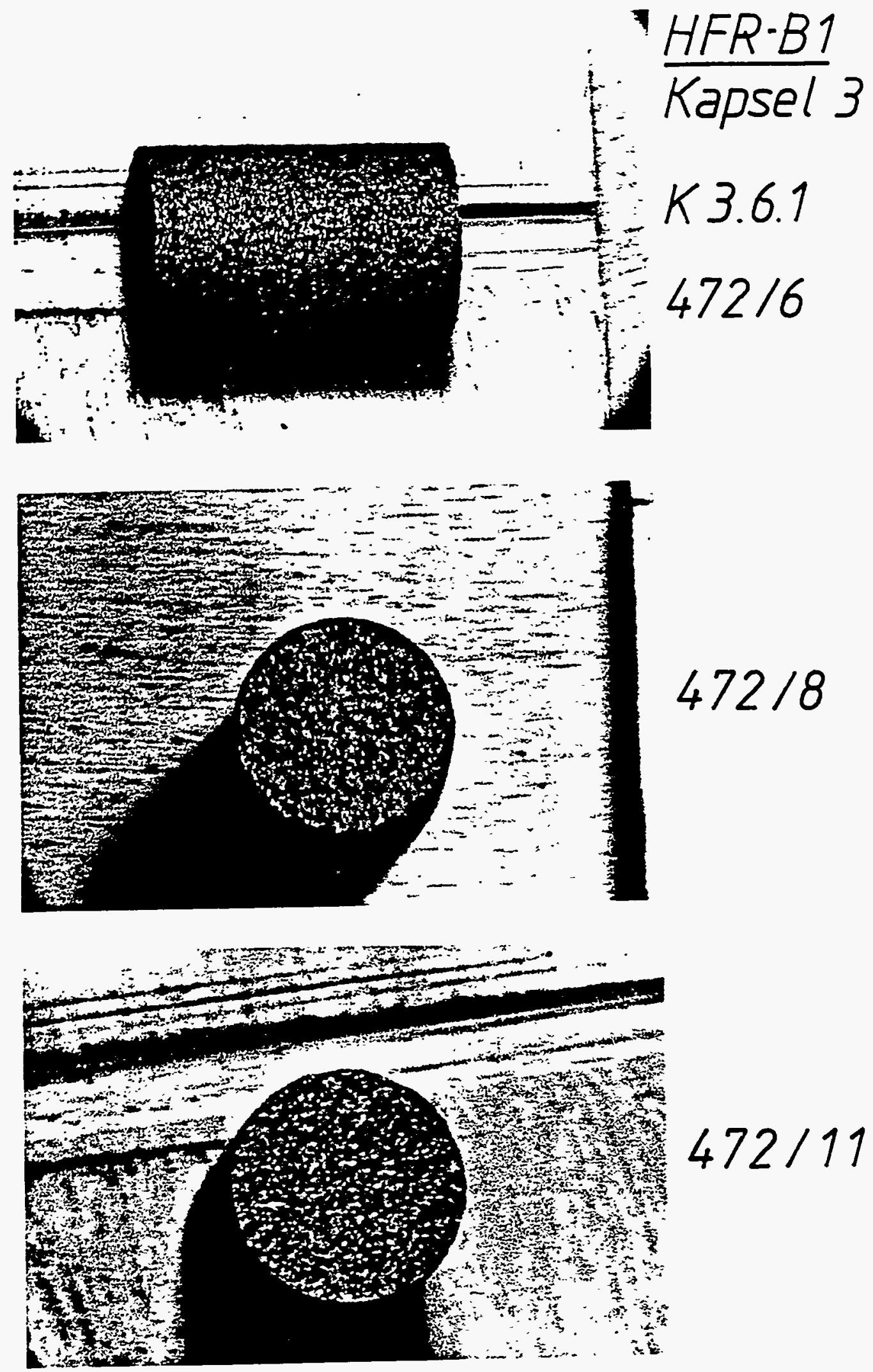

Fig. 4.89 Three views of the inert compact position 3.6.1 of capsule 3 Source: Forschungszentrum Julich GmbH, Julich, Germany 


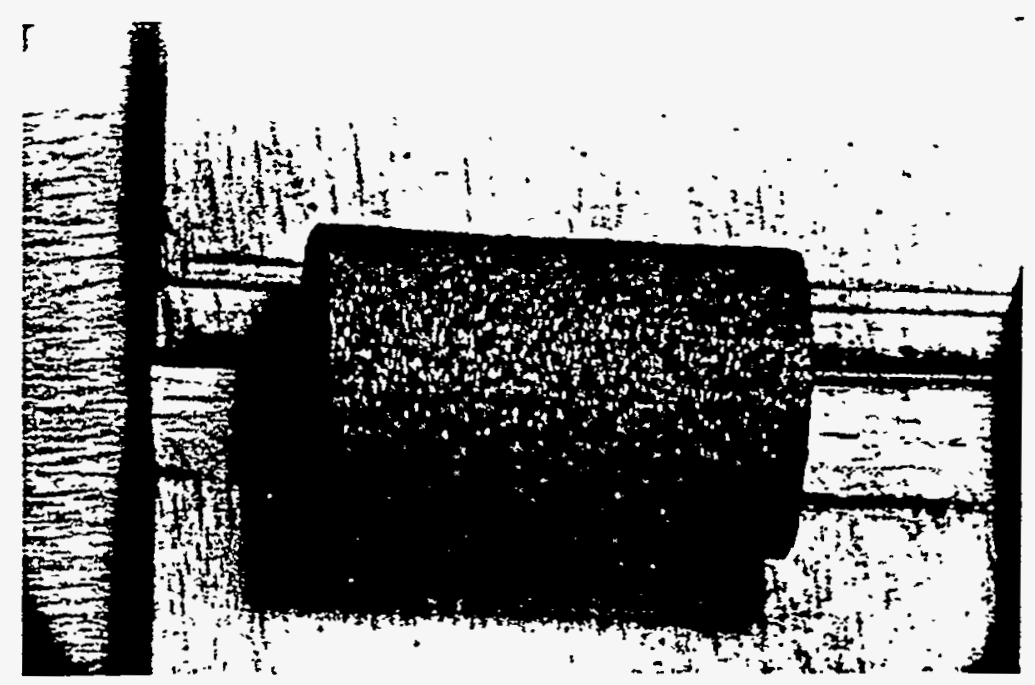

$\frac{\text { HFR-B1 }}{\text { Kapsel } 3}$

K 3.6 .2

$472 / 7$

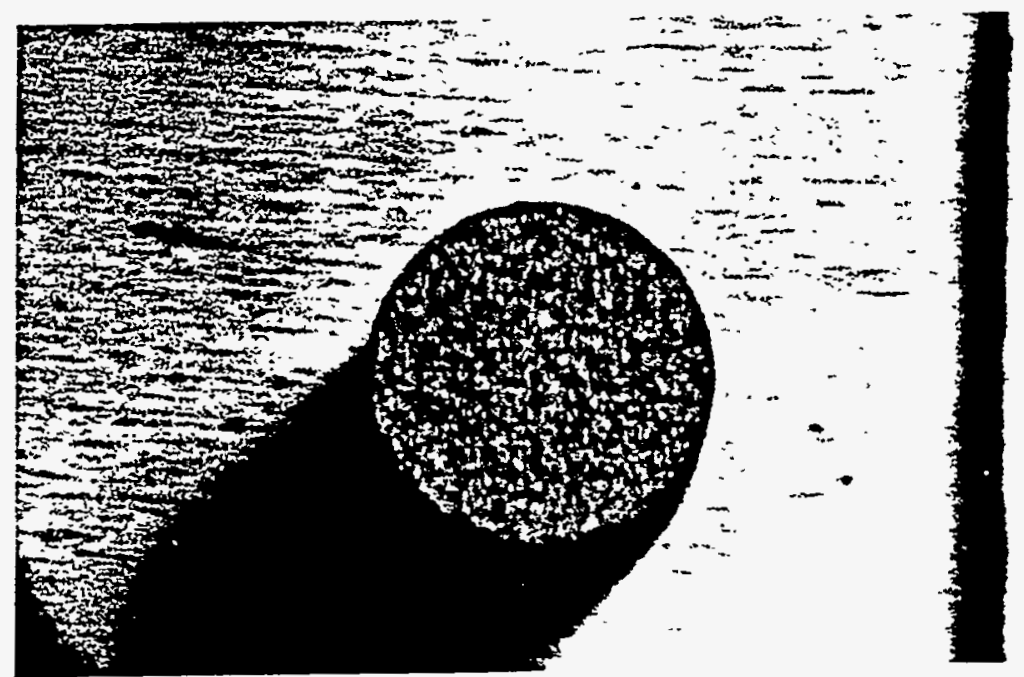

$472 / 9$

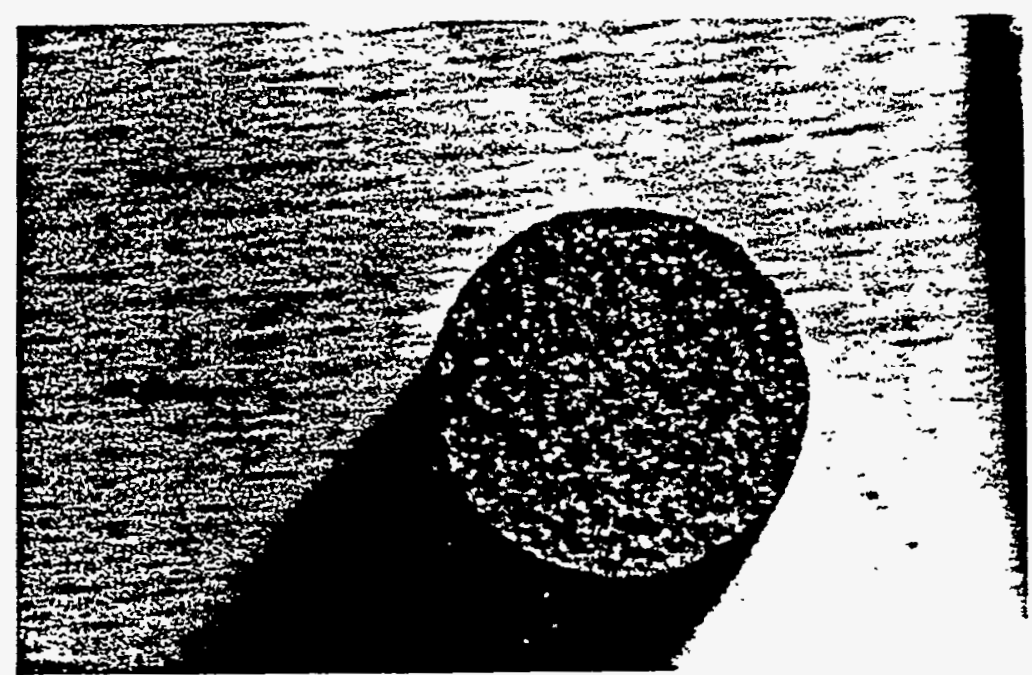

$472 / 10$

Fig. 4.90 Three views of the inert compact position 3.6.2 of capsule 3 Source: Forschungszentrum Julich GmbH, Julich, Germany 

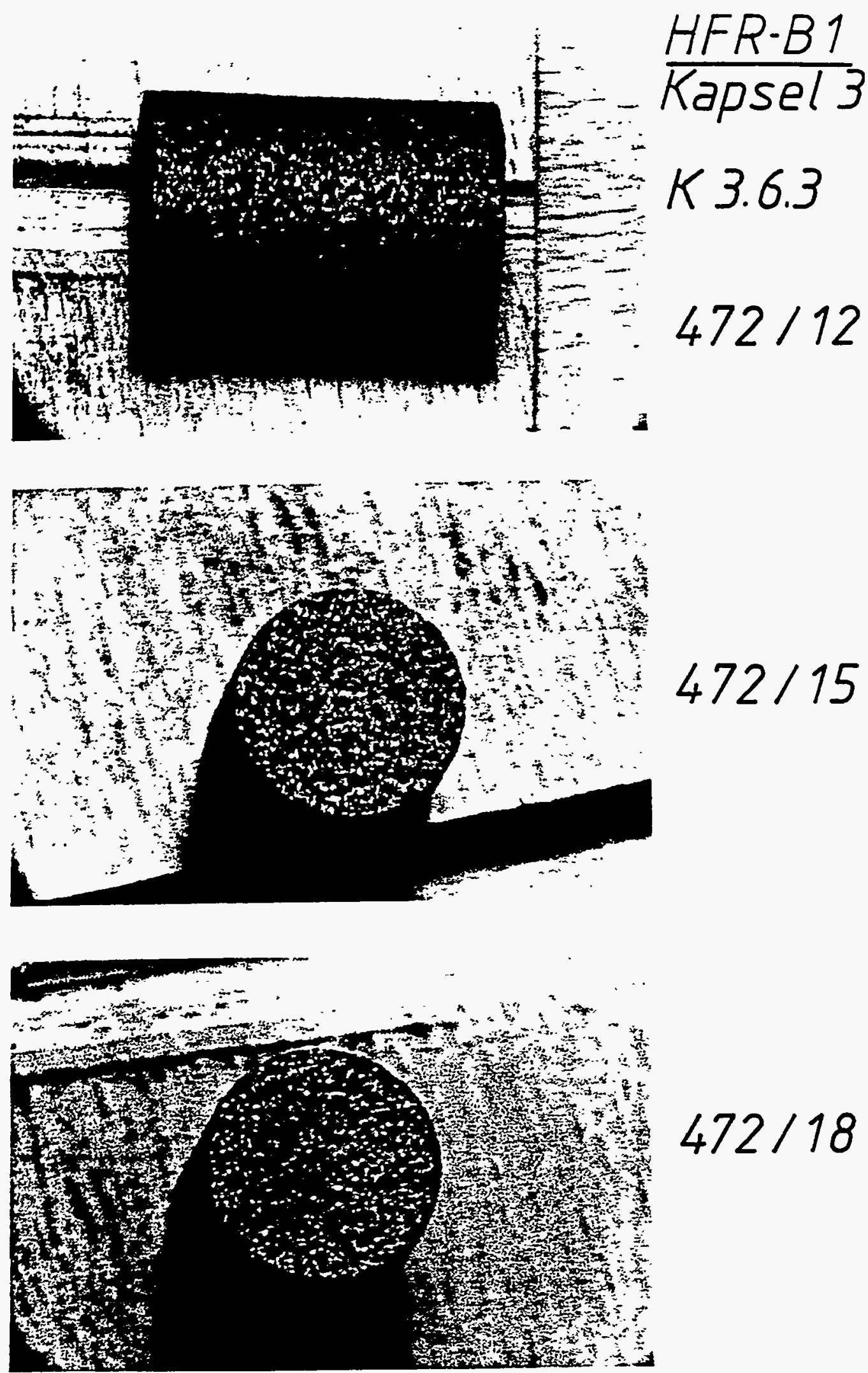

Fig. 4.91 Three views of the inert compact position 3.6.3 of capsule 3 Source: Forschungszentrum Jalich GmbH, Julich, Germany 

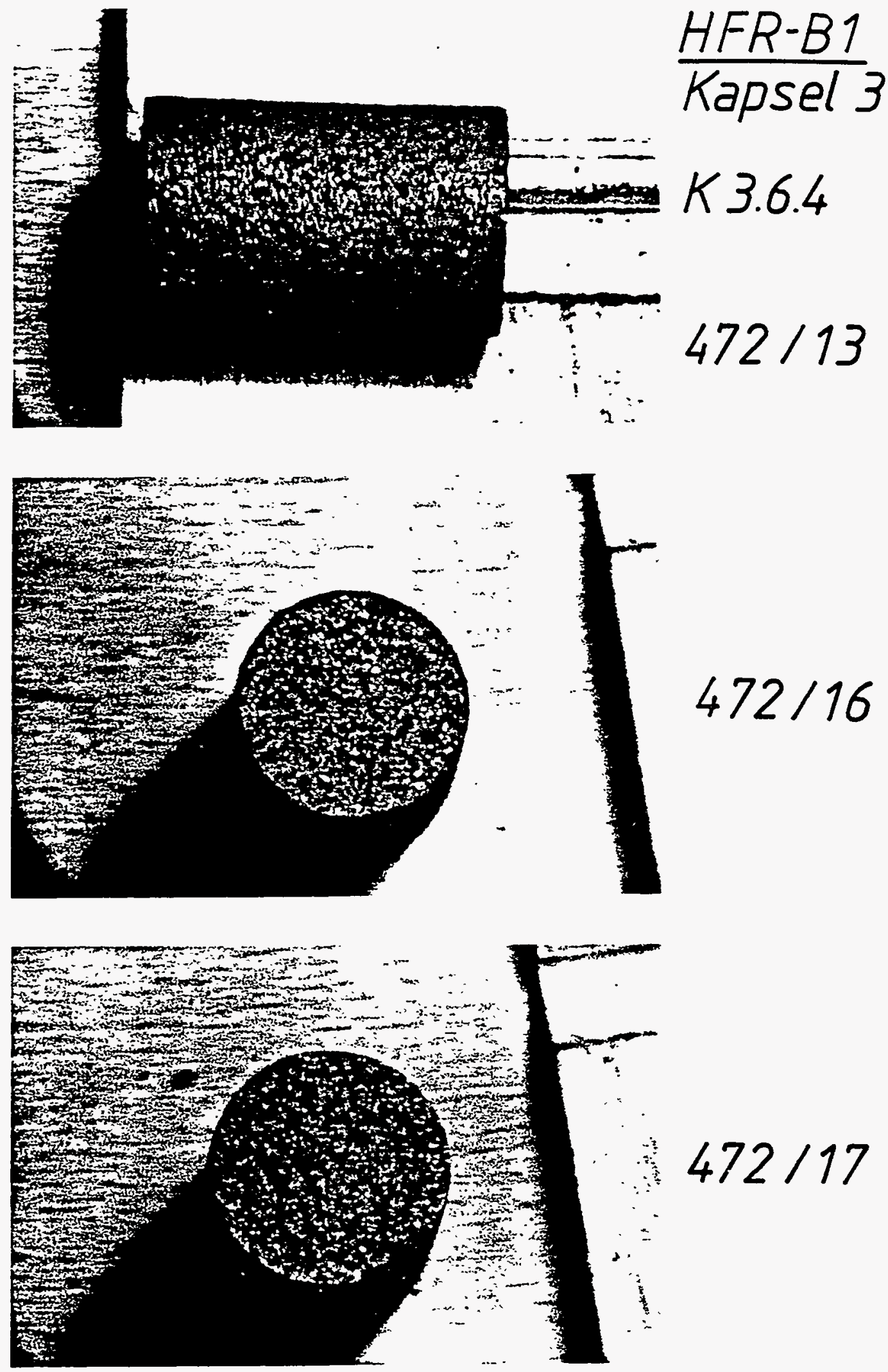

Fig. 4.92 Three views of the inert compact position 3.6.4 of capsule 3 Source: Forschungszentrum Julich GmbH, Julich, Germany 

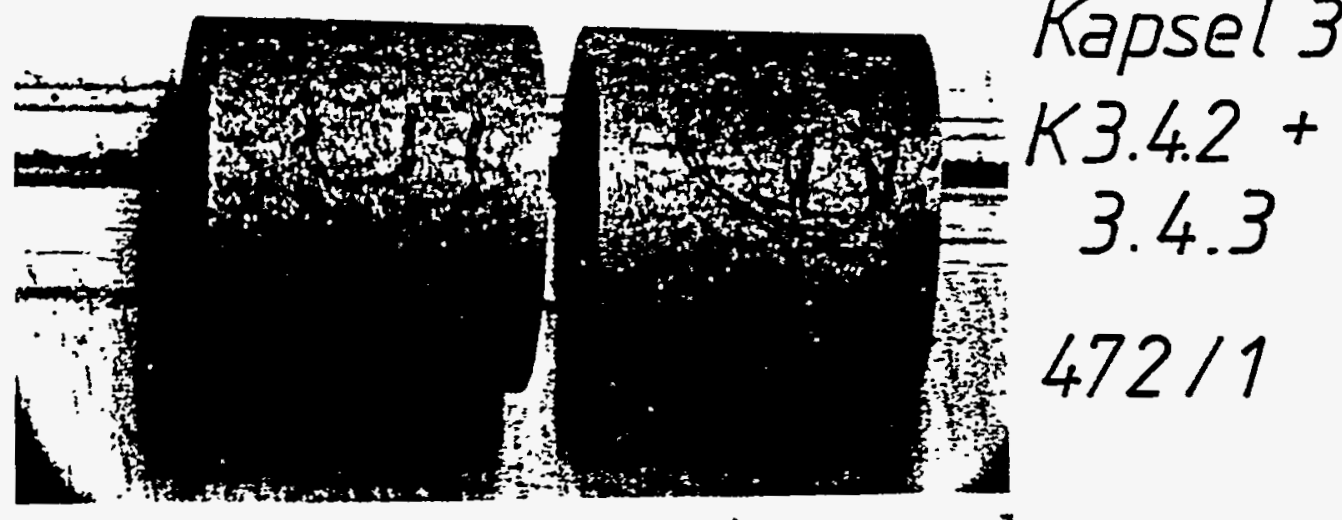

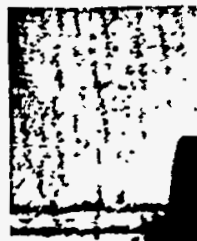

ib
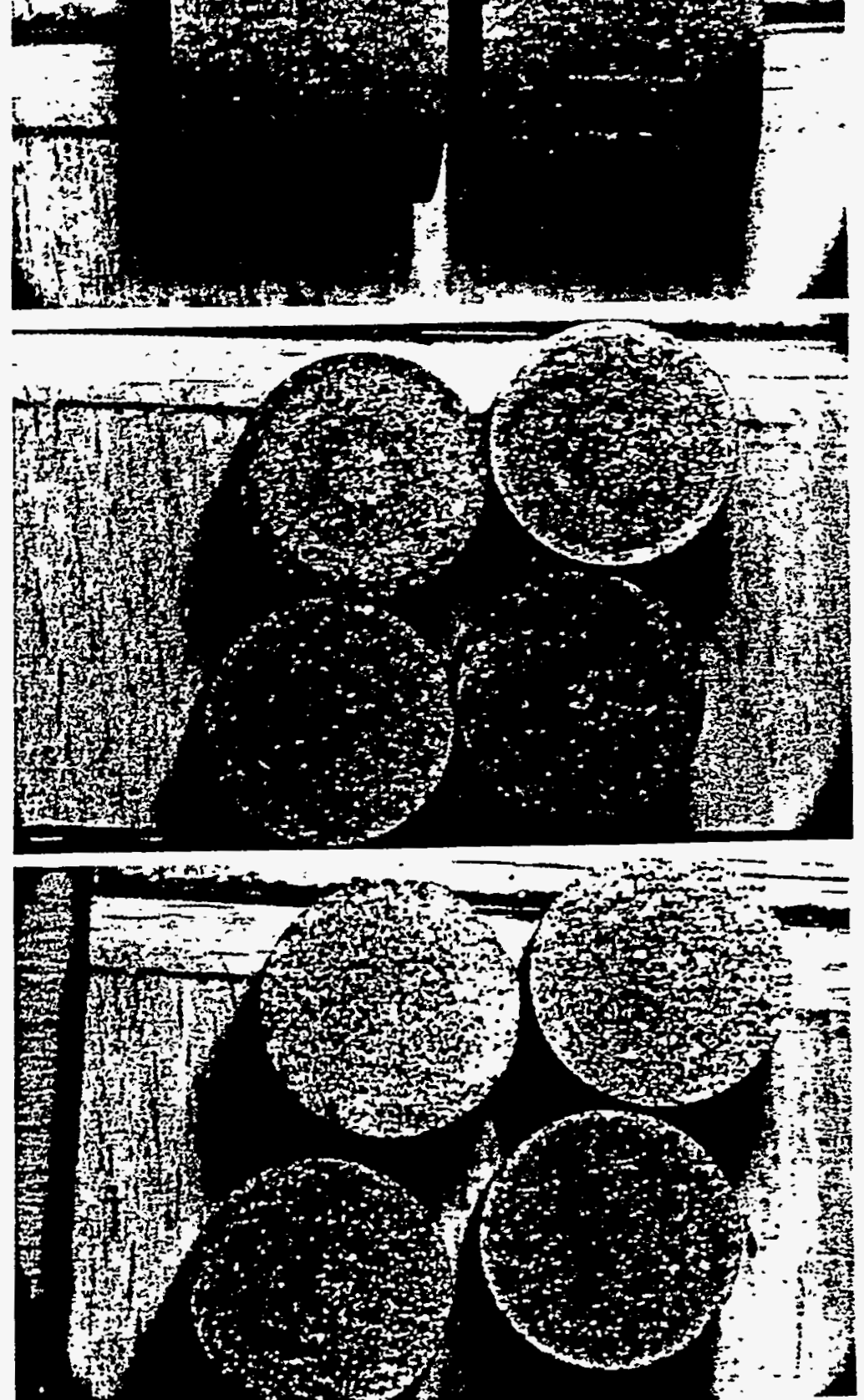

Fig. 4.93 Three views of the graphite cylinders from positions 3.4.2, 3.4.3, 3.4.4 and 3.4.5 of capsule 3 Source: Forschungszentrum Julich GmbH, Jalich, Germany

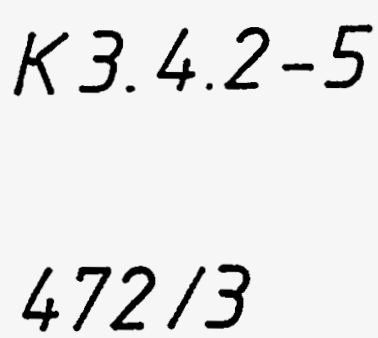

K3.4.2-5

$472 / 4$ 


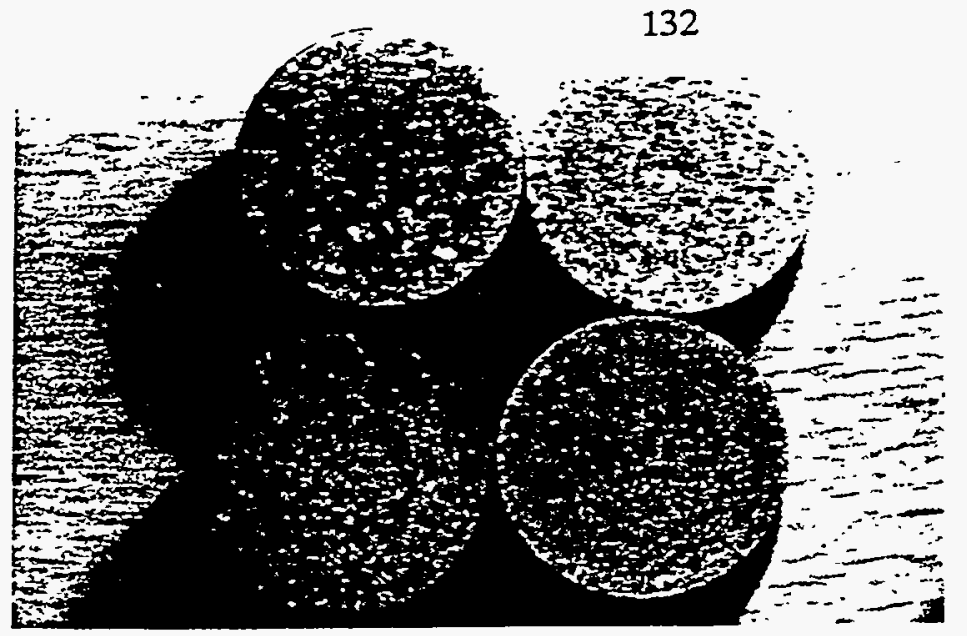

\title{
HFR-B1
}

\author{
K.3.5.2-5 \\ Seite 1 \\ $471 / 25$
}

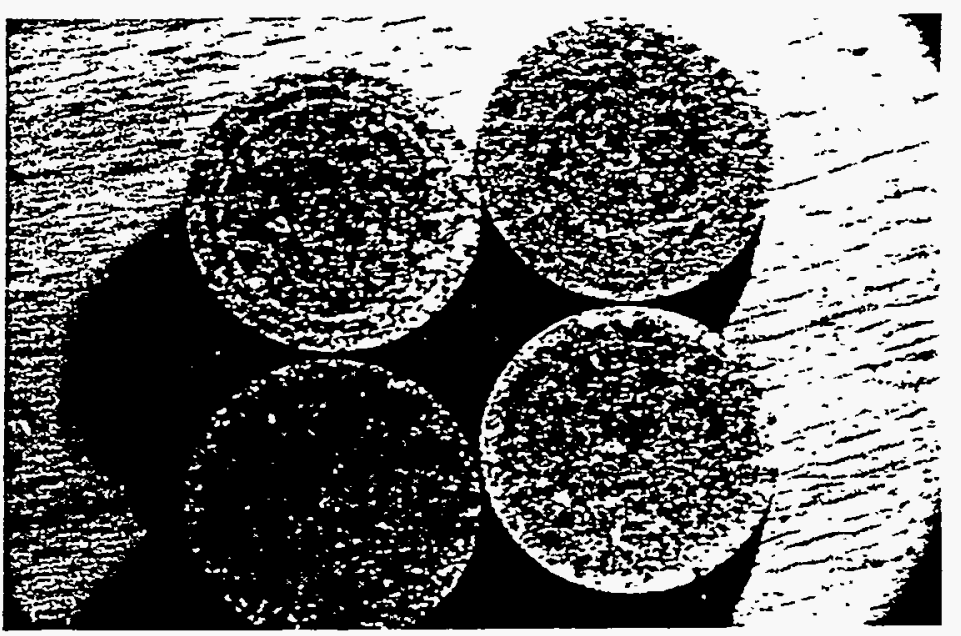

K.3.5.2-5

Seite 2

$471 / 28$

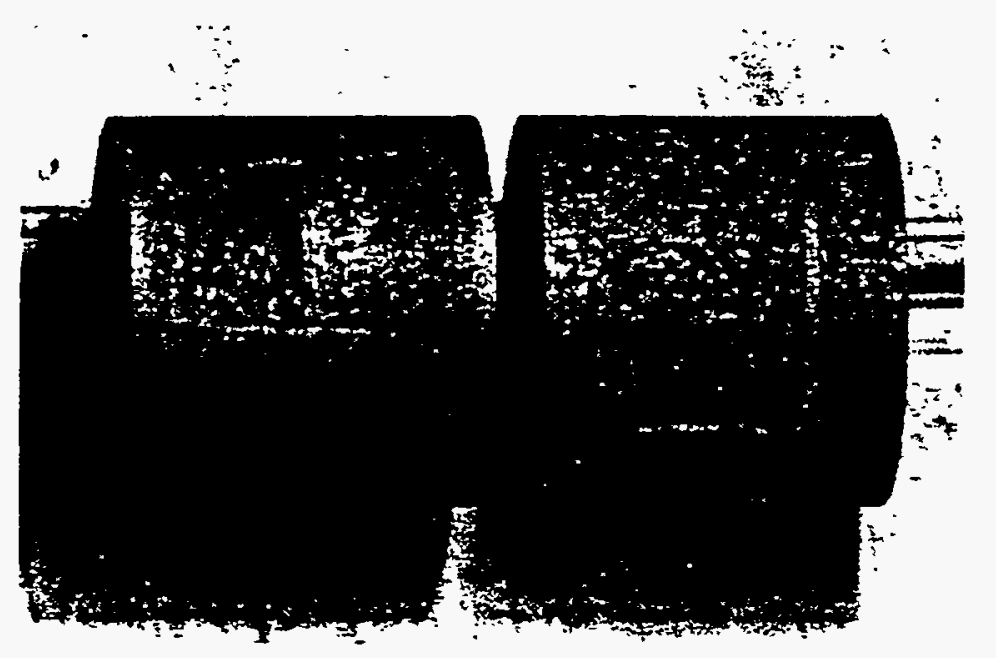

$K 3.5 .4+5$

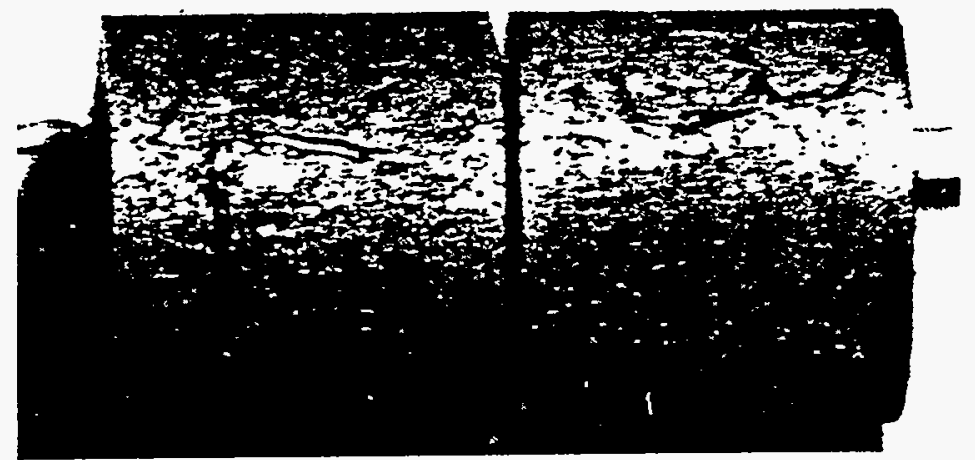

$471 / 22$

Fig. 4.94 Three views of the graphite cylinders from positions 3.5.2, 3.5.3, 3.5.4 and 3.5.5 of capsule 3 Source: Forschungszentrum Julich $\mathrm{GmbH}$, Julich, Germany 
Table 4.31 Dimensional measurements on cylinders of grades H-451 and H451I graphite ${ }^{(2)}$ from capsules 2 and 3. Source: Forschungszentrum Jalich GmbH, Julich, Germany

$\begin{array}{ll}\text { Measurement apparatus: } & \text { Micrometer state } \\ \text { Measurement accuracy: } & \pm 0.05 \mathrm{~mm}^{(b)} \\ & \\ \text { Measurement apparatus: } & \text { Leitz Wegaufnehmer } \\ \text { Measurement accuracy: } & \pm 0.01 \mathrm{~mm}^{(c)}\end{array}$

\begin{tabular}{|c|c|c|c|c|c|c|c|c|c|}
\hline Capsule & Cylinder & Leng & $(\mathrm{mm})$ & & ngth & Diamet & $\mathrm{r}(\mathrm{mm})$ & $\Delta \mathrm{Di}$ & ameter \\
\hline Position $^{(d)}$ & No. & before & after & $(\mathrm{mm})$ & $(\%)$ & before & after & $(\mathrm{mm})$ & (\%) \\
\hline 2.4 .2 & 1 & 14.00 & 13.79 & 0.21 & 0.03 & 14.99 & 14.82 & 0.17 & 0.03 \\
\hline 2.4 .3 & 2 & 13.97 & 13.8 & 0.17 & 1.2 & 14.99 & 14.80 & 0.19 & 1.3 \\
\hline 2.4 .4 & 11 & 13.96 & 13.77 & 0.19 & 0.03 & 14.99 & 14.70 & 0.29 & 0.04 \\
\hline 2.4 .5 & 12 & 13.96 & 13.7 & 0.26 & 1.9 & 14.99 & 14.70 & 0.29 & 1.9 \\
\hline 2.5 .2 & 4 & 14.00 & 13.8 & 0.20 & 1.4 & 14.99 & 14.80 & 0.19 & 1.3 \\
\hline 2.5 .3 & 3 & 14.00 & 13.74 & 0.26 & 0.04 & 14.99 & 14.79 & 0.20 & 0.03 \\
\hline 2.5 .4 & 13 & 13.84 & 13.65 & 0.19 & 0.03 & 14.99 & 14.68 & 0.31 & 0.05 \\
\hline 2.5 .5 & 14 & 13.94 & 13.7 & 0.24 & 1.7 & 14.97 & 14.80 & 0.17 & 1.1 \\
\hline 3.4 .2 & 5 & 14.02 & 14.0 & 0.02 & 0.14 & 14.99 & 15.0 & -0.01 & -0.07 \\
\hline 3.4.3 & 6 & 13.97 & 13.92 & 0.05 & 0.01 & 14.99 & 14.91 & 0.08 & 0.01 \\
\hline 3.4.4 & 15 & 13.91 & 13.9 & 0.01 & 0.07 & 14.99 & 14.9 & 0.09 & 0.60 \\
\hline 3.4.5 & 16 & 13.99 & 13.84 & 0.15 & 0.02 & 14.99 & 14.87 & 0.12 & 0.02 \\
\hline 3.5 .2 & 7 & 14.02 & 13.9 & 0.12 & 0.86 & 14.99 & 14.9 & 0.09 & 0.60 \\
\hline 3.5.4 & 17 & 13.95 & 13.9 & 0.05 & 0.36 & 14.99 & 14.9 & 0.09 & 0.60 \\
\hline 3.53 & 8 & 14.02 & 13.91 & 0.11 & 0.02 & 14.99 & 14.89 & 0.10 & 0.01 \\
\hline 3.5 .5 & 18 & 13.94 & 13.80 & 0.15 & 0.02 & 14.99 & 14.87 & 0.12 & 0.02 \\
\hline
\end{tabular}

(a) Grade H-451 graphite cylinders are numbered 1 through 8 . Grade $H-4511$ graphite cylinders are numbered 11 through 18.

(b) These apply to cylinder numbers $2,4,5,7$, and $12,14,15,17$.

(c) These apply to cylinder numbers $1,3,6,8$, and $11,13,16,18$.

(d) The capsule position is identified by $x . y . z$ where $x$ is the the capsule number, $y$, the hole number, and $z$ the stack number. See also Figs. 3.2 and 3.3. 
Table 4.32. Weight measurements on cylinders of grades H-451 and H451I graphite ${ }^{(2)}$ from capsules 2 and 3. Source: Forschungszentrum Julich GmbH, Julich, Germany

$$
\begin{aligned}
& \text { Weighing apparatus: Mettler PT } 320 \mathrm{SE}^{(\text {b) }} \\
& \text { Weighing accuracy: } \quad \pm 0.05 \mathrm{~mm}^{(b)} \\
& \text { Weighing apparatus: Mettler PM } 400^{(c)} \\
& \text { Weighing accuracy: } \quad \pm 02 \mathrm{mg}^{(\mathrm{c})}
\end{aligned}
$$

\begin{tabular}{|c|c|c|c|c|c|}
\hline $\begin{array}{l}\text { Capsule } \\
\text { Position }^{(d)}\end{array}$ & $\begin{array}{c}\text { Compact } \\
\text { No. }\end{array}$ & before & after & (g) & $\%$ \\
\hline 2.4 .2 & 1 & 4.272 & 4.271 & 0.001 & 0.0 \\
\hline 2.4 .3 & 2 & 4.2274 & 4.227 & 0.0004 & - \\
\hline 2.4 .4 & 11 & 4.386 & 4.384 & 0.002 & 0.0 \\
\hline 2.4 .5 & 12 & 4.3753 & 4.372 & 0.003 & 0.08 \\
\hline 2.5 .2 & 4 & 4.2410 & 4.240 & 0.001 & 0.02 \\
\hline 2.5 .3 & 3 & 4.266 & 4.265 & 0.001 & 0.0 \\
\hline 2.5 .4 & 13 & 4.351 & 4.350 & 0.001 & 0.0 \\
\hline 2.5 .5 & 14 & 4.2981 & 4.297 & 0.001 & 0.02 \\
\hline 3.4 .2 & 5 & 4.2686 & 4.264 & 0.005 & 0.1 \\
\hline 3.4 .3 & 6 & 4.214 & 4.211 & 0.003 & 0.0 \\
\hline 3.4 .4 & 15 & 4.3759 & 4.372 & 0.004 & 0.1 \\
\hline 3.4 .5 & 16 & 4.344 & 4.339 & 0.005 & 0.0 \\
\hline 3.5 .2 & 7 & 4.2686 & 4.265 & 0.004 & 0.1 \\
\hline 3.5.3 & 8 & 4.162 & 4.158 & 0.004 & 0.0 \\
\hline 3.5.4 & 17 & 4.3981 & 4.392 & 0.006 & 0.1 \\
\hline 3.5 .5 & 18 & 4.363 & 4.356 & 0.007 & 0.0 \\
\hline
\end{tabular}

(2) Grade $\mathrm{H}-451$ graphite cylinders are numbered 1 through 8 . Grade $\mathrm{H}-451 \mathrm{I}$ graphite cylinders are numbered 11 through 18.

(b) These apply to cylinder numbers $2,4,5,7$ and 12, 14, 15, 17 .

(c) These apply to cylinder numbers $1,3,6,8$ and $11,13,16$, and 18 .

(d) The capsule position is identified by $x . y . z$ where $x$ is the capsule number, $y$ the hole number, and $\mathrm{z}$ the stack number. See also Figs. 3.2 and 3.3. 
Table 4.33. Dimensional measurements on inert compacts and selected graphite annuli from capsules 2 and 3. Source: Forschungszentrum Julich GmbH, Jalich, Germany

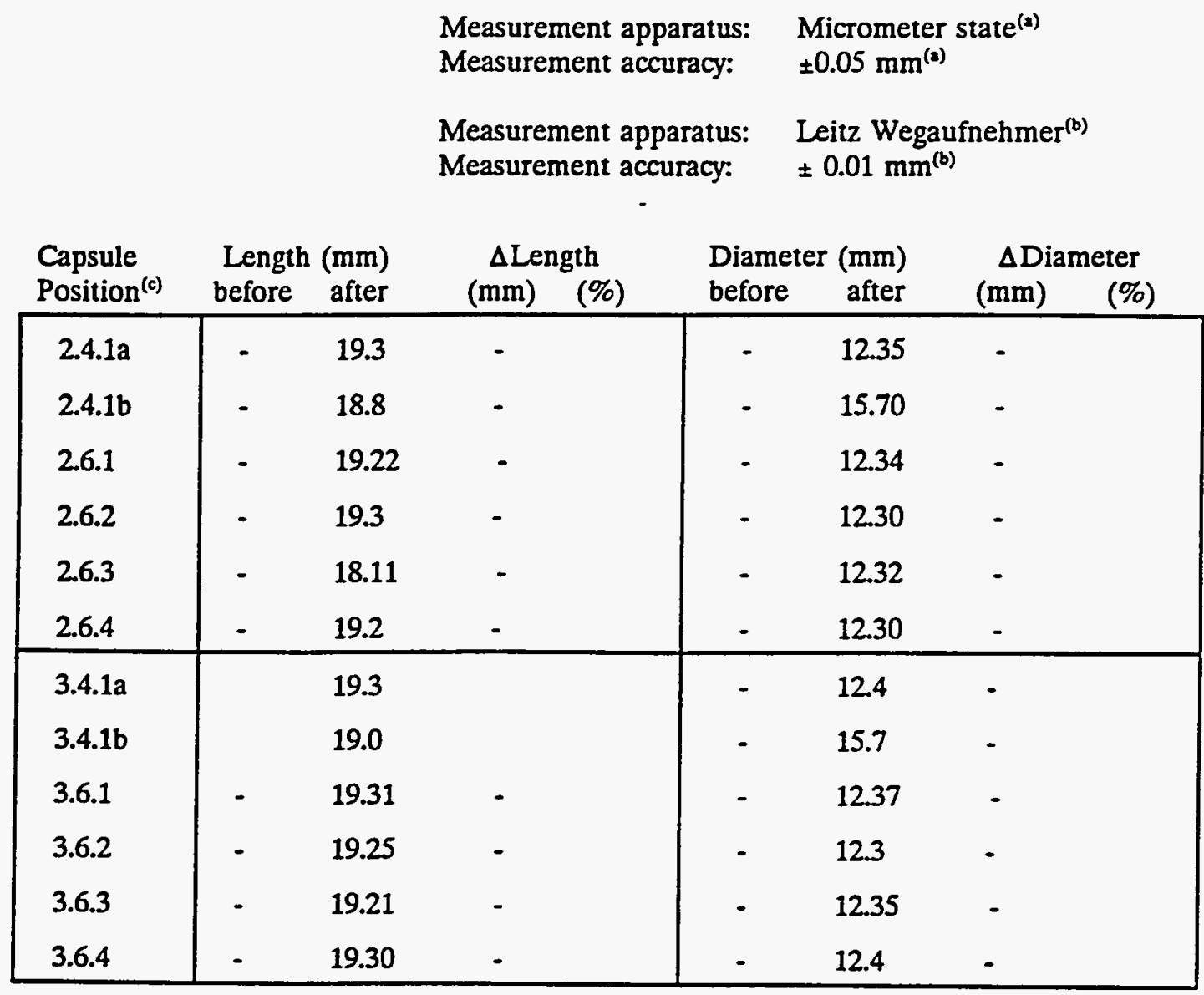

(a) These apply ${ }^{2}$ to inert compacts number 2.4.1a, 2.6.2, 2.6.4, 3.6.2, and 3.6.4.

(b) These apply ${ }^{11}$ to inert compacts number 2.6.1, 2.6.3, 3.6.1, and 3.6.3.

(e) The capsule position is identified by $x . y . z$ where $x$ is the capsule number, $y$, the hole number, and $z$ the stack number. The capsule position is identified by x.y.z.a or x.y.z.b for the compact and annulus, respectively, when both compact and annulus are measured; otherwise $x y . z$ represents the compact only. See also Figs. 3.2 and 3.3. 
Table 4.34. Weight measurements on inert compacts and selected graphite annuli from capsules 2 and 3 Source: Forschungszentrum Julich $\mathrm{GmbH}$, Julich, Germany

$\begin{array}{ll}\text { Weighing apparatus: } & \text { Mettler PT 320 SE(a) } \\ \text { Weighing accuracy: } & \pm 0.05 \mathrm{~mm}^{(2)}\end{array}$

Weighing apparatus: Mettler PM $400^{(\text {b) }}$

Weighing accuracy: $\quad \pm 02 \mathrm{mg}^{(\mathrm{b})}$

\begin{tabular}{|c|c|c|c|c|}
\hline \multirow{2}{*}{$\begin{array}{l}\text { Capsule } \\
\text { Position }^{(c)}\end{array}$} & \multicolumn{2}{|c|}{ Weight (g) } & \multicolumn{2}{|c|}{$\Delta$ Weight } \\
\hline & before & after & (g) & $\%$ \\
\hline 2.4.1a & - & 3.229 & - & - \\
\hline $2.4 .1 \mathrm{~b}$ & - & 2.142 & - & - \\
\hline 2.6.1 & - & 3.327 & - & - \\
\hline 2.6.2 & - & 3.338 & - & - \\
\hline 2.6.3 & - & 3.324 & - & - \\
\hline 2.6 .4 & - & 3.313 & - & - \\
\hline $3.4 .1 \mathrm{a}$ & - & 3.219 & - & - \\
\hline $3.4 .1 \mathrm{~b}$ & - & 2.154 & - & - \\
\hline 3.6 .1 & - & 3.338 & - & - \\
\hline 3.6 .2 & - & 3.326 & - & - \\
\hline 3.6.3 & - & 3.325 & - & - \\
\hline 3.6 .4 & - & 3.327 & - & - \\
\hline
\end{tabular}

(a) These apply ${ }^{2}$ to inert compacts number 2.4.1a, 2.6.2, 2.6.4, 3.6.2, and 3.6.4.

(b) These apply ${ }^{11}$ to inert compacts number 2.6.1, 2.6.3, 3.6.1, and 3.6.3.

(c) The capsule position is identified by x.y.z where $x$ is the capsule number, $y$, the hole number, and $z$ the stack number. The capsule position is identified by x.y.z.a or x.y.z.b for the compact and annulus, respectively, when both compact and annulus are measured; otherwise x.y.z represents the compact only. See also Figs. 3.2 and 3.3. 


\subsubsection{Visual Inspection and Photography ${ }^{12}$}

A particle tray, cover and screw, before adding coated fuel particles and irradiating, are shown in Fig. 4.95. Ten trays from capsule 2 after irradiation are shown in Fig. 4.96. Similarily, the graphite crucible and the niobium encapsulted fuel particles are shown in Fig. 4.97 before irradiation. The crucible after irradiation in capsule 2 is shown inFig. 4.98. Particle trays 2-3, 2-4, 2-7, 2-8, and 3-3, 3-4, 3-7, 3-8 were opened. Photographs are shown in Figs. 4.99 and 4.100.

\subsubsection{Gamma Counting of Kernels, Coatings and Particles ${ }^{13}$}

A total of 40 particles from capsules 2 and 3 were gamma counted individually, and after separating the kernels and coatings of each particle, these constituents were individually counted. From these measurements the kernel release of fission products in intact particles was determined. The separation of the kernels and coatings was made by cracking the particles in an apparatus with which the force upon cracking could be measred.

\subsubsection{Measurement}

The particles as well as the kernels and coatings were measured using a measurement plate located in the in the hall of the hot cells. The meaurement configuration and conditions are given in Table 4.3.5.

Twenty particles were taken from the trays in each capsule; five from each of the trays 2-3, 2-4, 2-7, $2-8$, and $3-3,3-4,3-7,3-8$. Trays $2-3,2-7,3-3$ and 3-7 each contained 110 UCO fissile particles and trays 2-4, 2-8, 3-4 and 3-8 each contained $50 \mathrm{ThO}^{2}$ fertile particles. Five particles were chosen from each tray.

\subsubsection{Results}

The activities of the intact particles are presented in Tables $4.36,4.37,4.38$, and 4.39 and plotted in Figs. 4.101, 4.102, 4.103, and 4.104 for the individual fissile and fertile particles from capsules 2 and 3 and for the isotopes ${ }^{154} \mathrm{Eu},{ }^{144} \mathrm{Ce},{ }^{137} \mathrm{Cs},{ }^{134} \mathrm{Cs},{ }^{125} \mathrm{Sb},{ }^{166} \mathrm{Ru}$, and ${ }^{60} \mathrm{Co}$.

The activities of the individual kernels from cracked particles are presented in Tables $4.40,4.41,4.42$, and 4.43 and plotted in Figs. 4.105, 4.106, 4.107, and 4.108 for particles from capsules 2 and 3 and for isotopes ${ }^{154} \mathrm{Eu},{ }^{144} \mathrm{Ce},{ }^{137} \mathrm{Cs},{ }^{134} \mathrm{Cs},{ }^{125} \mathrm{Sb}$, and ${ }^{106} \mathrm{Ru}$.

The activities of the coatings from cracked particles are presented in Tables $4.44,4.45,4.46$, and 4.47 and plotted in Figs. 4.109, 4.110, 4.111, and 4.112 for particles from capsules 2 and 3 and for isotopes ${ }^{154} \mathrm{Eu},{ }^{144} \mathrm{Ce},{ }^{137} \mathrm{Cs},{ }^{134} \mathrm{Cs},{ }^{135} \mathrm{Sb},{ }^{106} \mathrm{Ru}$, and ${ }^{60} \mathrm{Co}$.

The sums of the activities of the kernels and the associated coatings are given in Tables 4.48, 4.49, 4.50 and 4.51 .

The percent retention of fission products in the kernels of intact fissile and fertile particles from capsules 2 and 3 are given in Tables 4.52, 4.53, 4.54, and 4.55 and shown in Figs. 4.113, 4.114, 4.115, and 4.116. 


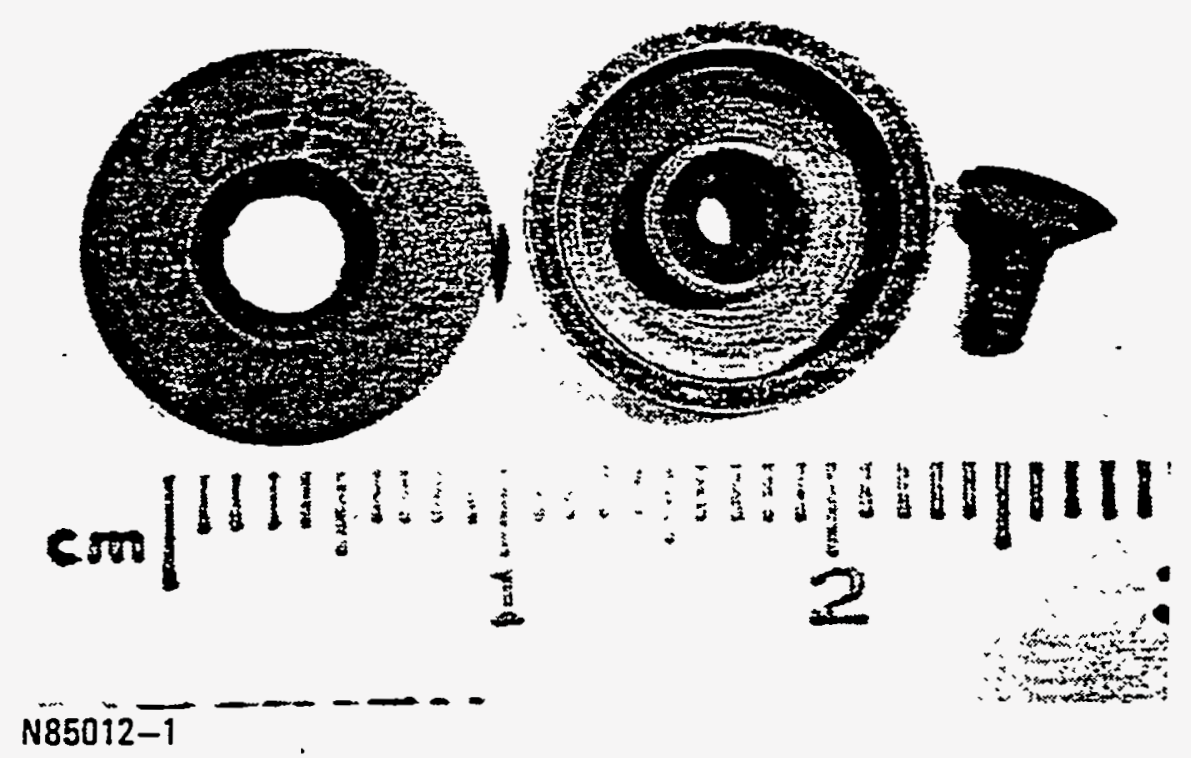

Fig. 4.95 Component of the particle trays before irradiation Source : General Atomics Company, San Diego, California
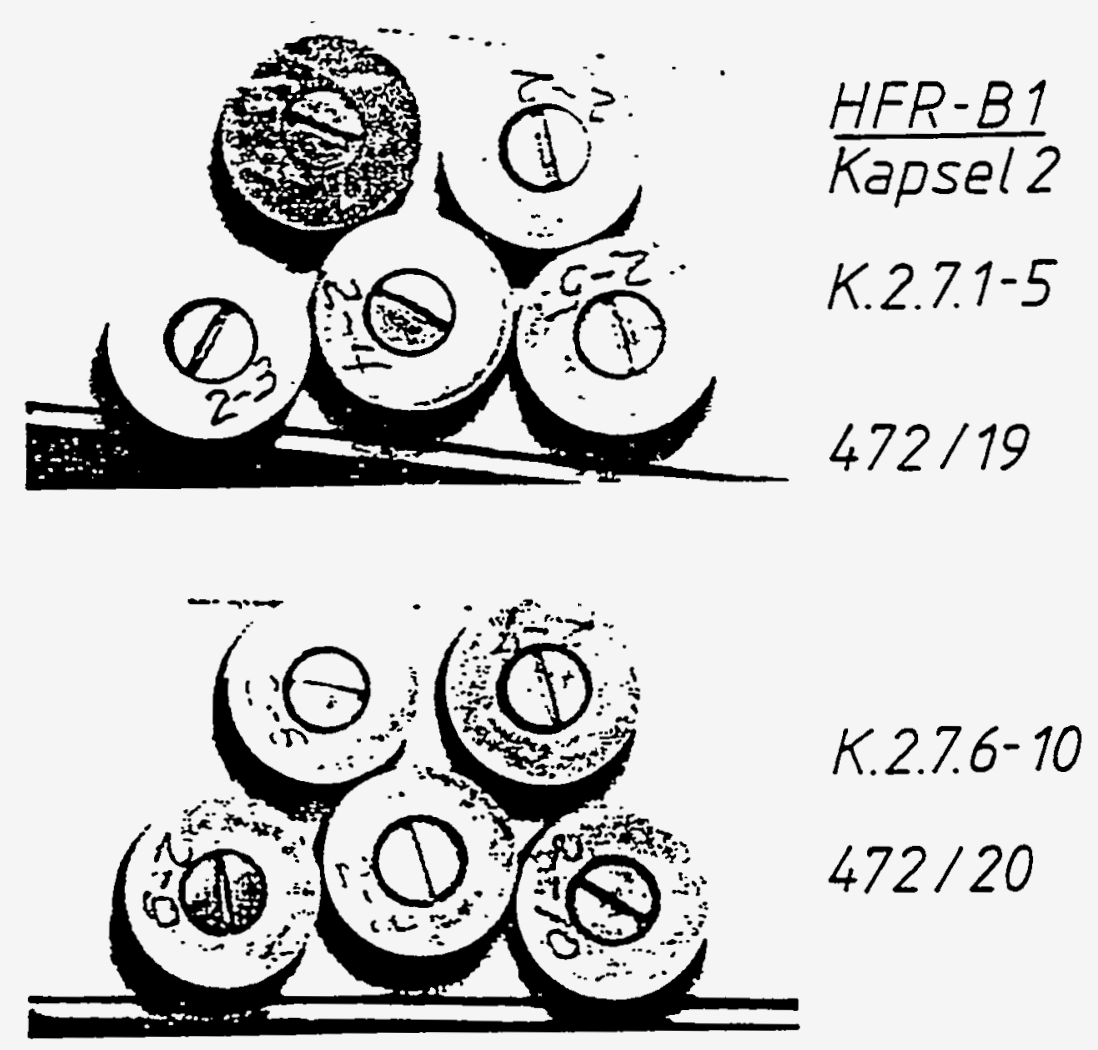

Fig. 4.96 The assembled trays after irradiation Source: Forschungszentrum Julich GmbH, Julich, Germany 


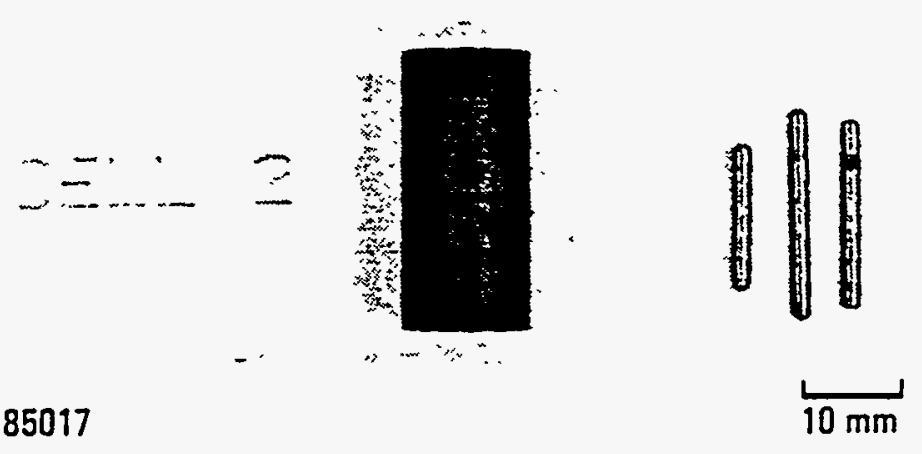

N85019

END VIEW OF

CELLS 2 AND 3

CRUCIBLES

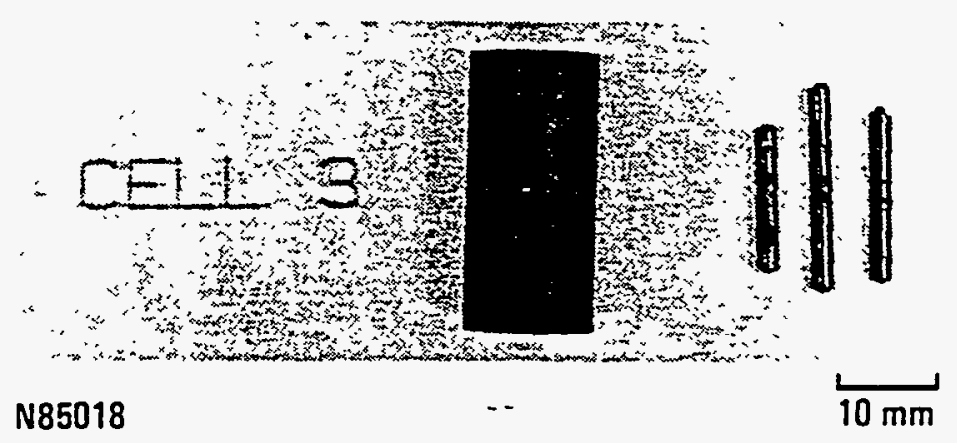

Fig. 4.97 The graphite crucible and niobium encapsulated fuel particles before irradiation Source: General Atomics Company, San Diego, California

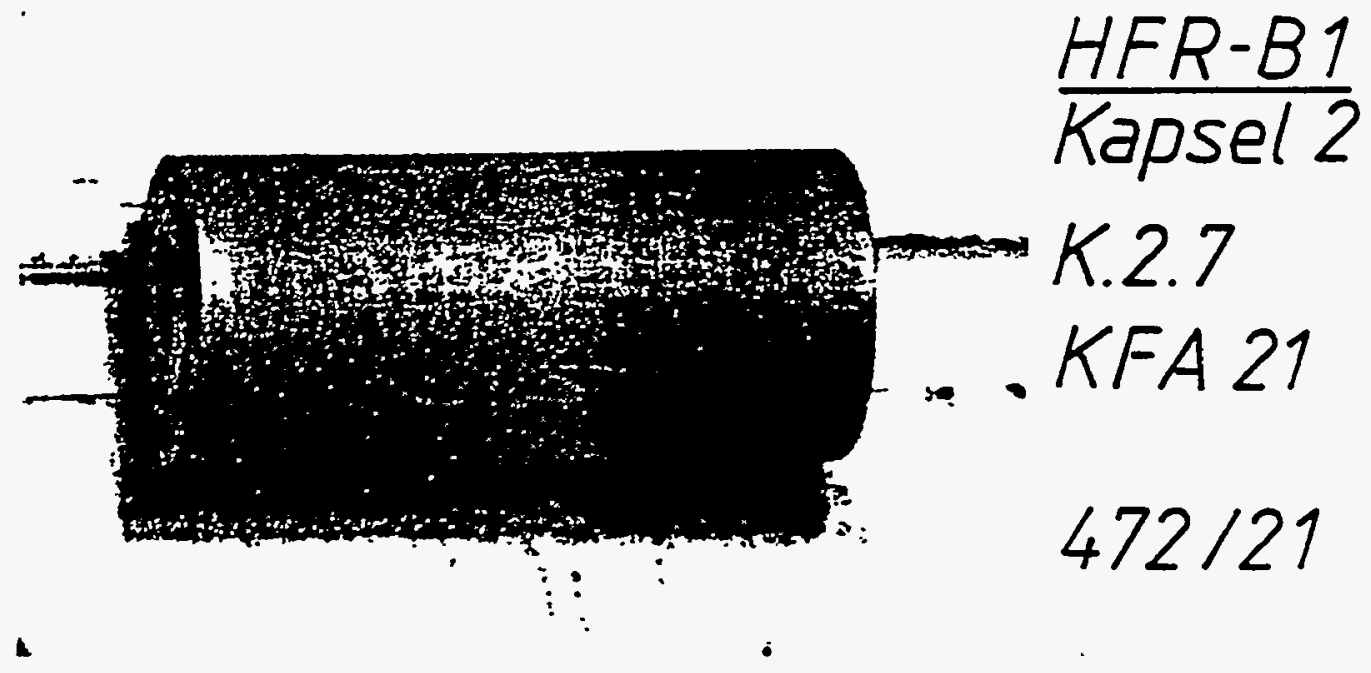

Fig. 4.98 The graphite crucible after irradiation in capsule 2 source: Forschungszentrum Jalich GmbH, Jalich, Germany 

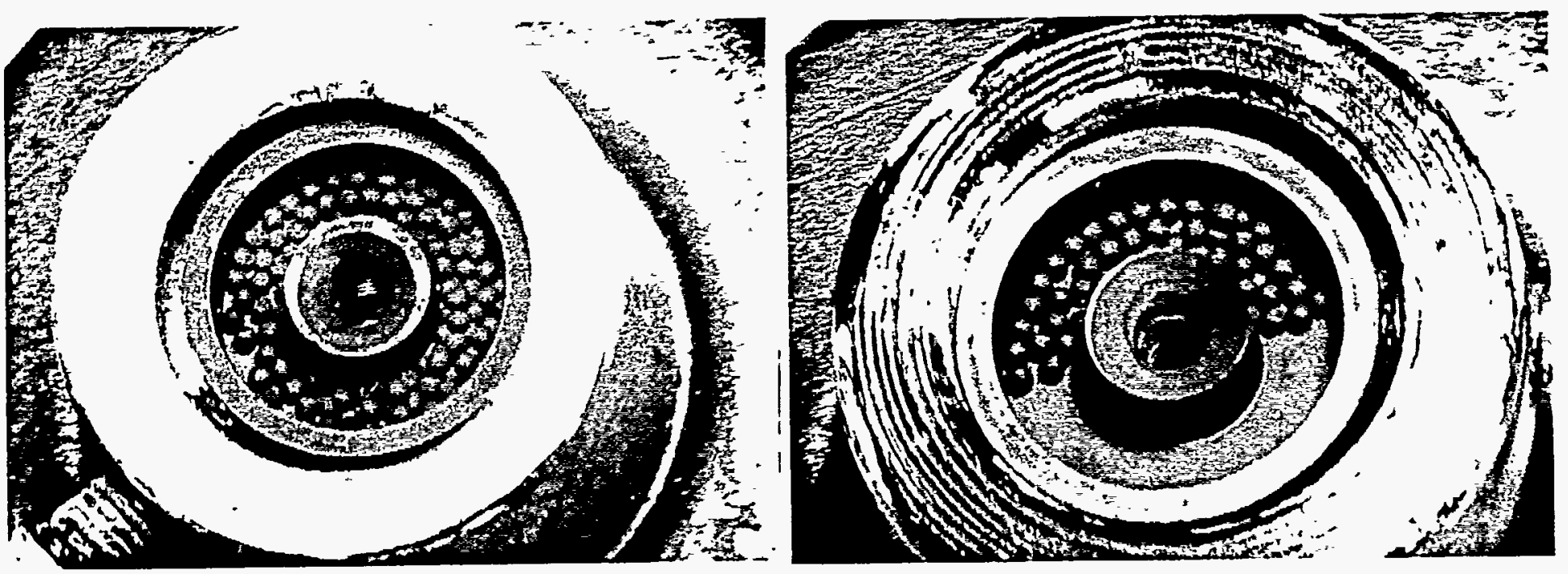

\section{$3-7$}

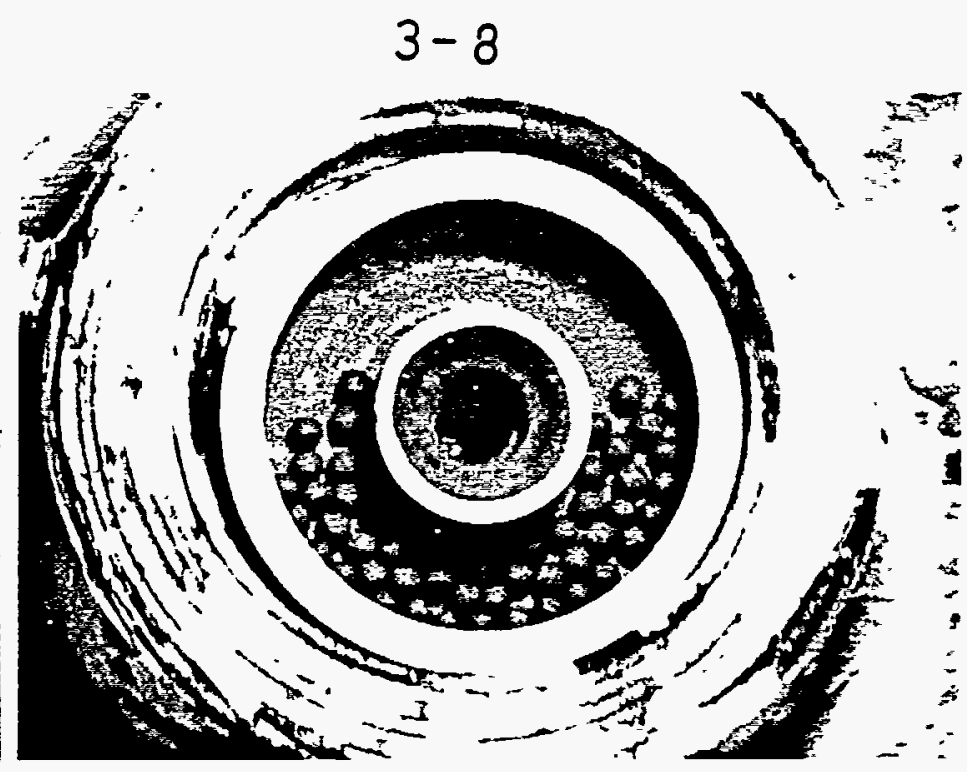

Fig. 4.100 Views of the opened unbonded particle trays 3-3, 3-4, 3-7, and 3-8 from capsule 3 Source: Forschungszentrum Julich GmbH, Julich, Germany 
Table 4.35 Measurement Configuration Source: Forschungszentrum Julich GmbH, Jalich, Germany

Detector

Voltage

Preamplifier

Main Amplifier

High Voltage Apparatus

Multichannel analyzer

Computer

Gamma analysis and evaluation system

Spread sheet

Calibration standard
DSG Typ PGP 1516 SNG-167 planar

$-3000 \mathrm{~V}$

DSG $51 \mathrm{P}$

Canberra Model 2011

Ortec Model 459

Canberra 35 plus

Compaq 386/20

Canberra Spectran F

Microsoft Excel

${ }^{152} \mathrm{Eu}$; preparation no. BV 938 from the firm Amersham Buchler

Activity on $1.12 .89: 407.1 \mathrm{kBq} \pm 3 \%$ 
Table 4.36 Inventory $(\mathrm{Bq})$ of individual fissile particles for selected nuclides from particle trays in capsule 2 Source: Forschungszentrum Jalich GmbH, Jalich, Germany

\begin{tabular}{|c|c|c|c|c|c|c|c|}
\hline Partikel Nr. & Ce 144 & Co 60 & Cs 134 & Cs 137 & Eu 154 & Ru 106 & Sb 125 \\
\hline $2-3 / 1$ & $4,57 E+07$ & $1,67 E+05$ & $7,06 E+06$ & $4,14 E+06$ & $1,62 E+05$ & $1,81 E+07$ & $1,86 E+05$ \\
\hline $2-3 / 2$ & $5,07 E+07$ & $2,24 E+05$ & $7,80 E+06$ & $4,62 E+06$ & $2,20 E+05$ & $2,08 E+07$ & $2,12 E+05$ \\
\hline $2-3 / 3$ & $4,71 E+07$ & $1,96 E+05$ & $7,71 E+06$ & $4,54 E+06$ & $1,89 E+05$ & $1,96 \mathrm{E}+07$ & $2,14 E+05$ \\
\hline $2-3 / 4$ & $5,61 E+07$ & $3,07 E+05$ & $7,89 E+06$ & $4,67 E+06$ & $1,85 E+05$ & $2,01 E+07$ & $2,36 E+05$ \\
\hline $2-3 / 5$ & $5,61 E+07$ & $2,08 E+05$ & $8,08 E+06$ & $4,76 E+06$ & $1,98 E+05$ & $2,12 E+07$ & $2,07 E+05$ \\
\hline $2-7 / 1$ & $4,89 E+07$ & $8,59 E+04$ & $7,52 E+06$ & $4,53 E+06$ & $1,90 E+05$ & $1,93 E+07$ & $2,17 E+05$ \\
\hline $2-7 / 2$ & $4,89 E+07$ & $7,93 E+04$ & $7,66 \mathrm{E}+06$ & $4,54 E+06$ & $2,00 E+05$ & $1,94 E+07$ & $1,56 E+05$ \\
\hline $2-7 / 3$ & $4,40 E+07$ & $1,56 E+05$ & $6,82 E+06$ & $4,06 E+06$ & $1,66 E+05$ & $1,79 E+07$ & $2.12 E+05$ \\
\hline $2-7 / 4$ & $4,53 E+07$ & $1,70 E+05$ & $6,78 E+06$ & $4,02 E+06$ & $1,65 E+05$ & $1,72 E+07$ & $1,92 E+05$ \\
\hline $2-7 / 5$ & $3,95 E+07$ & $9,33 E+04$ & $6,03 E+06$ & $3,61 E+06$ & $1,52 E+05$ & $1,61 E+07$ & $1,70 E+05$ \\
\hline
\end{tabular}

Table 4.37 Inventory $(\mathrm{Bq})$ of individual fertile particles for selected nuclides from particle trays in capsule 2 Source: Forschungszentrum Jalich GmbH, Julich, Germany

\begin{tabular}{|c|c|c|c|c|c|c|c|}
\hline Partikel Nr. & Ce 144 & Co 60 & Cs 134 & Cs 137 & Eu 154 & Ru 106 & Sb 125 \\
\hline $2-4 / 1$ & $1,71 E+07$ & $1,88 E+05$ & $1,25 E+06$ & $1,27 E+06$ & $3,13 E+04$ & $9,63 E+05$ & $1,95 E+05$ \\
\hline $2-4 / 2$ & $1,77 E+07$ & $1,92 E+05$ & $1,25 E+06$ & $1,27 E+06$ & $2,90 E+0.4$ & $9,26 E+05$ & $2,01 E+05$ \\
\hline $2-4 / 3$ & $1,88 E+07$ & $1,07 E+05$ & $1,33 E+06$ & $1,32 E+06$ & $2,47 E+04$ & $9,49 E+05$ & $2,16 E+05$ \\
\hline $2-4 / 4$ & $1,88 E+07$ & $1,51 E+05$ & $1,26 E+06$ & $1,28 E+06$ & $2,76 E+04$ & $8,93 E+05$ & $1,97 E+05$ \\
\hline $2-4 / 5$ & $1,93 E+07$ & $1,29 E+05$ & $1,36 E+06$ & $1,37 E+06$ & $2,39 E+04$ & $1,08 E+06$ & $2,13 E+05$ \\
\hline $2-8 / 1$ & $1,91 E+07$ & $4,91 E+04$ & $1,33 E+06$ & $1,34 E+06$ & $2,39 E+0.4$ & $1,02 E+06$ & $2,11 E+05$ \\
\hline $2-8 / 2$ & $1,93 E+07$ & $5,21 E+04$ & $1,31 E+06$ & $1,32 E+06$ & $2.29 E+04$ & $9,86 E+05$ & $2,14 E+05$ \\
\hline $2-8 / 3$ & $1,75 E+07$ & $7,84 E+04$ & $1,26 E+06$ & $1.27 E+06$ & $2,38 E+04$ & $1,03 E+06$ & $2,03 E+05$ \\
\hline $2-8 / 4$ & $1,98 E+07$ & $3,61 E+04$ & $1,30 E+06$ & $1,31 E+06$ & $1,91 E+04$ & $9,72 E+05$ & $2,06 E+05$ \\
\hline $2-8 / 5$ & $1,71 E+07$ & $8,54 E+04$ & $1,23 E+06$ & $1,25 E+06$ & $2,56 E+04$ & $8,93 E+05$ & $1,91 E+05$ \\
\hline
\end{tabular}


Table 4.38 Inventory (Bq) of individual fissile particles for selected nuclides from particle trays in capsule 3 Source: Forschungszentrum Julich GmbH, Jalich, Germany

\begin{tabular}{|c|c|c|c|c|c|c|c|}
\hline Partikel Nr. & Ce 144 & Co 60 & Cs 134 & Cs 137 & Eu 154 & Ru 106 & Sb 125 \\
\hline $3-3 / 1$ & $4,75 E+07$ & $1,28 E+05$ & $5,94 E+06$ & $4,20 E+06$ & $1,54 E+05$ & $1,54 E+07$ & $1,88 E+05$ \\
\hline $3-3 / 2$ & $4,62 E+07$ & $2,71 E+05$ & $5,85 E+06$ & $4,09 E+06$ & $1,69 E+05$ & $1,50 E+07$ & $1,86 \mathrm{E}+05$ \\
\hline $3-3 / 3$ & $4,46 E+07$ & $9,55 E+04$ & $5,89 E+06$ & $4,16 E+06$ & $1,67 E+05$ & $1,50 E+07$ & $1,90 E+05$ \\
\hline $3-3 / 4$ & $4.93 E+07$ & $1,18 E+05$ & $6,03 E+06$ & $4,24 E+06$ & $1,69 E+05$ & $1,55 E+07$ & $1,74 E+05$ \\
\hline $3-3 / 5$ & $4,24 E+07$ & $3,74 E+04$ & $5,76 \mathrm{E}+06$ & $4,03 E+06$ & $1,45 E+05$ & $1.41 E+07$ & $1,86 E+05$ \\
\hline $3-7 / 1$ & $3,28 E+07$ & $7,32 E+04$ & $4,01 E+06$ & $3,05 E+06$ & $1,18 E+05$ & $1,08 E+07$ & $1,34 \mathrm{E}+05$ \\
\hline $3-7 / 2$ & $4,48 E+07$ & $1,19 E+05$ & $5,11 E+06$ & $3,90 E+06$ & $1,45 E+05$ & $1,35 E+07$ & $1,76 E+05$ \\
\hline $3.7 / 3$ & $3,70 E+07$ & $8,50 E+04$ & $4,15 E+06$ & $3,16 E+06$ & $1,01 E+05$ & $1,11 E+07$ & $1,33 E+05$ \\
\hline $3-7 / 4$ & $4,44 E+07$ & $1,35 \mathrm{E}+05$ & $5,20 E+06$ & $3,95 E+06$ & $1,38 E+05$ & $1,40 E+07$ & $1,85 E+05$ \\
\hline $3-7 / 5$ & $4,53 E+07$ & $7,89 E+04$ & $5,11 E+06$ & $3,87 E+06$ & $1,31 E+05$ & $1,35 E+07$ & $1,71 E+05$ \\
\hline
\end{tabular}

Table 4.39 Inventory $(\mathrm{Bq})$ of individual fertile particles for selected nuclides from particle trays in capsule 3 Source: Forschungszentrum Julich GmbH, Jalich, Germany

\begin{tabular}{|c|c|c|c|c|c|c|c|}
\hline Partikel Nr. & Co 144 & Co 60 & Cs 134 & Cs 137 & Eu 154 & Ru 106 & Sb 125 \\
\hline $3-4 / 1$ & $1,50 E+07$ & $1,32 E+05$ & $7,94 E+05$ & $9,80 E+05$ & $2,26 E+04$ & $6,34 E+05$ & $1,60 E+05$ \\
\hline $3-4 / 2$ & $1,50 E+07$ & $1,19 E+05$ & $8,49 E+05$ & $1,04 E+06$ & & $7,45 E+05$ & $1,63 E+05$ \\
\hline $3-4 / 3$ & $1,28 E+07$ & $6,27 E+04$ & $7,84 E+05$ & $9,85 E+05$ & & $7,55 E+05$ & $1,64 E+05$ \\
\hline $3-4 / 4$ & $1,34 E+07$ & $9,16 E+04$ & $7,94 E+05$ & $9,71 E+05$ & $1,36 E+04$ & $6,90 E+05$ & $1,48 E+05$ \\
\hline $3-4 / 5$ & $1,33 E+07$ & $7,14 E+04$ & $7,57 E+05$ & $9,43 E+05$ & $1.77 E+04$ & $6,34 E+05$ & $1,52 E+05$ \\
\hline $3-8 / 1$ & $1,18 E+07$ & $1,78 E+05$ & $6,39 E+05$ & $8,51 E+05$ & & $6,57 E+05$ & $1,40 E+05$ \\
\hline $3-8 / 2$ & $1.12 E+07$ & $7,81 E+04$ & $5,98 E+05$ & $7,96 E+05$ & & $6,14 E+05$ & $1,31 E+05$ \\
\hline $3-8 / 3$ & $1,15 E+07$ & $4,73 E+04$ & $6,36 E+05$ & $8,54 E+05$ & & $6,42 E+05$ & $1,46 E+05$ \\
\hline $3-8 / 4$ & $1,19 E+07$ & $8,40 E+04$ & $6,48 E+05$ & $8,69 E+05$ & & $6,35 E+05$ & $1,45 E+05$ \\
\hline $3-8 / 5$ & $1,16 E+07$ & $1,05 E+05$ & $6.54 E+05$ & $8,81 E+05$ & & $6,92 E+05$ & $1,43 E+05$ \\
\hline
\end{tabular}



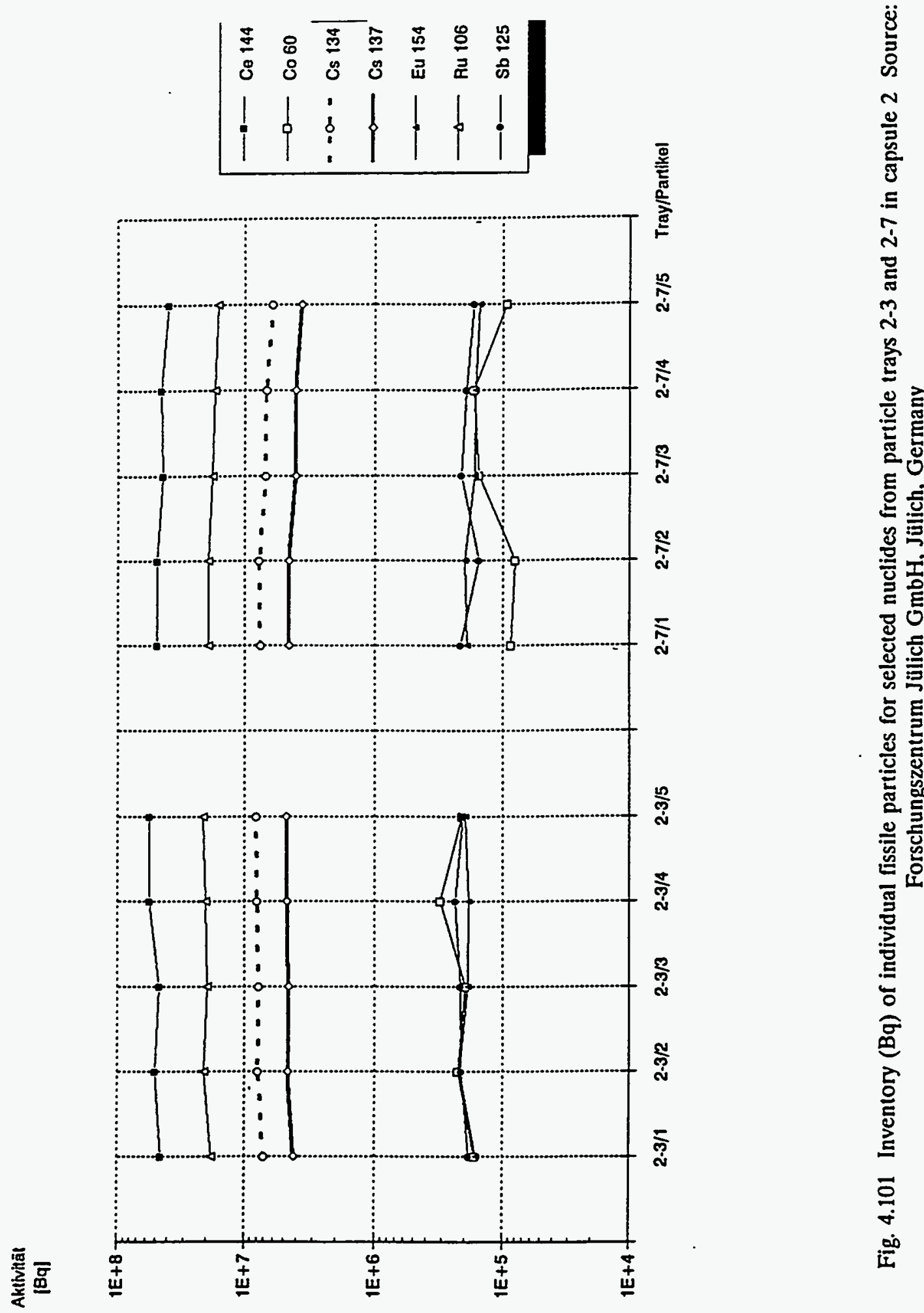

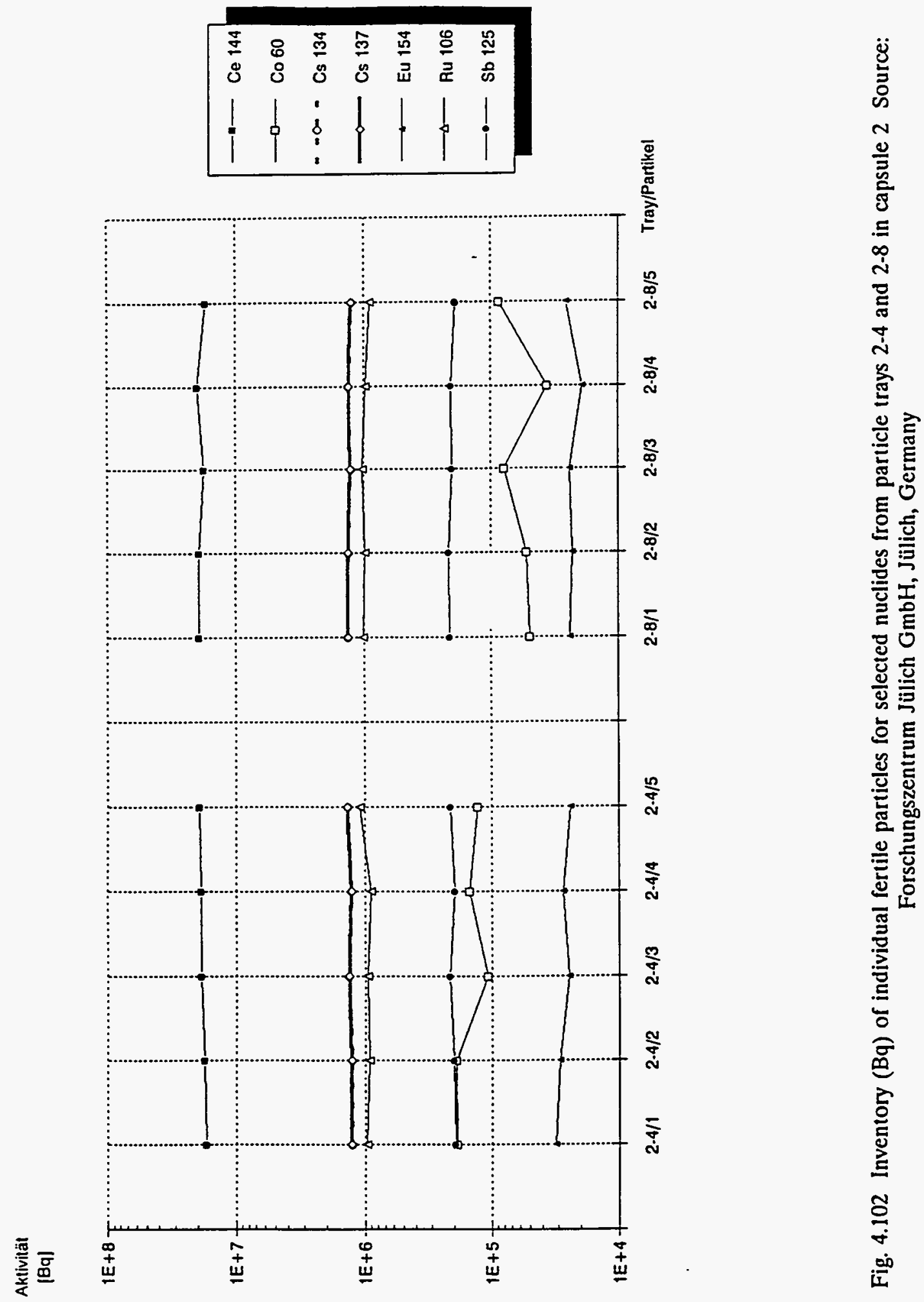

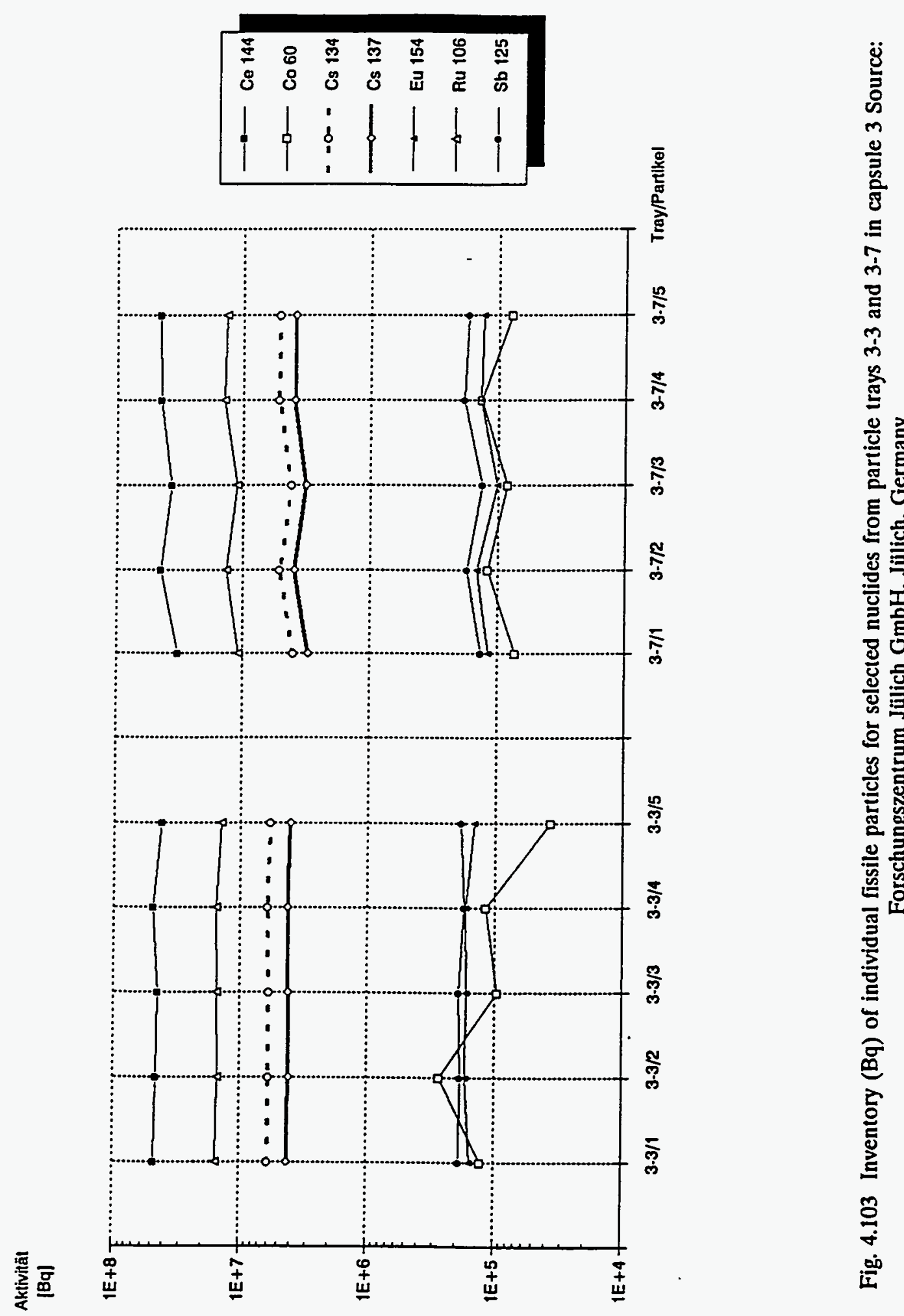

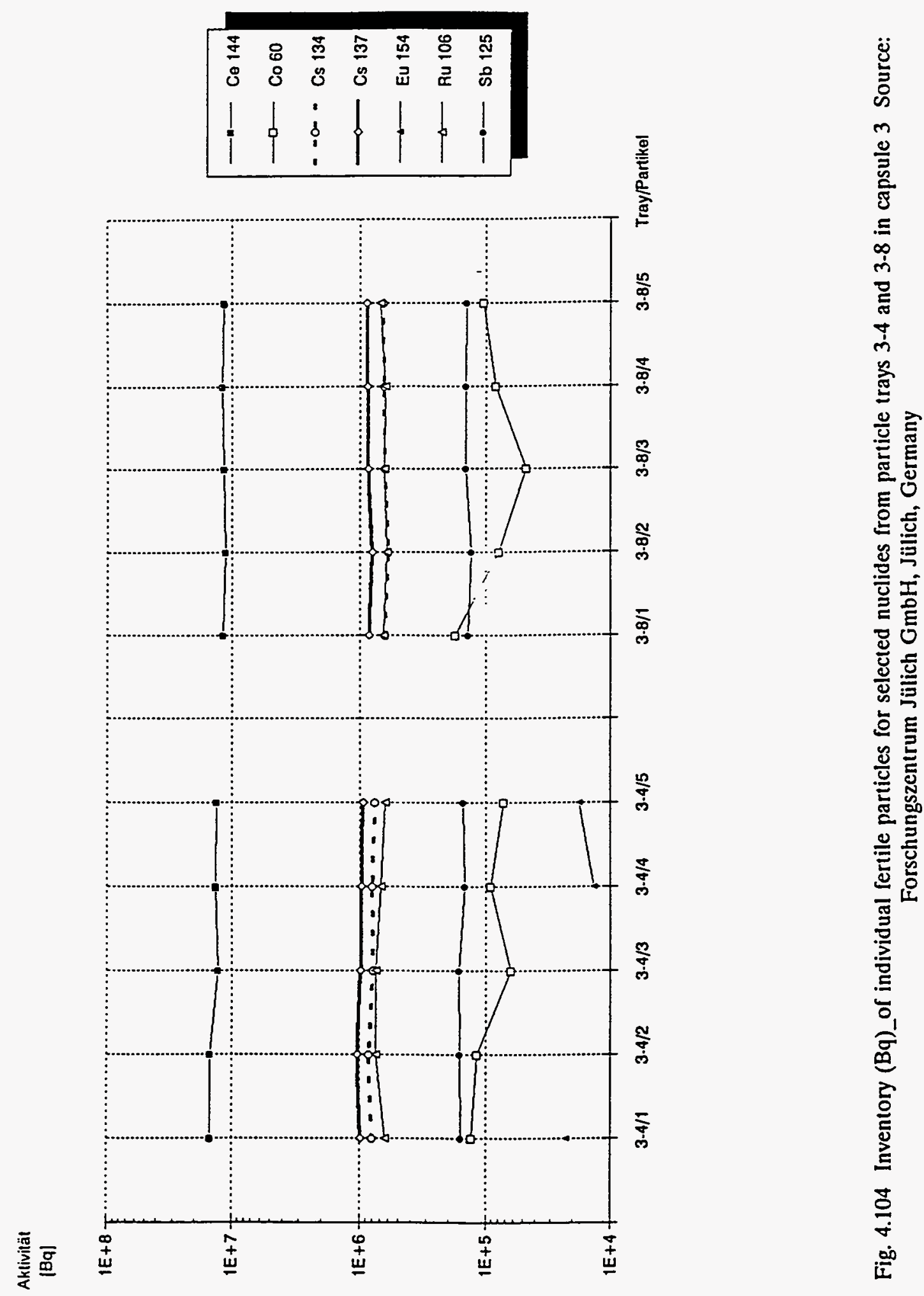
Table 4.40 Inventory $(\mathrm{Bq})$ of individual kernels from fissile particles for selected nuclides from particle trays in capsule 2 Source: Forschungszentrum Julich GmbH, Jalich, Germany

\begin{tabular}{|l|l|c|c|c|c|c|c|}
\hline \multirow{2}{*}{ Partik.Nr. } & \multicolumn{7}{|c|}{ Aktivitāt zum 4 Abschaltzeitpunkt [Bq] } \\
& Ce 144 & Co 60 & Cs 134 & Cs 137 & Eu 154 & Ru 106 & Sb 124 \\
\hline & & & & - & & & \\
$2-3 / 1$ & $4,45 E+7$ & & $6,74 E+6$ & $3,98 E+6$ & $1,87 E+5$ & $1,78 E+7$ & $2,02 E+5$ \\
$2-3 / 2$ & $2,60 E+7$ & & $3,84 E+6$ & $2,27 E+6$ & $1,05 E+5$ & $1,00 E+7$ & $1,06 E+5$ \\
$2-3 / 3$ & $4,91 E+7$ & & $7,47 E+6$ & $4,39 E+6$ & $1,77 E+5$ & $1,91 E+7$ & $1,99 E+5$ \\
$2-3 / 4$ & $4,94 E+7$ & & $7,66 E+6$ & $4,53 E+6$ & $1,97 E+5$ & $1,97 E+7$ & $2,32 E+5$ \\
$2-3 / 5$ & $4,68 E+7$ & & $7,08 E+6$ & $4,20 E+6$ & $1,79 E+5$ & $1,85 E+7$ & $1,92 E+5$ \\
& & & & & & & \\
$2-7 / 1$ & $5,06 E+7$ & & $7,35 E+6$ & $4,37 E+6$ & $1,83 E+5$ & $1,91 E+7$ & $2,09 E+5$ \\
$2-7 / 2$ & $4,76 E+7$ & & $7,38 E+6$ & $4,39 E+6$ & $1,68 E+5$ & $1,94 E+7$ & $2,11 E+5$ \\
$2-7 / 3$ & & & & Kernbruch & & & \\
$2-7 / 4$ & $4,54 E+7$ & & $5,97 E+6$ & $3,53 E+6$ & $1,33 E+5$ & $1,77 E+7$ & $1,88 E+5$ \\
$2-7 / 5$ & $4,11 E+7$ & & $5,85 E+6$ & $3,48 E+6$ & $1,41 E+5$ & $1,59 E+7$ & $1,55 E+5$ \\
& & & & & & & \\
\hline
\end{tabular}

Table 4.41 Inventory (Bq) of individual kerneis from fertile particles for selected nuclides from particle trays in capsule 2 Source: Forschungszentrum Jalich GmbH, Jalich, Germany

\begin{tabular}{|c|c|c|c|c|c|c|c|}
\hline \multirow{2}{*}{ Partik.Nr. } & \multicolumn{7}{|c|}{ Aktivität zum } \\
& Ce 144 & Co 60 & Cs 134 & Cs 137 & Eu 154 & Ru 106 & Sb 124 \\
\hline & & & & & & & \\
$2-4 / 1$ & $1,83 E+7$ & & $1,21 E+6$ & $1,22 E+6$ & $2,77 E+4$ & $9,01 E+5$ & $1,91 E+5$ \\
$2-4 / 2$ & $1,79 E+7$ & & $1,20 E+6$ & $1,21 E+6$ & $2,22 E+4$ & $9,01 E+5$ & $1,90 E+5$ \\
$2-4 / 3$ & $1,83 E+7$ & & $1,28 E+6$ & $1,28 E+6$ & $2,92 E+4$ & $8,76 E+5$ & $2,02 E+5$ \\
$2-4 / 4$ & $1,76 E+7$ & & $1,19 E+6$ & $1,19 E+6$ & $1,87 E+4$ & $9,28 E+5$ & $1,82 E+5$ \\
$2-4 / 5$ & $1,98 E+7$ & & $1,31 E+6$ & $1,33 E+6$ & $2,62 E+4$ & $1,03 E+6$ & $2,09 E+5$ \\
& & & & & & & \\
$2-8 / 1$ & $1,82 E+7$ & & $1,29 E+6$ & $1,29 E+6$ & $2,27 E+4$ & $9,96 E+5$ & $1,99 E+5$ \\
$2-8 / 2$ & & & & Kernbruch & & & \\
$2-8 / 3$ & $1,62 E+7$ & & $1,19 E+6$ & $1,21 E+6$ & $2,84 E+4$ & $8,81 E+5$ & $1,88 E+5$ \\
$2-8 / 4$ & $1,71 E+7$ & & $1,27 E+6$ & $1,28 E+6$ & $2,92 E+4$ & $9,63 E+5$ & $2,04 E+5$ \\
$2-8 / 5$ & $1,74 E+7$ & & $1,20 E+6$ & $1,22 E+6$ & $2,32 E+4$ & $8,45 E+5$ & $1,87 E+5$ \\
& & & & & & & \\
\hline
\end{tabular}


Table 4.42 Inventory $(\mathrm{Bq})$ of individual kernels from fissile particles for selected nuclides from particle trays in capsule 3 Source: Forschungszentrum Jalich GmbH, Jalich, Germany

\begin{tabular}{|l|l|l|l|l|l|l|l|}
\hline \multirow{2}{*}{ Partik.Nr. } & \multicolumn{7}{|c|}{ Aktivität zum } \\
& Ce 144 & Co 60 & Cs 134 & Cs 137 & Eu 154 & Ru 106 & Sb 124 \\
\hline & & & & & & & \\
$3-3 / 1$ & $4,29 E+7$ & & $5,91 E+6$ & $4,18 E+6$ & $1,61 E+5$ & $1,50 E+7$ & $1,96 E+5$ \\
$3-3 / 2$ & $4,65 E+7$ & & $5,79 E+6$ & $4,05 E+6$ & $1,51 E+5$ & $1,50 E+7$ & $1,98 E+5$ \\
$3-3 / 3$ & $4,37 E+7$ & & $5,83 E+6$ & $4,11 E+6$ & $1,63 E+5$ & $1,49 E+7$ & $1,87 E+5$ \\
$3-3 / 4$ & $4,78 E+7$ & & $5,99 E+6$ & $4,21 E+6$ & $1,60 E+5$ & $1,58 E+7$ & $2,01 E+5$ \\
$3-3 / 5$ & $4,40 E+7$ & & $5,65 E+6$ & $3,97 E+6$ & $1,40 E+5$ & $1,47 E+7$ & $1,80 E+5$ \\
& & & & & & & \\
$3-7 / 1$ & $3,34 E+7$ & & $3,95 E+6$ & $3,00 E+6$ & $9,90 E+4$ & $1,06 E+7$ & $1,48 E+5$ \\
$3-7 / 2$ & $4,21 E+7$ & & $5,04 E+6$ & $3,85 E+6$ & $1,38 E+5$ & $1,34 E+7$ & $1,80 E+5$ \\
$3-7 / 3$ & $3,63 E+7$ & & $4,08 E+6$ & $3,09 E+6$ & $1,07 E+5$ & $1,11 E+7$ & $1,47 E+5$ \\
$3-7 / 4$ & $4,06 E+7$ & & $5,09 E+6$ & $3,88 E+6$ & $1,49 E+5$ & $1,37 E+7$ & $1,84 E+5$ \\
$3-7 / 5$ & $4,59 E+7$ & & $5,01 E+6$ & $3,81 E+6$ & $1,53 E+5$ & $1,34 E+7$ & $1,66 E+5$ \\
& & & & & & & \\
\hline
\end{tabular}

Table 4.43 Inventory $(\mathrm{Bq})$ of individual kernels from fertile particles for selected nuclides from particle trays in capsule 3 Source: Forschungszentrum Jülich GmbH, Jullich, Germany

\begin{tabular}{|c|c|c|c|c|c|c|c|}
\hline \multirow{2}{*}{ Partik.Nr. } & \multicolumn{6}{|c|}{ Aktivität zum Abschaltzeitpunkt [Bq] } \\
& Ce 144 & Co 60 & Cs 134 & Cs 137 & Eu 154 & Ru 106 & Sb 124 \\
\hline & & & & & & & \\
$3-4 / 1$ & $1,25 E+7$ & & $7,62 E+5$ & $9,54 E+5$ & & $7,76 E+5$ & $1,50 E+5$ \\
$3-4 / 2$ & $1,35 E+7$ & & $8,16 E+5$ & $1,01 E+6$ & $1,96 E+4$ & $6,39 E+5$ & $1,59 E+5$ \\
$3-4 / 3$ & $1,45 E+7$ & & $7,86 E+5$ & $9,74 E+5$ & $1,67 E+4$ & $6,66 E+5$ & $1,61 E+5$ \\
$3-4 / 4$ & $1,37 E+7$ & & $7,75 E+5$ & $9,59 E+5$ & & $7,12 E+5$ & $1,53 E+5$ \\
$3-4 / 5$ & $1,27 E+7$ & & $7,49 E+5$ & $9,17 E+5$ & $1,79 E+4$ & $6,26 E+5$ & $1,48 E+5$ \\
& & & & & & & \\
$3-8 / 1$ & $1,22 E+7$ & & $6,16 E+5$ & $8,28 E+5$ & & $6,16 E+5$ & $1,26 E+5$ \\
$3-8 / 2$ & $1,14 E+7$ & & $5,71 E+5$ & $7,71 E+5$ & & $5,90 E+5$ & $1,27 E+5$ \\
$3-8 / 3$ & $1,20 E+7$ & & $6,20 E+5$ & $8,40 E+5$ & & $5,78 E+5$ & $1,43 E+5$ \\
$3-8 / 4$ & $1,27 E+7$ & & $6,29 E+5$ & $8,54 E+5$ & & $6,31 E+5$ & $1,43 E+5$ \\
$3-8 / 5$ & $1,23 E+7$ & & $6,41 E+5$ & $8,59 E+5$ & & $6,40 E+5$ & $1,36 E+5$ \\
& & & & & & $\cdot$ & \\
\hline
\end{tabular}




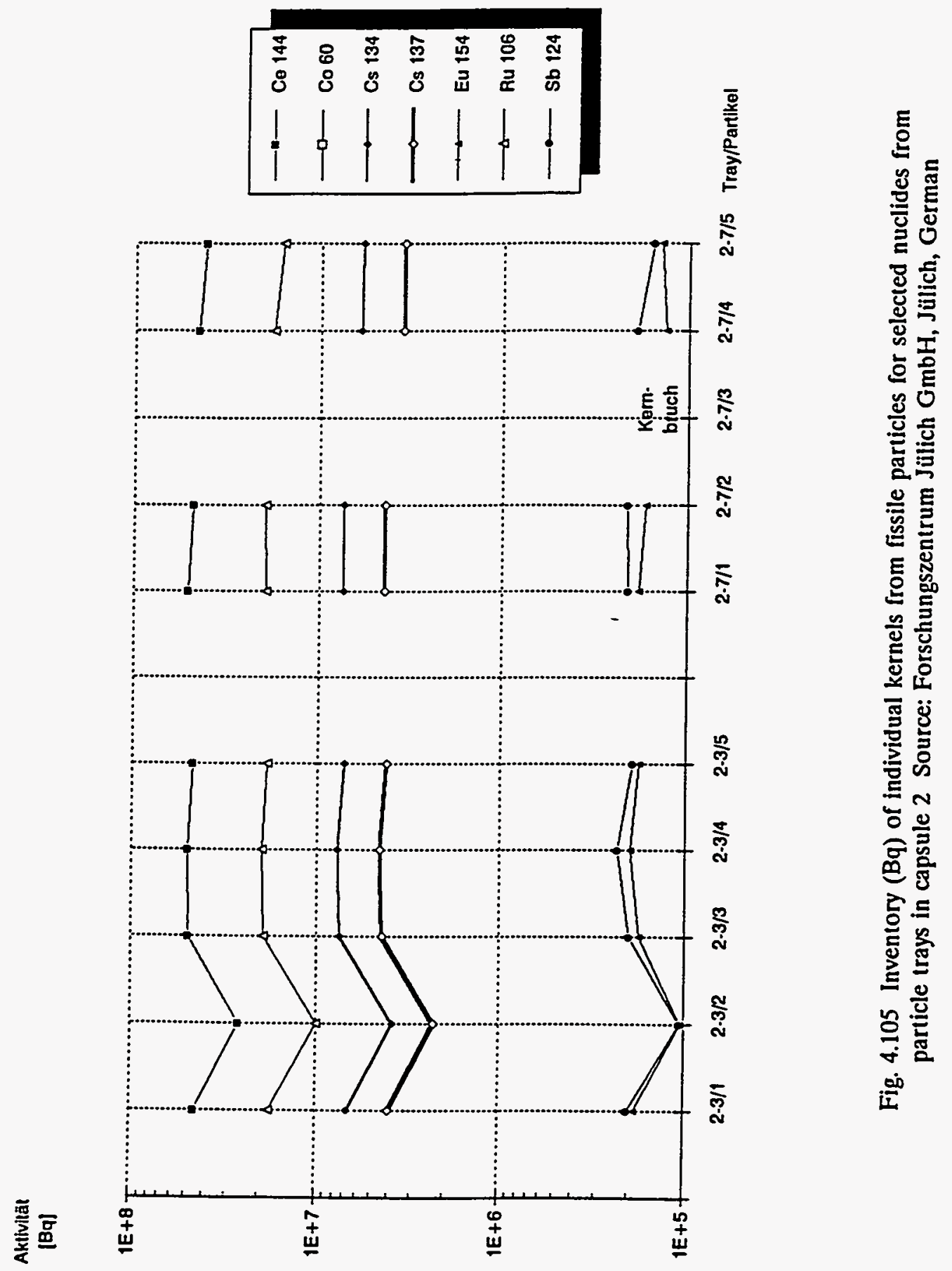




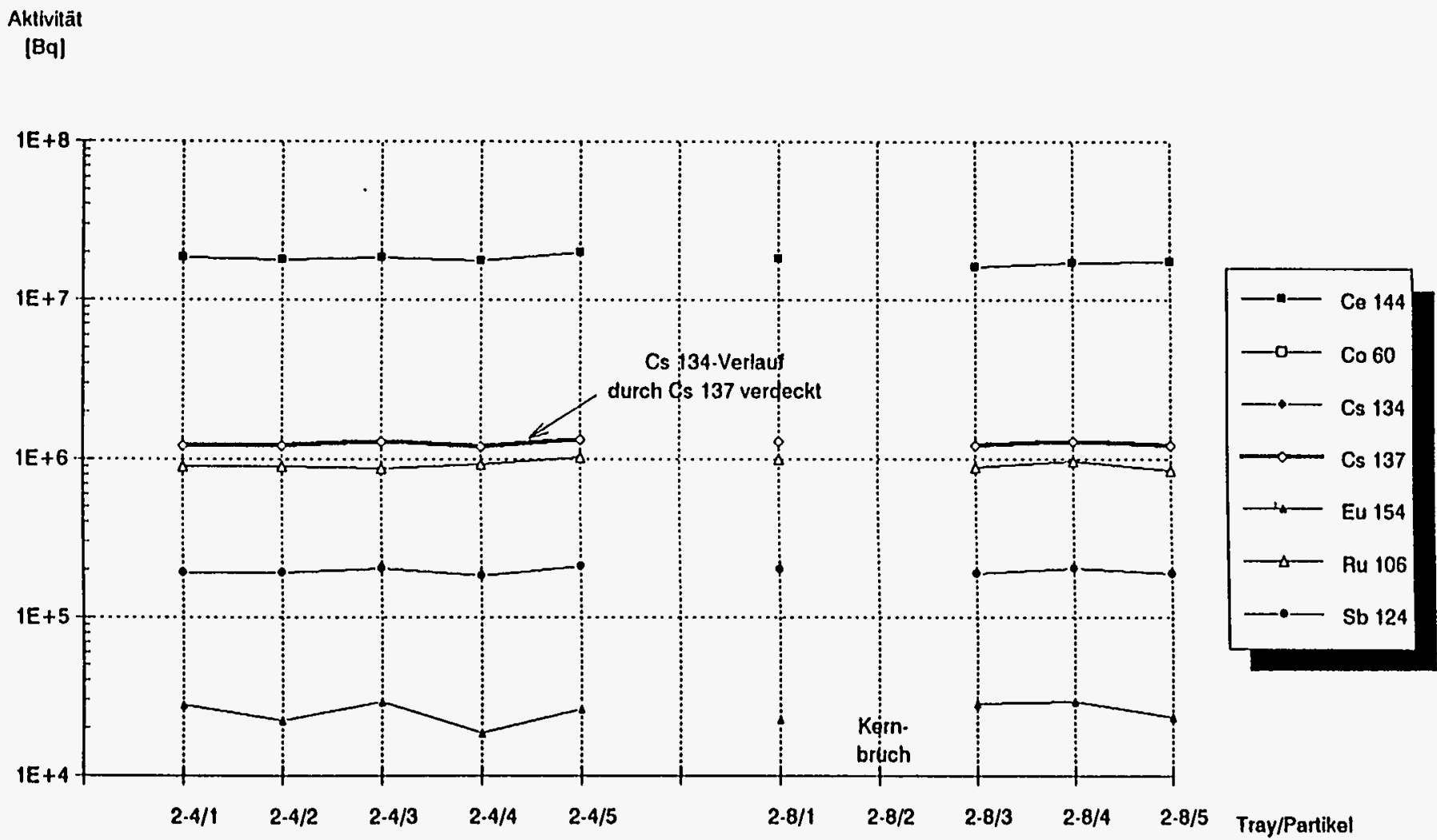

Fig. 4.106 Inventory (Bq) of individual kernels from fertile particles for selected nuclides from particle trays in capsule 2 Source: Forschungszentrum Jülich $\mathrm{GmbH}$, Jülich, Germany 


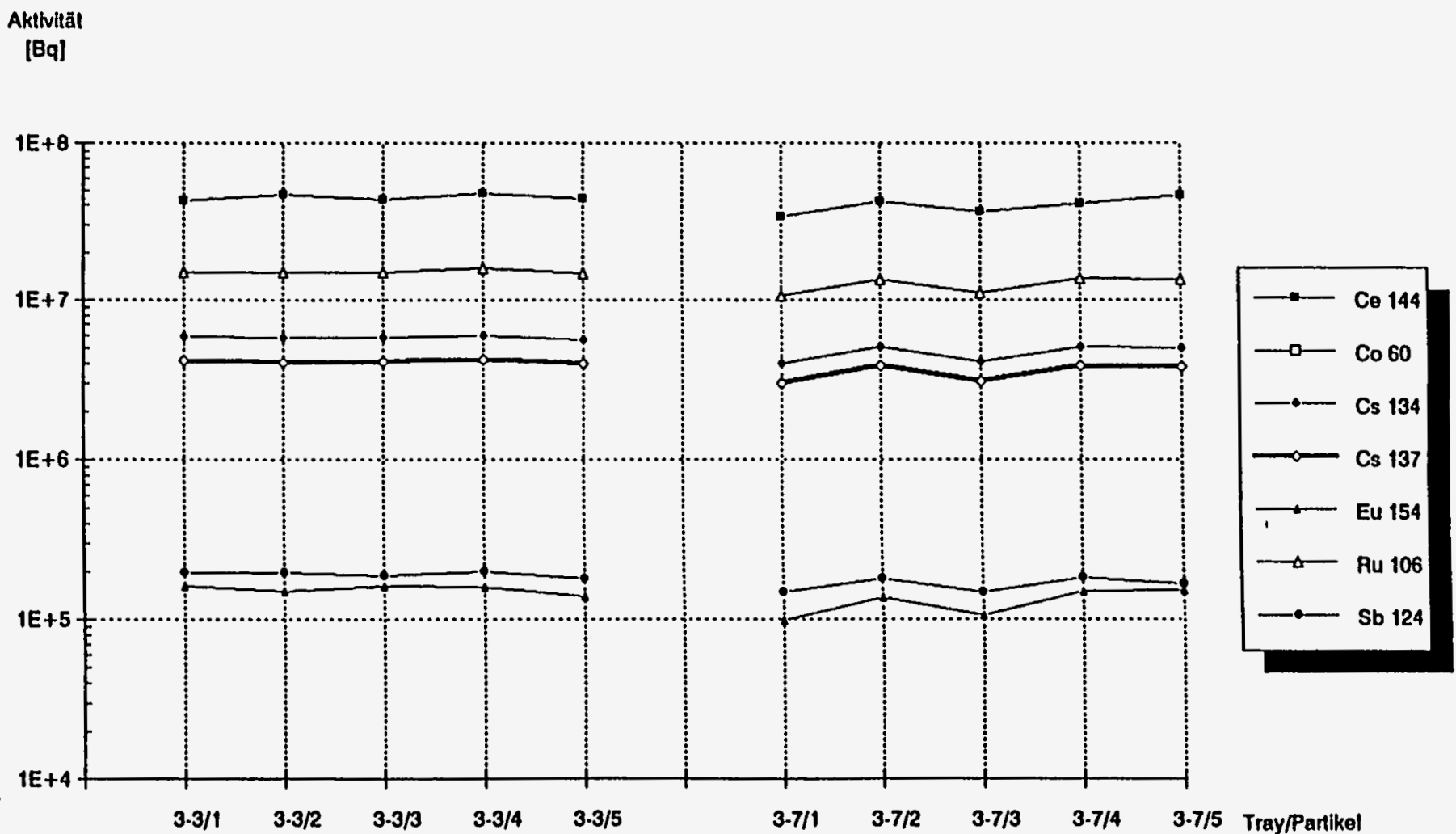

Fig. 4.107 Inventory $(\mathrm{Bq})$ of individual kernels from fissile particles for selected nuclides from particle trays in capsule 3 Source: Forschungszentrum Jülich $\mathrm{GmbH}$, Jülich, German 


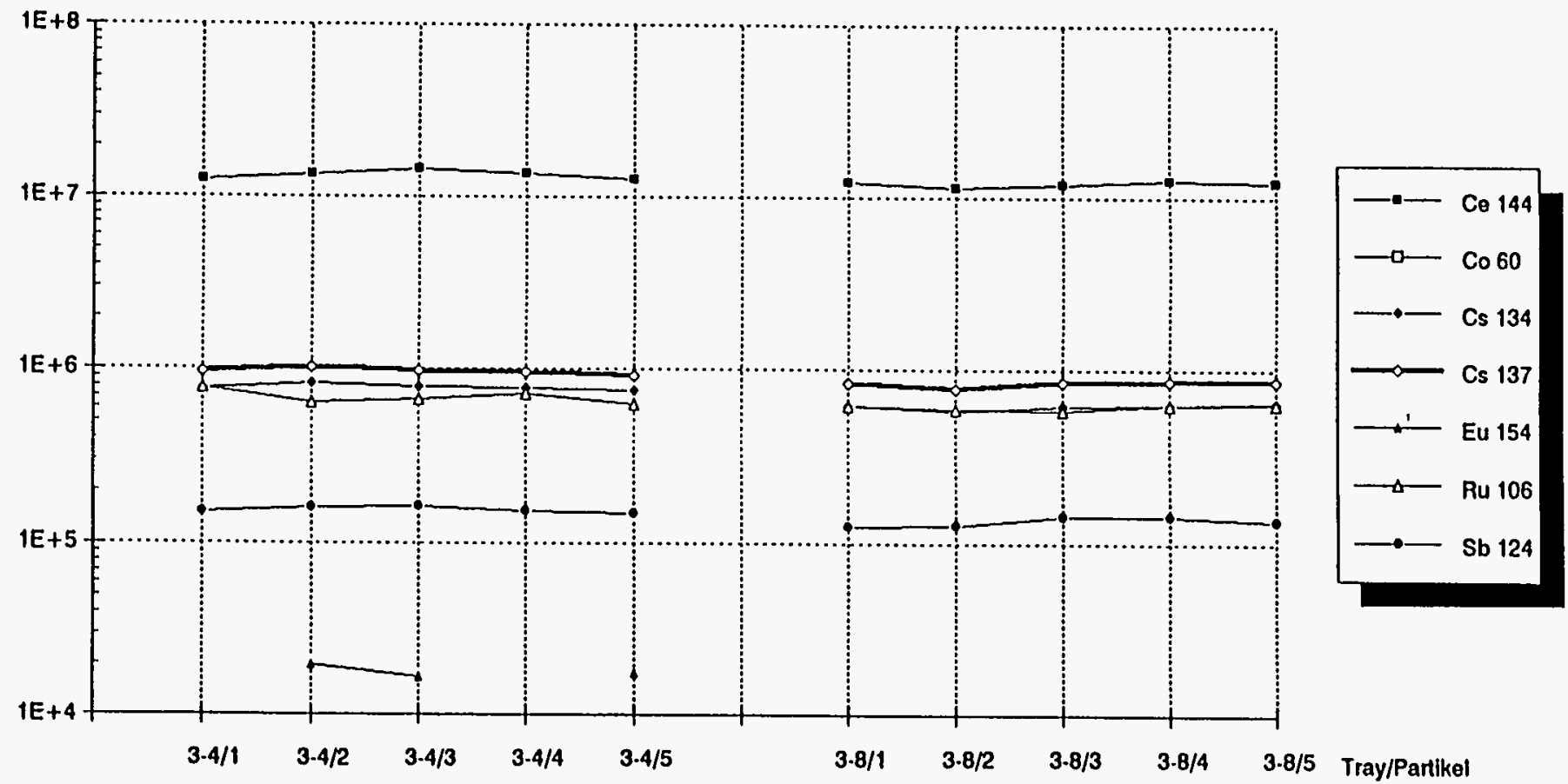

Fig. 4.108 Inventory $(\mathrm{Bq})$ of individual kernels from fertile particles for selected nuclides from particle trays in capsule 3 Source: Forschungszentrum Jülich $\mathrm{GmbH}$, Jülich, Germany 
Table 4.44 Inventory (Bq) of the coatings from fissile particles for selected nuclides from particle trays in capsule 2 Source: Forschungszentrum Julich GmbH, Jalich, Germany

\begin{tabular}{|c|c|c|c|c|c|c|c|}
\hline \multirow[t]{2}{*}{ Partik.Nr. } & \multicolumn{7}{|c|}{ Aktivitāt zum Abschaltzeitpunkt [Bq] } \\
\hline & Ce 144 & Co 60 & Cs 134 & Cs 137 & Eu 154 & Ru 106 & Sb 124 \\
\hline $2-3 / 1$ & & & $1,46 E+5$ & $7,89 E+4$ & $5,55 E+3$ & & \\
\hline $2-3 / 2$ & & & $1,75 E+5$ & $9,83 E+4$ & $8,07 E+3$ & & \\
\hline $2-3 / 3$ & & & $1,18 E+5$ & $6,23 E+4$ & $5,48 E+3$ & & \\
\hline $2-3 / 4$ & & $4,93 E+2$ & $1,13 E+5$ & $5,98 E+4$ & $5,98 E+3$ & & \\
\hline $2-3 / 5$ & & & $1,18 E+5$ & $6,30 E+4$ & $5,45 E+3$ & & \\
\hline $2-7 / 1$ & & & $8,78 E+4$ & $4,97 E+4$ & $8.67 E+3$ & & \\
\hline $2-7 / 2$ & & & $1,06 E+5$ & $5,91 E+4$ & $8,75 E+3$ & & \\
\hline $2.7 / 3$ & & & & Kernbruch & & & \\
\hline $2-7 / 4$ & & & $7,48 E+5$ & $4.33 E+5$ & $3,37 E+4$ & & \\
\hline $2-7 / 5$ & & $7,48 E+3$ & $1,54 E+5$ & $8,69 E+4$ & $1,23 E+4$ & & \\
\hline
\end{tabular}

Table 4.45 Inventory $(\mathrm{Bq})$ of the coatings from fertile particles for selected nuclides from particle trays in capsule 2 Source: Forschungszentrum Jalich GmbH, Jalich, Germany

\begin{tabular}{|c|c|c|c|c|c|c|c|}
\hline \multirow[t]{2}{*}{ Partik.Nr. } & \multicolumn{7}{|c|}{ Aktivitāt zum Abschaltzeitpunkt [Bq] } \\
\hline & Ce 144 & Co 60 & Cs 134 & Cs 137 & Eu 154 & Ru 106 & Sb 124 \\
\hline $2-4 / 1$ & & $3,50 E+2$ & $2,46 E+4$ & $2,32 E+4$ & $3,32 E+2$ & & $1,56 E+3$ \\
\hline $2-4 / 2$ & & $4,31 E+2$ & $1,52 E+4$ & $1,42 E+4$ & & & $1,31 E+3$ \\
\hline $2-4 / 3$ & & $5,47 \mathrm{E}+2$ & $2,16 E+4$ & $2,05 E+4$ & & & $1,60 E+3$ \\
\hline $2-4 / 4$ & $2,88 E+5$ & & $2,71 E+4$ & $2,63 E+4$ & & $2,41 E+4$ & $4,14 E+5$ \\
\hline $2-4 / 5$ & & $3,55 E+2$ & $1,80 E+4$ & $1,68 E+4$ & & & $6,87 E+2$ \\
\hline $2-8 / 1$ & & $6,37 E+2$ & $1,03 E+4$ & $1,04 E+4$ & & & \\
\hline $2-8 / 2$ & & & & Kernbruch & & & \\
\hline $2-8 / 3$ & $1,99 E+5$ & & $2,94 E+4$ & $2,83 E+4$ & & $1,33 E+4$ & $3,16 E+3$ \\
\hline $2-8 / 4$ & & & $4,04 E+3$ & $3,79 E+3$ & & & \\
\hline $2-8 / 5$ & & $5,30 E+2$ & $1,31 E+4$ & $1,26 E+4$ & & & \\
\hline
\end{tabular}


Table 4.46 Inventory $(\mathrm{Bq})$ of the coatings from fissile particles for selected nuclides from particle trays in capsule 3 Source: Forschungszentrum Jalich GmbH, Julich, Germany

\begin{tabular}{|c|c|c|c|c|c|c|c|}
\hline \multirow[t]{2}{*}{ Partik.Nr. } & \multicolumn{7}{|c|}{ Aktivitāt zum Abschaltzeitpunkt [Bq] } \\
\hline & Ce 144 & Co 60 & Cs 134 & Cs 137 & Eu 154 & Ru 106 & Sb 124 \\
\hline $3-3 / 1$ & & & $1,13 E+3$ & $1,04 E+3$ & & & \\
\hline $3-3 / 2$ & & & $2,31 E+4$ & $1,50 E+4$ & & & \\
\hline $3-3 / 3$ & & & $2,49 E+4$ & $1,67 E+4$ & $1,27 E+3$ & & \\
\hline $3-3 / 4$ & & $1,21 E+3$ & $2,15 E+4$ & $1,40 E+4$ & & & \\
\hline $3-3 / 5$ & & $2,46 E+3$ & $2,18 E+4$ & $1,39 E+4$ & $1,88 E+3$ & & \\
\hline $3-7 / 1$ & & & $2,45 E+4$ & $1,69 E+4$ & & & \\
\hline $3-7 / 2$ & & & $2,24 E+4$ & $1,64 E+4$ & & & \\
\hline $3-7 / 3$ & & & $3,02 E+4$ & $2,04 E+4$ & & & \\
\hline $3-7 / 4$ & & & $1,50 E+4$ & $1,12 E+4$ & & & \\
\hline $3.7 / 5$ & & & $1,64 E+4$ & $1.16 E+4$ & & & \\
\hline
\end{tabular}

Table 4.47 Inventory (Bq) of the coatings from fertile particles for selected nuclides from particle trays in capsule 3 Source: Forschungszentrum Julich GmbH, Jalich, Germany

\begin{tabular}{|c|c|c|c|c|c|c|c|}
\hline \multirow{2}{*}{ Partik.Nr. } & \multicolumn{6}{|c|}{ Aktivität zum Abschaltzeitpunkt [Bq] } \\
& Ce 144 & Co 60 & Cs 134 & Cs 137 & Eu 154 & Ru 106 & Sb 124 \\
\hline & & & & & & & \\
$3-4 / 1$ & & & $6,63 E+3$ & $7,27 E+3$ & & & \\
$3-4 / 2$ & & & $1,03 E+4$ & $8,54 E+3$ & & & \\
$3-4 / 3$ & & & $1,66 E+3$ & $5,63 E+3$ & & & \\
$3-4 / 4$ & & & $1,12 E+4$ & $1,24 E+4$ & & & \\
& & $3,13 E+2$ & $5,30 E+3$ & $5,26 E+3$ & & & \\
$3-8 / 1$ & & & & & & & \\
$3-8 / 2$ & & & $2,18 E+4$ & $2,23 E+4$ & & & \\
$3-8 / 3$ & & & $1,77 E+4$ & $2,34 E+4$ & & & \\
$3-8 / 4$ & $2,65 E+5$ & & $7,03 E+3$ & $6,34 E+3$ & & & $1,94 E+3$ \\
$3-8 / 5$ & & & $1,01 E+4$ & $1,26 E+4$ & & & \\
\hline
\end{tabular}




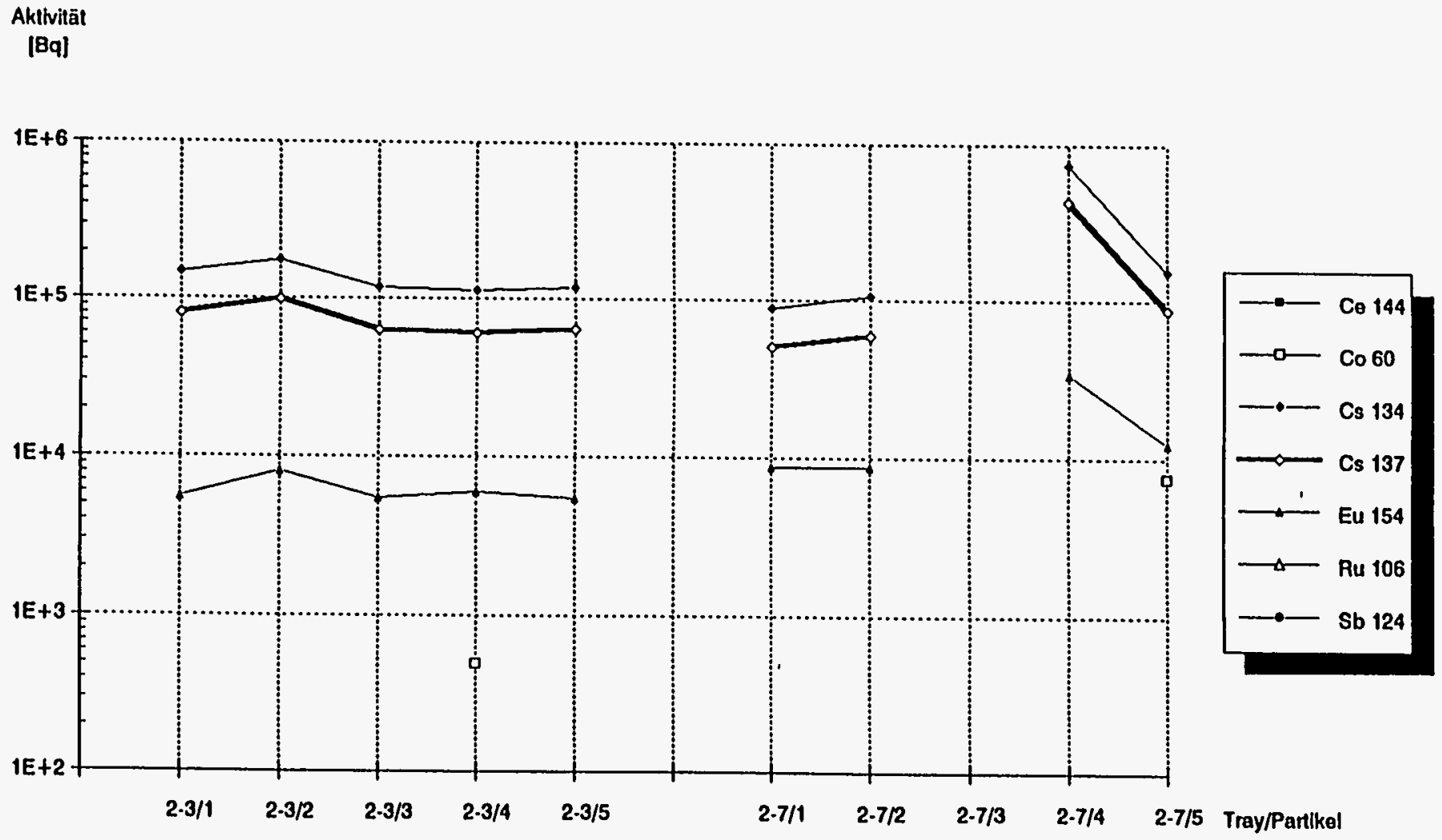

Fig. 4.109 Inventory (Bq) of the coatings from fissile particles for selected nuclides from particle trays in capsule 2 Source: Forschungszentrum Jülich $\mathrm{GmbH}$, Jülich, Germany 


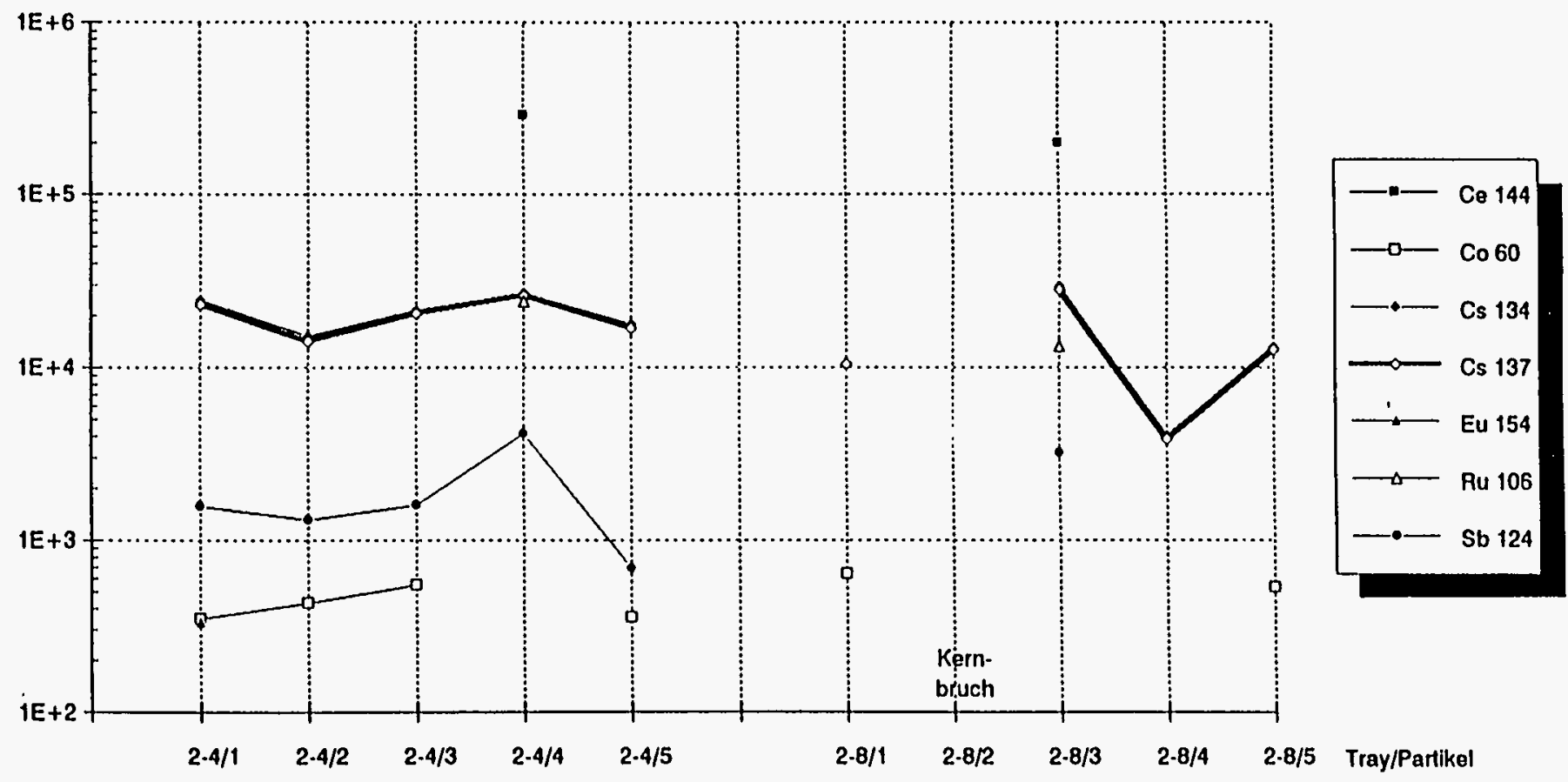

Fig. 4.110 Inventory $(\mathrm{Bq})$ of the coatings from fertile particles for selected nuclides from particle trays in capsule 2 Source: Forschungszentrum Jülich $\mathrm{GmbH}$, Jülich, Germany 


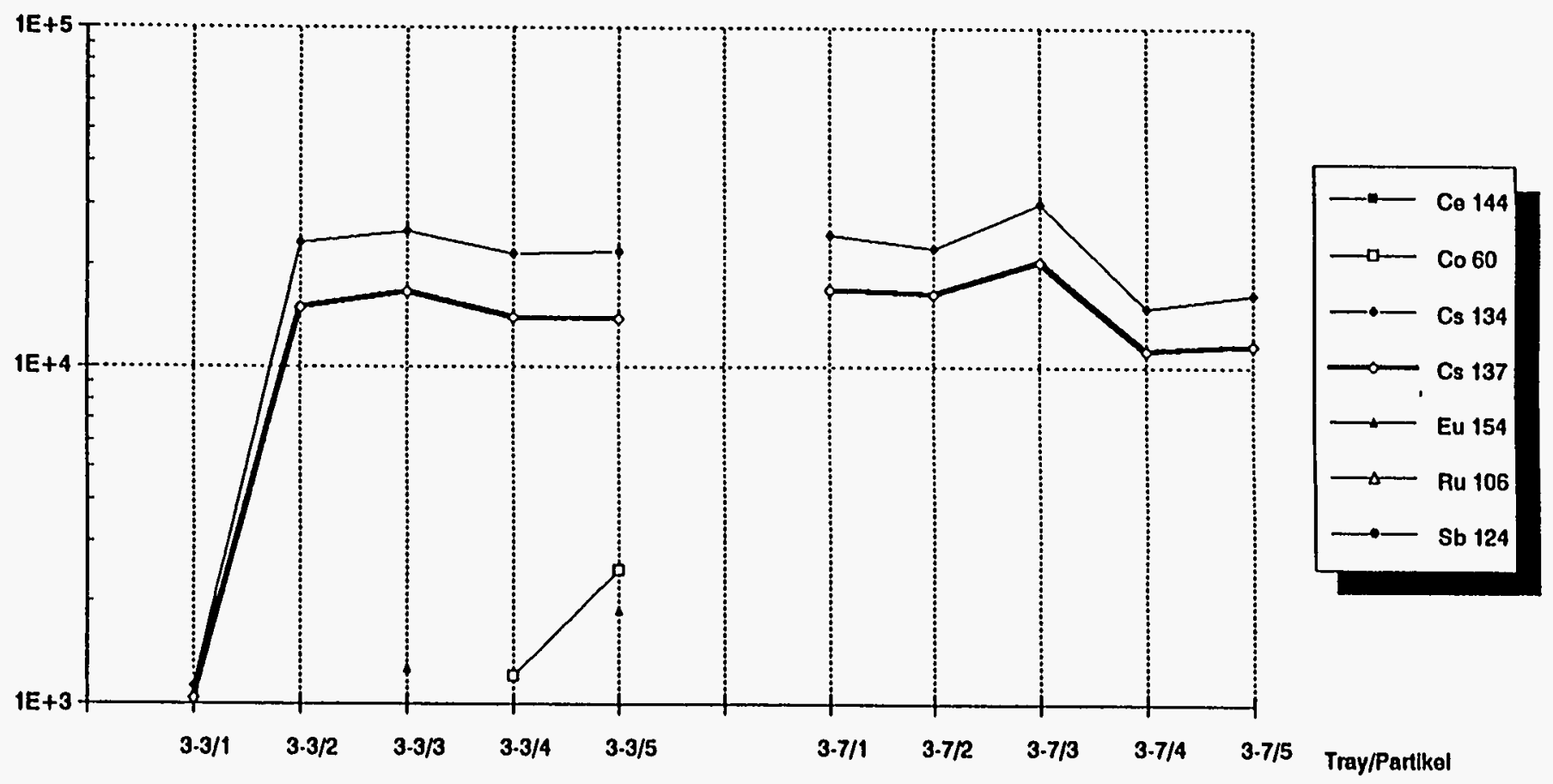

Fig. 4.111 Inventory $(\mathrm{Bq})$ of the coatings from fissile particles for selected nuclides from particle trays in capsule 3 Source: Forschungszentrum Jülich $\mathrm{GmbH}$, Jülich, Germany 


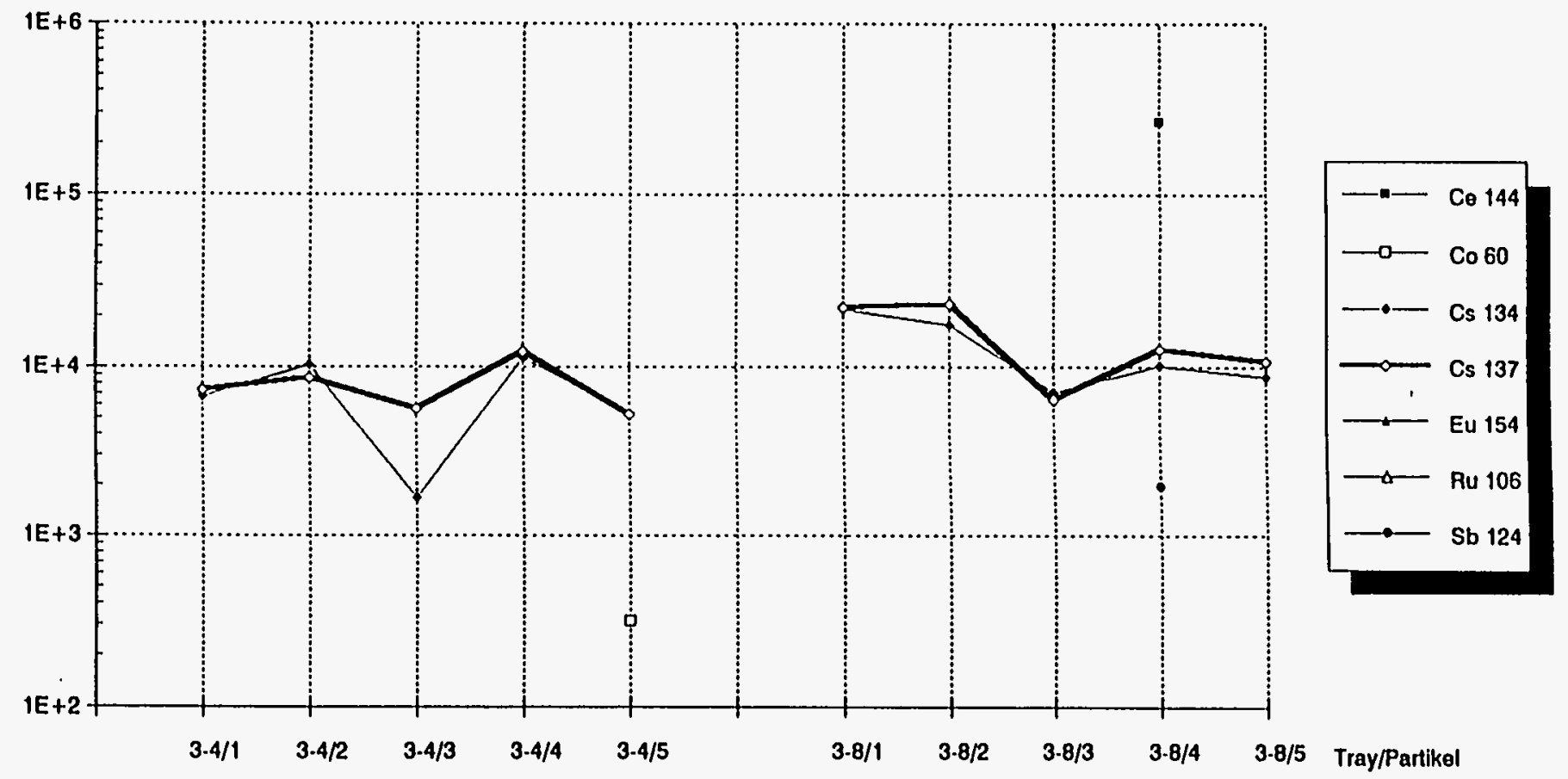

Fig. 4.112 Inventory $(\mathrm{Bq})$ of the coatings from fertile particles for selected nuclides from particle trays in capsule 3 Source: Forschungszentrum Jülich $\mathrm{GmbH}, \mathrm{Jülich}$, Germany 
Table 4.48 Inventory $(\mathrm{Bq})$ of bare kernels plus the associated coatings from fissile particles for selected nuclides from particle trays in capsule 2 Source: Forschungszentrum Jalich GmbH, Julich, Germany

\begin{tabular}{|c|c|c|c|c|c|c|c|}
\hline \multirow{2}{*}{ Partik.Nr. } & \multicolumn{7}{|c|}{ Aktivität zum Abschaltzeitpunkt [Bq] } \\
& Ce 144 & Co 60 & Cs 134 & Cs 137 & Eu 154 & Ru 106 & Sb 124 \\
\hline & & & & & & & \\
$2-3 / 1$ & $4,45 E+7$ & & $6,89 E+6$ & $4,06 E+6$ & $1,93 E+5$ & $1,78 E+7$ & $2,02 E+5$ \\
$2-3 / 2$ & $2,60 E+7$ & & $4,02 E+6$ & $2,37 E+6$ & $1,13 E+5$ & $1,00 E+7$ & $1,06 E+5$ \\
$2-3 / 3$ & $4,91 E+7$ & & $7,59 E+6$ & $4,45 E+6$ & $1,82 E+5$ & $1,91 E+7$ & $1,99 E+5$ \\
$2-3 / 4$ & $4,94 E+7$ & $4,93 E+2$ & $7,77 E+6$ & $4,59 E+6$ & $2,03 E+5$ & $1,97 E+7$ & $2,32 E+5$ \\
$2-3 / 5$ & $4,68 E+7$ & & $7,20 E+6$ & $4,26 E+6$ & $1,84 E+5$ & $1,85 E+7$ & $1,92 E+5$ \\
& & & & & & \\
$2-7 / 1$ & $5,06 E+7$ & & $7,44 E+6$ & $4,42 E+6$ & $1,92 E+5$ & $1,91 E+7$ & $2,09 E+5$ \\
$2-7 / 2$ & $4,76 E+7$ & & $7,49 E+6$ & $4,45 E+6$ & $1,77 E+5$ & $1,94 E+7$ & $2,11 E+5$ \\
$2-7 / 3$ & & & & Kernbruch & & & \\
$2-7 / 4$ & $4,54 E+7$ & & $6,72 E+6$ & $3,96 E+6$ & $1,67 E+5$ & $1,77 E+7$ & $1,88 E+5$ \\
$2-7 / 5$ & $4,11 E+7$ & $7,48 E+3$ & $6,00 E+6$ & $3,57 E+6$ & $1,53 E+5$ & $1,59 E+7$ & $1,55 E+5$ \\
& & & & & & & \\
\hline
\end{tabular}

Table 4.49 Inventory $(\mathrm{Bq})$ of bare kernels plus the associated coatings from fertile particles for selected nuclides from particle trays in capsule 2 Source: Forschungszentrum Julich GmbH, Julich,

Germany

\begin{tabular}{|c|c|c|c|c|c|c|c|}
\hline \multirow{2}{*}{ Partik.Nr. } & \multicolumn{7}{|c|}{ Aktivitāt zum Abschaltzeitpunkt [Bq } \\
& Ce 144 & Co 60 & Cs 134 & Cs 137 & Eu 154 & Ru 106 & Sb 124 \\
\hline & & & & & & & \\
$2-4 / 1$ & $1,83 E+7$ & $3,50 E+2$ & $1,23 E+6$ & $1,24 E+6$ & $2,80 E+4$ & $9,01 E+5$ & $1,93 E+5$ \\
$2-4 / 2$ & $1,79 E+7$ & $4,31 E+2$ & $1,22 E+6$ & $1,22 E+6$ & $2,22 E+4$ & $9,01 E+5$ & $1,91 E+5$ \\
$2-4 / 3$ & $1,83 E+7$ & $5,47 E+2$ & $1,30 E+6$ & $1,30 E+6$ & $2,92 E+4$ & $8,76 E+5$ & $2,04 E+5$ \\
$2-4 / 4$ & $1,79 E+7$ & & $1,22 E+6$ & $1,22 E+6$ & $1,87 E+4$ & $9,52 E+5$ & $1,86 E+5$ \\
$2-4 / 5$ & $1,98 E+7$ & $3,55 E+2$ & $1,33 E+6$ & $1,35 E+6$ & $2,62 E+4$ & $1,03 E+6$ & $2,10 E+5$ \\
& & & & & & & \\
$2-8 / 1$ & $1,82 E+7$ & $6,37 E+2$ & $1,30 E+6$ & $1,30 E+6$ & $2,27 E+4$ & $9,96 E+5$ & $1,99 E+5$ \\
$2-8 / 2$ & & & & Kernbruch & & & \\
$2-8 / 3$ & $1,64 E+7$ & & $1,22 E+6$ & $1,24 E+6$ & $2,84 E+4$ & $8,94 E+5$ & $1,91 E+5$ \\
$2-8 / 4$ & $1,71 E+7$ & & $1,27 E+6$ & $1,28 E+6$ & $2,92 E+4$ & $9,63 E+5$ & $2,04 E+5$ \\
$2-8 / 5$ & $1,74 E+7$ & $5,30 E+2$ & $1,21 E+6$ & $1,23 E+6$ & $2,32 E+4$ & $8,45 E+5$ & $1,87 E+5$ \\
& & & & & & & \\
\hline
\end{tabular}


Table 4.50 Inventory $(\mathrm{Bq})$ of bare kernels plus the associated coatings from fissile particles for selected nuclides from particle trays in capsule 3 Source: Forschungszentrum Jalich GmbH, Jalich, Germany

\begin{tabular}{|c|c|c|c|c|c|c|c|}
\hline \multirow{2}{*}{ Partik.Nr. } & \multicolumn{7}{|c|}{ Aktivität zum Abschaltzeitpunkt [Bq] } \\
& Ce 144 & Co 60 & Cs 134 & Cs 137 & Eu 154 & Ru 106 & Sb 124 \\
\hline & & & & & & & \\
$3-3 / 1$ & $4,29 E+7$ & & $5,91 E+6$ & $4,18 E+6$ & $1,61 E+5$ & $1,50 E+7$ & $1,96 E+5$ \\
$3-3 / 2$ & $4,65 E+7$ & & $5,79 E+6$ & $4,05 E+6$ & $1,51 E+5$ & $1,50 E+7$ & $1,98 E+5$ \\
$3-3 / 3$ & $4,37 E+7$ & & $5,83 E+6$ & $4,11 E+6$ & $1,63 E+5$ & $1,49 E+7$ & $1,87 E+5$ \\
$3-3 / 4$ & $4,78 E+7$ & & $5,99 E+6$ & $4,21 E+6$ & $1,60 E+5$ & $1,58 E+7$ & $2,01 E+5$ \\
$3-3 / 5$ & $4,40 E+7$ & & $5,65 E+6$ & $3,97 E+6$ & $1,40 E+5$ & $1,47 E+7$ & $1,80 E+5$ \\
& & & & & & & \\
$3-7 / 1$ & $3,34 E+7$ & & $3,97 E+6$ & $3,02 E+6$ & $9,90 E+4$ & $1,06 E+7$ & $1,48 E+5$ \\
$3-7 / 2$ & $4,21 E+7$ & & $5,06 E+6$ & $3,87 E+6$ & $1,38 E+5$ & $1,34 E+7$ & $1,80 E+5$ \\
$3-7 / 3$ & $3,63 E+7$ & & $4,11 E+6$ & $3,11 E+6$ & $1,07 E+5$ & $1,11 E+7$ & $1,47 E+5$ \\
$3-7 / 4$ & $4,06 E+7$ & & $5,11 E+6$ & $3,89 E+6$ & $1,49 E+5$ & $1,37 E+7$ & $1,84 E+5$ \\
$3-7 / 5$ & $4,59 E+7$ & & $5,03 E+6$ & $3,82 E+6$ & $1,53 E+5$ & $1,34 E+7$ & $1,66 E+5$ \\
& & & & & & & \\
\hline
\end{tabular}

Table 4.51 Inventory $(\mathrm{Bq})$ of bare kernels plus the associated coatings from fertile particles for selected nuclides from particle trays in capsule 3 Source: Forschungszentrum Julich GmbH, Jalich, Germany

\begin{tabular}{|c|c|c|c|c|c|c|c|}
\hline \multirow{2}{*}{ Partik.Nr. } & \multicolumn{7}{|c|}{ Aktivitāt zum Abschaltzeitpunkt [Bq] } \\
& Ce 144 & Co 60 & Cs 134 & Cs 137 & Eu 154 & Ru 106 & Sb 124 \\
\hline & & & & & & & \\
$3-4 / 1$ & $1,25 E+7$ & & $7,69 E+5$ & $9,61 E+5$ & & $7,76 E+5$ & $1,50 E+5$ \\
$3-4 / 2$ & $1,35 E+7$ & & $8,26 E+5$ & $1,02 E+6$ & $1,96 E+4$ & $6,39 E+5$ & $1,59 E+5$ \\
$3-4 / 3$ & $1,45 E+7$ & & $7,88 E+5$ & $9,80 E+5$ & $1,67 E+4$ & $6,66 E+5$ & $1,61 E+5$ \\
$3-4 / 4$ & $1,37 E+7$ & & $7,86 E+5$ & $9,71 E+5$ & & $7,12 E+5$ & $1,53 E+5$ \\
$3-4 / 5$ & $1,27 E+7$ & $3,13 E+2$ & $7,54 E+5$ & $9,22 E+5$ & $1,79 E+4$ & $6,26 E+5$ & $1,48 E+5$ \\
& & & & & & & \\
$3-8 / 1$ & $1,22 E+7$ & & $6,38 E+5$ & $8,50 E+5$ & & $6,16 E+5$ & $1,26 E+5$ \\
$3-8 / 2$ & $1,14 E+7$ & & $5,89 E+5$ & $7,94 E+5$ & & $5,90 E+5$ & $1,27 E+5$ \\
$3-8 / 3$ & $1,20 E+7$ & & $6,27 E+5$ & $8,46 E+5$ & & $5,78 E+5$ & $1,43 E+5$ \\
$3-8 / 4$ & $1,27 E+7$ & & $6,39 E+5$ & $8,67 E+5$ & & $6,31 E+5$ & $1,45 E+5$ \\
$3-8 / 5$ & $1,23 E+7$ & & $6,50 E+5$ & $8,70 E+5$ & & $6,40 E+5$ & $1,36 E+5$ \\
& & & & & & & \\
\hline
\end{tabular}


Table 4.52 The percent retention of fission products in the kernels of intact fissile particles for selected nuclides from particle trays in capsule 2 Source: Forschungszentrum Julich $\mathrm{GmbH}$, Jalich, Germany

\begin{tabular}{|c|c|c|c|c|c|c|c|}
\hline \multirow{2}{*}{ Partik.Nr. } & \multicolumn{8}{|c|}{ Spaltproduktanteil pro Kem [\%] } \\
& Ce 144 & Co 60 & Cs 134 & Cs 137 & Eu 154 & Ru 106 & Sb 124 \\
\hline & & & & & & & \\
$2-3 / 1$ & 100,0 & & 97,9 & 98,1 & 97,1 & 100,0 & 100,0 \\
$2-3 / 2$ & 100,0 & & 95,6 & 95,8 & 92,9 & 100,0 & 100,0 \\
$2-3 / 3$ & 100,0 & & 98,4 & 98,6 & 97,0 & 100,0 & 100,0 \\
$2-3 / 4$ & 100,0 & & 98,5 & 98,7 & 97,1 & 100,0 & 100,0 \\
$2-3 / 5$ & 100,0 & & 98,4 & 98,5 & 97,0 & 100,0 & 100,0 \\
& & & & & & & \\
$2-7 / 1$ & 100,0 & & 98,8 & 98,9 & 95,5 & 100,0 & 100,0 \\
$2-7 / 2$ & 100,0 & & 98,6 & 98,7 & 95,0 & 100,0 & 100,0 \\
$2-7 / 3$ & & & & Kernbruch & & & \\
$2-7 / 4$ & 100,0 & & 88,9 & 89,1 & 79,8 & 100,0 & 100,0 \\
$2-7 / 5$ & 100,0 & & 97,4 & 97,6 & 92,0 & 100,0 & 100,0 \\
& & & & & & & \\
\hline
\end{tabular}

Table 4.53 The percent retention of fission products in the kernels of intact fertile particles for selected nuclides from particle trays in capsule 2 Source: Forschungszentrum Jalich GmbH, Jalich, Germany

\begin{tabular}{|c|c|c|c|c|c|c|c|}
\hline \multirow{2}{*}{ Partik.Nr. } & \multicolumn{7}{|c|}{ Spaltproduktanteil pro Kern [\%] } \\
& Ce 144 & Co 60 & Cs 134 & Cs 137 & Eu 154 & Ru 106 & Sb 124 \\
\hline & & & & & & & \\
$2-4 / 1$ & 100,0 & & 98,0 & 98,1 & 98,8 & 100,0 & 99,2 \\
$2-4 / 2$ & 100,0 & & 98,7 & 98,8 & 100,0 & 100,0 & 99,3 \\
$2-4 / 3$ & 100,0 & & 98,3 & 98,4 & 100,0 & 100,0 & 99,2 \\
$2-4 / 4$ & 98,4 & & 97,8 & 97,8 & 100,0 & 97,5 & 97,8 \\
$2-4 / 5$ & 100,0 & & 98,6 & 98,8 & 100,0 & 100,0 & 99,7 \\
& & & & & & & \\
$2-8 / 1$ & 100,0 & & 99,2 & 99,2 & 100,0 & 100,0 & 100,0 \\
$2-8 / 2$ & & & & Kernbruch & & & \\
$2-8 / 3$ & 98,8 & & 97,6 & 97,7 & 100,0 & 98,5 & 98,3 \\
$2-8 / 4$ & 100,0 & & 99,7 & 99,7 & 100,0 & 100,0 & 100,0 \\
$2-8 / 5$ & 100,0 & & 98,9 & 99,0 & 100,0 & 100,0 & 100,0 \\
& & & & & & & \\
\hline
\end{tabular}


Table 4.54 The percent retention of fission products in the kernels of intact fissile particles for selected nuclides from particle trays in capsule 3 Source: Forschungszentrum Julich GmbH,

$$
\text { Julich, Germany }
$$

\begin{tabular}{|l|l|l|c|c|c|c|c|}
\hline \multirow{2}{*}{ Partik.Nr. } & \multicolumn{7}{|c|}{ Spaltproduktanteil pro Kern [\%] } \\
& Ce 144 & Co 60 & Cs 134 & Cs 137 & Eu 154 & Ru 106 & Sb 124 \\
\hline \multirow{3}{*}{$3-3 / 1$} & 100,0 & & & & & & \\
$3-3 / 2$ & 100,0 & & 100,0 & 100,0 & 100,0 & 100,0 & 100,0 \\
$3-3 / 3$ & 100,0 & & 99,6 & 99,6 & 100,0 & 100,0 & 100,0 \\
$3-3 / 4$ & 100,0 & & 99,6 & 99,6 & 99,2 & 100,0 & 100,0 \\
$3-3 / 5$ & 100,0 & & 99,6 & 99,7 & 100,0 & 100,0 & 100,0 \\
& & 99,6 & 99,7 & 98,7 & 100,0 & 100,0 \\
$3-7 / 1$ & 100,0 & & & & & & \\
$3-7 / 2$ & 100,0 & & 99,4 & 99,4 & 100,0 & 100,0 & 100,0 \\
$3-7 / 3$ & 100,0 & & 99,6 & 99,6 & 100,0 & 100,0 & 100,0 \\
$3-7 / 4$ & 100,0 & & 99,3 & 99,3 & 100,0 & 100,0 & 100,0 \\
$3-7 / 5$ & 100,0 & & 99,7 & 99.7 & 100,0 & 100,0 & 100,0 \\
& & & 99,7 & 99.7 & 100,0 & 100,0 & 100,0 \\
\hline
\end{tabular}

Table 4.55 The percent retention of fission products in the kernels of intact fertile particles for selected nuclides from particle trays in capsule 3 Source: Forschungszentrum Julich $\mathrm{GmbH}$, Julich, Germany

\begin{tabular}{|c|c|c|c|c|c|c|c|}
\hline \multirow{2}{*}{ Partik.Nr. } & \multicolumn{7}{|c|}{ Spaltproduktanteil pro Kern [\%] } \\
& Ce 144 & Co 60 & Cs 134 & Cs 137 & Eu 154 & Ru 106 & Sb 124 \\
\hline & & & & & & & \\
$3-4 / 1$ & 100,0 & & 99,1 & 99,2 & & 100,0 & 100,0 \\
$3-4 / 2$ & 100,0 & & 98,8 & 99,2 & 100,0 & 100,0 & 100,0 \\
$3-4 / 3$ & 100,0 & & 99,8 & 99,4 & 100,0 & 100,0 & 100,0 \\
$3-4 / 4$ & 100,0 & & 98,6 & 98,7 & & 100,0 & 100,0 \\
$3-4 / 5$ & 100,0 & & 99,3 & 99,4 & 100,0 & 100,0 & 100,0 \\
& & & & & & & \\
$3-8 / 1$ & 100,0 & & 96,6 & 97,4 & & 100,0 & 100,0 \\
$3-8 / 2$ & 100,0 & & 97,0 & 97,1 & & 100,0 & 100,0 \\
$3-8 / 3$ & 100,0 & & 98,9 & 99,3 & & 100,0 & 100,0 \\
$3-8 / 4$ & 97,9 & & 98,4 & 98,5 & & 100,0 & 98,7 \\
$3-8 / 5$ & 100,0 & & 98,7 & 98,8 & & 100,0 & 100,0 \\
& & & & & & & \\
\hline
\end{tabular}




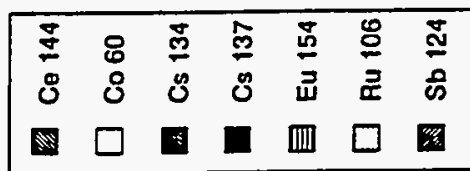

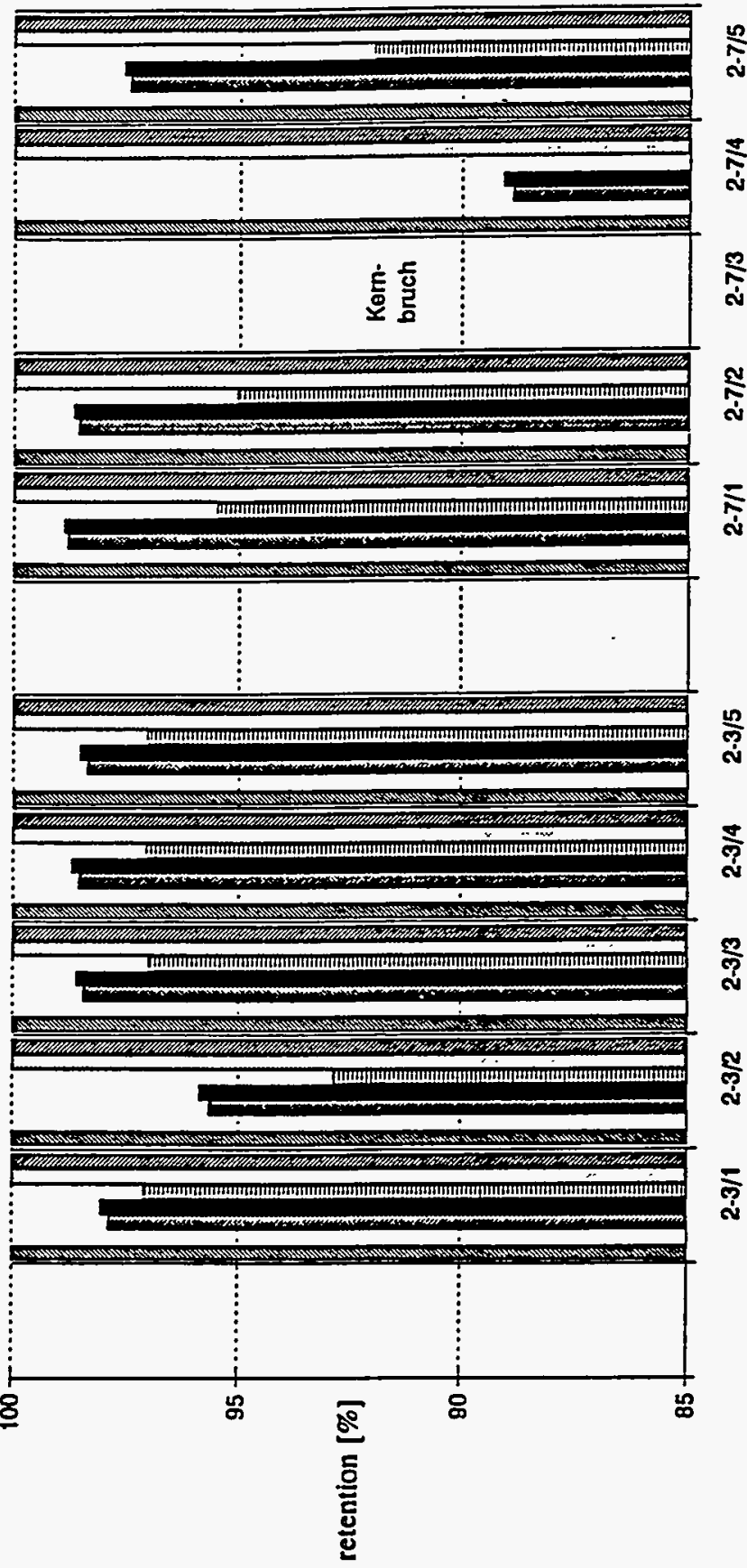

产

$\stackrel{\text { ง }}{\text { i }}$

ลัง

$\stackrel{\infty}{\grave{d}}$

ง

$\underset{\sim}{\dot{\alpha}}$

$\stackrel{\text { ș }}{\text { ஸे }}$

ลัง

옹

ฌั

믈

8

త్

잉

ษ

을

고

‥

है

는

펑 을

.

음

는

롤

产

号

$\equiv$

오

웡

을

ธิ

资

○

5

믈

త

픈

¿

$\stackrel{\mathscr{E}}{E}$

$\stackrel{9}{\exists}$

这 


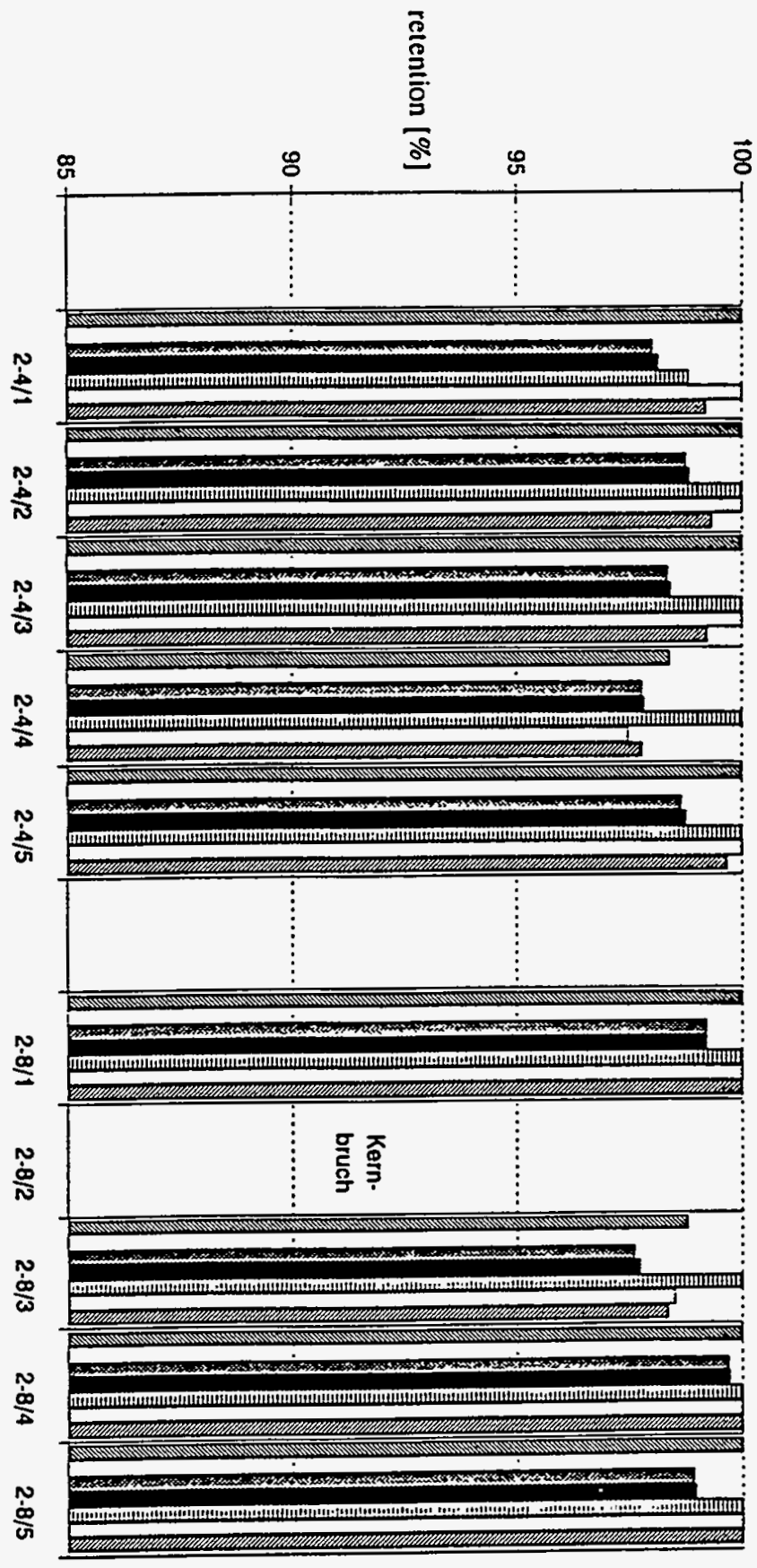

\begin{tabular}{|c|c|c|c|c|c|c|c|}
\hline $\begin{array}{l}\mathbb{Z} \\
\mathscr{E} \\
\vec{N}\end{array}$ & $\begin{array}{l}\text { 드 } \\
\text { D्र } \\
\text { 해 }\end{array}$ & $\frac{m}{2}$ & $\delta$ & & 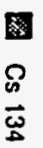 & $\begin{array}{l}\square \\
8 \\
8\end{array}$ & $\$$ \\
\hline
\end{tabular}




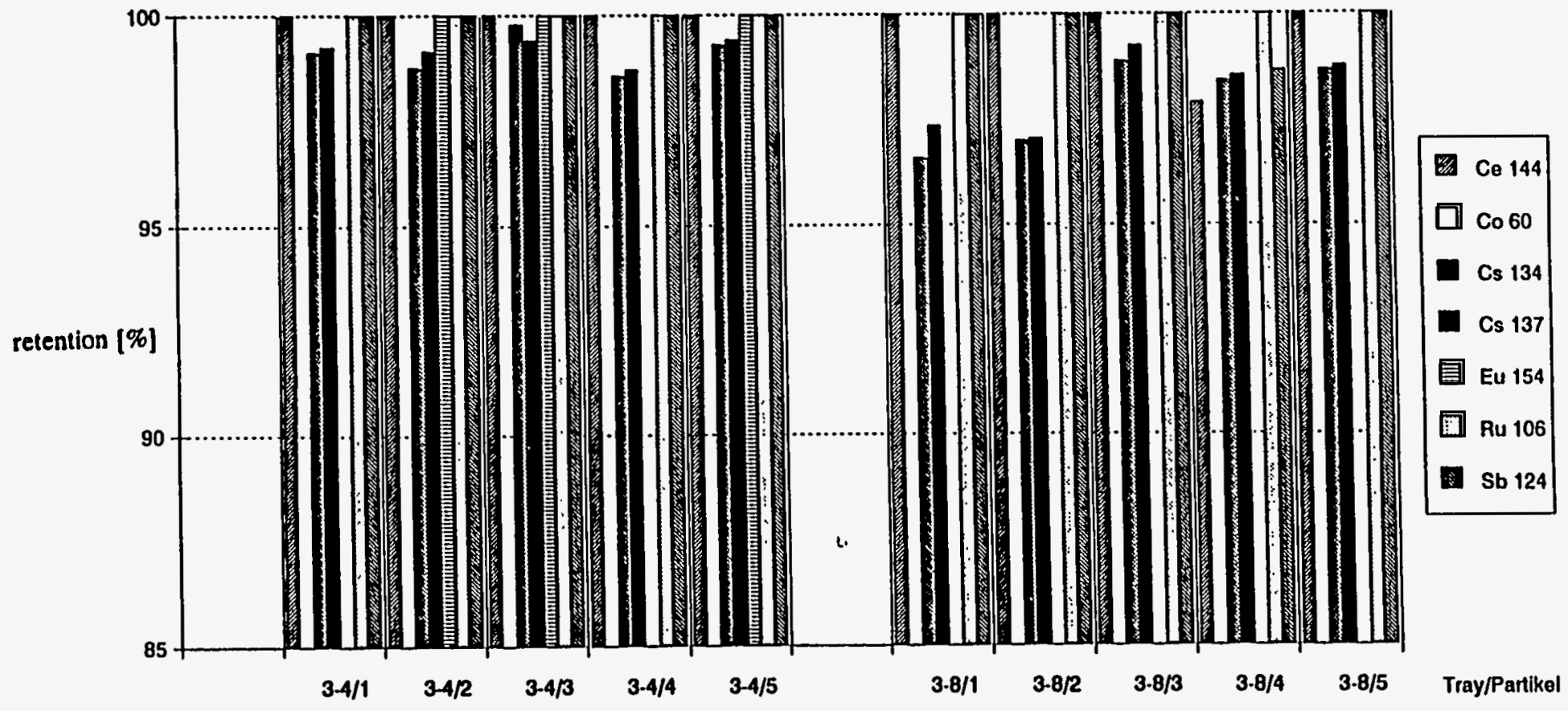

Fig. 4.115 The percent retention of fission products in the kernels of intact fissile particles for selected nuclides from particle trays in capsule 3 Source: Forschungszentrum Jülich GmbH, Jülich, Germany 


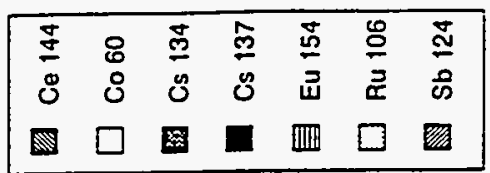

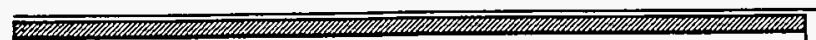

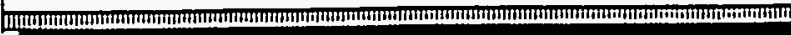
1) -

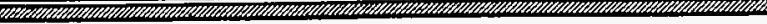
ก. (1) 19. .

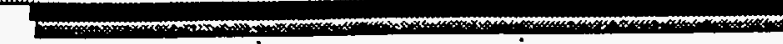

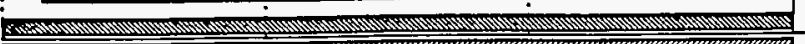

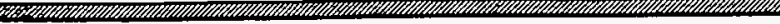

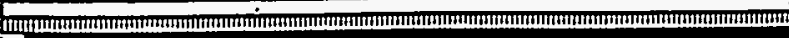
1) 2

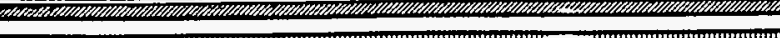

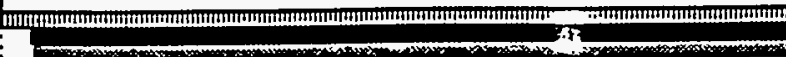

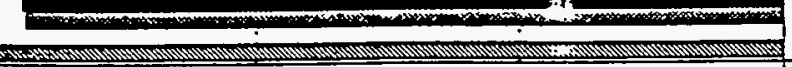

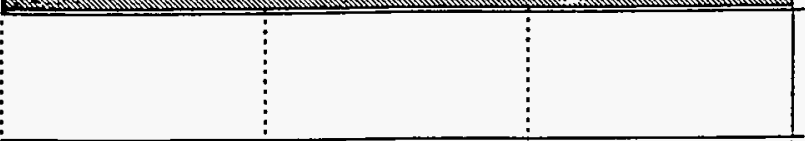

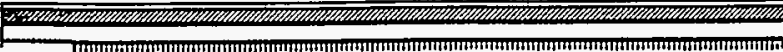
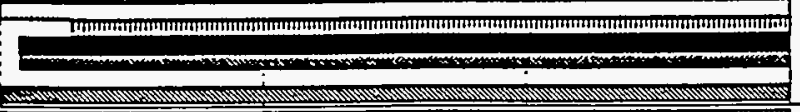

-

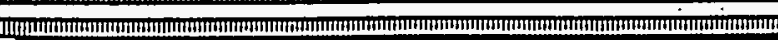

-

- :-

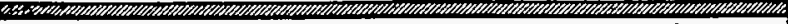

T.
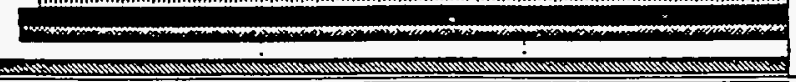

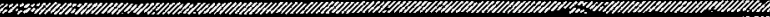

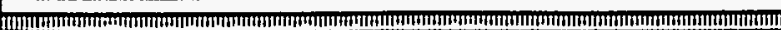
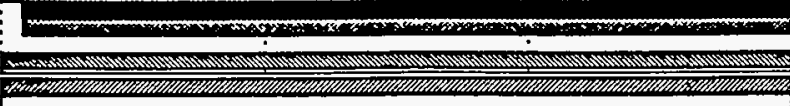

(7)
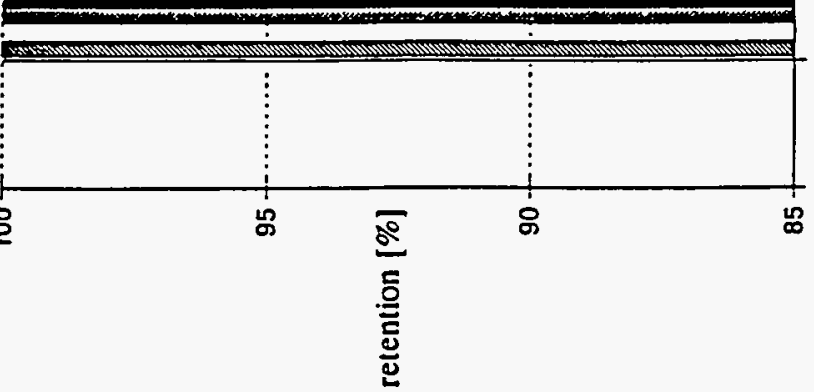

产

突

突

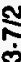

$\Sigma$

พొ

声

क্

กั

হై 


\subsubsection{Kernel Retention of Fission Products}

The retention of the fission products ${ }^{154} \mathrm{Eu},{ }^{144} \mathrm{Ce},{ }^{106} \mathrm{Ru},{ }^{125} \mathrm{Sb}$ and ${ }^{124} \mathrm{Sb}$ (an activation product) was essentially complete. For ${ }^{137} \mathrm{Cs}$ and ${ }^{134} \mathrm{Cs}$, the release from the kernel was between 1.5 and $3 \%$. The releases for cesium seem to be quite small for an irradiation lasting 446 effective full power days.

The release of fission products from the kernel in an intact particle is known to be small in comparison with the release from an exposed kernel. For example, in the experiment R2-K13 14 , the measured kernel release in intact particles was $13 \pm 7 \%$ of that for the exposed kernel. However, the averaged absolute release from the kernels in intact particles was about $15 \%$ for ${ }^{137} \mathrm{Cs}$ over the temperature range 900 to $1200^{\circ} \mathrm{C}$ during an irradiation of 517 effective full power days.

A valid assessment of kernel retention of fission products for experiment HFR-B1, in terms of the previously reported results, ${ }^{14}$ can be made only after the thermal analysis of HFR-B1 has been completed.

\subsubsection{Cracking of Intact Fuel Particles}

Five particles each from trays 2-3, 2-7, 2-4 and 2-8 were selected and cracked using a device which measures the applied load and the force at which the particle cracks. Upon cracking, the force decreases rapidly; the record of the force-time curves displays a maximum as a result. Aslo measured is the distance the arm, which transmits the applied force, has to move before cracking occurs. In the initial position, the arm touches the particle surface; this position is the zero distance.

The force and distance at which each particle cracks is given in Tables $4.56,4.57,4.58$, and 4.59 for each of the five particles. In the Tables, the fissile and fertile particles are distinguished. Plots of these data are shown in Figs. 4.117, 4.118, 4.119, and 4.120.

At the $67 \%$ confidence level, there is no statistical difference in either the force or the distance movement required to crack fissile or fertile particles from either capsule 2 or 3 . The overall average force and standard deviation is $12.5 \pm 2.7 \mathrm{~N}$ and the overall average distance movement and standard deviation is $0.039 \pm 0.021 \mathrm{~mm}$. This average distance movement represents about $5 \%$ of the particle diameter for either fissile or fertile particles.

\subsection{Heating Tests with Intermittent Water-Vapor Injections}

Heating tests with intermittent injections of water vapor have been conducted as indicated on Fig. 4.3 for the two tasks involving fuel compacts and unbonded fuel particles. These tests were conducted in the KORA facility ${ }^{15}$ at KFA under postirraidation conditions.

The KORA facility consists of a flow apparatus in which the sweep gas, $\mathrm{He}$, can be mixed with water vapor and sent through a furnace containing the fuel specimen (ie., particles, compacts or fuel spheres). The water vapor interacts or reacts with the exposed kernels and the carbonaceous material in the specimen. The former results in an enhanced release of fission products ${ }^{16}$. The sweep gas mixture containing the released fission products passes through and is acted upon by ion chambers and the various filters in the gas train. At the end, the activity of the fission gases is measured. In the tested specimens, the activity of the moderate- and short-lived fission gas isotopes is negligible because of the delay between the end of irradiation and the start of the KORA test. In KORA, only the long-lived gaseous isotope ${ }^{85} \mathrm{Kr}$ has been measured. Technical data for the KORA facility is given in Table 4.60 . 
Table 4.56 Force and movement conditions under which fissile particles from capsule 2 crack Source: Forschungszentrum Julich GmbH, Julich, Germany

\begin{tabular}{|c|c|c|}
\hline HFR-B1 & \multicolumn{2}{|c|}{ Zerdrück- Parameter } \\
\hline Tray/ Partikel & Kraft [N] & Weg [mm] \\
\hline $2-3 / 1$ & 14,31 & 0,020 \\
$2-3 / 2$ & $14,70^{-}$ & 0,028 \\
$2-3 / 3$ & 12,15 & 0,033 \\
$2-3 / 4$ & 15,23 & 0,030 \\
$2-3 / 5$ & 12,75 & 0,024 \\
\hline Mitteiwert & 13,83 & 0,027 \\
\hline $2-7 / 1$ & $8,5 \%$ & $16,9 \%$ \\
\hline $2-7 / 2$ & 20,19 & 0,038 \\
$2-7 / 3$ & 14,31 & 0,021 \\
$2-7 / 4$ & 15,09 & 0,029 \\
$2-7 / 5$ & 12,94 & 0,018 \\
\hline Mittelwert & 6,66 & 0.030 \\
\hline Standardabweichung & 13,84 & 0,027 \\
\hline
\end{tabular}

Table 4.57 Force and movement conditions under which fertile particles from capsule 2 crack Source: Forschungszentrum Julich GmbH, Julich, Germany

\begin{tabular}{|c|c|c|}
\hline HFR-B1 & \multicolumn{2}{|c|}{ Zerdrück- Parameter } \\
\hline Tray/Partikel & Kraft [N] & Weg [mm] \\
\hline $2-4 / 1$ & 11,76 & 0,029 \\
$2-4 / 2$ & 16,46 & 0,024 \\
$2-4 / 3$ & 15,48 & 0,019 \\
$2-4 / 4$ & 17,05 & 0,023 \\
$2-4 / 5$ & 9,60 & 0,036 \\
\hline Mittelwert & 14,07 & 0,026 \\
\hline Standardabweichung & $20,6 \%$ & $22,3 \%$ \\
\hline $2-8 / 1$ & 13,13 & 0,038 \\
$2-8 / 2$ & 12,35 & 0,083 \\
$2-8 / 3$ & 18,23 & 0,082 \\
$2-8 / 4$ & 11,76 & 0,022 \\
$2-8 / 5$ & 17,05 & 0,039 \\
\hline Mittelwert & 14,50 & 0,053 \\
\hline Standardabweichung & $18,1 \%$ & $47,3 \%$ \\
\hline
\end{tabular}

\footnotetext{
Zerdrack Parameter - Cracking Parameter Tray/Pertikel $=$ Tray/Particle Weg [mm] = Distance Movement [mm] Kraft $[\mathrm{N}]=$ Force $[\mathrm{N}]$ 
Table 4.58 Force and movement conditions under which fissile particles from capsule 3 crack Source: Forschungszentrum Julich GmbH, Jalich, Germany

\begin{tabular}{|c|c|c|}
\hline HFR-B1 & \multicolumn{2}{|c|}{ Zerdrūck- Parameter } \\
\hline Tray/ Partikel & Kraft [N] & Weg [mm] \\
\hline $3-3 / 1$ & 12,94 & 0,037 \\
$3-3 / 2$ & 10,58 & 0,026 \\
$3-3 / 3$ & 9,60 & 0,026 \\
$3-3 / 4$ & 12,35 & 0,026 \\
$3-3 / 5$ & 12,15 & 0,035 \\
\hline Mittelwert & 11.52 & 0,030 \\
\hline Standardabweichung & $10,7 \%$ & $16,5 \%$ \\
\hline $3-7 / 1$ & 12,74 & 0,030 \\
$3-7 / 2$ & 6,47 & 0,070 \\
$3-7 / 3$ & 13,52 & 0,037 \\
$3-7 / 4$ & 13,92 & 0,093 \\
$3-7 / 5$ & 11,37 & 0,024 \\
\hline Mittelwert & 11,60 & 0,051 \\
\hline Standardabweichung & $23,4 \%$ & $52,0 \%$ \\
\hline
\end{tabular}

Table 4.59 Force and movement conditions under which fertile particles from capsule 3 crack Source: Forschungszentrum Julich GmbH, Julich, Germany

\begin{tabular}{|c|c|c|}
\hline HFR-B1 & \multicolumn{2}{|c|}{ Zerdrück- Parameter } \\
\hline Tray/ Partikel & Kraft [N] & Weg [mm] \\
\hline $3-4 / 1$ & 16,86 & 0,033 \\
$3-4 / 2$ & 12,35 & 0,026 \\
$3-4 / 3$ & 10,39 & 0,037 \\
$3-4 / 4$ & 9,80 & 0,031 \\
$3-4 / 5$ & 12,54 & 0,025 \\
\hline Mittelwert & 12,39 & 0,030 \\
\hline Standardabweichung & $20,0 \%$ & $14,7 \%$ \\
\hline $3-8 / 1$ & 12,94 & 0,022 \\
$3-8 / 2$ & 16,66 & 0,051 \\
\hline $3-8 / 3$ & 10,19 & 0,087 \\
\hline $3-8 / 4$ & 14,11 & 0,031 \\
$3-8 / 5$ & 18,03 & 0,031 \\
\hline Mittelwert & 14,39 & 0,044 \\
\hline Standardabweichung & $19,2 \%$ & $52,5 \%$ \\
\hline
\end{tabular}

\footnotetext{
Zerdruck Parameter = Cracking Parameter

Tray/Pertikel - Tray/Particle

Weg [mm] = Distance Movement [mm]

Kraft $[N]=$ Force $[N]$

Mittelwert - Average Value

Standardabweichung $=$ Standard Deviation
} 


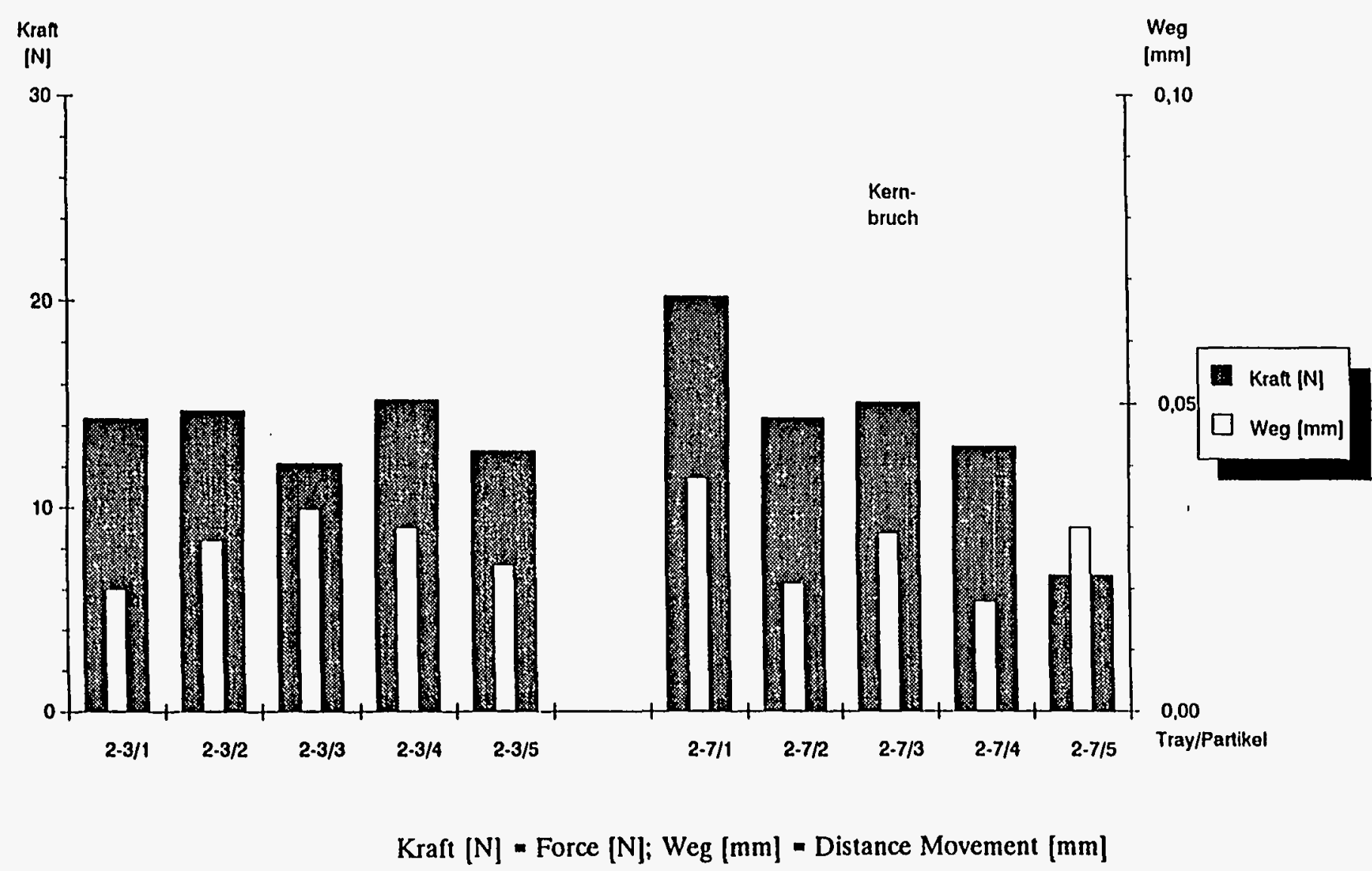

Fig. 4.117 Force and movement conditions under which fissile particles from capsule 2 crack Source: Forschungszentrum Jülich $\mathrm{GmbH}$, Jülich, Germany 


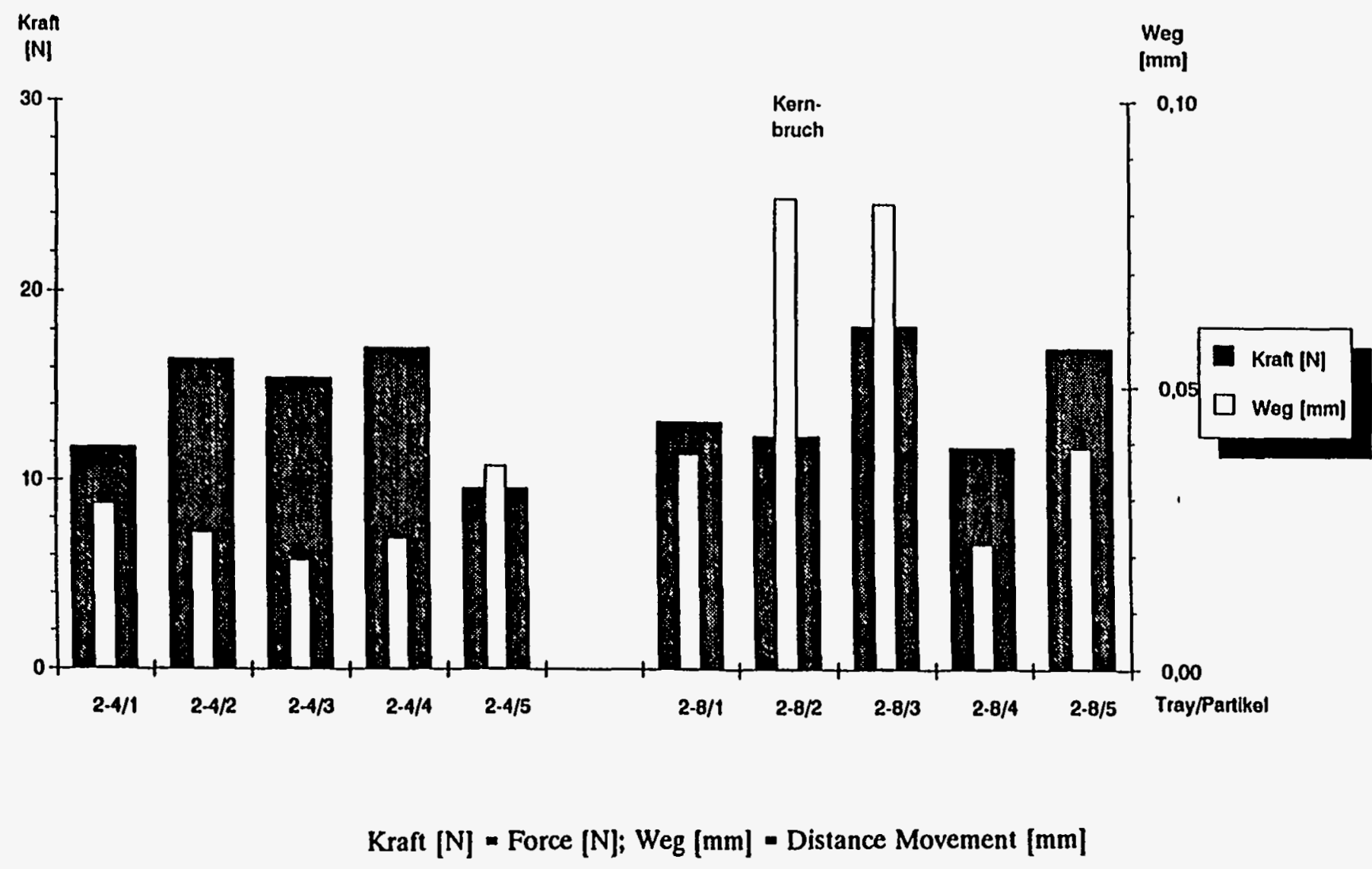

Fig. 4.118 Force and movement conditions under which fertile particles from capsule 2 crack Source: Forschungszentrum Jülich $\mathrm{GmbH}$, Jülich, Germany 


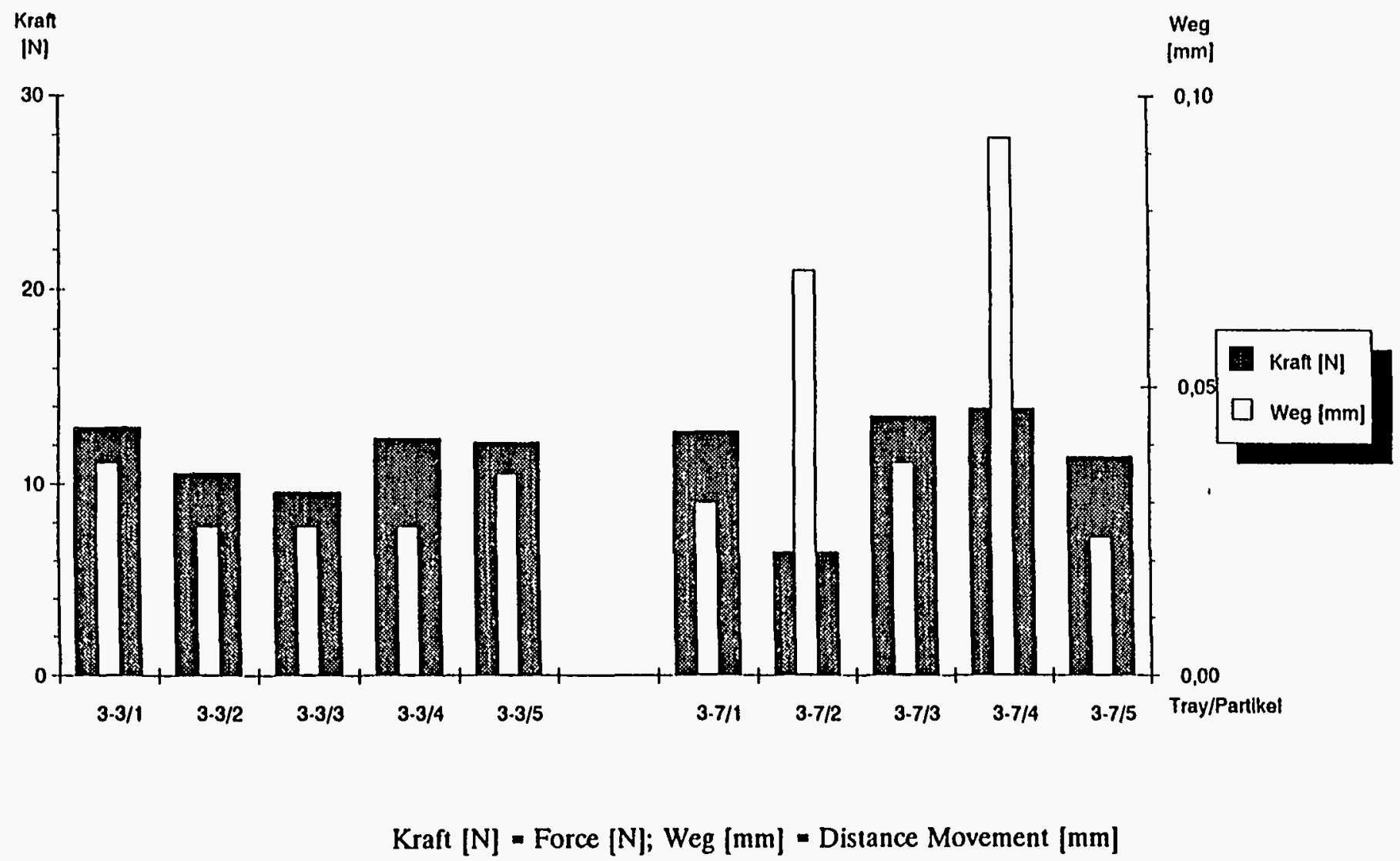

Fig. 4.119 Force and movement conditions under which fissile particles from capsule 3 crack Source: Forschungszentrum Jülich $\mathrm{GmbH}$, Jülich, Germany 


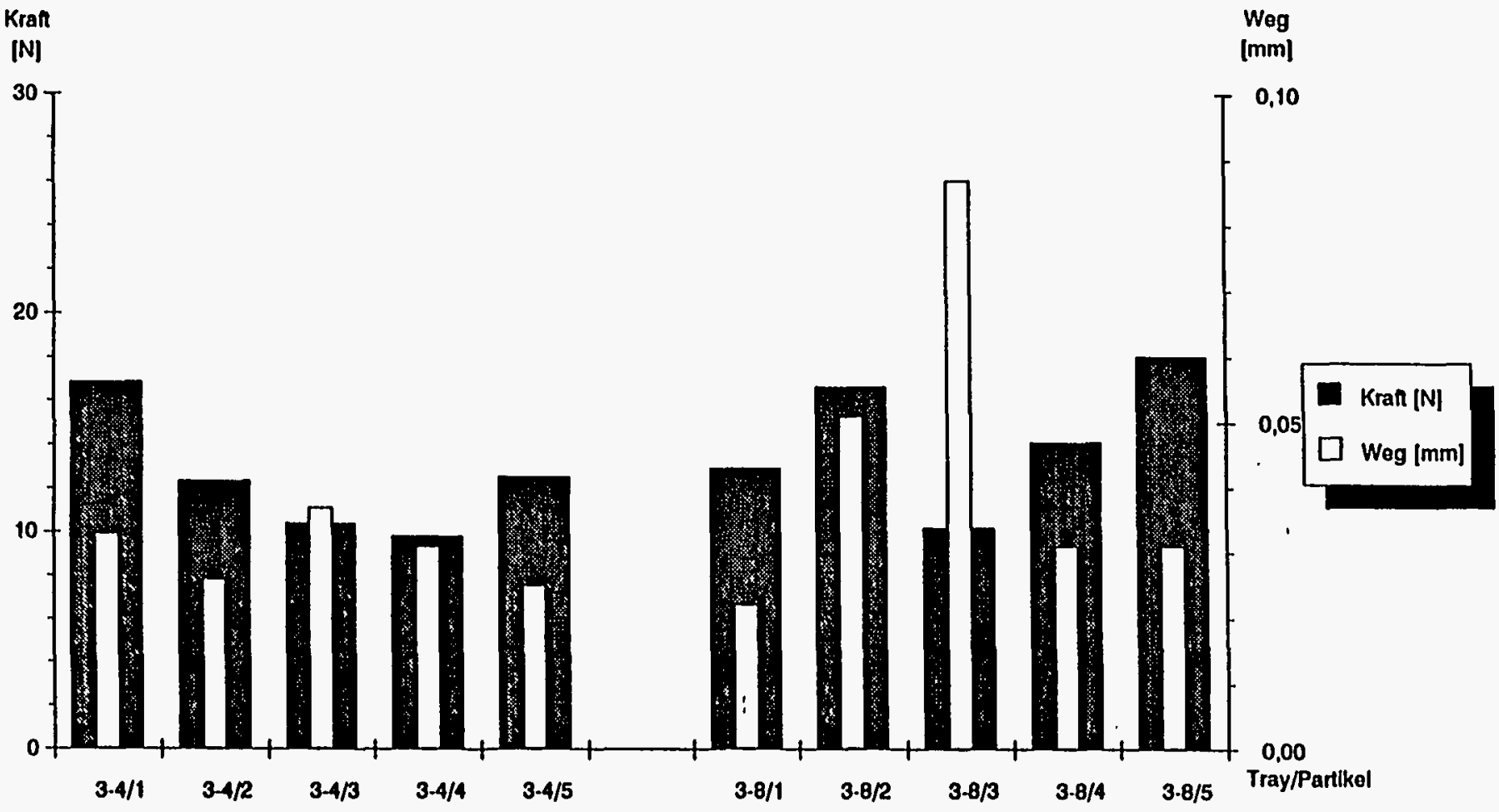

Kraft $[\mathrm{N}]$ - Force $[\mathrm{N}] ;$ Weg $[\mathrm{mm}]$ - Distance Movement $[\mathrm{mm}]$

Fig. 4.120 Force and movement conditions under which fertile particles from capsule 3 crack Source: Forschungszentrum Jülich GmbH, Jülich, Germany 
Table 4.60 Technical data for the KORA facility Source: Forschungszentrum Jalich $\mathrm{GmbH}$, Jalich, Germany

Resistance furnace with temperature control

Heating elements

Kantal (MoSi2)

Tube inset

Quartz glass up to $1000^{\circ} \mathrm{C}$

Alsint / SiC up to $1600^{\circ} \mathrm{C}$.

Inner diameter for samples

$70 \mathrm{~mm}$

Max. temperature

Gas pressure

$1600^{\circ} \mathrm{C}$

Temperature measurement

- 1300 mbar

Pt/Rh thermocouples

Open gas loop with throughput control

Throughput

$30 \mathrm{ltr} / \mathrm{h}(\max .100 \mathrm{ltr} / \mathrm{h})$

Medium

Helium, H2O, Air, $\mathrm{CO}, \mathrm{CO} 2$

Measurements

Water vapor levels

Throughput, pressure, humidity

$1-80 \mathrm{kPa}$

Fission product measurements

Fission gases

Solid fission products

Continuous

(lonization chamber, Nal detector)

Difference of sample inventory

before and after test (Cs-137) 
The specimens used in the four heating tests conducted with intermitent injections of water vapor were the fuel compacts 2.2.1 plus 2.2.2; 3.2.1 plus 3.2.2; and two sets of 5 kernels taken from 10 particles which had been irradiated in tray 3-7; tray 3-7 contained normally configured fissile UCO TRISO particles. Property data for the specimens are presented in Table 4.61; irradiation and test conditions are presented in Table 4.62.

\subsection{Water Vapor Injection Tests with Compacts 2.2 .1 and 2.2 .2}

The fuel compacts 2.2 .1 and 2.2 .2 were irradiated in capusle 2 and were not exposed to water vapor during irradiation. The release of ${ }^{85} \mathrm{Kr}$ during the heating test and water vapor injections at $800^{\circ} \mathrm{C}$ with the set of fuel compacts 2.2 .1 and 2.2 .2 is shown in Fig. 4.121 as a function of time in terms of the fractional release and the release rate; the latter is calculated according to the relation:

$$
R / N=\left\{f\left(t_{i}\right)-f\left(t_{i-1}\right)\right\} /\left(t_{i}-t_{i-1}\right)
$$

where

$$
\begin{aligned}
& R / N=\text { release rate }(1 / s) \\
& f\left(t_{j}\right) \quad=\text { fractional release at time } t_{j}
\end{aligned}
$$

The data plotted in Fig. 4.121 are presented in Table 4.63.

The data in Fig. 4.121 show a general decline in the release rate of ${ }^{85} \mathrm{Kr}$, a trend consistent with a decline in the inventory of this isotope. At the beginning of the two water vapor injections, at a partial pressure of $1 \mathrm{kPa}$, there is a detectable rapid increase in the release rate. Thus, the ${ }^{85} \mathrm{Kr}$ release is enhanced and therefore the release is a function of the water vapor pressure. The increases are, however, small in accord with a small inventory of ${ }^{85} \mathrm{Kr}$. The small inventory may be a consequence of the higher temperatures and frequent changes in temperature experienced during the irradiation undergone by the compacts in capusle 2 .

It appears, during the first water vapor injection shown in Fig. 4.121, that the release of ${ }^{85} \mathrm{Kr}$ following the initial rapid increase is higher than in the absence of the water vapor as indicated by the noticeable decline in release rate upon termination of the injection. However this persistent, enhanced release is not evident during the second water vapor injection and is somewhat obscured generally by the steady decline in release rate.

\subsection{Water Vapor Injection Tests with Compacts 3.2.1 and 3.2.2}

The fuel compacts 3.2.1 and 3.2.2 were irradiated in capusle 3 and were exposed to water vapor during irradiation. Unfortunately, after the water-vapor injections, but with one exception, insufficient time was allowed for sintering and annealing; the same can be said of the tests under discussion. These relatively high frequencies of injection complicate the analysis.

The release of ${ }^{85} \mathrm{Kr}$ during the second heating test and associated water vapor injections at $800^{\circ} \mathrm{C}$ with the set of fuel compacts, 3.2.1 and 3.2.2, is shown in Fig. 4.122 as a function of time in terms of the fractional release and the release rate. The data are presented in Table 4.64. The partial pressure of water vapor ranged from 1 to $50 \mathrm{kPa}$ and altogether there were nine injections. In seven of the injections there were distinct and rapid initial releases of ${ }^{85} \mathrm{Kr}$ in qualitative agreement with previous experiments ${ }^{16}$. Of the first three water vapor injections, all at $1 \mathrm{kPa}$ of water vapor, the response of the fuel compacts to the second and third resulted in a distinct decrease to a steady value of the release rate, which at the termination of water vapor injection, returned to the pre-injection level. This is shown clearly in Fig. 4.123. The suggestion was made ${ }^{15}$ that the release of ${ }^{85} \mathrm{Kr}$ atoms was 
Table 4.61 Property data on the fuel compacts and fuel kernels used in the heating tests with intermittent injections of water vapor

\begin{tabular}{|l|c|c|c|}
\hline Item & $\begin{array}{c}\text { Driver } \\
\text { Fissile }\end{array}$ & $\begin{array}{c}\text { Designed-to-Fail } \\
\text { Fissile }\end{array}$ & Fertile \\
\hline Particles & & & \\
Sample number & $26157-11-0100$ & $6450-00-0100$ & $6252-12$-COMP \\
Coating type & TRISO & Seal & TRISO \\
Total part. diam. & $824 \mu \mathrm{m}$ & $389 \mu \mathrm{m}$ & $786 \mu \mathrm{m}$ \\
Kernel composition & $\mathrm{UC}_{0.5} \mathrm{O}_{1.5}$ & $\mathrm{UC}_{0.4} \mathrm{O}_{1.6}$ & $\mathrm{ThO}_{2}$ \\
Kernel diameter & $353 \mu \mathrm{m}$ & $347 \mu \mathrm{m}$ & $452 \mu \mathrm{m}$ \\
Compacts & 896 & 87 & 500 \\
Number of particles & 0.1715 & 0.0185 & - \\
Uranium (g) & 0.0336 & 0.0032 & - \\
U-235 (g) & - & - & 0.2168 \\
Thorium $(g)$ & & & \\
\hline
\end{tabular}

(a) a $23 \mu \mathrm{m}$ thick pyrocarbon layer 
Table 4.62 Irradiation conditions, ${ }^{85} \mathrm{Kr}$ inventory at beginning of test and test conditions for the fuel compacts and fucl kernels used in the heating tests with intermittent injections of water vapor Source: Forschungszentrum Jülich GmbH, Jülich, Germany

\begin{tabular}{|c|c|c|c|c|c|c|}
\hline \multirow[b]{2}{*}{ Fuel sample } & \multirow[b]{2}{*}{ Sample type } & \multirow[b]{2}{*}{ Kemel } & \multirow[b]{2}{*}{$\begin{array}{c}\text { Defectivo } \\
\text { particles }\end{array}$} & \multicolumn{3}{|c|}{ Irradiation conditions } \\
\hline & & & & $\begin{array}{c}\text { Bumup } \\
\text { (\% FIMA) } \\
\text { (a) }\end{array}$ & $\begin{array}{c}\text { Fast fluence } \\
\text { 1E25 (1/m2) } \\
\text { E>0,1MeV (b) }\end{array}$ & $\begin{array}{c}\text { Irradiation } \\
\text { temperature } \\
\left({ }^{\circ} \mathrm{C}\right)\end{array}$ \\
\hline HFR-B1, 2.2.1+2 & Compacts & uco & 174 & 21.7 & 6,6 & $880-1230$ \\
\hline HFR-B1, 3.2.1+2 & Compacts & Uco & 174 & 19.7 & 5,1 & $820-1050$ \\
\hline HFR-B1, tr. 3-7a & Kemels & UCO & $\mathbf{s}$ & 19.7 & 5,1 & $820-1050$ \\
\hline HFR-B1, tr. 3-7a & Kemels & Uco & $\mathbf{s}$ & 19.7 & 5,1 & $820-1050$ \\
\hline
\end{tabular}

\begin{tabular}{|c|c|c|c|}
\hline \multirow[b]{2}{*}{ Fuel sample } & \multicolumn{3}{|c|}{ Kr-85-Inventory at test } \\
\hline & $\begin{array}{c}\text { Sample resp. } \\
\text { des.-to-fail part. } \\
(B q)\end{array}$ & $\begin{array}{l}1 \text { particle } \\
(B q)^{(c)}\end{array}$ & $\begin{array}{c}1 \text { particle } \\
\text { total release } \\
\text { from test }(B q)\end{array}$ \\
\hline $\begin{array}{l}\text { HFR-B1, } 2.2 .1+2 \\
\text { HFR-B1, } 3.2 .1+2\end{array}$ & $\begin{array}{l}6,89 E+07 \\
6,56 E+07\end{array}$ & $\begin{array}{l}4,02 E+05 \\
3,77 E+05\end{array}$ & \\
\hline HFR-B1, tr. 3-7a & $1,56 E+08$ & $3,12 E+05$ & $3,20 E+05$ \\
\hline HFR-B1, tr. 3-7a & $1,56 E+08$ & $3,12 E+05$ & $3,60 E+05$ \\
\hline
\end{tabular}

\begin{tabular}{|c|c|c|c|}
\hline \multirow{2}{*}{ Fuel sample } & \multicolumn{3}{|c|}{ Test conditions } \\
\cline { 2 - 4 } & Temperature & $\begin{array}{c}\text { Water } \\
\text { vapor } \\
(\mathrm{kPa})\end{array}$ & $\begin{array}{c}\text { Number } \\
\text { of } \\
\text { injections }\end{array}$ \\
\hline HFR-B1, 2.2.1+2 & 800 & 1 & 2 \\
HFR-B1, 3.2.1+2 & 800 & $1: 14: 50$ & 9 \\
\hline HFR-B1, tr. 3-7a & 800 & $1: 50$ & 4 \\
HFR-B1, tr. 3-7a & 800 & $1: 2$ & 1 \\
\hline
\end{tabular}

(a) Ref. 6

(b) Uncorrected for final gamma scan; values are for the HFR Petten; HGTR values would be smaller by the factor $0.803^{17}$

(c) Calculated from the ${ }^{137} \mathrm{Cs}$ measurements 


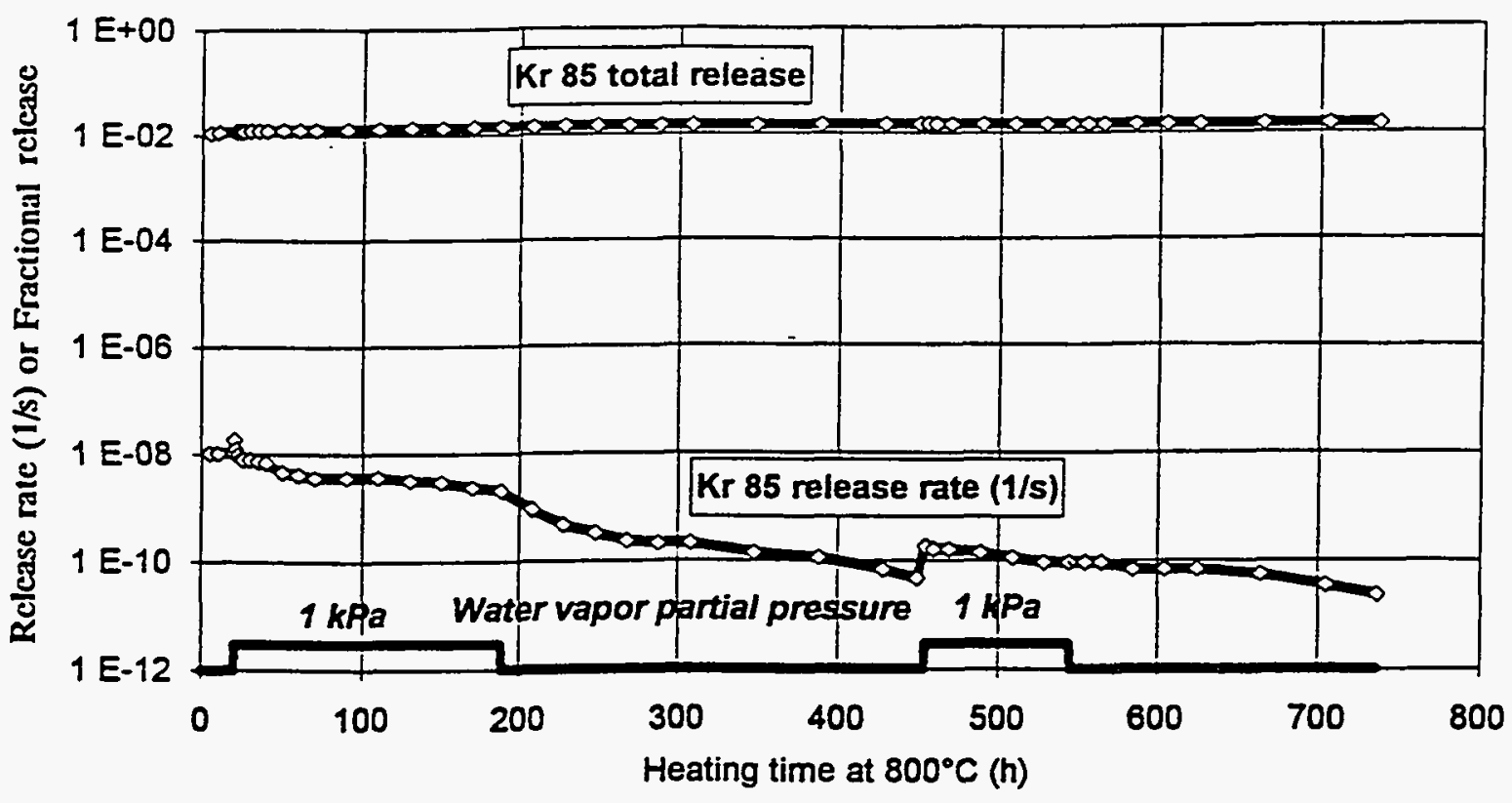

Fig. 4.121 The fractional release and release rate of ${ }^{85} \mathrm{Kr}$ at $800^{\circ} \mathrm{C}$ from fuel compacts 2.2 .1 and 2.2.2 as a function of time and the partial pressure of water vapor Source: Forschungszentrum Jalich GmbH, Julich, Germany 
Table 4.63 The fractional release and release rate of ${ }^{85} \mathrm{Kr}$ at $800^{\circ} \mathrm{C}$ from fuel compacts 2.2 .1 and 2.2.2 as a function of time and the partial pressure of water vapor Source: Forschungszentrum Jalich $\mathrm{GmbH}$, Jalich, Germany

\begin{tabular}{|c|c|c|c|c|c|c|}
\hline \multicolumn{7}{|c|}{ HFR-B1/2.2.1 u. 2} \\
\hline \multirow[b]{2}{*}{$\begin{array}{c}\text { Temperaturo } \\
T \\
\text { (C) }\end{array}$} & \multirow[b]{2}{*}{$\begin{array}{c}\text { Time without } \\
\text { humidity } \\
\text { (m) }\end{array}$} & \multirow[b]{2}{*}{$\begin{array}{c}\text { Tume with } \\
\text { numictity } \\
\text { (I) }\end{array}$} & \multirow[b]{2}{*}{$\begin{array}{l}\text { Redative } \\
\text { numicity } \\
\text { (5) }\end{array}$} & \multirow[b]{2}{*}{$\begin{array}{c}\text { Hoting } \\
\text { tho } \\
\text { (h) }\end{array}$} & \multicolumn{2}{|c|}{ Kras } \\
\hline & & & & & $\begin{array}{c}\text { Fractional } \\
\text { roteaso }\end{array}$ & $\begin{array}{c}\text { Releaso } \\
\text { rate RNN } \\
(1 / s)\end{array}$ \\
\hline 20 & 20 & & & -23.5 & & \\
\hline 100 & - & & & $-22,5$ & $4,86 E-05$ & \\
\hline 130 & - & & & $-21,5$ & $1,49 E-03$ & \\
\hline 170 & - & & & -19.5 & $0,28 E-03$ & \\
\hline 180 & - & & & -17 & $7,27 E-03$ & \\
\hline 270 & - & & & $-\infty$ & $9.26 E-03$ & \\
\hline 410 & - & & & -6 & $9,92 E-03$ & \\
\hline 570 & - & & & -4 & $1,05 E-02$ & \\
\hline 705 & - & & & $-1,5$ & $1,0 \pi E-02$ & \\
\hline 800 & - & & & $\overline{0}$ & $1,08 E-02$ & $1,70 E-08$ \\
\hline 800 & 5 & & & 5 & $1,10 E-02$ & $1,08 E-08$ \\
\hline 800 & 10 & & & 10 & $1,12 E-02$ & $1,06 E-08$ \\
\hline 800 & 20 & 0 & & 20 & 1,16E-02 & 1,08E-08 \\
\hline 800 & & $\overline{0.5}$ & 1 & 20.5 & $1,16 \mathrm{E}-02$ & $1,88 E-08$ \\
\hline 800 & & 1,5 & 1 & 21.5 & $1.17 E-02$ & $1,25 E-08$ \\
\hline 800 & 1. Water- & 2,5 & 1 & 22.5 & 1.17E-02 & $9,65 E-08$ \\
\hline 800 & Injoction & 4 & 1 & 24 & $1.18=-02$ & 8,27E-09 \\
\hline 800 & & 6 & 1 & 20 & $1.18 E-02$ & 8,04E-09 \\
\hline 800 & & 10 & 1 & 30 & $1,18 E-02$ & $7,00 E-09$ \\
\hline 800 & & 15 & 1 & 35 & 121E-02 & 7,40E-09 \\
\hline 800 & & 20 & 1 & 40 & $1,22 E-02$ & $6,89 E-09$ \\
\hline 800 & & 30 & 1 & 50 & 1,24E-02 & $4,60 E-00$ \\
\hline 800 & & 40 & 1 & 60 & $1,28 E-02$ & $4,14 E-09$ \\
\hline 800 & & 50 & 1 & 70 & $1,27 E-02$ & $3,68 E-09$ \\
\hline 800 & & 70 & 1 & $\infty$ & $1,30 E-02$ & $3,08 E-09$ \\
\hline 800 & & $\infty$ & 1 & 110 & $1,31 E-02$ & $3,68 E-09$ \\
\hline 800 & & 110 & 1 & 130 & $1,33 E-02$ & $3,222 E-09$ \\
\hline 800 & & 130 & 1 & 150 & $1,36 E-02$ & 2,09E-09 \\
\hline 800 & & 150 & 1 & 170 & $1,38 E-02$ & $2,30 E-09$ \\
\hline 800 & 0 & 188 & 1 & 188 & $1,40 E-02$ & 2,07E-09 \\
\hline 800 & 20 & & & 208 & $9,40 E-02$ & $0,19 E-10$ \\
\hline 800 & 40 & & & 228 & 1,41E-02 & $4,60 E-10$ \\
\hline 800 & 60 & & & 248 & 1,41E-02 & $3,22 E-10$ \\
\hline 800 & 80 & & & 208 & 1,41E-02 & $2.30 E-10$ \\
\hline 800 & 100 & & & 288 & $1,42 E-02$ & 2,07E-10 \\
\hline 800 & 120 & & & 308 & $1,42 E-02$ & 2,0TE-10 \\
\hline 800 & 160 & & & 248 & $1,42 E-02$ & $1,38 E-10$ \\
\hline 800 & 200 & & & 388 & $1,42 E-02$ & $1,15 E-10$ \\
\hline 800 & 240 & & & 428 & $1,42 E-02$ & 6,89E-11 \\
\hline 800 & 201 & 0 & & 48 & 1,42E-02 & $4,60 \mathrm{E}-11$ \\
\hline
\end{tabular}


Table 4.63 (continued)

\begin{tabular}{|c|c|c|c|c|c|c|}
\hline \multicolumn{7}{|c|}{ HFR-B1/2.21 u. 2} \\
\hline \multirow[b]{2}{*}{$\begin{array}{c}\text { Temporaturo } \\
T \\
\text { (C) }\end{array}$} & \multirow[b]{2}{*}{$\begin{array}{c}\text { Timo without } \\
\text { humidity } \\
\text { (m) }\end{array}$} & \multirow[b]{2}{*}{$\begin{array}{l}\text { Thme with } \\
\text { numidity } \\
\text { (n) }\end{array}$} & \multirow[b]{2}{*}{$\begin{array}{c}\text { Rolative } \\
\text { humidity } \\
\text { (a) }\end{array}$} & \multirow[b]{2}{*}{$\begin{array}{c}\text { Heating } \\
\text { tho } \\
\text { (h) }\end{array}$} & \multicolumn{2}{|c|}{$\mathrm{K}-85$} \\
\hline & & & & & $\begin{array}{c}\text { Frectional } \\
\text { rotesse }\end{array}$ & $\begin{array}{c}\text { Reloaso } \\
\text { rato } R N= \\
\text { (1/s) }\end{array}$ \\
\hline 800 & & 5 & 1 & 454 & $1,42 E-02$ & $1,84 \mathrm{E}-10$ \\
\hline 800 & & 10 & 1 & 40 & $1,42 E-02$ & $1,61 E-10$ \\
\hline 800 & 2. Water- & 20 & 1 & 468 & $1.42 E-02$ & $1,61 E-10$ \\
\hline 800 & injection & 40 & 1 & 489 & $1.43 E-02$ & $1,38 E-10$ \\
\hline 800 & & 60 & 1 & 509 & $1,43 E-02$ & $1,15 E-10$ \\
\hline 800 & & 80 & 1 & 529 & $1,43 E-02$ & $9,19 E-11$ \\
\hline 800 & 0 & 96 & 1 & 545 & $1,43 E-02$ & $8,19 E-11$ \\
\hline 800 & 10 & & & 555 & $1,43 E-02$ & $9,19 E-11$ \\
\hline 800 & 20 & & & 585 & $1.43 E-02$ & $8.19 E-11$ \\
\hline 800 & 40 & & & 585 & $1,43 E-02$ & $6.89 E-11$ \\
\hline 800 & 60 & & & 605 & $1,43 E-02$ & $6,88 E-11$ \\
\hline 800 & 80 & & & 625 & $1,43 E-02$ & $0,89 \mathrm{E}-19$ \\
\hline 800 & 120 & & & 685 & $1,43 E-02$ & 5,51E-11 \\
\hline 800 & 180 & & & 705 & $1,43 E-02$ & $3,45 E-11$ \\
\hline 800 & 191 & & & 738 & $1.43 E-02$ & 2.30E-11 \\
\hline
\end{tabular}




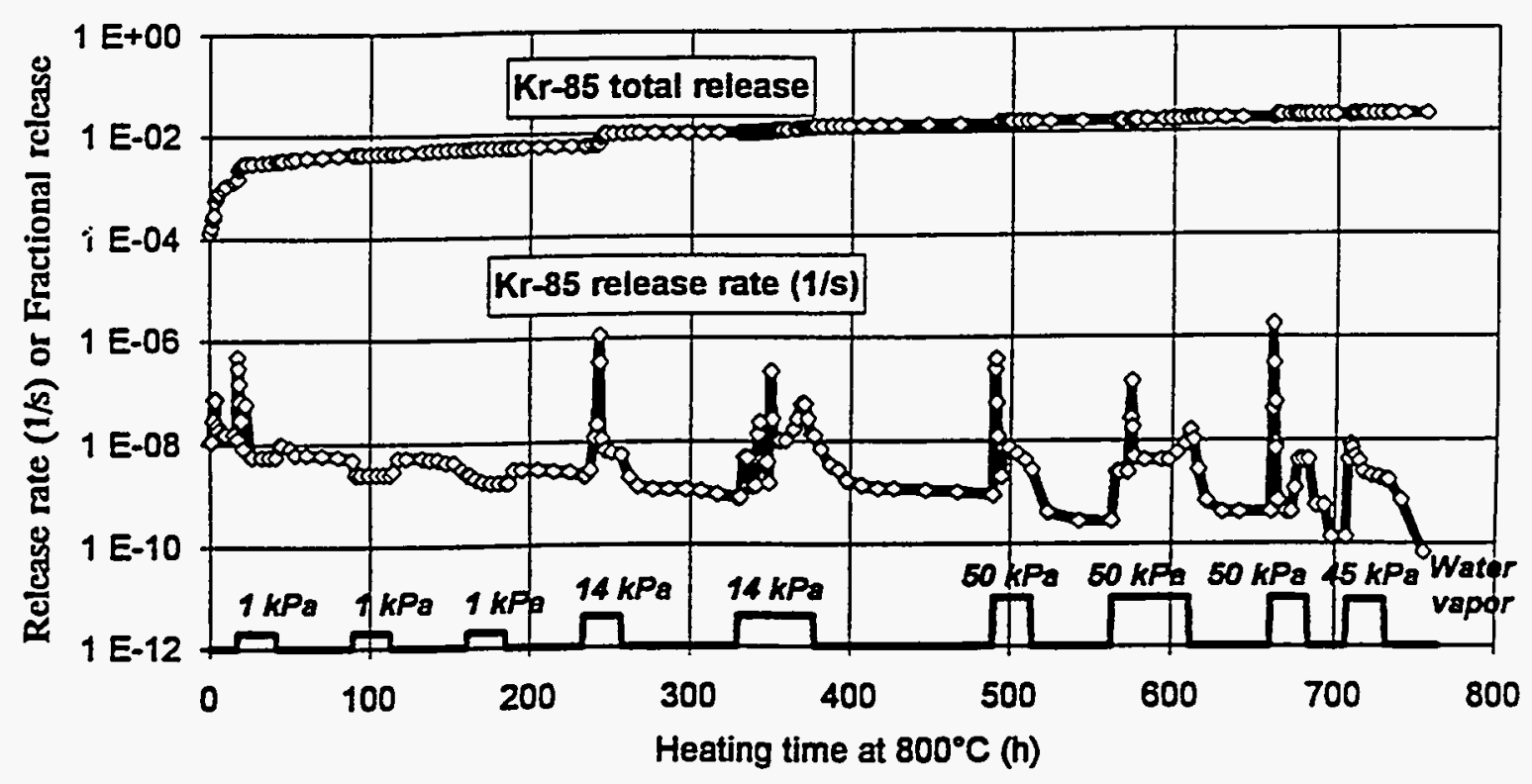

Fig. 4.122 The fractional release and release rate of ${ }^{85} \mathrm{Kr}$ at $800^{\circ} \mathrm{C}$ from fuel compacts 3.2.1 and 3.2.2 as a function of time and the partial pressure of water vapor Source: Forschungszentrum Julich

$\mathrm{GmbH}$, Jalich, Germany

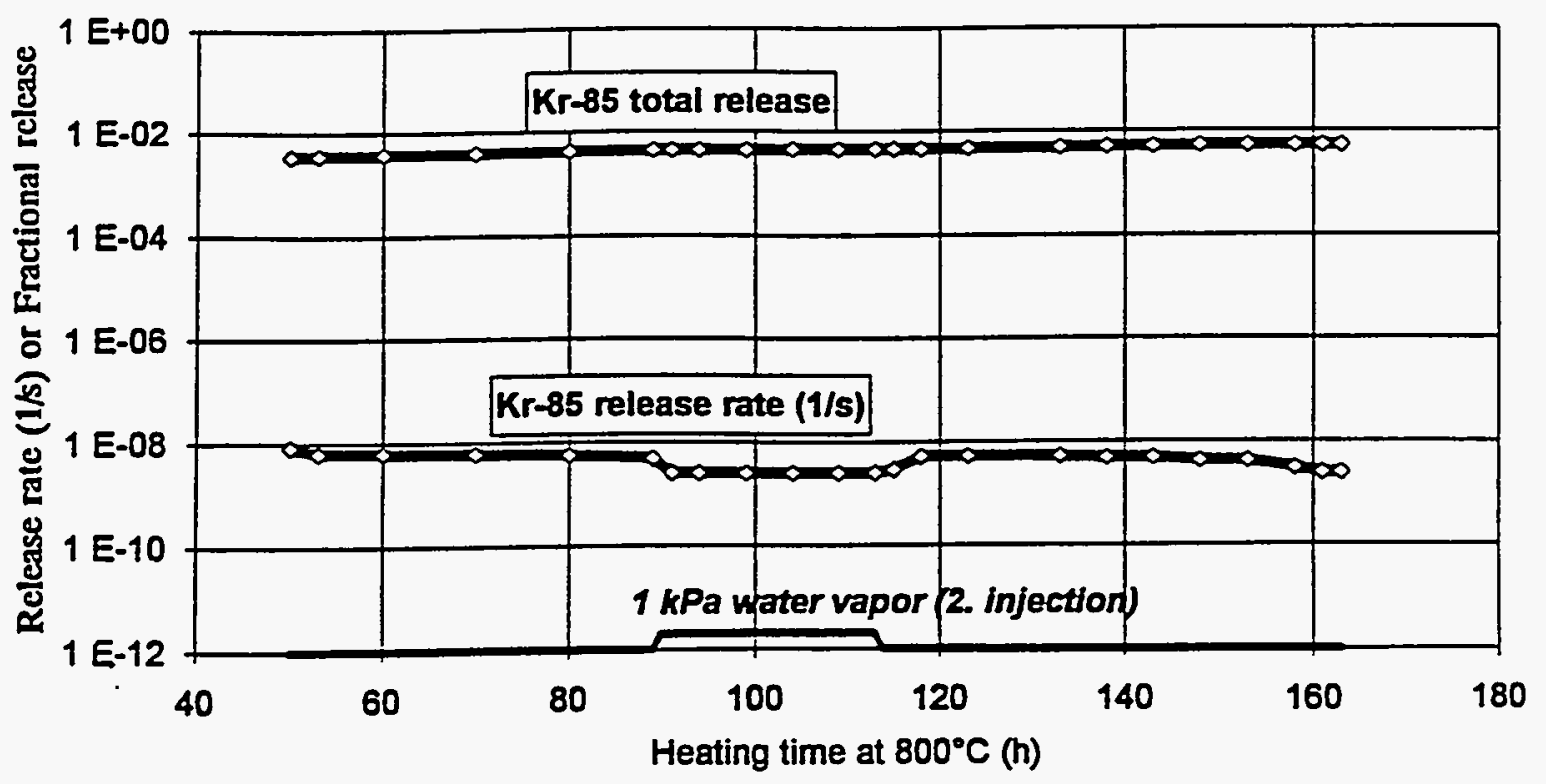

Fig. 4.123 The fractional release and release rate of ${ }^{85} \mathrm{Kr}$ at $800^{\circ} \mathrm{C}$ from fuel compacts 3.2.1 and 3.2.2 during the second $1 \mathrm{kPa}$ water vapor injection Source: Forschungszentrum Jalich GmbH, Julich, Germany 

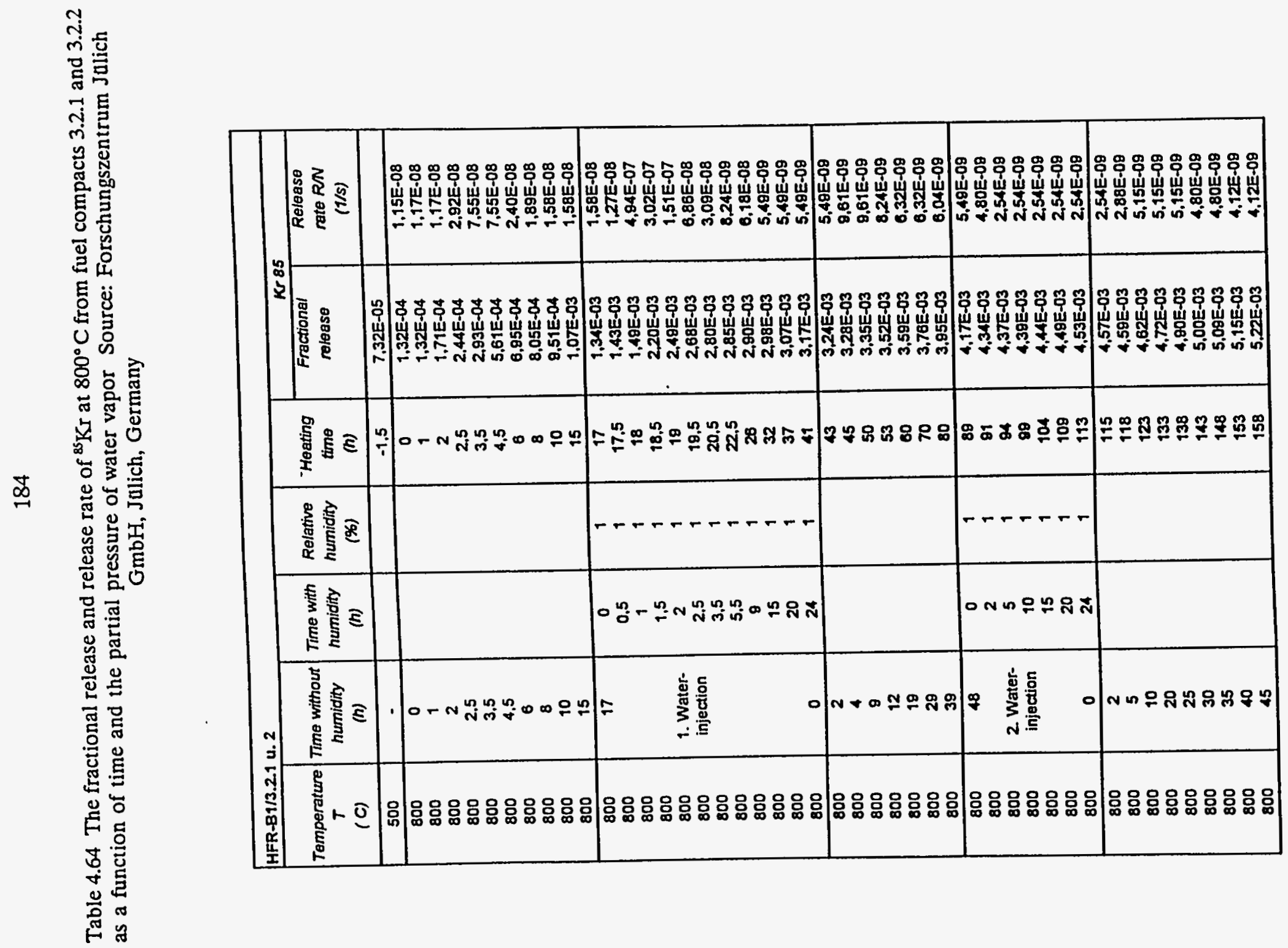
Table 4.64 (continued)

\begin{tabular}{|c|c|c|c|c|c|c|}
\hline \multicolumn{7}{|c|}{ HFR-B1/3.2.1 u. 2} \\
\hline \multirow[b]{2}{*}{$\begin{array}{c}\text { Temperature } \\
T \\
\text { (C) }\end{array}$} & \multirow[b]{2}{*}{$\left|\begin{array}{c}\text { Time without } \\
\text { humidity } \\
\text { (h) }\end{array}\right|$} & \multirow[b]{2}{*}{$\begin{array}{c}\text { Time with } \\
\text { humidity } \\
\text { (h) }\end{array}$} & \multirow[b]{2}{*}{$\begin{array}{l}\text { Relative } \\
\text { numidity } \\
\text { (\%) }\end{array}$} & \multirow[b]{2}{*}{$\begin{array}{c}\text { Heating } \\
\text { timo } \\
\text { (h) }\end{array}$} & \multicolumn{2}{|c|}{ Kr 85} \\
\hline & & & & & $\begin{array}{c}\text { Fractionsl } \\
\text { relesse }\end{array}$ & $\begin{array}{c}\text { Release } \\
\text { rate R/N } \\
(1 / s)\end{array}$ \\
\hline $\begin{array}{l}800 \\
800 \\
800 \\
800 \\
800 \\
800 \\
800 \\
\end{array}$ & $\begin{array}{c}48 \\
\text { 3. Water- } \\
\text { injection } \\
0 \\
\end{array}$ & $\begin{array}{c}0 \\
2 \\
5 \\
10 \\
15 \\
20 \\
24 \\
\end{array}$ & $\begin{array}{l}1 \\
1 \\
1 \\
1 \\
1 \\
1 \\
1 \\
\end{array}$ & $\begin{array}{l}181 \\
183 \\
188 \\
171 \\
178 \\
181 \\
185 \\
\end{array}$ & $\begin{array}{l}5,32 E-03 \\
5,34 E-03 \\
5,37 E-03 \\
5,40 E-03 \\
5,43 E-03 \\
5,46 E-03 \\
5,48 E-03 \\
\end{array}$ & $\begin{array}{l}2,40 \mathrm{E}-09 \\
2,40 \mathrm{E}-09 \\
2,08 \mathrm{E}-09 \\
1,78 \mathrm{E}-09 \\
1,65 \mathrm{E}-09 \\
1,65 \mathrm{E}-09 \\
1,65 \mathrm{E}-09\end{array}$ \\
\hline $\begin{array}{l}800 \\
800 \\
800 \\
800 \\
800 \\
800 \\
\end{array}$ & $\begin{array}{c}2 \\
5 \\
10 \\
20 \\
30 \\
40 \\
\end{array}$ & & & $\begin{array}{l}187 \\
100 \\
195 \\
205 \\
215 \\
225 \\
\end{array}$ & $\begin{array}{l}5,40 E=03 \\
5,52 E-03 \\
5,57 E-03 \\
5,67 E-03 \\
5,77 E-03 \\
5,88 E-03\end{array}$ & $\begin{array}{l}7,65 E=08 \\
2,95 E-09 \\
2,95 E-09 \\
2,88 E-09 \\
2,75 E-09 \\
2,61 E-09\end{array}$ \\
\hline $\begin{array}{l}800 \\
800 \\
800 \\
800 \\
800 \\
800 \\
800 \\
300 \\
800 \\
800 \\
800 \\
800\end{array}$ & $\begin{array}{l}\text { 4. Water- } \\
\text { injection }\end{array}$ & $\begin{array}{c}0 \\
2 \\
5 \\
7,5 \\
9 \\
10 \\
10,5 \\
11 \\
12 \\
14 \\
18 \\
24 \\
\end{array}$ & $\begin{array}{l}74 \\
14 \\
14 \\
14 \\
14 \\
14 \\
14 \\
14 \\
14 \\
14 \\
14 \\
14\end{array}$ & $\begin{array}{c}233 \\
235 \\
238 \\
240,5 \\
242 \\
243 \\
243.5 \\
244 \\
245 \\
247 \\
251 \\
257\end{array}$ & $\begin{array}{l}5,02 E-03 \\
5,04 E-03 \\
5,06 E-03 \\
6,01 E-03 \\
6,10 E-03 \\
6,59 E-03 \\
8,29 E-03 \\
9,76 E-03 \\
1,00 E-02 \\
1,00 E-02 \\
1,01 E-02 \\
1,01 E-02\end{array}$ & $\begin{array}{l}2,20 E=09 \\
2,20 E-09 \\
2,81 E-09 \\
1,24 E-08 \\
2,20 E-08 \\
3,43 E-07 \\
1,17 E-08 \\
3,43 E-07 \\
1,17 E-08 \\
6,88 E-09 \\
6,18 E-09 \\
5,49 E-09\end{array}$ \\
\hline $\begin{array}{l}800 \\
800 \\
800 \\
800 \\
800 \\
800 \\
800 \\
\end{array}$ & $\begin{array}{l}5 \\
10 \\
20 \\
30 \\
40 \\
50 \\
60\end{array}$ & & & $\begin{array}{l}282 \\
287 \\
277 \\
287 \\
297 \\
307 \\
317\end{array}$ & $\begin{array}{l}1,02 E=02 \\
1,02 E-02 \\
1,03 E-02 \\
1,03 E-02 \\
1,04 E-02 \\
1,04 E-02 \\
1,04 E-02\end{array}$ & $\begin{array}{l}2,06 E-09 \\
1,37 E-09 \\
1,17 E-09 \\
1,17 E-09 \\
1,17 E-09 \\
1,10 E-09 \\
9,61 E-10\end{array}$ \\
\hline $\begin{array}{l}800 \\
800 \\
800 \\
800 \\
800 \\
800 \\
800 \\
800 \\
800 \\
800 \\
800 \\
800 \\
800 \\
800\end{array}$ & $\begin{array}{l}\text { 5. Water- } \\
\text { injection }\end{array}$ & $\begin{array}{c} \\
2 \\
4 \\
6 \\
8 \\
10 \\
12 \\
13 \\
14 \\
15 \\
17 \\
18 \\
20 \\
20,5 \\
\end{array}$ & $\begin{array}{l}74 \\
14 \\
14 \\
14 \\
14 \\
14 \\
14 \\
14 \\
14 \\
14 \\
14 \\
14 \\
14 \\
14\end{array}$ & 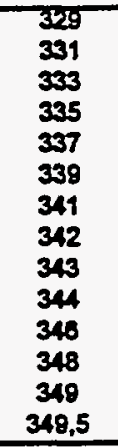 & $\begin{array}{l}1,05 E-02 \\
1,05 E-02 \\
1,05 E-02 \\
1,05 E-02 \\
1,06 E-02 \\
1,06 E-02 \\
1,06 E-02 \\
1,06 E-02 \\
1,07 E-02 \\
1,07 E-02 \\
1,07 E-02 \\
1,08 E-02 \\
1,08 E-02 \\
1,09 E-02\end{array}$ & $\begin{array}{l}8,24 E-10 \\
8,24 E-10 \\
4,80 E-09 \\
4,80 E-09 \\
1,37 E-09 \\
1,37 E-09 \\
1,37 E-09 \\
1,37 E-08 \\
2,40 E-08 \\
3,84 E-09 \\
3,84 E-09 \\
3,84 E-09 \\
1,51 E-09 \\
2,27 E-07 \\
\end{array}$ \\
\hline
\end{tabular}


Table 4.64 (continued)

\begin{tabular}{|c|c|c|c|c|c|c|}
\hline \multicolumn{7}{|c|}{ HFR-B1/3.2.1 u. 2} \\
\hline \multirow[b]{2}{*}{$\begin{array}{c}\text { Temperature } \\
T \\
\text { (C) }\end{array}$} & \multirow[b]{2}{*}{$\begin{array}{c}\text { Time without } \\
\text { humidity } \\
\text { (h) }\end{array}$} & \multirow[b]{2}{*}{$\begin{array}{l}\text { Time with } \\
\text { humidity } \\
\text { (h) }\end{array}$} & \multirow[b]{2}{*}{$\begin{array}{l}\text { Relativo } \\
\text { humidity } \\
\text { (\%) }\end{array}$} & \multirow[b]{2}{*}{$\begin{array}{c}\text { Heating } \\
\text { time } \\
\text { (h) }\end{array}$} & \multicolumn{2}{|c|}{ Kr 85} \\
\hline & & & & & $\begin{array}{l}\text { Frectional } \\
\text { release }\end{array}$ & $\begin{array}{c}\text { Release } \\
\text { rate } R N= \\
(1 / s)\end{array}$ \\
\hline $\begin{array}{l}800 \\
800 \\
800 \\
800 \\
800 \\
800 \\
800 \\
800 \\
800 \\
800 \\
800 \\
800 \\
800 \\
800\end{array}$ & $\begin{array}{l}\text { 5. Water- } \\
\text { injection }\end{array}$ & $\begin{array}{l}21 \\
22 \\
23 \\
24 \\
25 \\
27 \\
30 \\
35 \\
37.5 \\
40 \\
42 \\
44 \\
46 \\
48\end{array}$ & $\begin{array}{l}14 \\
14 \\
14 \\
14 \\
14 \\
14 \\
14 \\
14 \\
14 \\
14 \\
14 \\
14 \\
14 \\
14\end{array}$ & $\begin{array}{c}350 \\
351 \\
352 \\
353 \\
354 \\
356 \\
359 \\
364 \\
366,5 \\
369 \\
371 \\
373 \\
375 \\
377\end{array}$ & $\begin{array}{l}1,12 E-02 \\
1,15 E-02 \\
1,15 E-02 \\
1,16 E-02 \\
1,16 E-02 \\
1,17 E-02 \\
1,18 E-02 \\
1,20 E-02 \\
1,21 E-02 \\
1,24 E-02 \\
1,28 E-02 \\
1,31 E-02 \\
1,33 E-02 \\
1,33 E-02\end{array}$ & $\begin{array}{l}2,27 E-07 \\
2,75 E-08 \\
1,17 E-08 \\
1,10 E-08 \\
1,03 E-08 \\
1,03 E-08 \\
1,03 E-08 \\
1,72 E-08 \\
2,75 E-08 \\
5,22 E-08 \\
5,22 E-08 \\
2,75 E-08 \\
1,37 E-08 \\
1,30 E-08\end{array}$ \\
\hline $\begin{array}{l}800 \\
800 \\
800 \\
800 \\
800 \\
800 \\
800 \\
800 \\
800\end{array}$ & $\begin{array}{l}4 \\
10 \\
15 \\
20 \\
30 \\
40 \\
50 \\
70 \\
80 \\
\end{array}$ & & & $\begin{array}{l}389 \\
387 \\
382 \\
387 \\
407 \\
417 \\
427 \\
447 \\
467\end{array}$ & $\begin{array}{l}1,34 E-02 \\
1,35 E-02 \\
1,35 E-02 \\
1,38 E-02 \\
1,36 E-02 \\
1,37 E-02 \\
1,37 E-02 \\
1,38 E-02 \\
1,39 E-02\end{array}$ & $\begin{array}{l}6,86 E-09 \\
3,43 E-09 \\
2,75 E-09 \\
1,72 E-09 \\
1,37 E-09 \\
1,17 E-09 \\
1,17 E-09 \\
1,10 E-09 \\
1,03 E-09\end{array}$ \\
\hline $\begin{array}{l}800 \\
800 \\
800 \\
800 \\
800 \\
800 \\
800 \\
800 \\
800 \\
800 \\
800 \\
\end{array}$ & $\begin{array}{l}\text { 6. Water- } \\
\text { injection }\end{array}$ & $\begin{array}{c}0 \\
0.5 \\
1 \\
1,5 \\
2,5 \\
5 \\
7,5 \\
10 \\
15 \\
20 \\
24 \\
\end{array}$ & $\begin{array}{l}1 \\
20 \\
50 \\
50 \\
50 \\
.50 \\
50 \\
50 \\
50 \\
50 \\
50\end{array}$ & $\begin{array}{c}489 \\
489,5 \\
480 \\
490,5 \\
491,5 \\
484 \\
498,5 \\
499 \\
504 \\
509 \\
513 \\
\end{array}$ & $\begin{array}{l}1,40 E-02 \\
1,40 E-02 \\
1,54 E-02 \\
1,57 E-02 \\
1,57 E-02 \\
1,58 E-02 \\
1,58 E-02 \\
1,59 E-02 \\
1,60 E-02 \\
1,60 E-02 \\
1,61 E-02\end{array}$ & $\begin{array}{l}8,92 \mathrm{E}-10 \\
2,40 \mathrm{E}-07 \\
3,78 \mathrm{E}-07 \\
5,49 \mathrm{E}-08 \\
1,24 \mathrm{E}-08 \\
2,06 \mathrm{E}-09 \\
7,55 \mathrm{E}-09 \\
7,55 \mathrm{E}-09 \\
5,48 \mathrm{E}-09 \\
4,12 \mathrm{E}-09 \\
2,75 \mathrm{E}-09\end{array}$ \\
\hline $\begin{array}{l}800 \\
800\end{array}$ & $\begin{array}{l}10 \\
30 \\
\end{array}$ & & & $\begin{array}{l}523 \\
543\end{array}$ & $\begin{array}{l}1,61 E-02 \\
1,61 E-02\end{array}$ & $\begin{array}{l}4,12 \mathrm{E}-10 \\
2,75 \mathrm{E}-10\end{array}$ \\
\hline $\begin{array}{l}800 \\
800 \\
800 \\
800 \\
800 \\
800 \\
800 \\
800 \\
800 \\
800\end{array}$ & $\begin{array}{l}\text { 7. Water- } \\
\text { injection }\end{array}$ & $\begin{array}{c}0 \\
2.5 \\
5 \\
10 \\
11,5 \\
12 \\
12,5 \\
14 \\
20 \\
30 \\
\end{array}$ & $\begin{array}{l}1 \\
50 \\
50 \\
50 \\
50 \\
50 \\
50 \\
50 \\
50 \\
50 \\
\end{array}$ & $\begin{array}{c}563 \\
\mathbf{5 8 5 , 5} \\
\mathbf{5 8 8} \\
\mathbf{5 7 3} \\
\mathbf{5 7 4 . 5} \\
\mathbf{5 7 5} \\
\mathbf{5 7 5 . 5} \\
\mathbf{5 7 7} \\
\mathbf{5 8 3} \\
\mathbf{5 9 3} \\
\end{array}$ & $\begin{array}{l}1,61 E-02 \\
1,62 E-02 \\
1,62 E-02 \\
1,62 E-02 \\
1,63 E-02 \\
1,64 E-02 \\
1,65 E-02 \\
1,68 E-02 \\
1,68 E-02 \\
1,68 E-02\end{array}$ & $\begin{array}{l}2.75 E-10 \\
2,40 E-09 \\
2,40 E-09 \\
2,40 E-09 \\
2,75 E-08 \\
1,37 E-07 \\
1,85 E-08 \\
4,80 E-09 \\
4,12 E-09 \\
4.49 E-09\end{array}$ \\
\hline
\end{tabular}


Table 4.64 (continued)

\begin{tabular}{|c|c|c|c|c|c|c|}
\hline \multicolumn{7}{|c|}{ HFR-B1/3.2.1 U. 2} \\
\hline \multirow[b]{2}{*}{$\begin{array}{c}\text { Temperature } \\
T \\
\text { (C) }\end{array}$} & \multirow[b]{2}{*}{$\begin{array}{c}\text { Time without } \\
\text { humidity } \\
\text { (h) }\end{array}$} & \multirow[b]{2}{*}{$\begin{array}{l}\text { Turne with } \\
\text { numidity } \\
\text { (h) }\end{array}$} & \multirow[b]{2}{*}{$\begin{array}{l}\text { Relative } \\
\text { hernidity } \\
\text { (\%) }\end{array}$} & \multirow[b]{2}{*}{$\begin{array}{c}\text { Hoating } \\
\text { thre } \\
\text { (I) }\end{array}$} & \multicolumn{2}{|c|}{ Kr 86} \\
\hline & & & & & $\begin{array}{c}\text { Fractional } \\
\text { retease }\end{array}$ & $\begin{array}{c}\text { Release } \\
\text { rato RNN } \\
(1 / s)\end{array}$ \\
\hline $\begin{array}{l}800 \\
800 \\
800 \\
800\end{array}$ & $\begin{array}{c}\text { 7. Water- } \\
\text { injection } \\
0\end{array}$ & $\begin{array}{l}35 \\
40 \\
45 \\
48\end{array}$ & $\begin{array}{l}50 \\
50 \\
50 \\
50 \\
\end{array}$ & $\begin{array}{l}598 \\
603 \\
608 \\
691 \\
\end{array}$ & $\begin{array}{l}1,69 E-02 \\
1,69 E-02 \\
1,70 E-02 \\
1,72 E-02\end{array}$ & $\begin{array}{l}4,18 E-09 \\
5,83 E-09 \\
8,58 E-09 \\
1,58 E-08\end{array}$ \\
\hline $\begin{array}{l}800 \\
800 \\
800 \\
800 \\
800 \\
\end{array}$ & $\begin{array}{c}2 \\
5 \\
10 \\
20 \\
30 \\
\end{array}$ & & & $\begin{array}{l}613 \\
616 \\
621 \\
631 \\
641 \\
\end{array}$ & $\begin{array}{l}1,73 E-02 \\
1,73 E-02 \\
1,74 E-02 \\
1.74 E-02 \\
1,74 E-02\end{array}$ & $\begin{array}{l}1,03 E-08 \\
2,75 E-09 \\
6,86 E-10 \\
4,12 E-10 \\
4,12 E-10\end{array}$ \\
\hline $\begin{array}{l}800 \\
800 \\
800 \\
800 \\
800 \\
800 \\
800 \\
800 \\
800 \\
800 \\
800 \\
800 \\
800 \\
800 \\
\end{array}$ & $\begin{array}{l}\text { 8. Water- } \\
\text { injection }\end{array}$ & $\begin{array}{c}0 \\
0,5 \\
1 \\
1,5 \\
2 \\
2,5 \\
3 \\
5 \\
10 \\
13 \\
15 \\
17 \\
20 \\
23\end{array}$ & $\begin{array}{l}\mathbf{5 0} \\
\mathbf{5 0} \\
\mathbf{5 0} \\
\mathbf{5 0} \\
\mathbf{5 0} \\
\mathbf{5 0} \\
\mathbf{5 0} \\
\mathbf{5 0} \\
\mathbf{5 0} \\
\mathbf{5 0} \\
\mathbf{5 0}\end{array}$ & $\begin{array}{c}680 \\
680.5 \\
681 \\
681.5 \\
682 \\
682.5 \\
683 \\
685 \\
670 \\
673 \\
675 \\
677 \\
680 \\
603 \\
\end{array}$ & $\begin{array}{l}1,74 E-02 \\
1,74 E-02 \\
1,03 E-02 \\
1,09 E-02 \\
2,01 E-02 \\
2,02 E-02 \\
-2,02 E-02 \\
2,02 E-02 \\
2,03 E-02 \\
2,03 E-02 \\
2,03 E-02 \\
2,03 E-02 \\
2,03 E-02 \\
2,04 E-02\end{array}$ & $\begin{array}{l}4,12 E-10 \\
4,12 E-08 \\
1,78 E-06 \\
3,09 E-07 \\
5,48 E-08 \\
8,24 E-09 \\
6,88 E-09 \\
6,86 E-10 \\
4,12 E-10 \\
4,12 E-10 \\
1,17 E-09 \\
4,12 E-09 \\
4,12 E-09 \\
4,12 E-09\end{array}$ \\
\hline $\begin{array}{l}800 \\
800 \\
800 \\
\end{array}$ & $\begin{array}{c}5 \\
10 \\
15 \\
\end{array}$ & & & $\begin{array}{l}688 \\
693 \\
698 \\
\end{array}$ & $\begin{array}{l}2,04 E-02 \\
2,04 E-02 \\
2,04 E-02 \\
\end{array}$ & $\begin{array}{l}5,49 E-10 \\
5,49 E-10 \\
1,37 E-10\end{array}$ \\
\hline $\begin{array}{l}800 \\
800 \\
800 \\
800 \\
800 \\
800 \\
800 \\
800 \\
800 \\
800 \\
\end{array}$ & $\begin{array}{l}\text { 9. Water- } \\
\text { injection }\end{array}$ & $\begin{array}{l}0 \\
1 \\
2 \\
3 \\
5 \\
7,5 \\
10 \\
15 \\
20 \\
24\end{array}$ & $\begin{array}{l}45 \\
45 \\
45 \\
45 \\
45 \\
45 \\
45 \\
45 \\
45\end{array}$ & $\begin{array}{c}707 \\
708 \\
709 \\
710 \\
712 \\
714.5 \\
717 \\
722 \\
727 \\
731\end{array}$ & $\begin{array}{l}2,04 E-02 \\
2,04 E-02 \\
2,04 E-02 \\
2,05 E-02 \\
2,05 E-02 \\
2,05 E-02 \\
2,05 E-02 \\
2,06 E-02 \\
2,06 E-02 \\
2,07 E-02\end{array}$ & $\begin{array}{l}1,37 E-10 \\
4,12 E-09 \\
8,24 E-09 \\
6,86 E-09 \\
4,80 E-09 \\
3,84 E-09 \\
2,40 E-09 \\
2,06 E-09 \\
1,25 E-09 \\
1,72 E-09\end{array}$ \\
\hline $\begin{array}{l}800 \\
800 \\
800\end{array}$ & $\begin{array}{c}2 \\
10 \\
24\end{array}$ & & & $\begin{array}{l}7333 \\
741 \\
755\end{array}$ & $\begin{array}{l}2,07 E-02 \\
2,07 E-02 \\
2,07 E-02\end{array}$ & $\begin{array}{l}1,72 E-09 \\
6,86 E-10 \\
6,86 E-11\end{array}$ \\
\hline
\end{tabular}


retarded by the "moisturizing" of fuel and graphite grain surfaces.

Over the range of water-vapor partial pressures, a more or less typical release rate pattern is observed. There is an initial rapid release which declines to a level showing a much less rapid decline and then again, after the termination of the injection of water vapor, to a level with a still more gentle decline, a decline that over the period of $755 \mathrm{~h}$ of the test, apparently represents a roughly steady depletion rate for the inventory of ${ }^{85} \mathrm{Kr}$.

\subsection{Water Vapor Injection Tests with UCO Kernels}

The kernels of $\mathrm{UC}_{0,5} \mathrm{O}_{15}$ from unbonded particles irradiated in tray 7 in the central hole of capsule 3 were heated at $800^{\circ} \mathrm{C}$ in the KORA facility with intermittent injections of water vapor. The properties of the kernels and associated coatings are given in Table 4.61, and the irradiation conditions, ${ }^{85} \mathrm{Kr}$ inventory and KORA test conditions are given in Table 4.62. Two KORA experiments were conducted using 5 kernels in each test; the kernels had been removed from the particies after cracking the particles. The release profiles of ${ }^{85} \mathrm{Kr}$ during the heating tests are shown in Figs. 4.124 and 4.125 and the corresponding data are presented in Tables 4.65 and 4.66, for the two separate tests with the assumed identical sets of 5 kernels.

Figs. 4.124 and 4.125 indicate that a strong variation occurs between the two release rate profiles shown. In one case, a large release occurs upon b:-'nging the sample to the test temperature and a smaller release upon injecting water vapor at a pittial pressure of $1 \mathrm{kPa}$. In the other case, the inverse occurs, i.e., the release is smaller upon bringing the kernels to the test temprature and larger upon injecting water vapor at a partial pressure of $1 \mathrm{kPa}$. Thus a consistent response to the experimental conditions is absence. Such fuel behavior was not observed ${ }^{16}$ with essentially bare kernels embedded in fuel compacts heated under irradiation conditions with intermittent water vapor injections. Furthermore, the lack of a strong response to the injection of water vapor at a partial pressure of $50 \mathrm{kPa}$ as in Fig. 4.124, indicated that the ${ }^{85} \mathrm{Kr}$ inventory in gas bubbles is depleted.

\subsection{STATUS OF THE PIE OF CAPSULES 2 AND 3}

An overview of the status of the PIE of capsules 2 and 3 is given in Fig. 4.126 by using the modified PIE flow chart (Fig. 4.3) and indicating the remaining tasks. 
189

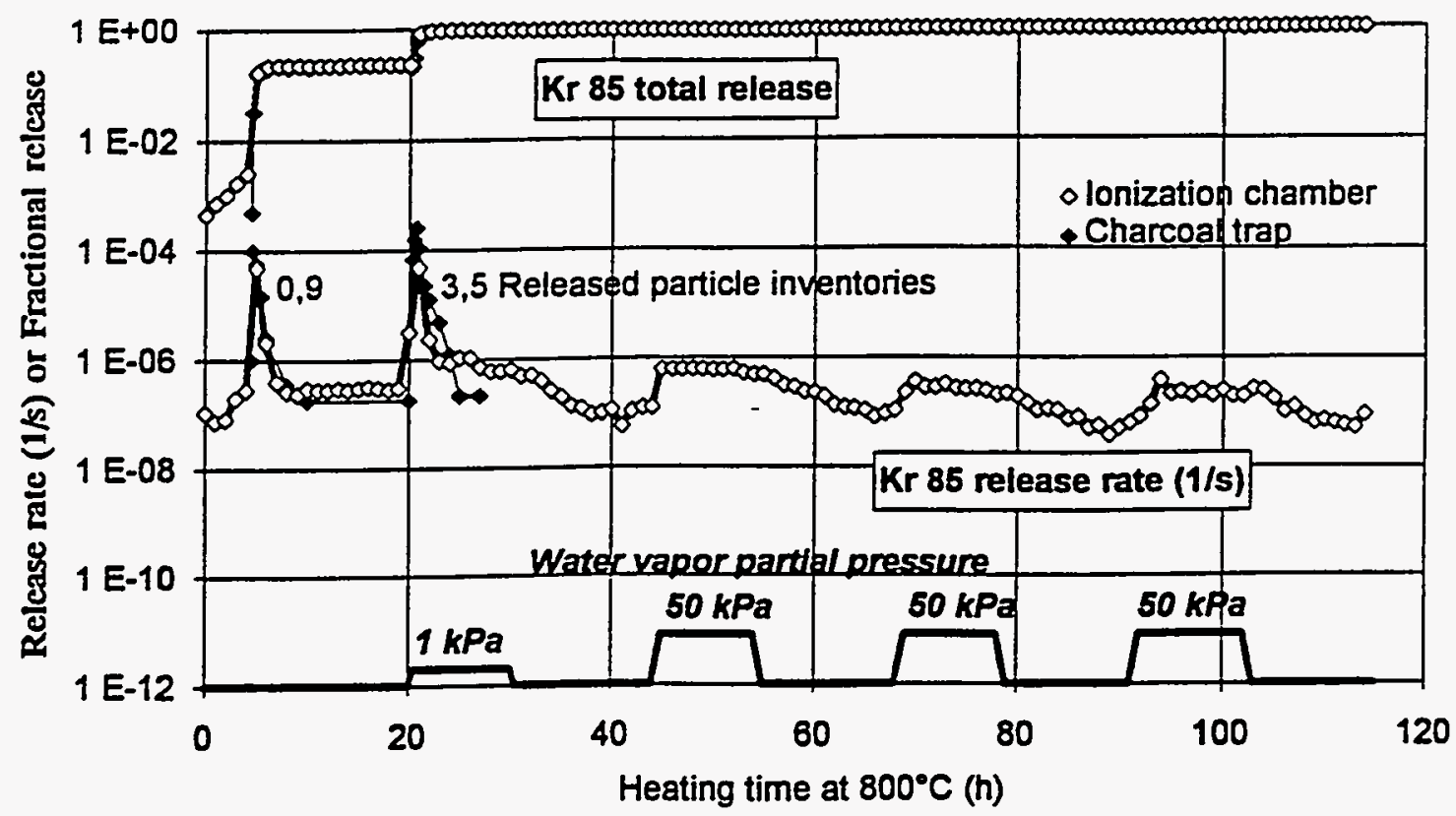

Fig. 4.124 The fractional release and release rate of ${ }^{B S} \mathrm{Kr}$ at $800^{\circ} \mathrm{C}$ from $5 \mathrm{UCO}$ kernels taken from particles in tray 3-7 as a function of time and the partial pressure of water vapor Source:

Forschungszentrum Jalich GmbH, Jalich, Germany

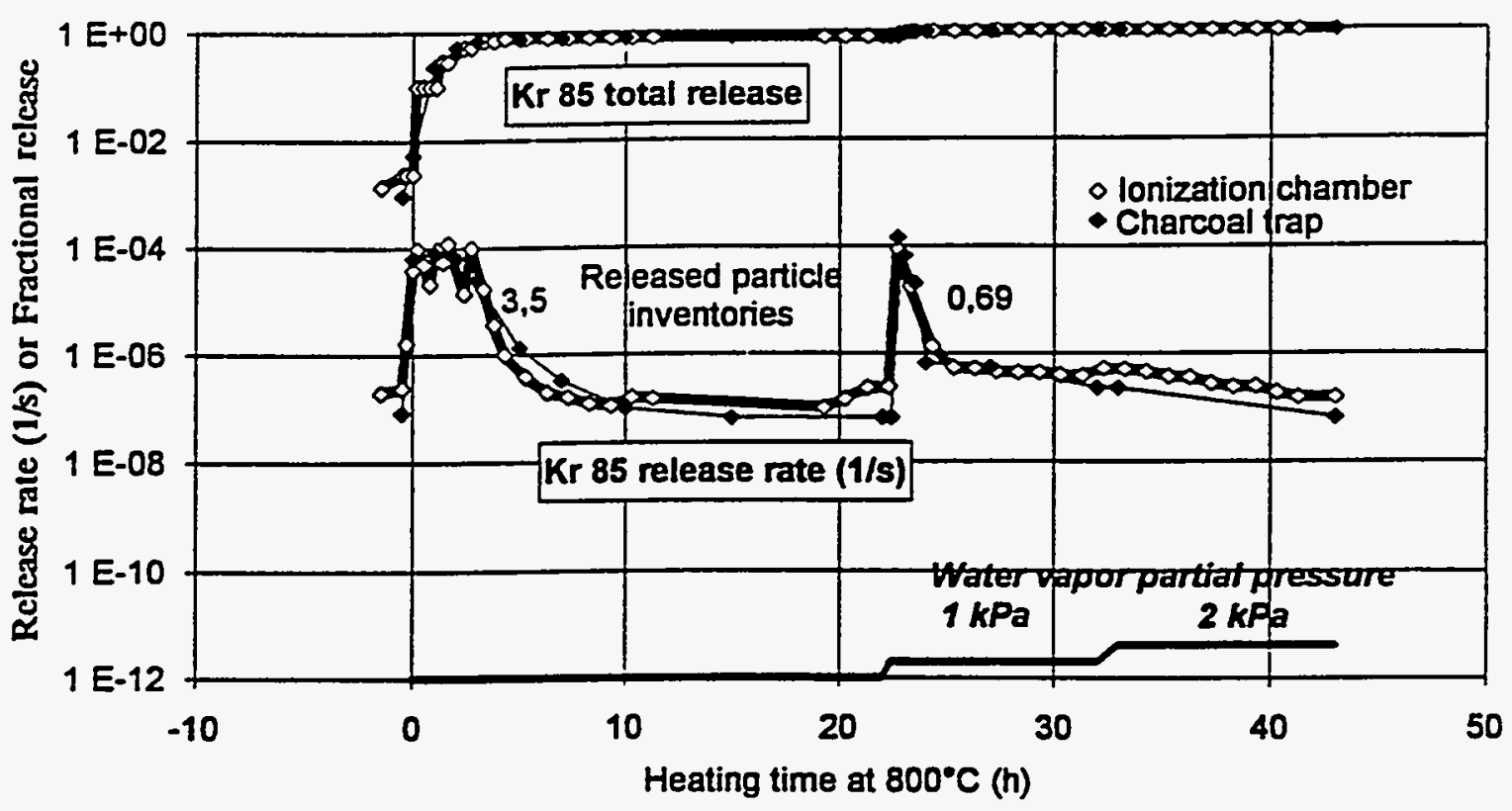

Fig. 4.125 The fractional release and release rate of ${ }^{85} \mathrm{Kr}$ at $800^{\circ} \mathrm{C}$ from $5 \mathrm{UCO}$ kernels taken from particles in tray 3-7 as a function of time and the partial pressure of water vapor Source:

Forschungszentrum Julich GmbH, Julich, Germany 
Table 4.65 The fractional release and release rate of ${ }^{85} \mathrm{Kr}$ at $800^{\circ} \mathrm{C}$ from $5 \mathrm{UCO}$ kernels taken from particles in tray 3-7 as a function of time and the partial pressure of water vapor Source:

Forschungszentrum Julich GmbH, Jalich, Germany

\begin{tabular}{|c|c|c|c|c|c|c|}
\hline \multicolumn{7}{|l|}{ HFR-B1, 3-7a } \\
\hline \multirow[b]{2}{*}{$\begin{array}{c}\text { Temperature } \\
T \\
\text { (C) }\end{array}$} & \multirow[b]{2}{*}{$\begin{array}{c}\text { Time without } \\
\text { water vapor } \\
\text { (h) }\end{array}$} & \multicolumn{2}{|c|}{ Water vapor } & \multirow[b]{2}{*}{$\begin{array}{c}\text { Heating } \\
\text { time } \\
\text { (h) }\end{array}$} & \multicolumn{2}{|c|}{$\mathrm{Kr} 85$} \\
\hline & & $\begin{array}{l}\text { Time } \\
\text { (b) }\end{array}$ & $\begin{array}{c}\text { Partial } \\
\text { pressure } \\
\text { (kPa) }\end{array}$ & & $\begin{array}{c}\text { Fractional } \\
\text { release }\end{array}$ & $\begin{array}{c}\text { Release } \\
\text { rate } R / N \\
(1 / s)\end{array}$ \\
\hline 800 & 1 & & & 1 & $4,38 E-04$ & $1,06 \mathrm{E}-07$ \\
\hline 800 & 2 & & & 2 & $6,88 E-04$ & 7.50E-08 \\
\hline 800 & 3 & & & 3 & $1,00 E-03$ & $8.13 E-08$ \\
\hline 800 & 4 & & & 4 & $1,63 E-03$ & $2.00 E-07$ \\
\hline 800 & 5 & & & 5 & 2,50E-03 & 2.75E-07 \\
\hline 800 & 6 & & & 6 & $1,68 E-01$ & $4,69 E-05$ \\
\hline 800 & 7 & & & 7 & 2.15E-01 & 2,04E-06 \\
\hline 800 & 8 & & & 8 & 2,18E-01 & $3,88 E-07$ \\
\hline 800 & $\theta$ & & & 9 & $2.19 E-01$ & 2.56E- 07 \\
\hline 800 & 10 & & & 10 & $2.20 E-01$ & 2,31E-07 \\
\hline 800 & 19 & & & 11 & $2,21 E-01$ & 2,94E-07 \\
\hline 800 & 12 & & & 12 & $2.22 E-01$ & $2,75 E-07$ \\
\hline 800 & 13 & & & 13 & $2,23 E-01$ & 2,75E-07 \\
\hline 800 & 14 & & & 14 & 2.24E-01 & $3,00 E-07$ \\
\hline 800 & 15 & & & 15 & $2.26 E-01$ & 2.81E-07 \\
\hline 800 & 16 & & & 16 & 2,27E-01 & 2.94E-07 \\
\hline 800 & 17 & & & 17 & $2,28 E-01$ & $3,13 E-07$ \\
\hline 800 & 18 & & & 18 & $2,29 E-01$ & $2,94 E-07$ \\
\hline 800 & 19 & & & 19 & 2.30E-01 & $2,75 E-07$ \\
\hline 800 & 20 & $\overline{0}$ & 0 & 20 & 2,31E-01 & $3,00 E-07$ \\
\hline 800 & & 1 & 1 & 21 & $2,32 E-01$ & $3,13 E-06$ \\
\hline 800 & & 2 & 1 & 22 & $8,23 E-01$ & $4,69 E-05$ \\
\hline 800 & & 3 & 1 & $\overline{23}$ & 8,TTE-01 & $2,31 E-06$ \\
\hline 800 & 1. Water- & 4 & 1 & 24 & $8.82 E-01$ & 9,13E-07 \\
\hline 800 & injection & 5 & 1 & 25 & $8,85 E-01$ & $8,25 E-07$ \\
\hline 800 & & 6 & 1 & 28 & $8,88 E-01$ & $1,06 E-06$ \\
\hline 800 & & 7 & 1 & 27 & $8,80 E-01$ & $1,06 E-08$ \\
\hline 800 & & 8 & 1 & 28 & $8,93 E-01$ & 6,88E-07 \\
\hline 800 & & 9 & 1 & 29 & $8,85 E-01$ & 5.94E-07 \\
\hline 800 & 0 & 10 & 1 & 30 & 8,97E-01 & $5,81 E-07$ \\
\hline 800 & 1 & & & 31 & $8,89 E-09$ & $6,19 E-07$ \\
\hline 800 & 2 & & & 32 & 9,01E-01 & 4,81E-07 \\
\hline 800 & 3 & & & 33 & 9,03E-01 & $5,00 E-07$ \\
\hline 800 & 4 & & & 34 & 9,05E-01 & $3.94 E-07$ \\
\hline 800 & 5 & & & 35 & $9,08 E-01$ & 2.58E-07 \\
\hline 800 & 6 & & & 38 & 9.07E-01 & 2.00E-07 \\
\hline 800 & 7 & & & 37 & 9.08E-01 & $1,38 E-07$ \\
\hline 800 & 8 & & & 38 & $9.08 E-01$ & $1,25 E-07$ \\
\hline 800 & 9 & & & 38 & $9.09 E-01$ & $9,38 E-08$ \\
\hline 800 & 10 & & & 40 & $9.09 E-01$ & $1,00 E-07$ \\
\hline
\end{tabular}


Table 4.65 (continued)

\begin{tabular}{|c|c|c|c|c|c|c|}
\hline \multicolumn{7}{|l|}{ HFR-B1, 3-7a } \\
\hline \multirow[b]{2}{*}{$\begin{array}{c}\text { Temperature } \\
T \\
\text { (C) }\end{array}$} & \multirow[b]{2}{*}{$\begin{array}{c}\text { Time without } \\
\text { water vapor } \\
\text { (h) }\end{array}$} & \multicolumn{2}{|c|}{ Watervapor } & \multirow[b]{2}{*}{$\begin{array}{c}\text { Heating } \\
\text { tims } \\
\text { (n) }\end{array}$} & \multicolumn{2}{|c|}{$K-85$} \\
\hline & & $\begin{array}{l}\text { Timo } \\
\text { (h) }\end{array}$ & $\begin{array}{c}\text { Partial } \\
\text { pressuro } \\
(\mathrm{kPa})\end{array}$ & & $\begin{array}{c}\text { Fractional } \\
\text { retease }\end{array}$ & $\begin{array}{l}\text { Roleaso } \\
\text { rate RNN } \\
(1 / s)\end{array}$ \\
\hline 800 & 11 & & & 41 & $9,10 E-01$ & $1,13 E-07$ \\
\hline 800 & 12 & & & 42 & $9,11 E-01$ & $5,63 E-08$ \\
\hline 800 & 13 & & & 43 & $9,11 E-01$ & 1,06E-07 \\
\hline 800 & 14 & 0 & 1 & 44 & $9,11 E-01$ & 1,25E-07 \\
\hline 800 & & 1 & 50 & 45 & $9,12 E-01$ & 1,25E-07 \\
\hline 800 & & 2 & 50 & 46 & $9,13 E-01$ & $2,69 E-07$ \\
\hline 800 & & 3 & 50 & 47 & $0,16 E-01$ & 8,69E-07 \\
\hline 800 & 2. Water & 4 & 50 & 48 & $9,19 E-01$ & 6,94E-07 \\
\hline 800 & injection & 5 & 50 & 48 & 9,21E-09 & 6,94E-07 \\
\hline 800 & & 6 & 50 & 50 & $0.24 E-01$ & $0,69 E-07$ \\
\hline 800 & & 7 & 50 & 51 & $9,26 E-01$ & 5.94E-07 \\
\hline 800 & & 8 & 50 & 52 & $0.28 E-01$ & 5.94E-07 \\
\hline 800 & & 9 & 50 & 53 & $9,30 E-01$ & $6,06 E-07$ \\
\hline 800 & 0 & 10 & 50 & 54 & Q,32E-01 & $5,06 E-07$ \\
\hline 800 & 1 & & & 55 & 9,34E-01 & $4,81 E-07$ \\
\hline 800 & 2 & & & 58 & $9,36 E-01$ & $4,81 E-07$ \\
\hline 800 & 3 & & & 57 & $8,38 E-01$ & $4,00 E-07$ \\
\hline 800 & 4 & & & 58 & $9,39 E-01$ & $3,08 E-07$ \\
\hline 800 & 5 & & & 59 & $9,40 E-01$ & $2,88 E-07$ \\
\hline 800 & 6 & & & 60 & $0,41 E-01$ & 2.31E-07 \\
\hline 800 & 7 & & & 61 & $0,42 E-01$ & 225E-07 \\
\hline 800 & 8 & & & 62 & $9,43 E-01$ & 1.84E-07 \\
\hline 800 & 9 & & & 63 & $0,44 E-01$ & $1.38 E-07$ \\
\hline 800 & 10 & & & 64 & 0,4 EE-01 & $1.25 E-07$ \\
\hline 800 & 11 & & & 65 & $0,45 E-01$ & $1,19 E-07$ \\
\hline 800 & 12 & & & 68 & $0,45 E-01$ & $1,06 E-07$ \\
\hline 800 & 13 & & & 67 & $0.48 E-01$ & $8,13 E-08$ \\
\hline 800 & 14 & 0 & 1 & 68 & 9,46E-01 & $0,38 E-08$ \\
\hline 800 & & 1 & 50 & 80 & $0,47 E-01$ & $1,06 E-07$ \\
\hline 800 & & 2 & 50 & 70 & $0,47 E-01$ & 2.25E-07 \\
\hline 800 & & 3 & 50 & 71 & $9,49 E-01$ & $3,50 E-07$ \\
\hline 800 & 3. Water & 4 & 50 & 72 & 0,50E-01 & $2,75 E-07$ \\
\hline 800 & injection & 5 & 50 & 73 & 2,51E-01 & 2,81E-07 \\
\hline 800 & & 6 & 50 & 74 & $9,52 \mathrm{E}-01$ & $3,19 E-07$ \\
\hline 800 & & 7 & 50 & 75 & $9,53 E-01$ & 2,69E-07 \\
\hline 800 & & 8 & 50 & 78 & $0,54 E-01$ & 2,56E-07 \\
\hline 800 & & 9 & 50 & $\pi$ & $0,55 E-01$ & $2,69 E-07$ \\
\hline 800 & 1 & 10 & 50 & 70 & 9.56E-01 & 2,44E-07 \\
\hline 800 & 2 & & & 70 & $9.57 E-01$ & 2.06E-07 \\
\hline 800 & 3 & & & 80 & 9,58E-01 & 2.19E-OT \\
\hline
\end{tabular}


Table 4.65 (continued)

\begin{tabular}{|c|c|c|c|c|c|c|}
\hline \multicolumn{7}{|l|}{ HFR-B1, 3-7a } \\
\hline \multirow[b]{2}{*}{$\begin{array}{c}\text { Temperature } \\
T \\
\text { (C) }\end{array}$} & \multirow[b]{2}{*}{$\begin{array}{c}\text { Time without } \\
\text { water vapor } \\
\text { (h) }\end{array}$} & \multicolumn{2}{|c|}{ Water vapor } & \multirow[b]{2}{*}{$\begin{array}{l}\text { Heating } \\
\text { - time } \\
\text { (h) }\end{array}$} & \multicolumn{2}{|c|}{ Kr85 } \\
\hline & & $\begin{array}{l}\text { Tume } \\
\text { (h) }\end{array}$ & $\begin{array}{c}\text { Partial } \\
\text { pressure } \\
\text { (kPa) }\end{array}$ & & $\begin{array}{l}\text { Fractional } \\
\text { release }\end{array}$ & $\begin{array}{c}\text { Release } \\
\text { rate RN } \\
(1 / s)\end{array}$ \\
\hline 800 & 3 & & & 81 & $9,59 E-01$ & $1,88 E-07$ \\
\hline 800 & 4 & & & 82 & $9,60 E-01$ & $1,44 E-07$ \\
\hline 800 & 5 & & & 83 & 9.60 E-01 & $1,06 E-07$ \\
\hline 800 & 6 & & & 84 & 9,61E-01 & $1.13 E-07$ \\
\hline 800 & 7 & & & 85 & $8,61 E-01$ & $1,08 E-07$ \\
\hline 800 & 8 & & & 88 & 9,61E-01 & $7,50 E-08$ \\
\hline 800 & 9 & & & 87 & $9,62 E-01$ & $8.13 E-08$ \\
\hline 800 & 10 & & & 88 & 9.62E-01 & $5,00 E-08$ \\
\hline 800 & 11 & & & 88 & $9,62 E-01$ & $5,63 E-08$ \\
\hline 800 & 12 & & & 80 & 9,62E-01 & $3,75 E-08$ \\
\hline 800 & 13 & 0 & $\overline{0}$ & 81 & $9,63 E-01$ & $5,00 E-0 B$ \\
\hline 800 & & 1 & so & 92 & $9,63 E-01$ & $6,25 E-08$ \\
\hline 800 & & 2 & 50 & 93 & $8,63 E-01$ & $8,13 E-08$ \\
\hline 800 & & 3 & 50 & 84 & $9,64 E-01$ & $1,38 E-07$ \\
\hline 800 & 4. Water- & 4 & 50 & 95 & $0,85 E-01$ & $3,75 E-07$ \\
\hline 800 & injection & 5 & 50 & 96 & 9,66E-01 & $2,13 E-07$ \\
\hline 800 & & 6 & 50 & 97 & 9,87E-01 & $2,38 E-07$ \\
\hline 800 & & 7 & 50 & 88 & $9,68 E-01$ & $2,00 E-07$ \\
\hline 800 & & 8 & 50 & 88 & $9,69 E-01$ & $2,44 E-07$ \\
\hline 800 & & 9 & 50 & 100 & $9,70 E-01$ & $2,00 E-07$ \\
\hline 800 & & 10 & 50 & 101 & $9,70 E-01$ & $2,44 E-07$ \\
\hline 800 & 0 & 11 & so & 102 & 9.71E-01 & $1,94 E-07$ \\
\hline 800 & 1 & & & 103 & $9,72 E-01$ & $1,88 E-07$ \\
\hline 800 & 2 & & & 104 & $0,73 E-01$ & $2,56=-07$ \\
\hline 800 & 3 & & & 105 & 0,74E-01 & $2,44 E-07$ \\
\hline 800 & 4 & & & 108 & $9,75 E-01$ & $1,75 E-07$ \\
\hline 800 & 5 & - & & 107 & $9,75 E-01$ & $1,00 E-07$ \\
\hline 800 & 6 & & & 108 & $9,76 E-01$ & $1.25 E-07$ \\
\hline 800 & 7 & & & 109 & $9,76 E-01$ & $8,13 E-08$ \\
\hline 800 & 8 & & & 110 & 9,77E-01 & $6.25 E-08$ \\
\hline 800 & 9 & & & 111 & 9,77E-01 & $6,88 E-08$ \\
\hline 800 & 10 & & & 112 & 9.7TE-01 & $6,25 E-08$ \\
\hline 800 & 11 & & • & 113 & 9.77E-01 & $5,63 E-08$ \\
\hline 800 & 12 & & & 114 & $9,78 E-01$ & $5,00 E-08$ \\
\hline 800 & 12 & & & 115 & $9.78 E-01$ & $8,75 E-08$ \\
\hline
\end{tabular}

- $K S 85$ inventory of 5 partides is 1,80E+06 (100\% release). The inventory calculated from measured Cs 137 is 1,58E+08 
Table 4.66 The fractional release and release rate of ${ }^{85} \mathrm{Kr}$ at $800^{\circ} \mathrm{C}$ from $5 \mathrm{UCO}$ kernels taken from particles in tray 3-7 as a function of time and the partial pressure of water vapor Source:

Forschungszentrum Jalich GmbH, Jalich, Germany

\begin{tabular}{|c|c|c|c|c|c|c|}
\hline \multicolumn{7}{|l|}{ HFR-B1, 3-7b } \\
\hline \multirow[b]{2}{*}{$\begin{array}{c}\text { Temperature } \\
T \\
\text { (C) }\end{array}$} & \multirow[b]{2}{*}{$\begin{array}{c}\text { Time without } \\
\text { water vapor } \\
\text { (h) }\end{array}$} & \multicolumn{2}{|c|}{ Water yopor } & \multirow[b]{2}{*}{$\begin{array}{c}\text { Heating } \\
\text { thro } \\
\text { (n) }\end{array}$} & \multicolumn{2}{|c|}{ Kr85 } \\
\hline & & $\begin{array}{l}\text { Time } \\
\text { (h) }\end{array}$ & $\begin{array}{l}\text { Pertial } \\
\text { prossuro } \\
\text { (KPa) }\end{array}$ & & $\begin{array}{c}\text { Fractional } \\
\text { resease }\end{array}$ & $\begin{array}{c}\text { Release } \\
\text { rate } R N= \\
(1 / s)\end{array}$ \\
\hline $\begin{array}{l}300 \\
520 \\
630 \\
770 \\
\end{array}$ & $\begin{array}{l}-2,5 \\
-1,5 \\
-0,5 \\
-0,3\end{array}$ & & & $\begin{array}{l}-2,5 \\
-1,5 \\
-0,5 \\
-0,3\end{array}$ & $\begin{array}{l}4,42 E-04 \\
1,38 E-03 \\
2,38 E-03 \\
2,38 E-03\end{array}$ & $\begin{array}{l}1,99 E-07 \\
2,38 E-07 \\
1,66 E-08\end{array}$ \\
\hline $\begin{array}{l}800 \\
800 \\
800 \\
800 \\
800 \\
800 \\
800 \\
800 \\
800 \\
800 \\
800 \\
800 \\
800 \\
800 \\
800 \\
800 \\
800 \\
800 \\
800 \\
800 \\
800 \\
800 \\
800 \\
\end{array}$ & $\begin{array}{l}0,0 \\
0,2 \\
0,5 \\
0,8 \\
1,1 \\
1,3 \\
1,4 \\
1,6 \\
2,4 \\
2,7 \\
3,3 \\
3,8 \\
4,3 \\
5,3 \\
6,3 \\
7,3 \\
8,3 \\
8,3 \\
10,3 \\
11,3 \\
19,3 \\
20,3 \\
21,3 \\
\end{array}$ & & & $\begin{array}{l}0,0 \\
0,2 \\
0,5 \\
0,8 \\
1,1 \\
1,3 \\
1,4 \\
1,6 \\
2,4 \\
2,7 \\
3,3 \\
3,8 \\
4,3 \\
5,3 \\
0,3 \\
7,3 \\
8,3 \\
9,3 \\
10,3 \\
11,3 \\
19,3 \\
20,3 \\
21,3\end{array}$ & $\begin{array}{l}2,38 E-03 \\
8,83 E-02 \\
8,88 E-02 \\
9,86 E-02 \\
8,86 E-02 \\
2,90 E-01 \\
2,80 E-01 \\
2,90 E-01 \\
5,22 E-01 \\
5,22 E-01 \\
7,06 E-01 \\
7,06 E-01 \\
7,81 E-01 \\
7,82 E-01 \\
7,83 E-01 \\
7,83 E-01 \\
7,83 E-01 \\
7,84 E-01 \\
7,84 E-01 \\
7,84 E-01 \\
7,84 E-01 \\
7,84 E-01 \\
7,84 E-01\end{array}$ & $\begin{array}{l}3,78 E-05 \\
9,56 E-05 \\
4,81 E-05 \\
2,07 E-05 \\
9,23 E-05 \\
6,46 E-05 \\
5,32 E-05 \\
1,23 E-04 \\
1,38 E-05 \\
9,83 E-05 \\
1,68 E-05 \\
3,70 E-06 \\
9,94 E-07 \\
3,81 E-07 \\
1,93 E-07 \\
1,60 E-07 \\
1,22 E-07 \\
1,10 E-07 \\
1,60 E-07 \\
1,49 E-07 \\
9,94 E-08 \\
1,44 E-07 \\
2,32 E-07\end{array}$ \\
\hline $\begin{array}{l}800 \\
800 \\
800 \\
800 \\
800 \\
800 \\
800 \\
800 \\
800 \\
800 \\
800 \\
800 \\
800 \\
800 \\
800 \\
800 \\
800 \\
800 \\
800 \\
800 \\
800 \\
800 \\
\end{array}$ & $\begin{array}{l}22,3 \\
22,7 \\
23,3 \\
24,3 \\
25,3 \\
28,3 \\
27,3 \\
28,3 \\
28,3 \\
30,3 \\
31,3 \\
32,3 \\
33,3 \\
34,3 \\
35,3 \\
38,3 \\
37,3 \\
38,3 \\
38,3 \\
40,3 \\
41,3 \\
42,3 \\
\end{array}$ & $\begin{array}{l}0,3 \\
0,7 \\
1,3 \\
2,3 \\
3,3 \\
4,3 \\
5,3 \\
6,3 \\
7,3 \\
8,3 \\
9,3 \\
10,3 \\
11,3 \\
12,3 \\
13,3 \\
14,3 \\
15,3 \\
16,3 \\
17,3 \\
18,3 \\
19,3 \\
20,3 \\
\end{array}$ & $\begin{array}{l}1 \\
1 \\
1 \\
1 \\
1 \\
1 \\
1 \\
1 \\
1 \\
1 \\
1 \\
1 \\
2 \\
2 \\
2 \\
2 \\
2 \\
2 \\
2 \\
2 \\
2 \\
2 \\
\end{array}$ & $\begin{array}{l}22,3 \\
22,7 \\
23,3 \\
24,3 \\
25,3 \\
20,3 \\
27,3 \\
28,3 \\
20,3 \\
30,3 \\
31,3 \\
32,3 \\
33,3 \\
34,3 \\
35,3 \\
38,3 \\
37,3 \\
38,3 \\
39,3 \\
40,3 \\
41,3 \\
42,3 \\
\end{array}$ & $\begin{array}{l}7,84 E-01 \\
7,84 E-01 \\
9,40 E-01 \\
9,60 E-01 \\
9,62 E-01 \\
9,64 E-01 \\
9,65 E-01 \\
9,67 E-01 \\
9,68 E-01 \\
9,68 E-01 \\
9,70 E-01 \\
9,72 E-01 \\
9,73 E-01 \\
9,75 E-01 \\
9,78 E-01 \\
9,77 E-01 \\
9,77 E-01 \\
9,78 E-01 \\
9,78 E-01 \\
9,79 E-01 \\
9,79 E-01 \\
9,79 E-01\end{array}$ & $\begin{array}{l}2,38 E-07 \\
8,54 E-05 \\
1,74 E-05 \\
1,38 E-06 \\
5,52 E-07 \\
5,25 E-07 \\
4,59 E-07 \\
4,42 E-07 \\
4,42 E-07 \\
4,03 E-07 \\
3,87 E-07 \\
5,25 E-07 \\
5,14 E-07 \\
4,53 E-07 \\
3,76 E-07 \\
3,59 E-07 \\
2,71 E-07 \\
2,43 E-07 \\
2,48 E-07 \\
1,88 E-07 \\
1,55 E-07 \\
1,55 E-07\end{array}$ \\
\hline
\end{tabular}

- Kr 85 inventory of 5 partictes is 1,81E+08 (100\% retease). The imventory calculated from meesured Cs 137 is 1.58E+08 
Fig. 4.126 Modified PIE flow chart for capsules 2 and 3 with remaining tasks to be completed or inserted into this report

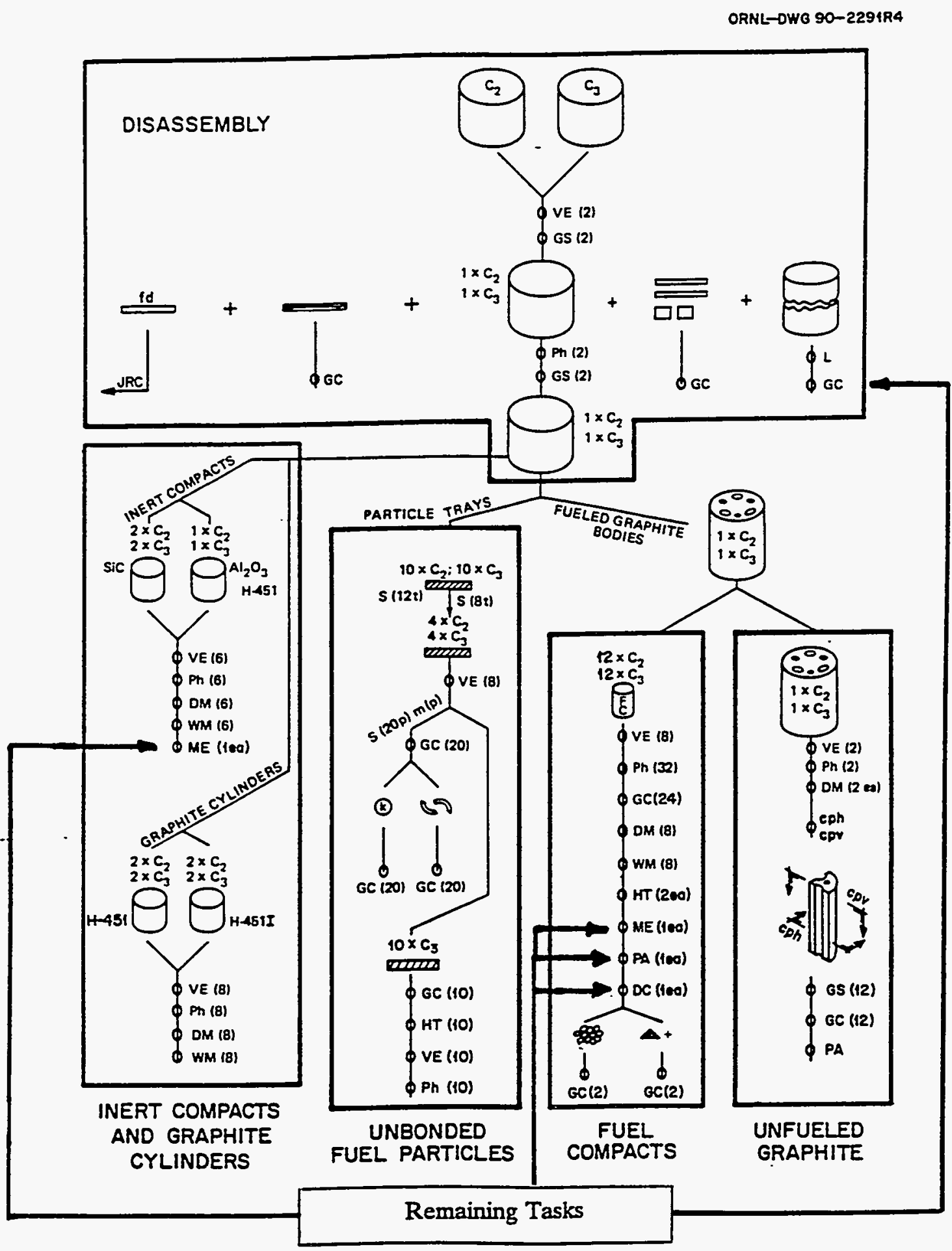




\section{REFERENCES}

1. Myers, B. F., "Plan for the Postirradiation Examination of the HFR-B1 Experiment,"ORNL/TM11498, Oak Ridge National Laboratory, November 1991

2. Bucker, H. J. und F. Nieveler, "Nachuntersuchungsergebnisse des Bestrahungs-experimentes HFRB1," Technische Notiz IRW-TN 42/91, Forschungszentrum Jalich GmbH, 03.06.1991

3. Schroder, R. und H. Dahmen, "Gammascan der Stahlkapseln," Technische Notiz IRW-TN-34/91, Forschungszentrum Julich $\mathrm{GmbH}, 23.04 .1991$

4. Schroder, R. und H. Dahmen, "Gammascan der Graphitkorper aus Kapsel 2 und 3 und der Brennstoffrods aus den Kanålen 1.," Technische Notiz IRW-TN 41/91, Forschungszentrum Jalich $\mathrm{GmbH}, 28.05 .1991$

5. Schroder, R. and H. Dahmen, "HFR Scan der Gammascandrăte," IRW-TN-29/91, Forschungszentrum Julich GmbH, 10.04.91.

6. Myers, B. F., "The Burnup and Power Data Reported for Experiment HFR-B1: Circumvention of Discrepancies", to be published as an ORNL/TM report, December 1994

7. Schroder, R., H. Dahmen und F. Nieveler, "Inventar und Abbrand der Brennstoffrods, Dimensonen der Graphitkorper," Technische Notiz IRW-TN 9/92, Forschungszentrum Julich $\mathrm{GmbH}, 25.02 .1992$

8. Conrad, R., "Irradiation of GA Fuel rods HTGR real time simulating operating conditions in The HFR Petten", Project D214.01, "Design and Safety Report", Technical Note P/F1/87/5, Joint Research Centre, Petten Establishment, May 1989.

9. Schroder, R. und H. Dahmen, "Gammascan der leeren Graphitsegmente, Inventar der Graphitproben," Technische Notiz IRW-TN 42/92, Forschungszentrum Jalich GmbH, 10/09/92

10. Hill, D. W. and B. F. Myers, "Temperature, Pressure and Oxidation Effects on Cesium Diffusion in H-451 Graphite," Proceedings of the 16th Biennial Conference on Carbon, Extended Abstracts and Program, University of California at San Diego, 18-22 Jul, 1983, pp 566-577

11. Bucker, H. J., "Dimensionsmessungen und Wagungen, Experiment HFR-B1," Technische Notiz IRW-TN 3/94, Forschungszentrum Jalich GmbH, Januar 1994

12. Backer, H.J., and F. Nieveler, "Nachuntersuchungsergebnisse des Bestrahlungsexperimentes HFRB1, Technische Notiz IRW-TN 12/92, Forschungszentrum Jalich GmbH, 12.03.1992

13. Schroder, R., H. Dahmen und K. Landsgesell, "Kernfreisetzung bei Partikeln aus Probentrăgern" Technische Notiz IRW-TN 11/94, Forschungszentrum Julich GmbH, Mărz, 1994

14. Myers, B. F. et al., "Capsule R2-K13; Final Report on Cells 2 and 3", HTGR-85-068, GA Technologies Inc., September 1985

15. Schenk, W., H. Knauf, und D. Pitzer, "Spaltgasfreisetzung aus Brennstoffproben unter dem Einfluß von Feuchte," IRW-IB-6/93, Forschungszentrum Jalich GmbH (KFA), Heisse Zellen, Juni 1993 
16. Myers, B. F., "Effect of Water Vapor on the Release of Fission Gases from Uranium Oxycarbide in High-Temperatuyre, Gas-Cooled Reactor Coated Fuel Particles," J. Am. Ceram. Soc. 75 6866931992

17. Myers, B. F., "Dimensional and Thermal Data for Experiment HFR-B1," to be issued 
ORNL/M-3768

\section{INTERNAL DISTRIBUTION}

1-2. Central Research Library

3. Document Reference Section

4-5. Laboratory Records Department

6. Laboratory Records ORNL-RC

7. ORNL Patent Office
8-10. M\&C Records Office

11. D. F. Craig

12. G. E. Michaels

13-17. B. F.Myers

18. P. L. Rittenhouse

\section{EXTERNAL DISTRIBUTION}

19-20. GENERAL ATOMICS, INC., P.O. Box 85608, San Diego, CA 92186-9784

C. B. Scott

R. F. Turner

21-22. FORSCHUNGSZENTRUM JÜLICH, D524225 Jülich, Germany

H. Nabielek, ISR (HTA)

G. Pott, Heissee Zellen

23. MODULAR HTGR PLANT DESIGN CONTROL OFFICE, Merex, Inc., 3206 Power Oaks Blvd., Suite 300, Rockville, MD 20852

R. R. Mills

24-25. MODULAR HTGR PLANT SEDIGN CONTROL OFFICE, P.O. Box 85608, San Diego, CA 92138-5608

D. Pettycord

J. Kendall

26-28. DOE, ACTINIDE RECYCLE DIVISION, Washington, DC 20585

W. P. Chernock, Acting Director

F. J. Goldner

J. W. Herczeg

29. DOE, OAKLAND OPERATIONS OFFICE, 1333 Broadway, Oakland, CA 94612

S. El-Safwany 
30. DOE, OAK RIDGE OPERATIONS OFFICE, P.O. Box 2001, Oak Ridge, TN 37831-6269

Office of Assistant Manager for Energy Research and Development

31-32. DOE, OFFICE OF SCIENTIFIC AND TECHNICAL INFORMATION, P.O. Box 62, Oak Ridge, TN 37831

For distribution by microfiche as shown in DOE/OSTI- 4500 Distribution Category UC-522 (Gas-Cooled Reactor Technology) 